UNIVERSIDADE DE BRASÍLIA

FACULDADE DE CIÊNCIAS DA SAÚDE

RIVIANE MATOS GONÇALVES

SITUAÇÃO DOS FITOTERÁPICOS NA FARMACOPEIA BRASILEIRA: UMA AVALIAÇÃO SISTEMATIZADA

BRASÍLIA 
Riviane Matos Gonçalves

SITUAÇÃO DOS FITOTERÁPICOS NA FARMACOPEIA BRASILEIRA: UMA AVALIAÇÃO SISTEMATIZADA

Dissertação de Mestrado apresentada ao Programa de Pós-Graduação em Ciências Farmacêuticas da Faculdade de Ciências da Saúde, Universidade de Brasília, como requisito parcial para obtenção do título de Mestre em Ciências Farmacêuticas

Orientadora: profa. Dra. Dâmaris Silveira 
Ficha catalográfica elaborada automaticamente, com os dados fornecidos pelo(a) autor(a)

Matos Gonçalves, Riviane
Situação dos Fitoterápicos na Farmacopeia
Brasileira: uma avaliação sistematizada / Riviane
Matos Gonçalves; orientador Dâmaris Silveira. --
Brasilia, 2017.
294 p.
Dissertação (Mestrado - Mestrado em Ciências
Farmacêuticas) - - Universidade de Brasilia, 2017.
1. planta medicinal. 2. farmacopeia. 3.
harmonização. 4. regulação. 5 . monografia. I.
Silveira, Dâmaris, orient. II. Título.


Riviane Matos Gonçalves

\section{SITUAÇÃO DOS FITOTERÁPICOS NA FARMACOPEIA BRASILEIRA: UMA AVALIAÇÃO SISTEMATIZADA}

Dissertação de Mestrado apresentada ao Programa de Pós-Graduação em Ciências Farmacêuticas da Faculdade de Ciências da Saúde, Universidade de Brasília, como requisito parcial para a obtenção do título de Mestre em Ciências Farmacêuticas

Aprovada em 02 de fevereiro de 2017.

\section{Banca examinadora}

Profa. Dra. Dâmaris Silveira - Universidade de Brasília

Prof. Dr. Cid Aimbiré de Moraes Santos - Universidade Federal do Paraná

Dra. Ana Cecília Bezerra Carvalho

Profa. Dra. Pérola de Oliveira Magalhães Dias Batista (suplente) - Universidade de Brasília 
Dedico este trabalho à minha querida família: minhas princesas e meu companheiro. 


\section{AGRADECIMENTO}

Agradeço as pessoas em geral, que a cada dia me ensinam um pouco o que realmente importa na vida.

Às queridas Lívia e Luísa, minhas pequenas aspirantes que me ajudam e ver a renovação da vida e que sempre têm paciência com a mamãe.

Ao Pedro pela sua compreensão e dedicação.

À minha orientadora pela paciência, apoio e comprometimento.

Aos membros dos Comitês Técnicos Temáticos da Farmacopeia Brasileira que escutaram minhas opiniões e devaneios.

Aos meus colegas da Agência Nacional de Vigilância Sanitária que me apoiaram com conversas e informações, em especial ao Varley Dias Sousa pelo incentivo e apoio, à equipe da Coordenação da Farmacopeia, e aos colegas Ana Cecília Bezerra Carvalho e João Paulo Silvério Perfeito da Gerência de Medicamentos Específicos, Fitoterápicos, Dinamizados, Notificados e Gases Medicinais. 
“A qualidade nunca se obtém por acaso; ela é sempre o resultado do esforço inteligente."

John Ruskin 


\section{RESUMO}

GONÇALVES, Riviane Matos. Situação dos fitoterápicos na Farmacopeia Brasileira: uma avaliação sistematizada. Brasília, 2017. Dissertação (Mestrado em Ciências Farmacêuticas) Faculdade de Ciências da Saúde, Universidade de Brasília, Brasília, 2017.

Farmacopeias são documentos que contêm registros de padrões de qualidade e especificações para produtos farmacêuticos e matérias-primas oficiais em um país ou região. Para atender aos mercados nacionais, há uma constante necessidade de promover o seu aprimoramento, com inclusão de especificações padronizadas, substâncias químicas de referência e métodos gerais. Ao mesmo tempo, é necessário que tais especificações estejam alinhadas ao mercado globalizado que deseja a harmonização. Nesse sentido, foi realizada uma avaliação das monografias de drogas vegetais e derivados da Farmacopeia Brasileira $5^{a}$ Edição, verificando a sua adequabilidade ao contexto nacional, e comparando, quanto às semelhanças entre as especificações, com as três farmacopeias internacionais alvo desse estudo: European Pharmacopoeia, The United States Phamacopeia and National Formulary e Farmacopea Argentina. Os resultados obtidos permitiram verificar que os métodos empregados nas monografias de drogas vegetais e derivados da Farmacopeia Brasileira estão consonantes com os empregados nas principais farmacopeias internacionais, sendo os seus requisitos mais convergentes com a Farmacopeia Europeia. Por outro lado, foi verificado que o Brasil tem inovado por meio da Farmacopeia Brasileira, oferecendo monografias para drogas vegetais que não estão contempladas nos outros compêndios. Porém, há necessidade de alinhamento entre os próprios documentos da Farmacopeia Brasileira (Farmacopeia e Formulário de Fitoterápicos $1^{a}$ edição), e, desses com a atividade de regulação da Anvisa (Instrução Normativa no 02/2014 e fitoterápicos registrados). Dessa forma, no que se refere à adequação de suas monografias de drogas vegetais à realidade do mercado brasileiro, há muito a ser realizado. Assim, ao final desse trabalho foi possível concluir que é necessário voltar o olhar da Farmacopeia Brasileira para o cenário nacional, sem perder de vista a circulação internacional das mercadorias, a fim de atender as demandas internas do Brasil.

Palavras-chave: planta medicinal, farmacopeia, harmonização, regulação, monografia 


\begin{abstract}
Pharmacopoeias are documents that provide quality control requirements in a country or region for pharmaceutical products and raw materials. There is a constant need to promote their improvement to attend national markets, including specifications, chemicals reference substance and general methods. Besides, such specifications need to be aligned with the global market. Therefore, an evaluation of the herbal drugs monographs of the Brazilian Pharmacopoeia 5th Edition was carried out, verifying their suitability to the regional context, and comparing the specifications with the three international pharmacopoeias aim of this study (European Pharmacopoeia, The United States Phamacopeia and National Formulary and the Argentine Pharmacopoeia). The obtained results reveal that the methods in the herbal drugs monographs of Brazilian Pharmacopoeia are in accordance with those used in the international pharmacopoeias, being they more convergent with the European Pharmacopoeia. On the other hand, it was verified that Brazil has innovated by the Brazilian Pharmacopoeia, offering herbal drug monographs that are not exist in the other pharmacopoeias. However, there is a need for alignment among Brazilian Pharmacopoeia documents (Pharmacopoeia and Herbal Medicines National Formulary $1^{\text {st }}$ edition), as well as these documents with Anvisa's regulation activity (Normative Instruction $\mathrm{N}^{\circ}$ 02/2014 and authorized herbal medicines). Therefore, considering the suitability of Brazilian Pharmacopoeia herbal drugs monographs to the reality of the Brazilian market, there is much to be done. And at the end of this work it was possible to conclude that it is necessary to turn over the Brazilian Pharmacopoeia's perspective to the national reality to attend the internal market, considering the global herbal drug market.
\end{abstract}

Keywords: herbal medicine, pharmacopoeia, harmonization, regulation, monograph 


\section{LISTA DE FIGURAS}

Figura 1 - Tela inicial do sítio eletrônico para a Consulta de Produto - Medicamentos, destacando o botão de acesso para a pesquisa de princípios ativos.

Figura 2 - Campo no qual foram digitados os termos de busca do Apêndice B e selecionados os princípios ativos.

Figura 3 - Tela com o resultado da consulta de um princípio ativo selecionado. .46

Figura 4 - Tela do detalhe do produto na qual foram verificados o vencimento do registro, as apresentações ativas e a categoria do produto.

Figura 5 - Exemplo de produto enquadrado como fitoterápico com apresentações ativas e validade do registro vencida.

Figura 6 - Exemplo de produto não enquadrado como fitoterápico. 50

Figura 7 - Espécies com monografia na Farmacopeia Brasileira $5^{a}$ edição (FB5) e no Formulário de Fitoterápicos da Farmacopeia Brasileira $1^{a}$ edição (FFFB1), com registros de fitoterápicos válidos junto à Anvisa (maio/2016) 


\section{LISTA DE QUADROS}

Quadro 1 - Símbolos utilizados para sistematizar as informações das monografias e seus significados.

Quadro 2 - Classificação adotada para as diferenças encontradas entre as monografias da Farmacopeia Brasileira $5^{a}$ edição e as monografias correspondentes nas farmacopeias internacionais em estudo.

Quadro 3 - Sistematização das informações contidas nas monografias de drogas vegetais e derivados da Farmacopeia Brasileira $5^{a}$ edição e as monografias correspondentes constantes nas edições anteriores da Farmacopeia Brasileira, $1^{\mathrm{a}}, 2^{\mathrm{a}}, 3^{\mathrm{a}}$ e $4^{\mathrm{a}}$ edição.

Quadro 4 - Monografias da Farmacopeia Brasileira $5^{\mathrm{a}}$ edição (FB5), do Formulário de Fitoterápicos da Farmacopeia Brasileira $1^{a}$ edição (FFFB1) e drogas vegetais da Instrução Normativa (IN) nº 02/2014.

Quadro 5 - Espécies vegetais da Farmacopeia Brasileira, nomenclatura popular, e registros de fitoterápicos válidos resultados de pesquisa em maio de 2016 e a respectiva ocorrência dessas espécies no Brasil.

Quadro 6 - Comparação entre as monografias na Farmacopeia Brasileira $5^{\text {a }}$ edição (FB5) e as monografias presentes na European Pharmacopoeia (EP8.8), na Farmacopea Argentina (FA7) e na The United States Pharmacopeia and National Formulary (USP39-NF-34) 106

Quadro 7 - Comparação entre as monografias de Aesculus hippocastanum L. [semente] das farmacopeias FB5, FA7 e USP39-NF34.

Quadro 8 - Comparação entre as monografias de Aloe africana Mill., Aloe ferox Mill. e Aloe spicata L. f. [folha; suco dessecado] das farmacopeias FB5, EP8.8 e USP39-NF34.

Quadro 9 - Comparação entre as monografias de Althaea officinalis L. [raiz] das farmacopeias FB5 e EP8.8

Quadro 10 - Comparação entre as monografias de Arnica montana L. [capítulo floral] das farmacopeias FB5 e EP8.8.

Quadro 11 - Comparação entre as monografias de Atropa belladonna L. [folha] das farmacopeias FB5, EP8.8, FA7 e USP39-NF34.

Quadro 12 - Comparação entre as monografias de Calendula officinalis L. [capítulo floral] das farmacopeias FB5, EP8.8 e FA7. 136

Quadro 13 - Comparação entre as monografias de Centella asiatica (L.) Urb. [folha] das farmacopeias FB5, FA7 e USP39-NF34. 140

Quadro 14 - Comparação entre as monografias de Cinchona calisaya Wedd. [casca] das farmacopeias FB5 e EP8.8. 146 
Quadro 15 - Comparação entre as monografias de Cinnamomum verum J. Presl [casca] das farmacopeias FB5, EP8.8 e FA7.

Quadro 16 - Comparação entre as monografias de Citrus aurantium L. subsp. aurantium [exocarpo] das farmacopeias FB5 e EP8.8.

Quadro 17 - Comparação entre as monografias de Cola nitida (Vent.) Schott \& Endl. [cotilédone] das farmacopeias FB5, EP8.8 e FA7.

Quadro 18 - Comparação entre as monografias de Crataegus monogyna Jacq., C. rhipidophylla Gand., C. laevigata (Poir.) DC., C. pentagyna Waldst. \& Kit. ex Willd., C. nigra Waldst. \& Kit., C. azarolus L. [ramo florido] das farmacopeias FB5, FA7 e USP39-NF34.

Quadro 19 - Comparação entre as monografias de Curcuma longa L. [rizoma] das farmacopeias FB5, EP8.8 e USP39-NF34.

Quadro 20 - Comparação entre as monografias de Datura stramonium L. [folha] das farmacopeias FB5 e EP8.8.

Quadro 21 - Comparação entre as monografias de Elettaria cardamomum (L.) Maton [semente] das farmacopeias FB5 e USP39-NF34.

Quadro 22 - Comparação entre as monografias de Gentiana lutea L. [raiz e rizoma] das farmacopeias FB5 e EP8.8 178

Quadro 23 - Comparação entre as monografias de Hydrastis canadensis L. [raiz e rizoma] das farmacopeias FB5, EP8.8 e USP39-NF34 181

Quadro 24 - Comparação entre as monografias de Illicium verum Hook. f. [fruto] das farmacopeias FB5 e EP8.8.

Quadro 25 - Comparação entre as monografias de Krameria lappacea (Dombey) Burdet \& B.B.Simpson [raiz] das farmacopeias FB5 e EP8.8.

Quadro 26 - Comparação entre as monografias de Krameria lappacea (Dombey) Burdet \& B.B.Simpson [raiz; tintura] das farmacopeias FB5 e EP8.8

Quadro 27 - Comparação entre as monografias de Melissa officinalis L. [folha] das farmacopeias FB5 e EP8.8.

Quadro 28 - Comparação entre as monografias de Mentha $x$ piperita L. [folha] das farmacopeias FB5, EP8.8 e USP39-NF34. 201

Quadro 29 - Comparação entre as monografias de Mentha x piperita L. [parte aérea fresca; óleo] das farmacopeias FB5, EP8.8 e USP39-NF34.

Quadro 30 - Comparação entre as monografias de Myroxylon balsamum (L.) Harms e M. balsamum var. pereirae (Royle) Harms [tronco; óleo-resina] das farmacopeias FB5, EP8.8, FA7 e USP39-NF34.

Quadro 31 - Comparação entre as monografias de Myroxylon balsamum (L.) Harms var. pereirae (Royle) Harms [tronco; bálsamo] das farmacopeias FB5, EP8.8 e FA7. 
Quadro 32 - Comparação entre as monografias de Peumus boldus Molina [folha] das farmacopeias FB5, da EP8.8 e da FA7.

Quadro 33 - Comparação entre as monografias de Pimpinella anisum L. [fruto] das farmacopeias FB5, EP8.8 e FA7. 225

Quadro 34 - Comparação entre as monografias de Polygala senega L. [raiz e rizoma] das farmacopeias FB5 e EP8.8.

Quadro 35 - Comparação entre as monografias de Quillaja saponaria Molina [casca] das farmacopeias FB5 e EP8.8.

Quadro 36 - Comparação entre as monografias de Rauvolfia serpentina (L.) Benth. ex Kurz [raiz] das farmacopeias FB5 e da USP39-NF34.

Quadro 37 - Comparação entre as monografias de Rheum officinale Baill. e/ou Rheum palmatum L. [raiz e rizoma] das farmacopeias FB5 e da EP8.8.

Quadro 38 - Comparação entre as monografias de Rosmarinus officinalis L. [sumidade florida; óleo] das farmacopeias FB5, FA7 e USP39-NF34

Quadro 39 - Comparação entre as monografias de Sambucus nigra L. [flor] das farmacopeias FB5 e EP8.8

Quadro 40 - Comparação entre as monografias de Senna alexandrina Mill. [folíolo] das farmacopeias FB5, EP8.8, FA7 e USP39-NF34. 250

Quadro 41 - Comparação entre as monografias de Styrax benzoin Dryand. ou Styrax paralleloneuron Perkins [tronco; resina balsâmica] das farmacopeias FB5, EP8.8 e USP39NF34.

Quadro 42 - Comparação entre as monografias de Vanilla planifolia Andrews [fruto imaturo] das farmacopeias FB5 e USP39-NF34. 


\section{LISTA DE TABELAS}

Tabela 1 - Presença de monografias da Farmacopeia Brasileira $5^{\text {a }}$ edição (FB5) nas edições anteriores, Farmacopeia Brasileira $4^{\mathrm{a}}$ edição (FB4), Farmacopeia Brasileira $3^{\mathrm{a}}$ edição (FB3), Farmacopeia Brasileira $2^{a}$ edição (FB2) e Farmacopeia Brasileira $1^{a}$ edição (FB1), relacionando as monografias com a ocorrência das espécies no Brasil. .68

Tabela 2 - Quantitativo de ensaios de identificação, testes, índices (incluindo descrição), doseamentos, perfil cromatográfico, embalagem e armazenamento, presença de figura botânica, quantitativo total de Cromatografias em Camada Delgada (CCD) e descrição dos métodos de doseamento das monografias da Farmacopeia Brasileira $5^{\text {a }}$ edição (FB5).

Tabela 3 - Espécies vegetais em monografias na Farmacopeia Brasileira $5^{\text {a }}$ edição (FB5), no Formulário de Fitoterápicos da Farmacopeia Brasileira $1^{\mathrm{a}}$ edição (FFFB1) e a ocorrência no Brasil 98

Tabela 4 - Espécies com monografia na Farmacopeia Brasileira, Farmacopeia Brasileira $5^{\text {a }}$ edição (FB5) e Formulário de Fitoterápicos da Farmacopeia Brasileira $1^{\text {a }}$ edição (FFFB1), com registros de fitoterápicos válidos na Anvisa (maio/2016).

Tabela 5 - Espécies com monografia na Farmacopeia Brasileira, Farmacopeia Brasileira $5^{\mathrm{a}}$ edição (FB5) e Formulário de Fitoterápicos da Farmacopeia Brasileira $1^{a}$ edição (FFFB1) com registros de fitoterápicos válidos na Anvisa (maio/2016) e listadas na Instrução Normativa (IN) $n^{\circ} 02 / 2014$

Tabela 6- Semelhança entre monografias da Farmacopeia Brasileira $5^{\mathrm{a}}$ edição (FB5) com as monografias listadas, para a mesma espécie vegetal, nas farmacopeias European Pharmacopoeia (EP8.8), Farmacopea Argentina (FA7) e The United States Pharmacopeia and The National Formulary (USP39-NF34). 


\section{LISTA DE ABRAVIATURAS E ACRÔNIMOS}

\begin{tabular}{|c|c|}
\hline ANMAT & $\begin{array}{l}\text { Administración Nacional de Medicamentos, Alimentos y Tecnologia } \\
\text { Médica }\end{array}$ \\
\hline Anvisa & Agência Nacional de Vigilância Sanitária \\
\hline $\mathrm{BS}$ & Solução Branco para ajuste do zero \\
\hline $\mathrm{CCD}$ & Cromatografia em Camada Delgada \\
\hline CCDAE & Cromatografia em Camada Delgada de Alta Eficiência \\
\hline $\mathrm{CFB}$ & Comissão da Farmacopeia Brasileira \\
\hline CG & Cromatografia Gasosa \\
\hline CLAE-UV & $\begin{array}{l}\text { Cromatografia Líquida de Alta Eficiência acoplada a detector por } \\
\text { Espectrofotometria por Absorção no Ultravioleta }\end{array}$ \\
\hline CLAE-VIS & $\begin{array}{l}\text { Cromatografia Líquida de Alta Eficiência acoplada a detector por } \\
\text { Espectrofotometria por Absorção no Visível }\end{array}$ \\
\hline CTT & Comitê Técnico Temático da Farmacopeia Brasileira \\
\hline DATAVISA & Sistema de Dados em Vigilância Sanitária \\
\hline EAUV & Espectrofotometria de Absorção no Ultravioleta \\
\hline EAVIS & Espectrofotometria de Absorção no Visível \\
\hline EIGA & European Industrial Gases Association \\
\hline $\mathrm{EM}$ & Espectrometria de Massas \\
\hline EMA & European Medicines Agency \\
\hline EP8.8 & European Pharmacopoeia $8^{\mathrm{a}}$ edição incluindo o $8^{\circ}$ suplemento \\
\hline $\mathrm{F}$ & presença de indicador de fluorescência na sílica-gel \\
\hline FA7 & Farmacopea Argentina $7^{\mathrm{a}}$ edição \\
\hline $\mathrm{FB}$ & Farmacopeia Brasileira \\
\hline FB1 & Farmacopeia Brasileira $1^{\mathrm{a}}$ edição incluindo o $1^{\mathrm{o}}$ e o $3^{\mathrm{o}}$ suplementos \\
\hline FB2 & Farmacopeia dos Estados Unidos do Brasil 2a edição \\
\hline FB3 & Farmacopeia Brasileira $3^{\mathrm{a}}$ edição \\
\hline FB4 & Farmacopeia Brasileira $4^{\mathrm{a}}$ edição \\
\hline FB5 & Farmacopeia Brasileira $5^{\mathrm{a}}$ edição \\
\hline FFFB & Formulário de Fitoterápicos da Farmacopeia Brasileira \\
\hline FFFB1 & Formulário de Fitoterápicos da Farmacopeia Brasileira $1^{\mathrm{a}}$ edição \\
\hline G & presença de gesso na sílica-gel ou no óxido de alumínio \\
\hline
\end{tabular}


GACP

GF

GMP

HMPC

IFAV

IN

IRCH

IRR

IS

JP

Mercosul

MR

NLT

NMT

NNHPN

ODS

PDG

Ph. Eur.

PNPIC

PNPMF

PTF

RDC

RDD

RENISUS

Rf

rpm

RS

SI

SQR

SR

SS
Good Agricultural and Collection Practices (Boas Práticas Agrícolas)

presença de gesso e indicador de fluorescência na sílica-gel

Good Manufacturing Practices (Boas Práticas de Fabricação)

Committee on Herbal Medicinal Products

Insumo Farmacêutico Ativo Vegetal

Instrução Normativa

International Regulatory Cooperation for Herbal Medicines

Índice de Retenção Relativo

Internal standard (Solução de padrão interno)

Japanese Pharmacopoeia (Farmacopeia Japonesa)

Mercado Comum do Sul

Cumpre o teste ou os requisitos

Não menor que

Não maior que

The Natural and Non-prescription Health Products Directorate

Coluna cromatográfica octadecilsilanizada

Pharmacopoeial Discussion Group

European Pharmacopoeia (Farmacopeia Europeia)

Política Nacional de Práticas Integrativas e Complementares no Sistema Único de Saúde

Política Nacional de Plantas Medicinais e Fitoterápicos

Produto Tradicional Fitoterápico

Resolução da Diretoria Colegiada

Relação entre a Droga e o Derivado

Relação Nacional de Plantas Medicinais de Interesse ao Sistema Único de

Saúde

Fator de retenção

Rotações por minuto

Reference solution (Solução padrão ou solução referência)

Solução indicadora

Substância química ou extrato de referência

Solução reagente

Stock solution (solução estoque ou intermediária) 
SUS Sistema Único de Saúde

SV

Solução volumétrica

TAMC Total Aerobic Microbial Count (contagem total de bactérias aeróbias)

TBMC Total Bile tolerant Microbial Count (contagem de bactérias Gram-negativas bile tolerantes)

TS Test solution (solução amostra ou solução teste)

TYMC Total Yeast/mold Microbial Count (contagem total de fungos e leveduras)

UFC Unidade Formadora de Colônia

USP United States Pharmacopeial Convention

USP39-NF34 The United States Pharmacopeia 39a edição e o National Formulary $34^{\mathrm{a}}$ edição, incluído os seus dois suplementos

USP-NF The United States Phamacopeia and National Formulary (Farmacopeia Americana e Formulário Nacional)

WHO World Health Organization (Organização Mundial da Saúde)

www World Wide Web 


\section{SUMÁRIO}

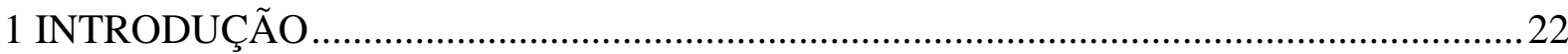

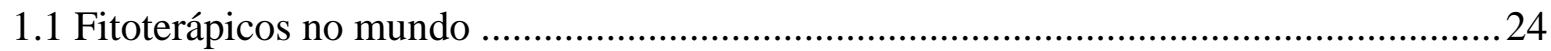

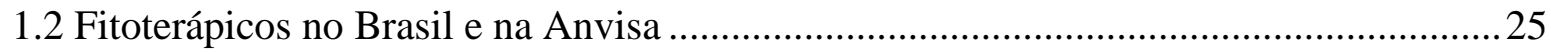

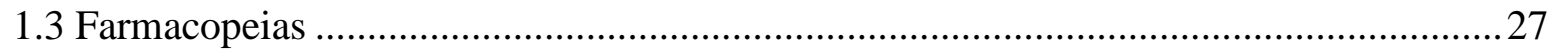

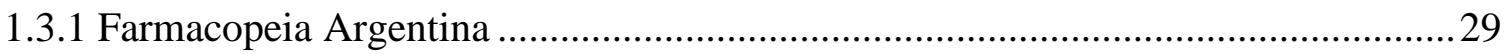

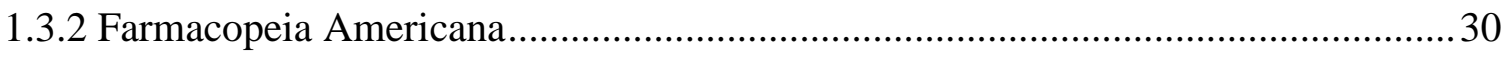

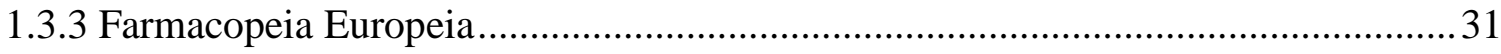

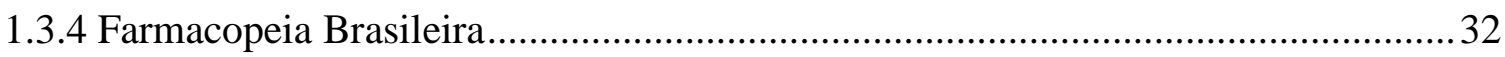

1.4 Harmonização internacional de critérios de qualidade .............................................. 35

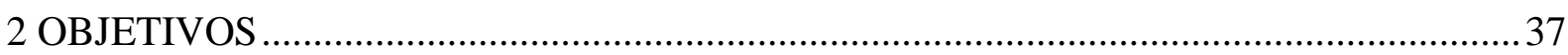

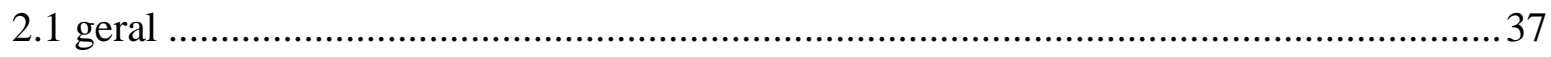

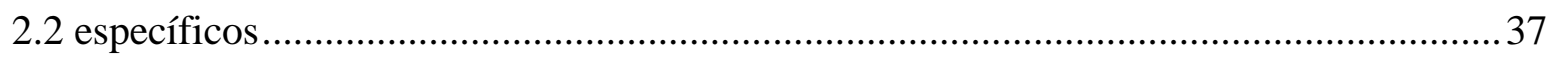

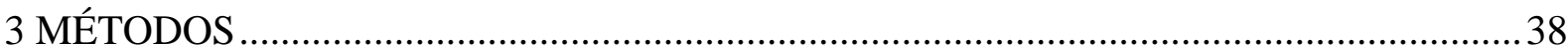

3.1 Avaliação da evolução histórica das monografias de drogas vegetais e derivados da

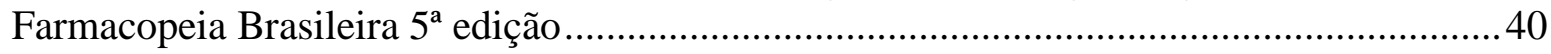

3.2 Avaliação das diferenças entre as monografias e espécies da Farmacopeia Brasileira e da

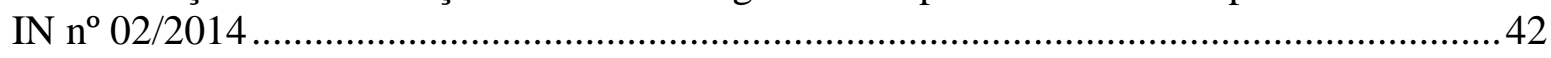

3.3 Avaliação da correlação entre as espécies da Farmacopeia Brasileira e a existência de registros de fitoterápicos válidos na Anvisa ................................................................ 43

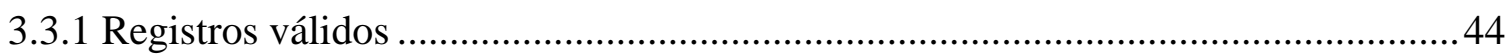

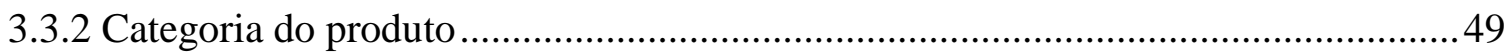

3.4 Comparação entre as monografias da FB5 e as monografias correspondentes nas

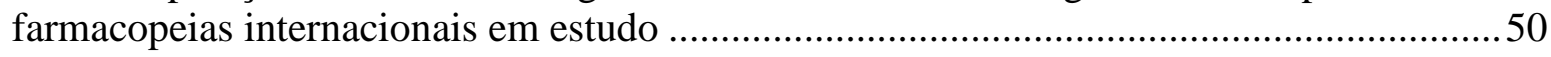

3.4.1 Comparação individual entre as monografias da FB5 e as monografias correspondentes encontradas nas farmacopeias internacionais em estudo .......................51

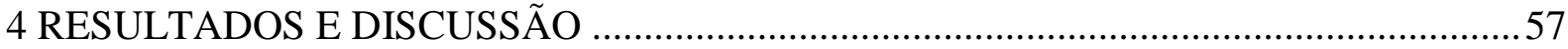

4.1 Evolução histórica das monografias de drogas vegetais e derivados da Farmacopeia

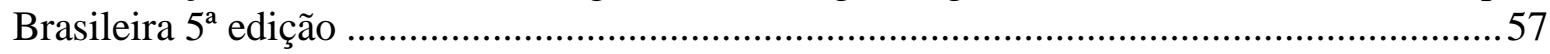


4.1.1 Ocorrência das monografias da Farmacopeia Brasileira $5^{\mathrm{a}}$ edição nas edições anteriores da Farmacopeia Brasileira

4.1.2 Composição das monografias de drogas vegetais e derivados da Farmacopeia Brasileira $5^{\mathrm{a}}$ edição.

4.2 Avaliação das monografias da Farmacopeia Brasileira e as espécies constantes na IN n ${ }^{\circ}$ $02 / 2014$

4.3 Avaliação quanto à existência de produtos registrados junto à Anvisa para as espécies vegetais da Farmacopeia Brasileira

4.4 Avaliação das drogas vegetais e derivados das monografias da Farmacopeia Brasileira $5^{\mathrm{a}}$ edição eM comparação com as monografias correspondentes nas farmacopeias internacionais em estudo 104

4.5 Avaliação sistematizada das monografias de drogas vegetais e derivados da Farmacopeia Brasileira $5^{\text {a }}$ edição em comparação aos compêndios internacionais em estudo. 111

4.5.1 Aesculus hippocastanum L. [semente]

4.5.2 Aloe africana Mill., Aloe ferox Mill. e Aloe spicata L. f. [folha; suco dessecado] 116

4.5.3 Althaea officinalis L. [raiz] 122

4.5.4 Arnica montana L. [capítulo floral] 124

4.5.5 Atropa belladonna L. [folha]

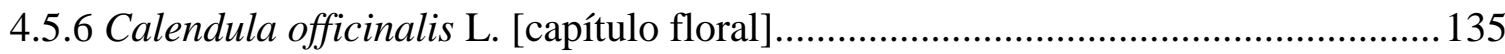

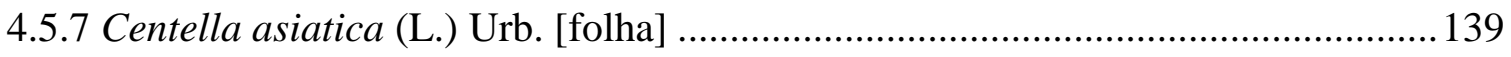

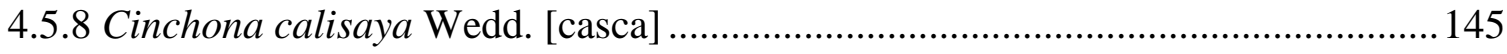

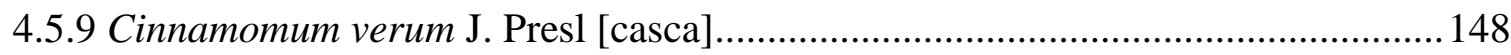

4.5.10 Citrus aurantium L. subsp. aurantium [exocarpo]......................................... 151

4.5.11 Cola nitida (Vent.) Schott \& Endl. [cotilédone] ................................................ 154

4.5.12 Crataegus monogyna Jacq., C. rhipidophylla Gand., C. laevigata (Poir.) DC., C. pentagyna Waldst. \& Kit. ex Willd., C. nigra Waldst. \& Kit., C. azarolus L. [ramo florido]

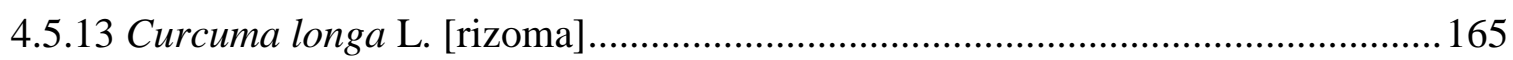

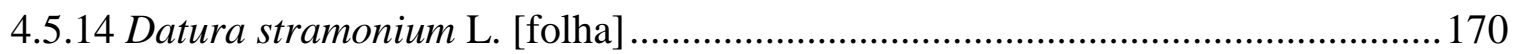

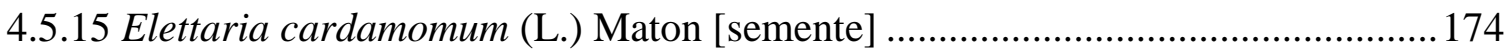

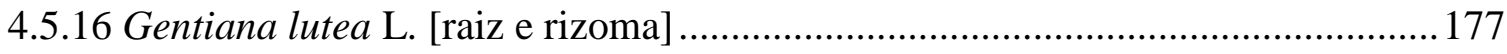




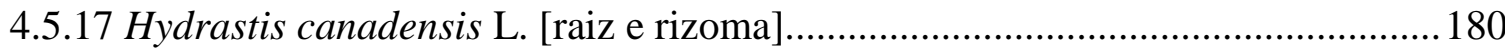

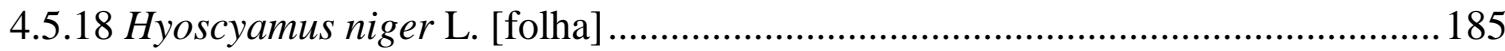

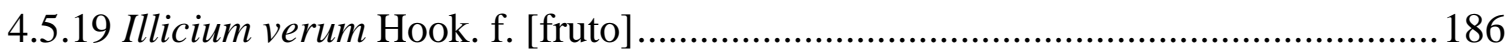

4.5.20 Krameria lappacea (Dombey) Burdet \& B.B.Simpson [raiz] .............................. 189

4.5.21 Krameria lappacea (Dombey) Burdet \& B.B.Simpson [raiz; tintura].................. 193

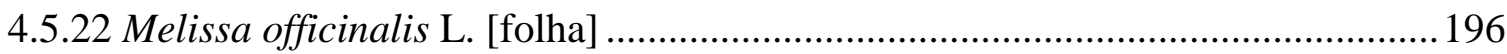

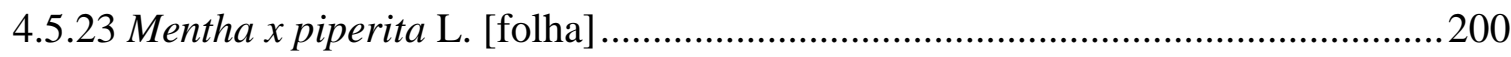

4.5.24 Mentha x piperita L. [parte aérea fresca; óleo] .................................................2203

4.5.25 Myroxylon balsamum (L.) Harms e M. balsamum var. pereirae (Royle) Harms

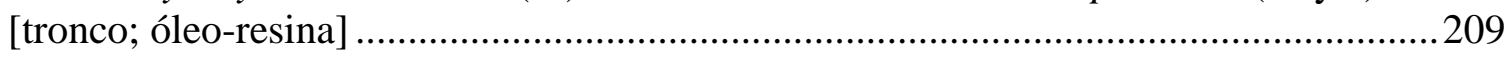

4.5.26 Myroxylon balsamum (L.) Harms var. pereirae (Royle) Harms [tronco; bálsamo] 215

4.5.27 Peumus boldus Molina [folha] ......................................................................2. 219

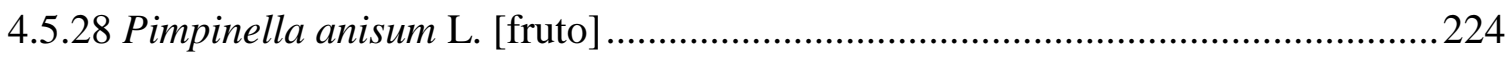

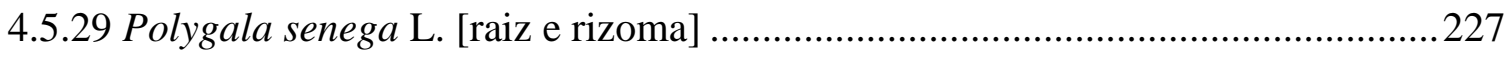

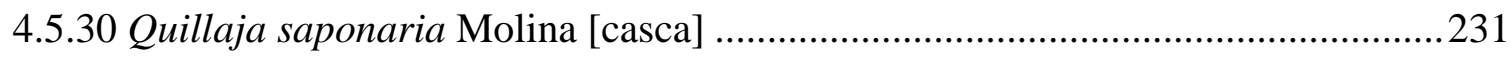

4.5.31 Rauvolfia serpentina (L.) Benth. ex Kurz [raiz] .............................................2. 235

4.5.32 Rheum officinale Baill. e/ou Rheum palmatum L. [raiz e rizoma] ......................239

4.5.33 Rosmarinus officinalis L. [sumidade florida; óleo]..........................................2242

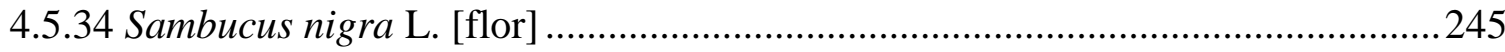

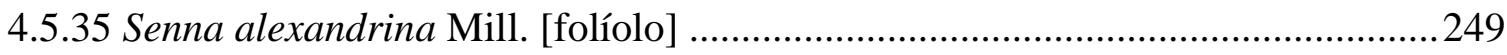

4.5.36 Styrax benzoin Dryand. ou Styrax paralleloneuron Perkins [tronco; resina

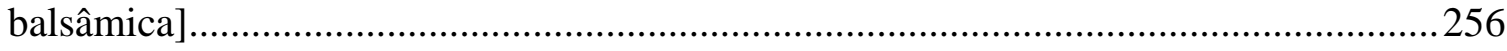

4.5.37 Vanilla planifolia Andrews [fruto imaturo] ..................................................2. 261

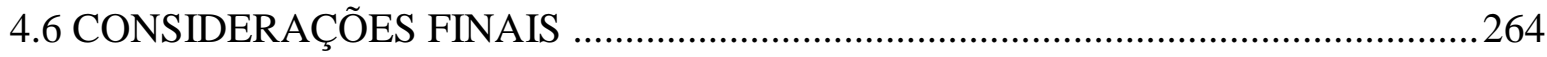

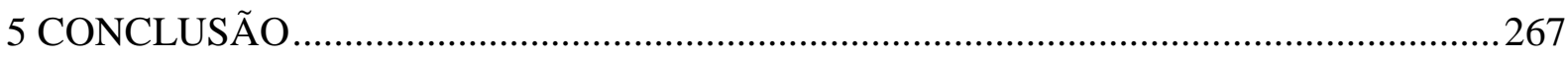

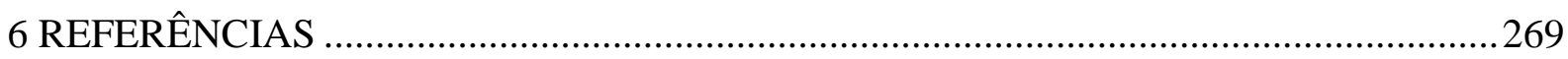

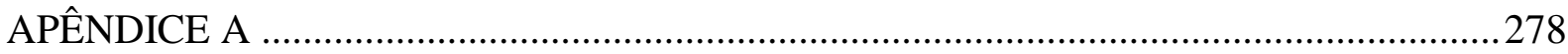


APÊNDICE B 


\section{INTRODUÇÃO}

Medicina tradicional é definida pela World Health Organization (WHO) como a "soma total do conhecimento, habilidades e práticas baseadas em teorias, crenças e experiências indígenas de diferentes culturas, explicáveis ou não, utilizadas na manutenção da saúde, bem como na prevenção, diagnóstico, melhora ou tratamento de doenças físicas ou mentais" (WHO, 2013b).

A importância da utilização da medicina tradicional pela população como ferramenta para a manutenção da saúde, prevenção, diagnóstico e para a melhora ou tratamento de doenças físicas e mentais é reconhecida mundialmente. As agências reguladoras internacionais e governamentais, preocupadas em preservar a saúde da população, têm apoiado a promoção da sua utilização de forma segura e eficaz por meio da regulamentação dos produtos, profissionais e práticas nos sistemas de saúde (WHO, 2013b).

Os fitoterápicos, ou seja, os medicamentos produzidos exclusivamente com matériaprima vegetal sem adição de substâncias ativas isoladas ou altamente purificadas (BRASIL, 2014c), são um dos elementos mais importantes dentro da Medicina Tradicional. Dentre as características de um fitoterápico, a qualidade dos produtos é considerada de essencial importância, junto a sua eficácia e segurança (BRASIL, 2014c; HÖLLEIN et al., 2015; WHO, 2013b). Assim, requisitos uniformes são o primeiro passo para a obtenção de fitoterápicos com alta qualidade, evitando, entre outros, os erros na identificação do produto, as adulterações e as contaminações (CALIXTO, 2000), que podem afetar os resultados esperados no tratamento.

Os parâmetros de qualidade a serem seguidos pelos produtos farmacêuticos estão definidos em compêndios denominados farmacopeias. Há atualmente, de acordo com o The Index of World Pharmacopoeias and Pharmacopoeial Authorities, publicado pela WHO, 40 farmacopeias no mundo (WHO, 2016b), das quais 37 são farmacopeias nacionais, duas regionais e uma internacional.

No mercado globalizado, um produto, por vezes, é fabricado em um país e é consumido em outro. Tal situação não é diferente para os fitoterápicos, os quais frequentemente são utilizados em um país diverso do de sua produção.

No que se refere às farmacopeias nacionais, os parâmetros de qualidade devem estar alinhados aos requisitos regulatórios do país, que nem sempre são iguais àqueles dos países de origem dos produtos. Desse modo, as indústrias farmacêutias detentoras de produtos que permeam o mercado mundial devem cumprir as regras de cada país ou região, o que significa, 
usualmente, realizar múltiplos e diferentes testes. Tantas regras diferentes contribuem para o aumento dos custos da pesquisa e desenvolvimento dos produtos e dos serviços de saúde, sendo este o principal apelo para a harmonização regulatória, que inclui os critérios de qualidade estabelecidos nas farmacopeias (ICH, 2012). O alinhamento de diretrizes entre as farmacopeias vai de encontro com a expectativa de disponibilizar novos tratamentos seguros e eficazes para os pacientes em um mínimo tempo possível (ICH, 2012; KEITEL, 2013), poupando tempo e dinheiro no desenvolvimento dos produtos (ICH, 2015).

Dentre os vários compêndios internacionais que determinam parâmetros de qualidade, a Resolução RDC nº 49, de 23 de novembro de 2010 define que a Farmacopeia é a referência de primeira escolha para o estabelecimento de critérios mínimos de qualidade no Brasil e a Farmacopeia Brasileira 5a edição (FB5) é a versão vigente desse documento (BRASIL, 1976b, 2010b). Contudo, na ausência de monografia na Farmacopeia Brasileira vigente, os compêndios listados na Resolução da Diretoria Colegiada (RDC) no 37, de 6 de julho de 2009 podem ser utilizados como referência, a saber: Farmacopeia Alemã; Farmacopeia Americana; Farmacopeia Argentina; Farmacopeia Britânica; Farmacopeia Europeia; Farmacopeia Francesa; Farmacopeia Internacional; Farmacopeia Japonesa; Farmacopeia Mexicana; e Farmacopeia Portuguesa (BRASIL, 2009a).

Tal possibilidade permite mais agilidade para o setor regulado, pois o desenvolvimento de um método analítico para a aplicação em materiais de origem vegetal não é uma tarefa simples, correspondendo a uma das maiores dificuldades para o uso industrial dos fitoterápicos (ELOFF; NTLOEDIBE; VAN BRUMMELEN, 2011). Essa etapa envolve vários desafios como: extração das substâncias de interesse a partir de uma matriz complexa; variação da composição química do material vegetal e a determinação de marcadores químicos (muitas vezes o princípio ativo não é conhecido); ausência de descrição da maioria das espécies nativas ou em uso em farmacopeias; e a falta de substâncias ou padrões de referência (FOLASHADE; OMOREGIE; OCHOGU, 2012; FORTE; RAMAN, 2000; PERFEITO, 2012).

Cerca de $42 \%$ das causas de indeferimento de registros de medicamentos fitoterápicos no Brasil são relacionadas ao não cumprimento de exigências relativas ao controle da qualidade (PERFEITO, 2012), o que tem dificultado o registro dos fitoterápicos no Brasil, diminuindo a oferta dessa alternativa terapêutica.

Assim, o cenário atual para o setor dos fitoterápicos indica que ao mesmo tempo em que há uma necessidade de promover o aprimoramento das farmacopeias com inclusão de especificações padronizadas, substâncias químicas de referência e métodos gerais, é necessário 
não perder de vista a necessidade de se alinhar ao cenário internacional do mercado globalizado que deseja a harmonização.

Um estudo da situação dos fitoterápicos na Farmacopeia Brasileira, correlacionando as monografias frente ao contexto brasileiro e internacional, pode evidenciar a sua situação, contribuindo para o desenvolvimento de ferramentas e para o aprimoramento da sua função.

\subsection{FITOTERÁPICOS NO MUNDO}

Os fitoterápicos foram utilizados mundialmente como o principal recurso medicamentoso durante um longo período da história da humanidade (FOLASHADE; OMOREGIE; OCHOGU, 2012; SAITO, 2000; SHARMA et al., 2015), tendo sido somente após a $2^{\mathrm{a}}$ Guerra Mundial que os medicamentos constituídos de insumos farmacêuticos sintéticos ocuparam a liderança (SAITO, 2000).

Desde a década de 60, as vendas de fitoterápicos têm aumentado na Europa e no mundo, impulsionadas pelo aparecimento dos efeitos colaterais associados ao uso dos produtos sintéticos (RATES, 2001) e pela necessidade crescente por produtos destinados às doenças relacionadas ao envelhecimento (SAITO, 2000), pois os fitoterápicos são, por muitos, considerados produtos "naturais" (ELOFF; NTLOEDIBE; VAN BRUMMELEN, 2011), ou produtos relacionados a um modo de viver mais saudável (FOLASHADE; OMOREGIE; OCHOGU, 2012). Por outro lado, os fitoterápicos têm sido utilizados no ambiente urbano como alternativa aos cuidados diários com a saúde e em automedicação contra doenças crônicas e de menor gravidade acompanhando o contexto de áreas rurais menos prósperas ou os tempos de crise mundial (LEONTI; CASU, 2013).

O mercado mundial de fitoterápicos, em 2000, era de 60 bilhões de dólares (UNCTAD, 2000), e projeções mais atuais indicam que o mercado de fitoterápicos e suplementos contendo espécies de plantas poderá alcançar 115 bilhões de dólares em 2020, impulsionado pelo crescimento da adoção de cuidados preventivos, como uma estratégia para promover a saúde e o bem estar (GIA, 2015).

Considerando esse nicho de mercado, muitas ações foram realizadas após a publicação pela WHO, em 2002, da primeira estratégia para a medicina tradicional (WHO, 2002). Assim, com o intuito de promover o uso eficaz e seguro da medicina tradicional e com qualidade, vários países desenvolveram seus padrões técnicos na forma de guias, políticas e regulamentos para melhorar a prestação desse serviço de saúde (WHO, 2013b). 
A WHO, após a publicação da estratégia, também publicou diversos documentos auxiliares para a área dos fitoterápicos, tais como: uma atualização do documento Quality control methods for medicinal plant materials (WHO, 2011), que contém diretrizes para o controle da qualidade de fitoterápicos; os volumes 2, 3 e 4 do WHO monographs on select plants (WHO, 2004, 2007c, 2009), que contêm informações sobre uso tradicional e dados de segurança e eficácia de fitoterápicos; o Guidelines on Good Manufacturing Practices (GMP) for Herbal Medicines (WHO, 2007b), que dispõe sobre boas práticas de fabricação de fitoterápicos; o Guidelines on Good Agricultural and Collection Practices (GACP) for Medicinal Plants (WHO, 2003), que dispõe sobre as boas práticas agrícolas; o Guidelines for Assessing Quality of Herbal Medicines with Reference to Contaminants and Residues (WHO, 2007a), que contém informações sobre a análise de contaminantes e resíduos em agrotóxicos; e o Traditional Herbal Remedies for Primary Health Care (WHO, 2010), documento com informações sobre o modo de uso, composição e padrões de qualidade para alguns fitoterápicos. Ainda, foi estabelecido em 2006 o International Regulatory Cooperation for Herbal Medicines (IRCH), um programa da WHO formado por autoridades reguladoras nacionais e regionais responsáveis pela regulação dos fitoterápicos, incluindo o Brasil, cuja missão é proteger e promover a segurança e a saúde pública por meio do aperfeiçoamento da regulação para os fitoterápicos (WHO, 2016c).

\subsection{FITOTERÁPICOS NO BRASIL E NA ANVISA}

Devido à sua biodiversidade, a flora brasileira representa uma das mais ricas fontes de material com potencial atividade farmacológica, sendo considerada por muitos uma das maiores biodiversidades do mundo (BRANDÃO et al., 2008, 2013; CARVALHO et al., 2014). Plantas medicinais são largamente usadas como remédios caseiros no Brasil e várias espécies utilizadas são nativas de outros continentes e foram introduzidas desde a colonização em 1500 (BRANDÃO et al., 2008). Essa rica biodiversidade gera uma grande expectativa sobre o mercado brasileiro, que movimenta no setor, atualmente, de 1,6 a 1,8 bilhões de reais (DE VALÉCIO, 2016; EUROMONITOR, 2016).

Em reconhecimento a essa realidade brasileira e ao panorama internacional de apoio a políticas para a medicina tradicional complementar, em 2006, foram publicadas a Política Nacional de Práticas Integrativas e Complementares (PNPIC) no Sistema Único de Saúde (SUS) e a Política Nacional de Plantas Medicinais e Fitoterápicos (PNPMF) (BRASIL, 2006a, 
b). Em consonância com essas políticas e respondendo à lacuna de ausência de listas de espécies para estudos de interesse no Brasil (VEIGA JUNIOR; MELLO, 2008), em 2009 o Ministério da Saúde publicou a Relação Nacional de Plantas Medicinais de Interesse ao SUS (RENISUS), composta por 71 espécies de plantas medicinais com potencial terapêutico, para orientar o desenvolvimento de pesquisas e a cadeia produtiva no Brasil (BRASIL, 2009b), uma prioridade estabelecida pelo Ministério da Saúde para o SUS que abrange também as áreas de atuação da Agência Nacional de Vigilância Sanitária (Anvisa) (CARVALHO, 2011).

A Anvisa, acompanhando as políticas, publicou, em 2013, regulamentos inéditos no país para a área de fitoterápicos: a Resolução RDC n 13, de 14 de março de 2013, que "dispõe sobre as Boas Práticas de Produtos Tradicionais Fitoterápicos" (BRASIL, 2013b); e a Resolução RDC n 18 de 03 de abril de 2013, que “dispõe sobre as Boas Práticas de Processamentos e Armazenamento de plantas medicinais, Preparação e Dispensação de produtos magistrais e oficiais de plantas medicinais e fitoterápicos em Farmácias Vivas no âmbito do Sistema Único de Saúde (SUS)" (BRASIL, 2013c). E, em 2014, a Anvisa publicou atualizações para os regulamentos técnicos de produtos fitoterápicos, dentre os quais se destacam: a Resolução RDC $\mathrm{n}^{\circ}$ 26, de 13 de maio de 2014 ( $\mathrm{RDC} \mathrm{n}^{\circ}$ 26/2014), que “dispõe sobre o registro de medicamentos fitoterápicos e o registro e a notificação de produtos tradicionais fitoterápicos" (BRASIL, 2014c); e a Instrução Normativa n ${ }^{\circ}$ 02, de 13 de maio de 2014 (IN nº 02/2014), que "Publica a Lista de medicamentos fitoterápicos de registro simplificado e a Lista de produtos tradicionais fitoterápicos de registro simplificado" (BRASIL, 2014a).

Com a atualização do marco legal para fitoterápicos no Brasil, os critérios para registro dos fitoterápicos se tornaram mais harmonizados com os critérios internacionais (CARVALHO et al., 2014; MOREIRA et al., 2014). Dentre as mudanças, a RDC n 26/2014 dispõe que poderão ser notificados como Produto Tradicional Fitoterápico (PTF) os Insumos Farmacêuticos Ativos Vegetais (IFAV) contidos na edição vigente do Formulário de Fitoterápicos da Farmacopeia Brasileira (FFFB), considerando a concentração, droga vegetal (ou o derivado) e a alegação de uso, desde que exista monografia farmacopeica, com os requisitos mínimos de qualidade, em compêndios reconhecidos pela Anvisa (BRASIL, 2014c). A notificação é um mecanismo de obtenção da concessão para a comercialização de produtos, independente de análise prévia, cuja autorização é imediata após a sua comunicação oficial pelos meios estabelecidos. Consequentemente, houve um automático aumento da importância dos compêndios da Farmacopeia Brasileira que podem facilitar a entrada de fitoterápicos no mercado brasileiro. Espécies nativas do Brasil com reconhecida tradicionalidade de uso e 
incorporadas ao FFFB, podem ser comercializadas no mercado brasileiro após notificação como PTF, desde que exista monografia estabelecida na Farmacopeia Brasileira (FB), ou em outra farmacopeia internacional aceita pela Anvisa.

Os fitoterápicos, então, para serem comercializados no mercado brasileiro podem cumprir processos menos complexos, com determinação da sua eficácia e segurança presumida por tradicionalidade de uso (PTF). Mas não somente a segurança e a eficácia são requisitos essenciais dos produtos; é necessário que sejam caracterizados por constância da sua qualidade (BRASIL, 2014c), para, assim, assegurar que o produto final possui a eficácia e a segurança previstas. No conceito de constância da qualidade estão incluídas, além dos critérios mínimos de qualidade, as Boas Práticas de Fabricação (GMP) (WHO, 2015b), que, no caso dos fitoterápicos, envolvem desde a produção agrícola, perpassando pela colheita, preparação da droga vegetal, extratos e produto final (FOLASHADE; OMOREGIE; OCHOGU, 2012; FORTE; RAMAN, 2000; VLIETINCK; PIETERS; APERS, 2009).

Nesse sentido, as farmacopeias se tornam ainda mais essenciais para o setor de fitoterápicos, na medida em que estabelecem padrões de qualidade, cujo desenvolvimento é claramente um desafio, para produtos cujos relatos de eventos adversos estão, em sua maioria, relacionados à baixa qualidade dos produtos (WHO, 2011).

\subsection{FARMACOPEIAS}

Farmacopeias são documentos que contêm registros de padrões de qualidade e especificações para produtos farmacêuticos e matérias-primas oficiais em um país ou região, sendo desejável a sua existência para uma apropriada regulação da produção de medicamentos (WHO, 2013a).

Os mais antigos "registros de farmácia", precursor das farmacopeias atuais, tem origem na China por volta do ano 2700 AC e no velho Egito entre 2000 e 1500 AC. Dois exemplos marcantes são o Shen Nung Pên-Ts'ao, atribuído a Shen Nung, que reinou entre 2838-2698 A.C., mas escrito no primeiro século AC, que descreve 365 ervas (KAN, 1965) e o papiro de Ebers, cuja origem remonta ao reinado de Amenophis (1536 AC) (HALLMANNMIKOŁAJCZAK, 2004). Depois desse período, instruções farmacêuticas também foram escritas pelos romanos e gregos, época em que se pode destacar a De Matéria Médica, 40-80

DC (INIC; KUJUNDZIC, 2012; LEONTI et al., 2009). A ideia do estabelecimento de uma farmacopeia como um estatuto oficial, a ser seguida por todos os boticários, com a finalidade 
de proteger a saúde humana, teve sua origem na Florença. O Nuovo Receptario, originalmente escrito em italiano, foi publicado e tornou-se o padrão legal na região em 1498 (URDANG, 1951).

Antigamente, as farmacopeias possuíam uma função mais relacionada a um formulário de produtos oficinais do que um compêndio que dispõe especificações de qualidade de produtos (ARGENTINA, 2003; BRASIL, 1929; URDANG, 1951). Em alguns casos, possuíam a função de regular os produtos no mercado, isentando de autorizações complementares para a comercialização dos produtos oficinais dispostos em seu compêndio, permitindo a sua manipulação por farmácias e laboratórios (BRASIL, 1943a). De acordo com Portaria n 47 de 06 de março de 1943, produto oficinal era "aquele de conservação boa e relativamente boa, de fórmula e preparação fixas, inscritas na Farmacopeia Brasileira ou, quando dela não constarem, em outra farmacopeia ou em formulários aprovados" e, àquela época, podia ser vendido independente de licença especial (BRASIL, 1943a).

Bem longo foi o caminho percorrido pelas farmacopeias até chegar ao padrão dos dias atuais. Atualmente vigente, a Lei ${ }^{\circ} 6.360$ de 23 de setembro de 1976 (Lei nº 6.360/76), em sua redação original dispunha, no $23^{\circ}$ artigo, que estavam isentos de registro os produtos cujas fórmulas estavam inscritas na Farmacopeia Brasileira (BRASIL, 1976b). Este artigo foi revogado pela Lei $n^{\circ} 10.742$ de 06 de outubro de 2003 (BRASIL, 2003b). Assim, a Lei $n^{\circ}$ 6.360/76, atualmente, dispõe apenas sobre a função da farmacopeia como requisito mínimo de qualidade "Art. 62. Considera-se alterado, adulterado ou impróprio para o uso o medicamento, a droga e o insumo farmacêutico: (...)IV - quando suas condições de pureza, qualidade e autenticidade não satisfizerem às exigências da Farmacopeia" (BRASIL, 1976b). Dessa forma, o objetivo das farmacopeias atuais é estabelecer padrões de qualidade, identidade ou autenticidade e pureza que os medicamentos devem obrigatoriamente seguir.

Por outro lado, o mercado atual, altamente globalizado, devido ao comércio internacional, televisão internacional e a World Wide Web (www), propicia grandes intercâmbios entre as farmacopeias de abrangência mais global e as farmacopeias locais (LEONTI; CASU, 2013).

Assim, é possível observar uma tendência à convergência de monografias nas diferentes farmacopeias oficiais, com a existência, no geral, de muito conteúdo harmonizado sem desenvolvimento próprio, enquanto as farmacopeias oficiais de cada país, cada vez mais se preocupam em desenvolver conteúdos para os seus fitoterápicos tradicionais (SAITO, 2000; SHIKOV et al., 2014). 
Dentre as farmacopeias existentes atualmente, algumas possuem uma maior utilização, com maior permeação entre os países, do que outras, servindo de referência e modelo para outras farmacopeias, das quais podem ser citadas a European Pharmacopoeia (Ph. Eur.), adotada pelos Estados membros da Comunidade Europeia (EDQM, 2016b) e que possui várias farmacopeias observadoras espalhadas pelo mundo, dentre elas a do Brasil (EDQM, 2016d); a The United States Pharmacopoeia and National Formulary (USP-NF) (USP, 2016h), utilizada como mandatória e como referência regulatória em muitos países; e a International Pharmacopoeia da WHO, que pode ser utilizada, pelos Estados membros, como fonte de referência para o estabelecimento de especificações farmacopeicas para seus próprios compêndios (WHO, 2015b).

Considerando o contexto brasileiro, também se destaca a Farmacopea Argentina devido à sua proximidade regional e ao fato da Argentina estar envolvida no Mercado Comum do Sul (Mercosul). O Mercosul abrange os países Argentina, Brasil, Paraguai, Uruguai e Venezuela (BRASIL, [S.d.]), sendo, além do Brasil, a Argentina, o único desses países com farmacopeia publicada (WHO, 2016b).

Assim, considerando a importância no contexto internacional e nacional das farmacopeias, para a realização de comparações neste trabalho, foram escolhidas as farmacopeias European Pharmacopoeia, The United States Pharmacopoeia and National Formulary (USP-NF) e Farmacopea Argentina. A International Pharmacopoeia não foi selecionada por seu escopo não incluir monografias para os fitoterápicos.

\subsubsection{Farmacopeia Argentina}

Em novembro de 1898 teve início a vigência do primeiro Codex Medicamentarius de la Republica Argentina, obrigatório para todas as farmácias. A partir de então foram mais seis edições, com a sétima edição lançada em 2003 (ANMAT, 2003c). Manter a Farmacopea Argentina atualizada é um dos objetivos prioritários da Administración Nacional de Medicamentos, Alimentos y Tecnologia Médica (ANMAT). A Farmacopea Argentina possui uma Comissão Permanente da Farmacopeia Argentina, subsidiada por 21 subcomissões de caráter técnico que prestam apoio técnico e científico a Comissão Permanente (ANMAT, 2003a).

As subcomissões técnicas que tratam de temas específicos possuem 8 a 10 integrantes especialistas, sendo um membro do Instituto Nacional de Medicamentos (ANMAT, 2003a). 
Pode haver, ainda, um Comitê Consultor Externo com especialistas destacados de instituições de ensino, profissionais, industriais e científicas, eleitos por sua trajetória e conhecimento científico (ANMAT, 2003a). Na Farmacopea Argentina $7^{\text {a }}$ edição estão listadas 17 subcomissões, sendo apenas uma na área de fitoterápicos, a subcomissão Medicamentos Herbarios constituída de 23 componentes (ANMAT, 2003b).

A Farmacopea Argentina é de uso obrigatório na Argentina pelas farmácias, drogarias, empresas fabricantes e importadoras e os estabelecimentos que comercializem ou distribuam produtos farmacêuticos, podendo, na ausência de especificação estabelecida na Farmacopea Argentina, ser utilizados outros compêndios de valor científico reconhecido (ARGENTINA, 1964, 2003).

A Farmacopea Argentina $7^{\text {a }}$ edição, atualmente vigente, possui 29 monografias de drogas vegetais (ANMAT, 2003b). De acordo com o Index of World Pharmacopoeias, a Farmacopea Argentina $8^{\text {a }}$ edição está em consulta pública desde 2011 (WHO, 2016b), porém, a sua publicação oficial não foi, ainda, realizada.

A Farmacopea Argentina é publicada em espanhol, e não há uma frequência estabelecida para a sua atualização.

\subsubsection{Farmacopeia Americana}

A história da USP-NF teve início em 1820, quando um grupo de 11 médicos vislumbrou a necessidade da construção de uma farmacopeia para os Estados Unidos com um sistema de padrões e fórmulas. Naquela época, por questões de embasamento e compreensão do seu uso, apenas 217 fármacos cumpriram com os requisitos para serem admitidos (USP, 2016d, e).

Em 1888 foi publicada a $1^{\text {a }}$ edição do National Formulary, pela American Pharmacists Association, porém, somente em 1977 a sua função, de conter especificações de qualidade para excipientes, foi estabelecida, enquanto a United States Pharmacopeia passou a conter as especificações para os fármacos e formas farmacêuticas (USP, 2016e).

A United States Pharmacopeia é publicada pela United States Pharmacopeial Convention (USP), uma convenção formada por membros da academia, organizações que representam os interesses dos consumidores, membros de governos, associações profissionais, associações do setor regulado e outros (USP, 2016c).

Atualmente há mais de 4900 monografias na The United States Pharmacopeia 39a edição e no National Formulary 34 a edição (USP39-NF34) (USP, 2016b, g). As monografias, 
em geral, são de produtos legalmente comercializados nos Estados Unidos (USP, 2016d). De acordo com o The Federal Food, Drug, and Cosmetic Act os produtos com padrões descritos na USP-NF devem cumprir com os seus requisitos de qualidade (USP, 2016b).

O comitê listado na USP39-NF34 diretamente vinculado a área de fitoterápicos é o Botanical Dietary Supplement and Herbal Medicines Expert Committee que contém 22 membros, que desenvolvem trabalhos para a United States Pharmacopeia e para o Dietary Supplements Compendium. Há, ainda, vinculados à área de fitoterápicos, alguns Expert panels, tais como o Herbal medicines compendium (HMC) East Asia Expert Panel e o Herbal medicines compendium (HMC) South Asia Expert Panel (USP, 2016f).

Uma nova edição da USP-NF, substituindo a anterior, é publicada anualmente com entrada em vigor em $1^{\circ}$ de maio de cada ano (USP, 2016b, d). A farmacopeia é atualizada, ainda, com a publicação de dois suplementos por ano com vigência iniciada em $1^{\circ}$ de agosto e $1^{\circ}$ de dezembro de cada ano (USP, 2016b, d). Além da atualização regular três vezes ao ano, é possível a atualização por meio da publicação de erratas, anúncios de revisão interinos e boletins de revisão, possuindo, assim, a USP-NF uma rápida taxa de atualização (USP, 2016b, d).

O processo de revisão padrão das monografias da USP obedece a um fluxo que envolve um período de consulta pública de 90 dias no Phamacopeial Forum, que, então, após aprovação pelo comitê especialista responsável, a revisão é incluída na próxima publicação da USP-NF (USP, 2016d).

A USP está disponível em espanhol, russo e chinês, sendo o russo e o chinês apenas para novas monografias ou revisões (USP, 2016d).

\subsubsection{Farmacopeia Europeia}

A história da Ph. Eur. teve início em 1964 por meio da Convention on the Elaboration of a European Pharmacopoeia sob a proteção do Council of Europe (EDQM, 2016g).

As monografias e os capítulos gerais da Ph. Eur. são mandatórios nos 37 Estados membros e na Comunidade Europeia (EDQM, 2016g).

A elaboração e aprovação de monografias e outros textos é realizada com a cooperação científica dos membros dos Groups of Experts em Working Parties (Reuniões de Trabalho) organizadas pela European Pharmacopoeia Commission (Comissão da Farmacopeia Europeia) (EDQM, 2016g). Os Groups of Experts são compostos por membros provenientes das 
autoridades regulatórias, laboratórios oficiais de controle de medicamentos, fabricantes de medicamentos e insumos químicos, membros da academia e de instituições de pesquisa (EDQM, 2016g).

Uma nova edição da Ph. Eur. é publicada a cada três anos, com a publicação de oito suplementos no intervalo, três por ano, possuindo, assim, uma eficiente taxa de atualização (EDQM, 2016g). Todas as monografias são verificadas experimentalmente e submetidas a Consulta Pública por meio da publicação online no fórum do Pharmaeuropa (EDQM, 2016g).

Na European Pharmacopoeia 8.8 há 278 monografias de fitoterápicos, incluindo derivados (tinturas, extratos secos, óleos etc.) (EDQM, 2016h). Em 2014, $12 \%$ das monografias da European Pharmacopoeia eram relacionadas a plantas medicinais (BOUIN; WIERER, 2014).

A Farmacopeia Europeia possui versões em inglês e em francês, línguas oficiais da Comunidade Europeia (EDQM, 2016d).

\subsubsection{Farmacopeia Brasileira}

A Pharmacopêa Geral para o Reino e domínios de Portugal, publicada em 1794, vigorou como único código farmacêutico oficial no Brasil até 1837, anos após a independência do Brasil, quando o Codex medicamentarius francez passou também a ser oficialmente adotado (BRASIL, 1929). Porém, estes códigos foram redigidos para realidades de outros países que não o Brasil, e, portanto, era esperado que não atendessem às necessidades do novo país.

Após várias tentativas fracassadas das associações médicas e farmacêuticas em constituir uma farmacopeia brasileira, o primeiro código farmacêutico brasileiro, a "Pharmacopeia Brasileira" 1ª edição (FB1), foi oficializada por meio do Decreto 17.509 de 4 de novembro de 1926 (BRASIL, 1926, 1929). A sua publicação, porém, só ocorreu em 1929, se tornando obrigatória em 15 de agosto de 1929 (BRASIL, 1929). Para a primeira edição, em 1943, foi aprovado e publicado um suplemento (o primeiro) no então Diário Oficial, Seção 1, na Portaria $\mathrm{n}^{\circ} 42$ de 02 de março de 1943 (BRASIL, 1943b); o segundo suplemento foi aprovado pela Portaria n ${ }^{\circ} 24$ de 14 de abril de 1945 (BRASIL, 1947); e o terceiro suplemento foi aprovado e publicado na Portaria ${ }^{\circ} 39$ de 13 de junho de 1950 (BRASIL, 1951).

Oito anos após a última atualização da primeira edição, em 1959, foi publicada a Farmacopeia dos Estados Unidos do Brasil $2^{\mathrm{a}}$ edição (FB2), tendo sido aprovada por meio do Decreto ${ }^{\circ} 45.502$ de 27 de fevereiro de 1959 (BRASIL, 1959a). Essa farmacopeia apresentava 
como novidade a supressão de fármacos e preparações galênicas oficinais destinados a compor o Formulário Nacional que, à época, se pensava seria publicado em curto espaço de tempo, como um complemento à Farmacopeia (BRASIL, 1959b). Contudo, a publicação do Formulário Nacional ocorreu somente em 2005 (BRASIL, 2005b). Ao mesmo tempo, foram excluídas diversas monografias, tendo em vista a nulidade de ação terapêutica de muitos fármacos e medicamentos, bem como o completo desuso de numerosos outros (BRASIL, 1959b). Por outro lado, foram incluídas monografias para produtos que dominavam a terapêutica, tais como: antibióticos, sulfas, hormônios, vitaminas, barbitúricos e outros (BRASIL, 1959b).

A Farmacopeia Brasileira $3^{\text {a }}$ edição (FB3) foi aprovada em 1976 por meio do Decreto $\mathrm{n}^{\circ} 78.840$ de 25 de novembro de 1976 (BRASIL, 1976a) e publicada em 1977 (BRASIL, 1977). Nesta farmacopeia houve um crescimento de monografias dos chamados, à época, quimioterápicos em detrimento dos produtos provenientes de plantas medicinais. As monografias da $2^{\mathrm{a}}$ edição foram revisadas e foram acrescidas outras para os novos agentes terapêuticos (BRASIL, 1977).

No mesmo ano da promulgação da nova constituição brasileira de 1988 (BRASIL, 1988a), foi publicada a Farmacopeia Brasileira $4^{a}$ Edição (FB4), época em que a Farmacopeia Brasileira era amparada na Secretaria Nacional de Vigilância Sanitária do Ministério da Saúde. Esta, por sua vez, apresentou um novo formato de publicação com fascículos (BRASIL, 1988c), que eram incorporados à edição após sua publicação a fim de possibilitar uma atualização mais constante da farmacopeia, acompanhando o, então denominado, rápido avanço das tecnologias (BRASIL, 1988c). Porém, enquanto a Parte 1, contendo os métodos de análise e generalidades, foi aprovada por meio do Decreto $\mathrm{n}^{\circ}$ 96.607, de 30 de agosto de 1988 (BRASIL, 1988b, c) e publicada no mesmo ano, a Parte 2 (Fascículo 1), contendo as monografias, foi publicada somente em 1996 (BRASIL, 1996). Ambas as partes foram atualizadas por mais cinco fascículos publicados em 2000, 2001, 2002, 2003 e 2005 (BRASIL, 2000, 2001, 2002, 2003a, 2005a).

Antes da publicação da $4^{a}$ edição da farmacopeia brasileira, as monografias das edições anteriores que não haviam sido expressamente revogadas permaneciam válidas (BRASIL, 1959b, 1977). Na publicação da $4^{\mathrm{a}}$ edição, tanto o seu Prefácio como o Decreto 96.607/88, dispunham que a Farmacopeia Brasileira $4^{\mathrm{a}}$ edição era o compêndio vigente e que as substâncias farmacêuticas que ali não estivessem dispostas poderiam atender outros códigos oficiais (BRASIL, 1988b). No Prefácio, esses códigos oficiais foram discriminados como sendo a 
Farmacopeia Internacional, a Farmacopeia Europeia ou outros em sua última edição (BRASIL, 1988c), porém, até a publicação, em 1988, da Parte 1 da FB4, não havia monografias vigentes para essa edição.

Com a publicação da Lei no 9782 de 26 de janeiro de 1999, a Anvisa passou a ser a responsável pela regulamentação e controle da produção e da comercialização de produtos e serviços submetidos à vigilância sanitária, incluindo em sua competência a promoção da revisão e atualização periódica da Farmacopeia Brasileira (BRASIL, 1999).

Com essa mudança, a dinâmica do funcionamento da farmacopeia se alterou. O cumprimento da competência da Anvisa de revisar e atualizar a Farmacopeia Brasileira foi possibilitado pela organização de uma Comissão da Farmacopeia Brasileira (CFB). A CFB é composta por: um Conselho Deliberativo formado por membros da academia, instituições públicas, incluindo a Anvisa, e representantes do setor regulado; por 18 Comitês Técnicos Temáticos (CTT) específicos compostos por cinco a oito profissionais com notório saber, constituídos por representantes da academia, do setor produtivo e da Anvisa; e pela Coordenação Técnico-Científica e Executiva realizadas pela Coordenação da Farmacopeia, uma coordenação inserida no organograma da Anvisa (BRASIL, 2013a).

A Farmacopeia Brasileira $5^{\text {a }}$ edição (FB5), obra atualmente vigente, que determina os requisitos mínimos de qualidade para várias categorias de produtos, foi elaborada pela CFB e publicada em 2010 pela Anvisa (BRASIL, 2010c, d). A FB5 inclui 605 monografias, das quais 58 são monografias para drogas vegetais e derivados (BRASIL, 2010d).

Os outros compêndios da CFB que abordam os fitoterápicos são: o Formulário de Fitoterápicos da Farmacopeia Brasileira $1^{a}$ edição (FFFB1) que possui 83 monografias de preparações farmacêuticas (BRASIL, 2011); e o Memento Fitoterápico da Farmacopeia Brasileira $1^{\text {a }}$ edição, que possui 28 monografias com informações sobre plantas medicinais, como identificação, indicações, modo de uso, advertências e dados científicos sobre ensaios clínicos e não clínicos (BRASIL, 2016d).

Dentre os Comitês Técnicos Temáticos, o de Farmacognosia é o responsável técnico por propor revisões e novas monografias de drogas vegetais e derivados para a Farmacopeia Brasileira. O CTT de Apoio a Política Nacional de Plantas Medicinais e Fitoterápicos é o responsável por propor revisões e novas monografias para o Formulário de Fitoterápicos e o Memento Fitoterápico da Farmacopeia Brasileira. 
A revisão e inclusão de novas monografias na farmacopeia brasileira ocorre majoritariamente por meio do desenvolvimento e validação de métodos em laboratórios credenciados e por meio da adaptação ou adoção de monografias de outras farmacopeias.

Os prazos para a atualização dos compêndios da CFB não estão pré-estabelecidos. O seu processo de atualização obedece às etapas previstas no Programa de Melhoria do Processo Regulatório da Anvisa, e envolve vários passos após a aprovação pela CFB. Há a necessidade de publicação prévia de iniciativa de atuação regulatória para cada produto ou documento, a publicação de consulta pública com prazo para a contribuição da sociedade, que geralmente varia de 30 a 90 dias, e a publicação do texto final, sendo todas as etapas precedidas de manifestação da diretoria da Anvisa (BRASIL, 2008a, b).

A Farmacopeia Brasileira é publicada em português, porém, há a disponibilização de versões em inglês e espanhol, consideradas, para fins de regulação, não oficiais.

\subsection{HARMONIZAÇÃO INTERNACIONAL DE CRITÉRIOS DE QUALIDADE}

O tema da harmonização de requisitos sanitários tem sido recorrente no âmbito internacional, motivado pela globalização do mercado de consumo (ICH, 2015; KEITEL, 2013; WECHSLER, 2013). A harmonização é desejável na medida em que, ao unificar procedimentos, oferece a possibilidade de redução do quantitativo de novos procedimentos exigidos para o controle sanitário e obtenção de autorização de comercialização, oferecendo vantagens econômicas e facilitando a circulação dos produtos no mercado globalizado.

A harmonização farmacopeica significa que uma substância ou produto testado por um procedimento harmonizado está sujeito aos mesmos parâmetros e aos mesmos critérios de aceitação e rejeição, seja qual for o mercado de destino (WHO, 2016a), enquanto a convergência farmacopeica significa que as farmacopeias procuram se tornar mais semelhantes ou alinhadas visando atingir, ao final, um mesmo objetivo sanitário (PAULA et al., 2016).

A deficiência em critérios harmonizados tem resultado com que o aspecto da qualidade seja considerado pelas empresas o mais desafiador para os registros nos diferentes países (FAN et al., 2012). Desse modo, tem sido frequente a preocupação de instituições e organismos internacionais com a harmonização desses critérios.

A Ph. Eur. identificou a necessidade de harmonização de critérios de qualidade para produtos farmacêuticos no mercado europeu há quase 50 anos (KEITEL, 2013). O Pharmacopoeial Discussion Group (PDG), um programa trilateral conduzido pela Ph. Eur., 
Japanese Pharmacopoeia (JP) e a United States Pharmacopeial Convention (USP) trilha, desde 1989, o caminho da harmonização de documentos farmacopeicos (PDG, 2010).

De acordo com o procedimento de trabalho do PDG, Working procedures of the Pharmacopoeial Discussion Group, a harmonização envolve sete estágios: identificação dos assuntos a serem harmonizados; investigação das especificações existentes; proposição de um documento de trabalho para ser revisto por comitês técnicos especialistas; consulta oficial com a publicação de uma proposta nos fóruns; consenso, quando é feito o máximo possível para atingir total concordância; adoção e implementação regional; e aceitação inter-regional (PDG, 2010).

Porém, devido à expansão do número de autoridades regulatórias ativas que dispõem de seus próprios requisitos, as questões relativas à harmonização não podem mais ser limitadas à Comunidade Europeia, Estados Unidos da América ou Japão e o pensamento deve continuar avançando no sentido de atender à realidade de que, se a harmonização não é possível, então a convergência, de políticas e procedimentos, deve ser um objetivo a ser alcançado (WECHSLER, 2013). Mais recentemente, foi instituída a Farmacopeia Mercosul, que une representantes da Argentina, Brasil, Paraguai, Uruguai e Venezuela (MERCOSUL, 2011) para, como o PDG, trabalhar na harmonização de métodos gerais e monografias para internalização em seus países.

Assim, em 2016, após quatro anos de discussões entre as farmacopeias mundiais (WHO, 2015a), a WHO publicou o documento World Health Organization - Good Pharmacopoeial Practices, cujo objetivo é definir abordagens e políticas para o estabelecimento de padrões farmacopeicos, para auxiliar as autoridades reguladoras no controle da qualidade dos produtos farmacêuticos com o objetivo fundamental de alcançar a harmonização (WHO, 2016a).

Embora o assunto, harmonização e convergência de farmacopeias, seja atual, poucos são, ainda, os estudos encontrados relacionados ao tema.

Em 2014, Shikov et al. (2014) sistematizaram informações sobre a história das plantas medicinais constantes na Farmacopeia Russa, destacando os seus diferenciais em comparação com a Ph. Eur. (SHIKOV et al., 2014).

A European Industrial Gases Association (EIGA) publicou em 2011 as especificações para gases medicinais contidas na Ph. Eur., na USP-NF e na JP com o objetivo de apresentar uma referência cruzada que possa possibilitar comparações dos dados (EIGA, 2011). 
Ainda, podem ser citados Redchenkova \& Khishova (2006) que compararam os conceitos de extratos de drogas vegetais entre as $\mathrm{Ph}$. Eur., Polonesa e Russa (REDCHENKOVA; KHISHOVA, 2006).

A harmonização com os critérios internacionais é um tema frequentemente abordado dentro dos Comitês Técnicos Temáticos da Farmacopeia Brasileira relacionados à área de plantas medicinais, porém, atualmente, não há, estabelecido, um método sistematizado de trabalho.

\section{OBJETIVOS}

\subsection{GERAL}

Realizar um estudo sistematizado sobre as monografias para drogas vegetais e fitoterápicos da Farmacopeia Brasileira, com destaque para a Farmacopeia Brasileira $5^{\text {a }}$ edição, relacionando e comparando com os padrões dispostos nos documentos internacionais similares.

\subsection{ESPECÍFICOS}

1) Avaliar a evolução histórica das monografias de drogas vegetais e derivados da Farmacopeia Brasileira 5 a edição (FB5);

2) Avaliar as diferenças entre as monografias e espécies de plantas medicinais constantes nos compêndios da Farmacopeia Brasileira e na Instrução Normativa nº 02/2014 (IN $\left.n^{\circ} 02 / 2014\right)$;

3) Analisar qualitativamente e quantitativamente a correlação entre as espécies constantes na Farmacopeia Brasileira $5^{\mathrm{a}}$ edição e no Formulário de fitoterápicos $1^{\mathrm{a}}$ edição com a existência de fitoterápicos registrados na Anvisa, e relacionar com a ocorrência das espécies no Brasil; e

4) Avaliar comparativamente as monografias da FB5 e as monografias correspondentes nas farmacopeias: Farmacopea Argentina $7^{\mathrm{a}}$ edição (FA7), European Pharmacopoeia $8^{\mathrm{a}}$ edição, incluindo seus oito suplementos (EP8.8) e The United States Pharmacopeia $39^{\text {a }}$ edição e o National Formulary $34^{\text {a }}$ edição, incluído os seus dois suplementos (USP39-NF34). 


\section{MÉTODOS}

A situação dos fitoterápicos na Farmacopeia Brasileira foi avaliada por meio de um estudo predominantemente qualitativo comparativo documental com busca de informações em publicações de caráter oficial, bases de dados de caráter científico, obras disponíveis em bibliotecas e base de dados públicos.

Neste estudo, a expressão "fitoterápicos da Farmacopeia Brasileira” compreende todas as drogas vegetais e derivados, bem como preparações farmacêuticas constantes na Farmacopeia Brasileira $5^{a}$ edição (FB5) e no Formulário de Fitoterápicos da Farmacopeia Brasileira $1^{\mathrm{a}}$ edição (FFFB1). A expressão “espécies da Farmacopeia Brasileira” compreende as espécies vegetais contidas na FB5 e no FFFB1 em conjunto, enquanto a expressão "monografias da Farmacopeia Brasileira" contempla o conjunto das monografias da FB5 e do FFFB1. Pode, ainda, haver referência de forma isolada aos fitoterápicos da FB5, ou os fitoterápicos do FFFB1, ou as espécies da FB5, ou as espécies do FFFB1, ou as monografias da FB5 e ou as monografias do FFFB1.

A expressão "compêndios em estudo" compreende a FB5, o FFFB1, a European Pharmacopeia $8^{\mathrm{a}}$ edição incluindo os seus oito suplementos (EP8.8), a Farmacopea Argentina $7^{\mathrm{a}}$ edição (FA7), a The United States Pharmacopeia 39 edição e o National Formulary $34^{\mathrm{a}}$ edição incluindo os seus dois suplementos (USP39-NF34). A expressão "farmacopeias em estudo" inclui a FB5, a EP8.8, a FA7 e a USP39-NF34.

As listas de espécies e monografias da FB5 foram determinadas por meio da consulta à versão eletrônica do segundo volume da obra, tendo sido desconsideradas as duas monografias para excipientes de espécies vegetais: óleo de amendoim (Arachis hypogaea L.) e óleo de gergelim (Sesamum indicum L.). As listas de espécies e monografias do FFFB1 foram determinadas por meio de consulta à versão eletrônica do compêndio.

A nomenclatura botânica das espécies da FB5 foi corrigida, quando necessário, conforme atualização, realizada pelo Comitê Técnico Temático de Farmacognosia da Farmacopeia Brasileira (CTT Farmacognosia), apresentada para a apreciação pública na Consulta Pública Anvisa no 241 de 05 de agosto de 2016 (CP no 241/2016) (BRASIL, 2016c). A nomenclatura botânica das espécies do FFFB1 foi mantida conforme descrito no documento original, com exceção das espécies coincidentes entre os dois compêndios e com exceção dos nomes dos autores, que foram corrigidos conforme a base de dados do sítio eletrônico do Missouri Botanical Garden (TROPICOS.ORG, 2016). 
Para o alcance dos objetivos do estudo, inicialmente, foi elaborado um quadro (Apêndice A) com informações sobre as espécies da Farmacopeia Brasileira, sendo elas: nomenclatura botânica corrigida, sinonímias consideradas conforme sítio eletrônico do Missouri Botanical Garden e do The Plant List (THE PLANT LIST, 2013; TROPICOS.ORG, 2016), nomenclatura popular, conforme encontrada nos compêndios da FB5 e do FFFB1, e ocorrência no Brasil para cada espécie, conforme sítio eletrônico do Missouri Botanical Garden e da Reflora (REFLORA, 2016; TROPICOS.ORG, 2016). As informações sobre as espécies e dados de ocorrência contidas neste quadro foram as utilizadas neste estudo.

Para a determinação das sinonímias, foram realizadas buscas primeiramente na base de dados do sítio eletrônico do Missouri Botanical Garden (TROPICOS.ORG, 2016). Foram extraídos e considerados como sinonímia, os nomes encontrados na página da nomenclatura botânica consultada (por exemplo, as nomenclaturas constantes em "basionym" e nas abas "synonyms" e "accepted names"). A seguir, a base de dados do sítio eletrônico do The Plant List (THE PLANT LIST, 2013) foi consultada, tendo sido extraídos e considerados como sinonímias, os nomes descritos com nível de confiança de pelo menos duas estrelas (nível médio de confiança). No caso em que uma sinonímia, considerada pelo sítio eletrônico do Missouri Botanical Garden, possuía apenas uma estrela de nível de confiança (baixo nível de confiança) no sítio eletrônico do The Plant List, esta nomenclatura foi excluída das sinonímias consideradas. Não foram incluídas as sinonímias relacionadas a variedades de espécies.

Para a determinação da ocorrência das espécies no Brasil, seja essa ocorrência devida a espécie ser nativa, naturalizada, ou por cultivo, primeiramente a base de dados do sítio eletrônico da Reflora (REFLORA, 2016) foi consultada inserindo o gênero da nomenclatura botânica e das sinonímias no campo "gênero". No caso de ocorrência de resultados para os gêneros consultados, as informações para as espécies foram verificadas. A seguir, a base de dados do sítio eletrônico do Missouri Botanical Garden (TROPICOS.ORG, 2016) foi consultada inserindo, em buscas separadas, a nomenclatura botânica e as sinonímias no campo "name search". Na página da nomenclatura foi verificada a existência de registros de ocorrência no Brasil na aba "distributions". Foi considerado que a espécie possuía ocorrência no Brasil quando foram encontradas informações sobre sua ocorrência no Brasil em uma ou nas duas bases de dados.

Nesse trabalho foi feita a opção por trabalhar com espécies com ocorrência no Brasil, incluindo as nativas, cultivadas e as naturalizadas, e não apenas as espécies nativas. Foi considerado que todas as espécies que ocorrem no Brasil representam espécies com potencial 
para promover o desenvolvimento da economia brasileira, podendo ser produzidas em escala agroindustrial e serem consideradas matéria-prima de origem nacional.

Após a obtenção desses dados iniciais, para alcançar os objetivos específicos do estudo, foram desenvolvidos os métodos descritos nos itens 3.1 a 3.4, sistematizando os dados encontrados em quadros e tabelas.

\subsection{AVALIAÇÃO DA EVOLUÇÃO HISTÓRICA DAS MONOGRAFIAS DE DROGAS VEGETAIS E DERIVADOS DA FARMACOPEIA BRASILEIRA 5 EDIÇÃO}

Para avaliar a evolução histórica das monografias de drogas vegetais e derivados constantes na FB5, foi realizada uma pesquisa em todas as edições anteriores da Farmacopeia Brasileira com o intuito de identificar se as monografias constantes na edição atual compuseram alguma das edições anteriores, sistematizando as informações encontradas.

Foram verificadas a Farmacopeia Brasileira $1^{a}$ edição (BRASIL, 1929), incluindo o primeiro (BRASIL, 1943b) e o terceiro suplementos (BRASIL, 1951) (FB1), a Farmacopeia dos Estados Unidos do Brasil $2^{\text {a }}$ edição (FB2) (BRASIL, 1959b), a Farmacopeia Brasileira $3^{\text {a }}$ edição (FB3) (BRASIL, 1977) e a Farmacopeia Brasileira $4^{\mathrm{a}}$ edição (BRASIL, 1988c), incluindo os seus seis fascículos (BRASIL, 1996, 2000, 2001, 2002, 2003a, 2005a) (FB4).

Para as monografias de drogas vegetais, foram consideradas como monografias semelhantes a FB5 e incluídas no estudo: 1 - as monografias das edições anteriores cujo descritivo da espécie era igual ao constante na FB5; ou 2 - as monografias cujo descritivo das espécies eram diferentes, porém eram sinonímias consideradas neste estudo (Apêndice A), ou variedades destas espécies; ou 3 - as monografias cujo descritivo das espécies eram diferentes, não eram sinonímias e nem variedades, porém havia indícios de erro no seu descritivo, caso em que as nomenclaturas botânicas não foram encontradas nas bases de dados consultadas, Missouri Botanical Garden (TROPICOS.ORG, 2016), The Plant List (THE PLANT LIST, 2013) e Reflora (REFLORA, 2016). Quando a monografia da FB5 era para uma droga vegetal, foram sistematizadas junto às informações das monografias de drogas vegetais das edições anteriores, também, as informações sobre as monografias de derivados dessas edições.

Para as monografias de derivados, foram consideradas como monografias semelhantes a FB5 e incluídas no estudo: 1 - as monografias cujo descritivo das espécies atendeu aos mesmos requisitos previstos para as monografias de drogas vegetais; e 2 - as monografias cujo derivado descrito era igual ou semelhante ao constante na FB5. Não foram incluídas como 
monografias semelhantes as monografias de drogas vegetais de edições anteriores cuja monografia na FB5 se refere apenas ao derivado.

Foram incluídas as informações sobre a ocorrência das espécies no Brasil. As informações sobre a composição das monografias obtidas foram sistematizadas em quadros e tabelas, contendo: a identificação da monografia da FB5 (nomenclatura botânica, o material botânico utilizado entre colchetes e o derivado vegetal, se o caso, após ponto e vírgula); as nomenclaturas populares descritas nas edições da Farmacopeia Brasileira consultadas; e a composição resumida das monografias constantes em cada edição.

Em seguida às informações sobre a composição das monografias, foi acrescentado entre parênteses, o número corresponde a página da monografia no respectivo compêndio (página inicial da monografia), com exceção da Farmacopeia Brasileira $4^{a}$ edição, para a qual o número entre parênteses corresponde ao número da monografia (essa edição não possui numeração nas páginas), e para os suplementos da FB1, que por terem sido publicados no Diário Oficial, não possuem numeração própria de páginas. Esta informação foi acrescentada para facilitar uma futura manipulação dos dados dessas monografias, pois as edições anteriores da Farmacopeia Brasileira são de difícil manipulação: não há possibilidade de busca na versão digitalizada, os índices contemplam apenas as nomenclaturas populares e houve, ao longo dos anos, alteração de nomenclaturas botânicas e populares de algumas das plantas medicinais.

Nestes quadros, as informações sobre a composição dos ensaios e testes contemplados nas monografias foram sistematizadas com o auxílio de letras representativas: "I" para características da droga vegetal (ou derivado), descrições microscópicas e macroscópicas, ensaios e testes de identificação; "T" para ensaios, testes e especificações de impurezas; "D" para ensaios de doseamento; "DM" para especificações de dose máxima recomendada; "IN" para testes e ensaios de índices de iodo, de acidez, de saponificação, de refração, de dulçor, de espuma, de intumescência e de amargor; "O" para informações sobre o emprego oficinal; "P" para o ensaio de perfil cromatográfico determinado por cromatografia gasosa; "A" para informações sobre armazenagem, embalagem e conservação; e "B" para figura ilustrativa dos materiais botânicos.

A informação sobre a condição "seca" dos materiais botânicos (drogas vegetais) foi suprimida, uma vez que a maioria das drogas vegetais é constituída de material botânico seco. A informação sobre a condição "fresca" da droga vegetal foi acrescentada, quando o caso. 
Para as monografias da FB5 foi elaborada uma tabela contemplando informações detalhadas do quantitativo de ensaios e testes, dispondo, ainda, do método de doseamento com a descrição do marcador.

Nesta tabela, para fins de quantificação, os ensaios e testes foram reunidos em grupos: "identificação" que inclui características da droga vegetal (ou derivado), descrições microscópicas e macroscópicas, ensaios e testes de identificação (incluindo os colorimétricos e os ensaios de precipitação e a identificação por CCD); "testes" que inclui ensaios, testes físicoquímicos e especificações de impurezas, incluindo solubilidade (mesmo que descrita dentro do item características), densidade, determinação de água, matéria estranha e outros; "índices” que foram, em sua maioria, subtraídos da categoria “testes", e incluem os índices de acidez, de saponificação, de refração, de espuma e de amargor. As informações sobre o quantitativo de Cromatografias em Camada Delgada (CCD) de cada monografia foi incluído em uma coluna à parte, porém o seu quantitativo não foi subtraído do quantitativo do grupo original ao qual estava incluída (“identificação" ou "testes”).

No campo "doseamento" foi adicionado o quantitativo de doseamentos incluídos na monografia e no campo "método (marcador)" foi discriminado qual o método e o marcador doseado. Nos campos "perfil cromatográfico", "embalagem e armazenamento", "figura botânica" e "CCD” foram incluídos o quantitativo de perfis cromatográficos determinados por cromatografia gasosa, observações sobre embalagem e armazenamento, figuras botânicas e $\mathrm{CCD}$, respectivamente.

\subsection{AVALIAÇÃO DAS DIFERENÇAS ENTRE AS MONOGRAFIAS E ESPÉCIES DA FARMACOPEIA BRASILEIRA E DA IN Nº 02/2014}

Para avaliar as diferenças existentes entre a Farmacopeia Brasileira e a Instrução Normativa (IN) $n^{\circ} 02 / 2014$, foram sistematizadas as informações sobre as drogas vegetais, derivados e formas farmacêuticas das monografias dos compêndios da Farmacopeia Brasileira, FB5 (BRASIL, 2010d) e FFFB1 (BRASIL, 2011) e das espécies de plantas medicinais constantes na IN n 02/2014 - "Lista de medicamentos fitoterápicos de registro simplificado" e "Lista de produtos tradicionais fitoterápicos de registro simplificado" (BRASIL, 2014a, b).

Foram incluídas, para as monografias da FB5 e do FFFB1, as informações sobre a nomenclatura botânica utilizada neste estudo (Apêndice A), a droga vegetal (entre colchetes) e a Relação entre a Droga e o Derivado (RDD) entre parênteses após a descrição do derivado. No 
caso das monografias do FFFB1, quando havia formulação farmacêutica elaborada a partir de um derivado (caso das monografias de géis, cremes, pomadas, xaropes e sabonete líquido), a informação do derivado foi omitida, tendo sido descrita apenas a forma farmacêutica, separada por ponto e vírgula, após a droga vegetal.

Ao lado das monografias da Farmacopeia Brasileira (FB5 e FFFB1) foram incluídas as informações de espécie e droga vegetal da IN no 02/2014. As informações de cada monografia da FB5 e do FFFB1 foram dispostas linhas separadas, de modo que poderia haver mais de uma linha para uma mesma espécie, uma para a droga vegetal e outra para o derivado e, ainda, outra para cada formulação farmacêutica (preparação extemporânea, tintura, pomada, etc.). No caso da IN no $02 / 2014$, foi incluída somente uma linha para cada espécie, pois não foram incluídas as possibilidades de derivados previstos na norma (tipos de extrato e RDD possíveis).

As informações sobre a ocorrência das espécies no Brasil também foram incluídas nessa sistematização

\subsection{AVALIAÇÃO DA CORRELAÇÃO ENTRE AS ESPÉCIES DA FARMACOPEIA BRASILEIRA E A EXISTÊNCIA DE REGISTROS DE FITOTERÁPICOS VÁLIDOS NA ANVISA}

A informação sobre os registros de fitoterápicos válidos para as espécies da Farmacopeia Brasileira foi obtida consultando o banco de dados eletrônico público do sítio eletrônico da Anvisa (ANVISA, 2003). As informações foram inicialmente coletadas nos meses de janeiro e fevereiro de 2016, tendo sido feita uma confirmação dos resultados obtidos em maio de 2016. Dessa forma, os resultados foram expressos como registros de fitoterápicos válidos em maio de 2016.

Foram considerados registros válidos, para fins desse estudo, os obtidos na busca efetuada que cumpriram com ao menos um dos requisitos: 1 - vencimento da concessão de registro igual ou posterior a data de maio de 2016 com pelo menos uma apresentação comercial ativa; ou 2 - vencimento da concessão de registro antes de maio de 2016, com pelo menos uma apresentação comercial ativa, e, cuja petição para a renovação de registro, se realizada tempestivamente pela empresa, não estava indeferida em caráter definitivo (após recurso).

Foram incluídos no estudo os fitoterápicos com registros válidos que continham, em sua composição, princípio(s) ativo(s) com espécie(s) apresentando monografia na Farmacopeia Brasileira. 
Não foram incluídos como registros válidos os fitoterápicos que: 1 - possuíam espécie(s) da Farmacopeia Brasileira em sua composição como excipiente; e 2 - os produtos que, embora possuíssem espécie(s) da Farmacopeia Brasileira como princípio ativo, não se enquadravam na categoria de fitoterápicos por conter insumo(s) farmacêutico(s) purificado(s) como outro(s) princípio(s) ativo(s) (BRASIL, 2014c).

As informações sobre a ocorrência das espécies no Brasil foram incluídas.

Os detalhes do passo a passo da pesquisa realizada estão descritos nos itens 3.3.1 e 3.3.2.

\subsubsection{Registros válidos}

Após acessar o sítio eletrônico de Consulta de Produto - Medicamentos da Anvisa (ANVISA, 2003), foi realizado o procedimento de busca, detalhado na sequência de figuras (Figura 1, 2, 3, 4 e 5), para cada termo escolhido (Apêndice B). Os termos de busca escolhidos correspondem, em sua maioria, ao início das nomenclaturas botânicas, sinonímias ou nomenclaturas populares relacionadas as espécies da Farmacopeia Brasileira. Todas essas possibilidades foram consideradas em razão do sistema não correlacionar os nomes atuais das espécies com as suas sinonímias (nomes não mais utilizados).

$\mathrm{Na}$ Tela inicial de Consulta de Produto foi selecionado ao lado do campo "Princípio Ativo” o botão “...” (Figura 1).

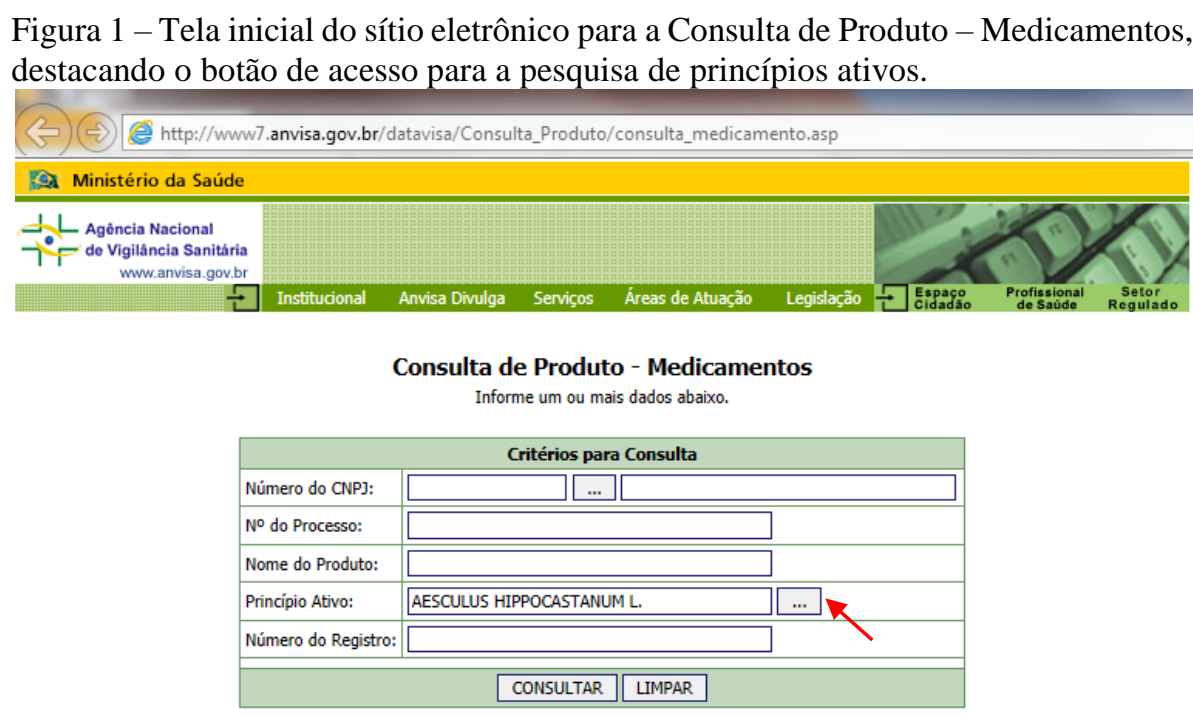


Na janela aberta, Selecionar Princípio ativo, foi inserido no campo "nome do Princípio Ativo", um por vez, cada termo de busca escolhido (Apêndice B) (Figura 2).

No campo "Resultado da Pesquisa" foram exibidos os princípios ativos resultantes da busca. Os termos de busca escolhidos (Apêndice B) resultaram, por vezes, em muitos princípios ativos não pertinentes as espécies da Farmacopeia Brasileira. Foram escolhidos, um por vez, cada princípio ativo pertinente as espécies da Farmacopeia Brasileira, sendo o outros desconsiderados.

Figura 2 - Campo no qual foram digitados os termos de busca do Apêndice B e selecionados os princípios ativos.

\begin{tabular}{|c|c|c|c|c|c|}
\hline \multicolumn{6}{|c|}{ (2) Selecionar Princípio Ativo - Internet Explorer } \\
\hline \multicolumn{6}{|c|}{ (2) http://www7.anvisa.gov.br/datavisa/Seleciona_Principio.asp?AREA=1 } \\
\hline \multicolumn{6}{|c|}{ Digite no campo addixo o nome do Principio Auvo e cilque eIII Pesquisar } \\
\hline \multicolumn{5}{|c|}{ AESCULUS HIPPOCASTANUM L. $R$} & $\wedge$ \\
\hline & PESQUISAR & LIMPAR & FECHAR & & \\
\hline \multicolumn{6}{|c|}{ Resultado da Pesquisa } \\
\hline \multicolumn{6}{|c|}{ Descriç̃̃o da Substância } \\
\hline \multicolumn{6}{|c|}{\begin{tabular}{|l} 
AESCULUS HIPPOCASTANUM L. \\
AESCULUS HIPPOCASTANUM LINN. \\
EXTRATO DE AESCULUS HIIPPOCASTANUM (CASTANHA-DA-ÍNDIA) \\
EXTRATO SECO DE AESCULUS HIPPOCASTANUM L.
\end{tabular}} \\
\hline OK & 4 substância(s) encontradas(s). & & & & $\checkmark$ \\
\hline
\end{tabular}

A consulta realizada para cada princípio ativo resultou em uma tela com os dados de nome comercial, número de registro, número de processo, empresa, situação do processo e vencimento do registro de cada produto constante no banco de dados (Figura 3). Cada nome comercial foi acessado para a verificação da validade do registro e a categoria do produto, se fitoterápico ou não. 
Figura 3 - Tela com o resultado da consulta de um princípio ativo selecionado.

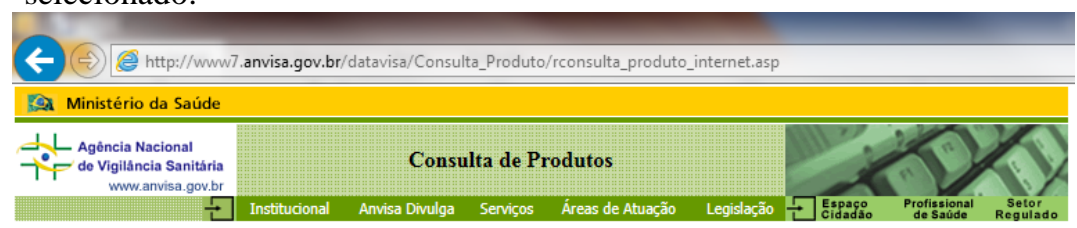

Resultado da Consulta de Produtos de Empresas - Medicamento

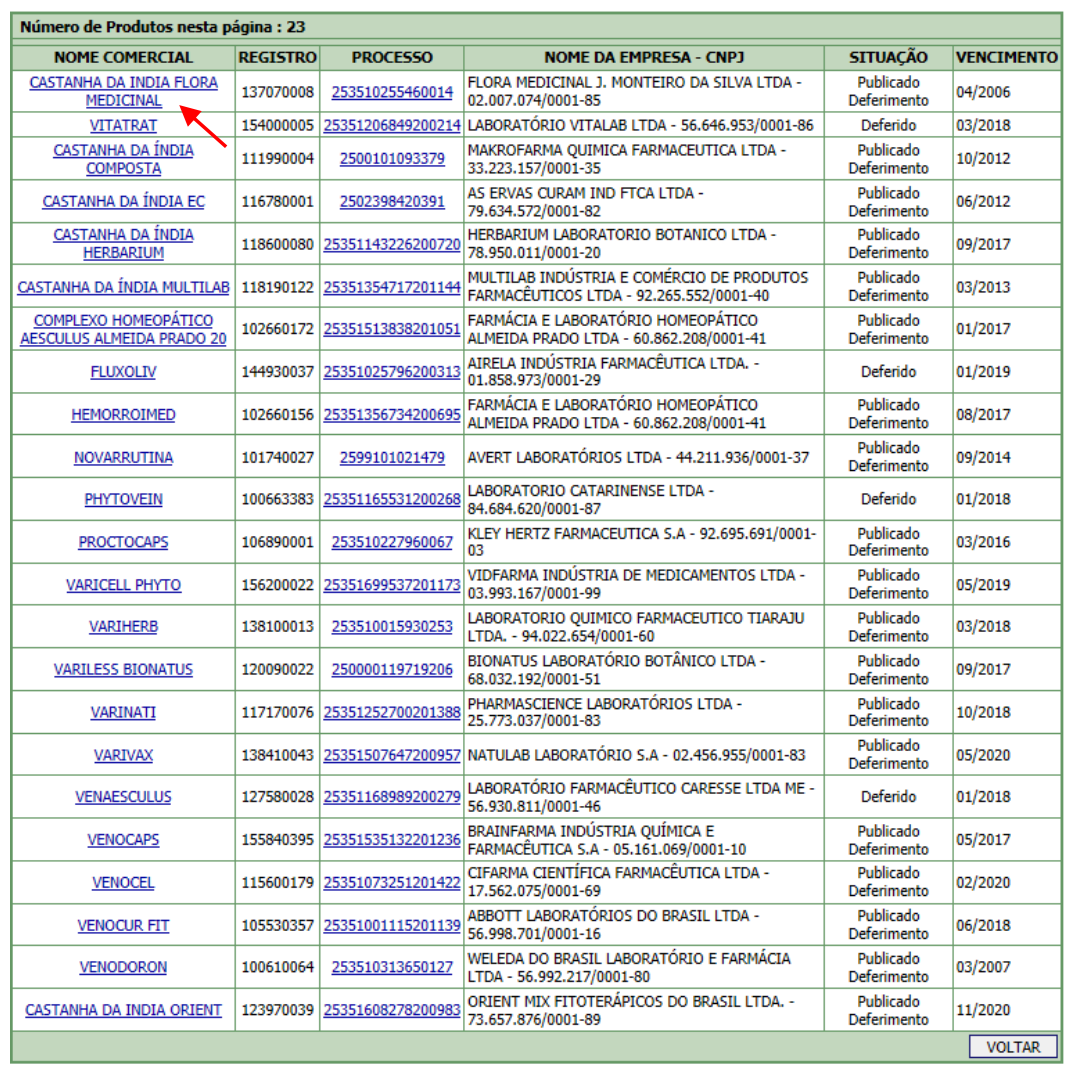

Na tela do "Detalhe do Produto" foi feita a confirmação da data do vencimento do registro e verificação da existência de pelo menos uma apresentação ativa (Figura 4).

O registro não foi considerado válido quando todas as apresentações comerciais estavam inativas, mesmo que a informação no campo "vencimento do registro" indicasse vigência do registro, conforme descrito no item 3.3.

Nessa tela foi verificada também a categoria do produto, conforme descrito no item 3.3.2. 
Figura 4 - Tela do detalhe do produto na qual foram verificados o vencimento do registro, as apresentações ativas e a categoria do produto.

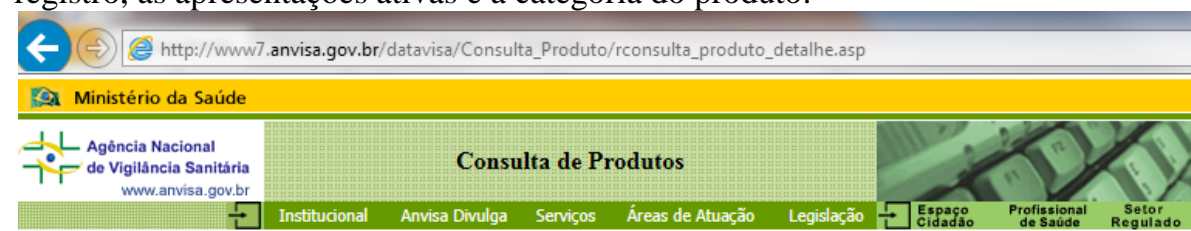

Detalhe do Produto : CASTANHA DA INDIA FLORA MEDICINAL

\begin{tabular}{|c|c|c|c|}
\hline Nome da Empresa: & \multicolumn{3}{|l|}{ FLORA MEDICINAL J. MONTEIRO DA SILVA LTDA } \\
\hline CNPJ: & 02.007.074/0001-85 & \multicolumn{2}{|l|}{ Autorização: } \\
\hline Nome Comercial: & \multicolumn{3}{|l|}{ CASTANHA DA INDIA FLORA MEDICINAL } \\
\hline Categoria: & \multicolumn{3}{|l|}{ FITOTERAPICO SIMPLES } \\
\hline Registro: & \multicolumn{3}{|l|}{137070008} \\
\hline Processo: & \multicolumn{3}{|l|}{$25351.025546 / 00-14$} \\
\hline Vencimento do Registro: & \multicolumn{3}{|l|}{$04 / 2006$} \\
\hline Apresentação [*** INATIVA ****] & Forma Física & No Apres. & $\begin{array}{l}\text { Data de } \\
\text { Publicação }\end{array}$ \\
\hline $\begin{array}{l}300 \text { MG CAP GEL DURA FR PLAS TRANS X } \\
90\end{array}$ & SAPSUla gelatinosa dura & 1 & 04/04/2001 \\
\hline Validade: & 24 meses & Registro: & 1370700080010 \\
\hline Princípio Ativo: & \multicolumn{3}{|l|}{ AESCULUS HIPPOCASTANUM L. } \\
\hline $\begin{array}{l}\text { Complemento Diferencial da } \\
\text { Apresentação: }\end{array}$ & \multicolumn{3}{|l|}{ [sen dados cadastrados] } \\
\hline Embalagem: & \multicolumn{3}{|l|}{ FRASCO DE PLASTICO TRANSPARENTE - Primária } \\
\hline Local de Fabricação: & \multicolumn{3}{|l|}{ Fabricantes Nacionais } \\
\hline & \multicolumn{3}{|l|}{$\begin{array}{l}\text { Fabricantes Internacionais } \\
{[\text { [sem dados cadastrados] }}\end{array}$} \\
\hline
\end{tabular}

O registro foi considerado válido quando havia pelo menos uma apresentação "ativa" e o "vencimento do registro" era em maio de 2016 ou data posterior, conforme descrito no item 3.3 . 
Figura 5 - Exemplo de produto enquadrado como fitoterápico com apresentações ativas e validade do registro vencida.

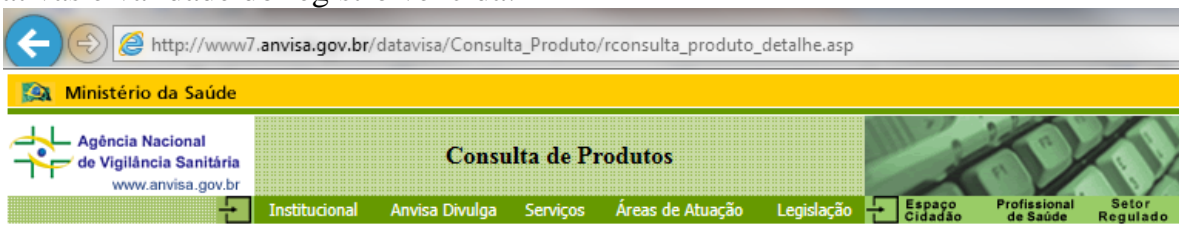

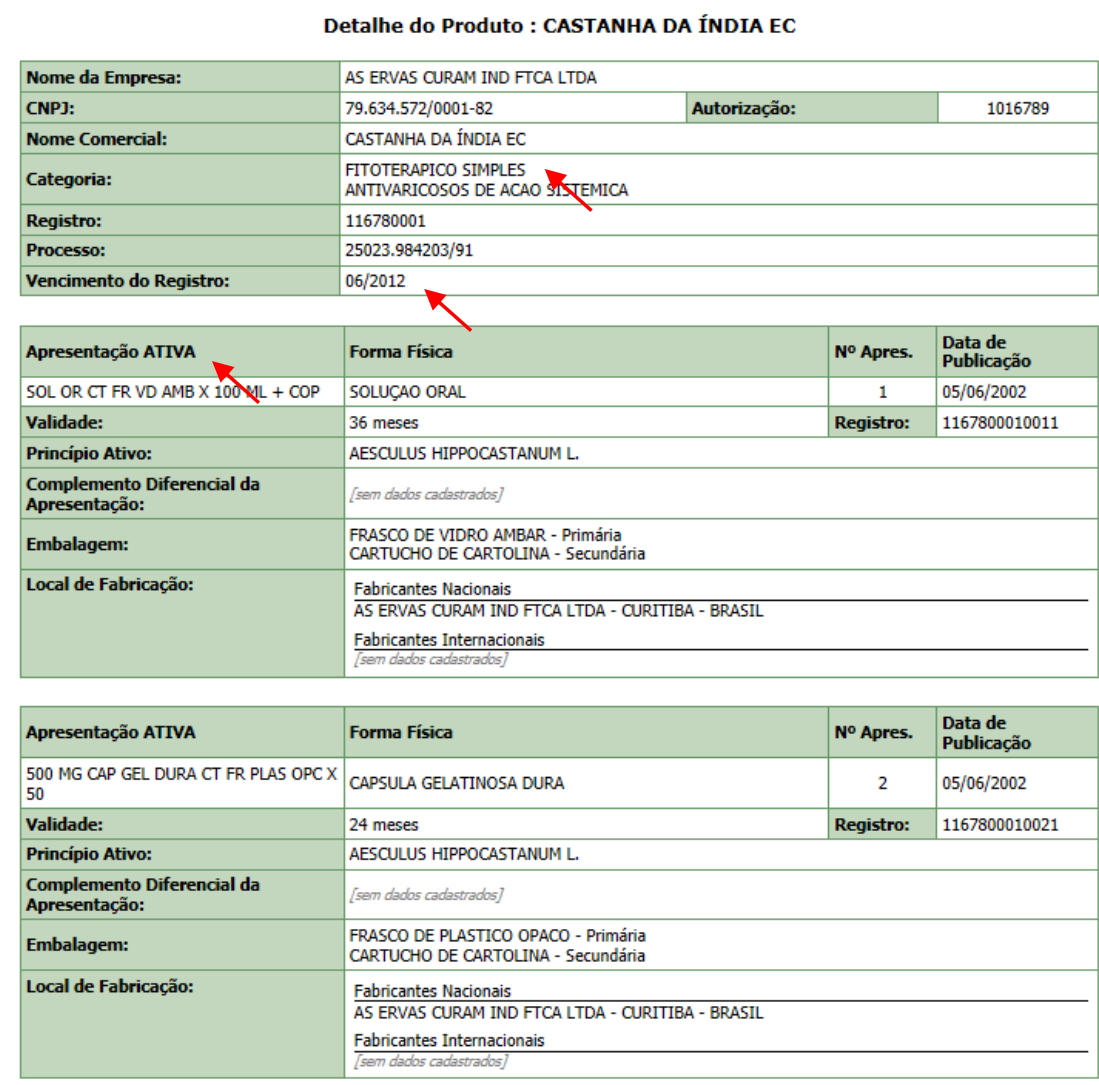

Quando, porém, o "vencimento do registro" ocorreu antes de maio de 2016 e havia pelo menos uma apresentação "ativa" (Figura 5), foi consultado o Sistema de Dados em Vigilância Sanitária (DATAVISA), sistema interno restrito aos servidores da Anvisa de consulta a situação de processos.

Para a confirmação da validade do registro, foi realizada consulta no DATAVISA, utilizando o nome comercial do produto, sobre o detalhamento virtual da tramitação do processo de registro do produto. Na tramitação do processo do registro foram verificados os assuntos das petições incluídas no sistema e o posicionamento de sua análise. 
Assim, para a determinação se o registro estava válido, ou não, foram avaliados na tramitação do processo os parâmetros:

1 - no caso de não constar protocolo de petição de "renovação de registro", foi verificado se havia petição de "cancelamento de registro" com status "publicado no DOU" o que confirmava que o registro não estava válido;

2 - quando havia protocolo de petição de "renovação do registro", foi verificado o seu status;

3 - se o status era "aguardando análise" ou "em exigência" o registro foi considerado válido;

4 - se o status era "indeferido", foi verificado se havia petição de "recurso administrativo" relacionado ao indeferimento da "renovação de registro";

5 - se não havia protocolo de petição de "renovação do registro" o registro foi considerado não válido;

6 - se havia petição de "recurso administrativo", se verificou o seu status;

7 - se era "aguardando análise" o registro foi considerado válido;

8 - se era "indeferido", o registro foi considerado não válido;

9 - se o status era "deferido", se verificou o status da nova petição de "renovação de registro" (que é criada para possibilitar uma nova análise da renovação de registro após deferimento de recurso), retornando ao parâmetro "3".

\subsubsection{Categoria do produto}

Para fins do levantamento de registros válidos para as espécies da Farmacopeia Brasileira, foram considerados apenas os registros de fitoterápicos, conforme descrito no item 3.3. Assim, na tela do "Detalhe do produto" de cada resultado obtido foi verificada a "categoria" do produto.

Foram considerados fitoterápicos: 1 - quando o campo "categoria" do produto indicava "fitoterápico simples" ou "fitoterápico composto"; ou 2 - quando no campo "categoria" havia outra informação não conclusiva e no campo "princípio ativo" estavam listadas apenas espécies vegetais.

Não foram incluídos no estudo, por não se enquadrarem na categoria de fitoterápicos, os produtos: 1 - cujo o campo "categoria" indicava produto da classe de dinamizados; ou 2 cujo o campo "Princípio ativo" continha insumos purificados (Figura 6). 
Figura 6 - Exemplo de produto não enquadrado como fitoterápico.

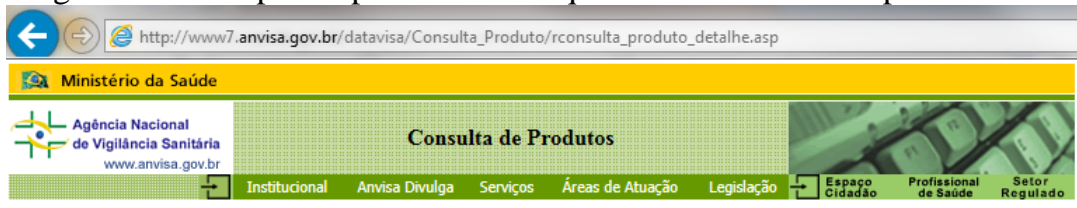

\begin{tabular}{|c|c|c|c|}
\hline \multicolumn{4}{|c|}{ Detalhe do Produto : CASTANHA DA ÍNDIA COMPOSTA } \\
\hline Nome da Empresa: & \multicolumn{3}{|l|}{ MAKROFARMA QUIMICA FARMACEUTICA LTDA } \\
\hline CNPJ: & $33.223 .157 / 0001-35$ & Autorização: & 1011994 \\
\hline Nome Comercial: & \multicolumn{3}{|l|}{ CASTANHA DA ÍNDIA COMPOSTA } \\
\hline Categoria: & \multicolumn{3}{|l|}{ ANTIVARICOSOS DE ACAO SISTEMICA } \\
\hline Registro: & \multicolumn{3}{|l|}{111990004} \\
\hline Processo: & \multicolumn{3}{|l|}{$25001.010933 / 79$} \\
\hline Vencimento do Registro: & \multicolumn{3}{|l|}{$10 / 2012$} \\
\hline Apresentação ATIVA & Forma Física & No Apres. & $\begin{array}{l}\text { Data de } \\
\text { Publicacãa }\end{array}$ \\
\hline DRG CT BL AL PLAS INC X 30 & DRAGEA SIMPLES & 1 & $10 / 10 / 1997$ \\
\hline Validade: & 24 meses & Registro: & 1119900040011 \\
\hline Principio Ativo: & \multicolumn{3}{|c|}{ AESCULUS HIPPOCASTANUM L. / Smilax papiracea / polygonum acre H.B.K. / RUTINA } \\
\hline $\begin{array}{l}\text { Complemento Diferencial da } \\
\text { Apresentaç̃o: }\end{array}$ & \multicolumn{3}{|l|}{ [sen dados cadastrados] } \\
\hline Embalagem: & \multicolumn{3}{|l|}{$\begin{array}{l}\text { BLISTER DE ALUMINIO/PLASTICO TRANSPARENTE - Primáría } \\
\text { CARTUCHO DE CARTOLINA - Secundária }\end{array}$} \\
\hline Local de Fabricação: & $\begin{array}{l}\text { Fabricantes Nacionais } \\
\text { MAKROFARMA QUIMICA FARMACEUTICA LTDA - RIO DE JANEIRO - BRASIL }\end{array}$ & 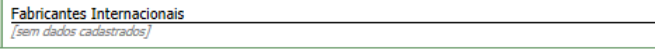 & \\
\hline Apresentação ATIVA & Forma Fisica & No Apres. & $\begin{array}{l}\text { Data de } \\
\text { Publicação }\end{array}$ \\
\hline DRG CT BL AL PLAS INC X 60 & DRAGEA SIMPLES & 2 & $10 / 10 / 1997$ \\
\hline Validade: & 24 meses & Registro: & 1119900040028 \\
\hline Principio Ativo: & \multicolumn{3}{|c|}{ AESCULUS HIPPOCASTANUM L. / Smilax papiracea / polygonum acre H.B.K. / RUTINA } \\
\hline $\begin{array}{l}\text { Complemento Diferencial da } \\
\text { Apresentação: }\end{array}$ & \multicolumn{3}{|l|}{ [sem dados cadestrados] } \\
\hline Embalagem: & \multicolumn{3}{|l|}{$\begin{array}{l}\text { BLISTER DE ALUMINIO/PLASTICO TRANSPARENTE - Primáría } \\
\text { CARTUCHO DE CARTOLINA - Secundária }\end{array}$} \\
\hline Local de Fabricação: & \multicolumn{3}{|c|}{$\begin{array}{l}\text { Fabricantes Nacionais } \\
\text { MAKROFARMA QUIMICA FARMACEUTICA LTDA - RIO DE JANEIRO - BRASIL }\end{array}$} \\
\hline
\end{tabular}

\subsection{COMPARAÇÃO ENTRE AS MONOGRAFIAS DA FB5 E AS MONOGRAFIAS} CORRESPONDENTES NAS FARMACOPEIAS INTERNACIONAIS EM ESTUDO

Para a avaliação comparativa das monografias da FB5 com as monografias correspondentes na EP8.8, na FA7 e na USP39-NF34, foram compiladas as informações sobre as espécies, nomenclatura popular, drogas vegetais e derivados. As informações sobre as espécies das monografias da FA7, da EP8.8 e da USP39-NF34 não foram incluídas, apenas as espécies da FB5.

A busca das monografias foi realizada nas versões eletrônicas das farmacopeias utilizando os termos de busca relacionados a nomenclatura botânica, sinonímias consideradas (Apêndice A) e nomenclaturas populares.

As informações compiladas foram sistematizadas. 


\subsubsection{Comparação individual entre as monografias da FB5 e as monografias correspondentes encontradas nas farmacopeias internacionais em estudo}

Após obtenção das monografias semelhantes entre a FB5 e as demais farmacopeias internacionais em estudo (FA7, EP8.8 e USP39-NF34), foram elaborados quadros para sistematizar as informações e possibilitar a comparação das monografias.

Foi elaborado um quadro para cada conjunto de monografias correspondentes a uma mesma espécie, droga vegetal ou derivado, incluindo as informações sobre os métodos, testes e especificações de qualidade dispostos nas monografias.

Foram omitidas as informações sobre a nomenclatura botânica constante nas monografias, quando era exatamente a mesma e correta em todas as monografias. Quanto aos requisitos de identificação botânica das monografias, foram incluídas nos quadros apenas as informações do quantitativo de ilustrações botânicas, descrições macroscópicas e microscópicas.

As especificações para solubilidade, mesmo que descritas nas monografias no item “características", foram realocadas no item "testes" dos quadros.

Para a sistematização, as descrições dos métodos, testes e especificações foram resumidas. As ações dos procedimentos foram expressas por meio de verbos no infinitivo tais como "aquecer”, “filtrar", “esfriar”, “extrair”, “agitar”, "ferver”, “evaporar”, “centrifugar” e "transferir".

Foram utilizados sinais matemáticos, siglas e acrônimos para simplificar o descritivo dos procedimentos constantes nas monografias. Essa sistemática foi adotada para melhor possibilitar a identificação e comparação das diferenças. O Quadro 1 apresenta os símbolos utilizados e os seus significados. 
Quadro 1 - Símbolos utilizados para sistematizar as informações das monografias e seus significados.

\begin{tabular}{|c|c|}
\hline Símbolo & Significado \\
\hline+ & indica adição de algum componente, adição de mais uma especificação ou sequência a ser \\
realizada no procedimento
\end{tabular}

Os métodos constantes nas monografias foram identificados por meio de abreviaturas: CCD, para Cromatografia em Camada Delgada; CG, para Cromatografia Gasosa; CLAE-UV, para Cromatografia Líquida de Alta Eficiência acoplada a detector por Espectrofotometria por absorção no Ultravioleta; EAVIS, para Espectrofotometria de Absorção no Visível; EAUV, para Espectrofotometria de Absorção no Ultravioleta; e CCDAE, para Cromatografia em Camada Delgada de Alta Eficiência.

As especificações foram descritas com o auxílio das siglas: NMT, para não maior que; NLT, para não menor que; MR, cumpre o teste ou os requisitos, disposto nos métodos gerais; UFC, para Unidade Formadora de Colônia; TAMC, para contagem total de bactérias aeróbias; TBMC, para contagem de bactérias Gram-negativas bile tolerantes; e TYMC, para contagem total de fungos e leveduras.

Para a descrição das soluções foram utilizadas as abreviaturas: TS, para solução amostra ou solução teste; RS, para solução padrão ou solução referência; SI, para solução indicadora, utilizada nas determinações volumétricas; SR, para solução reagente, descrita no método geral da respectiva farmacopeia; SS, para solução estoque ou solução intermediária; SV, para solução volumétrica, utilizadas nas determinações volumétricas; IS, para solução de padrão interno; e BS, para solução branco ou solução para ajuste do zero.

$\mathrm{Na}$ descrição dos procedimentos, dos métodos e ensaios, foram utilizadas as abreviaturas: SQR, para substância química ou extrato de referência sejam eles da EP8.8, da FA7, da FB5 ou da USP39-NF34; GF, na sílica-gel com gesso e indicador de fluorescência; F, na sílica-gel com indicador de fluorescência; e IRR, para índice de retenção relativo.

Detalhes de especificações ou procedimentos foram descritos entre parênteses. Foram omitidos detalhes não relevantes ou implícitos aos procedimentos, como o uso de balão 
volumétrico quando o procedimento indica necessidade de avolumar, o uso de funil de separação ou de um aparato de extração contínua quando o procedimento indica extração, a necessidade do desenvolvimento do cromatograma e o uso da luz visível para observar resultados na CCD. A ação de misturar uma solução ou preparado também foi omitida.

No caso dos ensaios de determinação de água, quando o método e os parâmetros do ensaio não estavam descritos nas monografias da FB5, foram utilizados, para fins de comparação, os parâmetros constantes no método geral da FB5 correspondente ao método descrito nas outras monografias do mesmo quadro de comparação.

As diferenças identificadas entre as monografias foram classificadas em: menor (mi) ou com impacto baixo não significativo; moderada (me), ou com impacto moderado; e substancial (su), ou com impacto alto significativo (Quadro 2). Adicionalmente, foi incluída a classificação para erro (er), quando foi avaliado que a diferença era causada por um erro ou omissão. Quando se considerou que não havia diferença, os procedimentos foram classificados como semelhantes (se).

A comparação foi realizada e as classificações foram atribuídas considerando a FB5 como referência. Dessa forma, os métodos e especificações dispostos na FB5 (ou a sua ausência), foram a referência para a comparação com as outras farmacopeias que possuíam um requisito.

Não foram comparadas e classificadas as diferenças existentes entre os itens das monografias: nomenclatura botânica, nomenclatura popular, sinonímia botânica, características, descrições macroscópicas e microscópicas, ilustração botânica, embalagem e armazenamento, padrões de referência e rotulagem. Para estes componentes das monografias foi indicado nas tabelas apenas o seu quantitativo. Ainda, não foram comparadas e classificadas as diferenças relacionadas aos ensaios para determinação de microrganismos.

O Quadro 2 detalha as situações de emprego das classificações. Diferenças envolvendo algarismos significativos não foram consideradas.

Nos casos em que um método, ensaio, ou especificação se enquadrou em mais de uma classificação, foi aplicada a correspondente ao maior grau de diferença. 
Quadro 2 - Classificação adotada para as diferenças encontradas entre as monografias da Farmacopeia Brasileira $5^{\text {a }}$ edição e as monografias correspondentes nas farmacopeias internacionais em estudo.

\begin{tabular}{|c|c|c|c|}
\hline $\begin{array}{l}\text { Método ou } \\
\text { ensaio }\end{array}$ & mi (menor) & me (moderada) & su (substancial) \\
\hline \multirow[t]{6}{*}{ CCD } & $\begin{array}{c}\text { fase estacionária: diferença na espessura; } \\
\text { diferença no uso ou não do indicador de } \\
\text { fluorescência }\end{array}$ & $\begin{array}{l}\text { fase estacionária: diferença no uso ou não de fase } \\
\text { com alta eficiência ou papel }\end{array}$ & - \\
\hline & - & $\begin{array}{l}\text { fase móvel: diferença quando os resultados } \\
\text { obtidos são comparáveis }\end{array}$ & $\begin{array}{l}\text { fase móvel: diferença quando os resultados } \\
\text { obtidos não são comparáveis (por exemplo: } \\
\text { quando há extratos ou outras substâncias de } \\
\text { referência) }\end{array}$ \\
\hline & soluções: diferença na concentração da RS & $\begin{array}{l}\text { soluções: diferença na concentração da TS; uso de } \\
\text { outras substâncias de referência quando os } \\
\text { resultados obtidos são comparáveis }\end{array}$ & - \\
\hline & $\begin{array}{l}\text { aplicação: diferença no formato da aplicação e no } \\
\text { volume (na mesma ordem de grandeza) para a TS } \\
\text { ou a RS }\end{array}$ & $\begin{array}{l}\text { aplicação: diferença no volume (de outra ordem } \\
\text { de grandeza) para a TS ou a RS }\end{array}$ & - \\
\hline & $\begin{array}{l}\text { desenvolvimento: diferença no método de } \\
\text { secagem da cromatoplaca; existência de segunda } \\
\text { eluição com a mesma fase móvel quando os } \\
\text { resultados obtidos são comparáveis }\end{array}$ & - & - \\
\hline & $\begin{array}{c}\text { revelador: diferentes quando os resultados obtidos } \\
\text { são comparáveis; uso de descrição de zonas ou } \\
\text { esquemas quando os resultados obtidos são } \\
\text { comparáveis }\end{array}$ & $\begin{array}{c}\text { revelador: diferentes quando os resultados não são } \\
\text { comparáveis (quando há substâncias de referência } \\
\text { diferentes); uso de descrição de zonas ou } \\
\text { esquemas quando os resultados não são } \\
\text { comparáveis (quando há substâncias de } \\
\text { referências diferentes); } \\
\text { outras: diferenças no uso de CCD ou CCDAE }\end{array}$ & outras: existência ou não do ensaio \\
\hline
\end{tabular}


Quadro 2 - Classificação adotada para as diferenças encontradas entre as monografias da Farmacopeia Brasileira $5^{\text {a }}$ edição e as monografias correspondentes nas farmacopeias internacionais em estudo.

\begin{tabular}{|c|c|c|c|}
\hline $\begin{array}{l}\text { Método ou } \\
\text { ensaio }\end{array}$ & mi (menor) & me (moderada) & su (substancial) \\
\hline \multirow[t]{6}{*}{ Doseamento } & $\begin{array}{l}\text { diferença no uso de concentração relativa ou } \\
\text { curva analítica ou coeficiente de absorção } \\
\text { específica e expressões de cálculos, desde que } \\
\text { possuam os mesmos fundamentos (mesmo } \\
\text { comprimento de onda e substância de referência); } \\
\text { diferença na concentração da TS e RS (incluindo } \\
\text { volume de injeção) }\end{array}$ & $\begin{array}{l}\text { diferença no uso de concentração relativa ou } \\
\text { curva analítica ou coeficiente de absorção } \\
\text { específica e expressões de cálculos, quando os } \\
\text { métodos não possuem os mesmos fundamentos } \\
\text { (por exemplo: diferentes comprimentos de onda } \\
\text { e/ou diferentes substâncias de referência e/ou uso } \\
\text { ou não de RS); diferença na fase móvel quando os } \\
\text { resultados obtidos são comparáveis; diferentes } \\
\text { métodos para um mesmo marcador }\end{array}$ & diferentes métodos para diferentes marcadores \\
\hline & $\begin{array}{c}\text { espectrofotometrias: diferença no preparo da } \\
\text { soluçãa de leitura; diferença na concentração dos } \\
\text { reagentes de coloração }\end{array}$ & $\begin{array}{l}\text { espectrofotometrias: diferença no uso ou não de } \\
\text { RS }\end{array}$ & - \\
\hline & $\begin{array}{l}\text { volumetria: diferença na SI; diferença no uso de } \\
\text { método indireto ou direto; diferença no solvente } \\
\text { de diluição da SV; diferentes titulantes }\end{array}$ & - & - \\
\hline & $\begin{array}{l}\text { destilação por arraste de vapor: diferença na } \\
\text { quantidade de líquido de arraste }\end{array}$ & $\begin{array}{l}\text { destilação por arraste de vapor: diferentes líquidos } \\
\text { de arraste }\end{array}$ & - \\
\hline & - & $\begin{array}{c}\text { cromatografia gasosa: diferença no gradiente de } \\
\text { temperatura quando os resultados obtidos são } \\
\text { comparáveis; diferença no uso de tempo de } \\
\text { retenção relativo ou tempo de retenção comparado } \\
\text { com RS }\end{array}$ & - \\
\hline & - & - & $\begin{array}{l}\text { perfil cromatográfico: existência de } \\
\text { especificações para outros marcadores }\end{array}$ \\
\hline Testes & $\begin{array}{l}\text { matéria estranha: mesmo percentual com } \\
\text { diferença no tipo de material estranho }\end{array}$ & - & - \\
\hline
\end{tabular}


Quadro 2 - Classificação adotada para as diferenças encontradas entre as monografias da Farmacopeia Brasileira $5^{\text {a }}$ edição e as monografias correspondentes nas farmacopeias internacionais em estudo.

\begin{tabular}{|c|c|c|c|}
\hline $\begin{array}{l}\text { Método ou } \\
\text { ensaio }\end{array}$ & mi (menor) & me (moderada) & su (substancial) \\
\hline & $\begin{array}{l}\text { perda por dessecação: diferença na quantidade de } \\
\text { amostra; diferença no tempo de secagem }\end{array}$ & - & - \\
\hline & - & $\begin{array}{l}\text { cinzas insolúveis em ácido clorídrico: diferença } \\
\text { na utilização do reagente diluído ou concentrado }\end{array}$ & - \\
\hline \multirow[t]{7}{*}{ Outros } & $\begin{array}{c}\text { ensaios de identificação qualitativos: diferença no } \\
\text { procedimento de preparo da amostra ou TS desde } \\
\text { que os resultados sejam comparáveis }\end{array}$ & & \\
\hline & $\begin{array}{l}\text { diferença no solvente de diluição da RS ou TS ou } \\
\text { do revelador: }\end{array}$ & - & - \\
\hline & $\begin{array}{l}\text { diferença no procedimento do preparo da amostra } \\
\text { ou TS desde que não envolvam diferenças em } \\
\text { técnicas de extração e solventes de extração }\end{array}$ & $\begin{array}{c}\text { diferença no procedimento do preparo da amostra } \\
\text { ou TS que envolvam técnicas de extração e } \\
\text { solventes de extração }\end{array}$ & - \\
\hline & - & $\begin{array}{c}\text { exigências, parâmetros e procedimentos } \\
\text { adicionais para os ensaios de identificação e } \\
\text { doseamento }\end{array}$ & $\begin{array}{l}\text { exigências e especificações adicionais para os } \\
\text { testes }\end{array}$ \\
\hline & - & - & $\begin{array}{l}\text { ensaios adicionais nos itens identificação, testes, } \\
\text { índices e doseamentos (por exemplo: matérias } \\
\text { extraíveis, metais pesados, agrotóxicos, CCD) }\end{array}$ \\
\hline & - & - & diferença na droga vegetal ou derivado \\
\hline & $\begin{array}{c}\text { especificação do marcador ou especificação do } \\
\text { teste ou especificação do parâmetro com } \\
\text { diferença até } 10 \%\end{array}$ & $\begin{array}{c}\text { especificação do marcador ou especificação do } \\
\text { teste ou especificação do parâmetro com diferença } \\
\text { entre } 10 \text { e } 30 \%\end{array}$ & $\begin{array}{l}\text { especificação do marcador ou especificação do } \\
\text { teste ou especificação do parâmetro com diferença } \\
\text { acima de } 30 \%\end{array}$ \\
\hline
\end{tabular}

Legenda: $\mathrm{CCD}$ = cromatografia em camada delgada; $\mathrm{RS}$ = solução padrão ou solução referência; TS = solução amostra ou solução teste; CCDAE = cromatografia em camada delgada de alta eficiência; SI = solução indicadora; SV = solução volumétrica. 


\section{RESULTADOS E DISCUSSÃO}

Foi constatado que as 58 monografias de drogas vegetais e derivados da FB5 contemplam 63 espécies (BRASIL, 2010d), enquanto as 83 monografias do FFFB1 contemplam 59 espécies (BRASIL, 2011). O FFFB1, assim como a FB5, contém monografias que contemplam mais de uma espécie, sendo que, dentre as 83 monografias do FFFB1, uma mesma espécie pode possuir mais de uma monografia para diferentes formulações, tais como: preparações extemporâneas, tinturas, cremes, pomadas entre outras.

Foram sistematizadas em quadros e em tabelas as informações sobre: as monografias da FB5 e as monografias semelhantes presente nas edições anteriores da Farmacopeia Brasileira (FB1, FB2, FB3 e FB4); as monografias de drogas vegetais e derivados da FB5; as monografias de drogas vegetais e derivados da FB5, do FFFB1 e as espécies e drogas vegetais contempladas na IN nº 02/2014; as espécies da FB5 e do FFFB1 e os registros de fitoterápicos válidos em maio/2016; as monografias de drogas vegetais e derivados da FB5 e as monografias correspondentes existentes nas farmacopeias internacionais em estudo (FA7, EP8.8 e USP39NF34); o detalhamento dos ensaios, métodos e especificações de cada monografia da FB5 e sua(s) correspondente(s) monografia(s) semelhante(s) nas farmacopeias internacionais em estudo.

Os dados foram correlacionados com a ocorrência das espécies no Brasil. As matériasprimas de origem nacional que representam um potencial de desenvolvimento do Brasil, por muitas vezes, não são consideradas relevantes no contexto internacional, assim, caberia à Farmacopeia Brasileira abarcar este importante nicho do mercado.

\subsection{EVOLUÇÃO HISTÓRICA DAS MONOGRAFIAS DE DROGAS VEGETAIS E DERIVADOS DA FARMACOPEIA BRASILEIRA $5^{\mathrm{a}}$ EDIÇÃO}

A avaliação da evolução histórica das 58 monografias de drogas vegetais e derivados da FB5 foi realizada por meio da verificação da existência de monografias semelhantes nas edições anteriores da Farmacopeia Brasileira (FB1, FB2, FB3 e FB4) (BRASIL, 1929, 1943b, 2005a, 2010d, 1951, 1959b, 1977, 1996, 2000, 2001, 2002, 2003a). As informações coletadas sobre a composição dessas monografias foram dispostas no Quadro 3, na Tabela 1 e na Tabela 2.

Foram publicados três suplementos complementares à FB1, sendo que, o conteúdo do $2^{\circ}$ Suplemento da Farmacopeia Brasileira $1^{\text {a }}$ edição, aprovado por meio da Portaria $n^{\circ} 24$ de 14 
de abril de 1945 (BRASIL, 1947), após buscas em bibliotecas, não foi localizado. Porém, analisando as informações da FB2, contidas na lista de "Monografias Suprimidas da 1a edição da Farmacopeia Brasileira e seus Suplementos" e na lista de "Monografias Incluídas na 2a edição da Farmacopeia Brasileira" (BRASIL, 1959b), e considerando as monografias semelhantes as da FB5 encontradas na FB2 (Quadro 3), foi inferido que este suplemento não continha monografias alvo deste estudo, ou seja, monografias semelhantes às que atualmente compõem a FB5.

Dessa maneira, foi construído o Quadro 3 com as informações extraídas das monografias das farmacopeias FB1, FB2, FB3, FB4 e FB5.

\subsubsection{Ocorrência das monografias da Farmacopeia Brasileira $5^{\mathrm{a}}$ edição nas edições anteriores da Farmacopeia Brasileira}

Conforme os critérios de exclusão descritos no item 3.1, não foram consideradas nesse estudo: as monografias da FB1 e FB2 para a espécie Echinodorus macrophyllus (Kunth) Micheli, pois, apesar de a espécie também ser denominada "chapéu-de couro", não é a mesma espécie de chapéu-de-couro da FB5 [Echinodorus grandiflorus (Cham. \& Schltdl.) Micheli]; e as monografias da FB1 e FB2 para a espécie Krameria argentea Mart. ex Spreng., que, apesar de também ser denominada de "ratânia", não é a mesma espécie de ratânia da FB5 [Krameria lappacea (Dombey) Burdet \& B.B.Simpson]. No caso da ratânia, é observado que a espécie contemplada na $1^{\mathrm{a}}$ e $2^{\mathrm{a}}$ edição da Farmacopeia Brasileira possui ocorrência no Brasil, sendo nativa, enquanto que a espécie da edição atual não possui ocorrência no Brasil (REFLORA, 2016).

Nos casos em que a FB5 contém monografia apenas para o derivado vegetal, como a tintura do jaborandi [Pilocarpus microphyllus Stapf ex Wardleworth], não foram incluídas informações sobre as monografias de droga vegetais das edições anteriores, como as informações sobre as monografias de droga vegetal do jaborandi da FB3 e da FB4.

Os dados sistematizados estão compilados no Quadro 3. 
Quadro 3 - Sistematização das informações contidas nas monografias de drogas vegetais e derivados da Farmacopeia Brasileira $5^{\mathrm{a}}$ edição e as monografias correspondentes constantes nas edições anteriores da Farmacopeia Brasileira, $1^{\mathrm{a}}, 2^{\mathrm{a}}, 3^{\mathrm{a}}$ e $4^{\mathrm{a}}$ edição.

\begin{tabular}{|c|c|c|c|c|c|c|c|c|}
\hline $\mathrm{N}^{\mathrm{o}}$ & Monografia & $\begin{array}{l}\text { Nomenclatura } \\
\text { popular }\end{array}$ & FB5 & FB4 & FB3 & FB2 & FB1 & $\begin{array}{c}\text { Ocorrência } \\
\text { no Brasil }\end{array}$ \\
\hline 1 & $\begin{array}{c}\text { Aesculus } \\
\text { hippocastanum } \mathrm{L} . \\
\text { [semente] }\end{array}$ & $\begin{array}{l}\text { castanha-da- } \\
\text { índia/ } \\
\text { castanheiro- } \\
\text { da-índia }\end{array}$ & $\begin{array}{l}\text { I, T, D, A, } \\
\text { B (749) }\end{array}$ & $\begin{array}{l}\text { I, T, D, A, } \\
\text { B (221) }\end{array}$ & - & $\mathrm{I}, \mathrm{T}, \mathrm{A}(203)$ & $\begin{array}{c}\text { casca: I, O (192); extrato fluido } \\
\text { (407) }\end{array}$ & não \\
\hline 2 & $\begin{array}{l}\text { Aloe ferox Mill., Aloe } \\
\text { africana Mill. e Aloe } \\
\text { spicata L. f. [folha; suco } \\
\text { dessecado] }\end{array}$ & $\begin{array}{l}\text { aloe/ aloe-do- } \\
\text { cabo }\end{array}$ & $\begin{array}{l}\mathrm{I}, \mathrm{T}, \mathrm{D}, \mathrm{A} \\
\quad(602)\end{array}$ & - & $\begin{array}{c}\text { [A. perryi Baker], } \\
\text { [A. vera }(\mathrm{L} .) \\
\text { Burm. f.], [A. ferox } \\
\text { Mill.], [A. africana } \\
\text { Mill.], [A. spicata } \\
\text { L. f.]: I, T, D, A } \\
(805)\end{array}$ & $\begin{array}{l}\text { [A. perryi Baker], [A. } \\
\text { vera }(\mathrm{L} .) \text { Burm. f.], [A. } \\
\text { ferox Mill.], [A. africana } \\
\text { Mill.], [A. spicata L. f.]: } \\
\text { I, T, D, A (93); pó (94) A }\end{array}$ & $\begin{array}{c}\text { [A. ferox Mill.]: I, T, O (77); } \\
\text { extrato I, O (353); pílula (672); } \\
\text { supositório (874); tintura I, O } \\
\text { (898) }\end{array}$ & não \\
\hline 3 & $\begin{array}{l}\text { Aloe vera }(\mathrm{L} .) \text { Burm. } \mathrm{f} . \\
\text { [folha fresca; gel } \\
\text { mucilaginoso] }\end{array}$ & aloe & $\begin{array}{l}\text { I, D, A, B } \\
\quad(600)\end{array}$ & - & - & - & - & não \\
\hline 4 & $\begin{array}{l}\text { Althaea officinalis L. } \\
\text { [raiz] }\end{array}$ & alteia & $\begin{array}{l}\text { I, T, A, B } \\
\text { (603) }\end{array}$ & - & - & I, T, A (95); pó I, A (97) & $\begin{array}{c}\text { I, T, O (78); pó I, O (690); xarope } \\
\text { A (985) }\end{array}$ & não \\
\hline 5 & $\begin{array}{l}\text { Anethum graveolens } \mathrm{L} . \\
\text { [fruto] }\end{array}$ & endro & $\begin{array}{l}\text { I, T, D, A, } \\
\text { B (918) }\end{array}$ & $\begin{array}{l}\text { I, T, D, A, } \\
\text { B (283) }\end{array}$ & - & - & - & $\operatorname{sim}$ \\
\hline 6 & $\begin{array}{l}\text { Arnica montana } \mathrm{L} \text {. } \\
\text { [capítulo floral] }\end{array}$ & arnica & $\begin{array}{l}\text { I, T, D, A, } \\
\text { B (648) }\end{array}$ & - & I, T, A (809) & $\mathrm{I}, \mathrm{T}, \mathrm{A}(115)$ & $\begin{array}{l}\text { rizoma e flor: I, O (98); extrato } \\
\text { fluido (393); tintura I (900) }\end{array}$ & não \\
\hline 7 & $\begin{array}{l}\text { Atropa belladonna } \mathrm{L} . \\
\text { [folha] }\end{array}$ & beladona & $\begin{array}{l}\mathrm{I}, \mathrm{T}, \mathrm{D}, \mathrm{A} \\
\mathrm{B}(679)\end{array}$ & $\begin{array}{c}\text { folha e } \\
\text { sumidade } \\
\text { florida: I, T, } \\
\text { D, A (10) }\end{array}$ & $\begin{array}{l}\text { folha e sumidade } \\
\text { florida: I, T, D, A } \\
\text { (813); tintura I, D, } \\
\text { A }(765)\end{array}$ & $\begin{array}{l}\text { folha e sumidade florida: } \\
\text { I, T, D, A (131); pó I } \\
\text { (133); extrato I, T, D } \\
\text { (420); extrato fluido I, D } \\
\text { (433); tintura I, D (812) }\end{array}$ & $\begin{array}{c}\text { I, T, D, O (119); cigarro (235); } \\
\text { extrato I, D, O, DM (354); extrato } \\
\text { fluido I, D, O, DM (396); } \\
\text { linimento (559); óleo A, O (620); } \\
\text { pó I, D, DM (692); pomada } \\
\text { (747); supositório (874); tintura } \\
\text { (903) I, D, O, DM; xarope DM } \\
\text { (988) }\end{array}$ & não \\
\hline
\end{tabular}


Quadro 3 - Sistematização das informações contidas nas monografias de drogas vegetais e derivados da Farmacopeia Brasileira $5^{\text {a }}$ edição e as monografias correspondentes constantes nas edições anteriores da Farmacopeia Brasileira, $1^{\mathrm{a}}, 2^{\mathrm{a}}, 3^{\mathrm{a}}$ e $4^{\mathrm{a}}$ edição.

\begin{tabular}{|c|c|c|c|c|c|c|c|c|}
\hline $\mathrm{N}^{\mathrm{o}}$ & Monografia & $\begin{array}{c}\text { Nomenclatura } \\
\text { popular }\end{array}$ & FB5 & FB4 & FB3 & FB2 & FB1 & $\begin{array}{c}\text { Ocorrência } \\
\text { no Brasil }\end{array}$ \\
\hline 8 & $\begin{array}{l}\text { Baccharis trimera } \\
\text { (Less.) DC. [caule } \\
\text { alado] }\end{array}$ & $\begin{array}{l}\text { carqueja/ } \\
\text { carqueja } \\
\text { amarga }\end{array}$ & $\begin{array}{l}\text { I, T, D, A, } \\
\text { B (744) }\end{array}$ & $\begin{array}{l}\text { I, T, IN, D, } \\
\text { A, B (182) }\end{array}$ & - & - & $\begin{array}{l}\text { [syn Baccharis genistelloides } \\
\text { Pers. var. trimera (Less.) } \\
\text { Backer], planta florida: I, O } \\
\text { (186); extrato fluido O (404); } \\
\text { tintura I (911) }\end{array}$ & $\operatorname{sim}$ \\
\hline 9 & $\begin{array}{l}\text { Calendula officinalis L. } \\
\text { [capítulo floral] }\end{array}$ & calêndula & $\begin{array}{l}\text { I, T, D, A, } \\
\text { B (714) }\end{array}$ & $\begin{array}{l}\mathrm{I}, \mathrm{T}, \mathrm{D}, \mathrm{A} \\
\mathrm{B}(134)\end{array}$ & - & - & - & sim \\
\hline 10 & $\begin{array}{c}\text { Centella asiatica }(\mathrm{L} .) \\
\text { Urb. [folha] }\end{array}$ & centela & $\begin{array}{l}\mathrm{I}, \mathrm{T}, \mathrm{IN}, \mathrm{D}, \\
\mathrm{A}, \mathrm{B}(768)\end{array}$ & $\begin{array}{l}\text { I, T, IN, D, } \\
\text { A, B (89) }\end{array}$ & - & - & - & sim \\
\hline 11 & $\begin{array}{l}\text { Cinchona calisaya } \\
\text { Wedd. [casca] }\end{array}$ & quina-amarela & $\begin{array}{l}\text { I, T, D, A, } \\
\text { B (1244) }\end{array}$ & - & I, T, D (840) & $\begin{array}{l}\text { I, T, D (679); pó I (680); } \\
\text { extrato I, D (428); } \\
\text { extrato fluido I, D (442); } \\
\text { tintura I, D (827) }\end{array}$ & $\begin{array}{l}\text { I, T, D, O (765); extrato I, D } \\
\text { (378); pó I, T, D (725); vinho } \\
\text { (978); xarope (1008) }\end{array}$ & não \\
\hline 12 & $\begin{array}{c}\text { Cinnamomum cassia } \\
\text { (L.) J. Presl [casca] }\end{array}$ & $\begin{array}{l}\text { canela-da- } \\
\text { china }\end{array}$ & $\begin{array}{l}\mathrm{I}, \mathrm{T}, \mathrm{D}, \mathrm{A} \\
\mathrm{B}(718)\end{array}$ & - & - & $\begin{array}{c}\text { [syn. Cinnamomum } \\
\text { cassia Ness ex Blume]: } \\
\text { I, T, A (179); pó I (180) }\end{array}$ & $\begin{array}{c}\text { [syn. Cinnamomum cassia Ness } \\
\text { ex Blume]: I, T, O (162); pó I, T } \\
\text { (694) }\end{array}$ & não \\
\hline 13 & $\begin{array}{c}\text { Cinnamomum verum J. } \\
\text { Presl [casca] }\end{array}$ & $\begin{array}{l}\text { canela-do- } \\
\text { ceilão }\end{array}$ & $\begin{array}{l}\mathrm{I}, \mathrm{T}, \mathrm{D}, \mathrm{A} \\
\mathrm{B}(721)\end{array}$ & $\begin{array}{l}\mathrm{I}, \mathrm{T}, \mathrm{D}, \mathrm{A} \\
\quad(86)\end{array}$ & $\begin{array}{l}\text { [Cinnamomum } \\
\text { zeylanicum Ness]: } \\
\text { I, T, D, A (816) }\end{array}$ & $\begin{array}{c}\text { [Cinnamomum } \\
\text { zeylanicum Ness]: I, T, A } \\
\text { (178); pó I, A (179) }\end{array}$ & $\begin{array}{l}\text { [Cinnamomum zeylanicum } \\
\text { (Ness)]: I, T, O (162); pó I, T } \\
\text { (695); xarope I (989) }\end{array}$ & não \\
\hline 14 & $\begin{array}{l}\text { Citrus aurantium L. } \\
\text { subsp. aurantium } \\
\text { [exocarpo] }\end{array}$ & $\begin{array}{l}\text { laranja- } \\
\text { amarga }\end{array}$ & $\begin{array}{l}\mathrm{I}, \mathrm{T}, \mathrm{D}, \mathrm{A} \\
\mathrm{B}(1084)\end{array}$ & - & - & $\begin{array}{l}\text { [Citrus aurantium L. } \\
\text { subsp. amara]: I, T, D, A } \\
\text { (550); pó I (550) }\end{array}$ & $\begin{array}{l}\text { [Citrus aurantium } \text { L. subsp. } \\
\text { amara], epicarpo: I, T, O (550); } \\
\text { pó I (717); xarope I, O (1004) }\end{array}$ & $\begin{array}{l}\text { sim [Citrus } x \\
\text { aurantium } \\
\text { L.] }\end{array}$ \\
\hline 15 & $\begin{array}{l}\text { Cola nitida (Vent.) } \\
\text { Schott \& Endl. } \\
\text { [cotilédone] }\end{array}$ & $\begin{array}{l}\text { noz-de-cola/ } \\
\text { cola }\end{array}$ & $\begin{array}{c}\mathrm{I}, \mathrm{T}, \mathrm{D}, \mathrm{A}, \\
\mathrm{B}(1168)\end{array}$ & $\begin{array}{l}\text { I, T, D, A, } \\
\text { B (164) }\end{array}$ & + & $\begin{array}{l}\text { I, T, D, A (314); extrato } \\
\text { fluido I, D (435) }\end{array}$ & $\begin{array}{c}\text { I, T, D, O (252); elixir (282); } \\
\text { extrato I, D (360); extrato fluido } \\
\text { I, D, O (413); pó I, T, D (700); } \\
\text { tintura I, D (917); vinho I, D } \\
\text { (975) }\end{array}$ & não \\
\hline 16 & $\begin{array}{c}\text { Crataegus monogyna } \\
\text { Jacq., } C \text {. rhipidophylla } \\
\text { Gand. [syn. } C \text {. } \\
\text { oxyacantha L.], } C \text {. }\end{array}$ & cratego & $\begin{array}{l}\mathrm{I}, \mathrm{T}, \mathrm{IN}, \mathrm{D} \\
\mathrm{A}, \mathrm{B}(886)\end{array}$ & - & $\begin{array}{l}\text { [syn. Crataegus } \\
\text { oxyacantha L.]: I, } \\
\text { T, A (822) }\end{array}$ & $\begin{array}{c}\text { [syn. Crataegus } \\
\text { oxyacantha L.]: I, T, A } \\
\text { (326) }\end{array}$ & - & $\begin{array}{l}\text { sim } \\
\text { [Crataegus } \\
\text { rhipidophylla } \\
\text { Gand.] }\end{array}$ \\
\hline
\end{tabular}


Quadro 3 - Sistematização das informações contidas nas monografias de drogas vegetais e derivados da Farmacopeia Brasileira $5^{\text {a }}$ edição e as monografias correspondentes constantes nas edições anteriores da Farmacopeia Brasileira, $1^{\mathrm{a}}, 2^{\mathrm{a}}, 3^{\mathrm{a}}$ e $4^{\mathrm{a}}$ edição.

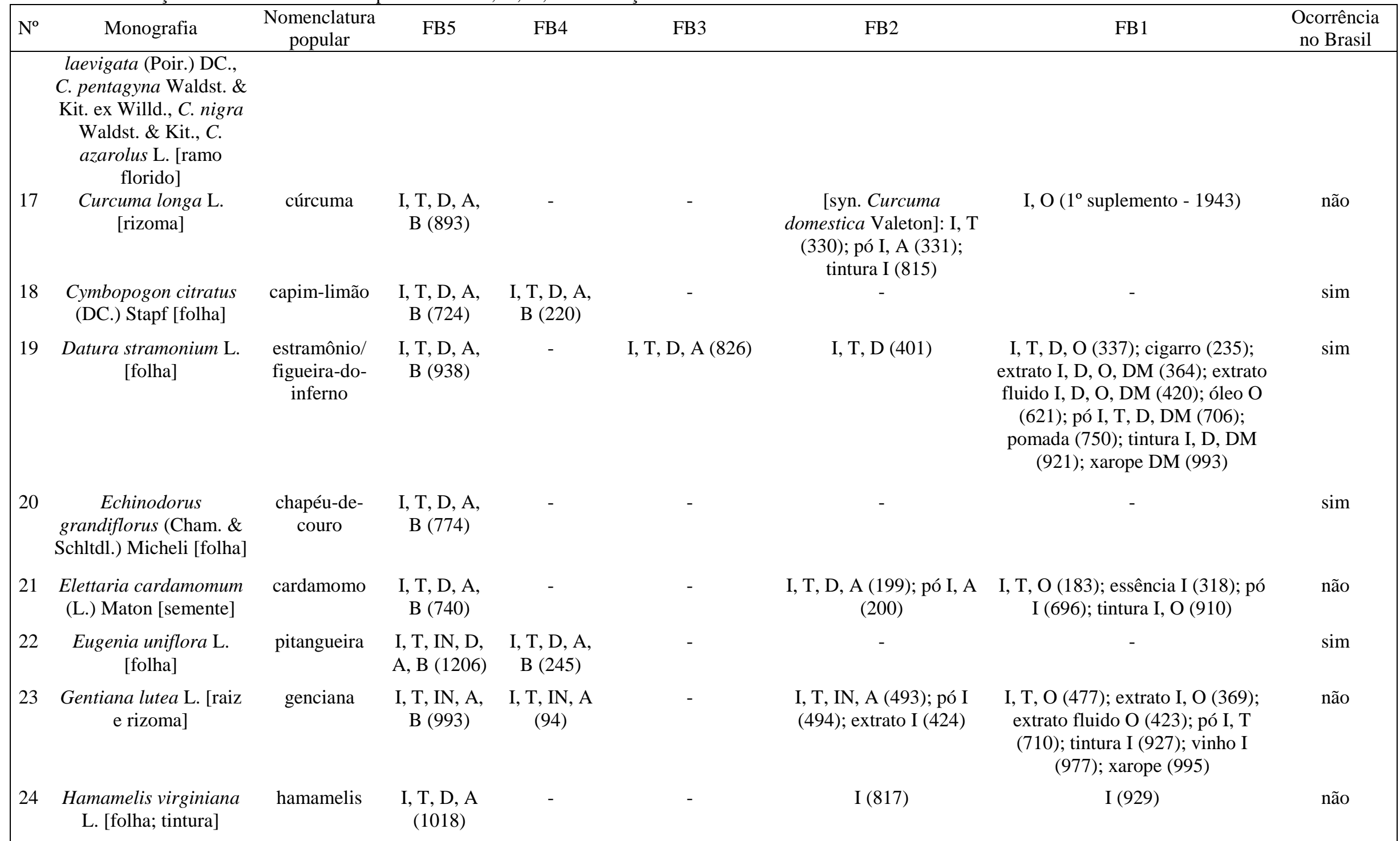


Quadro 3 - Sistematização das informações contidas nas monografias de drogas vegetais e derivados da Farmacopeia Brasileira $5^{\text {a }}$ edição e as monografias correspondentes constantes nas edições anteriores da Farmacopeia Brasileira, $1^{\mathrm{a}}, 2^{\mathrm{a}}, 3^{\mathrm{a}}$ e $4^{\mathrm{a}}$ edição.

\begin{tabular}{|c|c|c|c|c|c|c|c|c|}
\hline $\mathrm{N}^{\mathrm{o}}$ & Monografia & $\begin{array}{c}\text { Nomenclatura } \\
\text { popular }\end{array}$ & FB5 & FB4 & FB3 & FB2 & FB1 & $\begin{array}{c}\text { Ocorrência } \\
\text { no Brasil }\end{array}$ \\
\hline 25 & $\begin{array}{l}\text { Hydrastis canadensis } \mathrm{L} . \\
\text { [raiz e rizoma] }\end{array}$ & hidraste & $\begin{array}{l}\text { I, T, D, A, } \\
\text { B (1032) }\end{array}$ & $\begin{array}{l}\mathrm{I}, \mathrm{T}, \mathrm{D}, \mathrm{A} \\
\quad(96)\end{array}$ & $\mathrm{I}, \mathrm{T}, \mathrm{D}, \mathrm{A}(831)$ & $\begin{array}{l}\text { I, T, D (524); extrato I, D } \\
\text { (424); extrato fluido I, D } \\
\text { (438); tintura I, D (817) }\end{array}$ & $\begin{array}{c}\text { I, T, D, O (508); extrato I, D, DM } \\
\text { (370); extrato fluido I, D, DM } \\
\text { (430); pó I, T, D, DM (714); } \\
\text { tintura I, D, DM (930) }\end{array}$ & não \\
\hline 26 & $\begin{array}{l}\text { Hyoscyamus niger } \mathrm{L} . \\
\text { [folha] }\end{array}$ & meimendro & $\begin{array}{l}\text { I, T, D, A, } \\
\text { B (1123) }\end{array}$ & - & - & I, T, D (562); pó I (563) & $\begin{array}{l}\text { I, T, D, O (577); extrato I, D, O, } \\
\text { DM (373); extrato fluido I, D, } \\
\text { DM (439); óleo O (623); pó I, T, } \\
\text { D, DM (720); tintura I, D, DM } \\
\text { (940); xarope DM (1005) }\end{array}$ & não \\
\hline 27 & $\begin{array}{l}\text { Illicium verum Hook. f. } \\
\text { [fruto] }\end{array}$ & $\begin{array}{l}\text { anis- } \\
\text { estrelado/ } \\
\text { badiana }\end{array}$ & $\begin{array}{l}\text { I, T, D, A, } \\
\quad \text { B (642) }\end{array}$ & $\begin{array}{l}\text { I, T, D, A, } \\
\text { B (81) }\end{array}$ & $\mathrm{I}, \mathrm{T}, \mathrm{D}(811)$ & $\begin{array}{c}\text { I, T, D (122); pó A } \\
\text { (123); essência I, T, IN, } \\
\text { A (376) }\end{array}$ & $\begin{array}{c}\text { I, T, O (109); essência I (315); pó } \\
\text { I (692) }\end{array}$ & não \\
\hline 28 & $\begin{array}{l}\text { Krameria lappacea } \\
\text { (Dombey) Burdet \& } \\
\text { B.B.Simpson [raiz] }\end{array}$ & ratânia & $\begin{array}{l}\text { I, T, D, A, } \\
\text { B (1249) }\end{array}$ & - & - & - & - & não \\
\hline 29 & $\begin{array}{c}\text { Krameria lappacea } \\
\text { (Dombey) Burdet \& } \\
\text { B.B.Simpson [raiz; } \\
\text { tintura] }\end{array}$ & ratânia & $\begin{array}{l}\mathrm{I}, \mathrm{T}, \mathrm{D}, \mathrm{A} \\
\quad(1252)\end{array}$ & - & - & - & - & não \\
\hline 30 & $\begin{array}{c}\text { Maytenus ilicifolia } \\
\text { Mart. ex Reissek [folha] }\end{array}$ & $\begin{array}{l}\text { espinheira- } \\
\text { santa }\end{array}$ & $\begin{array}{l}\text { I, T, IN, D, } \\
\text { A, B (922) }\end{array}$ & $\begin{array}{l}\text { I, T, D, A, } \\
\text { B (194) }\end{array}$ & - & - & - & $\operatorname{sim}$ \\
\hline 31 & $\begin{array}{l}\text { Melissa officinalis L. } \\
\text { [folha] }\end{array}$ & $\begin{array}{l}\text { melissa/ erva- } \\
\text { cidreira }\end{array}$ & $\begin{array}{c}\text { I, T, D, A, } \\
\text { P, B (1127) }\end{array}$ & - & - & - & $\begin{array}{c}\text { sumidade florida: I, O (503); } \\
\text { essência I, O (323); extrato fluido } \\
\text { (428) }\end{array}$ & não \\
\hline 32 & $\begin{array}{c}\text { Mentha x piperita } \mathrm{L} . \\
\text { [folha] }\end{array}$ & $\begin{array}{l}\text { hortelã- } \\
\text { pimenta }\end{array}$ & $\begin{array}{l}\text { I, T, D, A, } \\
\text { B (1046) }\end{array}$ & - & - & - & $\begin{array}{l}\text { folha e sumidade florida: I, O } \\
\text { (508); extrato fluido (430); } \\
\text { xarope I, O (998) }\end{array}$ & não \\
\hline 33 & $\begin{array}{l}\text { Mentha x piperita L. } \\
\text { [parte aérea fresca; } \\
\text { óleo] }\end{array}$ & $\begin{array}{l}\text { hortelã- } \\
\text { pimenta }\end{array}$ & $\begin{array}{l}\mathrm{I}, \mathrm{T}, \mathrm{IN}, \mathrm{P} \\
\mathrm{A}(1050)\end{array}$ & - & - & $\mathrm{I}, \mathrm{T}, \mathrm{IN}, \mathrm{D}, \mathrm{A}(383)$ & $\begin{array}{l}\text { folha e sumidade florida: I, T, D, } \\
\qquad \mathrm{O}(324)\end{array}$ & não \\
\hline
\end{tabular}


Quadro 3 - Sistematização das informações contidas nas monografias de drogas vegetais e derivados da Farmacopeia Brasileira $5^{\text {a }}$ edição e as monografias correspondentes constantes nas edições anteriores da Farmacopeia Brasileira, $1^{\mathrm{a}}, 2^{\mathrm{a}}, 3^{\mathrm{a}}$ e $4^{\mathrm{a}}$ edição.

\begin{tabular}{|c|c|c|c|c|c|c|c|c|}
\hline $\mathrm{N}^{\mathrm{o}}$ & Monografia & $\begin{array}{l}\text { Nomenclatura } \\
\text { popular }\end{array}$ & FB5 & FB4 & FB3 & FB2 & FB1 & $\begin{array}{c}\text { Ocorrência } \\
\text { no Brasil }\end{array}$ \\
\hline 34 & $\begin{array}{l}\text { Myroxylon balsamum } \\
\text { (L.) Harms e Myroxylon } \\
\text { balsamum var. pereirae } \\
\text { (Royle) Harms [tronco; } \\
\text { óleo-resina] }\end{array}$ & $\begin{array}{l}\text { bálsamo-de- } \\
\text { tolu }\end{array}$ & $\begin{array}{l}\text { I, T, IN, D, } \\
\text { A }(670)\end{array}$ & - & - & $\begin{array}{l}\text { [Myroxylon balsamum } \\
\text { (L.) Harms var. } \\
\text { genuinum (Baill.) } \\
\text { Harms]: I, T, IN, A } \\
\text { (124); xarope I (870) }\end{array}$ & $\begin{array}{c}\text { [Toluifera balsamum L. var. } \\
\text { genuina Baill.]: I, T, IN, O (111); } \\
\text { xarope I (987) }\end{array}$ & $\operatorname{sim}$ \\
\hline 35 & $\begin{array}{l}\text { Myroxylon balsamum } \\
\text { (L.) Harms var. } \\
\text { pereirae (Royle) Harms } \\
\text { [tronco; bálsamo] }\end{array}$ & $\begin{array}{l}\text { bálsamo-de- } \\
\text { peru/ } \\
\text { bálsamo- } \\
\text { peruviano }\end{array}$ & $\begin{array}{l}\mathrm{I}, \mathrm{T}, \mathrm{IN}, \mathrm{D}, \\
\mathrm{A}(669)\end{array}$ & - & - & I, T, IN, D, A (125) & $\begin{array}{l}\text { [syn. Toluifera balsamum L. var. } \\
\text { pereirae (Royle) Baill.]: I, T, IN, } \\
\text { D, O (113) }\end{array}$ & $\operatorname{sim}$ \\
\hline 36 & $\begin{array}{l}\text { Passiflora alata Curtis } \\
\text { [folha] }\end{array}$ & $\begin{array}{l}\text { maracujá- } \\
\text { doce/ } \\
\text { maracujá }\end{array}$ & $\begin{array}{l}\mathrm{I}, \mathrm{T}, \mathrm{IN}, \mathrm{D}, \\
\mathrm{A}, \mathrm{B}(1116)\end{array}$ & - & $\begin{array}{l}\text { [syn. Passiflora } \\
\text { alata Aiton]: I, T, } \\
\text { A (839) }\end{array}$ & $\begin{array}{l}\text { [syn. Passiflora alata } \\
\text { Aiton]: I, T (561) }\end{array}$ & $\begin{array}{l}\text { [syn. Passiflora alata Aiton]: I, } \\
\text { T, O (574); extrato fluido (438); } \\
\text { tintura I (939) }\end{array}$ & $\operatorname{sim}$ \\
\hline 37 & $\begin{array}{l}\text { Passiflora edulis Sims } \\
\text { [folha] }\end{array}$ & $\begin{array}{l}\text { maracujá- } \\
\text { azedo }\end{array}$ & $\begin{array}{l}\mathrm{I}, \mathrm{T}, \mathrm{IN}, \mathrm{D}, \\
\mathrm{A}, \mathrm{B}(1111)\end{array}$ & - & - & - & - & $\operatorname{sim}$ \\
\hline 38 & $\begin{array}{l}\text { Paullinia cupana Kunth } \\
\text { [semente] }\end{array}$ & guaraná & $\begin{array}{l}\mathrm{I}, \mathrm{T}, \mathrm{D}, \mathrm{A} \\
\mathrm{B}(1009)\end{array}$ & $\begin{array}{l}\text { I, T, D, A, } \\
\text { B (236) }\end{array}$ & $\begin{array}{l}\text { fruto e semente: I, } \\
\qquad \mathrm{D}(829)\end{array}$ & $\begin{array}{c}\text { I, T, D (512); pó I, T, D } \\
\text { (512) }\end{array}$ & $\begin{array}{l}\text { I, T, D, O (498 e } 3^{\circ} \text { suplemento - } \\
\text { 1951); elixir (283); pó I, T, D } \\
\text { (713); extrato fluido D, O (3º } \\
\text { suplemento 1951) }\end{array}$ & $\operatorname{sim}$ \\
\hline 39 & $\begin{array}{l}\text { Persea americana Mill. } \\
\text { [folha] }\end{array}$ & abacateiro & $\begin{array}{l}\mathrm{I}, \mathrm{T}, \mathrm{D}, \mathrm{A} \\
\mathrm{B}(557)\end{array}$ & - & - & $\begin{array}{l}\text { [syn. Persea gratissima } \\
\text { C.F. Gaertn.] I, T (21); } \\
\text { extrato fluido I ( } 431)\end{array}$ & $\begin{array}{c}\text { [syn. Persea persea (L.) } \\
\text { Cockerell]: I,O (3); extrato fluido } \\
(387)\end{array}$ & $\operatorname{sim}$ \\
\hline 40 & $\begin{array}{l}\text { Peumus boldus Molina } \\
\text { [folha] }\end{array}$ & boldo & $\begin{array}{l}\text { I, T, D, A, } \\
\text { B (692) }\end{array}$ & $\begin{array}{l}\mathrm{I}, \mathrm{T}, \mathrm{D}, \mathrm{A} \\
\quad(11)\end{array}$ & - & $\begin{array}{l}\text { I, T, D, A (150); pó I } \\
(151)\end{array}$ & $\begin{array}{l}\text { [syn. Boldu boldus (Molina) } \\
\text { Lyons]: I, T, O (132) }\end{array}$ & não \\
\hline 41 & $\begin{array}{l}\text { Peumus boldus Molina } \\
\text { [folha; tintura] }\end{array}$ & boldo & $\begin{array}{l}\mathrm{I}, \mathrm{T}, \mathrm{D}, \mathrm{A} \\
\quad(698)\end{array}$ & - & - & I (813) & - & não \\
\hline 42 & $\begin{array}{l}\text { Phyllanthus niruri L. } \\
\text { [parte aérea] }\end{array}$ & quebra-pedra & $\begin{array}{l}\mathrm{I}, \mathrm{T}, \mathrm{D}, \mathrm{A} \\
\mathrm{B}(1229)\end{array}$ & $\begin{array}{l}\text { I, T, D, A, } \\
\text { B (246) }\end{array}$ & - & - & - & $\operatorname{sim}$ \\
\hline 43 & $\begin{array}{l}\text { Phyllanthus tenellus } \\
\text { Roxb. [parte aérea] }\end{array}$ & quebra-pedra & $\begin{array}{l}\mathrm{I}, \mathrm{T}, \mathrm{D}, \mathrm{A} \\
\mathrm{B}(1235)\end{array}$ & $\begin{array}{l}\text { I, T, D, A, } \\
\text { B (247) }\end{array}$ & - & - & - & $\operatorname{sim}$ \\
\hline
\end{tabular}


Quadro 3 - Sistematização das informações contidas nas monografias de drogas vegetais e derivados da Farmacopeia Brasileira $5^{\mathrm{a}}$ edição e as monografias correspondentes constantes nas edições anteriores da Farmacopeia Brasileira, $1^{\mathrm{a}}, 2^{\mathrm{a}}, 3^{\mathrm{a}}$ e $4^{\mathrm{a}}$ edição.

\begin{tabular}{|c|c|c|c|c|c|c|c|c|}
\hline $\mathrm{N}^{\mathrm{o}}$ & Monografia & $\begin{array}{l}\text { Nomenclatura } \\
\text { popular }\end{array}$ & FB5 & FB4 & FB3 & FB2 & FB1 & $\begin{array}{c}\text { Ocorrência } \\
\text { no Brasil }\end{array}$ \\
\hline 44 & $\begin{array}{c}\text { Pilocarpus } \\
\text { microphyllus Stapf ex } \\
\text { Wardleworth [folha; } \\
\text { tintura] }\end{array}$ & jaborandi & $\begin{array}{l}\mathrm{I}, \mathrm{T}, \mathrm{D}, \mathrm{A} \\
(1077)\end{array}$ & - & - & I, D (819) & I, D, DM (932) & $\operatorname{sim}$ \\
\hline 45 & $\begin{array}{l}\text { Pimpinella anisum } \mathrm{L} \text {. } \\
\text { [fruto] }\end{array}$ & $\begin{array}{l}\text { anis-doce/ } \\
\text { anis }\end{array}$ & $\begin{array}{l}\mathrm{I}, \mathrm{T}, \mathrm{D}, \mathrm{A} \\
\mathrm{B}(637)\end{array}$ & $\begin{array}{l}\mathrm{I}, \mathrm{T}, \mathrm{D}, \mathrm{A}, \\
\mathrm{B}(80)\end{array}$ & - & $\begin{array}{c}\text { I, T, D (110); pó I, A } \\
\text { (111) }\end{array}$ & I, T, O (93); pó I (691) & não \\
\hline 46 & $\begin{array}{l}\text { Polygala senega L. [raiz } \\
\text { e rizoma] }\end{array}$ & polígala & $\begin{array}{l}\mathrm{I}, \mathrm{T}, \mathrm{D}, \mathrm{A} \\
\mathrm{B}(1213)\end{array}$ & $\begin{array}{l}\text { I, T, D, A, } \\
\text { B (301) }\end{array}$ & - & $\begin{array}{l}\text { raiz: I, T (661); extrato } \\
\text { fluido I (442); tintura I } \\
\qquad(826)\end{array}$ & $\begin{array}{l}\text { raiz: I, T, O (743); extrato fluido } \\
\text { I, O (448); pó I, T (725); tintura I } \\
\text { (948); xarope (1008) }\end{array}$ & não \\
\hline 47 & $\begin{array}{l}\text { Quillaja saponaria } \\
\text { Molina [casca do ramo] }\end{array}$ & quilaia & $\begin{array}{l}\text { I, T, IN, A, } \\
\text { B (1241) }\end{array}$ & - & - & - & $\begin{array}{l}\text { I, T, O (765); extrato fluido } \\
\text { (449); tintura I (949) }\end{array}$ & não \\
\hline 48 & $\begin{array}{l}\text { Rauvolfia serpentina } \\
\text { (L.) Benth. ex Kurz } \\
\text { [raiz] }\end{array}$ & rauvólfia & $\begin{array}{l}\mathrm{I}, \mathrm{T}, \mathrm{D}, \mathrm{A} \\
\mathrm{B}(1253)\end{array}$ & - & - & I, T, D, A (686) & - & não \\
\hline 49 & $\begin{array}{l}\text { Rheum palmatum } \mathrm{L} . \\
\text { e/ou Rheum officinale } \\
\text { Baill. [raiz e rizoma] }\end{array}$ & ruibarbo & $\begin{array}{l}\mathrm{I}, \mathrm{T}, \mathrm{D}, \mathrm{A} \\
\mathrm{B}(1261)\end{array}$ & $\begin{array}{l}\text { I, T, D, A, } \\
\text { B (302) }\end{array}$ & I, T, D, A (843) & $\begin{array}{l}\text { I, T, A (692); pó I (693); } \\
\text { extrato I (430); extrato } \\
\text { fluido I (444) }\end{array}$ & $\begin{array}{c}\text { [Rheum palmatum L. var. } \\
\text { tanguticum Maxim. ex Regel], } \\
\text { [Rheum ssp], rizoma: I, T, A, O } \\
\text { (778); extrato I, O (380); extrato } \\
\text { fluido O (452); pílula (681); pó I, } \\
\text { T, O (727); tintura I (952); xarope } \\
\text { (1009) }\end{array}$ & não \\
\hline 50 & $\begin{array}{l}\text { Rosmarinus officinalis } \\
\text { L. [sumidade florida; } \\
\text { óleo] }\end{array}$ & alecrim & $\begin{array}{l}\text { I, T, IN, P, } \\
\text { A }(595)\end{array}$ & - & - & I, T, IN, D, A (373) & $\begin{array}{l}\text { folha e sumidade florida: essência } \\
\text { I, T, D, O (311) }\end{array}$ & não \\
\hline 51 & Salix alba L. [casca] & $\begin{array}{l}\text { salgueiro- } \\
\text { branco }\end{array}$ & $\begin{array}{l}\mathrm{I}, \mathrm{T}, \mathrm{D}, \mathrm{A} \\
\mathrm{B}(1279)\end{array}$ & - & - & - & - & não \\
\hline 52 & $\begin{array}{l}\text { Sambucus australis } \\
\text { Cham. \& Schltdl. [flor] }\end{array}$ & $\begin{array}{l}\text { sabugueiro- } \\
\text { do-brasil/ } \\
\text { sabugueiro }\end{array}$ & $\begin{array}{l}\mathrm{I}, \mathrm{T}, \mathrm{D}, \mathrm{A} \\
\mathrm{B}(1271)\end{array}$ & - & - & - & I, T, O (785) & $\operatorname{sim}$ \\
\hline
\end{tabular}


Quadro 3 - Sistematização das informações contidas nas monografias de drogas vegetais e derivados da Farmacopeia Brasileira $5^{\mathrm{a}}$ edição e as monografias correspondentes constantes nas edições anteriores da Farmacopeia Brasileira, $1^{\mathrm{a}}, 2^{\mathrm{a}}, 3^{\mathrm{a}} \mathrm{e} 4^{\mathrm{a}}$ edição.

\begin{tabular}{|c|c|c|c|c|c|c|c|c|}
\hline $\mathrm{N}^{\mathrm{o}}$ & Monografia & $\begin{array}{l}\text { Nomenclatura } \\
\text { popular }\end{array}$ & FB5 & FB4 & FB3 & FB2 & FB1 & $\begin{array}{c}\text { Ocorrência } \\
\text { no Brasil }\end{array}$ \\
\hline 53 & $\begin{array}{l}\text { Sambucus nigra L. } \\
\text { [flor] }\end{array}$ & sabugueiro & $\begin{array}{l}\text { I, T, D, A, } \\
\text { B (1265) }\end{array}$ & - & - & - & - & $\operatorname{sim}$ \\
\hline 54 & $\begin{array}{l}\text { Senna alexandrina Mill. } \\
\text { [folíolo] }\end{array}$ & sene/ senna & $\begin{array}{l}\mathrm{I}, \mathrm{T}, \mathrm{D}, \mathrm{A} \\
\mathrm{B}(1284)\end{array}$ & $\begin{array}{l}\text { fruto e } \\
\text { folíolo: I, T, } \\
\text { D, A (64) }\end{array}$ & $\begin{array}{l}\text { [syn. Cassia } \\
\text { acutifolia } \text { Delile], } \\
\text { [syn. Cassia } \\
\text { angustifolia } \text { Vahl]: } \\
\text { I, T, D, A }(845)\end{array}$ & $\begin{array}{l}\text { [syn. Cassia acutifolia } \\
\text { Delile], [syn. Cassia } \\
\text { angustifolia Vahl]: I, T, } \\
\text { A (708); pó I (709) }\end{array}$ & $\begin{array}{l}\text { [syn. Cassia acutifolia Delile], } \\
\text { [syn. Cassia angustifolia Vahl]: I, } \\
\text { T, O (808); extrato fluido O } \\
\text { (456); pó I, T (731); xarope } \\
\text { (1011) }\end{array}$ & $\operatorname{sim}$ \\
\hline 55 & $\begin{array}{l}\text { Stevia rebaudiana } \\
\text { (Bertoni) Bertoni } \\
\text { [folha] }\end{array}$ & estévia & $\begin{array}{l}\text { I, T, D, A, } \\
\text { B (930) }\end{array}$ & $\begin{array}{l}\text { I, T, D, A, } \\
\text { B (233) }\end{array}$ & - & - & - & $\operatorname{sim}$ \\
\hline 56 & $\begin{array}{c}\text { Stryphnodendron } \\
\text { adstringens (Mart.) } \\
\text { Coville [casca do caule] }\end{array}$ & barbatimão & $\begin{array}{l}\mathrm{I}, \mathrm{T}, \mathrm{D}, \mathrm{A} \\
\mathrm{B}(671)\end{array}$ & $\begin{array}{l}\text { I, T, D, A, } \\
\text { B (176) }\end{array}$ & - & $\begin{array}{l}\text { [syn. Stryphnodendron } \\
\text { barbatimam Mart.]: I, T, } \\
\text { D, A (126) }\end{array}$ & $\begin{array}{c}\text { [syn. Stryphnodendron } \\
\text { barbatimam Mart.]: I, O (116); } \\
\text { extrato fluido (395); tintura I } \\
(902)\end{array}$ & $\operatorname{sim}$ \\
\hline 57 & $\begin{array}{l}\text { Styrax benzoin Dryand. } \\
\text { ou Styrax } \\
\text { paralleloneuron Perkins } \\
\text { [tronco; resina } \\
\text { balsâmica] }\end{array}$ & benjoim & $\begin{array}{l}\mathrm{I}, \mathrm{T}, \mathrm{D}, \mathrm{A} \\
\quad(682)\end{array}$ & - & - & $\begin{array}{c}\text { [S. tonkinensis }(\text { Pierre) } \\
\text { Craib ex Hartwich], [S. } \\
\text { benzoin Dryand.], [S. } \\
\text { paralleloneurus } \\
\text { Perkins]: I, T, IN, A } \\
\text { (133) }\end{array}$ & $\begin{array}{l}\text { [Styrax tonkinensis (Pierre) Craib } \\
\text { ex Hartwich], [Styrax siamensis } \\
\text { Rordorf], [Styrax benzoides } \\
\text { Craib], [Styrax ssp]: I, T, O } \\
\text { (120); tintura I, T, O (904) }\end{array}$ & não \\
\hline 58 & $\begin{array}{c}\text { Vanilla planifolia } \\
\text { Andrews [fruto imaturo] }\end{array}$ & baunilha & $\begin{array}{l}\mathrm{I}, \mathrm{T}, \mathrm{D}, \mathrm{A} \\
\mathrm{B}(676)\end{array}$ & - & - & $\begin{array}{l}\text { fruto maduro: I, T, D, A } \\
\qquad(129)\end{array}$ & I, T,O (118); tintura I, O (903) & $\operatorname{sim}$ \\
\hline
\end{tabular}

(BRASIL, 1929, 1943b, 2005a, 2010d, 1951, 1959b, 1977, 1996, 2000, 2001, 2002, 2003a; REFLORA, 2016; TROPICOS.ORG, 2016)

Legenda: FB1 = Farmacopeia Brasileira $1^{\mathrm{a}}$ edição; FB2 = Farmacopeia Brasileira $2^{\mathrm{a}}$ edição; FB3 = Farmacopeia Brasileira $3^{\mathrm{a}}$ edição; FB4 = Farmacopeia Brasileira $4^{\mathrm{a}}$ edição; FB5 = Farmacopeia Brasileira $5^{\text {a }}$ edição; $\mathrm{I}=$ características, descrições micro e macroscópicas, testes de identificação; T = ensaios, impurezas e testes; D = doseamento; DM = dose máxima; $\mathrm{IN}$ = índices de iodo, de acidez, de saponificação, de refração, de dulçor, de espuma, de intumescência e de amargor; O = emprego oficinal; $\mathrm{P}=$ perfil cromatográfico; $\mathrm{A}$ = armazenagem e conservação ou armazenamento; $\mathrm{B}$ = figura botânica.

Nota: o número entre parênteses em seguida às informações sobre a composição das monografias corresponde a página da monografia no respectivo compêndio (página inicial da monografia), com exceção da Farmacopeia Brasileira $4^{\text {a }}$ edição em que corresponde ao número da monografia. 
Somente a Farmacopeia Brasileira $1^{\mathrm{a}}$ edição apresentava informações não relacionadas à qualidade, como o emprego oficinal e a dose máxima (Quadro 3), além do modo de preparo das formulações (tinturas, elixires etc.). Essas características aproximam a FB1 mais do conceito atual de um formulário do que de uma farmacopeia.

Na época da vigência da FB1 não existia um formulário nacional, sendo que a sua elaboração foi prevista no Decreto $n^{\circ} 45.502$ de 27 de fevereiro de 1959 (BRASIL, 1959a), que aprovou a $2^{\mathrm{a}}$ edição da Farmacopeia Brasileira. Assim, a Comissão Revisora da $2^{\mathrm{a}}$ edição deliberou que "drogas" e preparações galênicas oficinais fossem suprimidas da FB2 e incluídas no Formulário Nacional (BRASIL, 1959b). Essa migração das fórmulas oficinais da farmacopeia para o formulário acompanhava a tendência internacional, com a farmacopeia se especializando em requisitos de qualidade enquanto o formulário se especializava em ditar fórmulas oficinais (BRASIL, 2012).

Assim, devido à expectativa da criação do Formulário Nacional, várias monografias contidas na FB1 foram excluídas da FB2, tais como as formas de dispensação: cigarros, elixires, linimentos, pílulas, pomadas, supositórios, vinhos e xaropes (Quadro 3). A Farmacopeia Brasileira começou a assumir a função de um compêndio com especificações para a qualidade dos seus produtos.

Após 18 anos da publicação da $2^{\mathrm{a}}$ edição, foi publicada a FB3, na qual havia um número reduzido monografias de drogas vegetais (Quadro 3), não havendo monografias de derivados vegetais, com exceção de algumas tinturas (BRASIL, 1977). Na FB3, o número de monografias de drogas vegetais foi reduzido drasticamente, de 193 na FB2 (BRANDÃO et al., 2006) para 23 na FB3 (BRASIL, 1977), refletindo a tendência mundial, na época, de valorização do fármaco isolado/sintetizado.

A FB4 marca uma série de mudanças na Farmacopeia Brasileira (BRASIL, 1988c). Dentre elas, há um aprimoramento das técnicas de doseamento, com a adição de métodos por cromatografia gasosa (anis-estrelado e canela-do-ceilão, por exemplo) e por espectrofotometria (guaraná e ruibarbo, por exemplo) (BRASIL, 2000, 2003a, 2005a), e das descrições macroscópicas e microscópicas das drogas vegetais, com inserção de figuras ilustrativas do material botânico (Quadro 3) a partir do fascículo 2 (BRASIL, 2000).

A inserção de figuras ilustrativas do material botânico foi mantida na FB5 (Quadro 3), sendo encontradas em todas as suas monografias de drogas vegetais (BRASIL, 2010d).

Considerando apenas as monografias alvo desse estudo e não a totalidade das monografias de cada compêndio, 28\% (onze) das monografias continham requisitos de 
doseamento na FB1, 54\% (vinte) na FB2, 77\% (dez) na FB3, 96\% (vinte e três) na FB4, e 91\% (cinquenta e três) na FB5, ou 95\% (cinquenta e cinco) se os perfis cromatográficos por cromatografia gasosa forem considerados como doseamento.

Assim, os dados mostram que ao longo das edições da Farmacopeia Brasileira houve uma evolução no que se refere aos parâmetros de qualidade estabelecidos, especialmente quanto ao estabelecimento dos requisitos de doseamento e o aprimoramento dos requisitos botânicos.

A partir dos dados do Quadro 3 foi elaborada a Tabela 1 que apresenta o quantitativo de monografias semelhantes à FB5 constante nas edições anteriores da Farmacopeia Brasileira correlacionando essas monografias com a ocorrência das espécies no Brasil. 
Tabela 1 - Presença de monografias da Farmacopeia Brasileira $5^{\mathrm{a}}$ edição (FB5) nas edições anteriores, Farmacopeia Brasileira $4^{\mathrm{a}}$ edição (FB4), Farmacopeia Brasileira $3^{\mathrm{a}}$ edição (FB3), Farmacopeia Brasileira $2^{\mathrm{a}}$ edição (FB2) e Farmacopeia Brasileira 1 ${ }^{\mathrm{a}}$ edição (FB1), relacionando as monografias com a ocorrência das espécies no Brasil.

\begin{tabular}{|c|c|c|c|c|c|c|c|c|c|c|c|c|c|c|}
\hline & FB5 & & & & & & & & & & & Em n & \multicolumn{2}{|c|}{$\begin{array}{l}\text { Em pelo } \\
\text { menos uma }\end{array}$} \\
\hline $\begin{array}{l}\text { Monografias } \\
\text { semelhantes à }\end{array}$ & - & \multicolumn{2}{|c|}{24} & \multicolumn{2}{|c|}{13} & \multicolumn{2}{|c|}{37} & \multicolumn{2}{|c|}{39} & \multicolumn{2}{|c|}{7} & 7 & \multicolumn{2}{|c|}{51} \\
\hline FB5 & - & \multicolumn{2}{|c|}{$41 \%$} & \multicolumn{2}{|c|}{$22 \%$} & \multicolumn{2}{|c|}{$64 \%$} & \multicolumn{2}{|c|}{$67 \%$} & \multicolumn{2}{|c|}{$12 \%$} & $12 \%$ & \multicolumn{2}{|c|}{$88 \%$} \\
\hline Espécie (s) com & 26 & \multicolumn{2}{|c|}{13} & \multicolumn{2}{|c|}{5} & \multicolumn{2}{|c|}{12} & \multicolumn{2}{|c|}{13} & \multicolumn{2}{|c|}{2} & & \multicolumn{2}{|c|}{23} \\
\hline Brasil & $45 \%$ & $22 \%$ & $54 \%$ & $9 \%$ & $38 \%$ & $21 \%$ & $32 \%$ & $22 \%$ & $33 \%$ & $3 \%$ & $29 \%$ & $5 \%$ & $40 \%$ & $45 \%$ \\
\hline Espécie (s) sem & 32 & \multicolumn{2}{|c|}{11} & \multicolumn{2}{|c|}{8} & \multicolumn{2}{|c|}{25} & \multicolumn{2}{|c|}{26} & \multicolumn{2}{|c|}{5} & 4 & \multicolumn{2}{|c|}{28} \\
\hline Brasil & $55 \%$ & $19 \%$ & $46 \%$ & $14 \%$ & $62 \%$ & $43 \%$ & $68 \%$ & $45 \%$ & $67 \%$ & $9 \%$ & $71 \%$ & $7 \%$ & $48 \%$ & $55 \%$ \\
\hline
\end{tabular}

Nota: a porcentagem à esquerda é referente à quantidade total de monografias (58) e a porcentagem à direita é referente à quantidade de monografias semelhantes constantes na respectiva edição (FB1, quantidade de 39 monografias; FB2, quantidade de 37 monografias; FB3, quantidade de 13 monografias; e FB4, quantidade de 24 monografias). 
A Tabela 1 permite verificar que dentre as 58 monografias da FB5, 45\% contemplam ao menos uma espécie com ocorrência no Brasil.

Por outro lado, a maior parte das monografias de drogas vegetais e derivados da FB5 (88\%) esteve, previamente, em pelo menos uma das edições anteriores da Farmacopeia Brasileira, sendo que cerca de metade destas monografias (45\%), que estavam em pelo uma das edições anteriores, possui espécies com ocorrência no Brasil.

Dentre as monografias de drogas vegetais e derivados inseridas na FB5, $12 \%$ não estavam nas edições anteriores: Aloe vera (L.) Burm. f. [folha fresca; gel mucilaginoso], Echinodorus grandiflorus (Cham. \& Schltdl.) Micheli [folha], Krameria lappacea (Dombey) Burdet \& B.B.Simpson [raiz], Krameria lappacea (Dombey) Burdet \& B.B.Simpson [raiz; tintura], Passiflora edulis Sims [folha], Salix alba L. [casca do ramo], e Sambucus nigra L. [flor]. Destas, $43 \%$ se referem a espécies com ocorrência no Brasil: Echinodorus grandiflorus (Cham. \& Schltdl.) Micheli [folha], Passiflora edulis Sims [folha] e Sambucus nigra L. [flor].

Em contrapartida, dentre as monografias de drogas vegetais e derivados da FB5, 12\% estavam contidas em todas as edições anteriores: Atropa belladonna L. [folha], Cinnamomum verum J. Presl [casca], Hydrastis canadensis L. [raiz e rizoma], Illicium verum Hook. f. [fruto], Paullinia cupana Kunth [semente], Rheum palmatum L. e/ou Rheum officinale Baill. [raiz e rizoma], e Senna alexandrina Mill. [folíolo]. Destas, somente 29\% se referem a espécies ocorrentes no Brasil: Paullinia cupana Kunth [semente] e Senna alexandrina Mill. [folíolo].

Assim, dentre as monografias que aparecem como novidade apenas na FB5 (ausentes nas edições anteriores) há maior incidência de monografias com espécies com ocorrência no país (43\%), enquanto que as monografias mais populares nas farmacopeias brasileiras (presente em todas as edições) há menor incidência de monografias com espécies com ocorrência no Brasil (29\%). Por outro lado, a incidência de monografias com espécies com ocorrência no Brasil na FB5 (45\%) é menor do que a incidência de monografias que já estiveram em edições anteriores da Farmacopeia Brasileira (88\%).

Isso indica que a inclusão de uma monografia na Farmacopeia Brasileira $5^{\mathrm{a}}$ edição foi motivada mais pelo interesse em revisar e atualizar as monografias que faziam parte do repertório farmacopeico do que em adicionar novas monografias com ocorrência no Brasil, que poderiam representar um maior potencial de interesse econômico. Porém, considerando que havia várias edições da Farmacopeia Brasileira sendo utilizadas no país, com monografias que representavam diversos patamares de avanço tecnológico (desde 1929 a 2005), era desejável 
uma reavaliação dessas monografias para verificar a possibilidade da sua modernização e incorporação em uma única e nova edição.

\subsubsection{Composição das monografias de drogas vegetais e derivados da Farmacopeia} Brasileira $5^{\text {a }}$ edição

Para dar continuidade à avaliação da evolução das monografias de drogas vegetais e derivados da FB5, o seu quantitativo de métodos, ensaios e testes foi sistematizado na Tabela 2, conforme descrito no item 3.1 .

Um método ou ensaio foi quantificado em apenas um campo, com exceção das CCD que foram quantificadas mais uma vez, à parte, no campo "CCD”, para fins de se verificar, se todas as monografias possuíam esse ensaio e o seu quantitativo.

Os resultados do quantitativo de ensaios de identificação, testes, índices, doseamentos, perfil cromatográfico determinado por cromatografia gasosa, embalagem e armazenamento, figuras botânicas, total de CCD e descrição dos métodos de doseamento estão apresentados na Tabela 2. 
Tabela 2 - Quantitativo de ensaios de identificação, testes, índices (incluindo descrição), doseamentos, perfil cromatográfico, embalagem e armazenamento, presença de figura botânica, quantitativo total de Cromatografias em Camada Delgada (CCD) e descrição dos métodos de doseamento das monografias da Farmacopeia Brasileira $5^{\text {a }}$ edição (FB5)

\begin{tabular}{|c|c|c|c|c|c|c|c|c|c|c|}
\hline $\begin{array}{c}\mathrm{N} \\
\mathrm{o}\end{array}$ & Monografia na FB5 & $\begin{array}{c}\text { Identificaçã } \\
\text { o }\end{array}$ & Testes & Índices & Doseamento & Método (marcador) & $\begin{array}{c}\text { Perfil } \\
\text { cromatográfico }\end{array}$ & $\begin{array}{l}\text { Embalagem e } \\
\text { armazenament } \\
\text { o }\end{array}$ & $\begin{array}{l}\text { Figura } \\
\text { botânica }\end{array}$ & $\mathrm{CCD}$ \\
\hline 1 & $\begin{array}{c}\text { Aesculus hippocastanum L. } \\
\text { [semente] }\end{array}$ & 5 & 3 & - & 1 & EAVIS (escina) & - & 1 & 1 & 1 \\
\hline 2 & $\begin{array}{c}\text { Aloe africana Mill., Aloe } \\
\text { ferox Mill. e Aloe spicata L. f. } \\
\text { [folha; suco dessecado] }\end{array}$ & 6 & 3 & - & 1 & $\begin{array}{l}\text { EAVIS (derivados } \\
\text { hidroxiantracênicos) }\end{array}$ & - & 1 & - & 1 \\
\hline 3 & $\begin{array}{l}\text { Aloe vera }(\mathrm{L} .) \text { Burm. f. [folha } \\
\text { fresca; gel mucilaginoso] }\end{array}$ & 4 & - & - & 1 & EAVIS (carboidratos) & - & 1 & 1 & 1 \\
\hline 4 & Althaea officinalis L. [raiz] & 5 & 3 & - & - & - & - & 1 & 3 & 1 \\
\hline 5 & Anethum graveolens L. [fruto] & 5 & 3 & - & 3 & $\begin{array}{c}\text { CG (carvona)/ } \\
\text { destilação (óleo volátil)/ } \\
\text { volumetria (carvona) }\end{array}$ & - & 1 & 1 & 1 \\
\hline 6 & $\begin{array}{l}\text { Arnica montana L. [capítulo } \\
\text { floral] }\end{array}$ & 5 & 3 & - & 1 & $\begin{array}{l}\text { CLAE-UV } \\
\text { (sesquiterpenos } \\
\text { lactônicos) }\end{array}$ & - & 1 & 3 & 1 \\
\hline 7 & Atropa belladonna L. [folha] & 6 & 3 & - & 1 & volumetria (alcaloides) & - & 1 & 2 & 1 \\
\hline 8 & $\begin{array}{l}\text { Baccharis trimera (Less.) } \\
\text { DC. [caule alado] }\end{array}$ & 5 & 3 & - & 1 & $\begin{array}{l}\text { CLAE-UV (ácidos } \\
\text { cafeicos) }\end{array}$ & - & 1 & 2 & 1 \\
\hline 9 & $\begin{array}{l}\text { Calendula officinalis L. } \\
\text { [capítulo floral] }\end{array}$ & 5 & 3 & - & 1 & EAVIS (flavonoides) & - & 1 & 1 & 1 \\
\hline 10 & $\begin{array}{c}\text { Centella asiatica (L.) Urb. } \\
\text { [folha] }\end{array}$ & 5 & 3 & 1 (espuma) & 1 & $\begin{array}{l}\text { CLAE-UV } \\
\text { (asiaticosídeo) }\end{array}$ & - & 1 & 2 & 1 \\
\hline 11 & $\begin{array}{c}\text { Cinchona calisaya Wedd. } \\
\text { [casca] }\end{array}$ & 6 & 3 & - & 1 & EAUV (alcaloides) & - & 1 & 3 & 1 \\
\hline 12 & $\begin{array}{c}\text { Cinnamomum cassia (L.) J. } \\
\text { Presl [casca] }\end{array}$ & 5 & 1 & - & 2 & $\begin{array}{c}\text { CG (trans- } \\
\text { cinamaldeído)/ } \\
\text { destilação (óleo volátil) }\end{array}$ & - & 1 & 1 & $\begin{array}{c}1 \\
\text { (continu }\end{array}$ \\
\hline
\end{tabular}


Tabela 2 - Quantitativo de ensaios de identificação, testes, índices (incluindo descrição), doseamentos, perfil cromatográfico, embalagem e armazenamento, presença de figura botânica, quantitativo total de Cromatografias em Camada Delgada (CCD) e descrição dos métodos de doseamento das monografias da Farmacopeia Brasileira $5^{\text {a }}$ edição (FB5).

\begin{tabular}{|c|c|c|c|c|c|c|c|c|c|c|}
\hline $\begin{array}{c}\mathrm{N} \\
\mathrm{o}\end{array}$ & Monografia na FB5 & $\begin{array}{c}\text { Identificaçã } \\
\text { o }\end{array}$ & Testes & Índices & Doseamento & Método (marcador) & $\begin{array}{c}\text { Perfil } \\
\text { cromatográfico }\end{array}$ & $\begin{array}{l}\text { Embalagem e } \\
\text { armazenament } \\
\text { o }\end{array}$ & $\begin{array}{l}\text { Figura } \\
\text { botânica }\end{array}$ & $\mathrm{CCD}$ \\
\hline 13 & $\begin{array}{c}\text { Cinnamomum verum J. Presl } \\
\text { [casca] }\end{array}$ & 6 & 2 & - & 2 & $\begin{array}{c}\text { CG (trans- } \\
\text { cinamaldeído)/ } \\
\text { destilação (óleo volátil) }\end{array}$ & - & 1 & 1 & 1 \\
\hline 14 & $\begin{array}{l}\text { Citrus aurantium L. subsp. } \\
\text { aurantium [exocarpo] }\end{array}$ & 5 & 2 & - & 1 & destilação (óleo volátil) & - & 1 & 2 & 1 \\
\hline 15 & $\begin{array}{l}\text { Cola nitida (Vent.) Schott \& } \\
\text { Endl. [cotilédone] }\end{array}$ & 5 & 3 & - & 2 & $\begin{array}{l}\text { EAUV (metilxantinas)/ } \\
\text { EAVIS (taninos) }\end{array}$ & - & 1 & 1 & 1 \\
\hline 16 & $\begin{array}{l}\text { Crataegus monogyna Jacq., } \\
\text { C. rhipidophylla Gand. [syn. } \\
\text { C. oxyacantha L.], C. } \\
\text { laevigata (Poir.) DC., C. } \\
\text { pentagyna Waldst. \& Kit. ex } \\
\text { Willd., C. nigra Waldst. \& } \\
\text { Kit., C. azarolus L. [ramo } \\
\text { florido] }\end{array}$ & 10 & 4 & 1 (espuma) & 1 & EAVIS (flavonoides) & - & 1 & 4 & 1 \\
\hline 17 & Curcuma longa L. [rizoma] & 7 & 2 & - & 2 & $\begin{array}{l}\text { destilação (óleo volátil)/ } \\
\text { EAVIS (derivados do } \\
\text { dicinamoilmetano) }\end{array}$ & - & 1 & 2 & 2 \\
\hline 18 & $\begin{array}{c}\text { Cymbopogon citratus (DC.) } \\
\text { Stapf [folha] }\end{array}$ & 5 & 3 & - & 2 & $\begin{array}{c}\mathrm{CG} \text { (citral A e B)/ } \\
\text { destilação (óleo volátil) }\end{array}$ & - & 1 & 2 & 1 \\
\hline 19 & Datura stramonium L. [folha] & 6 & 4 & - & 1 & volumetria (alcaloides) & - & 1 & 2 & 1 \\
\hline 20 & $\begin{array}{c}\text { Echinodorus grandiflorus } \\
\text { (Cham. \& Schltdl.) Micheli } \\
\text { [folha] }\end{array}$ & 5 & 4 & - & 1 & $\begin{array}{l}\text { EAVIS (derivados do } \\
\text { ácido } o \text { - } \\
\text { hidroxicinâmico) }\end{array}$ & - & 1 & 3 & 1 \\
\hline 21 & $\begin{array}{c}\text { Elettaria cardamomum (L.) } \\
\text { Maton [semente] }\end{array}$ & 6 & 1 & - & 1 & destilação (óleo volátil) & - & 1 & 2 & 1 \\
\hline
\end{tabular}


Tabela 2 - Quantitativo de ensaios de identificação, testes, índices (incluindo descrição), doseamentos, perfil cromatográfico, embalagem e armazenamento, presença de figura botânica, quantitativo total de Cromatografias em Camada Delgada (CCD) e descrição dos métodos de doseamento das monografias da Farmacopeia Brasileira $5^{\text {a }}$ edição (FB5).

\begin{tabular}{|c|c|c|c|c|c|c|c|c|c|c|}
\hline $\begin{array}{c}\mathrm{N} \\
\mathrm{o}\end{array}$ & Monografia na FB5 & $\begin{array}{c}\text { Identificaçã } \\
\text { o }\end{array}$ & Testes & Índices & Doseamento & Método (marcador) & $\begin{array}{c}\text { Perfil } \\
\text { cromatográfico }\end{array}$ & $\begin{array}{c}\text { Embalagem e } \\
\text { armazenament } \\
\text { o }\end{array}$ & $\begin{array}{l}\text { Figura } \\
\text { botânica }\end{array}$ & $\mathrm{CCD}$ \\
\hline 22 & Eugenia uniflora L. [folha] & 11 & 4 & 1 (espuma) & 3 & $\begin{array}{l}\text { destilação (óleo volátil)/ } \\
\text { EAVIS (taninos e } \\
\text { flavonoides) }\end{array}$ & - & 1 & 2 & 1 \\
\hline 23 & $\begin{array}{l}\text { Gentiana lutea } \mathrm{L} . \text { [raiz e } \\
\text { rizoma] }\end{array}$ & 5 & 4 & 1 (amargor) & - & - & - & 1 & 2 & 1 \\
\hline 24 & $\begin{array}{l}\text { Hamamelis virginiana } \mathrm{L} \text {. } \\
\text { [folha; tintura] }\end{array}$ & 2 & 3 & - & 1 & EAVIS (taninos) & - & 1 & - & 1 \\
\hline 25 & $\begin{array}{c}\text { Hydrastis canadensis L. [raiz } \\
\text { e rizoma] }\end{array}$ & 6 & 3 & - & 1 & $\begin{array}{l}\text { CLAE-UV (hidrastina e } \\
\text { berberina) }\end{array}$ & - & 1 & 1 & 1 \\
\hline 26 & Hyoscyamus niger L. [folha] & 8 & 4 & - & 1 & volumetria (alcaloides) & - & 1 & 2 & 1 \\
\hline 27 & $\begin{array}{l}\text { Illicium verum Hook. f. } \\
\text { [fruto] }\end{array}$ & 6 & 3 & - & 2 & $\begin{array}{l}\text { CG (anetol)/ destilação } \\
\text { (óleo volátil) }\end{array}$ & - & 1 & 3 & 1 \\
\hline 28 & $\begin{array}{l}\text { Krameria lappacea (Dombey) } \\
\text { Burdet \& B.B.Simpson [raiz] }\end{array}$ & 9 & 5 & - & 1 & EAVIS (taninos) & - & 1 & 2 & 1 \\
\hline 29 & $\begin{array}{c}\text { Krameria lappacea (Dombey) } \\
\text { Burdet \& B.B.Simpson [raiz; } \\
\text { tintura] }\end{array}$ & 2 & 3 & - & 1 & EAVIS (taninos) & - & 1 & - & 1 \\
\hline 30 & $\begin{array}{c}\text { Maytenus ilicifolia Mart. ex } \\
\text { Reissek [folha] }\end{array}$ & 9 & 4 & 1 (espuma) & 2 & $\begin{array}{c}\text { CLAE-UV } \\
\text { (epicatequina)/ EAVIS } \\
\text { (taninos) }\end{array}$ & - & 1 & 2 & 1 \\
\hline 31 & Melissa officinalis L. [folha] & 7 & 3 & - & 4 & $\begin{array}{c}\text { CLAE-UV (ácido } \\
\text { rosmarínico)/ destilação } \\
\text { (óleo volátil)/ EAVIS } \\
\text { (derivados } \\
\text { hidroxicinâmicos) }\end{array}$ & 1 & 1 & 2 & 1 \\
\hline 32 & Mentha x piperita L. [folha] & 7 & 3 & - & 1 & destilação (óleo volátil) & - & 1 & 2 & 1 \\
\hline
\end{tabular}


Tabela 2 - Quantitativo de ensaios de identificação, testes, índices (incluindo descrição), doseamentos, perfil cromatográfico, embalagem e armazenamento, presença de figura botânica, quantitativo total de Cromatografias em Camada Delgada (CCD) e descrição dos métodos de doseamento das monografias da Farmacopeia Brasileira $5^{\text {a }}$ edição (FB5).

\begin{tabular}{|c|c|c|c|c|c|c|c|c|c|c|}
\hline$\underset{\mathrm{o}}{\mathrm{N}}$ & Monografia na FB5 & $\begin{array}{c}\text { Identificaçã } \\
0\end{array}$ & Testes & Índices & Doseamento & Método (marcador) & $\begin{array}{c}\text { Perfil } \\
\text { cromatográfico }\end{array}$ & $\begin{array}{c}\text { Embalagem e } \\
\text { armazenament } \\
\text { o }\end{array}$ & $\begin{array}{l}\text { Figura } \\
\text { botânica }\end{array}$ & $\mathrm{CCD}$ \\
\hline 33 & $\begin{array}{l}\text { Mentha x piperita L. [parte } \\
\text { aérea fresca; óleo] }\end{array}$ & 2 & 2 & $\begin{array}{l}2 \text { (refração e } \\
\text { acidez) }\end{array}$ & - & - & 1 & 1 & - & 1 \\
\hline 34 & $\begin{array}{c}\text { Myroxylon balsamum (L.) } \\
\text { Harms e Myroxylon } \\
\text { balsamum var. pereirae } \\
\text { (Royle) Harms [tronco; óleo- } \\
\text { resina] }\end{array}$ & 4 & 5 & $\begin{array}{c}2(\text { acidez e } \\
\text { saponificação) }\end{array}$ & 1 & $\begin{array}{l}\text { volumetria (ácidos } \\
\text { livres ou combinados) }\end{array}$ & - & 1 & - & 1 \\
\hline 35 & $\begin{array}{l}\text { Myroxylon balsamum }(\mathrm{L} .) \\
\text { Harms var. pereirae (Royle) } \\
\text { Harms [tronco; bálsamo] }\end{array}$ & 4 & 5 & $\begin{array}{c}2 \text { (acidez e } \\
\text { saponificação) }\end{array}$ & 1 & gravimetria (ésteres) & - & 1 & - & 1 \\
\hline 36 & Passiflora alata Curtis [folha] & 6 & 4 & 1 (espuma) & 1 & EAVIS (flavonoides) & - & 1 & 2 & 1 \\
\hline 37 & Passiflora edulis Sims [folha] & 6 & 4 & 1 (espuma) & 1 & EAVIS (flavonoides) & - & 1 & 2 & 1 \\
\hline 38 & $\begin{array}{c}\text { Paullinia cupana Kunth } \\
\text { [semente] }\end{array}$ & 11 & 3 & - & 2 & $\begin{array}{l}\text { EAUV (metilxantinas)/ } \\
\text { EAVIS (taninos) }\end{array}$ & - & 1 & 1 & 2 \\
\hline 39 & $\begin{array}{l}\text { Persea americana Mill. } \\
\text { [folha] }\end{array}$ & 5 & 4 & - & 2 & $\begin{array}{l}\text { destilação (óleo volátil)/ } \\
\text { EAVIS (flavonoides) }\end{array}$ & - & 1 & 2 & 1 \\
\hline 40 & $\begin{array}{l}\text { Peumus boldus Molina } \\
\text { [folha] }\end{array}$ & 6 & 4 & - & 2 & $\begin{array}{l}\text { CLAE-UV (alcaloides)/ } \\
\text { destilação (óleo volátil) }\end{array}$ & - & 1 & 3 & 1 \\
\hline 41 & $\begin{array}{c}\text { Peumus boldus Molina [folha; } \\
\text { tintura] }\end{array}$ & 3 & 2 & - & 2 & $\begin{array}{l}\text { CLAE-UV (alcaloides)/ } \\
\text { volumetria (alcaloides) }\end{array}$ & - & 1 & - & 1 \\
\hline 42 & $\begin{array}{c}\text { Phyllanthus niruri L. [parte } \\
\text { aérea] }\end{array}$ & 7 & 3 & - & 2 & $\begin{array}{l}\text { CLAE-UV (ácido } \\
\text { gálico)/ EAVIS } \\
\text { (taninos) }\end{array}$ & - & 1 & 3 & 2 \\
\hline 43 & $\begin{array}{c}\text { Phyllanthus tenellus Roxb. } \\
\text { [parte aérea] }\end{array}$ & 7 & 3 & - & 2 & $\begin{array}{l}\text { CLAE-UV (ácido } \\
\text { gálico)/ EAVIS } \\
\text { (taninos) }\end{array}$ & - & 1 & 3 & 2 \\
\hline
\end{tabular}


Tabela 2 - Quantitativo de ensaios de identificação, testes, índices (incluindo descrição), doseamentos, perfil cromatográfico, embalagem e armazenamento, presença de figura botânica, quantitativo total de Cromatografias em Camada Delgada (CCD) e descrição dos métodos de doseamento das monografias da Farmacopeia Brasileira $5^{\text {a }}$ edição (FB5).

\begin{tabular}{|c|c|c|c|c|c|c|c|c|c|c|}
\hline $\begin{array}{c}\mathrm{N} \\
\mathrm{o}\end{array}$ & Monografia na FB5 & $\begin{array}{l}\text { Identificaçã } \\
\text { o }\end{array}$ & Testes & Índices & Doseamento & Método (marcador) & $\begin{array}{c}\text { Perfil } \\
\text { cromatográfico }\end{array}$ & $\begin{array}{l}\text { Embalagem e } \\
\text { armazenament } \\
\text { o }\end{array}$ & $\begin{array}{l}\text { Figura } \\
\text { botânica }\end{array}$ & $\mathrm{CCD}$ \\
\hline 44 & $\begin{array}{c}\text { Pilocarpus microphyllus } \\
\text { Stapf ex Wardleworth [folha; } \\
\text { tintura] }\end{array}$ & 3 & 2 & - & 1 & volumetria (alcaloides) & - & 1 & - & 1 \\
\hline 45 & Pimpinella anisum L. [fruto] & 5 & 3 & - & 2 & $\begin{array}{c}\text { CG (anetol)/ destilação } \\
\text { (óleo volátil) }\end{array}$ & - & 1 & 2 & 1 \\
\hline 46 & $\begin{array}{c}\text { Polygala senega } \mathrm{L} . \text { [raiz e } \\
\text { rizoma] }\end{array}$ & 5 & 3 & - & 1 & EAVIS (saponinas) & - & 1 & 1 & 1 \\
\hline 47 & $\begin{array}{c}\text { Quillaja saponaria Molina } \\
\text { [casca] }\end{array}$ & 5 & 4 & 1 (espuma) & - & - & - & 1 & 2 & 1 \\
\hline 48 & $\begin{array}{l}\text { Rauvolfia serpentina (L.) } \\
\text { Benth. ex Kurz [raiz] }\end{array}$ & 5 & 3 & - & 1 & $\begin{array}{l}\text { EAUV (alcaloides } \\
\text { grupo reserpina- } \\
\text { rescinamina) }\end{array}$ & - & 1 & 1 & 1 \\
\hline 49 & $\begin{array}{c}\text { Rheum officinale Baill. e/ou } \\
\text { Rheum palmatum L. [raiz e } \\
\text { rizoma] }\end{array}$ & 6 & 4 & - & 1 & $\begin{array}{l}\text { EAVIS (derivados } \\
\text { hidroxiantracênicos) }\end{array}$ & - & 1 & 1 & 2 \\
\hline 50 & $\begin{array}{l}\text { Rosmarinus officinalis L. } \\
\text { [sumidade florida; óleo] }\end{array}$ & 3 & 2 & $\begin{array}{l}2 \text { (acidez e } \\
\text { refração) }\end{array}$ & - & - & 1 & 1 & - & 1 \\
\hline 51 & Salix alba L. [casca do ramo] & 5 & 3 & - & 1 & CLAE-UV (salicina) & - & 1 & 2 & 1 \\
\hline 52 & $\begin{array}{c}\text { Sambucus australis Cham. \& } \\
\text { Schltdl. [flor] }\end{array}$ & 8 & 3 & - & 2 & $\begin{array}{l}\text { CLAE-UV (rutina)/ } \\
\text { EAVIS (flavonoides) }\end{array}$ & - & 1 & 3 & 1 \\
\hline 53 & Sambucus nigra L. [flor] & 8 & 3 & - & 2 & $\begin{array}{l}\text { CLAE-UV (rutina)/ } \\
\text { EAVIS (flavonoides) }\end{array}$ & - & 1 & 3 & 1 \\
\hline 54 & $\begin{array}{l}\text { Senna alexandrina Mill. } \\
\text { [folíolo] }\end{array}$ & 9 & 3 & - & 2 & $\begin{array}{l}\text { CLAE-UV (senosídeo } \\
\text { A e B)/ EAVIS } \\
\text { (derivados } \\
\text { hidroxiantracênicos) }\end{array}$ & - & 1 & 2 & 1 \\
\hline
\end{tabular}


Tabela 2 - Quantitativo de ensaios de identificação, testes, índices (incluindo descrição), doseamentos, perfil cromatográfico, embalagem e armazenamento, presença de figura botânica, quantitativo total de Cromatografias em Camada Delgada (CCD) e descrição dos métodos de doseamento das monografias da Farmacopeia Brasileira $5^{\text {a }}$ edição (FB5)

\begin{tabular}{|c|c|c|c|c|c|c|c|c|c|c|}
\hline $\begin{array}{c}\mathrm{N} \\
\mathrm{o}\end{array}$ & Monografia na FB5 & $\begin{array}{c}\text { Identificaçã } \\
\mathrm{o}\end{array}$ & Testes & Índices & Doseamento & Método (marcador) & $\begin{array}{c}\text { Perfil } \\
\text { cromatográfico }\end{array}$ & $\begin{array}{c}\text { Embalagem e } \\
\text { armazenament } \\
\text { o }\end{array}$ & $\begin{array}{l}\text { Figura } \\
\text { botânica }\end{array}$ & $\mathrm{CCD}$ \\
\hline 55 & $\begin{array}{c}\text { Stevia rebaudiana (Bertoni) } \\
\text { Bertoni [folha] }\end{array}$ & 5 & 3 & - & 2 & $\begin{array}{c}\text { CLAE-UV } \\
\text { (esteviosídeo)/ EAVIS } \\
\text { (carboidratos) }\end{array}$ & - & 1 & 2 & 1 \\
\hline 56 & $\begin{array}{c}\text { Stryphnodendron adstringens } \\
\text { (Mart.) Coville [casca do } \\
\text { caule] }\end{array}$ & 9 & 4 & - & 2 & $\begin{array}{l}\text { CLAE-UV (ácido } \\
\text { gálico e galocatequina)/ } \\
\text { EAVIS (taninos) }\end{array}$ & - & 1 & 2 & 1 \\
\hline 57 & $\begin{array}{c}\text { Styrax benzoin } \text { Dryand. ou } \\
\text { Styrax paralleloneuron } \\
\text { Perkins [tronco; resina } \\
\text { balsâmica] }\end{array}$ & 6 & 7 & - & 1 & $\begin{array}{l}\text { volumetria (ácido } \\
\text { benzoico) }\end{array}$ & - & 1 & - & 2 \\
\hline 58 & $\begin{array}{l}\text { Vanilla planifolia Andrews } \\
\text { [fruto imaturo] }\end{array}$ & 6 & 1 & - & 1 & $\begin{array}{l}\text { gravimetria (extrato } \\
\text { hidroetanólico) }\end{array}$ & - & 1 & 1 & 1 \\
\hline
\end{tabular}

\section{(BRASIL, 2010d)}

Legenda: EAVIS = Espectrofotometria de Absorção no Visível;CG = Cromatografia Gasosa; CLAE-UV = Cromatografia Liquida de Alta Eficiência acoplada a detector por

Espectrofotometria por Absorção no Ultravioleta; EAUV = Espectrofotometria de Absorção no Ultravioleta 
As monografias referentes a drogas vegetais e derivados da FB5 apresentam em comum as seguintes características: possuem pelo menos um ensaio de identificação por CCD e possuem observações quanto a embalagem e armazenamento. Todas, com exceção da monografia Aloe vera (L.) Burm. f. [folha fresca; gel mucilaginoso], possuem especificação descrita para pelo menos um teste (cinzas totais, água, resíduo seco, matéria estranha, poder rotatório, densidade relativa, solubilidade etc.). No caso das monografias de drogas vegetais, todas possuem pelo menos uma ilustração do material botânico.

Quanto às monografias referentes a óleos voláteis, todas apresentam como requisito de qualidade a determinação do perfil cromatográfico. Este perfil é obtido por CG com identificação de vários picos cromatográficos, que devem ser quantificados e estar em determinado intervalo de especificação. A realização desse ensaio especifica um padrão mais bem definido para os óleos voláteis.

Dentre as monografias que não possuem ensaios de doseamento descritos, todas possuem índices de amargor ou de espuma ou perfil cromatográfico, sendo a única exceção a Althaea officinalis L. [raiz]. Esta monografia, porém, possui histórico de presença na $1^{\mathrm{a}}$ e $2^{\mathrm{a}}$ edição da FB5 (Quadro 3) sempre sem doseamento, índices ou perfil.

Os métodos verificados nos doseamentos podem ser agrupados em: dois (2) por gravimetria (extrato hidroetanólico e ésteres); oito (8) por volumetria (alcaloides, ácido benzoico e ácidos livres e combinados); vinte e oito (28) por Espectrofotometria por Absorção no Visível (EAVIS) (taninos, carboidratos, derivados hidroxiantracênicos, flavonoides, saponinas, derivados hidroxicinâmicos, derivados do ácido $o$-hidroxicinâmico, derivados do dicinamoilmetano e escina); quatro (4) por Espectrofotometria por Absorção no Ultravioleta (EAUV) (alcaloides, alcaloides grupo reserpina-rescinamina e metilxantinas); catorze (14) por destilação (hidrodestilação de óleos voláteis); dezenove (19) por Cromatografia Líquida de Alta Eficiência acoplada a detector por Espectrofotometria por Absorção no Ultravioleta (CLAEUV) (ácido gálico, epicatequina, ácido rosmarínico, rutina, esteviosídeo, senosídeo A e B, salicina, alcaloides, hidrastina e berberina, asiaticosídeo, ácidos cafeicos e sesquiterpênicos lactônicos); e sete (7) por Cromatografia Gasosa (CG) (anetol, citral A e B e trans-cinamaldeído e carvona).

Assim, o método mais utilizado na FB5 é o EAVIS (28), que com poucas exceções, consiste em ensaios para doseamento de grupos de substâncias, seguido pelo CLAE-UV (19), método bem mais seletivo que, na maioria das vezes, consegue dosear marcadores específicos. 
Os dados indicam que há um padrão estabelecido de ensaios e testes nas monografias de drogas vegetais e derivados na FB5, e, que as monografias, em geral, atendem a esse padrão, contendo ensaios de identificação, testes, índices, doseamentos, perfil cromatográfico e ilustração botânica, conforme o tipo de monografia.

Foi observado, ainda, que ao longo das edições da Farmacopeia Brasileira, houve um significativo incremento nos ensaios e testes exigidos. Porém, ainda há espaço para o desenvolvimento, e incorporação de metodologias mais avançadas, sendo exemplos de ações possíveis: o aumento no número de métodos que empregam a cromatografia, inclusão de métodos espectrométricos (Ressonância Magnética Nuclear Quantitativa, por exemplo) e incorporação dos princípios da química verde (reduzindo o uso de substâncias nocivas).

\subsection{AVALIAÇÃO DAS MONOGRAFIAS DA FARMACOPEIA BRASILEIRA E AS ESPÉCIES CONSTANTES NA IN No 02/2014}

As monografias do FFFB1, além da sua função de servir de referência para as farmácias de manipulação e farmácias vivas de todo o país (BRASIL, 2011), apresentam a possibilidade de notificação de Produtos Tradicionais Fitoterápicos - regime de concessão de autorização para a comercialização mais simples que o processo de registro - desde que haja monografia farmacopeica em compêndios oficiais reconhecidos, incluindo a FB5 (BRASIL, 2014c). Por outro lado, a IN nº 02/2014 que dispõe de informações sobre espécies, drogas vegetais e extratos, na "Lista de Medicamentos Fitoterápicos de registro simplificado" e na "Lista de Produtos Tradicionais Fitoterápicos de registro simplificado", apresenta a possibilidade do registro simplificado dos Produtos Tradicionais Fitoterápicos e de Medicamentos Fitoterápicos (BRASIL, 2014a).

Embora, internacionalmente, não seja comum a existência de documentos em formato de formulário, semelhante ao FFFB1, o seu papel no contexto regulatório nacional é semelhante ao papel de monografias publicadas por organismos internacionais como a European Medicines Agency (EMA) e o Health Canada.

A European Medicines Agency (EMA), por meio do Committee on Herbal Medicinal Products (HMPC), compila e avalia dados científicos com foco na segurança e eficácia para os fitoterápicos e publica monografias, que podem ser utilizados pelas autoridades reguladoras nacionais para a concessão de autorizações de comercialização, considerando os usos bem estabelecidos (com dados suficientes que demonstram segurança e eficácia), ou registro 
simplificado para produtos tradicionais, considerando o uso tradicional (com dados suficientes para a segurança e eficácia presumida) (EMA, 2016).

A Health Canada, por meio do The Natural and Non-prescription Health Products Directorate (NNHPD), publica um compêndio de monografias que podem ser utilizadas nas solicitações para autorização de comercialização com fins de acelerar a avaliação da segurança e eficácia dos IFAV comumente utilizados em produtos, cuja segurança e eficácia já é conhecida sob as condições descritas nas monografias (HEALTH CANADA, 2009).

O FFFB1 é constituído por monografias para infusos e decoctos, tinturas, xaropes, géis, pomadas, sabonetes e cremes. Estas fórmulas foram selecionadas dentre as que - à época da elaboração do FFFB1 - eram utilizadas em farmácias que dispensavam fitoterápicos de diversas regiões no país, sendo sustentadas por histórico de uso nos serviços de fitoterapia no país e estudos científicos (BRASIL, 2011). O formulário também contém formulações referenciadas na Resolução RDC nº 10 de 09 de março de 2010 (BRASIL, 2010a).

A Anvisa também utiliza, para fins de comprovação da segurança e eficácia/ efetividade, as monografias da EMA para registro simplificado e do Health Canada, em conjunto com outras referências, para a comprovação da tradicionalidade de uso para fins de registro (BRASIL, 2014c). Dessa forma, a notificação de fitoterápicos no Brasil é uma possibilidade exclusiva das fórmulas presentes no FFFB1 (BRASIL, 2014c).

No Quadro 4, para fins de comparação, foram incluídas para as monografias da FB5 as informações sobre as espécies, drogas vegetais e derivados. Para as monografias do FFFB1 foram incluídas as informações sobre as espécies, drogas vegetais, derivados e formulações. No caso da IN nº 02/2014 foram incluídas as informações sobre as espécies e as drogas vegetais.

É importante relatar que, embora as bases de dados dos sítio eletrônico do Missouri Botanical Garden e do The Plant List (THE PLANT LIST, 2013; TROPICOS.ORG, 2016) mencionem que Passiflora incarnata L. é sinonímia de Passiflora edulis Sims, a Comissão da Farmacopeia Brasileira, por meio do FB5 e do FFFB1, e a Anvisa, por meio da IN nº 02/2014, não as consideram como sinonímia. Essa relação de sinonímia não está na monografia da Passiflora edulis Sims na FB5 (BRASIL, 2010d) e nem nas monografias do FFFB1, que possui uma monografia para cada espécie (BRASIL, 2011). A Anvisa, por outro lado, retificou a IN n 02/2014 que apresentava a espécie Passiflora edulis Sims como nome correto para a Passiflora incarnata L., por meio da Instrução Normativa $\mathrm{n}^{\circ} 10$ de 26 de novembro de 2014 (IN no 10/2014), corrigindo a espécie para Passiflora incarnata L. a qual é, atualmente, a espécie constante na Lista de Produtos Tradicionais Fitoterápicos de Registro Simplificado 
(BRASIL, 2014a, b). Assim, como a avaliação dos fitoterápicos sob o aspecto regulatório é um dos objetivos deste trabalho, as espécies não foram consideradas, neste estudo, como sinonímias.

As monografias de fórmulas farmacêuticas do FFFB1 foram consideradas correspondentes às monografias de drogas vegetais da FB5 e às informações das espécies e drogas vegetais da IN n ${ }^{\circ} 02 / 2014$.

Para a sistematização dos dados do FFFB1 e da IN n ${ }^{\circ}$ 02/2014, foram alteradas as descrições de alguns materiais botânicos, mantendo a correspondência com a droga vegetal originalmente descrita, de modo a harmonizá-los com a descrição botânica da FB5.

Assim, para tornar mais harmônica a visualização e comparação dos dados, foram feitas as alterações a seguir: para a Arnica montana L e a Calendula officinalis L., o material botânico foi alterado de flor para capítulo floral, obedecendo a descrição botânica da FB5; no caso da Centella asiatica (L.) Urb., cuja droga vegetal, conforme descrição na FB5, é composta principalmente pela lâmina foliar e pelo pecíolo de até $15 \mathrm{~cm}$, ou seja, praticamente toda a parte aérea da centela, a descrição para a IN no 02/2014 foi alterada para folha; para a Matricaria chamomilla L., a descrição da droga vegetal foi alterada de inflorescência para capítulo floral no FFFB1, pois nesse caso são sinônimos.

No caso do Symphytum officinale L., constante no FFFB1, no lugar do material botânico, foi incluída a palavra "confrei”, pois não foi encontrada, na publicação, informações sobre a droga vegetal.

O Quadro 4 mostra as informações sistematizadas, considerando as adequações feitas quanto à descrição da droga vegetal. 
Quadro 4 - Monografias da Farmacopeia Brasileira $5^{\text {a }}$ edição (FB5), do Formulário de Fitoterápicos da Farmacopeia Brasileira $1^{\text {a }}$ edição (FFFB1) e drogas vegetais da Instrução Normativa (IN) $n^{\circ} 02 / 2014$.

\begin{tabular}{|c|c|c|c|}
\hline $\mathrm{N}^{\mathrm{o}}$ & Monografia FB5 & Monografias FFFB1 & IN no $02 / 2014$ \\
\hline 1 & - & Achillea millefolium L. [parte aérea] & - \\
\hline 2 & - & Achillea millefolium L. [parte aérea; tintura (1:5)] & - \\
\hline 3 & - & $\begin{array}{c}\text { Achyrocline satureioides (Lam.) DC. [sumidade } \\
\text { florida] }\end{array}$ & - \\
\hline 4 & - & - & Actaea racemosa L [raiz ou rizoma] \\
\hline 5 & Aesculus hippocastanum L. [semente] & - & Aesculus hippocastanum L. [semente] \\
\hline 6 & - & Allium sativum L. [bulbilhos; tintura (1:5)] & Allium sativum L. [bulbo] \\
\hline 7 & Aloe africana Mill. [folha; suco dessecado] & - & - \\
\hline 8 & Aloe ferox Mill. [folha; suco dessecado] & & - \\
\hline 9 & Aloe spicata L. f. [folha; suco dessecado] & - & - \\
\hline 10 & Aloe vera (L.) Burm. f. [folha fresca; gel & Aloe vera (L.) Burm. f. [gel mucilaginoso; pomada] & - \\
\hline 11 & mucilaginoso] & Aloe vera (L.) Burm. f. [gel mucilaginoso; gel] & - \\
\hline 12 & - & $\begin{array}{c}\text { Alpinia zerumbet (Pers.) B. L. Burtt \& R.M. Sm. } \\
\text { [folha; tintura }(1: 5)]\end{array}$ & - \\
\hline 13 & Althaea officinalis L. [raiz] & - & - \\
\hline 14 & Anethum graveolens L. [fruto] & - & - \\
\hline 15 & - & Arctium lappa L. [raiz] & - \\
\hline 16 & - & - & Arctostaphylos uva-ursi (L.) Spreng. [folha] \\
\hline 17 & Arnica montana L. [capítulo floral] & Arnica montana L. [capítulo floral] ${ }^{2}$ & Arnica montana L. [capítulo floral] \\
\hline 18 & & Arnica montana L. [capítulo floral; gel] ${ }^{2}$ & \\
\hline 19 & & Arnica montana L. [capítulo floral; pomada] ${ }^{2}$ & \\
\hline 20 & Atropa belladonna L. [folha] & - & - \\
\hline 21 & Baccharis trimera (Less.) DC. [caule alado] & Baccharis trimera (Less.) DC. [parte aérea] & - \\
\hline 22 & - & Caesalpinia ferrea Mart. ex Tul. [fruto; gel] & - \\
\hline 23 & Calendula officinalis L. [capítulo floral] & Calendula officinalis L. [capítulo floral] ${ }^{1}$ & Calendula officinalis L. [flor] \\
\hline
\end{tabular}


Quadro 4 - Monografias da Farmacopeia Brasileira $5^{\text {a }}$ edição (FB5), do Formulário de Fitoterápicos da Farmacopeia Brasileira $1^{\text {a }}$ edição (FFFB1) e drogas vegetais da Instrução Normativa (IN) $n^{\circ} 02 / 2014$.

\begin{tabular}{|c|c|c|c|}
\hline $\mathrm{N}^{\mathrm{o}}$ & Monografia FB5 & Monografias FFFB1 & IN no $02 / 2014$ \\
\hline 24 & & Calendula officinalis L. [capítulo floral; creme] & \\
\hline 25 & & Calendula officinalis L. [capítulo floral; gel] & \\
\hline 26 & & $\begin{array}{l}\text { Calendula officinalis L. [capítulo floral; tintura } \\
\qquad(1: 10)]\end{array}$ & \\
\hline 27 & - & Casearia sylvestris $\mathrm{Sw}$. [folha] & - \\
\hline 28 & Centella asiatica (L.) Urb. [folha] & - & Centella asiatica $(\text { L.) Urb. [folha }]^{2}$ \\
\hline 29 & Cinchona calisaya Wedd. [casca] & - & - \\
\hline 30 & Cinnamomum cassia (L.) J. Presl [casca] & - & - \\
\hline 31 & Cinnamomum verum J. Presl [casca] & Cinnamomum verum J. Presl [casca] & - \\
\hline 32 & Citrus aurantium L. subsp. aurantium [exocarpo] & Citrus aurantium L. [flor] & - \\
\hline 33 & Cola nitida (Vent.) Schott \& Endl. [cotilédone] & - & - \\
\hline 34 & - & Copaifera langsdorffii Desf. [óleo-resina; pomada] & - \\
\hline 35 & - & Copaifera multijuga Hayne [óleo-resina; pomada] & - \\
\hline 36 & - & $\begin{array}{c}\text { Copaifera paupera }(\text { Herzog) Dwyer [óleo-resina; } \\
\text { pomada] }\end{array}$ & - \\
\hline 37 & - & Copaifera reticulata Ducke [óleo-resina; pomada] & - \\
\hline 38 & - & Cordia verbenacea DC. [folha] & - \\
\hline 39 & - & Cordia verbenacea DC. [folha; pomada] & - \\
\hline 40 & Crataegus monogyna Jacq. [ramo florido] & - & - \\
\hline 41 & $\begin{array}{c}\text { Crataegus rhipidophylla Gand. [syn. C. oxyacantha } \\
\text { L.] [ramo florido] }\end{array}$ & - & - \\
\hline 42 & Crataegus laevigata (Poir.) DC. [ramo florido] & - & - \\
\hline 43 & $\begin{array}{c}\text { Crataegus pentagyna Waldst. \& Kit. ex Willd. [ramo } \\
\text { florido] }\end{array}$ & - & - \\
\hline 44 & Crataegus nigra Waldst. \& Kit. [ramo florido] & - & - \\
\hline 45 & Crataegus azarolus L. [ramo florido] & - & - \\
\hline
\end{tabular}


Quadro 4 - Monografias da Farmacopeia Brasileira $5^{\text {a }}$ edição (FB5), do Formulário de Fitoterápicos da Farmacopeia Brasileira $1^{\text {a }}$ edição (FFFB1) e drogas vegetais da Instrução Normativa (IN) nº 02/2014.

\begin{tabular}{|c|c|c|c|}
\hline $\mathrm{N}^{\mathrm{o}}$ & Monografia FB5 & Monografias FFFB1 & IN no $02 / 2014$ \\
\hline 46 & Curcuma longa L. [rizoma] & Curcuma longa L. [rizoma] & - \\
\hline 47 & & Curcuma longa L. [rizoma; tintura (1:10)] & - \\
\hline 48 & Cymbopogon citratus (DC.) Stapf [folha] & Cymbopogon citratus (DC.) Stapf [folha] & - \\
\hline 49 & - & Cynara scolymus L. [folha] & Cynara scolymus L. [folha] \\
\hline 50 & - & Cynara scolymus L. [folha; tintura (1:5)] & \\
\hline 51 & Datura stramonium L. [folha] & - & - \\
\hline 52 & - & - & Echinacea purpurea (L.) Moench [parte aérea florida] \\
\hline 53 & $\begin{array}{l}\text { Echinodorus grandiflorus (Cham. \& Schltdl.) Micheli } \\
\text { [folha] }\end{array}$ & - & - \\
\hline 54 & - & Echinodorus macrophyllus (Kunth) Micheli [folha] & - \\
\hline 55 & Elettaria cardamomum (L.) Maton [semente] & - & - \\
\hline 56 & - & - & Eucalyptus globulus Labill. [folha] \\
\hline 57 & Eugenia uniflora L. [folha] & - & - \\
\hline 58 & - & Foeniculum vulgare Mill. [fruto; tintura (1:10)] & - \\
\hline 59 & - & - & Frangula purshiana (DC.) [casca] \\
\hline 60 & Gentiana lutea L. [raiz e rizoma] & - & - \\
\hline 61 & - & - & Ginkgo biloba L. [folha] \\
\hline 62 & - & - & Glycine $\max$ (L.) Merr. [semente] \\
\hline 63 & - & - & Glycyrrhiza glabra L. [raiz] \\
\hline 64 & - & Hamamelis virginiana $\mathrm{L}$. [casca] & Hamamelis virginiana $\mathrm{L}$. [folha] \\
\hline 65 & Hamamelis virginiana L. [folha; tintura (1:10)] & - & \\
\hline 66 & - & - & $\begin{array}{c}\text { Harpagophytum procumbens DC. ex Meissn. [raiz } \\
\text { secundária] }\end{array}$ \\
\hline 67 & - & - & Harpagophytum zeyheri Decne [raiz secundária] \\
\hline 68 & Hydrastis canadensis L. [raiz e rizoma] & - & - \\
\hline 69 & Hyoscyamus niger L. [folha] & - & - \\
\hline 70 & - & - & Hypericum perforatum L. [parte aérea] \\
\hline 71 & Illicium verum Hook. f. [fruto] & Illicium verum Hook. f. [fruto] & - \\
\hline
\end{tabular}


Quadro 4 - Monografias da Farmacopeia Brasileira $5^{\text {a }}$ edição (FB5), do Formulário de Fitoterápicos da Farmacopeia Brasileira $1^{\text {a }}$ edição (FFFB1) e drogas vegetais da Instrução Normativa (IN) n ${ }^{\circ}$ 02/2014.

\begin{tabular}{|c|c|c|c|}
\hline $\mathrm{N}^{\mathrm{o}}$ & Monografia FB5 & Monografias FFFB1 & $\mathrm{IN} \mathrm{n}^{\circ} 02 / 2014$ \\
\hline 72 & - & Justicia pectoralis Jacq. [parte aérea] & - \\
\hline 73 & $\begin{array}{c}\text { Krameria lappacea (Dombey) Burdet \& B.B.Simpson } \\
\text { [raiz] }\end{array}$ & - & - \\
\hline 74 & $\begin{array}{c}\text { Krameria lappacea (Dombey) Burdet \& B.B.Simpson } \\
\text { [raiz; tintura }(1: 10)]\end{array}$ & - & - \\
\hline 75 & - & $\begin{array}{l}\text { Lippia alba (Mill.) N.E. Br. ex Britton \& P. Wilson } \\
\text { [parte aérea] }\end{array}$ & - \\
\hline 76 & - & Lippia sidoides Cham. [folha] & - \\
\hline 77 & - & Lippia sidoides Cham. [folha; gel] & - \\
\hline 78 & - & Lippia sidoides Cham. [folha; tintura (1:5)] & - \\
\hline 79 & - & Lippia sidoides Cham. [folha; sabonete líquido] & - \\
\hline 80 & - & Malva sylvestris L. [folha e flor] & - \\
\hline 81 & - & Matricaria chamomilla L. [capítulo floral] ${ }^{3}$ & Matricaria chamomilla L. [capítulo floral] \\
\hline 82 & - & - & Maytenus aquifolium Mart. [folha] \\
\hline 83 & Maytenus ilicifolia Mart. ex Reissek [folha] & Maytenus ilicifolia Mart. ex Reissek [folha] & Maytenus ilicifolia Mart. ex Reiss. [folha] \\
\hline 84 & Melissa officinalis L. [folha] & Melissa officinalis L. [sumidade florida] & Melissa officinalis L. [folha] \\
\hline 85 & Mentha $x$ piperita $\mathrm{L}$. [folha] & Mentha x piperita $\mathrm{L}$. [folha e sumidade florida] & Mentha $x$ piperita L. [folha] \\
\hline 86 & & Mentha x piperita L. [folha; tintura (1:5)] & \\
\hline 87 & Mentha x piperita L. [parte aérea fresca; óleo] & - & \\
\hline 88 & - & Mikania glomerata Spreng. [folha] & Mikania glomerata Spreng. [folha] \\
\hline 89 & - & Mikania glomerata Spreng. [folha; tintura (1:5)] & \\
\hline 90 & - & Mikania glomerata Spreng. [folha; xarope] & \\
\hline 91 & - & Mikania laevigata Sch. Bip. ex Baker [folha] & Mikania laevigata Sch. Bip. ex Baker [folha] \\
\hline 92 & - & $\begin{array}{l}\text { Mikania laevigata Sch. Bip. ex Baker [folha; tintura } \\
\qquad(1: 5)]\end{array}$ & \\
\hline 93 & - & Mikania laevigata Sch. Bip. ex Baker [folha; xarope] & \\
\hline 94 & - & Momordica charantia L. [fruto; tintura (1:10)] & - \\
\hline
\end{tabular}


Quadro 4 - Monografias da Farmacopeia Brasileira $5^{\text {a }}$ edição (FB5), do Formulário de Fitoterápicos da Farmacopeia Brasileira $1^{\text {a }}$ edição (FFFB1) e drogas vegetais da Instrução Normativa (IN) $n^{\circ} 02 / 2014$.

\begin{tabular}{|c|c|c|c|}
\hline $\mathrm{N}^{\mathrm{o}}$ & Monografia FB5 & Monografias FFFB1 & $\mathrm{IN} \mathrm{n}^{\circ} 02 / 2014$ \\
\hline 95 & Myroxylon balsamum (L.) Harms [tronco; óleo-resina] & - & - \\
\hline 96 & $\begin{array}{c}\text { Myroxylon balsamum var. pereirae (Royle) Harms } \\
\text { [tronco; óleo-resina] }\end{array}$ & - & - \\
\hline 97 & $\begin{array}{l}\text { Myroxylon balsamum (L.) Harms var. pereirae } \\
\text { (Royle) Harms [tronco; bálsamo] }\end{array}$ & - & - \\
\hline 98 & - & - & Panax ginseng C. A. Mey. [raiz] \\
\hline 99 & Passiflora alata Curtis [folha] & Passiflora alata Curtis [folha] & - \\
\hline 100 & Passiflora edulis Sims [folha] & Passiflora edulis Sims [folha] & - \\
\hline 101 & & Passiflora edulis Sims [folha; tintura (1:5)] & - \\
\hline 102 & - & Passiflora incarnata L. [parte aérea] & Passiflora incarnata L. [parte aérea] \\
\hline 103 & Paullinia cupana Kunth [semente] & Paullinia cupana Kunth [semente] & Paullinia cupana Kunth [semente] \\
\hline 104 & Persea americana Mill. [folha] & - & - \\
\hline 105 & Peumus boldus Molina [folha] & Peumus boldus Molina [folha] & Peumus boldus Molina [folha] \\
\hline 106 & Peumus boldus Molina [folha; tintura (1:10)] & - & - \\
\hline 107 & Phyllanthus niruri L. [parte aérea] & Phyllanthus niruri L. [parte aérea] & - \\
\hline 108 & & Phyllanthus niruri L. [parte aérea; tintura (1:10)] & - \\
\hline 109 & Phyllanthus tenellus Roxb. [parte aérea] & - & - \\
\hline 110 & $\begin{array}{l}\text { Pilocarpus microphyllus Stapf ex Wardleworth [folha; } \\
\text { tintura }(1: 10)]\end{array}$ & - & - \\
\hline 111 & Pimpinella anisum L. [fruto] & Pimpinella anisum L. [fruto] & Pimpinella anisum L. [fruto] \\
\hline 112 & - & - & Piper methysticum G. Forst. [rizoma] \\
\hline 113 & - & Plantago major L. [folha] & - \\
\hline 114 & - & Plantago major L. [parte aérea; tintura (1:10)] & - \\
\hline 115 & - & - & Plantago ovata Forssk. [casca da semente] \\
\hline 116 & - & Plectranthus barbatus Andrews [folha] & - \\
\hline 117 & - & Plectranthus barbatus Andrews [folha; tintura (1:5)] & - \\
\hline
\end{tabular}


Quadro 4 - Monografias da Farmacopeia Brasileira $5^{\text {a }}$ edição (FB5), do Formulário de Fitoterápicos da Farmacopeia Brasileira $1^{\text {a }}$ edição (FFFB1) e drogas vegetais da Instrução Normativa (IN) n ${ }^{\circ}$ 02/2014.

\begin{tabular}{|c|c|c|c|}
\hline $\mathrm{N}^{\mathrm{o}}$ & Monografia FB5 & Monografias FFFB1 & $\mathrm{IN} \mathrm{n}^{\circ} 02 / 2014$ \\
\hline 118 & Polygala senega L. [raiz e rizoma] & Polygala senega L. [raiz] & Polygala senega L. [raiz] \\
\hline 119 & - & Polygonum punctatum Elliot [parte aérea] & - \\
\hline 120 & - & Punica granatum L. [casca do fruto] & - \\
\hline 121 & - & Punica granatum L. [casca do fruto; tintura (1:5)] & - \\
\hline 122 & Quillaja saponaria Molina [casca] & - & - \\
\hline 123 & Rauvolfia serpentina (L.) Benth. ex Kurz [raiz] & - & - \\
\hline 124 & Rheum officinale Baill. [raiz e rizoma] & - & - \\
\hline 125 & Rheum palmatum L. [raiz e rizoma] & - & - \\
\hline 126 & - & Rosmarinus officinalis L. [folha] & - \\
\hline 127 & Rosmarinus officinalis L. [sumidade florida; óleo] & - & - \\
\hline 128 & Salix alba L. [casca do ramo] & Salix alba L. [casca do caule] & Salix alba L. [casca] \\
\hline 129 & - & - & Salix daphnoides Vill. [casca] \\
\hline 130 & - & - & Salix fragilis L. [casca] \\
\hline 131 & - & - & Salix purpurea L. [casca] \\
\hline 132 & - & Salvia officinalis L. [folha] & - \\
\hline 133 & Sambucus australis Cham. \& Schltdl. [flor] & - & - \\
\hline 134 & Sambucus nigra L. [flor] & Sambucus nigra L. [flor] & Sambucus nigra L. [flor] \\
\hline 135 & - & Schinus terebinthifolia Raddi [casca do caule] & - \\
\hline 136 & Senna alexandrina Mill. [folíolo] & - & Senna alexandrina Mill. [folha e fruto] \\
\hline 137 & - & - & Serenoa repens (W. Bartram) Small [fruto] \\
\hline 138 & - & - & Silybum marianum (L.) Gaertn. [fruto sem papilho] \\
\hline 139 & Stevia rebaudiana (Bertoni) Bertoni [folha] & - & - \\
\hline 140 & $\begin{array}{l}\text { Stryphnodendron adstringens (Mart.) Coville [casca } \\
\text { do caule] }\end{array}$ & $\begin{array}{l}\text { Stryphnodendron adstringens (Mart.) Coville [casca; } \\
\text { creme }]^{4}\end{array}$ & - \\
\hline 141 & Styrax benzoin Dryand. [tronco; resina balsâmica] & - & - \\
\hline
\end{tabular}


Quadro 4 - Monografias da Farmacopeia Brasileira $5^{\text {a }}$ edição (FB5), do Formulário de Fitoterápicos da Farmacopeia Brasileira $1^{\text {a }}$ edição (FFFB1) e drogas vegetais da Instrução Normativa (IN) $\mathrm{n}^{\circ} 02 / 2014$.

\begin{tabular}{|c|c|c|c|}
\hline $\mathrm{N}^{\mathrm{o}}$ & Monografia FB5 & Monografias FFFB1 & IN n ${ }^{\circ} 02 / 2014$ \\
\hline 142 & $\begin{array}{l}\text { Styrax paralleloneuron Perkins [tronco; resina } \\
\text { balsâmica] }\end{array}$ & - & - \\
\hline 143 & - & Symphytum officinale L. [confrei; pomada] ${ }^{5}$ & Symphytum officinale L. [raiz] \\
\hline 144 & - & - & Tanacetum parthenium (L.) Sch. Bip. [folha] \\
\hline 145 & - & Taraxacum officinale F. H. Wigg [planta inteira] & - \\
\hline 146 & - & - & $\begin{array}{c}\text { Uncaria tomentosa (Willd. ex Roem. \& Schult.) DC. } \\
\text { [casca do caule e raiz] }\end{array}$ \\
\hline 147 & - & - & Vaccinium myrtillus L. [fruto maduro] \\
\hline 148 & - & - & Valeriana officinalis L. [raiz] \\
\hline 149 & Vanilla planifolia Andrews [fruto imaturo] & - & - \\
\hline 150 & - & Vernonia condensata Baker [folha] & - \\
\hline 151 & - & Vernonia polyanthes (Spreng.) Less [folha] & - \\
\hline 152 & - & Zingiber officinale Roscoe [rizoma] & Zingiber officinale Roscoe [rizoma] \\
\hline 153 & - & Zingiber officinale Roscoe [rizoma; tintura (1:5)] & \\
\hline
\end{tabular}

(BRASIL, 2010d, 2011, 2014a, b)

Nota: ${ }^{1}=$ alterado de "flor " para "capítulo floral"; ${ }^{2}=$ alterado de "parte aérea" para "folha"; ${ }^{3}=$ alterado de "inflorescência" para "capítulo floral"; ${ }^{4}=$ não é especificado o local de retirada da casca, entendeu-se ser a mesma droga vegetal. ${ }^{5}=$ não foi localizada a droga vegetal correspondente no compêndio. 
Dentre as 153 entradas geradas pelas monografias da FB5 e do FFFB1 e das informações de espécies e drogas vegetais da IN nº 02/2014, apenas 17 (11\%) possuem correspondência nos três documentos, 35 (23\%) estão presentes em dois documentos, sendo o restante, 101 (66\%) entradas, sem correspondência em um ou em outro documento.

Dentre as 52 entradas que possuem correspondência em pelo menos um dos outros documentos, foi observado que não há harmonização em sete (13\%) casos:

1 - Citrus aurantium L., em que a droga vegetal descrita na FB5, “exocarpo”, diverge da descrita no FFFB1, "flor";

2 - Melissa officinalis L., em que há divergência entre a droga vegetal descrita na FB5 e na IN n 02/2014, "folha", e no FFFB1, "sumidade florida";

3 - Mentha x piperita L., em que há divergência entre a droga vegetal descrita na FB5 e na IN n ${ }^{\circ}$ 02/2014, “folha”, e no FFFB1, “folha e sumidade florida”. Nesse caso, foi verificado que a droga vegetal da monografia da USP39-NF também é "folha e sumidade florida" (USP, 2016h);

4 - Salix alba L., em que há divergência entre a droga vegetal descrita na FB5, "casca do ramo", e no FFFB1, "casca do caule";

5 - Senna alexandrina Mill., em que há divergência entre a droga vegetal descrita na FB5, "folíolo", e na IN n 02/2014, "folha e fruto". Nesse caso, existe monografia separada com a droga vegetal "folíolo" e com o "fruto", para uso bem estabelecido, na EMA (HMPC, 2006a, b), o que indica haver um erro na droga vegetal na $\mathrm{IN} \mathrm{n}^{\circ}$ 02/2014, que deveria ser folíolo ou fruto;

6 - Hamamelis virginiana L., em que há divergência entre a droga vegetal descrita na FB5 e na IN no 02/2014, "folha", e no FFFB1, “casca". Nesse caso, foi verificado que há monografias da EMA, para uso tradicional, contemplando, em separado, ambas as drogas vegetais (HMPC, 2009, 2011);

7 - Polygala senega L., em que a droga vegetal na FB5 é "raiz e curto rizoma", enquanto que no FFFB1 e na IN no 02/2014 é "raiz". Nesse caso, foi verificado que a monografia da EP8.8 descreve a droga vegetal como raiz e coroa da raiz, porém, analisando as descrições e visualizando fotos da espécie, foi considerado, neste estudo, que as nomenclaturas "curto rizoma" e "coroa da raiz" se referem a mesma estrutura (BRASIL, 2010d; EDQM, 2016a). Assim, as descrições "raiz e curto rizoma", "raiz" e "raiz e coroa da raiz" correspondem a mesma droga vegetal. 
Ainda, as espécies descritas para o chapéu-de-couro na FB5 e no FFFB1 não são as mesmas, sendo que a espécie descrita no formulário corresponde à espécie constante nas edições anteriores da Farmacopeia Brasileira.

Esses dados indicam uma deficiência na harmonização dentro da Anvisa e dentro da Farmacopeia Brasileira e apontam para a necessidade de reavaliação e correção, quando o caso.

Considerando apenas a correlação entre as monografias para droga vegetal da FB5 e as monografias do FFFB1, e, desconsiderando as monografias para as quais há divergência quanto a droga vegetal, foi verificado que 28 (34\%) das 83 possibilidades de notificação de fitoterápicos constantes no FFFB1 possuem monografia correspondente para a droga vegetal na FB5.

Embora os documentos listados possuam finalidades diferentes, também possuem caráter complementar, uma vez que o FFFB1 e a IN nº 02/2014 simplificam o processo de comprovação de eficácia e segurança, e, a FB5, simplifica o processo de estabelecimento de requisitos mínimos de qualidade. Assim, a FB5 junto a um dos outros dois documentos promove um caminho mais fácil para a entrada dos fitoterápicos no mercado. Seria esperado que não houvesse casos de drogas vegetais diversas, que os documentos fossem mais harmonizados, e que a FB5 contemplasse mais monografias para os fitoterápicos previstos no FFFB1 e na IN n ${ }^{\circ}$ $02 / 2014$.

\subsection{AVALIAÇÃO QUANTO À EXISTÊNCIA DE PRODUTOS REGISTRADOS JUNTO À ANVISA PARA AS ESPÉCIES VEGETAIS DA FARMACOPEIA BRASILEIRA}

Os dados sobre a existência de registros de fitoterápicos válidos contendo as espécies da Farmacopeia Brasileira foram obtidos, conforme descrito no item 3.3, por meio de pesquisa no banco de dados públicos do sítio eletrônico da Anvisa em maio de 2016 (ANVISA, 2003) com as entradas descritas no Apêndice B.

Para os casos em que, nessa consulta, foi verificado que a validade do registro estava vencida, foi realizada uma confirmação da validade do registro no DATAVISA. Essa confirmação foi necessária em função dos extensos prazos de análise de petições de renovação de registro e da manutenção da vigência do registro enquanto perduram as etapas de exigência e recurso administrativo.

A avaliação quanto aos registros válidos considerou somente as espécies da Farmacopeia Brasileira, não contemplando possíveis diferenças entre drogas vegetais e 
derivados constituintes dos fitoterápicos, uma vez que o banco de dados para a busca de medicamentos registrados não exibe informações sobre qual o IFAV utilizado no fitoterápico, somente sobre as espécies.

Os resultados contendo as espécies, nomenclatura popular, presença da espécie na FB5, no FFFB1 ou nos dois compêndios (FB5 e FFFB1) e os dados encontrados para registros de fitoterápicos válidos em maio de 2016 estão dispostos no Quadro 5.

É importante informar que o Quadro 5 reflete os resultados encontrados conforme metodologia descrita, não havendo neste estudo, a pretensão de afirmar que estes eram todos os registros de fitoterápicos válidos para as espécies à época, uma vez que as bases de dados podem apresentar erros não controláveis. 
Quadro 5 - Espécies vegetais da Farmacopeia Brasileira, nomenclatura popular, e registros de fitoterápicos válidos resultados de pesquisa em maio de 2016 e a respectiva ocorrência dessas espécies no Brasil.

\begin{tabular}{|c|c|c|c|c|c|c|c|}
\hline $\mathrm{N}^{\mathrm{o}}$ & Nomenclatura botânica & $\begin{array}{l}\text { Nomenclatura } \\
\text { popular }\end{array}$ & FB5 & $\begin{array}{c}\text { FB e } \\
\text { FFFB1 }\end{array}$ & FFFB1 & Registros válidos para fitoterápicos em maio de 2016 & $\begin{array}{c}\text { Ocorrência } \\
\text { no Brasil }\end{array}$ \\
\hline 1 & Achillea millefolium $\mathrm{L}$. & $\begin{array}{l}\text { mil-folhas/ mil-em- } \\
\text { rama }\end{array}$ & - & - & $\mathrm{x}$ & não & $\operatorname{sim}$ \\
\hline 2 & $\begin{array}{l}\text { Achyrocline satureioides } \\
\text { (Lam.) DC. }\end{array}$ & $\begin{array}{l}\text { macela/ marcela/ } \\
\text { marcela-do-campo }\end{array}$ & - & - & $\mathrm{x}$ & não & $\operatorname{sim}$ \\
\hline 3 & Aesculus hippocastanum L. & castanha-da-índia & $\mathrm{x}$ & - & - & $\begin{array}{c}\text { VITATRAT/ CASTANHA DA ÍNDIA (BELFAR)/ CASTANHA DA } \\
\text { ÍNDIA ATALAIA/ CASTANHA DA ÍNDIA EC/ CASTANHA DA } \\
\text { INDIA ORIENT/ CASTANHA DA ÍNDIA HERBARIUM/ CASTANHA } \\
\text { DA ÍNDIA MULTILAB/ FLUXOLIV/ NOVARRUTINA/ PHYTOVEIN/ } \\
\text { PROCTOCAPS/VARICELL PHYTO/ VARIHERB/ VARILESS } \\
\text { BIONATUS/ VARINATI/ VARIVAX/ VENAESCULUS/VENOCAPS/ } \\
\text { VENOCEL/ VENOCUR FIT/ CASTANHODO }\end{array}$ & não \\
\hline 4 & Allium sativum $\mathrm{L}$. & alho & - & - & $\mathrm{x}$ & não & não \\
\hline 5 & Aloe africana Mill. & aloe & $\mathrm{x}$ & - & - & não & não \\
\hline 6 & Aloe ferox Mill. & aloe/ aloe-do-cabo & $\mathrm{x}$ & - & - & OLINA-ESSÊNCIA DA VIDA & não \\
\hline 7 & Aloe spicata L. f. & aloe & $\mathrm{x}$ & - & - & não & não \\
\hline 8 & Aloe vera (L.) Burm. f. & aloe/ babosa & $\mathrm{x}$ & $\mathrm{x}$ & $\mathrm{x}$ & ALOAX & não \\
\hline 9 & $\begin{array}{l}\text { Alpinia zerumbet (Pers.) B. } \\
\text { L. Burtt \& R.M. Sm. }\end{array}$ & colônia & - & - & $\mathrm{x}$ & ZICLAGUE & $\operatorname{sim}$ \\
\hline 10 & Althaea officinalis L. & alteia & $\mathrm{x}$ & - & - & não & não \\
\hline 11 & Anethum graveolens L. & endro & $\mathrm{x}$ & - & - & não & $\operatorname{sim}$ \\
\hline 12 & Arctium lappa $\mathrm{L}$. & bardana & - & - & $\mathrm{x}$ & não & não \\
\hline 13 & Arnica montana L. & arnica & $\mathrm{x}$ & $\mathrm{x}$ & $\mathrm{x}$ & ARNICA MONTANA ADV/ ARNICA GEL/ ARNICA & não \\
\hline 14 & Atropa belladonna L. & beladona & $\mathrm{x}$ & - & - & COLEGÓRICO/ ELIXIR CÓLICO/THEOGÓRICO SOBRAL & não \\
\hline 15 & $\begin{array}{c}\text { Baccharis trimera (Less.) } \\
\text { DC. }\end{array}$ & $\begin{array}{c}\text { carqueja/ carqueja- } \\
\text { amarga }\end{array}$ & $\mathrm{x}$ & $\mathrm{x}$ & $\mathrm{x}$ & não & $\operatorname{sim}$ \\
\hline 16 & $\begin{array}{c}\text { Caesalpinia ferrea Mart. ex } \\
\text { Tul. }\end{array}$ & jucá & - & - & $\mathrm{x}$ & FIMATOSAN & $\operatorname{sim}$ \\
\hline 17 & Calendula officinalis $\mathrm{L}$. & calêndula & $\mathrm{x}$ & $\mathrm{x}$ & $\mathrm{x}$ & TINTURA DE CALÊNDULA YANTEN & $\operatorname{sim}$ \\
\hline
\end{tabular}


Quadro 5 - Espécies vegetais da Farmacopeia Brasileira, nomenclatura popular, e registros de fitoterápicos válidos resultados de pesquisa em maio de 2016 e a respectiva ocorrência dessas espécies no Brasil.

\begin{tabular}{|c|c|c|c|c|c|c|c|}
\hline $\mathrm{N}^{\mathrm{o}}$ & Nomenclatura botânica & $\begin{array}{l}\text { Nomenclatura } \\
\text { popular }\end{array}$ & FB5 & $\begin{array}{l}\text { FB e } \\
\text { FFFB } 1\end{array}$ & FFFB1 & Registros válidos para fitoterápicos em maio de 2016 & $\begin{array}{l}\text { Ocorrência } \\
\text { no Brasil }\end{array}$ \\
\hline 18 & Casearia sylvestris $\mathrm{Sw}$. & $\begin{array}{c}\text { guaçatonga/ erva-de- } \\
\text { bugre/ erva-de- } \\
\text { largato }\end{array}$ & - & - & $\mathrm{x}$ & não & $\operatorname{sim}$ \\
\hline 19 & Centella asiatica (L.) Urb. & centela & $\mathrm{x}$ & - & - & $\begin{array}{c}\text { CELLUFAN VITA/ CENTELLA HERBARIUM/ CENTELLA } \\
\text { BIONATUS/ CENTELLA ORIENT }\end{array}$ & $\operatorname{sim}$ \\
\hline 20 & Cinchona calisaya Wedd. & quina-amarela & $\mathrm{x}$ & - & - & INGLESA SOBRAL/ ÁGUA INGLESA CATARINENSE & não \\
\hline 21 & $\begin{array}{l}\text { Cinnamomum cassia (L.) J. } \\
\text { Presl }\end{array}$ & canela-da-china & $\mathrm{x}$ & - & - & não & não \\
\hline 22 & Cinnamomum verum J. Presl & $\begin{array}{l}\text { canela/ canela-do- } \\
\text { ceilão }\end{array}$ & $\mathrm{x}$ & $\mathrm{x}$ & $\mathrm{x}$ & BÁLSAMO BRANCO & não \\
\hline 23 & $\begin{array}{c}\text { Citrus aurantium L. subsp. } \\
\text { aurantium }\end{array}$ & laranja-amarga & $\mathrm{x}$ & $\mathrm{x}$ & $\mathrm{x}$ & não & $\begin{array}{l}\operatorname{sim} \\
\text { [Citrus } x \\
\text { aurantium } \\
\text { L.] }\end{array}$ \\
\hline 24 & $\begin{array}{l}\text { Cola nitida (Vent.) Schott \& } \\
\text { Endl. }\end{array}$ & noz-de-cola/ cola & $\mathrm{x}$ & - & - & não & não \\
\hline 25 & Copaifera langsdorffii Desf. & copaíba & - & - & $\mathrm{x}$ & não & $\operatorname{sim}$ \\
\hline 26 & Copaifera multijuga Hayne & copaíba & - & - & $\mathrm{x}$ & não & $\operatorname{sim}$ \\
\hline 27 & $\begin{array}{c}\text { Copaifera paupera (Herzog) } \\
\text { Dwyer }\end{array}$ & copaíba & - & - & $\mathrm{x}$ & não & $\operatorname{sim}$ \\
\hline 28 & Copaifera reticulata Ducke & copaíba & - & - & $\mathrm{x}$ & não & $\operatorname{sim}$ \\
\hline 29 & Cordia verbenacea DC. & erva-baleeira & - & - & $\mathrm{x}$ & CORDIAFLAN/ ACHEFLAN & $\operatorname{sim}$ \\
\hline 30 & Crataegus azarolus $L$. & cratego & $\mathrm{x}$ & - & - & não & não \\
\hline 31 & $\begin{array}{c}\text { Crataegus laevigata (Poir.) } \\
\text { DC. }\end{array}$ & cratego & $\mathrm{x}$ & - & - & não & não \\
\hline 32 & Crataegus monogyna Jacq. & cratego & $\mathrm{x}$ & - & - & não & não \\
\hline 33 & $\begin{array}{l}\text { Crataegus nigra Waldst. \& } \\
\text { Kit. }\end{array}$ & cratego & $\mathrm{x}$ & - & - & não & não \\
\hline
\end{tabular}


Quadro 5 - Espécies vegetais da Farmacopeia Brasileira, nomenclatura popular, e registros de fitoterápicos válidos resultados de pesquisa em maio de 2016 e a respectiva ocorrência dessas espécies no Brasil.

\begin{tabular}{|c|c|c|c|c|c|c|c|}
\hline $\mathrm{N}^{\mathrm{o}}$ & Nomenclatura botânica & $\begin{array}{l}\text { Nomenclatura } \\
\text { popular }\end{array}$ & FB5 & $\begin{array}{c}\text { FB e } \\
\text { FFFB1 }\end{array}$ & FFFB1 & Registros válidos para fitoterápicos em maio de 2016 & $\begin{array}{c}\text { Ocorrência } \\
\text { no Brasil }\end{array}$ \\
\hline 34 & $\begin{array}{c}\text { Crataegus pentagyna } \\
\text { Waldst. \& Kit. ex Willd. }\end{array}$ & cratego & $\mathrm{x}$ & - & - & não & não \\
\hline 35 & $\begin{array}{l}\text { Crataegus rhipidophylla } \\
\text { Gand. }\end{array}$ & cratego & $\mathrm{x}$ & - & - & $\begin{array}{l}\text { CALMAN/ MARACUGINA COMPOSTA/ SOMINEX COMPOSTO/ } \\
\text { MARACUJA CONCENTRIX/ PASALIX/ SERENUS/ ACALMIL }\end{array}$ & $\operatorname{sim}$ \\
\hline 36 & Curcuma longa $\mathrm{L}$. & $\begin{array}{l}\text { cúrcuma/ açafrão/ } \\
\text { açafrão-da-terra }\end{array}$ & $\mathrm{x}$ & $\mathrm{x}$ & $\mathrm{x}$ & MOTORE & não \\
\hline 37 & $\begin{array}{l}\text { Cymbopogon citratus (DC.) } \\
\text { Stapf }\end{array}$ & $\begin{array}{l}\text { capim-limão/ capim- } \\
\text { santo/ capim-cidró/ } \\
\text { capim-cidreira/ } \\
\text { cidreira }\end{array}$ & $\mathrm{x}$ & $\mathrm{x}$ & $\mathrm{x}$ & não & $\operatorname{sim}$ \\
\hline 38 & Cynara scolymus $\mathrm{L}$. & alcachofra & - & - & $\mathrm{x}$ & $\begin{array}{c}\text { ALCACHOFRA HERBARIUM/ ALCACHOFRA CELLOFARM/ } \\
\text { ALCACHOFRA MULTILAB/ ALCACHOFRA NATULAB/ } \\
\text { ALCACHOFRA SIMÕES/ ALCACHOFRAX/ ALCAGEST/ } \\
\text { ALCAHERB/ ALCANATAN/ FIGALINA/ FIGAREX/ FIGATIL/ } \\
\text { LINEVIT/ ALCACHOFRA BIONATUS }\end{array}$ & $\operatorname{sim}$ \\
\hline 39 & Datura stramonium L. & $\begin{array}{l}\text { estramônio/ figueira- } \\
\text { do-inferno }\end{array}$ & $\mathrm{x}$ & - & - & não & $\operatorname{sim}$ \\
\hline 40 & $\begin{array}{l}\text { Echinodorus grandiflorus } \\
\text { (Cham. \& Schltdl.) Micheli }\end{array}$ & chapéu-de-couro & $\mathrm{x}$ & - & - & não & $\operatorname{sim}$ \\
\hline 41 & $\begin{array}{l}\text { Echinodorus macrophyllus } \\
\quad \text { (Kunth) Micheli }\end{array}$ & chapéu-de-couro & - & - & $\mathrm{x}$ & não & $\operatorname{sim}$ \\
\hline 42 & $\begin{array}{l}\text { Elettaria cardamomum (L.) } \\
\text { Maton }\end{array}$ & cardamomo & $\mathrm{x}$ & - & - & não & não \\
\hline 43 & Eugenia uniflora $\mathrm{L}$. & pitangueira & $\mathrm{x}$ & - & - & não & $\operatorname{sim}$ \\
\hline 44 & Foeniculum vulgare Mill. & funcho & - & - & $\mathrm{x}$ & não & $\operatorname{sim}$ \\
\hline 45 & Gentiana lutea $\mathrm{L}$. & genciana & $\mathrm{x}$ & - & - & $\begin{array}{l}\text { OLINA-ESSÊNCIA DA VIDA/ GOTAS DIGESTIVAS (SIMÕES)/ } \\
\text { CAMOMILA COMPOSTA CATARINENSE }\end{array}$ & não \\
\hline 46 & Hamamelis virginiana $\mathrm{L}$. & hamamelis & $\mathrm{x}$ & $\mathrm{x}$ & $\mathrm{x}$ & HAMAMELIS ORIENT/ HEMOPROCT & não \\
\hline
\end{tabular}


Quadro 5 - Espécies vegetais da Farmacopeia Brasileira, nomenclatura popular, e registros de fitoterápicos válidos resultados de pesquisa em maio de 2016 e a respectiva ocorrência dessas espécies no Brasil.

\begin{tabular}{|c|c|c|c|c|c|c|c|}
\hline $\mathrm{N}^{\mathrm{o}}$ & Nomenclatura botânica & $\begin{array}{l}\text { Nomenclatura } \\
\text { popular }\end{array}$ & FB5 & $\begin{array}{c}\text { FB e } \\
\text { FFFB } 1\end{array}$ & FFFB1 & Registros válidos para fitoterápicos em maio de 2016 & $\begin{array}{c}\text { Ocorrência } \\
\text { no Brasil }\end{array}$ \\
\hline 47 & Hydrastis canadensis $\mathrm{L}$. & hidraste & $\mathrm{x}$ & - & - & não & não \\
\hline 48 & Hyoscyamus niger $\mathrm{L}$. & meimendro & $\mathrm{x}$ & - & - & não & não \\
\hline 49 & Illicium verum Hook. f. & $\begin{array}{l}\text { anis-estrelado/ } \\
\text { badiana }\end{array}$ & $\mathrm{x}$ & $\mathrm{x}$ & $\mathrm{x}$ & não & não \\
\hline 50 & Justicia pectoralis Jacq. & $\begin{array}{l}\text { chambá/ chachambá/ } \\
\text { trevo-cumaru }\end{array}$ & - & - & $\mathrm{x}$ & não & $\operatorname{sim}$ \\
\hline 51 & $\begin{array}{l}\text { Krameria lappacea } \\
\text { (Dombey) Burdet \& } \\
\text { B.B.Simpson }\end{array}$ & ratânia & $\mathrm{x}$ & - & - & não & não \\
\hline 52 & $\begin{array}{l}\text { Lippia alba (Mill.) N.E. Br. } \\
\quad \text { ex Britton \& P. Wilson }\end{array}$ & $\begin{array}{l}\text { erva-cidreira-de- } \\
\text { arbusto/ lípia }\end{array}$ & - & - & $\mathrm{x}$ & não & $\operatorname{sim}$ \\
\hline 53 & Lippia sidoides Cham. & alecrim-pimenta & - & - & $\mathrm{x}$ & não & $\operatorname{sim}$ \\
\hline 54 & Malva sylvestris $\mathrm{L}$. & malva & - & - & $\mathrm{x}$ & não & não \\
\hline 55 & Matricaria chamomilla L. & camomila & - & - & $\mathrm{x}$ & $\begin{array}{l}\text { COLUTÓIDE CAMOMILA/ GOTAS DIGESTIVAS/ KAMILLOSAN/ } \\
\text { AD-MUC }\end{array}$ & $\operatorname{sim}$ \\
\hline 56 & $\begin{array}{l}\text { Maytenus ilicifolia Mart. ex } \\
\text { Reissek }\end{array}$ & espinheira-santa & $\mathrm{x}$ & $\mathrm{x}$ & $\mathrm{x}$ & $\begin{array}{l}\text { ESPINHEIRA SANTA HERBARIUM/ ESPINHEIRA SANTA KLEIN/ } \\
\text { ESPINHEIRA SANTA NATULAB/ ESPINHEIRA SANTA ORIENT/ } \\
\text { ULCERAZINE/ GASTRINON/ GASTROHERB/ GASTRONAN/ } \\
\text { GASTROPLANTAS/ GASTROSIL/ TINTURA DE ESPINHEIRA } \\
\text { DIVINA COMPOSTA/ GASTRILESS BIONATUS/ UNIGASTROZOL }\end{array}$ & $\operatorname{sim}$ \\
\hline 57 & Melissa officinalis L. & $\begin{array}{l}\text { melissa/ erva- } \\
\text { cidreira }\end{array}$ & $\mathrm{x}$ & $\mathrm{x}$ & $\mathrm{x}$ & SONOLIS/ ÁGUA DE MELISSA/ TINTURA DE MELISSA YANTEN & não \\
\hline 58 & Mentha x piperita $\mathrm{L}$. & hortelã-pimenta & $\mathrm{x}$ & $\mathrm{x}$ & $\mathrm{x}$ & não & não \\
\hline 59 & Mikania glomerata Spreng. & guaco & - & - & $\mathrm{x}$ & $\begin{array}{l}\text { BIOTOSS XAROPE/ AGLIX/ XAROPE GUACO MELPOEJO/ } \\
\text { APIGUACO/ BIOEXPECTO/ BIOTOSS EDULITO/ BLUMEL GUACO/ } \\
\text { EXPECTRAT/ FIMATOSAN/ FIMATOSAN MGS/ FINETOSS/ G500 } \\
\text { BALSÂMICO/ GUACO EDULITO HERBARIUM/ GUACOFLUS/ } \\
\text { GUACOLIN/ GUACONAT/ GUACOPLEX/ GUACOTOSS/ } \\
\text { GUACOVITA/ LIVTÓS/ MELAGRIÃO/ PEITORAL MARTEL/ }\end{array}$ & $\operatorname{sim}$ \\
\hline
\end{tabular}


Quadro 5 - Espécies vegetais da Farmacopeia Brasileira, nomenclatura popular, e registros de fitoterápicos válidos resultados de pesquisa em maio de 2016 e a respectiva ocorrência dessas espécies no Brasil.

\begin{tabular}{|c|c|c|c|c|c|c|c|}
\hline $\mathrm{N}^{\mathrm{o}}$ & Nomenclatura botânica & $\begin{array}{l}\text { Nomenclatura } \\
\text { popular }\end{array}$ & FB5 & $\begin{array}{l}\text { FB e } \\
\text { FFFB1 }\end{array}$ & FFFB1 & Registros válidos para fitoterápicos em maio de 2016 & $\begin{array}{l}\text { Ocorrência } \\
\text { no Brasil }\end{array}$ \\
\hline & & & & & & $\begin{array}{l}\text { XAROPE DE GUACO BELFAR/ XAROPE DE GUACO HERBARIUM/ } \\
\text { XAROPE DE GUACO NATULAB }\end{array}$ & \\
\hline 60 & $\begin{array}{c}\text { Mikania laevigata Sch. Bip. } \\
\text { ex Baker }\end{array}$ & guaco & - & - & $\mathrm{x}$ & não & $\operatorname{sim}$ \\
\hline 61 & Momordica charantia L. & $\begin{array}{l}\text { melão-de-são- } \\
\text { caetano }\end{array}$ & - & - & $\mathrm{x}$ & não & $\operatorname{sim}$ \\
\hline 62 & $\begin{array}{c}\text { Myroxylon balsamum (L.) } \\
\text { Harms }\end{array}$ & $\begin{array}{c}\text { bálsamo-de-tolu } \\
\text { (óleo-resina)/ } \\
\text { bálsamo-do-peru } \\
\text { (bálsamo do tronco) }\end{array}$ & $\mathrm{x}$ & - & - & GUACOVITA & $\operatorname{sim}$ \\
\hline 63 & Passiflora alata Curtis & $\begin{array}{l}\text { maracujá-doce/ } \\
\text { maracujá }\end{array}$ & $\mathrm{x}$ & $\mathrm{x}$ & $\mathrm{x}$ & ANSIODORON/ FIMATOSAN/ MARACUGINA COMPOSTA/ & $\operatorname{sim}$ \\
\hline 64 & Passiflora edulis Sims & maracujá-azedo & $\mathrm{x}$ & $\mathrm{x}$ & $\mathrm{x}$ & não & $\operatorname{sim}$ \\
\hline 65 & Passiflora incarnata $\mathrm{L}$. & maracujá & - & - & $\mathrm{x}$ & $\begin{array}{l}\text { RITMONEURAN RTM/ PASALIX/ ALCAMIL/ ZEN/ CALMAN/ } \\
\text { CALMINTHEO/ CALMOPLANTAS/ MARACUJA CONCENTRIX/ } \\
\text { MARACUJÁ HERBARIUM/ PASALIX/ PASSIENE/ PASSIFLORA } \\
\text { KLEIN/ PASSIPAX/ PAZINE/ PRAKALMAR/ SEAKALM/ SERENUS/ } \\
\text { SINTOCALMY/ SOMINEX COMPOSTO/ TENSART/ CALMALIX }\end{array}$ & $\operatorname{sim}$ \\
\hline 66 & Paullinia cupana Kunth & guaraná & $\mathrm{x}$ & $\mathrm{x}$ & $\mathrm{x}$ & CATUAMA/ GUARANÁ SANTA TEREZINHA/ TUPI GUARANÁ & $\operatorname{sim}$ \\
\hline 67 & Persea americana Mill. & abacateiro & $\mathrm{x}$ & - & - & PIASCLEDINE & $\operatorname{sim}$ \\
\hline 68 & Peumus boldus Molina & $\begin{array}{l}\text { boldo/ boldo-do- } \\
\text { chile }\end{array}$ & $\mathrm{x}$ & $\mathrm{x}$ & $\mathrm{x}$ & $\begin{array}{c}\text { JURUBEBA ATALAIA/ BIOHEPATON/ BOLDINE/ BOLDO BELFAR/ } \\
\text { BOLDO KLEIN/ BOLDOVITA/ EPALIV/ FIGATIL/ FIGATOSAN/ } \\
\text { GOTAS DIGESTIVAS/ HEPALIVE S.O./ HEPATILON/ HEPOFIGON/ } \\
\text { INFALIVINA/ BIOGESTIL BIONATUS/ GOTAS PRECIOSAS/ } \\
\text { EPAREMA }\end{array}$ & não \\
\hline 69 & Phyllanthus niruri L. & quebra-pedra & $\mathrm{x}$ & $\mathrm{x}$ & $\mathrm{x}$ & não & $\operatorname{sim}$ \\
\hline 70 & Phyllanthus tenellus Roxb. & quebra-pedra & $\mathrm{x}$ & - & - & não & $\operatorname{sim}$ \\
\hline
\end{tabular}

(continua) 
Quadro 5 - Espécies vegetais da Farmacopeia Brasileira, nomenclatura popular, e registros de fitoterápicos válidos resultados de pesquisa em maio de 2016 e a respectiva ocorrência dessas espécies no Brasil.

\begin{tabular}{|c|c|c|c|c|c|c|c|}
\hline $\mathrm{N}^{\mathrm{o}}$ & Nomenclatura botânica & $\begin{array}{l}\text { Nomenclatura } \\
\text { popular }\end{array}$ & FB5 & $\begin{array}{l}\text { FB e } \\
\text { FFFB1 }\end{array}$ & FFFB1 & Registros válidos para fitoterápicos em maio de 2016 & $\begin{array}{c}\text { Ocorrência } \\
\text { no Brasil }\end{array}$ \\
\hline 71 & $\begin{array}{l}\text { Pilocarpus microphyllus } \\
\text { Stapf ex Wardleworth }\end{array}$ & jaborandi & $\mathrm{x}$ & - & - & não & $\operatorname{sim}$ \\
\hline 72 & Pimpinella anisum $\mathrm{L}$. & $\begin{array}{l}\text { anis-doce/ anis/ } \\
\text { erva-doce }\end{array}$ & $\mathrm{x}$ & $\mathrm{x}$ & $\mathrm{x}$ & não & não \\
\hline 73 & Plantago major L. & $\begin{array}{l}\text { tanchagem/ } \\
\text { tansagem/ } \\
\text { tranchagem }\end{array}$ & - & - & $\mathrm{x}$ & não & $\operatorname{sim}$ \\
\hline 74 & $\begin{array}{c}\text { Plectranthus barbatus } \\
\text { Andrews }\end{array}$ & $\begin{array}{l}\text { boldo-africano/ } \\
\text { boldo-brasileiro/ } \\
\text { boldo-nacional }\end{array}$ & - & - & $\mathrm{x}$ & não & não \\
\hline 75 & Polygala senega $\mathrm{L}$. & polígala & $\mathrm{x}$ & $\mathrm{x}$ & $\mathrm{x}$ & GAUCOVITA/ FITOBRONC/ MELAGRIÃO & não \\
\hline 76 & Polygonum punctatum Elliot & $\begin{array}{l}\text { erva-de-bicho/ } \\
\text { pimenteira-d'água }\end{array}$ & - & - & $\mathrm{x}$ & não & $\operatorname{sim}$ \\
\hline 77 & Punica granatum $\mathrm{L}$. & romã & - & - & $\mathrm{x}$ & não & não \\
\hline 78 & Quillaja saponaria Molina & quilaia & $\mathrm{x}$ & - & - & não & não \\
\hline 79 & $\begin{array}{l}\text { Rauvolfia serpentina }(\mathrm{L} .) \\
\text { Benth. ex Kurz }\end{array}$ & rauvólfia & $\mathrm{x}$ & - & - & não & não \\
\hline 80 & Rheum officinale Baill. & ruibarbo & $\mathrm{x}$ & - & - & não & não \\
\hline 81 & Rheum palmatum $\mathrm{L}$. & ruibarbo & $\mathrm{x}$ & - & - & EPAREMA & não \\
\hline 82 & Rosmarinus officinalis $\mathrm{L}$. & alecrim & $\mathrm{x}$ & $\mathrm{x}$ & $\mathrm{x}$ & não & não \\
\hline 83 & Salix alba $\mathrm{L}$. & $\begin{array}{l}\text { salgueiro-branco/ } \\
\text { salgueiro }\end{array}$ & $\mathrm{x}$ & $\mathrm{x}$ & $\mathrm{x}$ & $\begin{array}{l}\text { ACALMIL/ CALAMAN/ CEPHALIX/ SERENUS/ MARACUJÁ } \\
\text { CONCENTRIX/ PASALIX/ GALENOGAL ELIXIR }\end{array}$ & não \\
\hline 84 & Salvia officinalis L. & sálvia & - & - & $\mathrm{x}$ & não & $\operatorname{sim}$ \\
\hline 85 & $\begin{array}{l}\text { Sambucus australis Cham. \& } \\
\text { Schltdl. }\end{array}$ & sabugueiro-do-brasil & $\mathrm{x}$ & - & - & não & $\operatorname{sim}$ \\
\hline 86 & Sambucus nigra L. & sabugueiro & $\mathrm{x}$ & $\mathrm{x}$ & $\mathrm{x}$ & não & $\operatorname{sim}$ \\
\hline 87 & Schinus terebinthifolia Raddi & aroeira-da-praia & - & - & $\mathrm{x}$ & SANATIVO/ KIOS & $\operatorname{sim}$ \\
\hline
\end{tabular}


Quadro 5 - Espécies vegetais da Farmacopeia Brasileira, nomenclatura popular, e registros de fitoterápicos válidos resultados de pesquisa em maio de 2016 e a respectiva ocorrência dessas espécies no Brasil.

\begin{tabular}{|c|c|c|c|c|c|c|c|}
\hline $\mathrm{N}^{\mathrm{o}}$ & Nomenclatura botânica & $\begin{array}{l}\text { Nomenclatura } \\
\text { popular }\end{array}$ & FB5 & $\begin{array}{l}\text { FB e } \\
\text { FFFB 1 }\end{array}$ & FFFB1 & Registros válidos para fitoterápicos em maio de 2016 & $\begin{array}{c}\text { Ocorrência } \\
\text { no Brasil }\end{array}$ \\
\hline 88 & Senna alexandrina Mill. & sene/ senna & $\mathrm{x}$ & - & - & $\begin{array}{l}\text { LAXETTE/ AGIOLAX/ LACASS/ LASENE/ LAXASENE BIONATUS/ } \\
\text { MYRASENE/ NATURETTI/ TAMARINE/ SENARETI/ SENE TIARAJU/ } \\
\text { SENEBEN/ SENNALAX/ SENAN/ SANLAX/ CAPSPLAN/ SENUSLAX/ } \\
\text { SENE HERBARIUM/ NATULAXE/ FONTOLAX }\end{array}$ & $\operatorname{sim}$ \\
\hline 89 & $\begin{array}{l}\text { Stevia rebaudiana (Bertoni) } \\
\text { Bertoni }\end{array}$ & estévia & $\mathrm{x}$ & - & - & não & $\operatorname{sim}$ \\
\hline 90 & $\begin{array}{c}\text { Stryphnodendron } \\
\text { adstringens (Mart.) Coville }\end{array}$ & barbatimão & $\mathrm{x}$ & $\mathrm{x}$ & $\mathrm{x}$ & FITOSCAR & $\operatorname{sim}$ \\
\hline 91 & Styrax benzoin Dryand. & benjoim & $\mathrm{x}$ & - & - & não & não \\
\hline 92 & $\begin{array}{c}\text { Styrax paralleloneuron } \\
\text { Perkins }\end{array}$ & benjoim & $\mathrm{x}$ & - & - & não & não \\
\hline 93 & Symphytum officinale L. & confrei & - & - & $\mathrm{x}$ & FLEXIVE CDM & não \\
\hline 94 & $\begin{array}{c}\text { Taraxacum officinale F. H. } \\
\text { Wigg }\end{array}$ & dente-de-leão & - & - & $\mathrm{x}$ & não & $\operatorname{sim}$ \\
\hline 95 & Vanilla planifolia Andrews & baunilha & $\mathrm{x}$ & - & - & não & $\operatorname{sim}$ \\
\hline 96 & Vernonia condensata Baker & boldo-baiano & - & - & $\mathrm{x}$ & não & $\operatorname{sim}$ \\
\hline 97 & $\begin{array}{l}\text { Vernonia polyanthes } \\
\text { (Spreng.) Less }\end{array}$ & assa-peixe & - & - & $\mathrm{x}$ & não & $\operatorname{sim}$ \\
\hline 98 & Zingiber officinale Roscoe & gengibre & - & - & $\mathrm{x}$ & ZINGIB/ GENGIMIN & $\operatorname{sim}$ \\
\hline
\end{tabular}

(ANVISA, 2003; BRASIL, 2010d, 2011; REFLORA, 2016; TROPICOS.ORG, 2016).

Legenda: FB5 = Farmacopeia Brasileira $5^{\mathrm{a}}$ edição; FFFB1 = Formulário de Fitoterápicos da Farmacopeia Brasileira $1^{\mathrm{a}}$ edição; $\mathrm{x}=$ presença da espécie. 
Há um total de 98 espécies distribuídas nas monografias na Farmacopeia Brasileira, sendo 63 espécies na FB5 e 59 espécies no FFFB1, das quais 24 (24\%) são coincidentes, estando em ambos os documentos (Tabela 3).

Tabela 3 - Espécies vegetais em monografias na Farmacopeia Brasileira $5^{\text {a }}$ edição (FB5), no Formulário de Fitoterápicos da Farmacopeia Brasileira $1^{\text {a }}$ edição (FFFB1) e a ocorrência no Brasil.

\begin{tabular}{|c|c|c|c|c|}
\hline & FB5 & FFFB1 & Coincidentes & Total \\
\hline Espécies & 63 & 59 & 24 & 98 \\
\hline $\begin{array}{c}\text { Espécies } \\
\text { coincidentes }(\%)\end{array}$ & $38 \%$ & $41 \%$ & - & $24 \%$ \\
\hline $\begin{array}{c}\text { Ocorrência no } \\
\text { Brasil }(\%)\end{array}$ & $25(40 \%)$ & $40(68 \%)$ & $11(46 \%)$ & $54(55 \%)$ \\
\hline
\end{tabular}

Os dados permitem observar que o FFFB1 possui uma ligeira maior porcentagem de espécies coincidentes entre os compêndios, 41\%, quando comparado com a FB5, 38\%.

A porcentagem de espécies com ocorrência no Brasil é maior dentre as espécies do FFFB1, 68\%, do que dentre as espécies das monografias da FB5, 40\%. Considerando o total de espécies dos compêndios da Farmacopeia Brasileira, 54 (55\%) possuem ocorrência no Brasil.

O FFFB é elaborado e revisado pelo Comitê Técnico Temático de Apoio a Política Nacional de Plantas Medicinais e Fitoterápicos (CTT APF) (BRASIL, 2011) cujo propósito é apoiar à Política Nacional de Plantas Medicinais e Fitoterápicos. Essa política possui ações previstas, dispostas em diretrizes do seu programa, que incluem a realização de pesquisas para a ampliação do conhecimento sobre as espécies nativas brasileiras, contemplando a possibilidade da inserção na Farmacopeia Brasileira de espécies nativas da flora brasileira (BRASIL, 2006a). Como as espécies nativas estão dentre as com ocorrência no Brasil e o CTT APF é o responsável tecnicamente pelo FFFB, se espera que este compêndio possua um quantitativo maior de espécies com ocorrência no Brasil.

Os dados podem ser comparados com o estudo de Brandão et al. (2006), no qual é apresentada a evolução da participação de espécies nativas brasileiras entre as monografias de drogas vegetais e derivados das quatro primeiras edições da Farmacopeia Brasileira. Os autores mostraram que, com relação a espécies nativas, a porcentagem de monografias era $27,5 \%$ na $1^{\text {a }}$ edição, $15,6 \%$ na $2^{\mathrm{a}}$ edição, $17,4 \%$ na $3^{\mathrm{a}}$ edição e $25 \%$ na $4^{\mathrm{a}}$ edição (BRANDÃO et al., 2006).

Os valores encontrados neste estudo, para a FB5 e FFFB1, embora superiores (40\% e $68 \%$, respectivamente), foram obtidos considerando a ocorrência das espécies no Brasil e não apenas as espécies nativas. 
Considerando as 25 espécies com ocorrência no Brasil da FB5, foi verificado que há, nesta edição, 16 (28\%) monografias com espécies nativas (REFLORA, 2016), sendo essa porcentagem comparável a das edições que continham maior porcentagem de monografias com espécies nativas.

A Tabela 4 mostra o quantitativo de espécies da Farmacopeia Brasileira, da FB5, do FFFB1 e coincidentes, que constavam em registros de fitoterápicos válidos na Anvisa em maio de 2016, contendo, ainda, a correlação dessas espécies com a sua ocorrência no Brasil.

Tabela 4 - Espécies com monografia na Farmacopeia Brasileira, Farmacopeia Brasileira $5^{\text {a }}$ edição (FB5) e Formulário de Fitoterápicos da Farmacopeia Brasileira $1^{\text {a }}$ edição (FFFB1), com registros de fitoterápicos válidos na Anvisa (maio/2016).

\begin{tabular}{|c|c|c|c|c|c|c|c|c|}
\hline & \multicolumn{2}{|c|}{ FB5 } & \multicolumn{2}{|c|}{ Coincidentes } & \multicolumn{2}{|c|}{ FFB1 } & \multicolumn{2}{|c|}{ Total (FB5 e FFFB1) } \\
\hline Espécies com & \multicolumn{2}{|c|}{25} & \multicolumn{2}{|c|}{14} & \multicolumn{2}{|c|}{24} & \multicolumn{2}{|c|}{35} \\
\hline válidos & \multicolumn{2}{|c|}{$40 \%$} & \multicolumn{2}{|c|}{$58 \%$} & \multicolumn{2}{|c|}{$41 \%$} & \multicolumn{2}{|c|}{$36 \%$} \\
\hline $\begin{array}{c}\text { Com registros } \\
\text { válidos e }\end{array}$ & \multicolumn{2}{|c|}{10} & \multicolumn{2}{|c|}{5} & \multicolumn{2}{|c|}{14} & \multicolumn{2}{|c|}{19} \\
\hline $\begin{array}{c}\text { ocorrência no } \\
\text { Brasil }\end{array}$ & $16 \%$ & $40 \%$ & $21 \%$ & $36 \%$ & $24 \%$ & $58 \%$ & $19 \%$ & $54 \%$ \\
\hline $\begin{array}{l}\text { Com registros } \\
\text { válidos e sem }\end{array}$ & \multicolumn{2}{|c|}{15} & \multicolumn{2}{|c|}{9} & \multicolumn{2}{|c|}{10} & \multicolumn{2}{|c|}{16} \\
\hline $\begin{array}{c}\text { ocorrência no } \\
\text { Brasil }\end{array}$ & $24 \%$ & $60 \%$ & $38 \%$ & $64 \%$ & $17 \%$ & $42 \%$ & $16 \%$ & $46 \%$ \\
\hline
\end{tabular}

Nota: a porcentagem à esquerda é calculada utilizando como referência à quantidade total de espécies (FB5 = 63 espécies; FFFB1 $=59$ espécies; coincidentes $=24$ espécies; Total $=98$ espécies) e a porcentagem à direita é calculada utilizando como referência à quantidade de espécies com registros válidos do compêndio (FB5 = 25 espécies; FFFB1 = 24 espécies; coincidentes $=14$ espécies; Total $=35$ espécies).

O percentual de fitoterápicos com registros válidos junto à Anvisa é próximo a $40 \%$ tanto nas espécies com monografia na FB5 quanto no FFFB1, 40\% e 41\%, respectivamente. Quando consideradas todas as 98 espécies, o percentual com registros válidos reduz para 36\%; e, dentre as espécies coincidentes, aumenta para 58\%. Esse resultado é esperado, uma vez que espécies para as quais a indústria farmacêutica possui interesse e mantém registros válidos tendem a ter uma maior movimentação técnico-científica em seu entorno e, portanto, são mais lembradas e recorrentes nas discussões técnicas, aumentando a chance de serem incluídas em ambos os compêndios.

Dentre as espécies com registros válidos desse estudo, 25 espécies (40\%) na FB5, e 24 espécies (41\%) no FFFB1, a porcentagem de espécies com ocorrência no Brasil é maior para as espécies com monografia no FFB1 (58\%) do que na FB5 (40\%). Esse resultado é esperado 
uma vez que o FFFB1 possui maior porcentagem de espécies com ocorrência no Brasil (68\%), quando comparado a FB5 (40\%).

Quando se observa somente as 14 espécies coincidentes (entre os dois compêndios) com registros válidos (58\%), 64\% não possuem ocorrência no Brasil. Ou seja, as espécies coincidentes tendem a ter uma taxa maior de ocorrência de registros (58\%), porém, esses registros em sua maioria são de espécies sem ocorrência no Brasil (64\%).

No trabalho de Carvalho et al. (2014), em um total de 98 espécies (que abrangiam todos os registros à época), apenas $25 \%$ correspondiam a espécies originárias da América do Sul (CARVALHO et al., 2014). Estes dados podem ser visualizados em conjunto com os dados obtidos neste estudo, de que dentre as espécies da Farmacopeia Brasileira, 35 espécies possuem registros válidos, das quais 54\% possuem ocorrência no Brasil (Tabela 4). Assim, pode ser observado que dentre as espécies, no geral, contidas em registros válidos, as constantes da Farmacopeia Brasileira (FB5 e FFFB1), possuem uma maior porcentagem de espécies com ocorrência no Brasil, o que é esperado, uma vez que se espera que compêndios nacionais se especializem em atender as necessidades regionais (SAITO, 2000; SHIKOV et al., 2014).

A Tabela 5 apresenta as 23 espécies da Farmacopeia Brasileira (FB5 e FFFB1) que possuem registros válidos e que estão listadas na IN nº 02/2014, sendo 12 espécies as coincidentes entre a Farmacopeia Brasileira e a IN no 02/2014.

Tabela 5 - Espécies com monografia na Farmacopeia Brasileira, Farmacopeia Brasileira $5^{\mathrm{a}}$ edição (FB5) e Formulário de Fitoterápicos da Farmacopeia Brasileira $1^{\text {a }}$ edição (FFFB1) com registros de fitoterápicos válidos na Anvisa (maio/2016) e listadas na Instrução Normativa (IN) nº 02/2014.

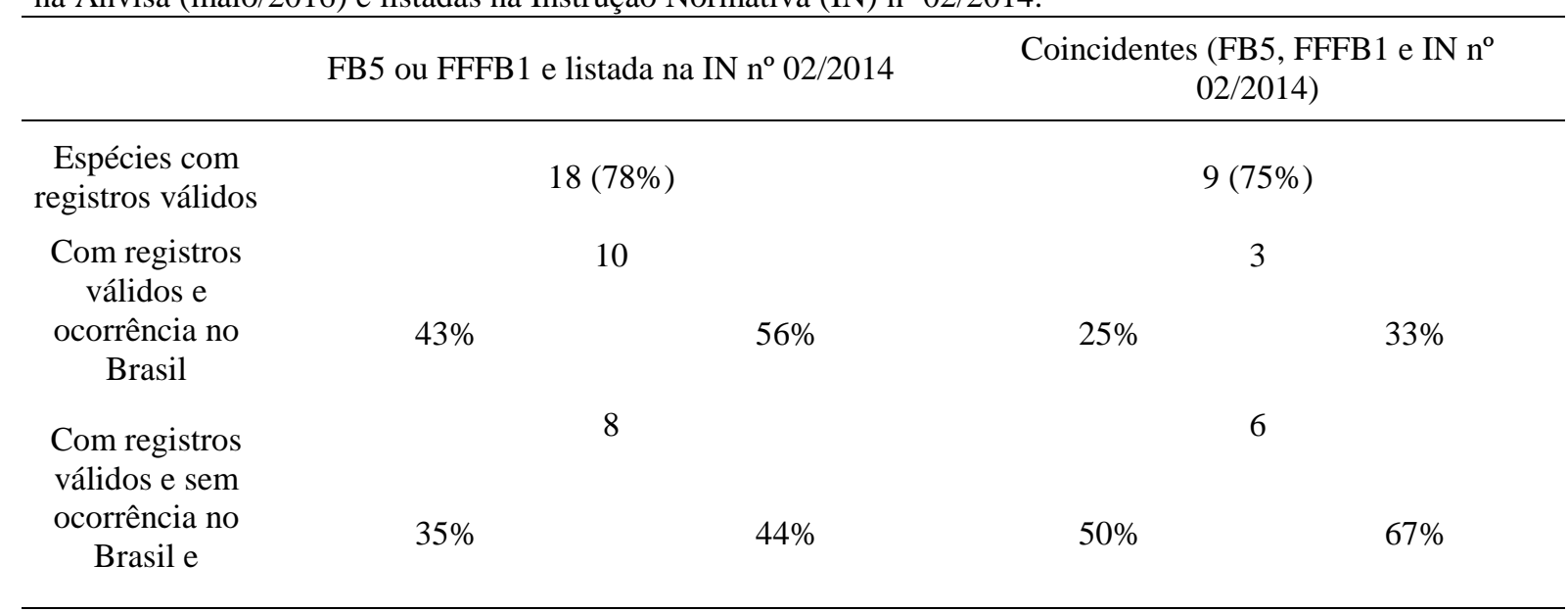

Nota: a porcentagem à esquerda é calculada utilizando como referência a quantidade total de espécies (FB5 ou FFFB 1 e IN n $n^{\circ} 02 / 2014=23$ espécies; coincidentes $=12$ espécies $)$ e a porcentagem à direita é calculada utilizando como referência a quantidade de espécies com registros válidos da situação (FB5 ou FFFB1 e IN nº 02/2014 = 23 espécies; coincidentes $=9$ espécies $)$. 
Quando são consideradas as espécies com monografia na Farmacopeia Brasileira (FB5 e FFFB1), que estão nas listas da IN nº 02/2014, o percentual de espécies com registros válidos sobe para 78\%, o que é esperado, pois a presença das espécies nas listas da IN nº 02/2014 significa a possibilidade adicional do registro simplificado. E, quando a espécie possui monografia farmacopeica, o processo de registro do produto pode ser facilitado em razão da existência de padrões de referência a serem seguidos para o controle da qualidade do fitoterápico.

A Figura 7 apresenta o quantitativo de registros de fitoterápicos válidos encontrados por espécies da Farmacopeia Brasileira. 
Figura 7 - Espécies com monografia na Farmacopeia Brasileira $5^{\mathrm{a}}$ edição (FB5) e no Formulário de Fitoterápicos da Farmacopeia Brasileira $1^{\mathrm{a}}$ edição (FFFB1), com registros de fitoterápicos válidos junto à Anvisa (maio/2016).

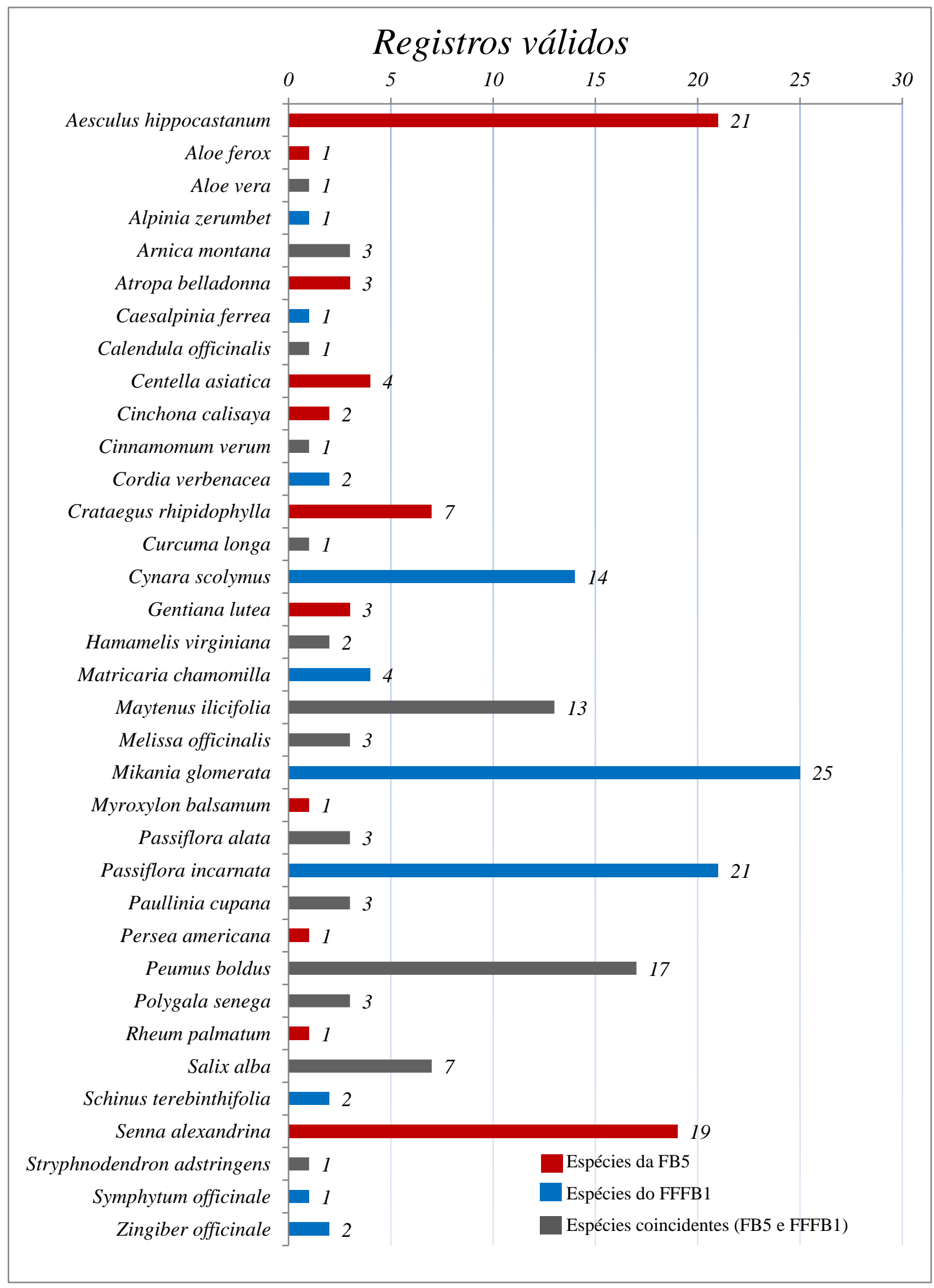


No período analisado, foram encontrados, na base de dados pública da Anvisa,195 registros de fitoterápicos contendo espécies da Farmacopeia Brasileira (FB5 e/ou FFFB1). Considerando todas as 98 espécies da Farmacopeia Brasileira, incluindo as que não possuem registros válidos, se obtém uma taxa média de 2 registros a cada espécie pesquisada.

Foram encontrados 59 registros válidos relativos às 24 espécies constantes tanto na FB5 quanto no FFB1 (espécies coincidentes), o que representa uma taxa média de 2,5 registros por espécie coincidente, incluindo para o cálculo de taxa média as espécies que não possuem registros válidos.

Considerando as 55 espécies com ocorrência no Brasil, para as quais foram observados 127 registros válidos, a taxa média encontrada foi 2,3 registros por espécie, incluindo para o cálculo de taxa média as espécies que não possuem registros válidos.

Para as espécies listadas no FFFB1 a taxa foi de 2,2 registros por espécie (132 resultados e 59 espécies) e para as espécies listadas na FB5 a taxa foi de 1,9 registro por espécie (122 resultados e 63 espécies), incluindo para o cálculo de taxa média as espécies que não possuem registros válidos.

A maior taxa encontrada foi para as espécies coincidentes, o que era esperado, uma vez que o fato das espécies estarem em ambos os compêndios, indica que são mais populares nas discussões técnicas, e a popularidade de uma espécie está associada ao interesse da sociedade, incluindo o setor regulado.

A distribuição do quantitativo de registros válidos entre as espécies contempladas não foi homogênea, sendo que a maioria das espécies com registros válidos (26 das 35, 74\%) corresponderam a até quatro resultados de registros válidos.

No mesmo sentido, as sete espécies (20\%) com mais de 10 registros válidos cada uma (Mikania glomerata Spreng., Passiflora incarnata L., Aesculus hippocastanum L., Senna alexandrina Mill., Peumus boldus Molina, Cynara scolymus L., Maytenus ilicifolia Mart. ex Reissek), totalizaram 130 registros válidos (67\% dos resultados). Sendo que, destas, apenas duas, Aesculus hippocastanum L. e Peumus boldus Molina, não possuem ocorrência no Brasil.

Ainda, foi verificado que a espécie com maior quantitativo de registros, a Mikania glomerata Spreng., não possui monografia na FB5. Essa espécie, devido a quantidade de registros e ao fato de ser uma espécie nativa do Brasil (REFLORA, 2016), deveria ser contemplada em uma monografia na Farmacopeia Brasileira. 
Os resultados evidenciam que há várias espécies da Farmacopeia Brasileira ainda não contempladas no registro de fitoterápicos. Essas espécies representam um potencial para o desenvolvimento de novos produtos para o mercado brasileiro.

Por outro lado, é questionável a existência de monografias descritas na FB5, quando o cenário dos produtos registrados evidencia falta de interesse econômico na produção desses fitoterápicos. Esse cenário, além de diverso da tendência mundial (de que as farmacopeias possuam monografias de produtos comercializados em seus países), indica que ainda há um distanciamento, considerando a área de fitoterápicos, da Farmacopeia Brasileira com a Anvisa, causado, provavelmente, pelo período em que a Farmacopeia esteve longe dos objetivos regulatórios e sanitários a que se destina atualmente e pela característica da FB5 de conter (para as monografias de drogas vegetais e derivados), em sua maioria, monografias provenientes das edições anteriores. Há, portanto a necessidade de se caminhar para uma maior aproximação.

\subsection{AVALIAÇÃO DAS DROGAS VEGETAIS E DERIVADOS DAS MONOGRAFIAS DA FARMACOPEIA BRASILEIRA $5^{\mathrm{a}}$ EDIÇÃO EM COMPARAÇÃO COM AS MONOGRAFIAS CORRESPONDENTES NAS FARMACOPEIAS INTERNACIONAIS EM ESTUDO}

As informações sobre a definição das drogas vegetais e derivados das monografias da FB5 foram dispostas em um quadro e comparadas com as informações constantes nas monografias correspondentes nas farmacopeias EP8.8, FA7 e USP39-NF34.

Nos casos em que foi verificado que a Farmacopeia Brasileira e as outras farmacopeias descreviam um mesmo material botânico com nomenclaturas diferentes, para facilitar a comparação, foi adotada a nomenclatura da FB5.

Assim, foram alteradas as descrições para: aloe (suco dessecado), utilizando "suco" ao invés de "látex" como o descrito na USP39-NF34 (USP, 2016h); laranja-amarga (exocarpo), utilizando "exocarpo" ao invés de "epicarpo e parte do mesocarpo" como o descrito na EP8.8 (EDQM, 2016b); noz-de-cola (cotilédone), utilizando "cotilédone" ao invés de "semente sem tegumento" como o descrito na EP8.8 e FA7 (ANMAT, 2003a; EDQM, 2016b); polígala (raiz e rizoma), utilizando "raiz e (curto) rizoma" ao invés de "raiz e coroa da raiz" como o descrito na EP8.8 (EDQM, 2016b); centela (folha), utilizando "folha" ao invés de "parte aérea" como o descrito na EP8.8, USP39-NF34 e na FA7 (ANMAT, 2003c; EDQM, 2016b; USP, 2016h). 
O Quadro 6 contém as informações sobre nomenclaturas botânicas, nomenclaturas populares, drogas vegetais e derivados das monografias da FB5 e as informações sobre os nomes das monografias (que obedecem às nomenclaturas populares regionais), drogas vegetais e derivados constantes nas monografias correspondentes nas farmacopeias EP8.8, FA7 e USP39-NF34. 
Quadro 6 - Comparação entre as monografias na Farmacopeia Brasileira 5a edição (FB5) e as monografias presentes na European Pharmacopoeia (EP8.8), na Farmacopea Argentina (FA7) e na The United States Pharmacopeia and National Formulary (USP39-NF-34).

\begin{tabular}{|c|c|c|c|c|c|c|}
\hline $\begin{array}{c}\mathrm{N} \\
\mathrm{o}\end{array}$ & Monografia na FB5 & $\begin{array}{c}\text { Nomenclatura } \\
\text { popular no Brasil }\end{array}$ & Monografia na EP8.8 & Monografia na FA7 & $\begin{array}{l}\text { Monografia na USP39- } \\
\text { NF34 }\end{array}$ & $\begin{array}{l}\text { Ocorrência no } \\
\text { Brasil }\end{array}$ \\
\hline 1 & Aesculus hippocastanum L. [semente] & castanha-da-índia & - & $\begin{array}{l}\text { castaño de indias, semilla } \\
\text { [semente] }\end{array}$ & horse chestnut [semente] & não \\
\hline 2 & $\begin{array}{l}\text { Aloe africana Mill., Aloe ferox Mill. e } \\
\text { Aloe spicata L. f. [folha; suco dessecado] }\end{array}$ & aloe & $\begin{array}{l}\text { Aloes, cape [folha; suco } \\
\text { dessecado] }\end{array}$ & - & $\begin{array}{l}\text { aloe [folha; suco } \\
\text { dessecado] }\end{array}$ & não \\
\hline 3 & $\begin{array}{l}\text { Aloe vera (L.) Burm. f. [folha fresca; gel } \\
\text { mucilaginoso] }\end{array}$ & aloe & - & - & - & não \\
\hline 4 & Althaea officinalis L. [raiz] & alteia & marshmallow root [raiz] & - & - & não \\
\hline 5 & Anethum graveolens L. [fruto] & endro & - & - & - & $\operatorname{sim}$ \\
\hline 6 & Arnica montana L. [capítulo floral] & arnica & arnica flower [capítulo floral] & - & - & não \\
\hline 7 & Atropa belladonna L. [folha] & beladona & $\begin{array}{l}\text { belladonna leaf [folha ou } \\
\text { sumidade florida ou } \\
\text { sumidade com folha e fruto] }\end{array}$ & $\begin{array}{c}\text { belladona, hoja [folha ou } \\
\text { sumidade florida ou } \\
\text { sumidade com folha e } \\
\text { fruto] }\end{array}$ & $\begin{array}{l}\text { belladonna leaf [folha ou } \\
\text { sumidade florida ou } \\
\text { sumidade com folha e } \\
\text { fruto] }\end{array}$ & não \\
\hline 8 & $\begin{array}{c}\text { Baccharis trimera (Less.) DC. [caule } \\
\text { alado] }\end{array}$ & carqueja & - & - & - & $\operatorname{sim}$ \\
\hline 9 & Calendula officinalis L. [capítulo floral] & calêndula & $\begin{array}{l}\text { calendula flower [capítulo } \\
\text { floral] }\end{array}$ & $\begin{array}{l}\text { caléndula, flor [capítulo } \\
\text { floral] }\end{array}$ & - & $\operatorname{sim}$ \\
\hline 10 & Centella asiatica (L.) Urb. [folha] & centela & centella [folha] & centella, hierba [folha] & centella asiatica [folha] & $\operatorname{sim}$ \\
\hline 11 & Cinchona calisaya Wedd. [casca] & quina-amarela & cinchona bark [casca] & - & - & não \\
\hline 12 & Cinnamomum cassia (L.) J. Presl [casca] & canela-da-china & - & - & - & não \\
\hline 13 & Cinnamomum verum J. Presl [casca] & canela-do-ceilão & cinnamon [casca] & $\begin{array}{c}\text { canela de ceilan, corteza } \\
\text { [casca] }\end{array}$ & - & não \\
\hline 14 & $\begin{array}{c}\text { Citrus aurantium L. subsp. aurantium } \\
\text { [exocarpo] }\end{array}$ & laranja-amarga & $\begin{array}{l}\text { bitter-orange epicarp and } \\
\text { mesocarp [exocarpo] }\end{array}$ & - & - & $\begin{array}{l}\operatorname{sim}[\text { Citrus } x \\
\text { aurantium L.] }\end{array}$ \\
\hline 15 & $\begin{array}{c}\text { Cola nitida (Vent.) Schott \& Endl. } \\
\text { [cotilédone] }\end{array}$ & noz-de-cola & cola [cotilédone] & cola, nuez de [cotilédone] & - & não \\
\hline 16 & $\begin{array}{c}\text { Crataegus monogyna Jacq., } C \text {. } \\
\text { rhipidophylla Gand. [syn. C. oxyacantha } \\
\text { L.], C. laevigata (Poir.) DC., C. } \\
\text { pentagyna Waldst. \& Kit. ex Willd., } C . \\
\text { nigra Waldst. \& Kit., C. azarolus L. } \\
\text { [ramo florido] }\end{array}$ & cratego & $\begin{array}{l}\text { hawthorn leaf and flower } \\
\text { [ramo florido] }\end{array}$ & - & $\begin{array}{l}\text { hawthorn feaf with flower } \\
\text { [ramo florido] }\end{array}$ & $\begin{array}{l}\text { sim } \\
\text { [Crataegus } \\
\text { rhipidophylla } \\
\text { Gand.] }\end{array}$ \\
\hline 17 & Curcuma longa L. [rizoma] & cúrcuma & turmeric rhizome [rizoma] & - & turmeric [rizoma] & não \\
\hline 18 & Cymbopogon citratus (DC.) Stapf [folha] & capim-limão & - & - & - & $\operatorname{sim}$ \\
\hline
\end{tabular}


Quadro 6 - Comparação entre as monografias na Farmacopeia Brasileira 5a edição (FB5) e as monografias presentes na European Pharmacopoeia (EP8.8), na Farmacopea Argentina (FA7) e na The United States Pharmacopeia and National Formulary (USP39-NF-34).

\begin{tabular}{|c|c|c|c|c|c|c|}
\hline $\begin{array}{l}\mathrm{N} \\
\mathrm{o}\end{array}$ & Monografia na FB5 & $\begin{array}{c}\text { Nomenclatura } \\
\text { popular no Brasil }\end{array}$ & Monografia na EP8.8 & Monografia na FA7 & $\begin{array}{l}\text { Monografia na USP39- } \\
\text { NF34 }\end{array}$ & $\begin{array}{l}\text { Ocorrência no } \\
\text { Brasil }\end{array}$ \\
\hline 19 & Datura stramonium L. [folha] & estramônio & $\begin{array}{l}\text { stramonium leaf [folha ou } \\
\text { folha e sumidade florida ou } \\
\text { folha e sumidade com fruto] }\end{array}$ & - & $x_{-1}+2+2$ & $\operatorname{sim}$ \\
\hline 20 & $\begin{array}{c}\text { Echinodorus grandiflorus (Cham. \& } \\
\text { Schltdl.) Micheli [folha] }\end{array}$ & chapéu-de-couro & - & - & - & $\operatorname{sim}$ \\
\hline 21 & $\begin{array}{c}\text { Elettaria cardamomum (L.) Maton } \\
\text { [semente] }\end{array}$ & cardamomo & - & - & cardamom seed [semente] & não \\
\hline 22 & Eugenia uniflora L. [folha] & pitangueira & - & - & - & $\operatorname{sim}$ \\
\hline 23 & Gentiana lutea L. [raiz e rizoma] & genciana & gentian root [raiz e rizoma] & - & - & não \\
\hline 24 & Hamamelis virginiana $\mathrm{L}$. [folha; tintura] & hamamelis & - & - & - & não \\
\hline 25 & Hydrastis canadensis L. [raiz e rizoma] & hidraste & $\begin{array}{l}\text { goldenseal rhizome [raiz e } \\
\text { rizoma] }\end{array}$ & - & goldenseal [raiz e rizoma] & não \\
\hline 26 & Hyoscyamus niger L. [folha] & meimendro & $\begin{array}{l}\text { hyoscyamus for } \\
\text { homoeopathic preparations } \\
\text { [planta florida fresca] }\end{array}$ & - & - & não \\
\hline 27 & Illicium verum Hook. f. [fruto] & anis-estrelado & star anise [fruto] & - & - & não \\
\hline 28 & $\begin{array}{c}\text { Krameria lappacea (Dombey) Burdet \& } \\
\text { B.B.Simpson [raiz] }\end{array}$ & ratânia & rhatany root [raiz] & - & - & não \\
\hline 29 & $\begin{array}{c}\text { Krameria lappacea (Dombey) Burdet \& } \\
\text { B.B.Simpson [raiz; tintura] }\end{array}$ & ratânia & rhatany tincture [raiz; tintura] & - & - & não \\
\hline 30 & $\begin{array}{c}\text { Maytenus ilicifolia Mart. ex Reissek } \\
\text { [folha] }\end{array}$ & espinheira-santa & - & - & - & $\operatorname{sim}$ \\
\hline 31 & Melissa officinalis L. [folha] & melissa & melissa leaf [folha] & - & - & não \\
\hline 32 & Mentha $x$ piperita $\mathrm{L}$. [folha] & hortelã-pimenta & peppermint leaf [folha] & - & $\begin{array}{l}\text { peppermint [folha e } \\
\text { sumidades floridas] }\end{array}$ & não \\
\hline 33 & $\begin{array}{c}\text { Mentha x piperita } \mathrm{L} \text {. [parte aérea fresca; } \\
\text { óleo] }\end{array}$ & hortelã-pimenta & $\begin{array}{l}\text { peppermint oil [parte aérea } \\
\text { florida fresca; óleo] }\end{array}$ & - & $\begin{array}{l}\text { peppermint oil [parte } \\
\text { aérea florida fresca; óleo] }\end{array}$ & não \\
\hline 34 & $\begin{array}{l}\text { Myroxylon balsamum (L.) Harms e } \\
\text { Myroxylon balsamum var. pereirae } \\
\text { (Royle) Harms [tronco; óleo-resina] }\end{array}$ & bálsamo-de-tolu & $\begin{array}{l}\text { tolu balsam [tronco, óleo- } \\
\text { resina] }\end{array}$ & $\begin{array}{c}\text { bálsamo de tolú [tronco, } \\
\text { óleo-resina] }\end{array}$ & tolu balsam [óleo-resina] & $\operatorname{sim}$ \\
\hline 35 & $\begin{array}{c}\text { Myroxylon balsamum (L.) Harms var. } \\
\text { pereirae (Royle) Harms [tronco; } \\
\text { bálsamo] }\end{array}$ & bálsamo-de-peru & $\begin{array}{l}\text { peru balsam [tronco, } \\
\text { bálsamo] }\end{array}$ & $\begin{array}{c}\text { bálsamo de perú [tronco, } \\
\text { bálsamo] }\end{array}$ & - & $\operatorname{sim}$ \\
\hline 36 & Passiflora alata Curtis [folha] & maracujá-doce & - & - & - & $\operatorname{sim}$ \\
\hline
\end{tabular}


Quadro 6 - Comparação entre as monografias na Farmacopeia Brasileira $5^{\text {a }}$ edição (FB5) e as monografias presentes na European Pharmacopoeia (EP8.8), na Farmacopea Argentina (FA7) e na The United States Pharmacopeia and National Formulary (USP39-NF-34).

\begin{tabular}{|c|c|c|c|c|c|c|}
\hline $\begin{array}{c}\mathrm{N} \\
\mathrm{o}\end{array}$ & Monografia na FB5 & $\begin{array}{c}\text { Nomenclatura } \\
\text { popular no Brasil }\end{array}$ & Monografia na EP8.8 & Monografia na FA7 & $\begin{array}{c}\text { Monografia na USP39- } \\
\text { NF34 }\end{array}$ & $\begin{array}{l}\text { Ocorrência no } \\
\text { Brasil }\end{array}$ \\
\hline 37 & Passiflora edulis Sims [folha] & maracujá-azedo & - & - & - & $\operatorname{sim}$ \\
\hline 38 & Paullinia cupana Kunth [semente] & guaraná & - & - & - & $\operatorname{sim}$ \\
\hline 39 & Persea americana Mill. [folha] & abacateiro & - & - & - & $\operatorname{sim}$ \\
\hline 40 & Peumus boldus Molina [folha] & boldo & boldo leaf [folha] & boldo, hoja [folha] & - & não \\
\hline 41 & Peumus boldus Molina [folha; tintura] & boldo & - & - & - & não \\
\hline 42 & Phyllanthus niruri L. [parte aérea] & quebra-pedra & - & - & - & $\operatorname{sim}$ \\
\hline 43 & Phyllanthus tenellus Roxb. [parte aérea] & quebra-pedra & - & - & - & $\operatorname{sim}$ \\
\hline 44 & $\begin{array}{l}\text { Pilocarpus microphyllus Stapf ex } \\
\text { Wardleworth [folha; tintura] }\end{array}$ & jaborandi & - & - & - & $\operatorname{sim}$ \\
\hline 45 & Pimpinella anisum L. [fruto] & anis-doce & aniseed [fruto] & anís, fruto [fruto] & - & não \\
\hline 46 & Polygala senega L. [raiz e rizoma] & polígala & senega root [raiz e rizoma] & - & - & não \\
\hline 47 & Quillaja saponaria Molina [casca] & quilaia & quillaia bark [casca] & - & - & não \\
\hline 48 & $\begin{array}{l}\text { Rauvolfia serpentina (L.) Benth. ex Kurz } \\
\text { [raiz] }\end{array}$ & rauvólfia & - & - & $\begin{array}{l}\text { rauwolfia serpentina } \\
\text { [raiz) }\end{array}$ & não \\
\hline 49 & $\begin{array}{l}\text { Rheum officinale Baill. e/ou Rheum } \\
\text { palmatum L. [raiz e rizoma] }\end{array}$ & ruibarbo & rhubarb [raiz e rizoma] & - & - & não \\
\hline 50 & $\begin{array}{l}\text { Rosmarinus officinalis L. [sumidade } \\
\text { florida; óleo] }\end{array}$ & alecrim & $\begin{array}{l}\text { rosemary oil [sumidade } \\
\text { florida; óleo] }\end{array}$ & - & - & não \\
\hline 51 & Salix alba L. [casca do ramo] & salgueiro-branco & - & - & - & não \\
\hline 52 & $\begin{array}{l}\text { Sambucus australis Cham. \& Schltdl. } \\
\text { [flor] }\end{array}$ & $\begin{array}{l}\text { sabugueiro-do- } \\
\text { brasil }\end{array}$ & - & - & - & $\operatorname{sim}$ \\
\hline 53 & Sambucus nigra L. [flor] & sabugueiro & elder flower [flor] & - & - & $\operatorname{sim}$ \\
\hline 54 & Senna alexandrina Mill. [folíolo] & sene & senna leaf [folíolo] & sen, hoja [folíolo] & senna leaf [folíolo] & $\operatorname{sim}$ \\
\hline 55 & $\begin{array}{l}\text { Stevia rebaudiana (Bertoni) Bertoni } \\
\text { [folha] }\end{array}$ & estévia & - & - & - & $\operatorname{sim}$ \\
\hline 56 & $\begin{array}{l}\text { Stryphnodendron adstringens (Mart.) } \\
\text { Coville [casca do caule] }\end{array}$ & barbatimão & - & - & - & $\operatorname{sim}$ \\
\hline 57 & $\begin{array}{c}\text { Styrax benzoin Dryand. ou Styrax } \\
\text { paralleloneuron Perkins [tronco; resina } \\
\text { balsâmica] }\end{array}$ & benjoim & $\begin{array}{l}\text { benzoin, sumatra [tronco, } \\
\text { resina balsâmica] }\end{array}$ & - & $\begin{array}{l}\text { benzoin [resina } \\
\text { balsâmica] }\end{array}$ & não \\
\hline 58 & $\begin{array}{l}\text { Vanilla planifolia Andrews [fruto } \\
\text { imaturo] }\end{array}$ & baunilha & - & - & vanilla [fruto imaturo] & $\operatorname{sim}$ \\
\hline
\end{tabular}

(ANMAT, 2003b; BRASIL, 2010d; EDQM, 2016b; REFLORA, 2016; TROPICOS.ORG, 2016; USP, $2016 \mathrm{~h}$ ). 
Há 37 monografias da FB5 (64\%) para as quais existem monografias correspondentes nas outras farmacopeias em estudo. Contudo, foram observadas divergências quanto a definição de algumas drogas vegetais e derivados entre as farmacopeias.

A droga vegetal para a Atropa belladonna L. na FB5 é referida como "folha", enquanto nas monografias das farmacopeias FA7, EP8.8 e USP29-NF34 a droga vegetal é definida como "folha, sumidade florida e sumidade com folha e fruto".

A droga vegetal para a Datura stramonium L. na FB5 é referida como "folha", enquanto que na EP8.8 é definida como "folha ou folha e sumidade florida ou folha e sumidade com fruto".

Para o Hyoscyamus niger L. a droga vegetal na FB5 é descrita como "folha”, e na EP8.8 é definida como "planta florida fresca”, porém a monografia na EP8.8 é destinada a preparações homeopáticas.

A droga vegetal para a Mentha x piperita L. na FB5 é descrita como "folha" e na USP39NF34, como "folha e sumidade florida". Da mesma forma, há divergências quanto ao óleo. A FB5 define como óleo da "parte aérea fresca" da Mentha x piperita L., enquanto a EP8.8 e a USP39-NF34 descrevem como óleo da "parte aérea florida fresca".

No total, cinco (14\%) monografias continham drogas vegetais ou derivados que foram considerados diferentes. Foi verificado que estas monografias se referem a espécies sem ocorrência no Brasil, com exceção da Datura stramonium L.; assim, na maioria desses casos, o material botânico utilizado no Brasil seria importado. Dessa forma, era de se esperar que a droga vegetal ou derivado previsto na FB5 fosse o mesmo da região de origem dessas espécies, pois caso contrário, a FB5 pode não servir como referência para os produtos em circulação no mercado brasileiro. Ainda, em edições anteriores da Farmacopeia Brasileira, as monografias Atropa belladonna L. e Mentha x piperita L. (espécies sem ocorrência no Brasil) descreviam a droga vegetal como "folha e sumidade florida", definição mais próxima ao disposto nas farmacopeias internacionais em estudo (Quadro 3).

Dessas espécies, apenas a Atropa belladonna L. está presente na lista de fitoterápicos com registros válidos na Anvisa (Quadro 5). Contudo, a consulta ao banco de dados não permitiu determinar qual a droga vegetal utilizada no produto registrado (por limitações anteriormente descritas neste estudo), ou se confere com a Farmacopeia Brasileira ou com as outras farmacopeias.

Estes dados mostram uma das dificuldades enfrentadas em um processo de harmonização entre as farmacopeias, pois, se a droga vegetal já não é exatamente a mesma, as 
especificações das monografias podem não possuir correspondência entre si, sendo mais difícil o processo de harmonização.

A Tabela 6 mostra o quantitativo de monografias correspondentes às da FB5 existente nas farmacopeias internacionais avaliadas, correlacionando a informação com a ocorrência das espécies no Brasil.

Tabela 6- Semelhança entre monografias da Farmacopeia Brasileira 5a edição (FB5) com as monografias listadas, para a mesma espécie vegetal, nas farmacopeias European Pharmacopoeia (EP8.8), Farmacopea Argentina (FA7) e The United States Pharmacopeia and The National Formulary (USP39-NF34).

\begin{tabular}{ccccccc}
\hline & EP8.8 & FA7 & $\begin{array}{c}\text { USP39- } \\
\text { NF34 }\end{array}$ & Em todas & $\begin{array}{c}\text { Em pelo } \\
\text { menos uma }\end{array}$ & $\begin{array}{c}\text { Em } \\
\text { nenhuma }\end{array}$ \\
\hline Monografias & 33 & 11 & 15 & 4 & 37 & 21 \\
semelhantes às da & $57 \%$ & $19 \%$ & $26 \%$ & $7 \%$ & $64 \%$ & $36 \%$ \\
FB5 & 9 & 5 & 5 & 3 & 10 & 16 \\
Espécies com & $27 \%$ & $45 \%$ & $33 \%$ & $75 \%$ & $27 \%$ & $76 \%$ \\
ocorrência & 24 & 6 & 10 & 1 & 27 & 5 \\
Espécies sem & $73 \%$ & $55 \%$ & $67 \%$ & $25 \%$ & $73 \%$ & $24 \%$ \\
ocorrência & & & & &
\end{tabular}

A maior parte das monografias de drogas vegetais e derivados da FB5 (64\%) possui monografia correspondente em pelo menos uma das três farmacopeias internacionais em estudo, dentre as quais se pode destacar a EP8.8 que possui monografias correspondentes à $57 \%$ das monografias da FB5.

A distribuição de porcentagem de espécies com ocorrência no Brasil, dentre as monografias da FB5 com monografias semelhantes nos compêndios em estudo, varia de 27\% na EP8.8, 33\% na USP39-NF34 e 45\% na FA7. Um maior percentual para a FA7 é esperado, uma vez que a proximidade regional com a Argentina possibilita maiores chances de coincidência na ocorrência de espécies nas regiões abrangidas pelas FB5 e FA7, resultando em um interesse em comum por essas espécies.

Quando são consideradas apenas as monografias de drogas vegetais e derivados da FB5 que não estão descritas nas outras farmacopeias em estudo (36\% das monografias), $76 \%$ possuem espécies que ocorrem no Brasil, ou seja, apenas $24 \%$ dessas monografias conteriam espécies sem ocorrência no Brasil. Esse resultado acompanha a expectativa, na medida em que é esperado que o Brasil invista e desenvolva monografias inéditas para espécies com ocorrência no Brasil ou de interesse regional. 


\subsection{AVALIAÇÃO SISTEMATIZADA DAS MONOGRAFIAS DE DROGAS VEGETAIS E DERIVADOS DA FARMACOPEIA BRASILEIRA $5^{\mathrm{a}}$ EDIÇÃO EM COMPARAÇÃO AOS COMPÊNDIOS INTERNACIONAIS EM ESTUDO}

As monografias de drogas vegetais e derivados constantes na FB5, e as monografias correspondentes nas farmacopeias EP8.8, FA7 e USP39-NF34, descritas no Quadro 6, foram submetidas a uma avaliação sistematizada, conforme descrito no item 3.4.1. O conteúdo das monografias que possuem correspondência entre si foi comparado, utilizando como referência as monografias da FB5.

Os dados dos métodos (ensaios e testes) e especificações, para cada conjunto de monografias, foram sistematizados, dispostos lado a lado, nos Quadros 7 a 42.

Diferenças substanciais (su), geralmente de caráter quantitativo, são as que potencialmente oferecem risco à imposição de barreiras sanitárias ao comércio mundial dos fitoterápicos, por outro lado, as diferenças menores (me), geralmente de caráter qualitativo, se caracterizam por serem diferenças que provavelmente não impactam em imposição de barreiras sanitárias. As diferenças moderadas (me) são as que foram consideradas em situação intermediária, de menor risco a imposição de barreiras do que as classificadas como substanciais e mais significativas que as menores.

Os requisitos farmacopeicos de execução obrigatória previstos nos métodos ou monografias gerais para drogas vegetais e para derivados das Farmacopeias não foram incluídos nas tabelas de comparação, exceto quando o requisito estava disposto em uma das monografias em comparação.

Exemplos dessa situação são os requisitos obrigatórios para drogas vegetais descritos no método geral Herbal drug da Ph. Eur., tais como: a determinação de matéria estranha, com o limite especificado de não maior que (NMT) 2,0\%, e a obrigatoriedade de cumprir com os requisitos para agrotóxicos e metais pesados (EDQM, 2016c).

No caso do controle microbiológico, a Ph. Eur. e a FB5 têm limites de aceitação que variam de acordo com o processo de produção, finalidade e via de administração do produto (BRASIL, 2010c; EDQM, 2016e, f), não sendo, em geral, definidos na monografia específica.

Com o comércio internacional de mercadorias, era esperado que os requisitos de qualidade confluíssem para uma convergência ou harmonização. Matérias-primas constituídas por espécies que não possuem ocorrência no Brasil (cuja origem não seria nacional), 
geralmente, antes de serem destinadas ao Brasil, cumprem com as especificações em seus países de origem.

A existência de critérios harmonizados de qualidade pode facilitar o trânsito das mercadorias, enquanto a divergência de critérios entre farmacopeias pode ocasionar barreiras sanitárias ao comércio de produtos. Importante lembrar que os critérios dispostos nas farmacopeias são mínimos, ou seja, pode ser que um produto cumpra os requisitos de uma monografia menos restritiva e também cumpra os requisitos mais restritivos de outra monografia, ou seja, o fato do produto não ter sido submetido ao ensaio previsto em uma farmacopeia, não quer dizer que quando se submeter não poderá cumpri-lo. Sendo assim, a barreira sanitária a ser ocasionada por requisitos farmacopeicos é uma possibilidade, não uma certeza.

Dessa forma, neste estudo, foram consideradas monografias convergentes, as que possuíam especificações para marcadores semelhantes ou sem diferenças substanciais, mesmo que houvesse outras diferenças substanciais (testes adicionais ou diferenças substanciais na identificação). As monografias foram consideradas harmonizadas quando todos os critérios analíticos eram semelhantes (lembrando que os critérios botânicos não foram comparados e classificados). No enquadramento como convergente ou harmonizado, os erros detectados foram desconsiderados.

\subsubsection{Aesculus hippocastanum L. [semente]}

A castanha-da-índia, como monografia para semente, esteve presente na $2^{a}$ edição e na $4^{\mathrm{a}}$ edição da Farmacopeia Brasileira (Quadro 3); contudo, não está relacionada no FFFB1 (BRASIL, 2011), estando na Lista de Medicamentos Fitoterápicos de Registro Simplificado (IN nº 02/2014) (BRASIL, 2014a) e na FB5. O fato de ser a segunda espécie da Farmacopeia Brasileira com maior número de registros válidos (21) na Anvisa (Quadro 5) pode ser justificado, ao menos em parte, por possuir monografia farmacopeica e por poder ser submetida a um processo de registro simplificado. Conforme a literatura consultada, a espécie não possui ocorrência no Brasil (Apêndice A), havendo registro de ocorrência no Canadá, China e nos Estados Unidos da América (TROPICOS.ORG, 2016). Em buscas realizadas nos compêndios internacionais em estudo, foram localizadas monografias na FA7 e na USP39-NF34. Os dados extraídos das monografias estão descritos no Quadro 7. 
Quadro 7 - Comparação entre as monografias de Aesculus hippocastanum L. [semente] das farmacopeias FB5, FA7 e USP39-NF34.

\begin{tabular}{|c|c|c|c|c|}
\hline & FB5 & FA7 & USP-39-NF34 & Classificação \\
\hline Nomenclatura popular & castanha-da-índia & castaño de indias & horse chestnut & - \\
\hline Droga vegetal & semente & semente & semente & - \\
\hline & glicosídeos triterpênicos (escina) (NLT & glicosídeos triterpênicos (escina) (NLT & glicosídeos triterpênicos (escina) (NLT & \\
\hline Marcador I & $3,0 \%)$ & $3,0 \%)$ & $3,0 \%)$ & $\mathrm{se}$ \\
\hline Características & $\begin{array}{c}\text { semente inodora + odor fraco } \\
\text { (fragmentada) + sabor adstringente (casca) } \\
\text { + sabor amargo (embrião) + salivação ao } \\
\text { mastigar }\end{array}$ & - & - & - \\
\hline Descrição macroscópica & 1 & 1 & 1 & - \\
\hline Descrição microscópica & 2 & 2 & 1 & - \\
\hline Figura botânica & 1 & - & - & - \\
\hline Identificação - método 1 & $\mathrm{CCD}$ & $\mathrm{CCD}$ & CCD & se \\
\hline Procedimento 1 & sílica-gel $\left(\mathrm{GF}_{254}+0,25 \mathrm{~mm}\right)$ & sílica-gel (fluorescência $+0,25 \mathrm{~mm}$ ) & sílica-gel $(0,25 \mathrm{~mm})$ & $\mathrm{mi}$ \\
\hline Procedimento 2 & $\begin{array}{c}\text { 1- butanol:ácido acético glacial:água } \\
(50: 10: 40) \text { (camada superior) }\end{array}$ & $\begin{array}{l}\text { 1-butanol:água:ácido acético glacial } \\
(50: 40: 10) \text { (camada superior) }\end{array}$ & $\begin{array}{l}\text { 1- butanol:ácido acético glacial:água } \\
(5: 1: 4) \text { (camada superior) }\end{array}$ & se \\
\hline Procedimento 3 & $20 \mu \mathrm{L}$ (TS); $10 \mu \mathrm{L}$ (RS) (banda) & 25-40 $\mu \mathrm{L}$ (TS); $10 \mu \mathrm{L}$ (RS) (banda); & $10 \mu \mathrm{L}(\mathrm{TS})(\mathrm{RS})$ & $\mathrm{mi}$ \\
\hline Procedimento 4 & $\begin{array}{c}1 \mathrm{~g} \text { droga vegetal pulverizada }+10 \mathrm{~mL} \\
\text { etanol } 70 \%+\text { aquecer (refluxo) }\left(15^{\prime}\right)+ \\
\text { esfriar + filtrar (TS) }\end{array}$ & $\begin{array}{l}2 \mathrm{~g} \text { droga vegetal pulverizada }+10 \mathrm{~mL} \\
\text { etanol } 70 \%+\text { aquecer (refluxo) }\left(10^{\prime}\right)+ \\
\text { filtrar + evaporar até } 5 \mathrm{~mL}(\mathrm{TS})\end{array}$ & $\begin{array}{c}1 \mathrm{~g} \text { droga vegetal pulverizada }+10 \mathrm{~mL} \\
\text { etanol:água }(7: 3)+\text { aquecer (banho-maria) } \\
\left(15^{\prime}\right)+\text { centrifugar (usar sobrenadante) } \\
(\mathrm{TS})\end{array}$ & me \\
\hline Procedimento 5 & $10 \mathrm{mg} / \mathrm{mL}$ escina em etanol $70 \%(\mathrm{RS})$ & $10 \mathrm{mg} / \mathrm{mL}$ escina em metanol $(\mathrm{RS})$ & $10 \mathrm{mg} / \mathrm{mL}$ escina SQR em metanol (RS) & $\mathrm{mi}$ \\
\hline Procedimento 6 & secar $(\operatorname{ar})$ & secar $(\operatorname{ar})$ & secar $(\operatorname{ar})$ & se \\
\hline Procedimento 7 & $254 \mathrm{~nm}$ & & & $\mathrm{mi}$ \\
\hline Procedimento 8 & $\begin{array}{c}\text { anisaldeído SR }+ \text { aquecer }\left(100-105^{\circ} \mathrm{C}\right) \\
\left(5-10^{\prime}\right)\end{array}$ & $\begin{array}{l}\text { anisaldeído sulfúrico } \mathrm{SR}+\text { aquecer (100- } \\
\left.\qquad 105^{\circ} \mathrm{C}\right)\left(5-10^{\prime}\right)\end{array}$ & $\begin{array}{c}\text { metanol:ácido acético glacial:ácido } \\
\text { sulfúrico:p- anisaldeído }(85: 10: 5: 0.5)+ \\
\text { aquecer }\left(100^{\circ} \mathrm{C}\right)\left(5^{\prime}\right)\end{array}$ & $\mathrm{mi}$ \\
\hline Procedimento 9 & descrição de zonas & descrição de zonas & descrição de zonas & se \\
\hline Testes - método 1 & matéria estranha (NMT 2\%) & matéria estranha (NMT 2\%) & matéria estranha orgânica (NMT 2,0\%) ${ }^{1}$ & me \\
\hline Testes - método 2 & água (NMT 10\%) $\left(100-105^{\circ} \mathrm{C}\right)(5 \mathrm{~h})^{2}$ & $\begin{array}{c}\text { perda por dessecação (NMT 10\%) (105 } \\
\left.{ }^{\circ} \mathrm{C}\right)(5 \mathrm{~h})^{3}\end{array}$ & $\begin{array}{l}\text { perda por dessecação (NMT 10,0\%) (105 } \\
\left.{ }^{\circ} \mathrm{C}\right)(2 \mathrm{~h})\end{array}$ & $\mathrm{mi}$ \\
\hline Testes - método 3 & cinzas totais (NMT 4\%) & cinzas totais (NMT 4\%) & $\begin{array}{l}\text { cinzas totais (NMT } 4,0 \% \text { ) } \\
\text { matérias extraíveis (solúveis em etanol) }\end{array}$ & se \\
\hline Testes - método 4 & - & - & $\begin{array}{c}\text { (método 2) (metanol:água }(8: 2) \text { ) (NLT } \\
18,0 \%)\end{array}$ & su \\
\hline Testes - método 5 & - & metais pesados (método I) (NMT 0,001\%) & impurezas elementais (MR) & $\begin{array}{l}\mathrm{su} \\
\text { (continua) }\end{array}$ \\
\hline
\end{tabular}


Quadro 7 - Comparação entre as monografias de Aesculus hippocastanum L. [semente] das farmacopeias FB5, FA7 e USP39-NF34.

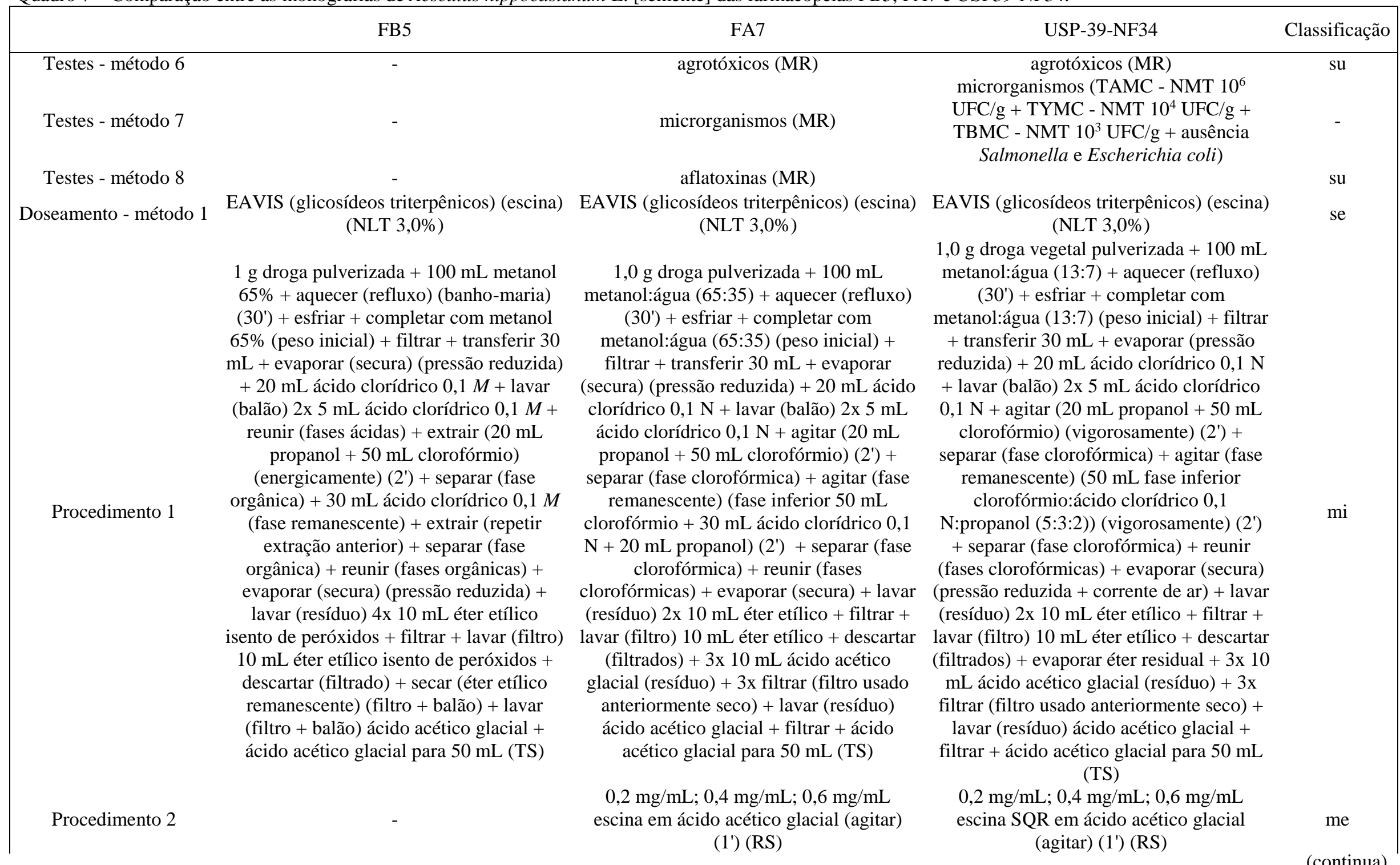


Quadro 7 - Comparação entre as monografias de Aesculus hippocastanum L. [semente] das farmacopeias FB5, FA7 e USP39-NF34.

\begin{tabular}{|c|c|c|c|c|}
\hline & FB5 & FA7 & USP-39-NF34 & Classificação \\
\hline Procedimento 3 & ácido acético glacial (BS) & ácido acético glacial (BS) & ácido acético glacial (BS) & se \\
\hline & & & & \\
\hline Procedimento 4 & $\begin{array}{c}\text { glacial:ácido sulfúrico }(1: 1)+\text { aquecer } \\
\text { (banho-maria) }\left(60^{\circ} \mathrm{C}\right)\left(25^{\prime}\right)+\text { resfriar } \\
\text { (ambiente) }\end{array}$ & $\begin{array}{c}\text { glacial:ácido sulfúrico }(50: 50)+\text { aquecer } \\
\text { (banho-maria) }\left(60^{\circ} \mathrm{C}\right)\left(25^{\prime}\right)(\text { agitar } \\
\text { ocasionalmente) }\end{array}$ & $\begin{array}{c}\text { glacial:ácido sulfúrico }(50: 50)+\text { aquecer } \\
\left(\text { banho-maria) }\left(60^{\circ} \mathrm{C}\right)\left(25^{\prime}\right) \text { (agitar }\right. \\
\text { ocasionalmente) }\end{array}$ & $\mathrm{mi}$ \\
\hline Procedimento 5 & $540 \mathrm{~nm}$ & $540 \mathrm{~nm}$ & $540 \mathrm{~nm}$ & se \\
\hline Procedimento 6 & concentração relativa & curva analítica & curva analítica & $\mathrm{mi}$ \\
\hline Procedimento 7 & Escina $\%=\frac{8,333 \times \mathrm{A}}{m}$ & $\left(\frac{50}{3}\right) \times\left(\frac{C}{P}\right)$ & Result $=\left(\frac{\mathrm{C}}{W}\right) \times\left(\frac{50}{3}\right)$ & me \\
\hline $\begin{array}{l}\text { Embalagem e } \\
\text { armazenamento }\end{array}$ & 1 & 1 & 1 & - \\
\hline Rotulagem & - & - & 1 & - \\
\hline Padrões de referência & - & - & escina SQR & - \\
\hline
\end{tabular}

(ANMAT, 2003b; BRASIL, 2010c, d; USP, 2016h).

Legenda: $\mathrm{mi}=$ menor; $\mathrm{me}=$ moderado; su = substancial; se = semelhante; $\mathrm{NLT}=$ não menos que; $\mathrm{MNT}=$ não mais que; $\mathrm{MR}=$ cumpre os requisitos ou o teste; $\mathrm{CCD}=$ cromatografia em camada delgada; RS = solução referência; TS = solução amostra; BS = solução branco; $\mathrm{SR}$ = solução reagente; SQR = substância química de referência; TAMC $=$ contagem total de bactérias aeróbias; TBMC $=$ contagem de bactérias Gram-negativas bile tolerantes; TYMC $=$ contagem total de fungos e leveduras; UFC $=$ unidade formadora de colônia; EAVIS = espectrofotometria de absorção no visível; $\mathrm{A}=$ absorvância; $m=P=W=$ massa; $\mathrm{C}=$ concentração.

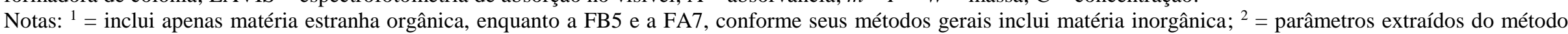
geral. 
No geral, as monografias são convergentes, com ensaio de identificação por CCD e doseamento de glicosídeos triterpênicos expressos em escina por EAVIS, com a mesma especificação de não menos que (NLT) 3,0\%.

As diferenças substanciais entre as monografias se concentram nos testes adicionais, quando comparados à FB5, previstos na FA7 (metais pesados, agrotóxicos e aflatoxinas), e na USP39-NF34 (impurezas elementais, agrotóxicos e matéria extraível).

Como espécie que não possui ocorrência no Brasil, a origem da matéria-prima não é nacional. Em se tratando de espécie com registros válidos no Brasil, a importação de matériasprimas e/ou produto acabado é quase certa. Dessa forma, é desejável e esperado, pelas empresas envolvidas no trânsito internacional das mercadorias, que os critérios a que ela se submete no exterior (em seus países de origem) sejam semelhantes aos quais é submetida no Brasil. Assim, há uma expectativa de que os métodos e especificações sejam mais harmonizados, e, nesse caso, os resultados acompanharam a expectativa.

\subsubsection{Aloe africana Mill., Aloe ferox Mill. e Aloe spicata L. f. [folha; suco dessecado]}

A aloe, como monografia para o suco dessecado da folha, esteve presente em quase todas as edições anteriores da Farmacopeia Brasileira, com exceção da $4^{\mathrm{a}}$ edição (Quadro 3); contudo, não está relacionada no FFFB1 e nem na IN nº 02/2014 (BRASIL, 2011, 2014a), estando apenas na FB5. Foi encontrado apenas um registro de fitoterápico válido na Anvisa, contendo a espécie Aloe ferox Mill (Quadro 5). Conforme a literatura consultada, as espécies não possuem ocorrência no Brasil (Apêndice A), havendo registro de ocorrência na África do Sul (TROPICOS.ORG, 2016). Em buscas realizadas nos compêndios internacionais em estudo, foram localizadas monografias na EP8.8 e na USP39-NF34. Os dados extraídos das monografias estão descritos no Quadro 8. 
Quadro 8 - Comparação entre as monografias de Aloe africana Mill., Aloe ferox Mill. e Aloe spicata L. f. [folha; suco dessecado] das farmacopeias FB5, EP8.8 e USP39NF34.

\begin{tabular}{|c|c|c|c|c|}
\hline & FB5 & EP8.8 & USP39-NF34 & Classificação \\
\hline Nomenclatura botânica & $\begin{array}{c}\text { Aloe africana Mill., Aloe ferox Mill. e } \\
\text { Aloe spicata L. f. }\end{array}$ & Aloe ferox Mill. e Aloe ssp. & $\begin{array}{l}\text { Aloe africana Mill., Aloe ferox Mill. e } \\
\text { Aloe spicata L. f. [cape aloe]; Aloe vera } \\
\text { (L.) Burm. f. [aloe vera] }\end{array}$ & - \\
\hline Sinonímia botânica & - & - & $\begin{array}{c}\text { Aloe vera (L.) Burm. f. (syn. Aloe } \\
\text { barbadensis Mill.) }\end{array}$ & - \\
\hline Nomenclatura popular & aloe + aloe-do-cabo & aloes cape & $\begin{array}{l}\text { aloe }+ \text { aloe vera }+ \text { curaçao aloe }+ \\
\text { barbados aloe }+ \text { cape aloe }\end{array}$ & - \\
\hline Droga vegetal & folha & folha & folha & se \\
\hline Derivado & suco seco & suco seco & suco seco & se \\
\hline Marcador 1 & $\begin{array}{l}\text { derivados hidroxiantracênicos } \\
\text { (barbaloína) (NLT 18\%) }\end{array}$ & $\begin{array}{l}\text { derivados hidroxiantracênicos } \\
\text { (barbaloína) (NLT 18\%) (droga seca) }\end{array}$ & $\begin{array}{c}\text { barbaloína (NLT 16,0\%) [aloe vera]; } \\
\text { barbaloína (NLT 6,0\%) [cape aloe] (droga } \\
\text { seca) }\end{array}$ & $\mathrm{su}^{1}$ \\
\hline Características & $\begin{array}{l}\text { odor acre desagradável característico }+ \\
\text { sabor muito amargo nauseante }+ \\
\text { parcialmente solúvel em água fervente }+ \\
\text { solúvel em etanol quente }+ \text { praticamente } \\
\quad \text { insolúvel em éter etílico }\end{array}$ & $\begin{array}{l}\text { parcialmente solúvel em água fervente + } \\
\text { solúvel em etanol } 96 \% \text { quente }\end{array}$ & $x_{0}$ & - \\
\hline Descrição macroscópica & 1 & $1^{*}$ & 1 & - \\
\hline Identificação - método 1 & $\mathrm{CCD}$ & $\mathrm{CCD}$ & $\mathrm{CCD}$ & se \\
\hline Procedimento 1 & sílica-gel $\left(\mathrm{GF}_{254}+0,25 \mathrm{~mm}\right)$ & sílica-gel G & sílica-gel (placa CCDAE $+5 \mu \mathrm{m})$ & me \\
\hline Procedimento 2 & água:metanol:acetato de etila $(13: 17: 100)$ & água:metanol:acetato de etila $(13: 17: 100)$ & acetato de etila:metanol:água (100:17:13) & se \\
\hline Procedimento 3 & $10 \mu \mathrm{L}(\mathrm{TS})(\mathrm{RS})($ banda) & $10 \mu \mathrm{L}(\mathrm{TS})(\mathrm{RS})(20 \times 3 \mathrm{~mm})$ (banda) & $2 \mu \mathrm{L}(\mathrm{RS}) ; 5 \mu \mathrm{L}$ (TS) $(8 \mathrm{~mm})$ (banda) & $\mathrm{mi}$ \\
\hline Procedimento 4 & $\begin{array}{c}\text { 0,25 g droga vegetal pulverizada }+20 \mathrm{~mL} \\
\text { metanol + aquecer (ebulição) + agitar } \\
(\text { minutos })+\text { decantar }\left(4^{\circ} \mathrm{C}\right)(\text { utilizar até } \\
24 \mathrm{~h})(\mathrm{TS})\end{array}$ & $\begin{array}{l}0,25 \mathrm{~g} \text { droga vegetal pulverizada }+20 \mathrm{~mL} \\
\text { metanol + aquecer (ebulição) (banho- } \\
\text { maria) + agitar (minutos) + decantar }+ \\
\text { armazenar }\left(4{ }^{\circ} \mathrm{C}\right)(\text { utilizar até } 24 \mathrm{~h})(\mathrm{TS})\end{array}$ & $\begin{array}{c}0,5 \text { g droga vegetal finamente pulverizada } \\
+10 \mathrm{~mL} \text { metanol }+ \text { sonicar }\left(15^{\prime}\right)+ \\
\text { centrifugar ou filtrar }+ \text { usar sobrenadante } \\
\text { ou filtrado }(\mathrm{TS})\end{array}$ & me \\
\hline Procedimento 5 & 25 mg barbaloína + 10 mL metanol (RS) & 25 mg barbaloína + 10 mL metanol (RS) & $\begin{array}{c}1,0 \mathrm{mg} / \mathrm{mL} \text { barbaloína SQR em metanol } \\
(\mathrm{RS})\end{array}$ & mi \\
\hline Procedimento 6 & - & - & umidade relativa $33 \%$ & - \\
\hline Procedimento 7 & secar (ar) & secar (ar) & secar (ar) & se \\
\hline Procedimento 8 & hidróxido de potássio $10 \%$ em metanol & $\begin{array}{l}\text { hidróxido de potássio } 10 \% \text { em metanol + } \\
\text { aquecer }\left(110^{\circ} \mathrm{C}\right)\left(5^{\prime}\right)\end{array}$ & $\begin{array}{l}\text { hidróxido de potássio } 10 \% \text { em metanol + } \\
\text { aquecer }\left(110^{\circ} \mathrm{C}\right)\left(5^{\prime}\right)\end{array}$ & se \\
\hline Procedimento 9 & $365 \mathrm{~nm}$ & $365 \mathrm{~nm}$ & $365 \mathrm{~nm}$ & se \\
\hline Procedimento 10 & aquecer $\left(110^{\circ} \mathrm{C}\right)\left(5^{\prime}\right)$ & - & - & se \\
\hline
\end{tabular}


Quadro 8 - Comparação entre as monografias de Aloe africana Mill., Aloe ferox Mill. e Aloe spicata L. f. [folha; suco dessecado] das farmacopeias FB5, EP8.8 e USP39NF34.

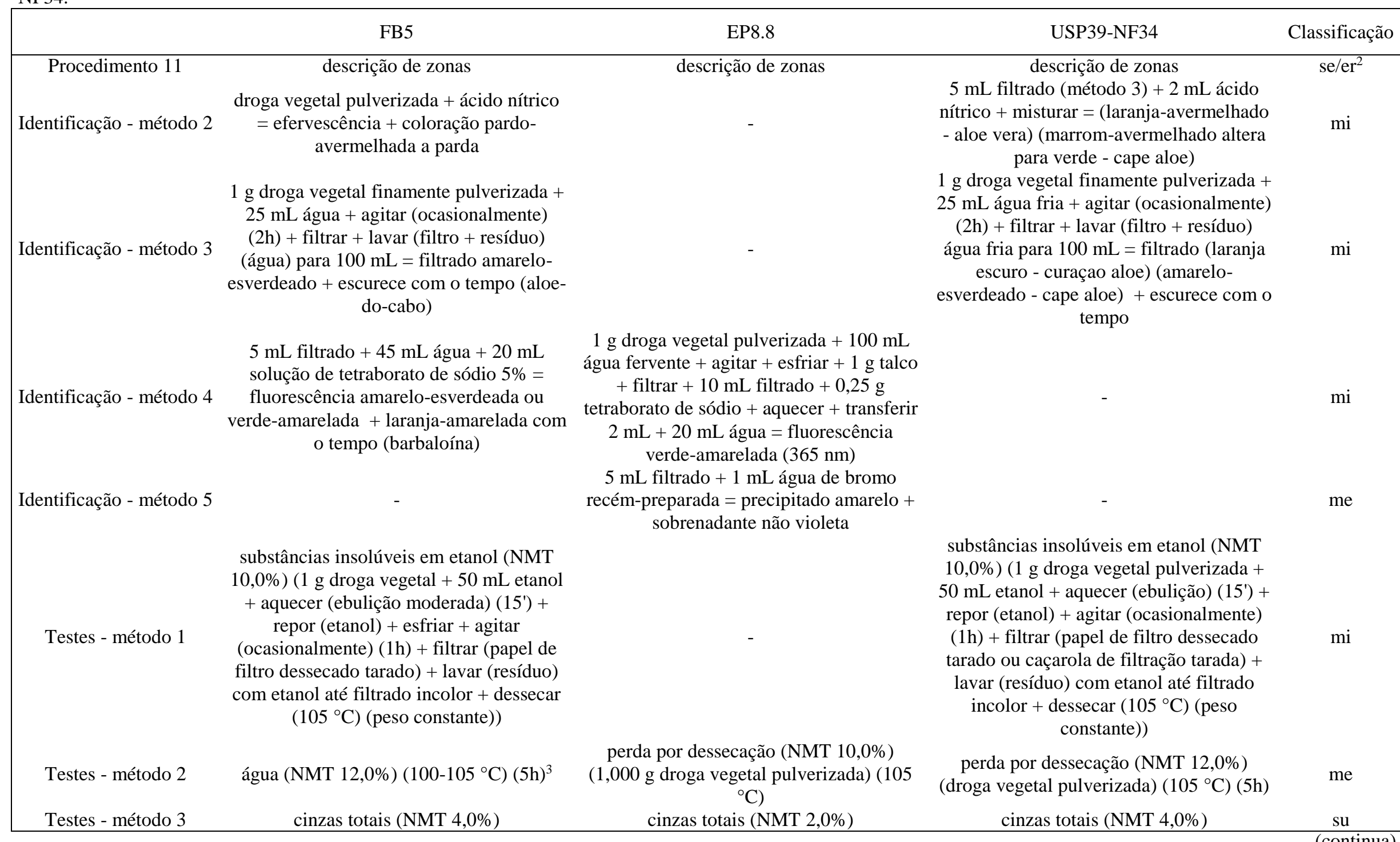


Quadro 8 - Comparação entre as monografias de Aloe africana Mill., Aloe ferox Mill. e Aloe spicata L. f. [folha; suco dessecado] das farmacopeias FB5, EP8.8 e USP39NF34.

\begin{tabular}{|c|c|c|c|c|}
\hline & FB5 & EP8.8 & USP39-NF34 & Classificação \\
\hline Testes - método 4 & - & $\begin{array}{c}\text { barbados aloe (CCD identificação) } \\
\text { (descrição de zonas) }\end{array}$ & - & $\mathrm{su}$ \\
\hline Testes - método 5 & - & 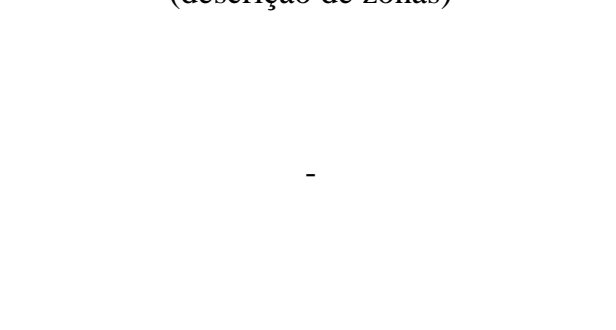 & $\begin{array}{c}\text { matéria extraível em água (NLT 50\%) (2 } \\
\text { g droga vegetal pulverizada }+70 \mathrm{~mL} \text { água } \\
+ \text { agitar (a cada } 30 ')(8 \mathrm{~h})+\text { descansar } \\
(16 \mathrm{~h})+\text { filtrar }+ \text { lavar (recipiente }+ \\
\text { resíduo) porções pequenas água para } \\
100,0 \mathrm{~mL}+\text { evaporar } 50 \mathrm{~mL}(\text { secura }) \\
\text { (banho-maria) }+ \text { dessecar }\left(110^{\circ} \mathrm{C}\right) \text { até } \\
\text { (peso constante) })^{4}\end{array}$ & su \\
\hline Doseamento - método 1 & $\begin{array}{c}\text { EAVIS (derivados hidroxiantracênicos) } \\
\text { (barbaloína) (NLT 18\%) }\end{array}$ & $\begin{array}{l}\text { EAVIS (derivados hidroxiantracênicos) } \\
\text { (barbaloína) (NLT 18,0\%) }\end{array}$ & - & se \\
\hline Procedimento 1 & $\begin{array}{l}0,4 \mathrm{~g} \text { droga vegetal pulverizada }+2 \mathrm{~mL} \\
\text { metanol }+5 \mathrm{~mL} \text { água }\left(60^{\circ} \mathrm{C}\right)+75 \mathrm{~mL} \\
\text { água }\left(60^{\circ} \mathrm{C}\right)+\text { agitar }\left(30^{\prime}\right)+\text { esfriar }+ \\
\text { filtrar + lavar } 20 \mathrm{~mL} \text { água (recipiente }+ \\
\text { filtro) + água para } 1000 \mathrm{~mL}+\text { transferir } 10 \\
\mathrm{~mL}+1 \mathrm{~mL} \text { cloreto férrico } 60 \%+6 \mathrm{~mL} \\
\text { ácido clorídrico + aquecer (refluxo) } \\
\text { (banho-maria) }(4 \mathrm{~h}) \text { (abrigo luz intensa) + } \\
\text { esfriar + transferir + lavar (4 mL água + } 4 \\
\text { mL hidróxido de sódio } M+4 \mathrm{~mL} \text { água) }+ \\
\text { reunir (líquidos de lavagem) }+ \text { agitar } 3 \mathrm{x} \\
20 \text { mL éter etílico + reunir (fases etéreas) } \\
\text { + lavar } 2 x 10 \mathrm{~mL} \text { água }+ \text { descartar } \\
\text { (líquidos de lavagem) }+ \text { éter etílico para } \\
100 \mathrm{~mL}+\text { evaporar } 20 \mathrm{~mL} \text { (resíduo) } \\
\text { (banho-maria) }+10 \mathrm{~mL} \text { acetato de } \\
\text { magnésio } 0,5 \% \text { em metanol (TS) }\end{array}$ & 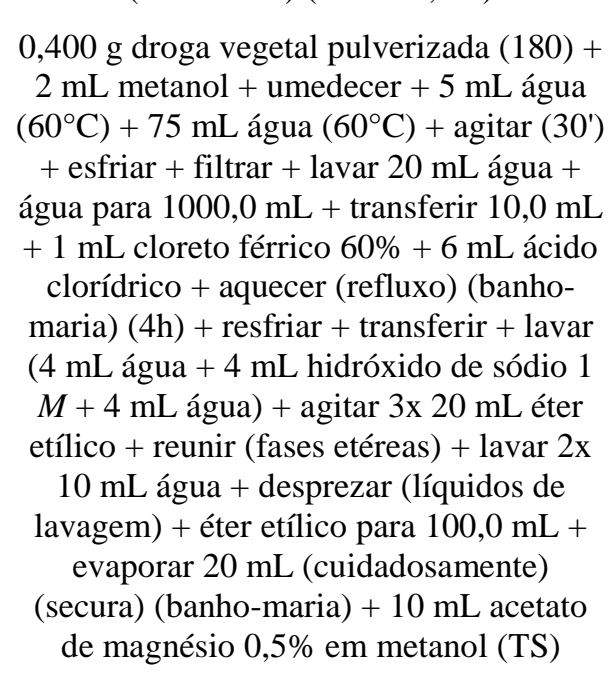 & - & se \\
\hline Procedimento 2 & metanol (BS) & metanol (BS) & - & se \\
\hline Procedimento 3 & 512 nm (imediata determinação) & $512 \mathrm{~nm}$ & - & mi \\
\hline Procedimento 4 & concentração relativa & concentração relativa & - & se \\
\hline Procedimento 5 & $\mathrm{DHC}=\frac{\mathrm{A} \times 19,6}{m}$ & $\frac{\mathrm{A} \times 19,6}{m}$ & - & se \\
\hline
\end{tabular}


Quadro 8 - Comparação entre as monografias de Aloe africana Mill., Aloe ferox Mill. e Aloe spicata L. f. [folha; suco dessecado] das farmacopeias FB5, EP8.8 e USP39NF34.

\begin{tabular}{|c|c|c|c|c|}
\hline & FB5 & EP8.8 & USP39-NF34 & Classificação \\
\hline Doseamento - método 2 & - & - & $\begin{array}{c}\text { CLAE-UV (barbaloína (NLT 16,0\%) } \\
\text { [aloe vera]; barbaloína (NLT 6,0\%) [cape } \\
\text { aloe]) }\end{array}$ & $\mathrm{su}$ \\
\hline Procedimento 1 & - & - & $295 \mathrm{~nm}$ & su \\
\hline Procedimento 2 & - & - & ODS $(4.6 \mathrm{~mm} \times 25 \mathrm{~cm})(5 \mu \mathrm{m})$ & $\mathrm{su}$ \\
\hline Procedimento 3 & - & - & acetonitrila:água (3:7) $(1 \mathrm{~mL} / \mathrm{min})$ & su \\
\hline Procedimento 4 & - & - & $\begin{array}{c}0,1 \mathrm{~g} \text { aloe vera ou } 0.2 \mathrm{~g} \text { cape aloe } \\
\text { finamente pulverizada }+75 \mathrm{~mL} \text { metanol }+ \\
\text { sonicar }\left(30^{\prime}\right)+\text { esfriar (ambiente) }+ \\
\text { metanol para } 100 \mathrm{~mL}+\text { misturar }+ \text { filtrar } \\
\text { (membrana } 0,45 \mu \mathrm{m})(\text { desprezar primeiros } \\
\mathrm{mL})(\mathrm{TS})\end{array}$ & su \\
\hline Procedimento 5 & - & - & $\begin{array}{c}0,1 \mathrm{mg} / \mathrm{mL} \text { barbaloína USP em } \\
\text { metanol:água }(1: 1)(\mathrm{RS})\end{array}$ & su \\
\hline Procedimento 6 & - & - & $\begin{array}{c}20 \mu \mathrm{L} \\
\text { fator de simetria (NMT 2,0\% - pico } \\
\text { barbaloína) + eficiência da coluna (NLT }\end{array}$ & su \\
\hline Procedimento 7 & - & - & $\begin{array}{c}2000 \text { pratos teóricos - pico barbaloína) + } \\
\text { desvio padrão relativo (NMT } 2.0 \% \text { - pico } \\
\text { barbaloína) }\end{array}$ & su \\
\hline Procedimento 8 & - & - & concentração relativa & su \\
\hline Procedimento 9 & - & - & Result $=\left(\frac{r_{U}}{r_{S}}\right) \times \mathrm{C}_{\mathrm{S}} \times\left(\frac{\mathrm{V}}{\mathrm{W}}\right) \times 100$ & su \\
\hline Padrões de referência & - & - & barbaloína SQR & - \\
\hline $\begin{array}{c}\text { Embalagem e } \\
\text { armazenamento }\end{array}$ & 1 & $1^{5}$ & - & - \\
\hline
\end{tabular}

(BRASIL, 2010c, d; EDQM, 2016b; USP, 2016h).

Legenda: mi = menor; me = moderado; su = substancial; er = erro; se = semelhante; NLT = não menos que; $M N T=$ não mais que; $C C D=$ cromatografia em camada delgada; CCDAE = cromatografia em camada delgada de alta eficiência; RS = solução referência; TS = solução amostra; $\mathrm{BS}=$ solução branco; SQR = substância química de referência; EAVIS = espectrofotometria de absorção no visível; $\mathrm{A}=$ absorvância; $m=W=$ massa; DHC $=$ derivados hidroxiantracênicos; CLAE-UV $=$ cromatografia liquida de alta eficiência acoplada a detector por espectrofotometria por absorção no ultravioleta; ODS = coluna cromatográfica octadecilsilanizada; $\mathrm{C}=$ concentração; $\mathrm{r}=$ resposta; $\mathrm{V}=$ volume. 
Notas: ${ }^{1}=$ considerado apenas a especificação para aloe cape ${ }^{2}=$ a descrição de zonas da FB5 menciona mancha de fluorescência violeta imediatamente abaixo a barbaloína, que segundo a EP8.8 e a UPS39-NF34 refere-se a Aloe vera (L.) Burm. f.; ${ }^{3}=$ parâmetros extraídos do método geral; ${ }^{4}=$ é descrito como doseamento, porém, a especificação não está na descrição da droga vegetal; ${ }^{5}=$ apenas armazenamento.

(conclusão) 
No geral, as monografias da FB5 e da EP8.8 são convergentes e a monografia da USP39NF34 contém diferenças mais marcantes. Todas as monografias apresentam ensaios de identificação por CCD e doseamento com o marcador barbaloína.

Quanto ao doseamento, na monografia da USP39-NF34 consta a especificação e o método de doseamento por CLAE-UV, ao invés do EAVIS preconizado nas outras duas farmacopeias, e a presença do teste de matéria extraível em água. Há, ainda, diferenças substanciais no teste adicional para identificação da aloe barbados na EP8.8 e da diferença na especificação de cinzas totais acima de 30\% entre a FB5, a EP8.8 e a USP39-NF34.

Como espécies que não possuem ocorrência no Brasil, a origem da matéria-prima não é nacional. Em se tratando da espécie Aloe ferox Mill. com registros válidos no Brasil, a importação de matérias-primas e/ou produto acabado é quase certa. Assim, com o objetivo de facilitar o trânsito internacional dessa matéria-prima e/ou produto acabado, se esperava que os métodos e especificações fossem mais harmonizados, porém, nesse caso, os resultados acompanharam apenas parcialmente a expectativa.

\subsubsection{Althaea officinalis L. [raiz]}

A alteia esteve presente na $1^{\mathrm{a}}$ e $2^{\mathrm{a}}$ edição da Farmacopeia Brasileira (Quadro 3), mas não está relacionada no FFFB1 e nem na IN nº 02/2014 (BRASIL, 2011, 2014a), estando apenas na FB5. Não foram encontrados, para a espécie, registros de fitoterápicos válidos na Anvisa (Quadro 5). Conforme a literatura consultada, a espécie não possui ocorrência no Brasil (Apêndice A), havendo registro de ocorrência no Afeganistão, Canadá, China, Cazaquistão, Quirguistão, Paquistão, Rússia, Tajiquistão, Turquemenistão, Estados Unidos da América e Uzbequistão (TROPICOS.ORG, 2016). Em buscas realizadas nos compêndios internacionais em estudo, foram localizadas monografias apenas na EP8.8. Os dados extraídos das monografias estão descritos no Quadro 9. 
Quadro 9 - Comparação entre as monografias de Althaea officinalis L. [raiz] das farmacopeias FB5 e EP8.8.

\begin{tabular}{|c|c|c|c|}
\hline & FB5 & EP8.8 & Classificação \\
\hline Nomenclatura popular & alteia & marshmallow root & - \\
\hline Droga vegetal & raiz & raiz & - \\
\hline Características & $\begin{array}{c}\text { odor doce }+ \text { insípido }+ \text { consistência mucilaginosa }+ \text { sabor } \\
\text { adocicado }\end{array}$ & - & - \\
\hline Descrição macroscópica & 1 & 1 & - \\
\hline Descrição microscópica & 2 & 1 & - \\
\hline Figura botânica & 3 & 1 & - \\
\hline Identificação - método 1 & CCD & - & su \\
\hline Procedimento 1 & sílica-gel $\left(\mathrm{GF}_{254}+0,25 \mathrm{~mm}\right)$ & - & su \\
\hline Procedimento 2 & acetato de etila:butanona:ácido fórmico:água (50:30:10:10) & - & su \\
\hline Procedimento 3 & $20 \mu \mathrm{L}$ (banda) (TS) (RS) & - & su \\
\hline Procedimento 4 & $\begin{array}{l}1 \mathrm{~g} \text { droga vegetal }+10 \mathrm{~mL} \text { metanol }+ \text { aquecer (banho-maria) } \\
\qquad\left(15^{\prime}\right)+\text { filtrar }\end{array}$ & - & su \\
\hline Procedimento 5 & $2,5 \mathrm{mg}$ rutina $+1 \mathrm{mg}$ ácido clorogênico $+10 \mathrm{~mL}$ metanol & - & su \\
\hline Procedimento 6 & secar (ar) & - & su \\
\hline Procedimento 7 & difenilborato de aminoetanol SR & - & su \\
\hline Procedimento 8 & $365 \mathrm{~nm}$ & - & su \\
\hline Procedimento 9 & descrição de zonas & - & su \\
\hline Testes - método 1 & $\begin{array}{c}\text { matéria estranha (NMT 2,0\% - elementos cor castanho) (NMT } \\
\text { 2,0\% - elementos do súber) }\end{array}$ & $\begin{array}{c}\text { matéria estranha (NMT 2,0\% - elementos deteriorados cor } \\
\text { castanho) }\end{array}$ & su \\
\hline Testes - método 2 & $\begin{array}{c}\text { água (NMT 12,0\%) }(1 \mathrm{~g} \mathrm{droga} \mathrm{vegetal} \mathrm{moída} \mathrm{(710))}(100- \\
\left.105^{\circ} \mathrm{C}\right)(2 \mathrm{~h})\end{array}$ & 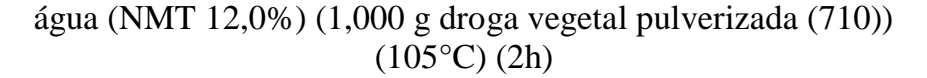 & $\mathrm{mi}$ \\
\hline Testes - método 3 & $\begin{array}{c}\text { cinzas totais (NMT 6,0\% - raiz mondada) (NMT 8.0\% - raiz não } \\
\text { mondada) }\end{array}$ & $\begin{array}{c}\text { cinzas totais (NMT 6,0\% - raiz mondada) (NMT 8.0\% - raiz não } \\
\text { mondada) }\end{array}$ & se \\
\hline Índices - método 1 & - & índice de intumescência (NLT 10) (droga vegetal pulverizada) & su \\
\hline $\begin{array}{l}\text { Embalagem e } \\
\text { armazenamento }\end{array}$ & 1 & - & - \\
\hline
\end{tabular}

(BRASIL, 2010d; EDQM, 2016b).

Legenda: $\mathrm{mi}=$ menor; $\mathrm{su}=$ substancial; $\mathrm{se}=$ semelhante $\mathrm{CCD}=$ cromatografia em camada delgada; $\mathrm{RS}=$ solução padrão ou solução referência; TS = solução amostra ou solução teste; $\mathrm{SR}=$ solução reagente; NLT = não menos que; $\mathrm{MNT}$ = não mais que. 
No geral, as monografias da FB5 e da EP8.8 não são convergentes, embora possuam testes semelhantes.

As diferenças substanciais se concentram nos ensaios adicionais na EP8.8 (índice de intumescência) e na FB5 (ensaio de identificação por CCD). Há, ainda, diferença substancial no teste para matéria estranha com especificação adicional na FB5.

Como espécie que não possui ocorrência no Brasil, a origem da matéria-prima não é nacional. Assim, se esperava que os métodos e especificações fossem mais harmonizados, porém, nesse caso, a espécie não possui registros válidos junto à Anvisa, nem está listada em outros compêndios e nem na lista de registro simplificado. Isso pode indicar que há baixa utilização da monografia no Brasil e, pode, eventualmente, explicar, o porquê de a monografia não ser tão harmonizada quanto o esperado.

\subsubsection{Arnica montana $\mathrm{L}$. [capítulo floral]}

A arnica esteve presente em quase todas as edições anteriores da Farmacopeia Brasileira, com exceção da $4^{a}$ edição (Quadro 3), atualmente, está relacionada no FFFB1, na Lista de Produtos Tradicionais Fitoterápicos de Registro Simplificado da IN no 02/2014 (BRASIL, 2011, 2014a) e na FB5. Foram encontrados, para a espécie, apenas três registros de fitoterápicos válidos na Anvisa (Quadro 5). Conforme a literatura consultada, a espécie não possui ocorrência no Brasil (Apêndice A). Em buscas realizadas nos compêndios internacionais em estudo, foram localizadas monografias apenas na EP8.8. Os dados extraídos das monografias estão descritos no Quadro 10. 
Quadro 10 - Comparação entre as monografias de Arnica montana L. [capítulo floral] das farmacopeias FB5 e EP8.8.

\begin{tabular}{|c|c|c|c|}
\hline & FB5 & EP8.8 & Classificação \\
\hline Nomenclatura popular & arnica & arnica & - \\
\hline Droga vegetal & capítulo floral & capítulo floral & - \\
\hline Marcador 1 & $\begin{array}{l}\text { sesquiterpenos lactônicos (tiglato de helenalina) (NLT 0,4\%) } \\
\text { (droga seca) }\end{array}$ & $\begin{array}{l}\text { sesquiterpenos lactônicos (tiglato de diidrohelenalina) (NLT } \\
0,40 \% \text { ) (droga seca) }\end{array}$ & se \\
\hline Características & odor aromático + agradável + sabor acre + amargo & odor aromático & - \\
\hline Descrição macroscópica & 1 & 2 & - \\
\hline Descrição microscópica & 2 & 1 & - \\
\hline Figura botânica & 3 & 1 & - \\
\hline Identificação - método 1 & $\mathrm{CCD}$ & $\mathrm{CCD}$ & se \\
\hline Procedimento 1 & sílica-gel $\left(\mathrm{GF}_{254}+0,25 \mathrm{~mm}\right)$ & sílica gel & se \\
\hline Procedimento 2 & $\begin{array}{l}\text { ácido fórmico anidro:água:butanona:acetato de etila } \\
\qquad(10: 10: 30: 50)\end{array}$ & $\begin{array}{l}\text { ácido fórmico anidro:água:butanona:acetato de etila } \\
\qquad(10: 10: 30: 50)\end{array}$ & se \\
\hline Procedimento 3 & $15 \mu \mathrm{L}(20 \mathrm{~mm})(\mathrm{TS})(\mathrm{RS})(\mathrm{banda})$ & $15 \mu \mathrm{L}(\mathrm{TS})(\mathrm{RS})$ (banda) & se \\
\hline Procedimento 4 & $\begin{array}{l}2 \mathrm{~g} \text { droga vegetal pulverizada }+10 \mathrm{~mL} \text { metanol }+ \text { aquecer } \\
\text { (banho-maria) }\left(60^{\circ} \mathrm{C}\right)+\operatorname{agitar}\left(5^{\prime}\right)+\text { resfriar }+ \text { filtrar }(\mathrm{TS})\end{array}$ & $\begin{array}{c}2,00 \mathrm{~g} \text { droga vegetal pulverizada }(710)+10 \mathrm{~mL} \text { metanol }+ \\
\text { aquecer (banho-maria) }\left(60^{\circ} \mathrm{C}\right)+\operatorname{agitar}\left(5^{\prime}\right)+\text { resfriar }+ \text { filtrar } \\
(\mathrm{TS})\end{array}$ & se \\
\hline Procedimento 5 & $\begin{array}{c}2 \mathrm{mg} \text { ácido cafeico }+2 \mathrm{mg} \text { ácido clorogênico }+5 \mathrm{mg} \text { rutina }+ \\
\text { metanol para } 30 \mathrm{~mL}(\mathrm{RS})\end{array}$ & $\begin{array}{c}\text { 2,0 mg ácido cafeico }+2,0 \mathrm{mg} \text { ácido clorogênico }+, 05 \mathrm{mg} \\
\text { rutina }+ \text { metanol para } 30 \mathrm{~mL}(\mathrm{RS})\end{array}$ & se \\
\hline Procedimento 6 & secar (ar) & secar $(\operatorname{ar})$ & se \\
\hline Procedimento 7 & $\begin{array}{l}\text { difenilborato de aminoetanol } 1 \% \text { em metanol + macrogol } 400 \\
5 \% \text { em metanol + aquecer }\left(100-105^{\circ} \mathrm{C}\right)\left(5^{\prime}\right)\end{array}$ & $\begin{array}{l}\text { difenilborato de aminoetanol } 1 \% \text { em metanol }+ \text { macrogol } 400 \\
5 \% \text { em metanol }+ \text { aquecer }\left(100-105^{\circ} \mathrm{C}\right)\left(5^{\prime}\right)\end{array}$ & se \\
\hline Procedimento 8 & $365 \mathrm{~nm}$ & $365 \mathrm{~nm}$ & se \\
\hline Procedimento 9 & descrição de zonas & descrição de zonas & se \\
\hline Testes - método 1 & matéria estranha (NMT 5,0\% - caules $>5 \mathrm{~mm}$ ) & matéria estranha (NMT 5,0\%) & se \\
\hline Testes - método 2 & cinzas totais (NMT $10,0 \%$ ) & cinzas totais (NMT 10,0\%) & se \\
\hline Testes - método 3 & $\begin{array}{c}\text { perda por dessecação (NMT } 10,0 \%)(1 \mathrm{~g} \text { droga vegetal } \\
\text { pulverizada) }\left(100-105^{\circ} \mathrm{C}\right)(2 \mathrm{~h})\end{array}$ & $\begin{array}{c}\text { perda por dessecação (NMT } 10,0 \%)(1,000 \mathrm{~g} \text { droga vegetal } \\
\text { pulverizada }(355))\left(105^{\circ} \mathrm{C}\right)(2 \mathrm{~h})\end{array}$ & se \\
\hline Doseamento - método 1 & $\begin{array}{l}\text { CLAE-UV (sesquiterpenos lactônicos) (tiglato de helenalina) } \\
\text { (NLT 0,4\%) }\end{array}$ & $\begin{array}{l}\text { CLAE-UV (sesquiterpenos lactônicos) (tiglato de } \\
\text { diidrohelenalina) (NLT } 0,40 \% \text { ) }\end{array}$ & se \\
\hline Procedimento 1 & $225 \mathrm{~nm}$ & $225 \mathrm{~nm}$ & se \\
\hline Procedimento 3 & $\begin{array}{c}\text { ODS }(4 \mathrm{~mm} \times 0,12 \mathrm{~m})(4 \mu \mathrm{m}) \\
\text { metanol } 62 \%\left(3^{\prime}\right)+\text { metanol } 62 \% \rightarrow \text { metanol } 55 \%\left(17^{\prime}\right)+ \\
\text { metanol } 55 \%\left(10^{\prime}\right)+\text { metanol } 55 \% \rightarrow \text { metanol } 45 \%\left(25^{\prime}\right)+ \\
\text { metanol } 45 \% \rightarrow \text { água }\left(2^{\prime}\right)+\text { água }\left(133^{\prime}\right)+\text { água } \rightarrow \text { metanol } 62 \% \\
\left(20^{\prime}\right)(1,2 \mathrm{~mL} / \mathrm{min})\end{array}$ & $\begin{array}{c}\text { ODS }(4 \mathrm{~mm} \times 0,12 \mathrm{~m})(4 \mu \mathrm{m}) \\
\text { metanol } 38 \%\left(3^{\prime}\right)+\text { metanol } 38 \% \rightarrow \text { metanol } 45 \%\left(17^{\prime}\right)+ \\
\text { metanol } 45 \%\left(10^{\prime}\right)+\text { metanol } 45 \% \rightarrow \text { metanol } 55 \%\left(25^{\prime}\right)+ \\
\text { metanol } 55 \% \rightarrow \text { metanol }\left(2^{\prime}\right)+\text { metanol }(13 ')+\text { metanol } \rightarrow \\
\text { metanol } 38 \%\left(20^{\prime}\right)(1,2 \mathrm{~mL} / \mathrm{min})\end{array}$ & $\mathrm{me} / \mathrm{er}{ }^{1}$ \\
\hline
\end{tabular}


Quadro 10 - Comparação entre as monografias de Arnica montana L. [capítulo floral] das farmacopeias FB5 e EP8.8.

\begin{tabular}{|c|c|c|c|}
\hline & FB5 & EP8.8 & Classificação \\
\hline Procedimento 4 & 0,01 g santonina + 10 mL metanol (imediata utilização) (IS) & $\begin{array}{l}0,010 \text { g santonina SQR + } 10 \text { mL metanol (imediata utilização) } \\
\text { (IS) }\end{array}$ & se \\
\hline Procedimento 5 & 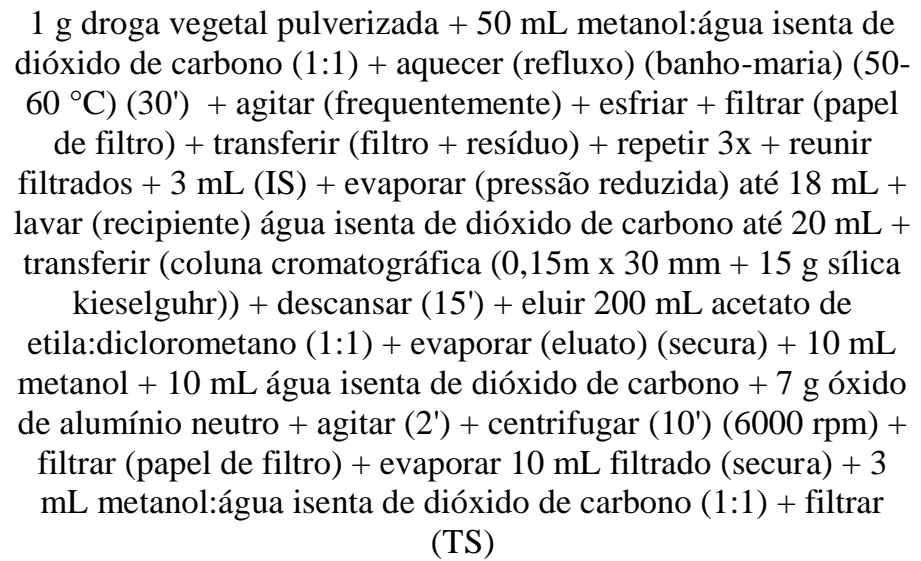 & $\begin{array}{c}1,00 \mathrm{~g} \text { droga vegetal pulverizada }(355)+50 \mathrm{~mL} \text { metanol:água } \\
(1: 1)+\text { aquecer (refluxo) (banho-maria) }\left(50-60{ }^{\circ} \mathrm{C}\right)\left(30^{\prime}\right)+ \\
\text { agitar (frequentemente) + esfriar + filtrar (papel de filtro })+ \\
\text { transferir (filtro + resíduo) + repetir } 3 \mathrm{x}+\text { reunir filttrados }+3 \mathrm{~mL} \\
\text { (IS) + evaporar (pressão reduzida) até } 18 \mathrm{~mL}+\text { lavar (recipiente) } \\
\text { água até } 20 \mathrm{~mL}+\text { transferir (coluna cromatográfica }(0,15 \mathrm{~m} \times 30 \\
\mathrm{mm}+15 \mathrm{~g} \text { kieselguhr) })+ \text { descansar }\left(20^{\prime}\right)+\text { eluir } 200 \mathrm{~mL} \text { acetato } \\
\text { de etila:diclorometano }(1: 1)+\text { evaporar (eluato) (secura) }+10,0 \\
\mathrm{~mL} \text { metanol }+10,0 \mathrm{~mL} \text { água }+7,0 \mathrm{~g} \text { óxido de alumínio neutro }+ \\
\left.\text { agitar }\left(2^{\prime}\right)+\text { centrifugar }\left(10^{\prime}\right)(5000 \mathrm{~g})+\text { filtrar (papel de filtro }\right)+ \\
\text { evaporar } 10 \mathrm{~mL} \text { filtrado (secura) }+3 \mathrm{~mL} \text { metanol:água }(1: 1)+ \\
\text { filtrar }(\mathrm{TS})\end{array}$ & $\mathrm{se}$ \\
\hline Procedimento 6 & $20 \mu \mathrm{L}(\mathrm{IS})(\mathrm{TS})$ & $20 \mu \mathrm{L}$ (IS) (TS) & se \\
\hline Procedimento 7 & concentração relativa & concentração relativa & se \\
\hline \multirow{2}{*}{ Procedimento 8} & $\mathrm{FLS} \times \mathrm{C} \times \mathrm{V} \times 1,187$ & $\mathrm{~S}_{\mathrm{LS}} \times \mathrm{C} \times \mathrm{V} \times 1,187 \times 100$ & \multirow{2}{*}{ se } \\
\hline & $\mathrm{FS} \times m \times 10$ & $\mathrm{~S}_{\mathrm{S}} \times m \times 1000$ & \\
\hline $\begin{array}{l}\text { Embalagem e } \\
\text { armazenamento }\end{array}$ & 1 & - & - \\
\hline Padrões de referência & - & santonina SQR & - \\
\hline
\end{tabular}

(BRASIL, 2010d; EDQM, 2016b).

Legenda: me = moderado; su = substancial; er = erro; NLT = não menos que; MNT = não mais que; $\mathrm{CCD}=$ cromatografia em camada delgada; RS = solução referência; TS = solução amostra; CLAE-UV = cromatografia liquida de alta eficiência acoplada a detector por espectrofotometria por absorção no ultravioleta; ODS = coluna cromatográfica octadecilsilanizada; IS = solução de padrão interno; $\mathrm{C}=$ concentração; $\mathrm{V}=$ volume; $\mathrm{SQR}=$ substância química de referência; rpm = rotações por minuto; FLS = S = FS = resposta.

Nota: ${ }^{1}=$ o gradiente de fase móvel empregado é exatamente o inverso entre uma monografia e a outra. 
No geral, quantos aos requisitos avaliados as duas monografias são harmonizadas (os requisitos botânicos não foram avaliados). A única diferença encontrada, classificada como erro, é o gradiente da fase móvel empregado no doseamento por CLAE-UV, que é exatamente o inverso entre as duas monografias. Como os resultados obtidos são semelhantes, com ambas as monografias doseando lactonas sesquiterpênicas expressas em tiglato de helenalina (FB5) diidrohelenalina (EP8.8) com a especificação esperada de NLT 0,40\%, há indícios de que essa inversão seja um erro em uma das duas monografias. Considerando a natureza da coluna empregada, coluna cromatográfica octadecilsilanizada (ODS), de fase reversa, o gradiente correto parece ser o na EP8.8, que inicia com um eluente mais polar, mistura de metanol e água $(38: 62)$.

Como espécie que não possui ocorrência no Brasil e com registros de fitoterápicos válidos no Brasil, se esperava que as monografias fossem harmonizadas, nesse caso, com exceção do erro, os resultados acompanharam a expectativa.

\subsubsection{Atropa belladonna L. [folha]}

A beladona, como monografia para a folha, esteve presente em todas as edições da Farmacopeia Brasileira, sendo que na $2^{\mathrm{a}}, 3^{\mathrm{a}}$ e $4^{\mathrm{a}}$ edição a droga vegetal era descrita como sumidade florida ao invés de folhas (Quadro 3). A espécie não foi incluída no FFFB1 e nem na IN nº 02/2014 (BRASIL, 2011, 2014a), estando apenas na FB5. Foram encontrados para a espécie três registros de fitoterápicos válidos na Anvisa (Quadro 5). Conforme a literatura consultada, a espécie não possui ocorrência no Brasil (Apêndice A), havendo registro de ocorrência no Estados Unidos da América (TROPICOS.ORG, 2016). Em buscas realizadas nos compêndios internacionais em estudo, foram localizadas monografias na EP8.8, na FA7 e na USP39-NF34. Os dados extraídos das monografias estão descritos no Quadro 11. 
Quadro 11 - Comparação entre as monografias de Atropa belladonna L. [folha] das farmacopeias FB5, EP8.8, FA7 e USP39-NF34.

\begin{tabular}{|c|c|c|c|c|c|}
\hline & B5 & EP8.8 & FA7 & USP39-NF34 & Classificação \\
\hline Nomenclatura botânica & Atropa belladonna $\mathrm{L}$. & Atropa belladonna L. & Atropa belladonna $\mathrm{L}$. & $\begin{array}{l}\text { Atropa belladonna L. ou var. } \\
\text { acuminata Royle ex Lindley }\end{array}$ & - \\
\hline Nomenclatura popular & beladona & belladonna & belladona & belladona & - \\
\hline Droga vegetal & folha & $\begin{array}{l}\text { folha ou sumidade florida ou } \\
\text { sumidade com folha e fruto }\end{array}$ & $\begin{array}{l}\text { folha ou sumidade florida ou } \\
\text { sumidade com folha e fruto }\end{array}$ & $\begin{array}{l}\text { folha ou sumidade florida ou } \\
\text { sumidade com folha e fruto }\end{array}$ & $\mathrm{su}$ \\
\hline Marcador 1 & $\begin{array}{l}\text { alcaloides (hiosciamina) (NLT } \\
0,3 \% \text { ) (droga seca) }\end{array}$ & $\begin{array}{c}\text { alcaloides (hiosciamina) (NLT } \\
0,30 \%) \text { (droga seca) }\end{array}$ & $\begin{array}{c}\text { alcaloides (hiosciamina) (NLT } \\
0,3 \%)\end{array}$ & alcaloides (NLT 0,35\%) & me \\
\hline Características & $\begin{array}{l}\text { odor fracamente nauseoso }+ \\
\text { lembra fumo }\end{array}$ & odor ligeiramente nauseante & - & - & - \\
\hline Descrição macroscópica & 1 & 1 & 1 & 1 & - \\
\hline Descrição microscópica & 2 & 1 & 2 & 2 & - \\
\hline Figura botânica & 2 & 1 & 1 & - & - \\
\hline Identificação - método 1 & $\mathrm{CCD}$ & CCD & $\mathrm{CCD}$ & - & se \\
\hline Procedimento 1 & sílica-gel $\left(\mathrm{GF}_{254}+0,25 \mathrm{~mm}\right)$ & sílica-gel G & $\begin{array}{c}\text { sílica-gel (fluorescência }+0,25 \\
\mathrm{~mm})\end{array}$ & - & se \\
\hline Procedimento 2 & $\begin{array}{l}\text { tolueno:acetato de } \\
\text { etila:dietilamina }(7: 2: 1)\end{array}$ & $\begin{array}{c}\text { amônia } \\
\text { concentrada:água:acetona } \\
(3: 7: 90)\end{array}$ & $\begin{array}{l}\text { acetona:água:amoníaco } \\
\text { concentrado }(90: 7: 3)\end{array}$ & - & me \\
\hline Procedimento 3 & $20 \mu \mathrm{L}$ (TS) (RS) (banda) & $\begin{array}{c}10 \mu \mathrm{L}+20 \mu \mathrm{L}(20 \mathrm{~mm} \times 3 \\
\mathrm{mm})(\mathrm{TS})(\mathrm{RS})(\text { banda })\end{array}$ & $\begin{array}{c}10 \mu \mathrm{L}+20 \mu \mathrm{L}(\mathrm{TS})(\mathrm{RS}) \\
\text { (banda) }\end{array}$ & - & mi \\
\hline Procedimento 4 & $\begin{array}{c}3 \mathrm{~g} \text { droga vegetal pulverizada }+ \\
30 \mathrm{~mL} \text { ácido sulfúrico } 0,05 \mathrm{M} \\
+ \text { agitar }\left(2^{\prime}\right)+\text { filtrar }+3 \mathrm{~mL} \\
\text { hidróxido de amônio }+15 \mathrm{~mL} \\
\text { água + extrair } 3 \times 15 \mathrm{~mL} \\
\text { clorofórmio + Reunir (fases } \\
\text { clorofórmicas) + sulfato de } \\
\text { sódio anidro + filtrar + } \\
\text { evaporar + } 0,25 \mathrm{~mL} \text { metanol } \\
(\mathrm{TS})\end{array}$ & $\begin{array}{c}\text { 0,6 g droga vegetal pulverizada } \\
(180)+15 \mathrm{~mL} \text { ácido sulfúrico } \\
0,05 \mathrm{M}+\text { agitar }\left(15^{\prime}\right)+\text { filtrar + } \\
\text { lavar (filtro) ácido sulfúrico } \\
0,05 \mathrm{M} \text { até } 20 \mathrm{~mL}+1 \mathrm{~mL} \\
\text { amônia concentrada + agitar } 2 \mathrm{x} \\
10 \mathrm{~mL} \text { éter etílico isento de } \\
\text { peróxidos + reunir (fases } \\
\text { etéreas) + secar (sulfato de } \\
\text { sódio anidro) + filtrar + } \\
\text { evaporar (secura) (banho- } \\
\text { maria) + 0,5 mL metanol (TS) }\end{array}$ & $\begin{array}{c}600 \mathrm{mg} \text { droga vegetal } \\
\text { pulverizada }+15 \mathrm{~mL} \text { ácido } \\
\text { sulfúrico } 0,05 M+\text { agitar }(15 ') \\
\text { + filtrar + lavar (filtro) ácido } \\
\text { sulfúrico } 0,05 \mathrm{M} \text { até } 20 \mathrm{~mL}+1 \\
\text { mL hidróxido de amônio } \\
\text { concentrado + extrair } 2 \text { x } 10 \\
\text { mL éter etílico isento de } \\
\text { peróxidos + reunir (fases } \\
\text { etéreas) + secar (sulfato de } \\
\text { sódio anidro) + filtrar + } \\
\text { evaporar (secura) + 0,5 mL } \\
\text { metanol (TS) }\end{array}$ & - & me \\
\hline
\end{tabular}


Quadro 11 - Comparação entre as monografias de Atropa belladonna L. [folha] das farmacopeias FB5, EP8.8, FA7 e USP39-NF34.

\begin{tabular}{|c|c|c|c|c|c|}
\hline & B5 & EP8.8 & FA7 & USP39-NF34 & Classificação \\
\hline & $\begin{array}{c}9 \mathrm{~mL} \text { (sulfato de } \\
\text { atropina:metanol }(24 \mathrm{mg}: 9\end{array}$ & $\begin{array}{c}8 \mathrm{~mL} \text { (sulfato de } \\
\text { hiosciamina:metanol (50 mg:9 }\end{array}$ & $\begin{array}{l}9 \mathrm{~mL} \text { (sulfato de hiosciamina } \\
\text { SR-FA:metanol }(50 \mathrm{mg}: 9 \mathrm{~mL}) \text { ) }\end{array}$ & & \\
\hline Procedimento 5 & $\begin{array}{l}\mathrm{mL}))+1 \mathrm{~mL} \text { (bromidrato de } \\
\text { escopolamina:metanol }(7,5 \\
\text { mg:10 mL)) (RS) }\end{array}$ & $\begin{array}{c}\mathrm{mL})+1,8 \mathrm{~mL} \text { (bromidrato de } \\
\text { escopolamina:metanol }(15 \\
\mathrm{mg}: 10 \mathrm{~mL}))(\mathrm{RS})\end{array}$ & $\begin{array}{l}+1,8 \mathrm{~mL} \text { (bromidrato de } \\
\text { escopolamina SR-FA:metanol } \\
\quad(15 \mathrm{mg}: 10 \mathrm{~mL}))(\mathrm{RS})\end{array}$ & - & me \\
\hline Procedimento 6 & $\begin{array}{l}\text { secar }\left(100-105^{\circ} \mathrm{C}\right)\left(15^{\prime}\right) \\
\text { iodeto de potássio e subnitrato }\end{array}$ & $\operatorname{secar}\left(100-105^{\circ} \mathrm{C}\right)\left(15^{\prime}\right)$ & $\operatorname{secar}\left(100-105^{\circ} \mathrm{C}\right)\left(15^{\prime}\right)$ & - & se \\
\hline Procedimento 7 & $\begin{array}{c}\text { de bismuto } \mathrm{SR}+\text { ácido } \\
\text { sulfúrico (ou nitrito de sódio) } \\
5 \% \text { em etanol }\end{array}$ & $\begin{array}{c}\text { solução de iodobismutato de } \\
\text { potássio SR }\end{array}$ & $\begin{array}{l}\text { solução de iodobismutato de } \\
\text { potássio SR }\end{array}$ & - & mi \\
\hline Procedimento 8 & & solução de nitrito de sódio & nitrito de sódio $0,1 M$ & - & $\mathrm{mi}$ \\
\hline Procedimento 9 & descrição de zonas & descrição de zonas & descrição de zonas & - & $\mathrm{mi}$ \\
\hline Identificação - método 2 & $\begin{array}{c}3 \text { g droga vegetal pulverizada + } \\
30 \text { mL ácido sulfúrico } 0,05 \mathrm{M} \\
+ \text { agitar }(2 \text { ') + filtrar }+3 \mathrm{~mL} \\
\text { hidróxido de amônio }+15 \mathrm{~mL} \\
\text { água + extrair } 3 \mathrm{x} 15 \mathrm{~mL} \\
\text { clorofórmio + reunir (fases } \\
\text { clorofórmicas) + sulfato de } \\
\text { sódio anidro + filtrar + } \\
\text { evaporar + 0,5 mL ácido } \\
\text { nítrico fumegante + evaporar } \\
\text { (secura) (banho-maria) }+2 \mathrm{~mL} \\
\text { acetona + gotejar hidróxido de } \\
\text { potássio } 10 \% \text { em etanol = } \\
\text { violeta intensa }\end{array}$ & $\begin{array}{c}1 \text { g droga vegetal pulverizada } \\
(180)+10 \text { mL ácido sulfúrico } \\
0,05 M+\text { agitar }(2 ')+\text { filtrar }+ \\
1 \mathrm{~mL} \text { amônia concentrada }+5 \\
\text { mL água + agitar } 15 \text { mL éter } \\
\text { etílico (cuidadosamente) + } \\
\text { reunir (fase etérea) + sulfato de } \\
\text { sódio anidro + filttrar + } \\
\text { evaporar + 0,5 mL ácido } \\
\text { nítrico fumegante + evaporar } \\
\text { (secura) (banho-maria) + } 10 \\
\text { mL acetona + gotejar } \\
\text { hidróxido de potássio } 3 \% \text { em } \\
\text { etanol } 96 \%=\text { violeta intensa }\end{array}$ & $\begin{array}{c}\text { 1,0 g droga vegetal pulverizada } \\
+10 \text { mL ácido sulfúrico } 0,05 \\
M+\text { agitar }(2 ')+\text { filtrar }+1,0 \\
\text { mL amoníaco concentrado + } \\
5,0 \text { mL água }+15,0 \mathrm{~mL} \text { éter } \\
\text { etílico + agitar } \\
\text { (cuidadosamente) + reunir } \\
\text { (fase etérea) + secar (sulfato de } \\
\text { sódio anidro) + filtrar + } \\
\text { evaporar + 0,5 mL ácido } \\
\text { nítrico fumegante + evaporar } \\
\text { (secura) (banho-maria) + } 10 \\
\text { mL acetona + gotejar } \\
\text { hidróxido de potássio a 3\% em } \\
\text { etanol = violeta intensa }\end{array}$ & - & mi \\
\hline Testes - método 1 & $\begin{array}{c}\text { matéria estranha (NMT 3,0\% - } \\
\text { caules > } 5 \mathrm{~mm}+\text { sem } \\
\text { fragmentos folhas com ráfides } \\
\text { no mesofilo (Phytolacca } \\
\text { americana L.) + sem células } \\
\text { com maclas de oxalato de } \\
\text { cálcio (Ailanthus altissima } \\
\text { Swingle)) }\end{array}$ & $\begin{array}{l}\text { matéria estranha (NMT 3\% - } \\
\text { caules }>5 \mathrm{~mm})\end{array}$ & $\begin{array}{c}\text { matéria estranha }(\mathrm{NMT} 3 \% \text { - } \\
\text { caules }>5 \mathrm{~mm})\end{array}$ & $\begin{array}{l}\text { caules de belladonna (NMT } \\
3,0 \% \text { - caules }>10 \mathrm{~mm})\end{array}$ & me \\
\hline
\end{tabular}


Quadro 11 - Comparação entre as monografias de Atropa belladonna L. [folha] das farmacopeias FB5, EP8.8, FA7 e USP39-NF34.

\begin{tabular}{|c|c|c|c|c|c|}
\hline & B5 & EP8.8 & FA7 & USP39-NF34 & Classificação \\
\hline Testes - método 2 & cinzas totais (NMT $10,0 \%)$ & cinzas totais (NMT 16,0\%) & cinzas totais (NMT 16\%) & - & $\mathrm{su}$ \\
\hline Testes - método 3 & $\begin{array}{c}\text { cinzas insolúveis em ácido } \\
\text { (NMT 4,0\%) }\end{array}$ & $\begin{array}{l}\text { cinzas insolúveis em ácido } \\
\text { clorídrico (NMT 4,0\%) }\end{array}$ & $\begin{array}{l}\text { cinzas insolúveis em ácido } \\
\text { clorídrico (NMT 4\%) }\end{array}$ & $\begin{array}{c}\text { cinzas insolúveis em ácido } \\
\text { (NMT 3,0\%) }\end{array}$ & me \\
\hline Testes - método 4 & - & - & microrganismos (MR) & - & - \\
\hline Testes - método 5 & - & - & aflatoxinas (MR) & - & su \\
\hline Testes - método 6 & - & - & $\begin{array}{c}\text { metais pesados (NMT 0,001\%) } \\
\text { perda por dessecação (NMT }\end{array}$ & - & $\mathrm{su}$ \\
\hline Testes - método 7 & - & - & $\begin{array}{l}10 \%)(2 \mathrm{~g} \text { droga vegetal } \\
\text { pulverizada) }\left(100-105^{\circ} \mathrm{C}\right)(4 \mathrm{~h})\end{array}$ & - & $\mathrm{su}$ \\
\hline Testes - método 8 & - & - & resíduos de agrotóxicos (MR) & - & su \\
\hline Doseamento - método 1 & $\begin{array}{c}\text { volumetria (alcaloides) } \\
\text { (hiosciamina) (NLT 0,3\%) }\end{array}$ & $\begin{array}{c}\text { volumetria (alcaloides) } \\
\text { (hiosciamina) (NLT 0,30\%) } \\
\text { perda por dessecação }(2,000 \mathrm{~g}\end{array}$ & $\begin{array}{c}\text { volumetria (alcaloides) } \\
\text { (hiosciamina) (NLT 0,3\%) }\end{array}$ & - & se \\
\hline Procedimento 1 & - & $\begin{array}{c}\text { droga vegetal pulverizada } \\
(180))\left(105^{\circ} \mathrm{C}\right)\end{array}$ & - & - & $\mathrm{se}^{1}$ \\
\hline Procedimento 2 & $\begin{array}{l}10 \mathrm{~g} \text { droga vegetal pulverizada } \\
(180)+5 \mathrm{~mL} \text { hidróxido de } \\
\text { amônio }+10 \mathrm{~mL} \text { etanol }+30 \\
\text { mL éter etílico isento de } \\
\text { peróxidos + macerar }(4 \mathrm{~h})+ \\
\text { percolar (clorofórmio:éter } \\
\text { etílico isento de peróxidos } \\
(1: 3)) \text { até extração completa }+ \\
\text { evaporar } 1 \text { mL percolado } \\
\text { (secura) + ácido sulfúrico } 0,25 \\
M+\text { iodeto de potássio } \\
\text { mercúrio SR (ausência } \\
\text { alcaloides) + reduzir para } 50 \\
\text { mL + transferir com éter isento } \\
\text { de peróxidos }+2,5 \times \text { volume } \\
\text { (percolador) éter etílico isento } \\
\text { de peróxidos }+ \text { extrair } 3 \times 20 \\
\text { mL ácido sulfúrico } 0,25 M+ \\
\text { transferir (fase ácida) }+ \\
\text { alcalinizar (pH } 8,0-9,0)\end{array}$ & $\begin{array}{c}10,00 \mathrm{~g} \text { droga vegetal } \\
\text { pulverizada }(180)+5 \mathrm{~mL} \\
\text { amônia }+10 \mathrm{~mL} \text { etanol } 96 \%+ \\
30 \mathrm{~mL} \text { éter etílico isento de } \\
\text { peróxidos + macerar }(4 \mathrm{~h})+ \\
\text { percolar (clorofórmio:éter } \\
\text { etílico isento de peróxidos } \\
\text { (1:3)) até extração completa }+ \\
\text { evaporar alguns mL percolado } \\
\text { (secura) + ácido sulfúrico } 0,25 \\
M+\text { iodeto de potássio } \\
\text { mercúrio SR (ausência } \\
\text { alcaloides) + reduzir para } 50 \\
\text { mL (banho-maria) + transferir } \\
\text { com éter isento de peróxidos }+ \\
2,1 \mathrm{x} \text { volume (percolador) éter } \\
\text { etílico isento de peróxidos }+ \\
\text { agitar } 3 \times 20 \text { mL ácido sulfúrico } \\
0,25 M+\text { transferir (fase ácida) } \\
+ \text { alcalinizar (amônia) }+ \text { agitar }\end{array}$ & $\begin{array}{c}10 \mathrm{~g} \text { droga vegetal pulverizada } \\
\text { (previamente dessecada) }+5 \\
\mathrm{~mL} \text { amoníaco concentrado }+ \\
10 \mathrm{~mL} \text { etanol }+30 \mathrm{~mL} \text { éter } \\
\text { etílico isento de peróxidos }+ \\
\text { transferir (percolador) + } \\
\text { macerar }(4 \mathrm{~h})+\text { percolar } \\
\text { (clorofórmio:éter }(1: 3) \text { ) até } \\
\text { extração completa + evaporar } \\
\text { alguns mL (secura) + ácido } \\
\text { sulfúrico } 0,25 M+\text { solução de } \\
\text { iodeto de potássio mercúrio } \\
\text { (SR) + reduzir para } 50 \mathrm{~mL}+ \\
\text { transferir com éter etílico } \\
\text { isento de peróxidos }+2,1 \mathrm{x} \\
\text { volume éter etílico isento de } \\
\text { peróxidos }+ \text { extrair } 3 \mathrm{x} 20 \mathrm{~mL} \\
\text { ácido sulfúrico } 0,25 \mathrm{M}+ \\
\text { transferir (fases ácidas) }+ \\
\text { alcalinizar (amoníaco }\end{array}$ & - & se \\
\hline
\end{tabular}


Quadro 11 - Comparação entre as monografias de Atropa belladonna L. [folha] das farmacopeias FB5, EP8.8, FA7 e USP39-NF34.

\begin{tabular}{|c|c|c|c|c|c|}
\hline & B5 & EP8.8 & FA7 & USP39-NF34 & Classificação \\
\hline Procedimento 3 & $\begin{array}{c}\text { (hidróxido de amônio) + } \\
\text { extrair } 3 \mathrm{x} 30 \mathrm{~mL} \text { clorofórmio + } \\
\text { reunir (fases clorofórmicas) + } \\
4 \mathrm{~g} \text { sulfato de sódio anidro + } \\
\text { descansar (30') (agitação } \\
\text { ocasional) + separar (fase } \\
\text { clorofórmica) + lavar (sulfato } \\
\text { de sódio) } 3 \mathrm{x} 10 \mathrm{~mL} \\
\text { clorofórmio + reunir (fases } \\
\text { clorofórmicas) + evaporar } \\
\text { (secura) (banho-maria) (TS) } \\
\left.\text { aquecer (100-105 }{ }^{\circ} \mathrm{C}\right)\left(15^{\prime}\right)+5 \\
\text { mL clorofórmio + } 20 \mathrm{~mL} \text { ácido } \\
\text { sulfúrico } 0,01 \mathrm{MSV}+ \\
\text { evaporar (clorofórmio) (banho- } \\
\text { maria) + titular (hidróxido de } \\
\text { sódio } 0,02 M \mathrm{SV} \text { ) }\end{array}$ & $\begin{array}{c}\text { 3x } 30 \text { mL clorofórmio + reunir } \\
\text { (fases clorofórmicas) + } 4 \mathrm{~g} \\
\text { sulfato de sódio anidro + } \\
\text { descansar }(30 \text { ') (agitação } \\
\text { ocasional) + separar (fase } \\
\text { clorofórmica) + lavar (sulfato } \\
\text { de sódio) } 3 \times 10 \mathrm{~mL} \\
\text { clorofórmio + reunir (fases } \\
\text { clorofórmicas) + evaporar } \\
\text { (secura) (banho-maria) }(\mathrm{TS}) \\
\left.\text { aquecer (100-105 }{ }^{\circ} \mathrm{C}\right)\left(15^{\prime}\right)+ \\
\text { alguns mL clorofórmio + } 20,0 \\
\text { mL ácido sulfúrico } 0,01 M+ \\
\text { evaporar (clorofórmio) (banho- } \\
\text { maria) + titular (hidróxido de } \\
\text { sódio } 0,02 M \text { ) }\end{array}$ & $\begin{array}{l}\text { concentrado) + extrair 3x } 30 \\
\text { mL clorofórmio + reunir (fases } \\
\text { clorofórmicas) + } 4 \text { g sulfato de } \\
\text { sódio anidro + descansar }\left(30^{\prime}\right) \\
\text { (agitação periódica) + separar } \\
\text { (fase clorofórmica) + lavar } \\
\text { (sulfato de sódio) 3x } 10 \mathrm{~mL} \\
\text { clorofórmio + reunir (fases } \\
\text { clorofórmicas) + evaporar } \\
\text { (secura) (TS) } \\
\left.\text { aquecer (100-105 }{ }^{\circ} \mathrm{C}\right)\left(15^{\prime}\right)+ \\
\text { alguns mL clorofórmio }+20 \\
\text { mL ácido sulfúrico } 0,01 M+ \\
\text { descartar (fase clorofórmica) }+ \\
\text { titular (hidróxido de sódio } 0,02 \\
\mathrm{~N} \mathrm{SV)}\end{array}$ & - & se \\
\hline Procedimento 4 & vermelho de metila SI & $\begin{array}{l}\text { solução mista de vermelho de } \\
\text { metila SR }\end{array}$ & vermelho de metila SR & - & mi \\
\hline Procedimento 5 & $\begin{array}{l}\text { \%alcaloides } \\
=\frac{57,88 \times(20-\mathrm{n})}{(100-\mathrm{d}) \times m}\end{array}$ & $\frac{57,88 \times(20-\mathrm{n})}{(100-\mathrm{d}) \times m}$ & $\frac{57,88 \times(20-n)}{P \times(100-d)}$ & - & se \\
\hline Doseamento - método 2 & - & - & - & CG (alcaloides) (NLT 0,35\%) & me \\
\hline Procedimento 1 & - & - & - & $\begin{array}{c}\text { hélio }(65 \mathrm{~mL} / \mathrm{min}) \\
\text { coluna - sílica }(1,2 \mathrm{~m} \times 4 \mathrm{~mm})\end{array}$ & me \\
\hline Procedimento 2 & - & - & - & $\begin{array}{c}+ \text { filme } \\
\text { (fenilmetilpolisiloxano) }\end{array}$ & me \\
\hline Procedimento 3 & - & - & - & $\begin{array}{c}\text { injetor } 240{ }^{\circ} \mathrm{C}+\text { detector } 240 \\
{ }^{\circ} \mathrm{C}\end{array}$ & me \\
\hline Procedimento 4 & - & - & - & $\begin{array}{c}215^{\circ} \mathrm{C} \\
40 \mathrm{mg} \text { bromidrato de }\end{array}$ & me \\
\hline Procedimento 5 & - & - & - & $\begin{array}{l}\text { homatropina SQR + ácido } \\
\text { sulfúrico diluído para } 50 \mathrm{ml} \\
\text { (prepara no dia do uso) (IS) }\end{array}$ & me \\
\hline
\end{tabular}


Quadro 11 - Comparação entre as monografias de Atropa belladonna L. [folha] das farmacopeias FB5, EP8.8, FA7 e USP39-NF34.

\begin{tabular}{|c|c|c|c|c|c|}
\hline & B5 & EP8.8 & FA7 & USP39-NF34 & Classificação \\
\hline Procedimento 6 & - & - & - & 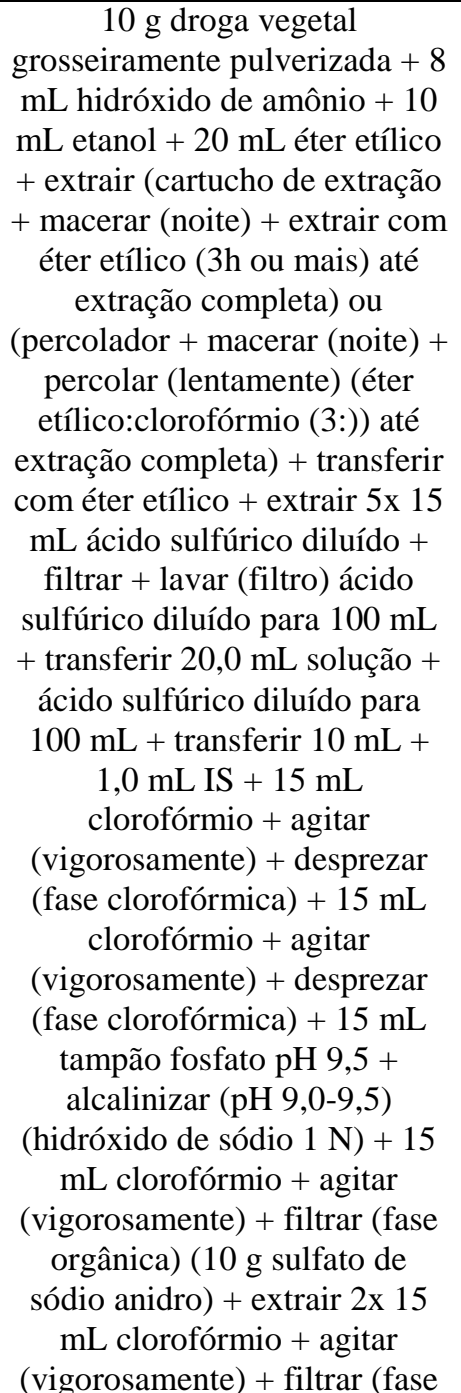 & me \\
\hline
\end{tabular}


Quadro 11 - Comparação entre as monografias de Atropa belladonna L. [folha] das farmacopeias FB5, EP8.8, FA7 e USP39-NF34.

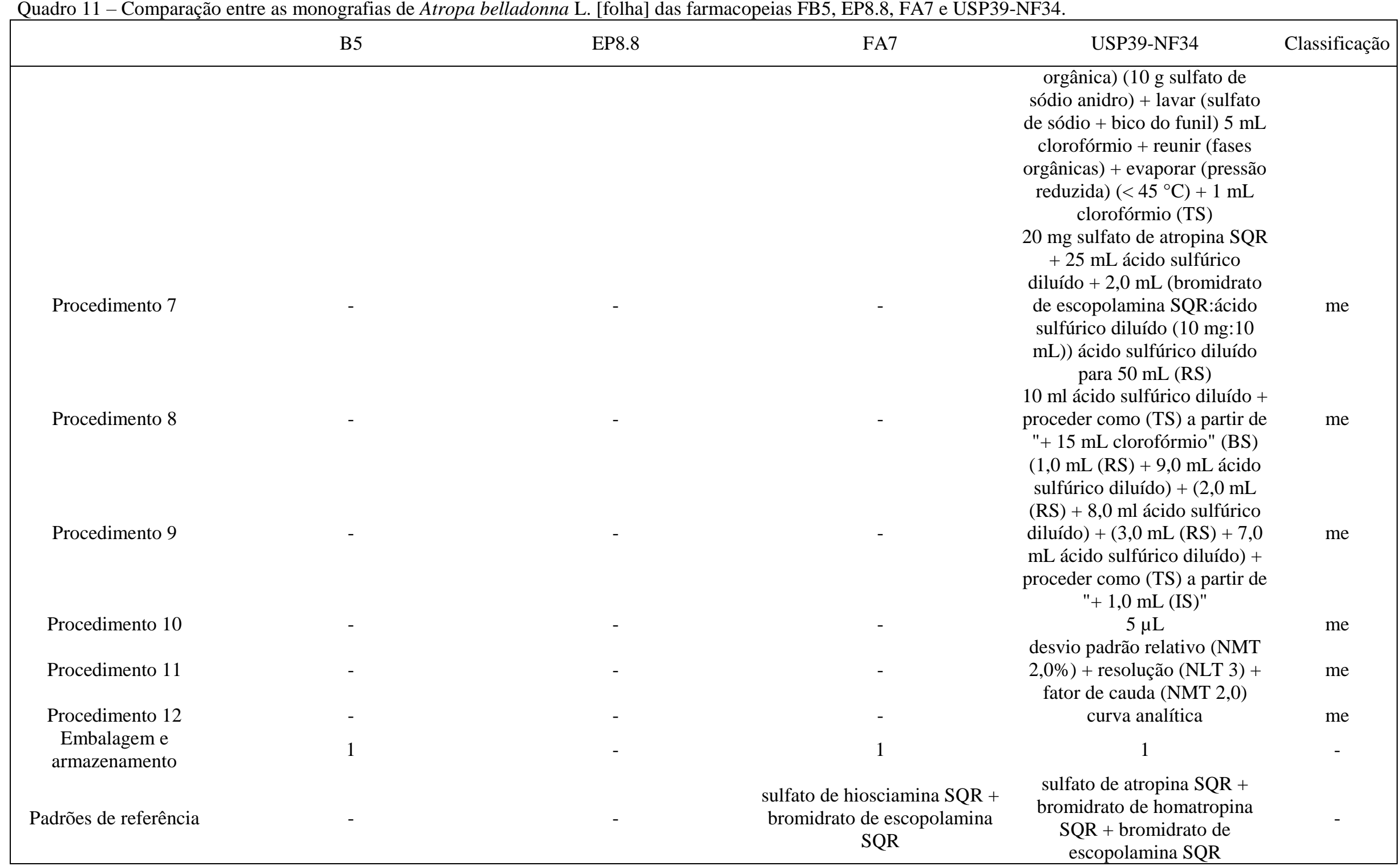


(ANMAT, 2003b; BRASIL, 2010d; EDQM, 2016b; USP, 2016h).

Legenda: $\mathrm{mi}=$ menor; $\mathrm{me}=$ moderado; $\mathrm{su}=$ substancial; se = semelhante; $\mathrm{NLT}=$ não menos que; $\mathrm{MNT}=$ não mais que; $\mathrm{MR}=$ cumpre os requisitos ou o teste; $\mathrm{CCD}=$ cromatografia em camada delgada; $\mathrm{RS}$ = solução referência; TS = solução amostra; $\mathrm{SQR}$ = substância química de referência; $\mathrm{SR}$ = solução reagente; $\mathrm{SI}$ = solução indicadora; $\mathrm{SV}=$ solução volumétrica; $\mathrm{P}=m=$ massa; $\mathrm{n}=$ volume; $\mathrm{d}$ = perda por dessecação; $\mathrm{CG}=$ cromatografia gasosa; $\mathrm{IS}$ = solução de padrão interno.

Nota: ${ }^{1}$ = a FB5 indica na descrição que o doseamento é calculado considerando a droga seca e a FA7 indica que a massa a ser utilizada no ensaio foi previamente dessecada.

(conclusão) 
No geral, as monografias da FB5, da EP8.8 e da FA7 são convergentes, e a monografia da USP39-NF34 contém diferenças mais marcantes. Em todas, os alcaloides são os marcadores, expressos em hiosciamina na FB5, na EP8.8 e na FA7 e em bromidrato de homatropina na USP39-NF34.

Há diferenças substanciais entre as drogas vegetais, sendo a monografia da FB5 a única que descreve somente as folhas, enquanto as outras reconhecem como droga vegetal as sumidades floridas ou as sumidades com folha e fruto. Há, ainda, os testes adicionais na FA7 (metais pesados, agrotóxicos, aflatoxinas), ausência do teste de determinação de água na FB5 e a diferença da especificação de cinzas totais acima de 30 \% entre a FB5 e a EP8.8 e a FA7. É importante ressaltar que estão previstos, na monografia geral Herbal Drugs da EP8.8, os testes para metais pesados e resíduos de agrotóxicos.

Como espécie que não possui ocorrência no Brasil e com registros de fitoterápicos válidos no Brasil, se esperava que as monografias fossem harmonizadas. Nesse caso, os resultados não acompanham a expectativa. Há, inicialmente, uma diferença na droga vegetal, o que pode indicar, uma vez que a origem da matéria-prima não é nacional, que a monografia na FB5, atualmente, não se correlaciona com os produtos comercializados no Brasil.

\subsubsection{Calendula officinalis L. [capítulo floral]}

A calêndula esteve presente na $4^{a}$ edição da Farmacopeia Brasileira (Quadro 3), está relacionada na FB5, no FFFB1 e na Lista de Produtos Tradicionais Fitoterápicos de Registro Simplificado (BRASIL, 2011, 2014a). Foi encontrado, para a espécie, apenas um registro de fitoterápico válido na Anvisa (Quadro 5). Conforme a literatura consultada, a espécie possui ocorrência no Brasil (Apêndice A), havendo registro de ocorrência, ainda, na Argentina, Austrália, Bolívia, Chile, China, Colômbia, Costa Rica, Equador, Guatemala, Honduras, México, Nova Zelândia, Peru e Estados Unidos da América (TROPICOS.ORG, 2016). Em buscas realizadas nos compêndios internacionais em estudo, foram localizadas monografias na EP8.8 e na FA7. Os dados extraídos das monografias estão descritos no Quadro 12. 
Quadro 12 - Comparação entre as monografias de Calendula officinalis L. [capítulo floral] das farmacopeias FB5, EP8.8 e FA7.

\begin{tabular}{|c|c|c|c|c|}
\hline & FB5 & EP8.8 & FA7 & Classificação \\
\hline Nomenclatura popular & calêndula & calendula & caléndula & - \\
\hline Droga vegetal & capítulo floral & capítulo floral & capítulo floral & - \\
\hline Marcador 1 & $\begin{array}{l}\text { flavonoides (hiperosídeo) (NLT 0,4\%) } \\
\text { (droga seca) }\end{array}$ & $\begin{array}{l}\text { flavonoides (hiperosídeo) (NLT 0,4\%) } \\
\text { (droga seca) }\end{array}$ & $\begin{array}{l}\text { flavonoides (hiperosídeo) (NLT 0,4\%) } \\
\text { (droga seca) }\end{array}$ & se \\
\hline Características & odor fraco + sabor levemente amargo & - & - & - \\
\hline Descrição macroscópica & 1 & 1 & 1 & - \\
\hline Descrição microscópica & 2 & 1 & 2 & - \\
\hline Figura botânica & 1 & 1 & 1 & - \\
\hline Identificação - método 1 & $\mathrm{CCD}$ & $\mathrm{CCD}$ & $\mathrm{CCD}$ & se \\
\hline Procedimento 1 & sílica-gel $\left(\mathrm{GF}_{254}+0,25 \mathrm{~mm}\right)$ & sílica-gel & sílica-gel (fluorescência + 0,25 mm) & se \\
\hline Procedimento 2 & $\begin{array}{l}\text { ácido fórmico anidro:água:acetato de etila } \\
\qquad(10: 10: 80)\end{array}$ & $\begin{array}{l}\text { ácido fórmico anidro:água:acetato de etila } \\
\qquad(10: 10: 80)\end{array}$ & $\begin{array}{l}\text { ácido fórmico:acetato de etila:água } \\
(80: 10: 10)\end{array}$ & me/er ${ }^{2}$ \\
\hline Procedimento 3 & $20(\mathrm{TS})(\mathrm{RS})($ banda $)$ & $20 \mu \mathrm{L}(\mathrm{TS}) ; 10 \mu \mathrm{L}(\mathrm{RS})$ (banda) & $20 \mu \mathrm{L}(\mathrm{TS})(\mathrm{RS})$ & se \\
\hline Procedimento 4 & $\begin{array}{c}1 \mathrm{~g} \text { droga vegetal pulverizada }+10 \mathrm{~mL} \\
\text { metanol }+ \text { ferver (refluxo) }\left(10^{\prime}\right)+\text { filtrar } \\
(\mathrm{TS})\end{array}$ & $\begin{array}{l}1,0 \mathrm{~g} \text { droga vegetal pulverizada }(500)+10 \\
\mathrm{~mL} \text { metanol }+ \text { aquecer (refluxo) (banho- } \\
\text { maria) }\left(10^{\prime}\right)+\text { esfriar + filtrar (TS) }\end{array}$ & $\begin{array}{c}1,0 \mathrm{~g} \text { droga vegetal pulverizada }+10,0 \mathrm{~mL} \\
\text { metanol + aquecer (refluxo) }\left(10^{\prime}\right)+\text { esfriar } \\
+ \text { filtrar (TS) }\end{array}$ & se \\
\hline Procedimento 5 & $\begin{array}{c}2,5 \mathrm{mg} \text { rutina }+1 \mathrm{mg} \text { ácido cafeico }+1 \mathrm{mg} \\
\text { ácido clorogênico + metanol para } 10 \mathrm{~mL} \\
(\mathrm{RS})\end{array}$ & $\begin{array}{c}1,0 \mathrm{mg} \text { ácido cafeico }+1,0 \mathrm{mg} \text { ácido } \\
\text { clorogênico }+2,5 \mathrm{mg} \text { rutina }+10 \mathrm{~mL} \\
\text { metanol }(\mathrm{RS})\end{array}$ & $\begin{array}{c}1,0 \mathrm{mg} \text { ácido cafeico }+1,0 \mathrm{mg} \text { ácido } \\
\text { clorogênico }+2,5 \mathrm{mg} \text { rutina }+10 \mathrm{~mL} \\
\text { metanol }(\mathrm{RS})\end{array}$ & se \\
\hline Procedimento 6 & secar $\left(100-105^{\circ} \mathrm{C}\right)$ & $\operatorname{secar}\left(100-105^{\circ} \mathrm{C}\right)$ & $\operatorname{secar}\left(100-105^{\circ} \mathrm{C}\right)$ & se \\
\hline Procedimento 7 & $\begin{array}{c}\text { difenilborato de aminoetanol } 1 \% \text { em } \\
\text { metanol + macrogol } 4005 \% \text { em metanol } \\
+ \text { secar }(\operatorname{ar})\left(30^{\prime}\right)\end{array}$ & $\begin{array}{l}\text { difenilborato de aminoetanol } 1 \% \text { em } \\
\text { metanol }+ \text { macrogol } 4005 \% \text { em metanol } \\
+ \text { secar }(\operatorname{ar})\left(30^{\prime}\right)\end{array}$ & $\begin{array}{l}\text { difenilborato de } 2 \text {-aminoetila } 1 \% \text { em } \\
\text { metanol }\end{array}$ & mi \\
\hline Procedimento 8 & $365 \mathrm{~nm}$ & $365 \mathrm{~nm}$ & $365 \mathrm{~nm}$ & se \\
\hline Procedimento 9 & descrição de zonas & descrição de zonas & descrição de zonas & se \\
\hline Testes - método 1 & matéria estranha (NMT 3,0\%) & $\begin{array}{c}\text { matéria estranha (NMT 5\% - brácteas) } \\
\text { (NMT 2\% - outros) } \\
\text { perda por dessecacão (NMT 12.0\%) }\end{array}$ & $\begin{array}{l}\text { matéria estranha (NMT 5\% - brácteas) } \\
\text { (NMT 2\% - outros) } \\
\text { perda por dessecacão (NMT } 12.0 \% \text { ) }(1.0 \mathrm{~g}\end{array}$ & su \\
\hline Testes - método 2 & água (NMT 12,0\%) $\left(100-105^{\circ} \mathrm{C}\right)(5 \mathrm{~h})^{3}$ & $\begin{array}{c}(1,000 \mathrm{~g} \text { droga vegetal pulverizada }(500)) \\
\left(105^{\circ} \mathrm{C}\right)(2 \mathrm{~h})\end{array}$ & droga vegetal pulverizada) $\left(100-105^{\circ} \mathrm{C}\right)$ & mi \\
\hline Testes - método 3 & cinzas totais (NMT 10,0\%) ${ }^{3}$ & cinzas totais (NMT 10,0\%) & cinzas totais (NMT 10,0\%) & se \\
\hline Testes - método 4 & - & - & microrganismos (MR) & - \\
\hline Testes - método 5 & - & - & aflatoxinas (MR) & su \\
\hline Testes - método 6 & - & - & metais pesados (NMT $0,001 \%$ ) & su \\
\hline Testes - método 7 & - & - & resíduos de agrotóxicos (MR) & $\begin{array}{c}\text { su } \\
\text { (conti }\end{array}$ \\
\hline
\end{tabular}


Quadro 12 - Comparação entre as monografias de Calendula officinalis L. [capítulo floral] das farmacopeias FB5, EP8.8 e FA7.

\begin{tabular}{|c|c|c|c|c|}
\hline & FB5 & EP8.8 & FA7 & Classificação \\
\hline Doseamento - método 1 & $\begin{array}{c}\text { EAVIS (flavonoides) (hiperosídeo) (NLT } \\
0,4 \% \text { ) }\end{array}$ & $\begin{array}{c}\text { EAVIS (flavonoides) (hiperosídeo) (NLT } \\
0,4 \% \text { ) }\end{array}$ & $\begin{array}{c}\text { EAVIS (flavonoides) (hiperosídeo) (NLT } \\
0,4 \% \text { ) }\end{array}$ & se \\
\hline Procedimento 1 & $\begin{array}{c}0,4 \mathrm{~g} \text { droga vegetal pulverizada }(800)+1 \\
\text { mL metenamina } 0,5 \%+20 \mathrm{~mL} \text { acetona }+ \\
2 \mathrm{~mL} \text { ácido clorídrico + aquecer (banho- } \\
\text { maria) (refluxo) (30') + filtrar (algodão) + } \\
\text { retornar (resíduo + algodão) + extrair } 20 \\
\text { mL acetona (refluxo) }\left(10^{\prime}\right)+\text { resfriar } \\
(\text { ambiente) + filtrar + repetir (extração) + } \\
\text { acetona para } 100 \mathrm{~mL}+\text { transferir } 20 \mathrm{~mL}+ \\
\text { extrair } 20 \mathrm{~mL} \text { água + extrair } 15 \mathrm{~mL} \\
\text { acetato de etila + repetir } 3 \times 10 \mathrm{~mL} \text { acetato } \\
\text { de etila + reunir (fases de acetato de etila) } \\
+ \text { lavar (fases de acetato de etila) } 2 \times 50 \\
\text { mL água + acetato de etila para } 50 \mathrm{~mL} \\
\text { (TS) }\end{array}$ & $\begin{array}{c}0,800 \mathrm{~g} \text { droga vegetal pulverizada }(500)+ \\
1 \mathrm{~mL} \text { metenamina } 0,5 \%+7 \mathrm{~mL} \text { ácido } \\
\text { clorídrico }+20 \mathrm{~mL} \text { acetona }+ \text { ferver } \\
\text { (refluxo) }\left(30^{\prime}\right)+\text { filtrar (algodão) }+ \\
\text { retornar (resíduo + algodão) + extrair } 2 \mathrm{x} \\
20 \mathrm{~mL} \text { acetona }+ \text { ferver }\left(\text { refluxo }\left(10^{\prime}\right)+\right. \\
\text { esfriar (ambiente) }+ \text { filtrar (algodão) + } \\
\text { reunir (fase acetônica) + filtrar (papel de } \\
\text { filtro) + lavar (recipiente }+ \text { filtro) com } \\
\text { acetona para } 100 \mathrm{~mL}+\text { transferir } 20 \mathrm{~mL}+ \\
20 \mathrm{~mL} \text { água }+ \text { extrair } 15 \mathrm{~mL} \text { acetato de } \\
\text { etila }+ \text { repetir } 3 \times 10 \mathrm{~mL} \text { acetato de etila }+ \\
\text { reunir (fases de acetato de etila) + lavar } \\
\text { (fases de acetato de etila) } 2 \times 50 \mathrm{~mL} \text { água } \\
+ \text { filtrar (10 g sulfato de sódio anidro) + } \\
\text { acetato de etila para } 50 \mathrm{~mL}(\mathrm{TS})\end{array}$ & $\begin{array}{c}\text { 0,800 g droga vegetal finamente } \\
\text { pulverizada }+1,0 \mathrm{~mL} \text { metenamina } 0,5 \%+ \\
20 \mathrm{~mL} \text { acetona }+7 \mathrm{~mL} \text { ácido clorídrico }+ \\
\text { aquecer (refluxo) }\left(30^{\prime}\right)+\text { filtrar (algodão) } \\
\text { + retornar (resíduo + algodão) + extrair } \\
2 \times 20 \mathrm{~mL} \text { acetona (refluxo) }\left(10^{\prime}\right)+\text { esfriar } \\
\text { (ambiente) + filtrar (algodão) + reunir } \\
\text { (extratos) + filtrar (papel de filtro) + lavar } \\
\text { (balão + filttro com acetona para } 100 \mathrm{~mL} \\
\text { + transferir } 20,0 \mathrm{~mL}+20 \mathrm{~mL} \text { água }+ \\
\text { extrair com } 1 \times 15 \mathrm{~mL} \text { acetato de etila }+3 \mathrm{x} \\
10 \mathrm{~mL} \text { acetato de etila + reunir (extratos) } \\
\text { + lavar (extratos) com } 2 \times 50 \mathrm{~mL} \text { água + } \\
\text { filtrar (10 g sulfato de sódio anidro) + } \\
\text { acetato de etila para } 50 \mathrm{~mL} \text { (TS) }\end{array}$ & $\mathrm{mi}$ \\
\hline Procedimento 2 & $\begin{array}{l}10 \mathrm{~mL} \text { (TS) + } 1 \mathrm{~mL} \text { cloreto de alumínio } \\
2 \% \text { em solução de ácido acético } 5 \% \text { em } \\
\text { metanol + ácido acético } 5 \% \text { em metanol } \\
\text { para } 25 \mathrm{~mL}\end{array}$ & $\begin{array}{c}\text { 10,0 mL (TS) + } 1 \text { mL cloreto de alumínio } \\
2 \% \text { em ácido acético glacial 5\% em } \\
\text { metanol + ácido acético glacial 5\% em } \\
\text { metanol para } 25 \mathrm{~mL}\end{array}$ & $\begin{array}{c}\text { 10,0 mL (TS) + } 1 \mathrm{~mL} \text { cloreto de alumínio } \\
2 \% \text { em ácido acético glacial } 5 \% \text { em } \\
\text { metanol + ácido acético glacial } 5 \% \mathrm{em} \\
\text { metanol para } 25 \mathrm{~mL}\end{array}$ & $\mathrm{mi} / \mathrm{er}^{4}$ \\
\hline Procedimento 3 & $\begin{array}{c}10 \mathrm{~mL} \text { (TS) + ácido acético 5\% em } \\
\text { metanol para } 25 \mathrm{~mL} \text { (BS) }\end{array}$ & $\begin{array}{c}10,0 \mathrm{~mL} \text { (TS) + ácido acético glacial 5\% } \\
\text { em metanol para } 25 \mathrm{~mL}(\mathrm{BS})\end{array}$ & $\begin{array}{l}10 \mathrm{~mL} \text { (TS) + ácido acético glacial 5\% } \\
\text { metanol para } 25 \mathrm{~mL}\end{array}$ & $\mathrm{mi} / \mathrm{er}^{4}$ \\
\hline Procedimento 4 & $425 \mathrm{~nm}\left(30^{\prime}\right)$ & $425 \mathrm{~nm}\left(30^{\prime}\right)$ & $425 \mathrm{~nm}\left(30^{\prime}\right)$ & se \\
\hline Procedimento 5 & $\mathrm{TFT}=\frac{\mathrm{A} \times 1,25}{(m-\mathrm{Dd})}$ & $\mathrm{A} \times 1,25$ & $\mathrm{~A} \times 1,25$ & se \\
\hline & $(m-\mathrm{Pd})$ & $m$ & $\mathrm{P}$ & \\
\hline armazenamento & 1 & - & 1 & - \\
\hline
\end{tabular}

(ANMAT, 2003b; BRASIL, 2010c, d; EDQM, 2016b).

Legenda: $(\mathrm{mi}=$ menor; $\mathrm{me}=$ moderado; $\mathrm{su}=$ substancial; se = semelhante; er = erro; NLT = não menos que; $\mathrm{MNT}=$ não mais que; $\mathrm{MR}=$ cumpre os requisitos ou o teste; $\mathrm{CCD}$ = cromatografia em camada delgada; $\mathrm{RS}=$ solução referência; $\mathrm{TS}$ = solução amostra; EAVIS = espectrofotometria de absorção no visível; BS = solução branco; TFT = flavonoides totais; $\mathrm{A}=$ absorvância; $m=P=$ massa; $\mathrm{Pd}=$ perda por dessecação 
Nota: ${ }^{2}=$ parece ser um erro da FA7, pois há inversão dos valores das proporções e o resultado obtido na CCD é semelhante aos das outras farmacopeias; ${ }^{3}=$ parâmetros extraídos do método geral; ${ }^{4}=$ parece haver um erro na utilização do termo ácido acético na FB5 ao invés de ácido acético glacial como nas outras farmacopeias.

(conclusão) 
No geral, as monografias são convergentes, com a mesma proposta de ensaios e testes.

As diferenças substanciais se concentram nos testes adicionais previstos na FA7 (metais pesados, aflatoxinas e resíduos de agrotóxicos). É importante ressaltar que estão previstos, na monografia geral Herbal Drugs da EP8.8, os testes para metais pesados e resíduos de agrotóxicos.

Há, ainda, diferenças, classificadas como menores ou moderadas, como a inversão na proporção do ácido fórmico anidro com o acetato de etila pela FA7 em comparação a FB5 e a EP8.8 e a omissão da informação de que o ácido acético utilizado no doseamento é glacial na FB5, que pelo caráter de inversão e omissão foram considerados como erros.

\subsubsection{Centella asiatica (L.) Urb. [folha]}

A centela esteve presente na $4^{\mathrm{a}}$ edição da Farmacopeia Brasileira (Quadro 3), não está relacionada no FFFB1 (BRASIL, 2011), estando na FB5 e na Lista de Medicamentos Fitoterápicos de Registro Simplificado (IN nº 02/2014) (BRASIL, 2014a). Foram encontrados, para a espécie, quatro registros de fitoterápicos válidos na Anvisa (Quadro 5). Conforme a literatura consultada, possui ocorrência no Brasil (Apêndice A), sendo naturalizada (REFLORA, 2016). Há, ainda, registro de ocorrência no Belize, Bolívia, Butão, Burma, Caribe, Chile, China, Colômbia, Equador, Gabão, Guatemala, Honduras, Índia, Japão, Laos, México, Nepal, Paquistão, África do Sul, Coreia do Sul, Tailândia, Estados Unidos da América, Venezuela e Vietnã (TROPICOS.ORG, 2016). Em buscas realizadas nos compêndios internacionais em estudo, foram localizadas monografias na EP8.8, na FA7 e na USP39-NF34. Os dados extraídos das monografias estão descritos no Quadro 13. 
Quadro 13 - Comparação entre as monografias de Centella asiatica (L.) Urb. [folha] das farmacopeias FB5, FA7 e USP39-NF34.

\begin{tabular}{|c|c|c|c|c|c|}
\hline & FB5 & EP8.8 & FA7 & USP39-NF34 & Classificação \\
\hline Sinonímia botânica & - & - & Hydrocotyle asiatica $\mathrm{L}$. & - & - \\
\hline Nomenclatura popular & centela & centella & centella & centella asiatica/ gotu kola & - \\
\hline Droga vegetal & folha & folha & folha & folha & se \\
\hline Marcador 1 & $\begin{array}{l}\text { asiaticosídeo (NLT 2,0\%) } \\
\text { (droga seca) }\end{array}$ & $\begin{array}{c}\text { derivados triterpênicos } \\
\text { (asiaticosídeo) (NLT 6,0\%) } \\
\text { (droga seca) }\end{array}$ & $\begin{array}{l}\text { asiaticosídeo (NLT 2,0\%) } \\
\text { (droga seca) }\end{array}$ & $\begin{array}{c}\text { derivados triterpênicos (NLT } \\
2,0 \%) \text { (droga seca) }\end{array}$ & $\mathrm{su}$ \\
\hline Descrição macroscópica & 1 & 1 & 1 & 1 & - \\
\hline Descrição microscópica & 2 & 1 & 2 & 1 & - \\
\hline Figura botânica & 2 & 1 & 1 & - & - \\
\hline Identificação - método 1 & CCD & CCD & CCD & CCD & se \\
\hline Procedimento 1 & sílica-gel $\left(\mathrm{GF}_{254}+0,25 \mathrm{~mm}\right)$ & $\begin{array}{c}\text { sílica-gel }(5-40 \mu \mathrm{m} \text { ou } 2-10 \\
\mu \mathrm{m})\end{array}$ & $\begin{array}{c}\text { sílica-gel (fluorescência }+0,25 \\
\mathrm{~mm})\end{array}$ & $\begin{array}{c}\text { sílica-gel (CCD - 10-15 } \mu \mathrm{m} \text { ou } \\
\text { CCDAE - } 5 \mu \mathrm{m})\end{array}$ & me \\
\hline Procedimento 2 & $\begin{array}{l}\text { clorofórmio:ácido acético } \\
\text { glacial:metanol:água } \\
(60: 32: 12: 8)\end{array}$ & $\begin{array}{l}\text { água:metanol:diclorometano } \\
\qquad(1: 6: 14)\end{array}$ & $\begin{array}{c}\text { butanol:2- } \\
\text { propanol:água:etanol:amoníaco } \\
\text { concentrado }(30: 30: 20: 5: 1)\end{array}$ & $\begin{array}{l}\text { diclorometano:metanol:água } \\
\qquad(14: 6: 1)\end{array}$ & me \\
\hline Procedimento 3 & $20 \mu \mathrm{L}$ (TS); $5 \mu \mathrm{L}$ (RS) (banda) & $\begin{array}{c}(10 \mu \mathrm{L} \text { ou } 4 \mu \mathrm{L})(10 \mathrm{~mm} \text { ou } 8 \\
\mathrm{mm})(\mathrm{TS})(\mathrm{RS})(\text { banda })\end{array}$ & $5 \mu \mathrm{L}+10 \mu \mathrm{L}(\mathrm{TS})(\mathrm{RS})$ & $\begin{array}{c}10 \mu \mathrm{L}(\mathrm{CCD}) \text { ou } 4 \mu \mathrm{L} \\
\text { (CCDAE) (banda) }\end{array}$ & me \\
\hline Procedimento 4 & $\begin{array}{c}3 \mathrm{~g} \text { droga vegetal }+30 \mathrm{~mL} \\
\text { etanol:água }(1: 1)+\text { ferver }+ \\
\text { filttrar + concentrar (secura) }+ \\
0,5 \mathrm{~mL} \text { metanol }(\mathrm{TS})\end{array}$ & $\begin{array}{c}0,5 \text { g droga vegetal pulverizada } \\
(355)+5 \mathrm{~mL} \text { etanol } 96 \%+ \\
\text { sonicar }\left(10^{\prime}\right)+\text { centrifugar } \\
\text { (usar sobrenadante) }(\mathrm{TS})\end{array}$ & $\begin{array}{l}5 \mathrm{~g} \text { droga vegetal finamente } \\
\text { pulverizada }+ \text { extrair (Soxhlet) } \\
\text { com metanol }(4 \mathrm{~h})+\text { filtrar }+ \\
\text { metanol para } 50 \mathrm{~mL}(\mathrm{TS})\end{array}$ & $\begin{array}{l}0,5 \mathrm{~g} \text { droga vegetal finamente } \\
\text { pulverizada }+5 \mathrm{~mL} \text { metanol }+ \\
\text { sonicar }\left(10^{\prime}\right)+\text { centrifugar } \\
\text { (usar sobrenadante) }(\mathrm{TS})\end{array}$ & me \\
\hline Procedimento 5 & $\begin{array}{c}1 \mathrm{mg} \text { asiaticosídeo }+1 \mathrm{~mL} \\
\text { metanol }(\mathrm{RS})\end{array}$ & - & $\begin{array}{c}20 \mathrm{mg} \text { asiaticosídeo }+10 \mathrm{~mL} \\
\text { metanol (RS) }\end{array}$ & $\begin{array}{c}0,5 \mathrm{mg} / \mathrm{mL} \text { asiaticosídeo } \mathrm{SQR} \\
\text { em metanol }\left(\mathrm{RS}_{1}\right) \\
10 \mathrm{mg} / \mathrm{mL} \text { extrato em pó de }\end{array}$ & $\mathrm{mi}$ \\
\hline Procedimento 6 & - & $\begin{array}{l}50 \mathrm{mg} \text { extrato seco de centella } \\
\mathrm{SQR}+2 \mathrm{~mL} \text { etanol } 96 \%(\mathrm{RS})\end{array}$ & - & $\begin{array}{l}\text { Centella SQR em metanol + } \\
\text { sonicar }\left(10^{\prime}\right)+\text { centrifugar } \\
\text { (usar sobrenadante) }\left(\mathrm{RS}_{2}\right)\end{array}$ & me \\
\hline Procedimento 7 & secar (capela) (5') & secar (ar) & secar (ar quente) & secar & $\mathrm{mi}$ \\
\hline Procedimento 8 & $\begin{array}{l}\text { 2x (anisaldeído SR + aquecer } \\
\left.\quad\left(100-105^{\circ} \mathrm{C}\right)\left(10^{\prime}\right)\right)\end{array}$ & $\begin{array}{c}\text { ácido sulfúrico } 10 \% \text { em } \\
\text { metanol + aquecer }\left(120^{\circ} \mathrm{C}\right) \\
\left(3^{\prime}\right)\end{array}$ & $\begin{array}{c}\text { anidrido acético:ácido } \\
\text { sulfúrico }(9: 1)+\text { aquecer }(100- \\
\left.110^{\circ} \mathrm{C}\right)\left(20^{\prime}\right)\end{array}$ & $\begin{array}{c}\text { ácido sulfúrico } 10 \% \text { em } \\
\text { metanol + aquecer }\left(120^{\circ} \mathrm{C}\right) \\
\left(3^{\prime}\right)\end{array}$ & $\mathrm{mi}$ \\
\hline Procedimento 9 & descrição de zonas & esquema & descrição de zonas & descrição de zonas & $\begin{array}{l}\text { mi } \\
\text { (continua) }\end{array}$ \\
\hline
\end{tabular}


Quadro 13 - Comparação entre as monografias de Centella asiatica (L.) Urb. [folha] das farmacopeias FB5, FA7 e USP39-NF34.

\begin{tabular}{|c|c|c|c|c|c|}
\hline & FB5 & EP8.8 & FA7 & USP39-NF34 & Classificação \\
\hline Identificação - método 2 & $\begin{array}{c}1 \text { g droga vegetal pulverizada } \\
\text { ou fragmentada }+10 \mathrm{~mL} \text { água } \\
+ \text { ferver }\left(2^{\prime}\right)+\text { resfriar }+ \text { agitar } \\
\quad \text { (vigorosamente) }\left(15^{\prime \prime}\right)+ \\
\text { gotejar ácido clorídrico } 10 \%= \\
\text { espuma persistente (saponinas) }\end{array}$ & - & - & - & su \\
\hline Testes - método 1 & matéria estranha (NMT 2\%) & $\begin{array}{c}\text { matéria estranha (NMT 5\% - } \\
\text { órgãos subterrâneos) (NMT } \\
2 \% \text { - outros) }\end{array}$ & matéria estranha (NMT 2\%) & $\begin{array}{c}\text { matéria estranha (NMT 7,0\% } \\
\text { (NMT 5\% - órgãos } \\
\text { subterrâneos + NMT 2\% - } \\
\text { outros) }\end{array}$ & su \\
\hline Testes - método 2 & $\begin{array}{c}\text { água (NMT 6\%) }\left(100-105^{\circ} \mathrm{C}\right) \\
(5 \mathrm{~h})^{2}\end{array}$ & $\begin{array}{c}\text { perda por dessecação (NMT } \\
12,0 \%)(1,000 \text { g droga vegetal } \\
\text { pulverizada }(355))\left(105^{\circ} \mathrm{C}\right) \\
(2 \mathrm{~h})\end{array}$ & $\begin{array}{c}\text { perda por dessecação (NMT } \\
11 \%)\end{array}$ & $\begin{array}{l}\text { perda por dessecação (NMT } \\
12,0 \%)(1,0 \mathrm{~g} \text { droga vegetal } \\
\text { finamente pulverizada) }(105 \\
\left.{ }^{\circ} \mathrm{C}\right)(2 \mathrm{~h})\end{array}$ & su \\
\hline Testes - método 3 & cinzas totais (NMT 11\%) & cinzas totais (NMT 12\%) & cinzas totais (NMT 12\%) & $\begin{array}{c}\text { cinzas totais (NMT 12\%) }(1,0 \\
\text { g droga vegetal finamente } \\
\text { pulverizada) }\end{array}$ & mi \\
\hline Testes - método 4 & - & $\begin{array}{l}\text { cinzas insolúveis em ácido } \\
\text { clorídrico (NMT 2,0\%) }\end{array}$ & - & $\begin{array}{c}\text { cinzas insolúveis em ácido } \\
\text { (NMT 3,5\%) }\end{array}$ & su \\
\hline Testes - método 5 & - & - & - & impurezas elementais (MR) & $\mathrm{su}$ \\
\hline Testes - método 6 & - & - & agrotóxicos (MR) & $\begin{array}{c}\text { agrotóxicos (MR) } \\
\text { microrganismos (TAMC - } \\
\text { NMT } 10^{5} \mathrm{CFU} / \mathrm{g}+\mathrm{TYMC}-\end{array}$ & su \\
\hline Testes - método 7 & - & - & microrganismos (MR) & $\begin{array}{c}\text { NMT } 10^{3} \mathrm{CFU} / \mathrm{g}+\mathrm{TBMC}- \\
\text { NMT } 10^{3} \mathrm{CFU} / \mathrm{g}+\text { ausência } \\
\text { Salmonella e Escherichia coli) }\end{array}$ & - \\
\hline Testes - método 8 & $\begin{array}{c}- \\
\text { índice de espuma (NMT 100) }\end{array}$ & - & aflatoxinas (MR) & - & $\mathrm{su}$ \\
\hline Índices - método 4 & $\begin{array}{l}\text { (1 g droga vegetal pulverizada } \\
\left.+100 \mathrm{~mL} \text { água }+ \text { ferver }\left(2^{\prime}\right)\right)\end{array}$ & - & - & - & $\mathrm{su}$ \\
\hline Doseamento - método 1 & $\begin{array}{l}\text { CLAE-UV (asiaticosídeo) } \\
\text { (NLT 2,0\%) }\end{array}$ & $\begin{array}{c}\text { CLAE-UV (derivados } \\
\text { triterpênicos) (asiaticosídeo) } \\
\text { (NLT } 6,0 \%)\end{array}$ & $\begin{array}{c}\text { CLAE-UV (asiaticosídeo) } \\
\text { (NLT 2,0\%) }\end{array}$ & $\begin{array}{l}\text { CLAE-UV (derivados } \\
\text { triterpênicos) (NLT 2,0\%) }\end{array}$ & su \\
\hline Procedimento 1 & $200 \mathrm{~nm}$ & $200 \mathrm{~nm}$ & $210 \mathrm{~nm}$ & $200 \mathrm{~nm}$ & $\begin{array}{l}\text { mi } \\
\text { (continua) }\end{array}$ \\
\hline
\end{tabular}


Quadro 13 - Comparação entre as monografias de Centella asiatica (L.) Urb. [folha] das farmacopeias FB5, FA7 e USP39-NF34.

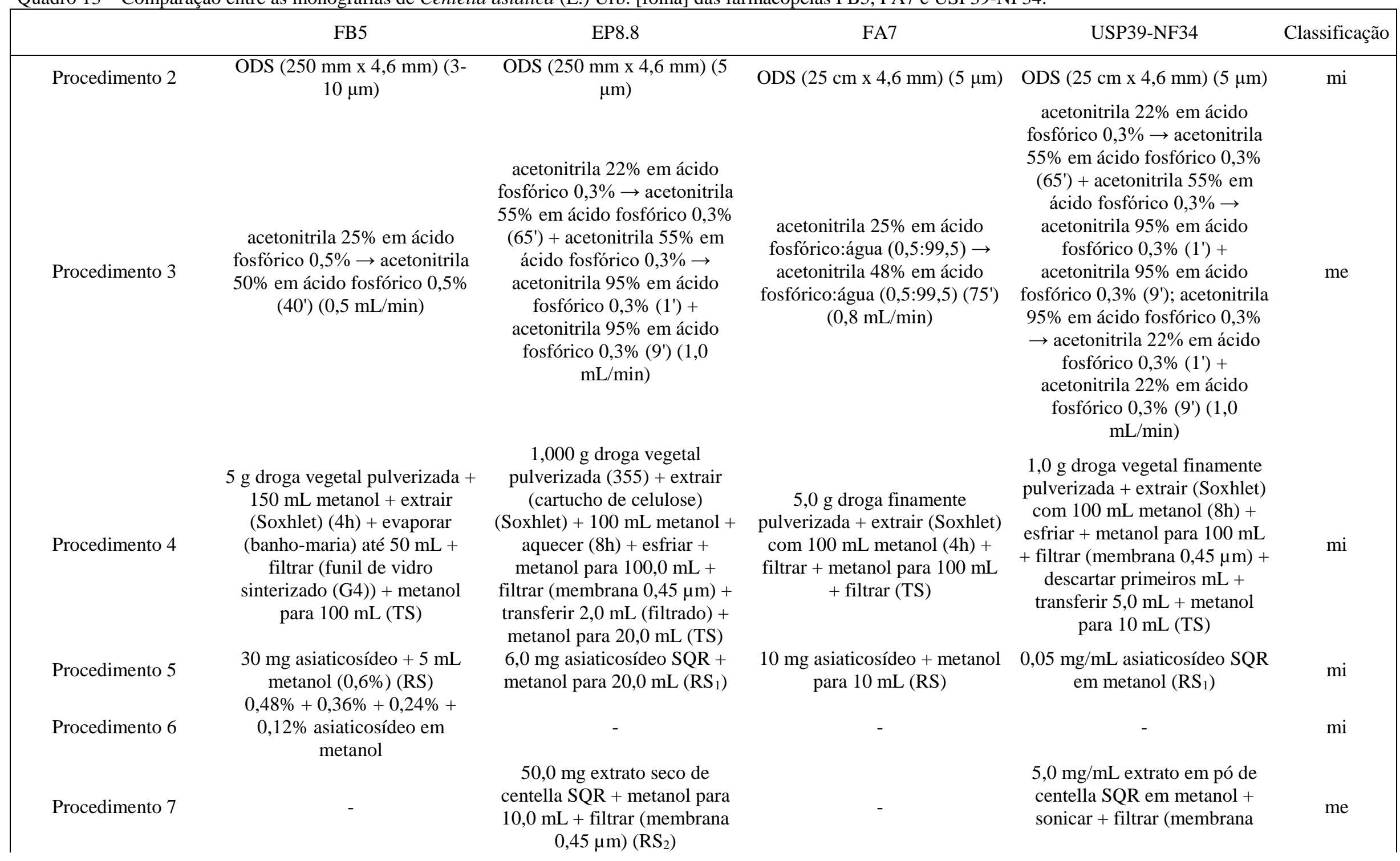


Quadro 13 - Comparação entre as monografias de Centella asiatica (L.) Urb. [folha] das farmacopeias FB5, FA7 e USP39-NF34.

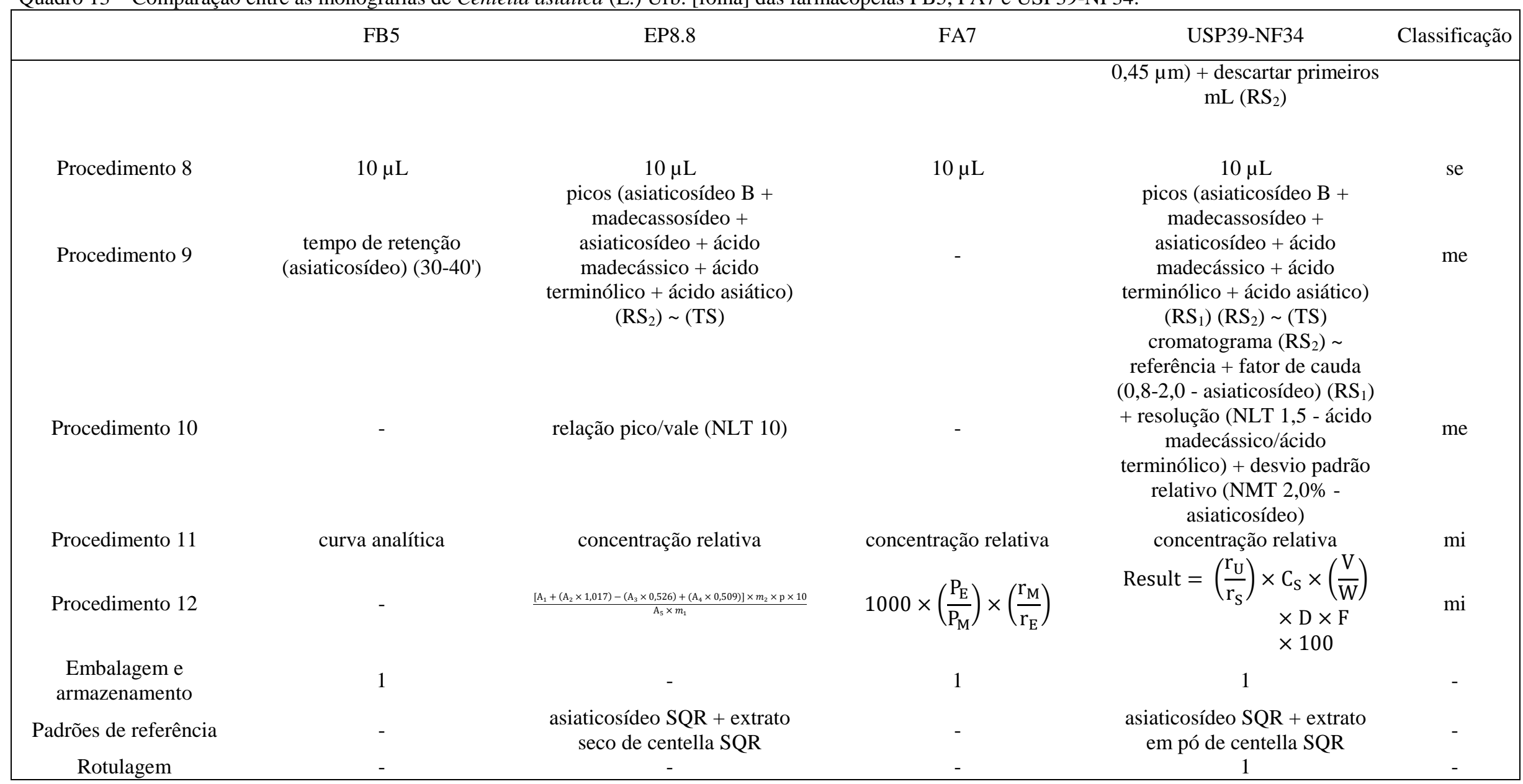

(ANMAT, 2003b; BRASIL, 2010c, d; EDQM, 2016b; USP, 2016h).

Legenda: mi $=$ menor; me $=$ moderado su $=$ substancial; se $=$ semelhante; NLT $=$ não menos que; MNT $=$ não mais que; MR $=$ cumpre os requisitos ou o teste; CCD = cromatografia em camada delgada; CCDAE = cromatografia em camada delgada de alta eficiência; RS = solução referência; TS = solução amostra; SR = solução reagente; $\mathrm{SQR}=$ substância química de referência; TAMC = contagem total de bactérias aeróbias; TBMC = contagem de bactérias Gram-negativas bile tolerantes; TYMC = contagem 
total de fungos e leveduras; UFC = unidade formadora de colônia; CLAE-UV = cromatografia liquida de alta eficiência acoplada a detector por espectrofotometria por absorção no ultravioleta; ODS = coluna cromatográfica octadecilsilanizada; $\mathrm{A}=$ absorvância; $m=\mathrm{P}=\mathrm{W}=$ massa; $\mathrm{C}=$ concentração; $\mathrm{r}=$ resposta; $\mathrm{V}=$ volume; $\mathrm{p}=$ pureza da $\mathrm{SQR} ; \mathrm{D}$ = fator de diluição; $F$ = fator de correção.

Nota: ${ }^{1}=$ parâmetros extraídos do método geral.

(conclusão) 
No geral, as monografias possuem propostas de ensaios e testes semelhantes, porém com especificações substancialmente diferentes. Há diferença substancial na especificação de asiaticosídeo e/ou derivados triterpênicos acima de 30\% para a EP8.8 quando comparadas as outras farmacopeias em estudo.

Há, ainda diferenças substanciais nas especificações acima de 30\% para os testes matéria estranha e água entre as farmacopeias, nos testes adicionais da FB5 (identificação de saponinas e índice de espuma), da FA7 (aflatoxinas e resíduos de agrotóxicos), da USP39-NF34 (cinzas insolúveis em ácido, resíduo de agrotóxicos e impurezas elementais) e da EP8.8 (cinzas insolúveis em ácido clorídrico). É importante ressaltar que estão previstos, na monografia geral Herbal Drugs da EP8.8, os testes para metais pesados e resíduos de agrotóxicos.

Diferenças nas especificações, como as encontradas, podem ocasionar barreiras sanitárias ao comércio internacional de matérias-primas e produtos acabados a depender da sua origem. Esse é um caso de um produto com ocorrência bem disseminada pelo mundo, com registros válidos de fitoterápicos no Brasil e com presença de monografia em todas as farmacopeias em estudo.

\subsubsection{Cinchona calisaya Wedd. [casca]}

A quina-amarela esteve presente em quase todas as edições da Farmacopeia Brasileira, com exceção da $4^{a}$ edição (Quadro 3), não está relacionada no FFFB1 e nem na IN nº 02/2014 (BRASIL, 2011, 2014a), estando apenas na FB5. Foram encontrados, para a espécie, apenas dois registros de fitoterápicos válidos na Anvisa (Quadro 5). Conforme a literatura consultada, a espécie não possui ocorrência no Brasil (Apêndice A), havendo registro de ocorrência ainda na Bolívia, China, Guatemala e Peru (TROPICOS.ORG, 2016). Em buscas realizadas nos compêndios internacionais em estudo, foi localizada monografia apenas na EP8.8. Os dados extraídos das monografias estão descritos no Quadro 14. 
Quadro 14 - Comparação entre as monografias de Cinchona calisaya Wedd. [casca] das farmacopeias FB5 e EP8.8.

\begin{tabular}{|c|c|c|c|}
\hline & FB5 & EP8.8 & Classificação \\
\hline Nomenclatura botânica & Cinchona calisaya Wedd. & $\begin{array}{c}\text { Cinchona pubescens Vahl, Cinchona calisaya Wedd. e } \\
\text { Cinchona ledgeriana Moens ex Trimen }\end{array}$ & - \\
\hline Sinonímia botânica & - & Cinchona pubescens Vahl (syn. Cinchona succirubra Pav.) & - \\
\hline Nomenclatura popular & quina-amarela & cinchona & - \\
\hline Droga vegetal & casca & casca & se \\
\hline Marcador 1 & alcaloides (NLT 6,0\%) & alcaloides (NLT 6,5\%) (droga seca) & $\mathrm{mi}$ \\
\hline Marcador 2 & quinina (alcaloides) $(60 \%)$ & quinina (alcaloides) $(30-60 \%)$ & mi/er ${ }^{1}$ \\
\hline Características & odor fracamente aromático + sabor amargo & sabor amargo intenso + adstringente & - \\
\hline Descrição macroscópica & 1 & 1 & - \\
\hline Descrição microscópica & 2 & 1 & - \\
\hline Figura botânica & 3 & 1 & - \\
\hline Identificação - método 1 & $\mathrm{CCD}$ & $\mathrm{CCD}$ & se \\
\hline Procedimento 1 & sílica-gel $\left(\mathrm{GF}_{254}+0,25 \mathrm{~mm}\right)$ & sílica-gel & $\mathrm{se}$ \\
\hline Procedimento 2 & clorofórmio:dietilamina (90:10) & dietilamina:acetato de etila:tolueno (10:20:70) & me \\
\hline Procedimento 3 & $15-20 \mu \mathrm{L}$ (TS); 3-5 $\mu \mathrm{L}$ (RS) & $10 \mu \mathrm{L}$ (TS) RS) (banda) & $\mathrm{mi}$ \\
\hline Procedimento 4 & $\begin{array}{c}0,1 \mathrm{~g} \text { droga vegetal pulverizada }+0,1 \mathrm{~mL} \text { hidróxido de amônio } \\
25 \%+5 \mathrm{~mL} \text { diclorometano }+ \text { repousar }(30 \text { ') (agitar } \\
\text { ocasionalmente })+ \text { filtrar }+ \text { evaporar (secura) }(\text { banho-maria })+1 \\
\text { mL etanol absoluto }(\mathrm{TS})\end{array}$ & $\begin{array}{c}0,10 \mathrm{~g} \text { droga vegetal pulverizada }+0,1 \mathrm{~mL} \text { amônia concentrada } \\
+5 \mathrm{~mL} \text { diclorometano }+ \text { agitar (ocasionalmente) } \\
\begin{array}{c}\text { (vigorosamente) }\left(30^{\prime}\right)+\text { filtrar }+ \text { evaporar (secura) (banho-maria) } \\
+1 \mathrm{~mL} \text { etanol absoluto }(\mathrm{TS})\end{array}\end{array}$ & mi \\
\hline Procedimento 5 & $\begin{array}{c}17,5 \mathrm{mg} \text { quinina }+0,5 \mathrm{mg} \text { quinidina }+10 \mathrm{mg} \text { cinchonina }+5 \mathrm{~mL} \\
\text { etanol absoluto }(\mathrm{RS})\end{array}$ & $\begin{array}{c}17,5 \mathrm{mg} \text { quinina }+2,5 \mathrm{mg} \text { quinidina }+10 \mathrm{mg} \text { cinchonina }+10 \\
\text { mg cinchonidina }+5 \mathrm{~mL} \text { etanol absoluto }(\mathrm{RS})\end{array}$ & me \\
\hline Procedimento 6 & - & desenvolver $2 \mathrm{x}$ & $\mathrm{mi}$ \\
\hline Procedimento 7 & secar $\left(100-105^{\circ} \mathrm{C}\right)\left(10^{\prime}\right)$ & $\operatorname{secar}\left(100-105^{\circ} \mathrm{C}\right)$ & $\mathrm{mi}$ \\
\hline Procedimento 8 & ácido sulfúrico $50 \%$ em etanol & ácido fórmico anidro & $\mathrm{mi}$ \\
\hline Procedimento 9 & $365 \mathrm{~nm}$ & $365 \mathrm{~nm}$ & - \\
\hline Procedimento 10 & - & reagente iodoplatinado SR & $\mathrm{mi}$ \\
\hline Procedimento 11 & descrição de zonas & esquema & $\mathrm{mi}$ \\
\hline Identificação - método 2 & $\begin{array}{l}500 \mathrm{mg} \text { droga vegetal pulverizada }+ \text { aquecer }(\text { chama })=\text { vapores } \\
\text { púrpura }+ \text { condensação nas paredes }(\text { destilado solúvel etanol })\end{array}$ & - & su \\
\hline Testes - método 1 & matéria estranha (NMT 2\%) & matéria estranha (NMT $2 \%)^{2}$ & $\mathrm{se}$ \\
\hline Testes - método 2 & água $(\mathrm{NMT} 8 \%)\left(100-105^{\circ} \mathrm{C}\right)(5 \mathrm{~h})^{3}$ & $\begin{array}{c}\text { perda por dessecação (NMT } 10 \%)(1.000 \mathrm{~g} \text { droga vegetal } \\
\text { pulverizada }(355))\left(105^{\circ} \mathrm{C}\right)(2 \mathrm{~h})\end{array}$ & me \\
\hline Testes - método 3 & cinzas totais (NMT 12,5\%) & cinzas totais (NMT 6,0\%) & su \\
\hline Doseamento -método 1 & EAUV (alcaloides) (NLT 6,0\%) & EAUV (alcaloides) (NLT 6,5\%) & $\mathrm{mi}$ \\
\hline
\end{tabular}


Quadro 14 - Comparação entre as monografias de Cinchona calisaya Wedd. [casca] das farmacopeias FB5 e EP8.8.

FB5

\begin{tabular}{|c|c|c|c|}
\hline Procedimento 1 & $\begin{array}{l}1 \text { g droga vegetal pulverizada }+10 \mathrm{~mL} \text { água }+7 \mathrm{~mL} \text { ácido } \\
\text { clorídrico } 2 M+\text { aquecer (banho-maria) }\left(30^{\prime}\right)+\text { esfriar }+25 \mathrm{~mL} \\
\text { diclorometano }+50 \mathrm{~mL} \text { éter etílico }+5 \mathrm{~mL} \text { hidróxido de sódio } \\
20 \%+\text { agitar }\left(30^{\prime}\right)+3 \mathrm{~g} \text { goma adraganta em pó }+ \text { agitar até se } \\
\text { tornar clara }+ \text { filtrar (papel de filtro) }+ \text { lavar (recipiente }+ \text { filtro) } \\
\text { com } 100 \mathrm{~mL} \text { diclorometano:éter etílico }(1: 2)+\text { reunir (líquidos } \\
\text { das lavagens) + evaporar (secura) }+10 \mathrm{~mL} \text { etanol absoluto }+ \\
\text { evaporar 5,0 mL (secura) + ácido clorídrico } 0,1 M \text { para } 1000 \mathrm{~mL} \\
\text { (TS) }\end{array}$ & $\begin{array}{c}\text { 1,000 g droga vegetal pulverizada }(180)+10 \mathrm{~mL} \text { água }+7 \mathrm{~mL} \\
\text { ácido clorídrico diluído }+ \text { aquecer (banho-maria) }\left(30^{\prime}\right)+\text { esfriar } \\
+25 \mathrm{~mL} \text { diclorometano }+50 \mathrm{~mL} \text { éter etílico }+5 \mathrm{~mL} \text { hidróxido } \\
\text { de sódio } 20 \%+\text { agitar }\left(30^{\prime}\right)+3 \text { g goma adraganta em pó }+ \text { agitar } \\
\text { até se tornar clara }+ \text { filtrar (algodão) + lavar (recipiente }+ \\
\text { algodão) } 5 \mathrm{x} 20 \mathrm{~mL} \text { diclorometano:éter etílico }(1: 2)+\text { reunir } \\
\text { (filtrados + líquidos das lavagens) + evaporar (secura) }+10 \mathrm{~mL} \\
\text { etanol absoluto + evaporar } 5,0 \mathrm{~mL}(\text { secura })+\text { ácido clorídrico } \\
0,1 M \text { para } 1000,0 \mathrm{~mL}(\mathrm{TS})\end{array}$ & mi \\
\hline Procedimento 2 & $30 \mathrm{mg}$ quinina + ácido clorídrico $0,1 \mathrm{M}$ para $100 \mathrm{~mL}\left(\mathrm{RS}_{1}\right)$ & $30,0 \mathrm{mg}$ quinina + ácido clorídrico $0,1 \mathrm{M}$ para $1000,0 \mathrm{~mL}\left(\mathrm{RS}_{1}\right)$ & $\mathrm{mi} / \mathrm{er}^{4}$ \\
\hline Procedimento 3 & $30 \mathrm{mg}$ cinchonina + ácido clorídrico $0,1 M$ para $100 \mathrm{~mL}\left(\mathrm{RS}_{2}\right)$ & $\begin{array}{c}\text { 30,0 mg cinchonina + ácido clorídrico 0,1 M para 1000,0 mL } \\
\left(\mathrm{RS}_{2}\right)\end{array}$ & $\mathrm{mi} / \mathrm{er}^{4}$ \\
\hline Procedimento 4 & ácido clorídrico $0,1 M(\mathrm{BS})$ & ácido clorídrico $0,1 M(\mathrm{BS})$ & se \\
\hline Procedimento 5 & $\begin{array}{c}316 \mathrm{~nm}+348 \mathrm{~nm} \\
{\left[\mathrm{~A}_{316} \times \mathrm{A}_{\mathrm{c} 348}\right]-\left[\mathrm{A}_{\mathrm{c} 346} \times \mathrm{A}_{348}\right] \times 100 \times 2}\end{array}$ & $\begin{array}{r}316 \mathrm{~nm}+348 \mathrm{~nm} \\
{\left[\mathrm{~A}_{316} \times \mathrm{A}_{348 \mathrm{c}}\right]-\left[\mathrm{A}_{316 \mathrm{c}} \times \mathrm{A}_{348}\right] \quad 100}\end{array}$ & se \\
\hline Procedimento 6 & $y=\frac{\left[\mathrm{A}_{\mathrm{q} 316} \times \mathrm{A}_{\mathrm{c} 348}\right]-\left[\mathrm{A}_{\mathrm{c} 316} \times \mathrm{A}_{\mathrm{q} 348}\right] \times m \times 1000}{}$ & $y=\frac{\left[A_{316 q} \times A_{348 c}\right]-\left[A_{316 c} \times A_{348 q}\right]}{m} \times \frac{}{1000}$ & $\mathrm{er}^{5}$ \\
\hline Procedimento 7 & $y=\frac{\left[\mathrm{A}_{316} \times \mathrm{A}_{\mathrm{q} 348}\right]-\left[\mathrm{A}_{\mathrm{q} 346} \times \mathrm{A}_{348}\right] \times 100 \times 2}{\left[\mathrm{~A}_{\mathrm{c} 316} \times \mathrm{A}_{\mathrm{q} 348}\right]-\left[\mathrm{A}_{\mathrm{q} 316} \times \mathrm{A}_{\mathrm{c} 348}\right] \times m \times 1000}$ & $y=\frac{\left[\mathrm{A}_{316} \times \mathrm{A}_{348 \mathrm{q}}\right]-\left[\mathrm{A}_{316 \mathrm{q}} \times \mathrm{A}_{348}\right]}{\left[\mathrm{A}_{316 \mathrm{c}} \times \mathrm{A}_{348 \mathrm{q}}\right]-\left[\mathrm{A}_{316 \mathrm{q}} \times \mathrm{A}_{348 \mathrm{c}}\right]} \times \frac{100}{m} \times \frac{2}{1000}$ & $\mathrm{er}^{5}$ \\
\hline Procedimento 8 & $(100 x)+(x+y)$ & $x+y$ & $\mathrm{er}^{4}$ \\
\hline $\begin{array}{l}\text { Embalagem e } \\
\text { armazenamento }\end{array}$ & 1 & - & - \\
\hline
\end{tabular}

(BRASIL, 2010d; EDQM, 2016b).

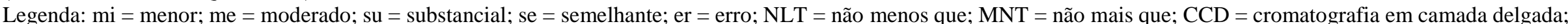
$\mathrm{RS}=$ solução referência; TS = solução amostra; $\mathrm{BS}=$ solução branco; $\mathrm{SR}=$ solução reagente; EAUV = espectrofotometria de absorção no ultravioleta; $\mathrm{A}=$ absorvância; $m=$ massa; $\mathrm{y}=$ alcaloides tipo cinchonina; $\mathrm{x}=$ alcaloides tipo quinina.

Nota: ${ }^{1}=$ a FB5 não inclui definição de NLT ou NMT para esse marcador, o que parece ser um erro ${ }^{2}=$ especificação descrita no método geral; ${ }^{3}=$ parâmetros extraídos do método geral; ${ }^{4}=$ provavelmente erros que são apresentados corrigidos na $\mathrm{CP} \mathrm{n}^{\circ} 241 / 2016 ;{ }^{5}$ = não há medida de absorção em 346 nm o que indica um erro. 
No geral, as monografias são convergentes, com a mesma proposta de ensaios e testes.

As diferenças substanciais se concentram no teste adicional da FB5 (identificação para alcaloides quinolínicos) e na diferença da especificação de cinzas totais acima de $30 \%$ entre as farmacopeias.

Há, ainda, diferenças classificadas como menores, na especificação do alcaloide quinina, na diluição da (RS) e nas três expressões de cálculos do doseamento, que foram considerados erros, tendo sido alguns corrigidos na revisão das monografias de drogas vegetais e derivados da FB5 apresentada na Consulta Pública no 241 de 05 de agosto de 2016 (BRASIL, 2016c). Não foi corrigido o erro no comprimento de onda da expressão de cálculo do teor de alcaloides, na qual é descrito que se deve inserir um resultado de absorvância em 346 nm, quando no método a absorvância de leitura prevista é em 316 nm, como na EP8.8.

Como espécie que não possui ocorrência no Brasil e com registros de fitoterápicos válidos no Brasil, se esperava que as monografias fossem mais harmonizadas, nesse caso, os resultados acompanharam a expectativa, com exceção dos erros e de duas diferenças substanciais.

\subsubsection{Cinnamomum verum J. Presl [casca]}

A canela-do-ceilão esteve presente em todas as edições da Farmacopeia Brasileira (Quadro 3), não está relacionada na IN no 02/2014 (BRASIL, 2014a), estando no FFFB1 (BRASIL, 2011) e na FB5. Foi encontrado, para a espécie, apenas um registro de fitoterápico válido na Anvisa (Quadro 5). Conforme a literatura consultada, a espécie não possui ocorrência no Brasil (Apêndice A), havendo registro de ocorrência na Bolívia, China, El Salvador, Gabão, Sri Lanka e Taiwan (TROPICOS.ORG, 2016). Em buscas realizadas nos compêndios internacionais em estudo, foram localizadas monografias na EP8.8 e na FA7. Os dados extraídos das monografias estão descritos no Quadro 15. 
Quadro 15 - Comparação entre as monografias de Cinnamomum verum J. Presl [casca] das farmacopeias FB5, EP8.8 e FA7.

\begin{tabular}{|c|c|c|c|c|}
\hline & FB5 & EP8.8 & FA7 & Classificação \\
\hline Sinonímia botânica & Cinnamonum zeylanicum Blume & - & Cinnamonum zeylanicum Nees & - \\
\hline Nomenclatura popular & canela-do-ceilão & cinnamon & canela de ceilan & - \\
\hline Droga vegetal & casca & casca & casca & se \\
\hline Marcador 1 & óleo volátil (NLT 1,2\%) & óleo volátil (NLT 1,2\%) & óleo volátil (NLT 1,2\%) & se \\
\hline Marcador 2 & $\begin{array}{l}\text { trans-cinamaldeído (óleo volátil) (NLT } \\
60,0 \%)\end{array}$ & -1 & - & su \\
\hline Características & $\begin{array}{l}\text { aroma aldeído cinâmico }+ \text { sabor picante }+ \\
\text { adocicado }\end{array}$ & odor aromático & - & - \\
\hline Descrição macroscópica & 1 & 1 & 1 & - \\
\hline Descrição microscópica & 2 & 1 & 2 & - \\
\hline Figura botânica & 1 & 1 & 1 & - \\
\hline Identificação - método 1 & CCD & CCD & $\mathrm{CCD}$ & se \\
\hline Procedimento 1 & sílica-gel $\left(\mathrm{G}_{254}+0,25 \mathrm{~mm}\right)$ & sílica-gel $\left(\mathrm{GF}_{254}\right)$ & sílica-gel (fluorescência $+0,25 \mathrm{~mm}$ ) & mi \\
\hline Procedimento 2 & diclorometano & diclorometano & diclorometano & se \\
\hline Procedimento 3 & $10 \mu \mathrm{L}(\mathrm{TS})(\mathrm{RS})(\mathrm{banda})$ & $10 \mu \mathrm{L}(20 \mathrm{~mm} \times 3 \mathrm{~mm})(\mathrm{TS})(\mathrm{RS})$ (banda) & $10 \mu \mathrm{L}$ (TS) (RS) (banda) & mi \\
\hline Procedimento 4 & $\begin{array}{c}3 \text { g droga vegetal pulverizada }+15 \mathrm{~mL} \\
\text { diclorometano }+ \text { agitar }\left(15^{\prime}\right)+\text { filtrar }+ \\
\text { evaporar (quase secura) (banho-maria) }+1 \\
\text { mL tolueno }(\mathrm{TS})\end{array}$ & $\begin{array}{l}0,1 \text { g droga vegetal pulverizada }+2 \mathrm{~mL} \\
\text { diclorometano }+ \text { agitar }\left(15^{\prime}\right)+\text { filtrar }+ \\
\text { evaporar (cuidadosamente) (quase secura) } \\
\text { (banho-maria) }+0,4 \mathrm{~mL} \text { tolueno }(\mathrm{TS})\end{array}$ & $\begin{array}{l}100 \mathrm{mg} \text { droga vegetal pulverizada }+2 \mathrm{~mL} \\
\text { diclorometano + extrair (agitação } \\
\text { contínua) }\left(15^{\prime}\right)+\text { filttrar + evaporar } \\
\text { (pressão reduzida) }+0,4 \text { mL tolueno }(\mathrm{TS})\end{array}$ & me \\
\hline Procedimento 5 & $10 \mu \mathrm{L}$ eugenol $+1 \mathrm{~mL}$ tolueno $(\mathrm{RS})$ & $\begin{array}{l}50 \mu \mathrm{L} \text { cinamaldeído }+10 \mu \mathrm{L} \text { eugenol }+ \\
\text { tolueno para } 10 \mathrm{~mL}(\mathrm{RS})\end{array}$ & $\begin{array}{l}50 \mu \mathrm{L} \text { cinamaldeído }+10 \mu \mathrm{L} \text { eugenol }+ \\
\text { tolueno para } 10,0 \mathrm{~mL}(\mathrm{RS})\end{array}$ & me \\
\hline Procedimento 6 & secar (ar) & secar (ar) & secar $(\operatorname{ar})$ & se \\
\hline Procedimento 7 & $\begin{array}{l}\text { vanilina sulfúrica } S R+\text { aquecer (100-105 } \\
\left.{ }^{\circ} \mathrm{C}\right)\left(5^{\prime}\right)\end{array}$ & $254 \mathrm{~nm}+365 \mathrm{~nm}$ & $254 \mathrm{~nm}+365 \mathrm{~nm}$ & mi \\
\hline Procedimento 8 & - & solução de floroglucinol SR & floroglucinol SR & mi \\
\hline Procedimento 9 & descrição de zonas & descrição de zonas & descrição de zonas & mi \\
\hline Identificação - método 2 & $\begin{array}{c}0,05 \mathrm{~mL} \text { óleo volátil }+5 \mathrm{~mL} \text { etanol }+0,05 \\
\mathrm{~mL} \text { cloreto férrico } 5 \%=\text { azul }(\text { compostos } \\
\text { fenólicos })\end{array}$ & - & 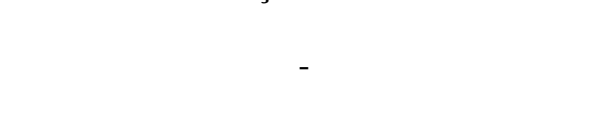 & su \\
\hline Testes - método 1 & matéria estranha (NMT 2,0\%) & matéria estranha (NMT 2,0\%) ${ }^{2}$ & matéria estranha (ausência) & su \\
\hline Testes - método 2 & cinzas totais (NMT 5,0\%) & cinzas totais (NMT 6,0\%) & cinzas totais (NMT 6,0\%) & me \\
\hline Testes - método 3 & - & - & microrganismos (MR) & - \\
\hline Testes - método 4 & - & - & aflatoxinas (MR) & su \\
\hline Testes - método 5 & - & - & metais pesados (NMT $0,001 \%$ ) & $\mathrm{su}$ \\
\hline
\end{tabular}


Quadro 15 - Comparação entre as monografias de Cinnamomum verum J. Presl [casca] das farmacopeias FB5, EP8.8 e FA7.

\begin{tabular}{|c|c|c|c|c|}
\hline & FB5 & EP8.8 & FA7 & Classificação \\
\hline Testes - método 6 & - & - & $\begin{array}{c}\text { perda por dessecação (NMT } 12 \%)(2,0 \mathrm{~g} \\
\text { droga vegetal pulverizada) }\left(100-105{ }^{\circ} \mathrm{C}\right) \\
(2 \mathrm{~h})\end{array}$ & su \\
\hline Testes - método 7 & - & - & agrotóxicos (MR) & su \\
\hline Doseamento - método 1 & destilação (óleo volátil) (NLT 1,2\%) & destilação (óleo volátil) (NLT 1,2\%) & destilação (óleo volátil) (NLT 1,2\%) & se \\
\hline Procedimento 1 & $500 \mathrm{~mL}$ água & $200 \mathrm{~mL}$ ácido clorídrico $0,1 \mathrm{M}$ & $200 \mathrm{~mL}$ ácido clorídrico $0,1 \mathrm{M}$ & me \\
\hline Procedimento 2 & - & $0,50 \mathrm{~mL}$ xileno & $0,5 \mathrm{~mL}$ xileno & me \\
\hline Procedimento 3 & $\begin{array}{c}50 \text { g droga vegetal (pó grosseiro + } \\
\text { imediata determinação) }\end{array}$ & $\begin{array}{c}20,0 \text { g droga vegetal (pó grosseiro (710) + } \\
\text { imediata determinação) }\end{array}$ & $\begin{array}{c}20,0 \mathrm{~g} \text { droga vegetal pulverizada (imediata } \\
\text { determinação) }\end{array}$ & $\mathrm{mi}$ \\
\hline Procedimento 4 & $4 \mathrm{~h}$ & $2,5-3,5 \mathrm{~mL} / \mathrm{min}(3 \mathrm{~h})$ & $2,5-3,5 \mathrm{~mL} / \mathrm{min}(3 \mathrm{~h})$ & me \\
\hline Doseamento - método 2 & CG (trans-cinamaldeído) (NLT 60,0\%) & - & - & su \\
\hline Procedimento 1 & $\begin{array}{l}\text { ionização por chama (nitrogênio:ar } \\
\text { sintético:hidrogênio }(1: 1: 10))\end{array}$ & - & - & su \\
\hline Procedimento 2 & hélio (1 mL/minuto) & - & - & su \\
\hline Procedimento 3 & $\begin{array}{l}\text { coluna - }(30 \mathrm{~m} \times 0,25 \mathrm{~mm})+\text { filme - } \\
\text { polidifenildimetilsiloxano }(0,25 \mu \mathrm{m})\end{array}$ & - & - & su \\
\hline Procedimento 4 & injetor $220^{\circ} \mathrm{C}+$ detector $250{ }^{\circ} \mathrm{C}$ & - & - & su \\
\hline Procedimento 5 & $60 \rightarrow 300{ }^{\circ} \mathrm{C}\left(3^{\circ} \mathrm{C} / 1^{\prime}\right)$ & - & - & su \\
\hline Procedimento 6 & óleo volátil:éter etílico (2:100) (TS) & - & - & su \\
\hline Procedimento 7 & $1 \mu \mathrm{L}+$ divisão de fluxo (1:50) & - & - & su \\
\hline Procedimento 8 & concentração relativa & - & - & su \\
\hline Procedimento 9 & $\begin{array}{l}\text { IRR (aldeído cinâmico Z - } 1266 \text { + E - } \\
\text { 1214) }\end{array}$ & - & - & su \\
\hline $\begin{array}{l}\text { Embalagem e } \\
\text { armazenamento }\end{array}$ & 1 & - & 1 & - \\
\hline
\end{tabular}

(ANMAT, 2003b; BRASIL, 2010d; EDQM, 2016b).

Legenda: $\mathrm{mi}=$ menor; $\mathrm{me}=$ moderado; su = substancial; se = semelhante; $\mathrm{er}=$ erro; $\mathrm{NLT}=$ não menos que; $\mathrm{MNT}=$ não mais que; $\mathrm{MR}=$ cumpre os requisitos ou o teste; $\mathrm{CD}$ = cromatografia em camada delgada; $\mathrm{RS}$ = solução referência; $\mathrm{TS}$ = solução amostra; $\mathrm{SR}$ = solução reagente; $\mathrm{CG}$ = cromatografia gasosa; IRR = índice de retenção relativo. Nota: ${ }^{1}=$ há uma monografia na EU8.8 específica para o óleo volátil $;{ }^{2}=$ especificação extraída do método geral. 
No geral, as monografias possuem ensaios e testes semelhantes, e algumas diferenças substanciais.

Uma diferença substancial importante é que a monografia da FB5 estabelece para a droga vegetal da canela-do-ceilão requisitos para o seu óleo vegetal de NLT 60,0\% de transcinamaldeído, enquanto que a EP8.8 apresenta especificações para o óleo volátil apenas na monografia específica para o óleo volátil (EDQM, 2016c), que não foi alvo deste estudo.

Há diferenças substanciais nos testes adicionais da FB5 (identificação de compostos fenólicos), da FA7 (metais pesados, resíduos de agrotóxicos, aflatoxinas e perda por dessecação) e na especificação de ausência de matéria estranha da FA7. É importante ressaltar que estão previstos, na monografia geral Herbal Drugs da EP8.8, os testes para metais pesados e resíduos de agrotóxicos.

Como espécie que não possui ocorrência no Brasil e com registros de fitoterápicos válidos no Brasil, se esperava que as monografias fossem mais harmonizadas. Nesse caso, os resultados não acompanharam a expectativa. As diferenças substanciais encontradas, com destaque para a especificação para o óleo volátil na droga vegetal, podem ocasionar em barreiras sanitárias ao comércio internacional de matérias-primas e produtos acabados.

\subsubsection{Citrus aurantium L. subsp. aurantium [exocarpo]}

A laranja-amarga esteve presente na $1^{\mathrm{a}}$ e $2^{\mathrm{a}}$ edição da Farmacopeia Brasileira (Quadro 3), não está relacionada na IN nº 02/201 (BRASIL, 2014a), estando no FFFB1 (espécie Citrus aurantium L.) (BRASIL, 2011) e na FB5. Não foram encontrados, para a espécie, registros de fitoterápicos válidos na Anvisa (Quadro 5). Conforme a literatura consultada, a espécie Citrus aurantium L. possui ocorrência no Brasil (Apêndice A), sendo naturalizada (REFLORA, 2016). Há registro, ainda, de ocorrência da espécie Citrus aurantium L. na Argentina, Bolívia, Caribe, China, Colômbia, Costa Rica, El Salvador, Índia, Panamá, Paraguai, Estados Unidos da América e Venezuela (TROPICOS.ORG, 2016). Em buscas realizadas nos compêndios internacionais em estudo, foi localizada monografia apenas na EP8.8. Os dados extraídos das monografias estão descritos no Quadro 16. 
Quadro 16 - Comparação entre as monografias de Citrus aurantium L. subsp. aurantium [exocarpo] das farmacopeias FB5 e EP8.8.

\begin{tabular}{|c|c|c|c|}
\hline & FB5 & EP8.8 & Classificação \\
\hline Sinonímia botânica & Citrus aurantium L. subsp. amara (L.) Engl. & Citrus aurantium L. subsp. amara (L.) Engl. & - \\
\hline Nomenclatura popular & laranja-amarga & bitter-orange & - \\
\hline Droga vegetal & exocarpo & exocarpo & se \\
\hline Marcador 1 & óleo volátil (NLT 2,0\%) & óleo volátil (NLT 2,0\%) (droga seca) & se/er ${ }^{1}$ \\
\hline Características & odor forte aromático + sabor aromático muito + amargo & - & - \\
\hline Descrição macroscópica & 1 & 1 & - \\
\hline Descrição microscópica & 2 & 1 & - \\
\hline Figura botânica & 2 & 1 & - \\
\hline Identificação -método 1 & $\mathrm{CCD}$ & CCD & se \\
\hline Procedimento 1 & sílica-gel $\left(\mathrm{G}_{254}+0,25 \mathrm{~mm}\right)$ & sílica-gel & se \\
\hline Procedimento 2 & água:ácido fórmico:acetato de etila (10:15:75) & água:ácido fórmico anidro:acetato de etila (10:15:75) & se \\
\hline Procedimento 3 & $20 \mu \mathrm{L}(\mathrm{TS})(\mathrm{RS})$ (banda) & $20 \mu \mathrm{L}(\mathrm{TS})(\mathrm{RS})$ (banda) & se \\
\hline Procedimento 4 & $\begin{array}{c}1 \mathrm{~g} \text { droga vegetal pulverizada }(710)+10 \mathrm{~mL} \text { metanol }+ \text { aquecer } \\
\left.(\text { banho-maria })\left(60^{\circ} \mathrm{C}\right)\left(10^{\prime}\right)+\text { agitar (frequentemente }\right)+ \text { esfriar }+ \\
\text { filtrar }(\mathrm{TS})\end{array}$ & $\begin{array}{c}1,0 \mathrm{~g} \text { droga vegetal pulverizada }(710)+10 \mathrm{~mL} \text { metanol }+ \\
\text { aquecer (banho-maria) }\left(65^{\circ} \mathrm{C}\right)\left(5^{\prime}\right)+\text { agitar }+ \text { esfriar }+ \text { filtrar } \\
(\mathrm{TS})\end{array}$ & mi \\
\hline Procedimento 5 & $1 \mu \mathrm{g}$ naringina $+10,0 \mu \mathrm{g}$ ácido cafeico $+1 \mathrm{~mL}$ metanol $(\mathrm{RS})$ & 1,0 mg naringina $+1,0 \mathrm{mg}$ ácido cafeico $+1 \mathrm{~mL}$ metanol $(\mathrm{RS})$ & mi \\
\hline Procedimento 6 & secar (ar) & secar $(\operatorname{ar})+$ aquecer $\left(110-120^{\circ} \mathrm{C}\right)\left(5^{\prime}\right)$ & $\mathrm{mi}$ \\
\hline Procedimento 7 & difenilborato de aminoetanol $1 \%$ em metanol & $\begin{array}{l}\text { difenilborato de aminoetanol 1,0\% em metanol + macrogol } 400 \\
5,0 \% \text { em metanol + descansar }(1 \mathrm{~h})\end{array}$ & $\mathrm{mi}$ \\
\hline Procedimento 8 & $365 \mathrm{~nm}$ & $365 \mathrm{~nm}$ & se \\
\hline Procedimento 9 & descrição de zonas & esquema & mi \\
\hline Testes - método 1 & água (NMT 10\%) (20,0 g droga vegetal pulverizada (355)) & $\begin{array}{c}\text { água (NMT 10\%) (destilação) (20,0 g droga vegetal pulverizada } \\
(355))\end{array}$ & se \\
\hline Testes - método 2 & cinzas totais (NMT 7,0\%) & cinzas totais (NMT 7,0\%) & se \\
\hline Testes - método 3 & & $\begin{array}{c}\text { matéria extraível (NLT 25,0\%) }(2,000 \mathrm{~g} \text { droga vegetal } \\
\text { pulverizada }(250)+10,0 \mathrm{~mL} \text { água:etanol }(96 \%)(30: 70)+\text { extrair } \\
\text { (agitação frequente) }(2 \mathrm{~h})+\text { filtrar + evaporar } 2,000 \mathrm{~mL} \text { (secura) } \\
\text { (banho-maria) + secar }\left(100-105{ }^{\circ} \mathrm{C}\right)(3 \mathrm{~h})+\text { esfriar }(\text { dessecador }) \\
\text { (pentóxido de fósforo }+ \text { pesar }(\mathrm{NLT} 0,100 \mathrm{~g}))\end{array}$ & su \\
\hline Doseamento - método 1 & destilação (óleo volátil) (NLT 2,0\%) & destilação (óleo volátil) (NLT 2,0\%) & se \\
\hline Procedimento 1 & 200 mL água & 200 mL água & se \\
\hline Procedimento 2 & $0,5 \mathrm{~mL}$ xileno & $0,50 \mathrm{~mL}$ xileno & se \\
\hline Procedimento 3 & $15 \mathrm{~g}$ droga vegetal pulverizada (710) (imediata determinação) & 15,0 g droga vegetal pulverizada (710) (imediata determinação) & se \\
\hline Procedimento 4 & $\left(90^{\prime}\right)$ & $2-3 \mathrm{~mL} / \mathrm{min}\left(90^{\prime}\right)$ & $\begin{array}{l}\text { me } \\
\text { (contir }\end{array}$ \\
\hline
\end{tabular}


Quadro 16 - Comparação entre as monografias de Citrus aurantium L. subsp. aurantium [exocarpo] das farmacopeias FB5 e EP8.8.

Quadro 16 - Comparação entre as monografias de Citrus aurantium L. subsp. aurantium [exocarpo] das farmacopeias FB5 e EP8.8.
\begin{tabular}{|ccc|}
\hline & FB5 & EP8.8 \\
\hline $\begin{array}{c}\text { Embalagem e } \\
\text { armazenamento }\end{array}$ & 1 & - \\
Classificação & - \\
\hline
\end{tabular}

(BRASIL, 2010d; EDQM, 2016b).

Legenda: mi = menor; me = moderado; su = substancial; se = semelhante; er = erro; NLT = não menos que; MNT = não mais que; CCD = cromatografia em camada delgada;

RS = solução referência; TS = solução amostra.

Nota: ${ }^{1}=$ não há na monografia e nem no método geral indicação de que a base do cálculo é a droga seca, o que indica um erro ou omissão. 
No geral, as monografias são convergentes, possuindo como única diferença substancial o teste adicional de matéria extraível na EP8.8.

Há, ainda, a ausência na FB5 da indicação de que o óleo volátil deve ser calculado sem considerar a massa de água da droga vegetal, obtida na determinação de água, o que por ser uma omissão foi considerada um erro. Ainda, o método para determinação de óleo volátil na FB5 (BRASIL, 2010c) é bem semelhante ao da EP8.8 (EDQM, 2016b), porém a EP8.8 sempre esclarece, nas monografias específicas, a necessidade de se considerar a droga seca enquanto a FB5 não apresenta essa informação.

Como a espécie possui ocorrência no Brasil e em outros países, está listada no FFFB1 e possui monografia na FB5 convergente com a EP8.8, facilitando com que empresas multinacionais possam cumprir os requisitos para obter autorização de comercialização no Brasil, se esperava que houvesse registros válidos no Brasil, porém, nesse caso, os resultados não acompanharam a expectativa.

\subsubsection{Cola nitida (Vent.) Schott \& Endl. [cotilédone]}

A noz-de-cola esteve presente em quase todas as edições da Farmacopeia Brasileira, não tido sido contemplada apenas na $3^{\text {a }}$ edição (Quadro 3), não está relacionada no FFFB1 e nem na IN nº 02/2014 (BRASIL, 2011, 2014a), estando apenas na FB5. Não foram encontrados, para a espécie, registros de fitoterápicos válidos na Anvisa (Quadro 5). Conforme a literatura consultada, a espécie não possui ocorrência no Brasil (Apêndice A), havendo registro de ocorrência em Honduras (TROPICOS.ORG, 2016). Em buscas realizadas nos compêndios internacionais em estudo, foram localizadas monografias na EP8.8 e na FA7. Os dados extraídos das monografias estão descritos no Quadro 17. 
Quadro 17 - Comparação entre as monografias de Cola nitida (Vent.) Schott \& Endl. [cotilédone] das farmacopeias FB5, EP8.8 e FA7.

\begin{tabular}{|c|c|c|c|c|}
\hline & FB5 & EP8.8 & FA7 & Classificação \\
\hline Nomenclatura botânica & Cola nitida (Vent.) Schott \& Endl. & $\begin{array}{l}\text { Cola nítida (Vent.) Schott \& Endl. e Cola } \\
\text { acuminata (P. Beauv.) Schott \& Endl. } \\
\text { Cola nítida (Vent.) Schott \& Endl. (syn. } \\
\text { Cola vera K. Schum.) e Cola acuminata } \\
\text { (P. Beauv.) Schott \& Endl. (syn. Sterculia } \\
\text { acuminata P. Beauv.) }\end{array}$ & $\begin{array}{l}\text { Cola nítida (Vent.) Schott \& Endl. e Cola } \\
\text { acuminata (P. Beauv.) Schott \& Endl. } \\
\text { Cola nítida (Vent.) Schott \& Endl. (syn. } \\
\text { Cola vera K. Schum.) e Cola acuminata } \\
\text { (P. Beauv.) Schott \& Endl. (syn. Sterculia } \\
\text { acuminata P. Beauv.) }\end{array}$ & - \\
\hline Nomenclatura popular & noz-de-cola & cola & cola & - \\
\hline Droga vegetal & cotilédones & cotilédones & cotilédones & se \\
\hline Marcador 1 & taninos totais (NLT 1,7\%) & - & - & su \\
\hline Marcador 2 & cafeína (NLT 2,0\%) & cafeína (NLT 1,5\%) (droga seca) & cafeína (NLT 1,5\%) (droga seca) & me/er ${ }^{1}$ \\
\hline Características & $\begin{array}{c}\text { sabor adstringente }+ \text { amargo }+ \text { odor quase } \\
\text { nulo }\end{array}$ & - & - & - \\
\hline Descrição macroscópica & 1 & 1 & 1 & - \\
\hline Descrição microscópica & 2 & 1 & 1 & - \\
\hline Figura botânica & 1 & - & 1 & - \\
\hline Identificação - método 1 & $\mathrm{CCD}$ & $\mathrm{CCD}$ & $\mathrm{CCD}$ & se \\
\hline Procedimento 1 & sílica-gel $\left(\mathrm{G}_{254}+0,25 \mathrm{~mm}\right)$ & sílica-gel $F_{254}$ & sílica-gel (fluorescência + 0,25 mm) & $\mathrm{mi}$ \\
\hline Procedimento 2 & $\begin{array}{l}\text { acetato de etila:metanol:água } \\
\qquad(100: 13,5: 10)\end{array}$ & água:metanol:acetato de etila (10:13:77) & água:acetato de etila:metanol (10:77:13) & me \\
\hline Procedimento 3 & 5-10 $\mu \mathrm{L}$ (TS); $2-3 \mu \mathrm{L}$ (RS) (banda) & $20 \mu \mathrm{L}$ (TS) (RS) (banda) & $20 \mu \mathrm{L}(\mathrm{TS})(\mathrm{RS})$ & me \\
\hline Procedimento 4 & $\begin{array}{l}\text { droga vegetal pulverizada } 2 \%+\text { extrair } \\
\text { (refluxo) }\left(15^{\prime}\right) \text { com etanol }+ \text { filtrar }(\mathrm{TS})\end{array}$ & $\begin{array}{c}1,0 \mathrm{~g} \text { droga vegetal pulverizada }(355)+5 \\
\text { mL etanol a } 60 \%+\text { agitar } \\
(\text { mecanicamente })\left(40{ }^{\circ} \mathrm{C}\right)\left(30^{\prime}\right)+\text { filtrar } \\
(\mathrm{TS})\end{array}$ & $\begin{array}{c}1,0 \mathrm{~g} \text { droga finamente pulverizada }+5,0 \\
\mathrm{~mL} \text { etanol } 60 \%+\text { extrair (agitação } \\
\text { contínua) }\left(40^{\circ} \mathrm{C}\right)\left(30^{\prime}\right)\end{array}$ & me \\
\hline Procedimento 5 & $\begin{array}{c}10 \text { mg cafeína SQR + } 2 \mathrm{~mL} \text { etanol } \\
\text { absoluto (TS) }\end{array}$ & 25 mg cafeína $+10 \mathrm{~mL}$ etanol a $60 \%$ & $\begin{array}{c}25 \text { mg cafeína }+10 \mathrm{~mL} \text { etanol a } 60 \% \\
\left(\mathrm{RS}_{1}\right)\end{array}$ & $\mathrm{mi}$ \\
\hline Procedimento 6 & - & $\begin{array}{c}50 \mathrm{mg} \text { teobromina em } 10 \mathrm{~mL} \\
\text { água:metanol:acetato de etila }(10: 13: 77)+ \\
\text { filtrar }\left(\mathrm{RS}_{2}\right)\end{array}$ & $\begin{array}{l}50 \mathrm{mg} \text { teobromina em } 10 \mathrm{~mL} \text { água:acetato } \\
\text { de etila:metanol }(10: 77: 13)\left(\mathrm{RS}_{2}\right)\end{array}$ & me \\
\hline Procedimento 7 & secar (ar) & secar $(\operatorname{ar})\left(5^{\prime}\right)$ & secar $(\operatorname{ar})\left(5^{\prime}\right)$ & $\mathrm{mi}$ \\
\hline Procedimento 8 & $254 \mathrm{~nm}$ & $254 \mathrm{~nm}$ & $254 \mathrm{~nm}$ & se \\
\hline Procedimento 9 & $\begin{array}{l}\text { iodeto de potássio e subnitrato de bismuto } \\
\text { SR + nitrito de sódio } 5 \%\end{array}$ & $\begin{array}{l}\text { etanol 96\%:ácido clorídrico }(1: 1)+(1,0 \mathrm{~g} \\
\text { iodo }+1,0 \mathrm{~g} \text { iodeto de potássio }+100 \mathrm{~mL} \\
\text { etanol (imediata utilização) })\end{array}$ & $\begin{array}{l}\text { etanol:ácido clorídrico concentrado }(1: 1) \\
+(1,0 \mathrm{~g} \text { iodo }+1,0 \mathrm{~g} \text { iodeto de potássio }+ \\
100 \mathrm{~mL} \text { etanol (imediata utilização }))\end{array}$ & $\mathrm{mi}$ \\
\hline Procedimento 10 & descrição de zonas & descrição de zonas & descrição de zonas & $\begin{array}{l}\text { me } \\
\text { (continua) }\end{array}$ \\
\hline
\end{tabular}


Quadro 17 - Comparação entre as monografias de Cola nitida (Vent.) Schott \& Endl. [cotilédone] das farmacopeias FB5, EP8.8 e FA7.

\begin{tabular}{|c|c|c|c|c|}
\hline & FB5 & EP8.8 & FA7 & Classificação \\
\hline Testes - método 1 & matéria estranha (NMT 3,0\%) & matéria estranha (NMT $2,0 \%)^{2}$ & matéria estranha (ausência) & su \\
\hline Testes - método 2 & água (NMT $15,0 \%)\left(100-105^{\circ} \mathrm{C}\right)(5 \mathrm{~h})^{3}$ & $\begin{array}{c}\text { perda por dessecação (NMT } 12,0 \%)(2,00 \\
\text { g droga vegetal pulverizada) }\left(100-105{ }^{\circ} \mathrm{C}\right) \\
(2 \mathrm{~h})\end{array}$ & $\begin{array}{l}\text { perda por dessecação (NMT } 12 \%)(2,0 \mathrm{~g} \\
\text { droga vegetal pulverizada) }\left(100-105^{\circ} \mathrm{C}\right) \\
(2 \mathrm{~h})\end{array}$ & me \\
\hline Testes - método 3 & cinzas totais (NMT 5,0\%) & cinzas totais (NMT 9,0\%) & cinzas totais (NMT 9,0\%) & $\mathrm{su}$ \\
\hline Testes - método 4 & - & - & microrganismos (MR) & - \\
\hline Testes - método 5 & - & - & aflatoxinas (MR) & su \\
\hline Testes - método 6 & - & - & metais pesados (NMT $0,001 \%$ ) & su \\
\hline Testes - método 7 & - & - & agrotóxicos (MR) & su \\
\hline Doseamento - método 1 & EAVIS (taninos totais) (NLT 1,7\%) & - & - & su \\
\hline Procedimento 1 & $\begin{array}{l}\text { proteger da luz + água isenta de dióxido } \\
\text { de carbono }\end{array}$ & - & - & su \\
\hline Procedimento 2 & $\begin{array}{l}0,75 \mathrm{~g} \text { droga vegetal pulverizada }+150 \\
\mathrm{~mL} \text { água }+ \text { aquecer (fervura) (banho- } \\
\text { maria) }\left(80-90^{\circ} \mathrm{C}\right)\left(30^{\prime}\right)+\text { resfriar + água } \\
\text { para } 250 \mathrm{~mL}+\text { decantar + filtrar (papel de } \\
\text { filtro })+ \text { desprezar primeiros } 50 \mathrm{~mL}+ \\
\text { transferir } 5 \mathrm{~mL}+\text { água para } 25 \mathrm{~mL}(\mathrm{TS} 1)\end{array}$ & - & - & $\mathrm{su}$ \\
\hline Procedimento 3 & $\begin{array}{l}20 \mathrm{~mL} \text { (filtrado) + 0,2 g pó de pele } \mathrm{SQR}+ \\
\text { agitar (vigorosamente) }\left(60^{\prime}\right)+\text { filtrar }+ \\
\text { transferir } 5 \mathrm{~mL}+\text { água para } 25 \mathrm{~mL}(\mathrm{TS} 2)\end{array}$ & - & - & $\mathrm{su}$ \\
\hline Procedimento 4 & $\begin{array}{l}50 \mathrm{mg} \text { pirogalol + água para } 100 \mathrm{~mL}+ \\
\text { transferir } 5 \mathrm{~mL} \text { + água para } 100 \mathrm{~mL}(\mathrm{RS})\end{array}$ & - & - & $\mathrm{su}$ \\
\hline Procedimento 5 & água (BS) & - & - & su \\
\hline Procedimento 6 & $\begin{array}{l}\text { transferir } 5 \mathrm{~mL}(\mathrm{TS} 1)(\mathrm{TS} 2)(\mathrm{RS})+2 \mathrm{~mL} \\
\text { ácido fosfotúngstico } \mathrm{SR}+\text { carbonato de } \\
\text { sódio } 10,6 \% \text { para } 50 \mathrm{~mL}+\text { descansar }\left(3^{\prime}\right)\end{array}$ & - & - & su \\
\hline Procedimento 7 & $715 \mathrm{~nm}$ & - & - & su \\
\hline Procedimento 8 & concentração relativa & - & - & su \\
\hline Procedimento 9 & $\mathrm{TT}=\frac{13,12 \times\left(\mathrm{A}_{1}-\mathrm{A}_{2}\right)}{\mathrm{A}_{3} \times m}$ & - & - & $\mathrm{su}$ \\
\hline Doseamento - método 2 & EAUV (cafeína) (NLT 2,0\%) & CLAE-UV (cafeína) (NLT 1,5\%) & CLAE-UV (cafeína) (NLT 1,5\%) & me \\
\hline Procedimento 1 & $271 \mathrm{~nm}$ & $272 \mathrm{~nm}$ & $272 \mathrm{~nm}$ & mi \\
\hline Procedimento 2 & - & $\operatorname{ODS}(0,25 \mathrm{~m} \times 4,6 \mathrm{~mm})(5 \mu \mathrm{m})$ & ODS $(25 \mathrm{~cm} \mathrm{x} \mathrm{4,6} \mathrm{mm)}(3-10 \mu \mathrm{m})$ & me \\
\hline Procedimento 3 & - & metanol:água (25:75) $(1 \mathrm{~mL} / \mathrm{min})$ & água:metanol (75:25) (1,0 mL/min) & $\begin{array}{l}\text { me } \\
\text { (contir }\end{array}$ \\
\hline
\end{tabular}


Quadro 17 - Comparação entre as monografias de Cola nitida (Vent.) Schott \& Endl. [cotilédone] das farmacopeias FB5, EP8.8 e FA7.

\begin{tabular}{|c|c|c|c|c|}
\hline & FB5 & EP8.8 & FA7 & Classificação \\
\hline Procedimento 4 & $\begin{array}{l}0,25 \text { g droga vegetal pulverizada + extrair } \\
4 x 20 \mathrm{~mL} \text { ácido sulfúrico } 2,5 \% \text { (agitação } \\
\text { magnética) }\left(15^{\prime}\right)+\text { filtrar + ácido sulfúrico } \\
2,5 \% \text { para } 100 \mathrm{~mL}+\text { transferir } 10 \mathrm{~mL}+ \\
\text { ácido sulfúrico } 2,5 \% \text { para } 100 \mathrm{~mL}(\mathrm{TS})\end{array}$ & $\begin{array}{l}\text { 1,00 g droga vegetal pulverizada (355) + } \\
50 \mathrm{~mL} \text { metanol + aquecer (refluxo) } \\
\text { (banho-maria) }(30 \text { ') + esfriar + filtrar + } \\
\text { lavar (filtro) com } 10 \mathrm{~mL} \text { metanol + } \\
\text { retomar (resíduo) + repetir } 1 \mathrm{x}+\text { reunir } \\
\text { (filtrados + líquidos de lavagem) + } \\
\text { metanol para } 200,0 \mathrm{~mL}+\text { transferir } 20,0 \\
\mathrm{~mL}+\text { evaporar (secura) (pressão reduzida) } \\
\text { + metanol:água (25:75) para } 50 \mathrm{~mL} \text { (TS) }\end{array}$ & $\begin{array}{l}\text { 1,0 g droga vegetal finamente pulverizada } \\
+50 \mathrm{~mL} \text { metanol + aquecer (refluxo) } \\
\text { (banho-maria) }(30 \text { ') + esfriar (ambiente) }+ \\
\text { filtrar + lavar (filtro) com } 10 \mathrm{~mL} \text { metanol } \\
+ \text { retomar (resíduo) + repetir } 1 \mathrm{x}+\text { reunir } \\
\text { (filtrados + líquidos de lavagem) + } \\
\text { metanol para } 200 \mathrm{~mL}+\text { transferir } 20 \mathrm{~mL}+ \\
\text { evaporar (secura) (pressão reduzida) + } \\
\text { água:metanol (75:25) para } 50 \mathrm{~mL}(\mathrm{TS})\end{array}$ & me \\
\hline Procedimento 5 & $\begin{array}{c}25 \text { mg cafeína } S Q R+\text { ácido sulfúrico } \\
2,5 \% \text { para } 100 \mathrm{~mL}(\mathrm{RS})\end{array}$ & $\begin{array}{l}30,0 \mathrm{mg} \text { cafeína } \mathrm{SQR}+15,0 \mathrm{mg} \\
\text { teobromina }+ \text { metanol:água }(25: 75) \text { para } \\
100,0 \mathrm{~mL}+\text { transferir } 10,0 \mathrm{~mL}+ \\
\text { metanol:água }(25: 75) \text { para } 100,0 \mathrm{~mL}(\mathrm{TS})\end{array}$ & $\begin{array}{c}30 \mathrm{mg} \text { cafeína }+15 \mathrm{mg} \text { teobromina }+ \\
\text { água:metanol }(75: 25) \text { para } 100 \mathrm{~mL}+ \\
\text { transferir }(10 \mathrm{~mL})+\text { água:metanol }(75: 25) \\
\text { para } 100 \mathrm{~mL}(\mathrm{RS})\end{array}$ & me \\
\hline Procedimento 6 & $\begin{array}{c}2,5 \mu \mathrm{g} / \mathrm{mL} ; 5 \mu \mathrm{g} / \mathrm{mL} ; 10 \mu \mathrm{g} / \mathrm{mL} ; 15 \\
\mu \mathrm{g} / \mathrm{mL} ; 20 \mu \mathrm{g} / \mathrm{mL} \text { em ácido sulfúrico } \\
2,5 \%\end{array}$ & - & - & $\mathrm{mi}$ \\
\hline Procedimento 7 & ácido sulfúrico 2,5\% (BS) & - & - & me \\
\hline Procedimento 8 & - & $\begin{array}{c}\text { resolução (NLT 2,5 - cafeína e } \\
\text { teobromina) }\end{array}$ & $\begin{array}{c}\text { resolução (NLT 2,5 - cafeína e } \\
\text { teobromina) }\end{array}$ & me \\
\hline Procedimento 9 & curva analítica & concentração relativa & concentração relativa & $\mathrm{mi}$ \\
\hline Procedimento 10 & - & $\frac{m_{2} \times \mathrm{A}_{1} \times 50}{m_{1} \times \mathrm{A}_{2}}$ & $50 \times\left(\frac{P_{E}}{P_{M}}\right) \times\left(\frac{r_{M}}{r_{E}}\right)$ & $\mathrm{mi}$ \\
\hline $\begin{array}{l}\text { Embalagem e } \\
\text { armazenamento }\end{array}$ & 1 & - & 1 & - \\
\hline Padrões de referência & cafeína $\mathrm{SQR}$ + pó de pele $\mathrm{SQR}$ & cafeína SQR & - & - \\
\hline
\end{tabular}

(ANMAT, 2003b; BRASIL, 2010c, d; EDQM, 2016b).

Legenda: $\mathrm{mi}=$ menor; me = moderado; su = substancial; se = semelhante; er = erro; NLT = não menos que; MNT = não mais que; MR = cumpre os requisitos ou o teste; CCD = cromatografia em camada delgada; $\mathrm{RS}=$ solução referência; TS = solução amostra; BS = solução branco; SR = solução reagente; SQR = substância química de referência; CLAE-UV = cromatografia liquida de alta eficiência acoplada a detector por espectrofotometria por absorção no ultravioleta; ODS = coluna cromatográfica octadecilsilanizada; EAUV = espectrofotometria de absorção no ultravioleta; $\mathrm{A}=$ absorvância; $m=\mathrm{P}=$ massa; $r$ resposta.

Nota: ${ }^{1}=$ há omissão na monografia da FB5 sobre a consideração do teor de água no cálculo do doseamento; ${ }^{2}=$ especificação extraída do método geral; ${ }^{3}=$ parâmetros extraídos do método geral. 
No geral, as monografias possuem propostas semelhantes, com ensaios de identificação, testes e doseamentos.

As diferenças substanciais se concentram nos testes adicionais previstos na FA7 (metais pesados, aflatoxinas e resíduos de agrotóxicos), nas diferenças substanciais entre as especificações das monografias para matéria estranha e cinzas totais acima de $30 \%$ e na presença de especificação e método adicional na FB5 para o marcador taninos totais. É importante ressaltar que estão previstos, na monografia geral Herbal Drugs da EP8.8, os testes para metais pesados e resíduos de agrotóxicos.

Há, ainda, a ausência na FB5 da indicação de que o teor de cafeína deve ser calculado sem considerar a massa de água da droga vegetal, obtida na determinação de água, que por ser uma omissão foi considerada um erro. Considerado que a especificação para a determinação de água na FB5 é de não mais que (NMT) 15\%, a diferença no resultado obtido para o teor, considerando ou não a massa de água, é significativo.

Como espécie que não possui ocorrência no Brasil, a origem da matéria-prima não é nacional. Assim, se esperava que os métodos e especificações fossem mais harmonizados, porém, nesse caso, a espécie não possui registros válidos junto à Anvisa, nem está listada em outros compêndios e nem na lista de registro simplificado. Isso pode indicar que há baixa utilização da monografia no Brasil e, pode, eventualmente, explicar, o porquê de a monografia não ser tão harmonizada quanto o esperado.

4.5.12 Crataegus monogyna Jacq., C. rhipidophylla Gand., C. laevigata (Poir.) DC., C. pentagyna Waldst. \& Kit. ex Willd., C. nigra Waldst. \& Kit., C. azarolus L. [ramo florido]

O cratego esteve presente na $2^{\mathrm{a}}$ e $3^{\mathrm{a}}$ edição da Farmacopeia Brasileira (Quadro 3), não está relacionada no FFFB1 e nem na IN nº 02/2014 (BRASIL, 2011, 2014a), estando apenas na FB5. Foram encontrados, para a espécie Crataegus rhipidophylla Gand., sete registros de fitoterápicos válidos na Anvisa (Quadro 5). Conforme a literatura consultada, a espécie Crataegus rhipidophylla Gand. possui ocorrência no Brasil (Apêndice A), sendo cultivada (REFLORA, 2016). Há, ainda, registro de ocorrência das espécies no Canadá e no Estados Unidos da América (TROPICOS.ORG, 2016). Em buscas realizadas nos compêndios internacionais em estudo, foram localizadas monografias na EP8.8 e na USP39-NF34. Os dados extraídos das monografias estão descritos no Quadro 18. 
Quadro 18 - Comparação entre as monografias de Crataegus monogyna Jacq., C. rhipidophylla Gand., C. laevigata (Poir.) DC., C. pentagyna Waldst. \& Kit. ex Willd., C. nigra Waldst. \& Kit., C. azarolus L. [ramo florido] das farmacopeias FB5, FA7 e USP39-NF34.

\begin{tabular}{|c|c|c|c|c|}
\hline & FB5 & EP8.8 & USP39-NF34 & Classificação \\
\hline Nomenclatura botânica & $\begin{array}{l}\text { Crataegus monogyna Jacq., } C . \\
\text { rhipidophylla Gand. [syn. C. oxyacantha } \\
\text { L.], C. laevigata (Poir.) DC., C. } \\
\text { pentagyna Waldst. \& Kit. ex Willd., C. } \\
\text { nigra Waldst. \& Kit., C. azarolus L. }\end{array}$ & $\begin{array}{l}\text { Crataegus monogyna Jacq. (Lindm.), } C \text {. } \\
\text { laevigata (Poir.) DC., C. pentagyna } \\
\text { Waldst. \& Kit. ex Willd., C. nigra Waldst. } \\
\text { \& Kit. e C. azarolus } \mathrm{L} .\end{array}$ & $\begin{array}{c}\text { Crataegus monogyna Jacq. (Lindm.), } C . \\
\text { laevigata (Poir.) DC. }\end{array}$ & - \\
\hline Sinonímia botânica & o & $\begin{array}{c}\text { Crataegus laevigata (Poir.) DC. (syn. C. } \\
\text { oxyacanthoides Thuill.; C. oxyacantha } \\
\text { auct.) }\end{array}$ & $\begin{array}{l}\text { Crataegus laevigata (Poir.) DC. (syn. } \\
\text { Crataegus oxyacantha L.) }\end{array}$ & - \\
\hline Nomenclatura popular & cratego & hawthorn & hawthorn & - \\
\hline Droga vegetal & ramo florido & ramo florido & ramo florido & se \\
\hline Marcador 1 & $\begin{array}{c}\text { flavonoides totais (hiperosídeo) (NLT } \\
1,5 \%)(\text { droga seca) }\end{array}$ & $\begin{array}{l}\text { flavonoides totais (hiperosídeo) (NLT } \\
1,5 \%) \text { (droga seca) }\end{array}$ & $\begin{array}{l}\text { flavonas O-glicosiladas (hiperosídeo) } \\
\text { (NLT 0,45\%) }\end{array}$ & $\mathrm{su}$ \\
\hline Marcador 2 & - & - & $\begin{array}{l}\text { flavonas } C \text {-glicosiladas (vitexina) (NLT } \\
\qquad, 6 \% \text { ) }\end{array}$ & $\mathrm{su}$ \\
\hline Características & odor característico + insípido & - & - & - \\
\hline Descrição macroscópica & 1 & 1 & 1 & - \\
\hline Descrição microscópica & 2 & 1 & 1 & - \\
\hline Figura botânica & 4 & - & - & - \\
\hline Identificação - método 1 & CCD & $\mathrm{CCD}$ & CCD & se \\
\hline Procedimento 1 & sílica-gel $\left(\mathrm{F}_{254}+0,25 \mathrm{~mm}\right)$ & sílica-gel & sílica-gel $(0,50 \mathrm{~mm})$ & $\mathrm{mi}$ \\
\hline Procedimento 2 & $\begin{array}{l}\text { ácido fórmico } \\
\text { anidro:água:butanona:acetato de etila } \\
(10: 10: 30: 50)\end{array}$ & $\begin{array}{l}\text { ácido fórmico } \\
\text { anidro:água:butanona:acetato de etila } \\
(10: 10: 30: 50)\end{array}$ & $\begin{array}{l}\text { acetato de etila:ácido acético glacial:ácido } \\
\text { fórmico:água }(10: 1,1: 1,1: 2,6)\end{array}$ & me \\
\hline Procedimento 3 & $20 \mu \mathrm{L}(\mathrm{TS})\left(\mathrm{RS}_{1}\right)\left(\mathrm{RS}_{2}\right)$ (banda) & $20 \mu \mathrm{L}$ (TS) (RS) (banda) & $10 \mu \mathrm{L}(\mathrm{TS})(\mathrm{RS})$ & $\mathrm{mi}$ \\
\hline Procedimento 4 & $\begin{array}{c}1 \text { g droga vegetal moída }(355)+10 \mathrm{~mL} \\
\text { metanol }+ \text { aquecer (refluxo) }\left(65^{\circ} \mathrm{C}\right)\left(5^{\prime}\right)+ \\
\text { resfriar (ambiente) + filtrar (papel filtro) } \\
\text { (pressão reduzida) (TS) }\end{array}$ & $\begin{array}{c}\text { 1,0 g droga vegetal pulverizada }(355)+10 \\
\text { mL metanol + aquecer (banho-maria) } \\
(\text { refluxo })\left(65^{\circ} \mathrm{C}\right)\left(5^{\prime}\right)+\text { resfriar + filtrar } \\
(\mathrm{TS})\end{array}$ & $\begin{array}{l}1 \mathrm{~g} \text { droga vegetal finamente pulverizada }+ \\
10 \mathrm{~mL} \text { metanol + aquecer (banho-maria) } \\
\left(65^{\circ} \mathrm{C}\right)\left(5^{\prime}\right)+\text { resfriar + filtrar }(\mathrm{TS})\end{array}$ & $\mathrm{se}$ \\
\hline Procedimento 5 & $\begin{array}{l}1 \mathrm{mg} \text { ácido clorogênico } \\
\qquad\left(\mathrm{RS}_{1}\right)\end{array}$ & $\begin{array}{l}\text { 1,0 mg ácido clorogênico + 2,5 mg } \\
\text { hiperosídeo + } 10 \mathrm{~mL} \text { metanol }(\mathrm{RS})\end{array}$ & $\begin{array}{c}0,1 \mathrm{mg} / \mathrm{mL} \text { ácido clorogênico, rutina, } \\
\text { hiperosídeo } \mathrm{SQR} \text { e vitexina } \mathrm{SQR} \text { em } \\
\text { metanol (RS) }\end{array}$ & me \\
\hline Procedimento 6 & $1 \mathrm{mg}$ hiperosídeo $+5 \mathrm{~mL}$ metanol $\left(\mathrm{RS}_{2}\right)$ & - & - & $\mathrm{mi}$ \\
\hline Procedimento 7 & $\operatorname{secar}\left(100-105^{\circ} \mathrm{C}\right)\left(15^{\prime}\right)$ & $\operatorname{secar}\left(100-105^{\circ} \mathrm{C}\right)$ & $\operatorname{secar}\left(105^{\circ} \mathrm{C}\right)$ & $\begin{array}{l}\mathrm{mi} \\
\text { (contin }\end{array}$ \\
\hline
\end{tabular}


Quadro 18 - Comparação entre as monografias de Crataegus monogyna Jacq., C. rhipidophylla Gand., C. laevigata (Poir.) DC., C. pentagyna Waldst. \& Kit. ex Willd., C. nigra Waldst. \& Kit., C. azarolus L. [ramo florido] das farmacopeias FB5, FA7 e USP39-NF34.

\begin{tabular}{|c|c|c|c|c|}
\hline & FB5 & EP8.8 & USP39-NF34 & Classificação \\
\hline Procedimento 8 & $\begin{array}{c}\text { difenilborato de aminoetanol SR + } \\
\text { macrogol } 4005 \% \text { em metanol + descansar } \\
\left(30^{\prime}\right)\end{array}$ & $\begin{array}{c}\text { difenilborato de aminoetanol } 1 \% \text { em } \\
\text { metanol + macrogol } 4005 \% \text { em metanol } \\
+ \text { descansar }\left(30^{\prime}\right)\end{array}$ & $\begin{array}{c}\text { difenilborato de aminoetanol:metanol } \\
(1: 100)+\text { polietilenoglicol 4000:metanol } \\
(5: 100)+\text { descansar }(30)\end{array}$ & se \\
\hline Procedimento 9 & $365 \mathrm{~nm}$ & $365 \mathrm{~nm}$ & $365 \mathrm{~nm}$ & se \\
\hline Procedimento 10 & descrição de zonas & esquema & descrição de zonas & me \\
\hline Identificação - método 2 & $\begin{array}{c}3 \mathrm{~g} \text { droga vegetal pulverizada }+60 \mathrm{~mL} \\
\text { água }+ \text { aquecer (refluxo) }\left(15^{\prime}\right)+\text { esfriar }+ \\
\text { filtrar }+ \text { transferir } 2 \mathrm{~mL}+2 \text { gotas ácido } \\
\text { clorídrico } \mathrm{SR}+\text { gotejar gelatina } \mathrm{SR}= \\
\text { precipitado nítido (taninos) } \\
2 \mathrm{~mL} \text { extrato }+10 \mathrm{~mL} \text { água }+2-4 \text { gotas }\end{array}$ & - & - & $\mathrm{su}$ \\
\hline Identificação - método 3 & $\begin{array}{l}\text { cloreto férrico } 1 \% \text { em etanol = cinza- } \\
\text { escuro (taninos) } \\
2 \mathrm{~mL} \text { extrato }+0,5 \mathrm{~mL} \text { vanilina } 1 \% \mathrm{em}\end{array}$ & - & - & su \\
\hline Identificação - método 4 & $\begin{array}{c}\text { metanol }+1 \mathrm{~mL} \text { ácido clorídrico }= \\
\text { vermelha (taninos condensados) }\end{array}$ & - & - & su \\
\hline Identificação - método 5 & $\begin{array}{c}5 \mathrm{~mL} \text { extrato }+10 \mathrm{~mL} \text { ácido acético } 2 M+ \\
5 \mathrm{~mL} \text { acetato de chumbo } \mathrm{SR}=\text { precipitado } \\
\text { esbranquiçado (taninos) }\end{array}$ & - & - & su \\
\hline Identificação - método 6 & $\begin{array}{c}5 \mathrm{~mL} \text { extrato + pequenos fragmentos } \\
\text { magnésio metálico }+1 \mathrm{~mL} \text { ácido } \\
\text { clorídrico = vermelha (agliconas } \\
\text { flavonoídicas) }\end{array}$ & - & - & su \\
\hline Identificação - método 7 & - & - & CLAE-UV & su \\
\hline Procedimento 1 & - & - & $336 \mathrm{~nm}$ & $\mathrm{su}$ \\
\hline Procedimento 2 & - & - & $\operatorname{ODS}(10 \mathrm{~cm} \mathrm{x} \mathrm{4,0} \mathrm{mm)}(5 \mu \mathrm{m})$ & su \\
\hline Procedimento 3 & - & - & $\begin{array}{c}\text { tetraidrofurano:acetonitrila:metanol } \\
(92,4: 3,4: 4,2) 12 \% \text { em ácido fosfórico } \\
0,5 \%\left(12^{\prime}\right)+ \\
\text { tetraidrofurano:acetonitrila:metanol } \\
(92,4: 3,4: 4,2) 12 \% \text { em ácido fosfórico } \\
0,5 \% \rightarrow \\
\text { tetraidrofurano:acetonitrila:metanol } \\
(92,4: 3,4: 4,2) 18 \% \text { em ácido fosfórico }\end{array}$ & su \\
\hline
\end{tabular}


Quadro 18 - Comparação entre as monografias de Crataegus monogyna Jacq., C. rhipidophylla Gand., C. laevigata (Poir.) DC., C. pentagyna Waldst. \& Kit. ex Willd., C. nigra Waldst. \& Kit., C. azarolus L. [ramo florido] das farmacopeias FB5, FA7 e USP39-NF34.

\begin{tabular}{|c|c|c|c|c|}
\hline & FB5 & EP8.8 & USP39-NF34 & Classificação \\
\hline Procedimento 4 & - & - & $\begin{array}{c}0,5 \%(13 ')+ \\
\text { tetraidrofurano:acetonitrila:metanol } \\
(92,4: 3,4: 4,2) 18 \% \text { em ácido fosfórico } \\
0,5 \%\left(5^{\prime}\right)(1 \mathrm{~mL} / \mathrm{min}) \\
3 \text { g droga vegetal finamente pulverizada + } \\
60 \mathrm{~mL} \text { metanol:água }(4: 1)+\text { aquecer } \\
\text { (refluxo) }(1 \mathrm{~h})+\text { esfriar + filtrar + retomar } \\
\text { (resíduo) + 40 mL metanol:água }(4: 1)+ \\
\text { aquecer (refluxo) }(1 \mathrm{~h})+\text { esfriar + filtrar + } \\
\text { reunir (filtrados) + evaporar (pressão } \\
\text { reduzida) para } 20 \mathrm{~mL}+\text { metanol:água } \\
\text { (4:1) para 25,0 mL + transferir 5,0 mL } \\
\text { (coluna extração } 360 \mathrm{mg})+ \text { transferir } \\
\text { (eluato) + metanol:água }(4: 1) \text { para } 10 \mathrm{~mL} \\
\text { (TS) }\end{array}$ & su \\
\hline Procedimento 5 & - & - & $\begin{array}{c}0,1 \mathrm{mg} / \mathrm{mL} \text { ácido clorogênico, rutina, } \\
\text { hiperosídeo SQR e vitexina SQR em } \\
\text { metanol (RS) }\end{array}$ & su \\
\hline Procedimento 6 & - & - & $\begin{array}{c}5 \mu \mathrm{L} \\
\end{array}$ & su \\
\hline Procedimento 7 & - & - & $\begin{array}{c}\text { clorogênico; } 1,0 \text { - vitexina; } 1,16 \text { - rutina; } \\
\text { 1,4 - hiperosídeo) + desvio padrão } \\
\text { relativo (NMT 2,0\%) }\end{array}$ & su \\
\hline Procedimento 8 & - & - & tempos de retenção $(\mathrm{TS}) \sim(\mathrm{RS})$ & su \\
\hline Testes - método 1 & $\begin{array}{c}\text { matéria estranha (NMT 8,0\% - ramos } \\
\text { lignificados; NMT 2,0\% - outros) }\end{array}$ & $\begin{array}{c}\text { matéria estranha }(\mathrm{NMT} 8 \% \text { - ramos } \\
\text { lignificados }> \\
2,5 \mathrm{~mm} ; \mathrm{NMT} 2,0 \% \text { - } \\
\text { outros })\end{array}$ & $\begin{array}{c}\text { matéria estranha (NMT 8,0\% - matéria } \\
\text { lignificada) }\end{array}$ & me \\
\hline Testes - método 2 & água (NMT $11,0 \%)\left(100-105^{\circ} \mathrm{C}\right)(5 \mathrm{~h})^{1}$ & $\begin{array}{c}\text { perda por dessecação (NMT 10,0\%) } \\
(1,000 \mathrm{~g} \text { droga vegetal pulverizada }(355) \\
\left(105^{\circ} \mathrm{C}\right)(2 \mathrm{~h})\end{array}$ & $\begin{array}{l}\text { perda por dessecação (NMT 10,0\%) }(1,0 \\
\text { g droga vegetal finamente pulverizada } \\
\left(105^{\circ} \mathrm{C}\right)(2 \mathrm{~h})\end{array}$ & $\mathrm{mi}$ \\
\hline Testes - método 3 & cinzas totais (NMT 10,0\%) & cinzas totais (NMT 10,0\%) & cinzas totais (NMT 9,0\%) & mi \\
\hline Testes - método 4 & cinzas sulfatadas (NMT 12,0\%) & - & - & su \\
\hline Testes - método 5 & - & - & impurezas elementais (MR) & su \\
\hline Testes - método 6 & $z$ & - & agrotóxicos (MR) & $\mathrm{su}$ \\
\hline
\end{tabular}


Quadro 18 - Comparação entre as monografias de Crataegus monogyna Jacq., C. rhipidophylla Gand., C. laevigata (Poir.) DC., C. pentagyna Waldst. \& Kit. ex Willd., C. nigra Waldst. \& Kit., C. azarolus L. [ramo florido] das farmacopeias FB5, FA7 e USP39-NF34.

\begin{tabular}{|c|c|c|c|c|}
\hline & FB5 & EP8.8 & USP39-NF34 & Classificação \\
\hline Testes - método 7 & $=$ & - & $\begin{array}{c}\text { microrganismos (TAMC - NMT } 10^{4} \\
\mathrm{UFC} / \mathrm{g}+\mathrm{TYMC}-\mathrm{NMT} 10^{2} \mathrm{UFC} / \mathrm{g}+ \\
\text { ausência Salmonella e Escherichia coli) }\end{array}$ & - \\
\hline Índices - método 1 & índice de espuma (NLT 100) & - & - & su \\
\hline Procedimento 1 & $\begin{array}{c}1 \text { g droga vegetal moída }(180)+50 \mathrm{~mL} \\
\text { água fervente }+ \text { ferver (moderadamente) } \\
\left(15^{\prime}\right)+\text { resfriar + filtrar (algodão) + água } \\
\text { para } 100 \mathrm{~mL}(\mathrm{TS})\end{array}$ & - & - & $\mathrm{su}$ \\
\hline Procedimento 2 & $\begin{array}{c}\text { 1-10 mL }(\mathrm{TS})+\text { água para } 10 \mathrm{~mL}+\text { agitar } \\
\text { (vigorosamente) (movimentos verticais) } \\
\left(15^{\prime \prime}\right) 2 \times 1 "+\text { repouso }\left(15^{\prime}\right)+\text { medir } \\
\text { espuma }+1 \mathrm{~mL} \text { ácido clorídrico } 2 \mathrm{M}+\mathrm{se} \\
\text { altura inferior } 1 \mathrm{~cm}=\text { índice de espuma < } \\
100+\text { se altura permanecer igual ou } \\
\text { superior } 1 \mathrm{~cm}\left(10^{\prime}\right)=\text { diluição é o índice } \\
1000\end{array}$ & - & - & su \\
\hline Procedimento 3 & $\mathrm{IE}=\frac{\mathrm{IU00}}{\mathrm{V}}$ & - & - & su \\
\hline Doseamento - método 1 & $\begin{array}{l}\text { EAVIS flavonoides totais (hiperosídeo) } \\
\text { (NLT } 1,5 \%)\end{array}$ & $\begin{array}{l}\text { EAVIS flavonoides totais (hiperosídeo) } \\
\text { (NLT 1,5\%) }\end{array}$ & $\begin{array}{l}\text { CLAE-UV (flavonas O-glicosiladas) } \\
\text { (hiperosídeo) (NLT 0,45\%) }\end{array}$ & su \\
\hline Procedimento 1 & - & - & ODS (25 cm x 4,6 mm) & me \\
\hline Procedimento 2 & - & - & $\begin{array}{l}\text { metanol:ácido fosfórico:água (100:1:100) } \\
\qquad(1,5 \mathrm{~mL} / \mathrm{min})\end{array}$ & me \\
\hline Procedimento 3 & $\begin{array}{c}0,4 \mathrm{~g} \text { droga vegetal pulverizada }(250)+40 \\
\mathrm{~mL} \text { etanol } 60 \%+\text { aquecer }(\text { banho-maria) } \\
\left(\text { agitação frequente) }\left(60{ }^{\circ} \mathrm{C}\right)\left(10^{\prime}\right)+\right. \\
\text { resfriar + filtrar (algodão) + retornar } \\
\text { (resíduo + algodão }+40 \mathrm{~mL} \text { etanol } 60 \%+ \\
\text { aquecer (banho-maria) (agitação } \\
\text { frequente) }\left(10^{\prime}\right)+\text { filtrar (algodão) + etanol } \\
60 \% \text { para } 100 \mathrm{~mL}+\text { transferir } 5 \mathrm{~mL}+ \\
\text { evaporar (secura) (evaporador rotatório) + } \\
\text { transferir (resíduo) com } 8 \mathrm{~mL} \\
\text { metanol:ácido acético glacial }(10: 100)+\end{array}$ & $\begin{array}{l}0,400 \mathrm{~g} \text { droga vegetal pulverizada }(250)+ \\
40 \mathrm{~mL} \text { etanol } 60 \%+\text { aquecer }(\text { banho- } \\
\text { maria) (agitação frequente) }\left(60{ }^{\circ} \mathrm{C}\right)\left(10^{\prime}\right)+ \\
\text { resfriar + filtrar (algodão) + retornar } \\
\text { (resíduo + algodão) + } 40 \mathrm{~mL} \text { etanol } 60 \%+ \\
\text { aquecer (banho-maria) (agitação } \\
\text { frequente) }(10 \text { ') + esfriar + filtrar } \\
\text { (algodão) + lavar (recipiente) com etanol } \\
60 \% \text { para } 100 \mathrm{~mL}+\text { transferir } 5 \mathrm{~mL}+ \\
\text { evaporar (secura) (pressão reduzida) }+ \\
\text { transferir (resíduo) com } 8 \mathrm{~mL} \\
\text { metanol:ácido acético anidro }(10: 100)+\end{array}$ & $\begin{array}{c}4 \mathrm{~g} \text { droga vegetal finamente pulverizada }+ \\
80 \mathrm{~mL} \text { metanol + extrair (equipamento de } \\
\text { extração contínua) }(5 \mathrm{~h})+\text { esfriar }+ \\
\text { evaporar (pressão reduzida) para } 40 \mathrm{~mL}+ \\
\text { metanol to } 50 \mathrm{~mL}+\text { transferir } 10,0 \mathrm{~mL}+ \\
1 \mathrm{~mL} \text { ácido clorídrico } 25 \%+\text { aquecer } \\
\text { (refluxo) }\left(60^{\prime}\right)+\text { esfriar }+ \text { metanol para } 50 \\
\text { mL (TS) }\end{array}$ & me \\
\hline
\end{tabular}


Quadro 18 - Comparação entre as monografias de Crataegus monogyna Jacq., C. rhipidophylla Gand., C. laevigata (Poir.) DC., C. pentagyna Waldst. \& Kit. ex Willd., C. nigra Waldst. \& Kit., C. azarolus L. [ramo florido] das farmacopeias FB5, FA7 e USP39-NF34.

\begin{tabular}{|c|c|c|c|c|}
\hline & FB5 & EP8.8 & USP39-NF34 & Classificação \\
\hline & $\begin{array}{l}\text { lavar (balão) com } 3 \text { mL metanol:ácido } \\
\text { acético glacial (10:100) (SS) }\end{array}$ & $\begin{array}{l}\text { lavar (balão) com } 3 \mathrm{~mL} \text { metanol:ácido } \\
\text { acético anidro (10:100) (SS) }\end{array}$ & & \\
\hline Procedimento 4 & $\begin{array}{l}\text { (SS) + } 10 \mathrm{~mL} \text { (ácido bórico 2,5\% + ácido } \\
\text { oxálico } 2 \% \text { em ácido fórmico anidro) + } \\
\text { manter (banho de gelo) (10') (não } \\
\text { congelar) + ácido acético anidro para } 25 \\
\mathrm{~mL}+\text { manter (banho de gelo) até 10' antes } \\
\text { da leitura + descansar (30') (TS) }\end{array}$ & $\begin{array}{c}(\mathrm{SS})+10,0 \mathrm{~mL} \text { (ácido bórico } 2,5 \%+ \\
\text { ácido oxálico } 2 \% \text { em ácido fórmico } \\
\text { anidro) + ácido acético anidro para } 25 \mathrm{~mL} \\
+ \text { descansar }(30 \text { ') }(\mathrm{TS})\end{array}$ & - & me \\
\hline Procedimento 5 & - & - & $\begin{array}{c}0,05 \mathrm{mg} / \mathrm{mL} \text { quercetina SQR em metanol } \\
(\mathrm{RS})\end{array}$ & me \\
\hline Procedimento 6 & $\begin{array}{l}(\mathrm{SS})+10 \mathrm{~mL} \text { ácido fórmico anidro + } \\
\text { manter (banho de gelo) }\left(10^{\prime}\right) \text { (não } \\
\text { congelar) + ácido acético anidro para } 25 \\
\text { mL + manter (banho de gelo) até } 10^{\prime} \\
\text { antes da leitura + descansar }\left(30^{\prime}\right)(\mathrm{BS})\end{array}$ & $\begin{array}{c}(\mathrm{SS})+10,0 \mathrm{~mL} \text { ácido fórmico anidro }+ \\
\text { ácido acético anidro para } 25 \mathrm{~mL}+ \\
\text { descansar }(30 \text { ') }(\mathrm{BS})\end{array}$ & $x_{0}$ & me \\
\hline Procedimento 7 & $410 \mathrm{~nm}$ & $410 \mathrm{~nm}$ & $370 \mathrm{~nm}$ & $\mathrm{mi}$ \\
\hline Procedimento 8 & - & - & $\begin{array}{c}10 \mu \mathrm{L} \\
\end{array}$ & me \\
\hline Procedimento 9 & - & - & $\begin{array}{l}\text { pratos teoricos }(\mathrm{NLT} 3000)+\text { fator de } \\
\text { cauda }(0,8-2)+\text { desvio padrão relativo } \\
\text { (NMT } 2,0 \%)\end{array}$ & me \\
\hline Procedimento 10 & - & - & concentração relativa & me \\
\hline Procedimento 11 & $\mathrm{H}=\frac{\operatorname{Abs} \times 1,235}{m}$ & $\frac{\mathrm{A} \times 1,235}{m}$ & Result $=\left(\frac{\mathrm{r}_{U}}{\mathrm{r}_{\mathrm{S}}}\right) \times\left(\mathrm{C}_{\mathrm{S}} / \mathrm{C}_{\mathrm{U}}\right) \times\left(\frac{\mathrm{M}_{\mathrm{r} 1}}{\mathrm{M}_{\mathrm{r} 2}}\right) \times 100$ & me \\
\hline Doseamento - método 2 & - & $\begin{array}{l}m \\
-\end{array}$ & $\begin{array}{l}\text { CLAE-UV (flavonas } C \text {-glicosiladas) } \\
\text { (vitexina) (NLT } 0,6 \% \text { ) }\end{array}$ & $\mathrm{su}$ \\
\hline Procedimento 1 & - & - & $336 \mathrm{~nm}$ & su \\
\hline Procedimento 2 & - & - & $\begin{array}{c}\text { coluna octadecilsilanizada ( } 10 \mathrm{~cm} \text { x 4,0 } \\
\mathrm{mm}) \\
\text { ácido fosfórico }\end{array}$ & su \\
\hline Procedimento 3 & - & - & $\begin{array}{l}0,5 \%: \text { (tetraidrofurano:isopropanol:acetoni } \\
\text { trila }(10: 8: 3))(22: 3)(1 \mathrm{~mL} / \mathrm{min})\end{array}$ & su \\
\hline
\end{tabular}

(continua) 
Quadro 18 - Comparação entre as monografias de Crataegus monogyna Jacq., C. rhipidophylla Gand., C. laevigata (Poir.) DC., C. pentagyna Waldst. \& Kit. ex Willd., C. nigra Waldst. \& Kit., C. azarolus L. [ramo florido] das farmacopeias FB5, FA7 e USP39-NF34.

\begin{tabular}{|c|c|c|c|c|}
\hline & FB5 & EP8.8 & USP39-NF34 & Classificação \\
\hline Procedimento 4 & - & - & $\begin{array}{c}4 \text { g droga vegetal finamente pulverizada + } \\
80 \mathrm{~mL} \text { metanol + extrair (equipamento de } \\
\text { extração contínua) }(5 \mathrm{~h})+\text { esfriar }+ \\
\text { evaporar (pressão reduzida) para } 40 \mathrm{~mL}+ \\
\text { metanol to } 50 \mathrm{~mL}+\text { transferir } 10,0 \mathrm{~mL}+ \\
4 \mathrm{~mL} \text { ácido clorídrico } 25 \%+\text { aquecer } \\
\text { (refluxo) }\left(90^{\prime}\right)+\text { esfriar }+ \text { metanol para } 50 \\
\mathrm{~mL}(\mathrm{TS})\end{array}$ & su \\
\hline Procedimento 5 & - & - & $\begin{array}{c}0,3 \mathrm{mg} / \mathrm{mL} \text { vitexina } \mathrm{SQR} \text { em } \\
\text { tetraidrofurano:isopropanol:acetonitrila } \\
(10: 8: 3)\end{array}$ & $\mathrm{su}$ \\
\hline Procedimento 6 & - & - & $5 \mu \mathrm{L}$ & su \\
\hline Procedimento 7 & - & - & $\begin{array}{c}\text { pratos teóricos }(\text { NLT } 3000)+\text { fator de } \\
\text { cauda }(0,8-2)+\text { desvio padrão relativo } \\
(\text { NMT } 2,0 \%)\end{array}$ & $\mathrm{su}$ \\
\hline Procedimento 8 & - & - & concentração relativa & su \\
\hline Procedimento 9 & - & - & Result $=\left(\mathrm{C}_{\mathrm{S}} / \mathrm{C}_{\mathrm{U}}\right) \times\left(\frac{\Sigma \mathrm{r}_{\mathrm{U}}}{\mathrm{r}_{\mathrm{S}}}\right) \times 100$ & su \\
\hline $\begin{array}{l}\text { Embalagem e } \\
\text { armazenamento }\end{array}$ & 1 & - & 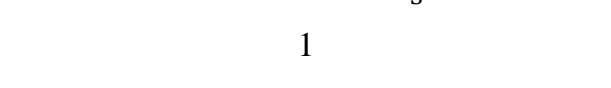 & - \\
\hline Padrões de referência & - & - & $\begin{array}{c}\text { hiperosídeo SQR + quercetina SQR + } \\
\text { vitexina SQR }\end{array}$ & - \\
\hline Rotulagem & - & - & 1 & - \\
\hline
\end{tabular}

(BRASIL, 2010c, d; EDQM, 2016b; USP, 2016h).

Legenda: $\mathrm{mi}=$ menor; $\mathrm{me}=$ moderado; $\mathrm{su}=$ substancial; $\mathrm{se}=$ semelhante; $\mathrm{NLT}=$ não menos que; $\mathrm{MNT}=$ não mais que; $\mathrm{MR}=$ cumpre os requisitos ou o teste; $\mathrm{CCD}=$ cromatografia em camada delgada; $\mathrm{RS}=$ solução referência; $\mathrm{TS}=$ solução amostra; $\mathrm{BS}=$ solução branco; $\mathrm{SR}=$ solução reagente; $\mathrm{SS}=$ solução estoque ou intermediária; $\mathrm{SQR}=$ substância química de referência; TAMC = contagem total de bactérias aeróbias; TYMC = contagem total de fungos e leveduras; UFC = unidade formadora de colônia; CLAE-UV = cromatografia liquida de alta eficiência acoplada a detector por espectrofotometria por absorção no ultravioleta; ODS = coluna cromatográfica octadecilsilanizada; EAVIS = espectrofotometria de absorção no visível; $\mathrm{IE}=$ índice de espuma; $\mathrm{V}=$ volume; $\mathrm{Abs}=\mathrm{A}=$ absorvância $; \mathrm{H}=\mathrm{flavonoides}$ totais; $m=$ massa; $\mathrm{M}=$ masa molar; $\mathrm{C}=$ concentração; $r=$ resposta.

Nota: ${ }^{1}=$ parâmetros extraídos do método geral . 
No geral, as monografias da FB5 e da EP8.8 são convergentes e a monografia da USP39NF34 contém diferenças mais marcantes.

As diferenças substanciais se concentram mais na monografia da USP39-NF34 que apresenta método e especificação adicional para o marcador vitexina e especificação com diferença substancial acima de $30 \%$ para o marcador hiperosídeo.

Há, ainda, diferenças substanciais nos testes adicionais da FB5 (cinco testes de identificação para taninos e agliconas flavonoídicas, índice de espuma e cinzas sulfatadas) e da USP39-NF34 (identificação por CLAE-UV, impurezas elementais e resíduos de agrotóxicos). É importante ressaltar que estão previstos, na monografia geral Herbal Drugs da EP8.8, os testes para metais pesados e resíduos de agrotóxicos.

Diferenças substanciais nas especificações como as encontradas, podem ocasionar barreiras sanitárias ao comércio internacional de matérias-primas e produtos acabados. Esse é um caso de um produto com espécie com ocorrência no Brasil e em outros países, com registros válidos de fitoterápicos no Brasil e com presença de monografia em outras farmacopeias em estudo.

\subsubsection{Curcuma longa L. [rizoma]}

A cúrcuma esteve presente na $1^{\mathrm{a}}$ e $2^{\mathrm{a}}$ edição da Farmacopeia Brasileira (Quadro 3), não está relacionada na IN nº 02/2014 (BRASIL, 2014a), estando no FFFB1 (BRASIL, 2011) e na FB5. Foi encontrado, para a espécie, apenas um registro de fitoterápico válido na Anvisa (Quadro 5). Conforme a literatura consultada, a espécie não possui ocorrência no Brasil (Apêndice A), havendo registro de ocorrência no Belize, Bolívia, China, Colômbia, Costa Rica, Equador, Gabão, Honduras, Índia e Madagascar (TROPICOS.ORG, 2016). Em buscas realizadas nos compêndios internacionais em estudo, foram localizadas monografias na EP8.8 e na USP39-NF34. Os dados extraídos das monografias estão descritos no Quadro 19. 
Quadro 19 - Comparação entre as monografias de Curcuma longa L. [rizoma] das farmacopeias FB5, EP8.8 e USP39-NF34.

\begin{tabular}{|c|c|c|c|c|}
\hline & FB5 & EP8.8 & USP29-NF34 & Classificação \\
\hline Sinonímia botânica & Curcuma domestica Valeton & Curcuma domestica Valeton & Curcuma domestica Valeton & - \\
\hline Nomenclatura popular & cúrcuma & turmeric & turmeric & - \\
\hline Droga vegetal & rizoma & rizoma & rizoma & se \\
\hline Marcador 1 & óleo volátil (NLT 2,5\%) ${ }^{2}$ & óleo volátil (NLT 2,5\%) (droga seca) & óleo volátil (NLT 3,0\%) $)^{1,2}$ & $\mathrm{me} / \mathrm{er}$ \\
\hline Marcador 2 & $\begin{array}{l}\text { derivados do dicinamoilmetano (curcumina) } \\
\text { (NLT 2,5\%) (droga seca) }{ }^{3}\end{array}$ & $\begin{array}{l}\text { derivados do dicinamoilmetano } \\
\text { (curcumina) (NLT 2,0\%) (droga seca) }\end{array}$ & - & me \\
\hline Marcador 3 & - & - & $\begin{array}{l}\text { curcuminoides (NLT 3,0\%) (droga } \\
\text { seca) }\end{array}$ & su \\
\hline Características & $\begin{array}{c}\text { odor fracamente aromático + lembra gengibre }+ \\
\text { sabor picante }+ \text { levemente amargo }\end{array}$ & odor picante & - & - \\
\hline $\begin{array}{l}\text { Descrição } \\
\text { macroscópica }\end{array}$ & 1 & 1 & 1 & - \\
\hline Descrição microscópica & 2 & 1 & 1 & - \\
\hline Figura botânica & 2 & 1 & - & - \\
\hline $\begin{array}{l}\text { Identificação - método } \\
1\end{array}$ & $\mathrm{CCD}$ & $\mathrm{CCD}$ & $\mathrm{CCD}$ & se \\
\hline Procedimento 1 & sílica-gel $\left(\mathrm{GF}_{254}+0,25 \mathrm{~mm}\right)$ & $\begin{array}{c}\text { sílica-gel }\left(\mathrm{F}_{254}+5-40 \mu \mathrm{m}\right) \text { ou }\left(\mathrm{F}_{254}+\right. \\
2-10 \mu \mathrm{m})\end{array}$ & sílica-gel $(0,25 \mathrm{~mm})$ & $\mathrm{mi}$ \\
\hline Procedimento 2 & $\begin{array}{lc}\text { clorofórmio:etanol:ácido } & \text { tolueno:acetato de } \\
\text { acético glacial }(95: 5: 0,5) & \text { etila }(97: 3)\end{array}$ & ácido acético glacial:tolueno (20:80) & $\begin{array}{l}\text { clorofórmio:metanol:ácido fórmico } \\
\qquad(96: 4: 1)\end{array}$ & me \\
\hline Procedimento 3 & $10 \mu \mathrm{L}(\mathrm{TS})(\mathrm{RS})$ (banda) & $\begin{array}{c}10 \mu \mathrm{L} \text { ou } 3 \mu \mathrm{L}(10 \mathrm{~mm} \text { ou } 8 \mathrm{~mm})(\mathrm{TS}) \\
\text { (RS) (banda) }\end{array}$ & $10 \mu \mathrm{L}(\mathrm{TS})(\mathrm{RS})($ banda) & $\mathrm{mi}$ \\
\hline Procedimento 4 & $\begin{array}{c}0,5 \mathrm{~g} \text { droga vegetal recentemente pulverizada }+ \\
5 \mathrm{~mL} \text { metanol }+ \text { agitar }\left(30^{\prime}\right)+\text { centrifugar }\left(10^{\prime}\right) \\
(2500 \mathrm{rpm})+\text { filtrar }(\mathrm{TS})\end{array}$ & $\begin{array}{l}1 \text { g droga vegetal recentemente } \\
\text { pulverizada }(355)+10 \text { mL etanol } 96 \% \\
+ \text { agitar + descansar (agitação } \\
\text { ocasional) }\left(30^{\prime}\right)+\text { filtrar (TS) }\end{array}$ & $\begin{array}{l}0,2 \mathrm{~g} \text { droga vegetal pulverizada }+3 \mathrm{~mL} \\
\text { acetona }+ \text { sonicar }\left(30^{\prime}\right)+\text { centrifugar } \\
\text { (usar sobrenadante) }(\mathrm{TS})\end{array}$ & me \\
\hline Procedimento 5 & 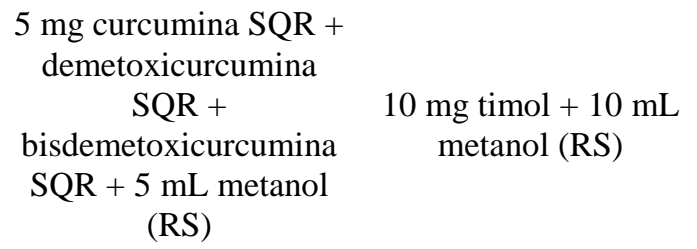 & $\begin{array}{c}20 \mathrm{mg} \text { curcuminoides }+10 \mathrm{mg} \text { timol }+ \\
10 \mathrm{~mL} \text { etanol }(96 \%)(\mathrm{RS})\end{array}$ & $\begin{array}{c}0,2 \mathrm{mg} / \mathrm{mL} \text { curcuminoides } \mathrm{SQR} \text { em } \\
\text { acetona }\end{array}$ & me \\
\hline Procedimento 6 & secar (ar) & secar (ar) & secar & $\mathrm{mi}$ \\
\hline Procedimento 7 & $365 \mathrm{~nm}$ & $365 \mathrm{~nm}$ & $365 \mathrm{~nm}$ & $\begin{array}{l}\text { se } \\
\text { (contil }\end{array}$ \\
\hline
\end{tabular}


Quadro 19 - Comparação entre as monografias de Curcuma longa L. [rizoma] das farmacopeias FB5, EP8.8 e USP39-NF34.

\begin{tabular}{|c|c|c|c|c|}
\hline & FB5 & EP8.8 & USP29-NF34 & Classificação \\
\hline Procedimento 8 & vanilina sulfúrica SR & $\begin{array}{l}\text { solução de anisaldeído SR + aquecer } \\
\left(100-105^{\circ} \mathrm{C}\right)\left(10^{\prime}\right)(365 \mathrm{~nm})\end{array}$ & - & me \\
\hline Procedimento 9 & descrição de zonas & esquema & descrição de zonas & me \\
\hline $\begin{array}{l}\text { Identificação - método } \\
2\end{array}$ & $\begin{array}{l}0,5 \text { g droga vegetal recentemente pulverizada }+ \\
5 \mathrm{~mL} \text { etanol + agitar }\left(5^{\prime}\right)+\text { filtrar + gotejar } \\
\text { (papel de filtro) (coloração amarela) + umedecer } \\
\text { (papel) gotas solução saturada ácido bórico } \\
\text { (coloração vermelho alaranjada) + hidróxido de } \\
\text { amônio (coloração azul-escura) }\end{array}$ & 1 & 3 & su \\
\hline Testes - método 1 & água (NMT 12,0\%) & $\begin{array}{l}\text { água (NMT 12,0\%) }(15,0 \mathrm{~g} \text { droga } \\
\text { vegetal pulverizada }(500)\end{array}$ & água (NMT 10\%) & me \\
\hline Testes - método 2 & cinzas totais (NMT 8,0\%) & cinzas totais (NMT 7,0\%) & cinzas totais (NMT 7,0\%) & me \\
\hline Testes - método 3 & - & - & matéria estranha (NMT 2,0\%) & su \\
\hline Testes - método 4 & - & - & $\begin{array}{l}\text { matéria extraível em etanol (NLT } 100 \\
\mathrm{mg} / \mathrm{g} \text { ) }\end{array}$ & su \\
\hline Testes - método 5 & - & - & matéria extraível em água (NLT 9,0\%) & su \\
\hline Testes - método 6 & - & - & $\begin{array}{c}\text { cinzas insolúveis em ácido (NMT } \\
1,0 \%)\end{array}$ & $\mathrm{su}$ \\
\hline Testes - método 7 & - & - & impurezas elementais (MR) & su \\
\hline Testes - método 8 & - & - & agrotóxicos (MR) & su \\
\hline Testes - método 9 & - & - & $\begin{array}{l}\text { aflatoxinas (MR) } \\
\text { microrganismos (TAMC - NMT } 10^{5}\end{array}$ & su \\
\hline Testes - método 10 & - & - & $\begin{array}{l}\mathrm{UFC} / \mathrm{g}+\mathrm{TYMC}-\mathrm{NMT} 10^{3} \mathrm{UFC} / \mathrm{g}+ \\
\mathrm{TBMC}-\mathrm{NMT} 10^{3} \mathrm{UFC} / \mathrm{g}+\text { ausência } \\
\text { Salmonella e Escherichia coli) }\end{array}$ & - \\
\hline Doseamento - método 1 & destilação (óleo volátil) (NLT 2,5\%) & destilação (óleo volátil) (NLT 2,5\%) & destilação (óleo volátil) (NLT 3,0\%) & me \\
\hline Procedimento 1 & 200 mL água & 400 mL água & água & $\mathrm{mi}$ \\
\hline Procedimento 2 & $0,5 \mathrm{~mL}$ xileno & $0,5 \mathrm{~mL}$ xileno & - & me \\
\hline Procedimento 3 & $\begin{array}{c}5 \mathrm{~g} \text { droga vegetal pulverizada (500) (imediata } \\
\text { determinação) }\end{array}$ & $\begin{array}{l}2,5 \mathrm{~g} \text { droga vegetal pulverizada (500) } \\
\text { (imediata determinação) }\end{array}$ & 33-100 g (pó grosseiro) & mi \\
\hline Procedimento 4 & $4 \mathrm{~h}$ & $2 \mathrm{~mL} / \mathrm{min}(3 \mathrm{~h})$ & $2 \mathrm{~h}$ & me \\
\hline Doseamento - método 2 & $\begin{array}{l}\text { EAVIS (derivados do dicinamoilmetano) } \\
\text { (curcumina) (NLT 2,5\%) }\end{array}$ & $\begin{array}{c}\text { EAVIS (derivados do } \\
\text { dicinamoilmetano) (curcumina) (NLT } \\
2,0 \% \text { ) }\end{array}$ & - & me \\
\hline
\end{tabular}


Quadro 19 - Comparação entre as monografias de Curcuma longa L. [rizoma] das farmacopeias FB5, EP8.8 e USP39-NF34.

\begin{tabular}{|c|c|c|c|c|}
\hline & FB5 & EP8.8 & USP29-NF34 & Classificação \\
\hline Procedimento 1 & $\begin{array}{l}10 \mathrm{mg} \text { droga vegetal }+6 \mathrm{~mL} \text { ácido acético } \\
\text { glacial }+ \text { aquecer (banho-maria) }\left(90^{\circ} \mathrm{C}\right)\left(60^{\prime}\right)+ \\
0,2 \mathrm{~g} \text { ácido bórico }+0,2 \mathrm{~g} \text { ácido oxálico }+ \\
\text { aquecer (banho-maria) }\left(90^{\circ} \mathrm{C}\right)\left(10^{\prime}\right)+\text { esfriar }+ \\
\text { ácido acético glacial para } 10 \mathrm{~mL}+\text { transferir } 1 \\
\mathrm{~mL}+\text { ácido acético glacial para } 10 \mathrm{~mL}(\mathrm{TS})\end{array}$ & $\begin{array}{c}0,500 \mathrm{~g} \text { droga vegetal pulverizada } \\
(500)+30 \mathrm{~mL} \text { etanol } 96 \%+\text { aquecer } \\
\text { (refluxo) }(2 \mathrm{~h} 30)+\text { esfriar }+ \text { filtrar }+ \\
\text { lavar (recipiente }+ \text { filtro) etanol } 96 \%+ \\
\text { etanol } 96 \% \text { para } 100,0 \mathrm{~mL}+\text { transferir } \\
1,0 \mathrm{~mL}+\text { etanol } 96 \% 50,0 \mathrm{~mL}(\mathrm{TS})\end{array}$ & - & me \\
\hline Procedimento 2 & ácido acético glacial (BS) & etanol 96\% (BS) & - & me \\
\hline Procedimento 3 & $530 \mathrm{~nm}$ & $425 \mathrm{~nm}$ & - & me \\
\hline Procedimento 4 & concentração relativa & concentração relativa & - & me \\
\hline \multirow{2}{*}{ Procedimento 5} & $0,0426 \times A$ & $A \times 5000$ & & me \\
\hline & $m$ & $\overline{1607 \times m}$ & & IIIE \\
\hline Doseamento - método 3 & - & - & $\begin{array}{c}\text { CLAE-VIS (curcuminoides) (NLT } \\
3,0 \% \text { ) }\end{array}$ & su \\
\hline Procedimento 1 & - & - & $420 \mathrm{~nm}$ & su \\
\hline Procedimento 2 & - & - & ODS $(20 \mathrm{~cm} \mathrm{x} \mathrm{4,6} \mathrm{mm})(5 \mu \mathrm{m})$ & su \\
\hline Procedimento 3 & - & - & $\begin{array}{l}\text { tetraidrofurano:ácido cítrico } 1 \mathrm{mg} / \mathrm{mL} \\
\qquad(4: 6)(1 \mathrm{~mL} / \mathrm{min})\end{array}$ & su \\
\hline Procedimento 4 & - & - & $\begin{array}{c}0,5 \mathrm{~g} \text { droga vegetal pulverizada }+30 \\
\mathrm{~mL} \text { acetona + sonicar }(30 ')+\text { acetona } \\
\text { para } 50 \mathrm{~mL}+\text { centrifugar }+ \text { transferir } 5 \\
\mathrm{~mL}+\text { tetraidrofurano:ácido cítrico } 1 \\
\mathrm{mg} / \mathrm{mL}(4: 6) \text { para } 50 \mathrm{~mL}(\mathrm{TS})\end{array}$ & su \\
\hline Procedimento 5 & - & - & $\begin{array}{c}40 \mu \mathrm{g} / \mathrm{mL} \text { curcuminoides } \mathrm{SQR} \text { em } \\
\text { tetraidrofurano:ácido cítrico1 mg/mL } \\
(4: 6)\left(\mathrm{RS}_{1}\right)\end{array}$ & su \\
\hline Procedimento 6 & - & - & $\begin{array}{c}40 \mu \mathrm{g} / \mathrm{mL} \text { curcumina } \mathrm{SQR} \text { em } \\
\text { tetraidrofurano:ácido cítrico1 mg/mL } \\
(4: 6)\left(\mathrm{RS}_{2}\right)\end{array}$ & su \\
\hline Procedimento 7 & - & - & $\begin{array}{c}10 \mu \mathrm{g} / \mathrm{mL} \text { demetoxicurcumina } \mathrm{SQR} \text { em } \\
\text { tetraidrofurano:ácido cítrico1 mg/mL } \\
(4: 6)\left(\mathrm{RS}_{3}\right)\end{array}$ & su \\
\hline Procedimento 8 & - & - & $\begin{array}{c}2 \mu \mathrm{g} / \mathrm{mL} \text { bisdemetoxicurcumina } \mathrm{SQR} \\
\text { em tetraidrofurano:ácido cítrico1 } \\
\mathrm{mg} / \mathrm{mL}(4: 6)\left(\mathrm{RS}_{4}\right)\end{array}$ & su \\
\hline Procedimento 9 & - & - & $20 \mu \mathrm{L}$ & $\begin{array}{l}\text { su } \\
\text { (continua) }\end{array}$ \\
\hline
\end{tabular}


Quadro 19 - Comparação entre as monografias de Curcuma longa L. [rizoma] das farmacopeias FB5, EP8.8 e USP39-NF34.

\begin{tabular}{|c|c|c|c|c|}
\hline & FB5 & EP8.8 & USP29-NF34 & Classificação \\
\hline Procedimento 10 & - & - & $\begin{array}{c}\text { tempo retenção (curcumina }+ \\
\text { demetoxicurcumina }+ \\
\text { bisdemetoxicurcumina }(\mathrm{TS}) \sim(\mathrm{RS}))\end{array}$ & su \\
\hline Procedimento 11 & - & - & $\begin{array}{c}\text { cromatograma }\left(\mathrm{SR}_{1}\right) \sim \text { referência }+ \\
\text { resolução (NLT } 2,0 \text { - curcumina e } \\
\text { demetoxicurcumina; } \\
\text { demetoxicurcumina e } \\
\text { bisdemetoxicurcumina) + fator de } \\
\text { cauda (NMT 1,5 - } \\
\text { bisdemetoxicurcumina, } \\
\text { demetoxicurcumina e curcumina) + } \\
\text { desvio padrão relativo (NMT } 2,0 \% \text { - } \\
\text { demetoxicurcumina) }\end{array}$ & su \\
\hline Procedimento 12 & - & - & concentração relativa & su \\
\hline Procedimento 13 & - & - & $\begin{aligned} \text { Result }=\left(\frac{r_{U}}{r_{S}}\right) \times & C_{S} \times\left(\frac{V}{W}\right) \times D \\
& \times 100\end{aligned}$ & $\mathrm{su}$ \\
\hline $\begin{array}{c}\text { Embalagem e } \\
\text { armazenamento }\end{array}$ & 1 & - & 1 & - \\
\hline Padrões de referência & $\begin{array}{c}\text { curcumina } \mathrm{SQR}+\text { demetoxicurcumina } \mathrm{SQR}+ \\
\text { bisdemetoxicurcumina } \mathrm{SQR}\end{array}$ & - & $\begin{array}{c}\text { curcumina } \mathrm{SQR}+\text { demetoxicurcumina } \\
\mathrm{SQR}+\text { bisdemetoxicurcumina } \mathrm{SQR}+ \\
\text { curcuminoides } \mathrm{SQR}\end{array}$ & - \\
\hline Rotulagem & - & - & 1 & - \\
\hline
\end{tabular}

(BRASIL, 2010d; EDQM, 2016b; USP, 2016h).

Legenda: $\mathrm{mi}=$ menor; $\mathrm{me}=$ moderado; $\mathrm{su}=$ substancial; $\mathrm{se}=$ semelhante $;$ er = erro; $\mathrm{NLT}=$ não menos que; $\mathrm{MNT}=$ não mais que; $\mathrm{MR}=\mathrm{cumpre}$ os requisitos ou o teste; $\mathrm{CCD}$ = cromatografia em camada delgada; RS = solução referência; $\mathrm{TS}=$ solução amostra; $\mathrm{BS}=$ solução branco; $\mathrm{SR}=$ solução reagente; rpm = rotações por minuto; $\mathrm{SQR}=$ substância química de referência; TAMC $=$ contagem total de bactérias aeróbias; TBMC $=$ contagem de bactérias Gram-negativas bile tolerantes; TYMC $=$ contagem total de fungos e leveduras; UFC = unidade formadora de colônia; EAVIS = espectrofotometria de absorção no visível; DC $=$ derivados do dicinamoilmetano; A = absorvância; $m=$ $\mathrm{W}=$ massa; CLAE-VIS = cromatografia liquida de alta eficiência acoplada a detector por espectrofotometria por absorção no visível; ODS = coluna cromatográfica octadecilsilanizada; $\mathrm{C}=$ concentração; $\mathrm{r}=$ resposta; $\mathrm{V}=$ volume.

Nota: ${ }^{1}=$ na monografia é descrito como teste e não doseamento ${ }^{2}=$ não há na monografia e nem no método geral indicação de que a base do cálculo é a droga seca, o que indica um erro ou omissão; ${ }^{3}=$ a consideração da determinação de água está na expressão no doseamento; ${ }^{4}=$ parâmetros extraídos do método geral. 
No geral, as monografias da FB5 e da EP8.8 são convergentes e a monografia da USP39NF34 contém diferenças mais marcantes.

As diferenças substanciais entre as monografias se concentram nos testes adicionais da FB5 (um ensaio de identificação) e da USP39-NF34 (matéria estranha, matéria extraível em etanol, matéria extraível em água, impurezas elementares, cinzas insolúveis em ácido, aflatoxinas e resíduos de agrotóxicos), com, ainda, o método e especificação adicional para os curcuminoides. É importante ressaltar que estão previstos, na monografia geral Herbal Drugs da EP8.8, os testes para metais pesados e resíduos de agrotóxicos.

Há, ainda, a ausência na FB5 da indicação de que o óleo volátil deve ser calculado sem considerar a massa de água da droga vegetal, obtida na determinação de água, que por ser uma omissão foi considerada um erro. Ainda, o método para determinação de óleo volátil na FB5 (BRASIL, 2010c) é bem semelhante ao da EP8.8 (EDQM, 2016b), porém a EP8.8 sempre esclarece, nas monografias específicas, a necessidade de se considerar a droga seca, enquanto a FB5 não apresenta essa informação.

A informação de não considerar a considerar a massa de água da droga vegetal no cálculo do óleo volátil também não está descrita na USP39-N34. Porém o seu método de determinação de óleo volátil é diferente dos métodos da FB5 e da EP8.8 e claramente descreve que o teor de óleo volátil deve ser calculado por $100 \mathrm{~g}$ de droga vegetal, considerando a tomada de ensaio (USP, 2016a).

Como espécie que não possui ocorrência no Brasil e com registros de fitoterápicos válidos no Brasil, se esperava que as monografias fossem mais harmonizadas, nesse caso, os resultados acompanharam a expectativa se for considerado a FB5 e a EP8.8, porém não se for considerada a USP39-NF34.

\subsubsection{Datura stramonium L. [folha]}

O estramônio esteve presente em quase todas as edições anteriores da Farmacopeia Brasileira, com exceção da $4^{\mathrm{a}}$ edição (Quadro 3), atualmente, não está relacionado no FFFB1 e nem na IN nº 02/2014 (BRASIL, 2011, 2014a), estando apenas na FB5. Não foram encontrados, para a espécie, registros de fitoterápicos válidos na Anvisa (Quadro 5). Conforme a literatura consultada, a espécie possui ocorrência no Brasil (Apêndice A), não sendo endêmica e sim naturalizada (REFLORA, 2016). Há registro, ainda, de ocorrência da espécie na Argentina,

Belize, Bolívia, Canadá, Caribe, Chile, China, Colômbia, Costa Rica, Equador, El Salvador, 
Guatemala, Madagascar e México (TROPICOS.ORG, 2016). Em buscas realizadas nos compêndios internacionais em estudo, foram localizadas monografias apenas na EP8.8. Os dados extraídos das monografias estão descritos no Quadro 20. 
Quadro 20 - Comparação entre as monografias de Datura stramonium L. [folha] das farmacopeias FB5 e EP8.8.

\begin{tabular}{|c|c|c|c|}
\hline & FB5 & EP8.8 & Classificação \\
\hline Nomenclatura popular & estramônio & stramonium & - \\
\hline Droga vegetal & folha & folha ou folha e sumidade florida ou folha e sumidade com fruto & su \\
\hline Marcador 1 & alcaloides (hiosciamina) (NLT 0,25\%) (droga seca) & alcaloides (hiosciamina) (NLT 0,25\%) (droga seca) & se \\
\hline Características & odor desagradável + sabor nauseoso + levemente salgado & odor desagradável & - \\
\hline Descrição macroscópica & 1 & 1 & - \\
\hline Descrição microscópica & 2 & 1 & - \\
\hline Figura botânica & 2 & 1 & - \\
\hline Identificação - método 1 & $\mathrm{CCD}$ & $\mathrm{CCD}$ & se \\
\hline Procedimento 1 & sílica-gel $\mathrm{GF}_{254}$ & sílica-gel G & se \\
\hline Procedimento 2 & amônia concentrada:água:acetona $(3: 7: 90)$ & amônia concentrada:água:acetona( $3: 7: 90)$ & se \\
\hline Procedimento 3 & $10 \mu \mathrm{L}$ (TS);20 $\mu \mathrm{L}(\mathrm{RS})$ (banda) & $10 \mu \mathrm{L}+20 \mu \mathrm{L}(20 \mathrm{~mm} \times 3 \mathrm{~mm})(\mathrm{TS})(\mathrm{RS})$ (banda) & $\mathrm{mi}$ \\
\hline Procedimento 4 & $\begin{array}{c}1 \mathrm{~g} \text { droga vegetal pulverizada }+10 \mathrm{~mL} \text { ácido sulfúrico } 0,05 M+ \\
\text { agitar }\left(15^{\prime}\right)+\text { filtrar + lavar (filtro) com ácido sulfúrico } 0,05 M \\
\text { até } 25 \mathrm{~mL}+1 \mathrm{~mL} \text { amônia concentrada }+ \text { agitar } 2 \times 10 \mathrm{~mL} \text { éter } \\
\text { etílico isento peróxido + reunir (fases etéreas) + secar (sulfato de } \\
\text { sódio anidro) + filtrar + evaporar (secura) (banho-maria) + 0,5 } \\
\text { mL metanol (TS) }\end{array}$ & $\begin{array}{c}\text { 1,0 g droga vegetal pulverizada }(180)+10 \mathrm{~mL} \text { ácido sulfúrico } \\
0,05 \mathrm{M}+\text { agitar }\left(15^{\prime}\right)+\text { filtrar + lavar (filtro) com ácido sulfúrico } \\
0,05 \mathrm{M} \text { até } 25 \mathrm{~mL}+1 \mathrm{~mL} \text { amônia concentrada + agitar } 2 \times 10 \\
\text { mL éter etílico isento peróxido + reunir (fases etéreas) + secar } \\
\text { (sulfato de sódio anidro) + filtrar + evaporar (secura) (banho- } \\
\text { maria) }+0,5 \mathrm{~mL} \text { metanol (TS) }\end{array}$ & se \\
\hline Procedimento 5 & $\begin{array}{l}\text { 3,8 } \mathrm{mL} \text { (sulfato de hiosciamina:metanol }(50 \mathrm{mg}: 9 \mathrm{~mL}))+4,2 \\
\mathrm{~mL} \text { (bromidrato de escopolamina:metanol }(15 \mathrm{mg}: 10 \mathrm{~mL}))(\mathrm{RS})\end{array}$ & $\begin{array}{l}3,8 \mathrm{~mL} \text { (sulfato de hiosciamina:metanol }(50 \mathrm{mg}: 9 \mathrm{~mL}))+4,2 \\
\mathrm{~mL} \text { (bromidrato de escopolamina:metanol }(15 \mathrm{mg}: 10 \mathrm{~mL}))(\mathrm{RS})\end{array}$ & se \\
\hline Procedimento 6 & $\sec a r\left(100-105^{\circ} \mathrm{C}\right)\left(15^{\prime}\right)+$ esfriar & $\operatorname{secar}\left(100-105^{\circ} \mathrm{C}\right)\left(15^{\prime}\right)+$ esfriar & $\mathrm{se}$ \\
\hline Procedimento 7 & iodobismutato de potássio $\mathrm{SR}^{1}$ & iodobismutato de potássio $\mathrm{SR}^{1}$ & se \\
\hline Procedimento 8 & nitrito de sódio $\mathrm{SR}^{2}+\left(15^{\prime}\right)$ & nitrito de sódio $\mathrm{SR}^{2}+\left(15^{\prime}\right)$ & se \\
\hline Procedimento 9 & descrição de zonas & descrição de zonas & se \\
\hline Identificação - método 2 & $\begin{array}{l}1 \mathrm{~g} \text { droga vegetal pulverizada }+10 \mathrm{~mL} \text { ácido sulfúrico } 0,05 M+ \\
\text { agitar }\left(2^{\prime}\right)+\text { filtrar }+1 \mathrm{~mL} \text { amônia concentrada }+5 \mathrm{~mL} \text { água }+ \\
15 \mathrm{~mL} \text { éter etílico isento peróxidos + agitar (precaução) }+ \text { secar } \\
\text { (fase etérea) (sulfato de sódio anidro) + filtrar + evaporar } \\
\text { (secura) (banho-maria) }+2 \mathrm{~mL} \text { acetona + gotejar hidróxido de } \\
\text { potássio } 3 \% \text { em etanol } 96 \%=\text { violeta intensa }\end{array}$ & $\begin{array}{c}1 \mathrm{~g} \text { droga vegetal pulverizada }(180)+10 \mathrm{~mL} \text { ácido sulfúrico } \\
0,05 M+\text { agitar }(2 ')+\text { filtrar }+1 \mathrm{~mL} \text { amônia concentrada }+5 \mathrm{~mL} \\
\text { água }+15 \mathrm{~mL} \text { éter etílico isento peróxidos }+ \text { agitar (precaução) }+ \\
\text { secar (fase etérea) (sulfato de sódio anidro }+ \text { filtrar }+ \text { evaporar }+ \\
0,5 \mathrm{~mL} \text { ácido nítrico }+ \text { evaporar (secura) (banho-maria) }+10 \mathrm{~mL} \\
\text { acetona }+ \text { gotejar hidróxido de potássio } 3 \% \text { em etanol } 96 \%= \\
\text { violeta intensa }\end{array}$ & me \\
\hline Testes - método 1 & matéria estranha (NMT $3 \%$ - caules $>5 \mathrm{~mm}$ ) & matéria estranha (NMT 3\% - caules > $5 \mathrm{~mm}$ ) & se \\
\hline Testes - método 2 & água (NMT 12,0\%) & - & su \\
\hline Testes - método 3 & cinzas totais (NMT 20\%) & cinzas totais (NMT 20,0\%) & se \\
\hline Testes - método 4 & cinzas insolúveis (NMT 4\%) ${ }^{2}$ & cinzas insolúveis em ácido clorídrico (NMT 4,0\%) & se \\
\hline Doseamento - método 1 & volumetria (alcaloides) (hiosciamina) (NLT 0,25\%) & volumetria (alcaloides) (hiosciamina) (NLT 0,25\%) & $\begin{array}{l}\text { se } \\
\text { conti }\end{array}$ \\
\hline
\end{tabular}


Quadro 20 - Comparação entre as monografias de Datura stramonium L. [folha] das farmacopeias FB5 e EP8.8.

\begin{tabular}{|c|c|c|c|}
\hline & FB5 & EP8.8 & Classificação \\
\hline Procedimento 1 & & $\begin{array}{l}\text { perda por dessecação }(2,000 \mathrm{~g} \text { droga vegetal pulverizada (180)) } \\
\qquad\left(105^{\circ} \mathrm{C}\right)\end{array}$ & se \\
\hline Procedimento 2 & $\begin{array}{c}10 \mathrm{~g} \text { droga vegetal pulverizada }(180)+5 \mathrm{~mL} \text { hidróxido de } \\
\text { amônio }+10 \text { mL etanol } 96 \%+30 \mathrm{~mL} \text { éter etílico isento de } \\
\text { peróxidos + macerar }(4 \mathrm{~h})+\text { percolar (clorofórmio:éter etílico } \\
\text { isento de peróxidos }(1: 3) \text { ) até extração completa + evaporar } 1 \\
\text { mL percolado (secura) + ácido sulfúrico } 0,25 M+\text { iodeto de } \\
\text { potássio mercúrico SR (ausência alcaloides) + reduzir para } 50 \\
\text { mL + transferir com éter etílico isento de peróxidos + 2,5 x } \\
\text { volume (percolador) éter etílico isento de peróxidos + extrair } 3 \mathrm{x} \\
20 \mathrm{~mL} \text { ácido sulfúrico } 0,25 M+\text { transferir (fase ácida) + } \\
\text { alcalinizar (pH 8,0-9,0) (hidróxido de amônio) + extrair 3x } 30 \\
\text { mL clorofórmio + reunir (fases clorofórmicas) + } 4 \mathrm{~g} \text { sulfato de } \\
\text { sódio anidro + descansar (30') (agitação ocasional) + separar } \\
\text { (fase clorofórmica) + lavar (sulfato de sódio) 3x } 10 \mathrm{~mL} \\
\text { clorofórmio + reunir (fases clorofórmicas) + evaporar (secura) } \\
\text { (banho-maria) }\end{array}$ & 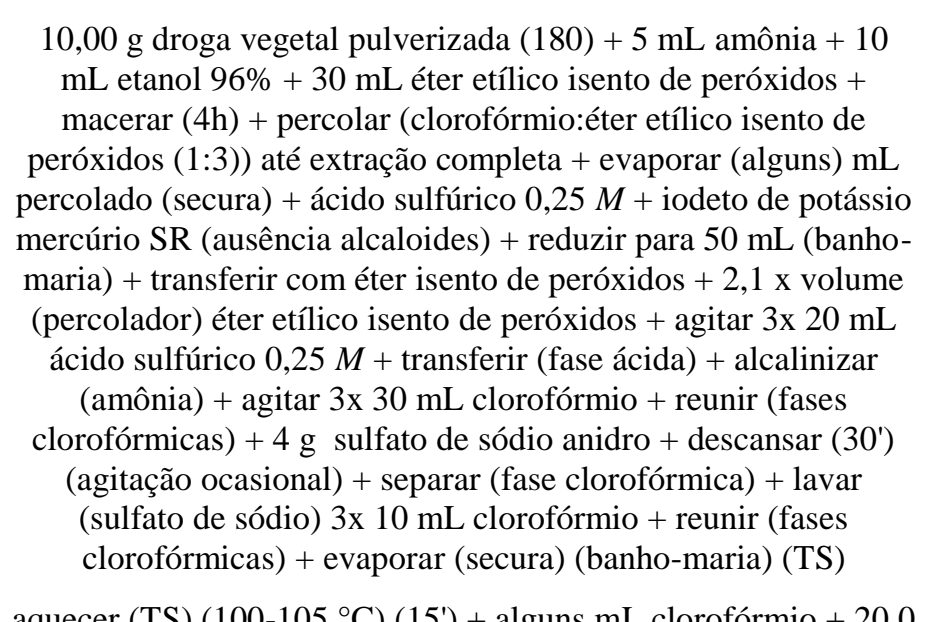 & $\mathrm{mi}$ \\
\hline Procedimento 3 & $\begin{array}{c}\text { aquecer (TS) }\left(100-105^{\circ} \mathrm{C}\right)\left(15^{\prime}\right)+5 \mathrm{~mL} \text { clorofórmio }+20 \mathrm{~mL} \\
\text { ácido sulfúrico 0,01 } \mathrm{M} \mathrm{SV}+\text { evaporar (clorofórmio) (banho- } \\
\text { maria) + titular (hidróxido de sódio 0,02 M SV) }\end{array}$ & $\begin{array}{c}\text { aquecer }(\mathrm{TS})\left(100-105^{\circ} \mathrm{C}\right)\left(15^{\prime}\right)+\text { alguns } \mathrm{mL} \text { clorofórmio }+20,0 \\
\text { mL ácido sulfúrico } 0,01 M+\text { evaporar (clorofórmio) }(\text { banho- } \\
\text { maria) + titular (hidróxido de sódio } 0,02 M)\end{array}$ & se \\
\hline Procedimento 4 & vermelho de metila SI & solução mista de vermelho de metila SR & $\mathrm{mi}$ \\
\hline Procedimento 5 & $\%$ alcaloides $=\frac{57,88 \times(20-\mathrm{n})}{(100-\mathrm{d}) \times m}$ & $\frac{57,88 \times(20-\mathrm{n})}{(100-\mathrm{d}) \times m}$ & se \\
\hline $\begin{array}{c}\text { Embalagem e } \\
\text { armazenamento }\end{array}$ & 1 & $1^{3}$ & - \\
\hline
\end{tabular}

(BRASIL, 2010d; EDQM, 2016b).

Legenda: mi = menor; me = moderado su = substancial; se = semelhante NLT = não menos que MNT = não mais que CCD = cromatografia em camada delgada RS = solução referência; $\mathrm{TS}=$ solução amostra; $\mathrm{SR}=$ solução reagente; $\mathrm{SI}=$ solução indicadora; $\mathrm{SV}=$ solução volumétrica; $m=$ massa; $\mathrm{n}=$ volume; $\mathrm{d}=$ perda por dessecação. Nota: ${ }^{1}=$ conforme capítulo de soluções reagentes ambas soluções são idênticas; ${ }^{2}=$ conforme método geral o ácido empregado é o ácido clorídrico a $7 \% ;{ }^{3}=$ apenas armazenamento. 
No geral, as monografias são convergentes. Porém, a diferença substancial na definição da droga vegetal para a qual a FB5 considera apenas a folha e a EP8.8 considera a folha, como na FB5, ou folha e sumidade florida, ou folha e sumidade com fruto, pode impactar nos resultados alcançados pela droga vegetal em todos os demais métodos, ensaios e especificações da monografia.

Há, ainda, diferença substancial no teste adicional da FB5 com especificação para a determinação da água, cuja execução é exigida no doseamento da monografia na EP8.8, porém, sem especificação estabelecida.

Como a espécie possui ocorrência no Brasil e em outros países, esteve listada em quase todas as edições anteriores da Farmacopeia Brasileira e possui monografia na FB5 convergente com a EP8.8 (com exceção da droga vegetal), facilitando com que empresas multinacionais possam cumprir os requisitos para obter autorização de comercialização no Brasil, se esperava que houvesse registros válidos de fitoterápicos no Brasil, porém, nesse caso, os resultados não acompanharam a expectativa.

\subsubsection{Elettaria cardamomum (L.) Maton [semente]}

O cardamomo esteve presente na $1^{\mathrm{a}}$ e $2^{\mathrm{a}}$ edição da Farmacopeia Brasileira (Quadro 3), atualmente, não está relacionada no FFFB1 e nem na IN nº 02/2014 (BRASIL, 2011, 2014a), estando apenas na FB5. Não foram encontrados, para a espécie, registros de fitoterápicos válidos na Anvisa (Quadro 5). Conforme a literatura consultada, a espécie não possui ocorrência no Brasil (Apêndice A), havendo registro de ocorrência da espécie na Colômbia, Costa Rica e Honduras (TROPICOS.ORG, 2016). Em buscas realizadas nos compêndios internacionais em estudo, foram localizadas monografias apenas na USP39-NF34. Os dados extraídos das monografias estão descritos no Quadro 21. 
Quadro 21 - Comparação entre as monografias de Elettaria cardamomum (L.) Maton [semente] das farmacopeias FB5 e USP39-NF34.

\begin{tabular}{|c|c|c|c|}
\hline & FB5 & USP39-NF34 & Classificação \\
\hline Nomenclatura botânica & Elettaria cardamomum (L.) Maton & Elettaria cardamomum (L.) Maton var. cardamomum & - \\
\hline Nomenclatura popular & cardamomo & cardamom & - \\
\hline Droga vegetal & semente (recentemente removida do fruto) & semente (recentemente removida do fruto) & se \\
\hline Marcador 1 & óleo volátil (NLT 5\%) & - & su \\
\hline Características & odor forte + sabor levemente acre & - & - \\
\hline Descrição macroscópica & 2 & 2 & - \\
\hline Descrição microscópica & 2 & 2 & - \\
\hline Figura botânica & 2 & - & - \\
\hline Identificação - método 1 & $\mathrm{CCD}$ & - & su \\
\hline Procedimento 1 & sílica-gel $\left(\mathrm{GF}_{254}+0,25 \mathrm{~mm}\right)$ & - & su \\
\hline Procedimento 2 & tolueno:acetato de etila $(93: 7)$ & - & su \\
\hline Procedimento 3 & $20 \mu \mathrm{L}$ (TS) (RS) (banda) & - & su \\
\hline Procedimento 4 & $\begin{array}{c}0,1 \mathrm{~g} \text { droga vegetal moída }+2 \mathrm{~mL} \text { diclorometano }+ \text { agitar }\left(15^{\prime}\right)+ \\
\text { filtrar }+ \text { evaporar (secura) (banho-maria) }\left(60^{\circ} \mathrm{C}\right)+2 \mathrm{~mL} \text { tolueno } \\
\text { (TS) }\end{array}$ & - & su \\
\hline Procedimento 5 & $\begin{array}{c}10 \mu \mathrm{g} \text { acetato de terpenila }+10 \mu \mathrm{g} 1,8 \text {-cineol }+10 \mu \mathrm{L} \text { linalol }+1 \\
\mathrm{~mL} \text { tolueno }(\mathrm{RS})\end{array}$ & - & su \\
\hline Procedimento 6 & secar $(\operatorname{ar})$ & - & su \\
\hline Procedimento 7 & vanilina sulfúrica $\mathrm{SR}+$ aquecer $\left(100-105^{\circ} \mathrm{C}\right)\left(5^{\prime}\right)$ & - & su \\
\hline Procedimento 8 & descrição de zonas & - & su \\
\hline Testes - método 1 & cinzas totais (NMT 4,0\%) & - & su \\
\hline Testes - método 2 & - & cinzas insolúveis em ácido (NMT 4,0\%) & su \\
\hline Doseamento - método 1 & destilação (óleo volátil) (NLT 0,5\%) & - & $\mathrm{su}$ \\
\hline Procedimento 1 & 200 mL água & - & su \\
\hline Procedimento 2 & $0,5 \mathrm{~mL}$ xileno & - & su \\
\hline Procedimento 3 & $\begin{array}{c}20 \mathrm{~g} \text { droga vegetal (remover semente do fruto + imediata } \\
\text { determinação) }\end{array}$ & - & $\mathrm{su}$ \\
\hline Procedimento 4 & $5 \mathrm{~h}$ & - & $\mathrm{su}$ \\
\hline $\begin{array}{l}\text { Embalagem e } \\
\text { armazenamento }\end{array}$ & 1 & 1 & - \\
\hline Rotulagem & - & 1 & - \\
\hline
\end{tabular}

(BRASIL, 2010d; USP, 2016h). 
Legenda: $\mathrm{su}=$ substancial; se = semelhante; NLT = não menos que; MNT = não mais que; CCD = cromatografia em camada delgada; RS = solução referência; TS = solução amostra; SR = solução reagente.

(conclusão) 
As monografias são substancialmente diferentes. A monografia da USP39-NF34 para o Elettaria cardamomum (L.) Maton [semente] pertence ao National Formulary, que apresenta especificações para a excipientes (USP, 2016e). Para uma monografia destinada a excipientes, não se espera que haja especificações para marcadores, havendo apenas testes e ensaios para garantir um mínimo de qualidade e autenticidade do excipiente.

Como espécie que não possui ocorrência no Brasil, a origem da matéria-prima não é nacional. Assim, se esperava que os métodos e especificações fossem mais harmonizados, porém, nesse caso, a espécie não possui registros válidos junto à Anvisa, nem está listada em outros compêndios e nem na lista de registro simplificado. Isso pode indicar que há baixa utilização da monografia no Brasil e, pode, eventualmente, explicar, o porquê de a monografia não ser tão harmonizada quanto o esperado, além, é claro da diversa destinação das monografias, uma para medicamentos e outra para excipientes.

\subsubsection{Gentiana lutea L. [raiz e rizoma]}

A genciana esteve presente em quase todas as edições da Farmacopeia Brasileira, com exceção da $3^{\mathrm{a}}$ edição (Quadro 3), atualmente, não está relacionada no FFFB1 e nem na IN no 02/2014 (BRASIL, 2011, 2014a), estando apenas na FB5. Foram encontrados, para a espécie, três registros de fitoterápicos válidos na Anvisa (Quadro 5). Conforme a literatura consultada, a espécie não possui ocorrência no Brasil (Apêndice A). Em buscas realizadas nos compêndios internacionais em estudo, foram localizadas monografias apenas na EP8.8. Os dados extraídos das monografias estão descritos no Quadro 22. 
Quadro 22 - Comparação entre as monografias de Gentiana lutea L. [raiz e rizoma] das farmacopeias FB5 e EP8.8.

\begin{tabular}{|c|c|c|c|}
\hline & FB5 & EP8.8 & Classificação \\
\hline Nomenclatura popular & genciana & gentian & - \\
\hline Droga vegetal & raiz e rizoma & raiz e rizoma & se \\
\hline Características & odor forte + sabor amargo persistente & sabor amargo forte persistente & - \\
\hline Descrição macroscópica & 1 & 1 & - \\
\hline Descrição microscópica & 2 & 1 & - \\
\hline Figura botânica & 2 & 1 & - \\
\hline Identificação - método 1 & $\mathrm{CCD}$ & $\mathrm{CCD}$ & se \\
\hline Procedimento 1 & sílica-gel $\left(\mathrm{GF}_{254}+0,25 \mathrm{~mm}\right)$ & sílica-gel $F_{254}$ & $\mathrm{mi}$ \\
\hline Procedimento 2 & acetona:diclorometano:água (70:30:2) & água:ácido fórmico anidro:metanoato de etila (4:8:88) & me \\
\hline Procedimento 3 & 15-20 $\mu \mathrm{L}$ (TS); 5-10 $\mu \mathrm{L}$ (RS) (banda) & $20 \mu \mathrm{L}$ (TS) (RS) (banda) & me \\
\hline Procedimento 4 & $\begin{array}{l}2 \mathrm{~g} \text { droga vegetal pulverizada }+20 \mathrm{~mL} \text { metanol }+ \text { agitar }\left(20^{\prime}\right)+ \\
\text { filtrar }+ \text { evaporar (secura) (pressão reduzida) }\left(<50^{\circ} \mathrm{C}\right)+5 \mathrm{~mL} \\
\text { metanol (TS) }\end{array}$ & $\begin{array}{c}1,0 \mathrm{~g} \text { droga vegetal pulverizada }(355)+25 \mathrm{~mL} \text { metanol }+ \text { agitar } \\
\left(15^{\prime}\right)+\text { filtrar + evaporar (secura) (pressão reduzida) }\left(<50^{\circ} \mathrm{C}\right)+ \\
5 \mathrm{~mL} \text { metanol (TS) }\end{array}$ & me \\
\hline Procedimento 5 & amarogentina $0,5 \%$ + gentiopicrosídeo $0,12 \%$ em metanol (RS) & $5 \mathrm{mg}$ hiperosídeo $+5 \mathrm{mg}$ fenazona $+10 \mathrm{~mL}$ metanol $(\mathrm{RS})$ & me \\
\hline Procedimento 6 & secar $(\operatorname{ar})\left(15^{\prime}\right)$ & secar (ar) & $\mathrm{mi}$ \\
\hline Procedimento 7 & $254 \mathrm{~nm}$ & $254 \mathrm{~nm}$ & se \\
\hline Procedimento 8 & vanilina sulfúrica $\mathrm{SR}+$ aquecer $\left(100-105^{\circ} \mathrm{C}\right)\left(5^{\prime}\right)$ & $\begin{array}{c}\text { hidróxido de potássio } 10 \% \text { em metanol + fast blue } B 0,2 \% \text { em } \\
\text { etanol anidro:água (50:50) (recém-preparado) }\end{array}$ & me \\
\hline Procedimento 9 & descrição de zonas & esquema & me \\
\hline Testes - método 1 & matéria estranha (NMT 2\%) & matéria estranha $(\mathrm{NMT} 2 \%)^{1}$ & se \\
\hline Testes - método 2 & água (NMT 8\%) & - & su \\
\hline Testes - método 3 & cinzas totais (NMT 6\%) & cinzas totais (NMT 6,0\%) & se \\
\hline Testes - método 4 & $\begin{array}{c}\text { matéria extraível com água (NLT 0,165g) (5 g droga vegetal } \\
\text { pulverizada }+200 \mathrm{~mL} \text { água fervente }+ \text { agitar (constantemente) } \\
\left(10^{\prime}\right)+\text { esfriar + água para } 200 \mathrm{~mL}+\text { filtrar }+ \text { transferir } 20 \mathrm{~mL}+ \\
\text { evaporar (secura) + dessecar (resíduo })\left(100-105^{\circ} \mathrm{C}\right) \text { até peso } \\
\text { constante) }\end{array}$ & $\begin{array}{c}\text { matéria extraível com água (NLT 33\%) }(5,0 \mathrm{~g} \text { droga vegetal } \\
\text { pulverizada }(710)+200 \mathrm{~mL} \text { água fervente }+ \text { descansar (agitar } \\
\text { ocasionalmente) }(10 \text { ') }+ \text { esfriar }+ \text { água para } 200,0 \mathrm{~mL}+\text { filtrar }+ \\
\text { transferir } 20 \mathrm{~mL}+\text { evaporar }(\text { secura })(\text { banho-maria })+\text { dessecar } \\
\left.\text { (resíduo) }\left(100-105^{\circ} \mathrm{C}\right)\right)\end{array}$ & se \\
\hline Índices - método 1 & $\begin{array}{l}\text { índice de amargor (NLT 10000) (1 g droga vegetal pulverizada } \\
\quad+1000 \mathrm{~mL} \text { água fervente + manter (banho-maria) (agitar } \\
\text { ocasionalmente) }(30 \text { ') + esfriar + água para } 1000 \mathrm{~mL}+\text { agitar } \\
\text { (vigorosamente })+ \text { filtrar + descartar primeiros } 20 \mathrm{~mL} \text { ) }\end{array}$ & $\begin{array}{c}\text { índice de amargor (NLT 10000) }(1,0 \mathrm{~g} \text { droga vegetal }+100 \mathrm{~mL} \\
\text { água fervente + aquecer (banho-maria) (agitar ocasionalmente) } \\
\left.\left(30^{\prime}\right)+\text { esfriar + água para } 100 \mathrm{~mL}+\text { agitar (vigorosamente }\right)+ \\
\text { filtrar + descartar primeiros } 2 \mathrm{~mL})^{2}\end{array}$ & $\mathrm{se} / \mathrm{er}^{3}$ \\
\hline $\begin{array}{l}\text { Embalagem e } \\
\text { armazenamento }\end{array}$ & 1 & - & - \\
\hline
\end{tabular}


(BRASIL, 2010d; EDQM, 2016b)

Legenda: mi = menor; me = moderado; $s u=$ substancial; se = semelhante; er = erro; NLT = não menos que; MNT = não mais que; CCD = cromatografia em camada delgada; $\mathrm{RS}=$ solução referência; $\mathrm{TS}$ = solução amostra; $\mathrm{SR}=$ solução reagente .

Nota: ${ }^{1}=$ parâmetros extraídos do método geral; ${ }^{2}=$ a diferença de diluição de uma potência sugere erro no método.

(conclusão) 
No geral as monografias da FB5 e da EP8.8 são convergentes, com métodos, ensaios e testes semelhantes. Há diferença substancial apenas no teste adicional da FB5 de determinação de água que não consta na EP8.8.

Há, ainda, no método de determinação do índice de amargor, uma diferença na diluição da preparação da solução inicial da ordem de 10 vezes, que, por seu caráter, foi considerada como um erro. A proposta de revisão da monografia da FB5 apresentada na Consulta Pública n 163 de 11 de abril de 2016 (CP n 163/2016) (BRASIL, 2016b) não contém mais os detalhes da preparação da solução amostra. Estes detalhes, embora não estivessem nos métodos de farmacognosia da FB5 estão apresentados na proposta de revisão dos métodos de farmacognosia na Consulta Pública n ${ }^{\circ} 159$ de 08 de abril de 2016 (CP nº 159/2016), no qual foi corrigido o erro da diluição (BRASIL, 2016a).

Como espécie que não possui ocorrência no Brasil e com registros de fitoterápicos válidos no Brasil, se esperava que as monografias fossem harmonizadas, nesse caso, os resultados acompanharam a expectativa.

\subsubsection{Hydrastis canadensis L. [raiz e rizoma]}

O hidraste esteve presente em todas as edições da Farmacopeia Brasileira (Quadro 3), atualmente, não está relacionada no FFFB1 e nem na IN nº 02/2014 (BRASIL, 2011, 2014a), estando apenas na FB5. Não foram encontrados, para a espécie, registros de fitoterápicos válidos na Anvisa (Quadro 5). Conforme a literatura consultada, a espécie não possui ocorrência no Brasil (Apêndice A), havendo registro de ocorrência no Canadá e nos Estados Unidos da América (TROPICOS.ORG, 2016). Em buscas realizadas nos compêndios internacionais em estudo, foram localizadas monografias na EP8.8 e na USP39-NF34. Os dados extraídos das monografias estão descritos no Quadro 23. 
Quadro 23 - Comparação entre as monografias de Hydrastis canadensis L. [raiz e rizoma] das farmacopeias FB5, EP8.8 e USP39-NF34.

\begin{tabular}{|c|c|c|c|c|}
\hline & FB5 & EP8.8 & USP39-NF34 & Classificação \\
\hline Nomenclatura popular & hidraste & goldenseal & goldenseal & - \\
\hline Droga vegetal & raiz e rizoma & raiz e rizoma & raiz e rizoma & se \\
\hline Marcador 1 & hidrastina (NLT 2,5\%) (droga seca) & hidrastina (NLT 2,5\%) (droga seca) & hidrastina (NLT 2,0\%) (droga seca) & me \\
\hline Marcador 2 & berberina (NLT 3,0\%) (droga seca) & berberina (NLT 3,0\%) (droga seca) & berberina (NLT 2,5\%) (droga seca) & me \\
\hline Características & odor fraco + sabor fortemente amargo & - & - & - \\
\hline Descrição macroscópica & 1 & 1 & 1 & - \\
\hline Descrição microscópica & 2 & 1 & 1 & - \\
\hline Figura botânica & 1 & 1 & - & - \\
\hline Identificação - método 1 & CCD & CCD & CCDAE & me \\
\hline Procedimento 1 & sílica-gel $\left(\mathrm{GF}_{254}+0,25 \mathrm{~mm}\right)$ & sílica-gel $(5-40 \mu \mathrm{m})$ ou $(2-10 \mu \mathrm{m})$ & sílica-gel $(5 \mu \mathrm{m})$ & me \\
\hline Procedimento 2 & propanol:ácido fórmico:água (90:1:9) & $\begin{array}{l}\text { ácido fórmico anidro:água:acetato de etila } \\
\qquad(10: 10: 80)\end{array}$ & $\begin{array}{l}\text { acetato de etila:metanol:ácido } \\
\text { fórmico:água (50:10:6:3) }\end{array}$ & me \\
\hline Procedimento 3 & $15-20 \mu \mathrm{L}$ (TS) ;3-5 $\mu \mathrm{L}$ (RS) (banda) & $20 \mu \mathrm{L}$ ou $2 \mu \mathrm{L}$ (TS) (RS) (banda) & $8 \mu \mathrm{L}(8 \mathrm{~mm})(\mathrm{TS})(\mathrm{RS})($ banda) & me \\
\hline Procedimento 4 & $\begin{array}{l}0,5 \mathrm{~g} \text { droga vegetal pulverizada }+15 \mathrm{~mL} \\
\text { etanol } 60 \%+\text { extrair (agitação magnética) } \\
\left(15^{\prime}\right)+\text { filtrar }+ \text { repetir } 2 \mathrm{x}+\text { reunir } \\
\text { (extratos) + evaporar (pressão reduzida) } \\
\text { até } 5 \mathrm{~mL}+\text { etanol } 60 \% \text { para } 10 \mathrm{~mL}(\mathrm{TS})\end{array}$ & $\begin{array}{c}250 \text { mg droga vegetal pulverizada }(180)+ \\
4 \text { mL água:metanol }(20: 80)+\text { sonicar }(10 ') \\
\text { + filtrar + lavar (resíduo) 2x } 2 \mathrm{~mL} \\
\text { metanol + reunir (filtrado + líquidos de } \\
\text { lavagem) + metanol para } 20 \mathrm{~mL}(\mathrm{TS})\end{array}$ & $\begin{array}{l}0,25 \mathrm{~g} \text { droga vegetal }+4 \mathrm{~mL} \text { metanol } 80 \% \\
+ \text { sonicar }(30 \text { ') + separar (sobrenadante) + } \\
\text { lavar (resíduo) } 2 \times 2 \mathrm{~mL} \text { metanol + reunir } \\
\text { (sobrenadante + líquidos de lavagem) + } \\
\text { metanol para } 20 \mathrm{~mL}+\text { filtrar (TS) }\end{array}$ & me \\
\hline Procedimento 5 & $\begin{array}{c}\text { cloridrato de hidrastina + cloridrato de } \\
\text { berberina } 0,1 \% \text { em etanol } 60 \% \text { (recém- } \\
\text { preparada) (RS) }\end{array}$ & $\begin{array}{c}5 \mathrm{mg} \text { cloridrato de hidrastina }+5 \mathrm{mg} \\
\text { cloridrato de berberina }+20 \mathrm{~mL} \text { metanol } \\
\text { (recém-preparada) }(\mathrm{RS})\end{array}$ & $\begin{array}{c}0,5 \mathrm{mg} / \mathrm{mL} \text { hidrastina } \mathrm{SQR}+0,025 \mathrm{mg} / \mathrm{L} \\
\text { cloridrato de berberina } \mathrm{SQR} \text { em metanol } \\
(\mathrm{RS})\end{array}$ & mi \\
\hline Procedimento 6 & secar (ar) & secar (ar) & secar (ar) & se \\
\hline Procedimento 7 & $365 \mathrm{~nm}$ & $365 \mathrm{~nm}$ & $365 \mathrm{~nm}$ & se \\
\hline Procedimento 8 & $\begin{array}{l}\text { iodeto de potássio subnitrato de bismuto } \\
\text { SR }\end{array}$ & - & - & mi \\
\hline Procedimento 9 & descrição de zonas & esquema & descrição de zonas & se \\
\hline Identificação - método 2 & $\begin{array}{c}1 \text { g droga vegetal pulverizada }+5 \mathrm{~mL} \\
\text { diclorometano }+ \text { maceração (agitação } \\
\text { ocasional) }(1 \mathrm{~h})+\text { filtrar }+ \text { evaporar }+1 \\
\mathrm{~mL} \text { ácido sulfúrico }+1 \text { cristal de } \\
\text { molibdato de amônio }=\text { azul intenso } \\
\text { (hidrastina) }\end{array}$ & - & - & su \\
\hline Testes - método 1 & matéria estranha (NMT 2\%) & matéria estranha (NMT 2,0\%)* & matéria estranha (NMT 2,0\%) & $\begin{array}{l}\text { se } \\
\text { (continua) }\end{array}$ \\
\hline
\end{tabular}


Quadro 23 - Comparação entre as monografias de Hydrastis canadensis L. [raiz e rizoma] das farmacopeias FB5, EP8.8 e USP39-NF34.

\begin{tabular}{|c|c|c|c|c|}
\hline & FB5 & EP8.8 & USP39-NF34 & Classificação \\
\hline Testes - método 2 & água (NMT 10\%) $\left(100-105^{\circ} \mathrm{C}\right)(5 \mathrm{~h})^{1}$ & $\begin{array}{c}\text { perda por dessecação (NMT 10,0\%) } \\
(1,000 \text { g droga vegetal pulverizada }(180)) \\
\left(105^{\circ} \mathrm{C}\right)(2 \mathrm{~h})\end{array}$ & $\begin{array}{l}\text { perda por dessecação (NMT 12,0\%) }(2,0 \mathrm{~g} \\
\text { droga vegetal finamente pulverizada) (100 } \\
\left.{ }^{\circ} \mathrm{C}\right)(5 \mathrm{~h})\end{array}$ & me \\
\hline Testes - método 3 & cinzas totais (NMT 8\%) & cinzas totais (NMT 8,0\%) & $\begin{array}{l}\text { cinzas totais (NMT 9,0\%) }(1,0 \mathrm{~g} \text { droga } \\
\text { vegetal finamente pulverizada) }\end{array}$ & me \\
\hline Testes - método 4 & - & $\begin{array}{c}\text { cinzas insolúveis em ácido clorídrico } \\
\text { (NMT 4,0\%) }\end{array}$ & cinzas insolúveis em ácido (NMT 5\%) & su \\
\hline Testes - método 5 & - & . & impurezas elementais (MR) & su \\
\hline Testes - método 6 & - & - & agrotóxicos (MR) & su \\
\hline Doseamento - método 1 & $\begin{array}{l}\text { CLAE-UV (NLT 2,5\% - hidrastina)(NLT } \\
\text { 3,0\% - berberina) }\end{array}$ & $\begin{array}{l}\text { CLAE-UV (NLT 2,5\% - hidrastina)(NLT } \\
\text { 3,0\% - berberina) }\end{array}$ & $\begin{array}{c}\text { CLAE-UV (NLT 2,0\% - hidrastina)(NLT } \\
\text { 2,5\% - berberina) }\end{array}$ & me \\
\hline Procedimento 1 & $235 \mathrm{~nm}$ & $235 \mathrm{~nm}$ & $235 \mathrm{~nm}$ & se \\
\hline Procedimento 2 & $\begin{array}{l}\text { pré-coluna octadecilsilanizada + ODS } \\
(0,75 \mathrm{~m} \times 4,6 \mathrm{~mm})(3,5 \mu \mathrm{m})\end{array}$ & ODS $(0,125 \mathrm{~m} \times 4 \mathrm{~mm})(5 \mu \mathrm{m})$ & ODS $(150 \mathrm{~m} \mathrm{x} \mathrm{4,6} \mathrm{mm)}$ & me \\
\hline Procedimento 3 & $\begin{array}{l}\text { fosfato monobásico de potássio } 0,05 \\
M: \text { acetonitrila }(73: 27)(0,30 \mathrm{~mL} / \mathrm{min})\end{array}$ & $\begin{array}{c}\text { fosfato monobásico de } \\
\text { potássio:água:acetonitrila }(9,93: 730: 270) \\
(1,2 \mathrm{~mL} / \mathrm{min})\end{array}$ & $\begin{array}{c}\text { fosfato monobásico de } \\
\text { potássio:água:acetonitrila }(9,93: 730: 270) \\
(1,8 \mathrm{~mL} / \mathrm{min})\end{array}$ & me \\
\hline Procedimento 4 & $\begin{array}{c}1000 \text { g droga vegetal pulverizada }+50 \mathrm{~mL} \\
\text { amônia } 1 \% \text { em etanol + aquecer } \\
\text { (ebulição) (refluxo) }\left(30^{\prime}\right)+\text { esfriar } \\
\text { (ambiente) + filttrar (algodão) + retomar } \\
\text { (algodão + resí́duo) + extrair } 2 \times 30 \mathrm{~mL} \\
\text { amônia } 1 \% \text { em etanol + aquecer (refluxo) } \\
\left(10^{\prime}\right)+\text { filtrar (algodão) + reunir (extratos) } \\
\text { + filtrar (papel de filtro) + lavar (balão + } \\
\text { papel de filtro) com } 20 \mathrm{~mL} \text { amônia } 1 \% \mathrm{em} \\
\text { etanol + evaporar (secura) (pressão } \\
\text { reduzida) (banho-maria) }\left(55^{\circ} \mathrm{C}\right)+50 \mathrm{~mL} \\
\text { fosfato monobásico de potássio } 0,05 \\
M \text { :acetonitrila (73:27) + transferir } 1 \mathrm{~mL}+ \\
\text { fosfato monobásico de potássio } 0,05 \\
M \text { :acetonitrila (73:27) para } 50 \mathrm{~mL}+\text { filtrar } \\
\text { (membrana } 0,45 \mu \mathrm{m})(\mathrm{TS})\end{array}$ & $\begin{array}{c}1,000 \mathrm{~g} \text { droga vegetal pulverizada }(355)+ \\
50 \mathrm{~mL} \text { amônia concentrada } 1 \% \text { em etanol } \\
96 \% \text { + ferver (refluxo) }\left(30^{\prime}\right)+\text { esfriar } \\
\text { (ambiente) + filtrar (algodão) + retomar } \\
\text { (algodão + resí́duo) + extrair } 2 \times 30 \mathrm{~mL} \\
\text { amônia concentrada } 1 \% \text { em etanol } 96 \%+ \\
\text { ferver (refluxo) }\left(10^{\prime}\right)+\text { filtrar (algodão) + } \\
\text { reunir (extratos) + filtrar (papel de filtro) } \\
\text { + lavar (balão + papel de filtro) com } 20 \\
\mathrm{~mL} \text { amônia concentrada } 1 \% \text { em etanol } \\
96 \% \text { + evaporar (secura) (pressão } \\
\text { reduzida) (banho-maria) }\left(55^{\circ} \mathrm{C}\right)+50 \mathrm{~mL} \\
\text { fosfato monobásico de } \\
\text { potássio:água:acetonitrila }(9,93: 730: 270) \\
\text { + transferir } 10,0 \mathrm{~mL}+\text { fosfato monobásico } \\
\text { de potássio:água:acetonitrila } \\
\text { (9,93:730:270) para } 50,0 \mathrm{~mL}(\mathrm{TS})\end{array}$ & $\begin{array}{l}0,12 \mathrm{~g} \text { droga vegetal finamente } \\
\text { pulverizada }+40 \mathrm{~mL} \text { fosfato monobásico } \\
\text { de potássio } 0,1 \mathrm{M} \text { :acetonitrila }(60: 40)+ \\
\text { sonicar }\left(5^{\prime}\right)+\text { agitar }\left(10^{\prime}\right)+\text { fosfato } \\
\text { monobásico de potássio } 0,1 \mathrm{M} \text { :acetonitrila } \\
(60: 40) \text { para } 50 \mathrm{~mL}+\text { filtrar (TS) }\end{array}$ & $\mathrm{me} / \mathrm{er}{ }^{2}$ \\
\hline
\end{tabular}


Quadro 23 - Comparação entre as monografias de Hydrastis canadensis L. [raiz e rizoma] das farmacopeias FB5, EP8.8 e USP39-NF34.

\begin{tabular}{|c|c|c|c|c|}
\hline & FB5 & EP8.8 & USP39-NF34 & Classificação \\
\hline Procedimento 5 & $\begin{array}{c}10 \mathrm{mg} \text { cloridrato de hidrastina }+10 \mathrm{mg} \\
\text { cloreto de berberina }+ \text { metanol para } 25 \\
\mathrm{~mL}+\text { transferir } 1 \mathrm{~mL}+\text { metanol para } 25 \\
\mathrm{~mL}(\mathrm{RS})\end{array}$ & $\begin{array}{c}\text { 10,0 mg cloridrato de hidrastina SQR + } \\
10,0 \mathrm{mg} \text { cloreto de berberina SQR + } \\
\text { metanol para } 100,0 \mathrm{~mL} \text { (imediata } \\
\text { utilização) }(\mathrm{RS})\end{array}$ & $\begin{array}{c}\text { 0,05 mg/mL cloridrato de berberina } \mathrm{SQR} \\
\text { + hidrastina SQR em metanol:água }(1: 1) \\
\left(\mathrm{RS}_{1}\right)\end{array}$ & $\mathrm{mi}$ \\
\hline Procedimento 6 & ( 250 & 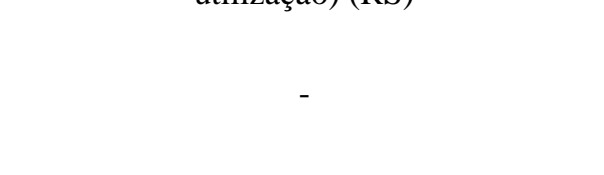 & $\begin{array}{l}(0,05 \mathrm{mg} / \mathrm{mL} \text { cloreto de palmatina em } \\
\text { água:metanol }(1: 1)):(0,05 \mathrm{mg} / \mathrm{mL} \\
\text { cloridrato de berberina } \mathrm{SQR}+\text { hidrastina } \\
\text { SQR em metanol:água }(1: 1))(1: 1)\left(\mathrm{RS}_{2}\right)\end{array}$ & me \\
\hline Procedimento 7 & $\begin{array}{c}3,2 \mu \mathrm{g} / \mathrm{mL} ; 6,4 \mu \mathrm{g} / \mathrm{mL} ; 9,6 \mu \mathrm{g} / \mathrm{mL} ; 16,0 \\
\mu \mathrm{g} / \mathrm{mL} ; 22,4 \mu \mathrm{g} / \mathrm{mL} \text { cloridrato de } \\
\text { hidrastina + cloreto de berberina em } \\
\text { fosfato monobásico de potássio } 0,05 \\
\text { M:acetonitrila (73:27) }\end{array}$ & - & - & $\mathrm{mi}$ \\
\hline Procedimento 8 & $10 \mu \mathrm{L}$ & $10 \mu \mathrm{L}$ & $10 \mu \mathrm{L}$ & se \\
\hline Procedimento 9 & $\begin{array}{c}\text { tempo retenção }(8,2 \text { - hidrastina; } 10,8 \\
\text { berberina })\end{array}$ & - & & me \\
\hline Procedimento 10 & $\begin{array}{c}\text { resolução (NLT } 1,5 \text { - hidrastina e } \\
\text { berberina) }\end{array}$ & $\begin{array}{c}\text { ordem de eluição (cloridrato de hidrastina } \\
\text { e cloreto de berberina) + resolução (NLT } \\
1,5 \text { - hidrastina e berberina) }\end{array}$ & $\begin{array}{c}\text { resolução (NLT 1,5 - hidrastina e } \\
\text { berberina; NLT 1,5 - hidrastina e } \\
\text { palmatina) + fator de capacidade (NLT } \\
3,0 \text { - hidrastina) + pratos teóricos (NLT } \\
5000 \text { ) + fator de cauda (NMT } 2,0 \text { - } \\
\text { hidrastina + berberina) + desvio padrão } \\
\text { relativo (NMT } 2,5 \% \text { - hidrastina + } \\
\text { berberina) }\end{array}$ & me \\
\hline Procedimento 11 & curva analítica & concentração relativa & concentração relativa & mi \\
\hline Procedimento 12 & - & $\frac{\mathrm{A}_{1} \times m_{2} \times \mathrm{p}}{\mathrm{A}_{2} \times m_{1}} \times 2,5$ & Result $=\left(\frac{\mathrm{r}_{\mathrm{U}}}{\mathrm{r}_{\mathrm{S}}}\right) \times \mathrm{C}_{\mathrm{S}} \times\left(\frac{\mathrm{V}}{\mathrm{W}}\right) \times 100$ & mi \\
\hline $\begin{array}{l}\text { Embalagem e } \\
\text { armazenamento }\end{array}$ & 1 & - & 1 & - \\
\hline Padrões de referência & - & $\begin{array}{c}\text { cloridrato de hidrastina } S Q R+\text { cloreto de } \\
\text { berberina } S Q R\end{array}$ & $\begin{array}{c}\text { hidrastina SQR + cloridrato de berberina } \\
\text { SQR }\end{array}$ & - \\
\hline Rotulagem & - & - & 1 & - \\
\hline
\end{tabular}

(BRASIL, 2010c, d; EDQM, 2016b; USP, 2016h). 
Legenda: $\mathrm{mi}=$ menor; me $=$ moderado $; \mathrm{su}=$ substancial $; \mathrm{se}=$ semelhante er $=$ erro $; \mathrm{NLT}=$ não menos que; $\mathrm{MNT}=$ não mais que; $\mathrm{MR}=$ cumpre os requisitos ou o teste CCD = cromatografia em camada delgada; CCDAE = cromatografia em camada delgada de alta eficiência; RS = solução referência; TS = solução amostra; SR = solução reagente; $\mathrm{SQR}=$ substância química de referência; CLAE-UV = cromatografia liquida de alta eficiência acoplada a detector por espectrofotometria por absorção no ultravioleta; ODS $=$ coluna cromatográfica octadecilsilanizada; $\mathrm{A}=$ absorvância; $m=\mathrm{W}=$ massa $; \mathrm{C}=$ concentração; $\mathrm{r}=$ resposta; $\mathrm{p}=$ pureza.

Nota: ${ }^{1}=$ parâmetros extraídos do método geral; ${ }^{2}=$ a quantidade da droga vegetal está mil vezes maior que a quantidade dos outros métodos, o que indica um erro

(conclusão) 
No geral, as monografias são convergentes, possuindo a mesma proposta, com ensaios para identificação, testes e doseamentos com fundamentos semelhantes.

As diferenças substanciais se concentram nos testes adicionais da FB5 (ensaio de identificação para a hidrastina), da EP8.8 (cinzas insolúveis em ácido) e da USP39-NF34 (cinzas insolúveis em ácido, impurezas elementais e resíduos de agrotóxicos). É importante ressaltar que estão previstos, na monografia geral Herbal Drugs da EP8.8, os testes para metais pesados e resíduos de agrotóxicos.

Há ainda, no doseamento diferença na quantidade de droga vegetal para tomada de ensaio, sendo na FB5 $1000 \mathrm{~g}$, mil vezes maior que a quantidade na EP8.8 e 10.000 vezes maior que a quantidade na USP39-NF34, o que foi considerado um erro. Este procedimento não foi corrigido na proposta de revisão da monografia apresentada na CP n 241/2016 (BRASIL, 2016c).

Como espécie que não possui ocorrência no Brasil, a origem da matéria-prima não é nacional. Assim, se esperava que os métodos e especificações fossem mais harmonizados, nesse caso, os resultados acompanharam a expectativa.

Por outro lado, como espécie contemplada em todas as edições da Farmacopeia Brasileira, com monografia na FB5 convergente com a EP8.8 e com a USP39-NF34, embora não contemplada no FFFB 1 e nem na IN nº 02/2014, se esperava que houvesse registros válidos junto à Anvisa, porém, nesse caso, os resultados não acompanharam as expectativas.

\subsubsection{Hyoscyamus niger L. [folha]}

O meimendro esteve presente na $1^{\mathrm{a}}$ e $2^{\mathrm{a}}$ edição da Farmacopeia Brasileira(Quadro 3), atualmente, não está relacionada no FFFB1 e nem na IN nº 02/2014 (BRASIL, 2011, 2014a), estando apenas na FB5. Não foram encontrados, para a espécie, registros de fitoterápicos válidos na Anvisa (Quadro 5). Conforme a literatura consultada, a espécie não ocorre no Brasil (Apêndice A), havendo registro de ocorrência no Canadá, China e Estados Unidos da América (TROPICOS.ORG, 2016).

A busca por monografias semelhantes nas farmacopeias em estudo, resultou em apenas uma monografia para preparações homeopáticas da EP 8.8. (EDQM, 2016b). Esta monografia foi, inicialmente, avaliada em conjunto com a monografia da FB5 (BRASIL, 2010d). Porém, por se tratar de droga vegetal diferente [planta florida fresca] para uma finalidade totalmente diversa (homeopatia) do objetivo do estudo, de estudar fitoterápicos, e, considerando que os 
ensaios de identificação e doseamento são realizados para a tintura mãe homeopática, se considerou desnecessária a realização da sistematização e comparação; sendo as monografias substancialmente diferentes.

\subsubsection{Illicium verum Hook. f. [fruto]}

O anis estrelado esteve presente em todas as edições da Farmacopeia Brasileira (Quadro 3), atualmente, não está relacionado na IN nº 02/2014 (BRASIL, 2014a), estando no FFFB1 (BRASIL, 2011) e na FB5. Não foram encontrados, para a espécie, registros de fitoterápicos válidos na Anvisa (Quadro 5). Conforme a literatura consultada, a espécie não possui ocorrência no Brasil (Apêndice A), havendo registro de ocorrência na China (TROPICOS.ORG, 2016). Em buscas realizadas nos compêndios internacionais em estudo, foram localizadas monografias apenas na EP8.8. Os dados extraídos das monografias estão descritos no Quadro 24. 
Quadro 24 - Comparação entre as monografias de Illicium verum Hook. f. [fruto] das farmacopeias FB5 e EP8.8.

\begin{tabular}{|c|c|c|c|}
\hline & FB5 & EP8.8 & Classificação \\
\hline Nomenclatura popular & anis-estrelado + badiana + badiana-da-china & atar anise & - \\
\hline Droga vegetal & fruto & fruto & se \\
\hline Marcador 1 & óleo volátil (NLT 7,0\%) & óleo volátil (NLT 7,0\%) (droga seca) & $\mathrm{se} / \mathrm{er}^{1}$ \\
\hline Marcador 2 & anetol (óleo volátil) (NLT 80\%) & trans-anetol (óleo volátil) (NLT 86\%) & $\mathrm{mi}$ \\
\hline Características & $\begin{array}{l}\text { pericarpo odor aromático agradável + sabor doce anisado; } \\
\text { semente inodora + sabor desagradável }\end{array}$ & marrom + odor de anetol & - \\
\hline Descrição macroscópica & 1 & 2 & - \\
\hline Descrição microscópica & 2 & 1 & - \\
\hline Figura botânica & 3 & - & - \\
\hline Identificação - método 1 & $\mathrm{CCD}$ & $\mathrm{CCD}$ & se \\
\hline Procedimento 1 & sílica-gel $\left(\mathrm{GF}_{254}+0,25 \mathrm{~mm}\right)$ & sílica-gel $(2-10 \mu \mathrm{m})$ & $\mathrm{mi}$ \\
\hline Procedimento 2 & tolueno & $\begin{array}{l}\text { ácido fórmico anidro:ácido acético glacial:água:acetato de etila } \\
\qquad(11: 11: 26: 100)\end{array}$ & me \\
\hline Procedimento 3 & $6 \mu \mathrm{L}$ (TS1); $10 \mu \mathrm{L}$ (TS2); $4 \mu \mathrm{L}$ (RS) (banda) & $5 \mu \mathrm{L}(\mathrm{TS})(\mathrm{RS})($ banda) & $\mathrm{mi}$ \\
\hline Procedimento 4 & $\begin{array}{c}1 \mathrm{~g} \text { folículos moídos }(\text { sem sementes })+10 \mathrm{~mL} \text { etanol } 90 \%+ \\
\text { ferver }\left(2^{\prime}\right)+\text { filtrar }\left(\mathrm{TS}_{1}\right)\end{array}$ & $\begin{array}{l}2,0 \mathrm{~g} \text { droga vegetal pulverizada }(355)+10 \mathrm{~mL} \text { metanol }+ \\
\text { aquecer (refluxo) (banho-maria) }\left(60^{\circ} \mathrm{C}\right)\left(5^{\prime}\right)+\text { esfriar }+ \text { filtrar } \\
\text { (TS) }\end{array}$ & me \\
\hline Procedimento 5 & óleo volátil:éter etílico $(1: 30)\left(\mathrm{TS}_{2}\right)$ & - & me \\
\hline Procedimento 6 & $3 \mu \mathrm{L}$ anetol $+1 \mathrm{~mL}$ tolueno $(\mathrm{RS})$ & $\begin{array}{c}1 \mathrm{mg} \text { ácido cafeico }+1 \mathrm{mg} \text { ácido clorogênico }+2,5 \mathrm{mg} \\
\text { quercetina }+2,5 \mathrm{mg} \text { rutina }+2,5 \mathrm{mg} \text { hiperosídeo }+10 \mathrm{~mL} \\
\text { metanol }(\mathrm{RS})\end{array}$ & me \\
\hline Procedimento 7 & secar & secar (ar quente) & $\mathrm{mi}$ \\
\hline Procedimento 8 & $254 \mathrm{~nm}$ & $\begin{array}{l}\text { difenilborato de aminoetanol } 1 \% \text { em metanol + macrogol } 400 \\
5 \% \text { em metanol + descansar }\left(30^{\prime}\right)\end{array}$ & me \\
\hline Procedimento 9 & anisaldeído SR + aquecer $\left(100-105^{\circ} \mathrm{C}\right)\left(5^{\prime}\right)$ & $365 \mathrm{~nm}$ & me \\
\hline Procedimento 10 & descrição de zonas & esquema + descrição de zonas & me \\
\hline Identificação - método 2 & $\begin{array}{l}\text { 1g folículos moídos (sem sementes) }+10 \mathrm{~mL} \text { etanol } 90 \%+ \\
\text { ferver }\left(2^{\prime}\right)+\text { filtrar }(\mathrm{TS})+10 \mathrm{~mL} \text { água }=\text { opalescência }(\text { mentol }) \\
(\mathrm{TS})+25 \mathrm{~mL} \text { água }+ \text { extrair } 2 \times 20 \mathrm{~mL} \text { éter de petróleo }+ \\
\text { evaporar (resíduo) }+2 \mathrm{~mL} \text { ácido acético }+3 \text { gotas cloreto férrico } \\
\text { SR }+2 \mathrm{~mL} \text { ácido sulfúrico = anel pardo (interface) (anetol) }\end{array}$ & q & su \\
\hline Testes - método 1 & matéria estranha (NMT 2,0\%) & matéria estranha (NMT 2,0\%) ${ }^{2}$ & $\mathrm{se}$ \\
\hline Testes - método 2 & água (NMT 7,0\%) & $\begin{array}{c}\text { água (NMT 10,0\%) (20,0 g droga vegetal pulverizada (355)) } \\
\text { (destilação) }\end{array}$ & me \\
\hline Testes - método 3 & cinzas totais (NMT $6,0 \%$ ) & cinzas totais (NMT 4,0\%) & su \\
\hline
\end{tabular}

(continua) 
Quadro 24 - Comparação entre as monografias de Illicium verum Hook. f. [fruto] das farmacopeias FB5 e EP8.8.

\begin{tabular}{|c|c|c|c|}
\hline & FB5 & EP8.8 & Classificação \\
\hline Doseamento - método 1 & destilação (óleo volátil) (NLT 7,0\%) & destilação (óleo volátil) (NLT 7,0\%) & se \\
\hline Procedimento 1 & $100 \mathrm{~mL}$ água & $100 \mathrm{~mL}$ água & se \\
\hline Procedimento 2 & - & $0,50 \mathrm{~mL}$ xileno & me \\
\hline Procedimento 3 & 20 g droga vegetal (pó grosseiro + imediata determinação) & $\begin{array}{l}2,5 \mathrm{~g} \text { droga vegetal }(\sim 2,0 \mathrm{~g} \text { pó grosseiro }(1400)+\sim 0,5 \mathrm{~g} \\
\text { finamente pulverizada }(710)+\text { imediata determinação })\end{array}$ & me \\
\hline Procedimento 4 & $2 \mathrm{~h}$ & $2-3 \mathrm{~mL} / \mathrm{min}(2 \mathrm{~h})$ & me \\
\hline Doseamento - método 2 & GC (anetol) (NLT 80\%) & GC (trans-anetol) (NLT 86\%) & $\mathrm{mi}$ \\
\hline Procedimento 2 & $\begin{array}{l}\text { ionização por chama (nitrogênio:ar sintético:hidrogênio } \\
\qquad(1: 1: 10))\end{array}$ & ionização por chama & me \\
\hline Procedimento 3 & hélio purificado (1 mL/min) & hélio purificado ( $1 \mathrm{~mL} / \mathrm{min})$ & se \\
\hline Procedimento 4 & $\begin{array}{c}\text { coluna - }(30 \mathrm{~m} \times 0,25 \mathrm{~mm})+\text { filme - polidifenildimetilsiloxano } \\
\qquad(0,25 \mu \mathrm{m})\end{array}$ & coluna - $(30 \mathrm{~m} \times 0,25 \mathrm{~mm})+$ filme - macrogol 20000 & me \\
\hline Procedimento 5 & injetor $220^{\circ} \mathrm{C}+$ detector $250^{\circ} \mathrm{C}$ & injetor $220^{\circ} \mathrm{C}+$ detector $250^{\circ} \mathrm{C}$ & se \\
\hline Procedimento 6 & $60 \rightarrow 300^{\circ} \mathrm{C}\left(3^{\circ} \mathrm{C} / 1^{\prime}\right)$ & $60\left(5^{\prime}\right)+60 \rightarrow 210^{\circ} \mathrm{C}\left(2^{\circ} \mathrm{C} / 1^{\prime}\right)+210\left(15^{\prime}\right)$ & me \\
\hline Procedimento 7 & óleo volátil:éter etílico (2:100) (TS) & (óleo volátil + xileno) + lavar (aparato) 5,0 mL xileno (RS) & $\mathrm{mi}$ \\
\hline Procedimento 8 & - & $\begin{array}{c}1,0 \mathrm{~mL} \text { xileno }+20 \mu \mathrm{L} \text { estragol }+20 \mathrm{mg} \alpha \text {-terpineol }+60 \mu \mathrm{L} \\
\text { anetol }(\mathrm{RS})\end{array}$ & me \\
\hline Procedimento 9 & $1 \mu \mathrm{L}+$ divisão de fluxo $(1: 50)$ & $1 \mu \mathrm{L}+$ divisão de fluxo $(1: 100)$ & me \\
\hline Procedimento 10 & tempo de retenção linear (1277 - anetol) & $\begin{array}{l}\text { ordem de eluição (estragol + } \alpha \text {-terpineol + anetol) }+ \text { resolução } \\
\text { (NLT } 5 \text { - estragol e } \alpha \text {-terpineol) }\end{array}$ & me \\
\hline Procedimento 11 & concentração relativa & concentração relativa & $\mathrm{mi}$ \\
\hline $\begin{array}{l}\text { Embalagem e } \\
\text { armazenamento }\end{array}$ & 1 & - & - \\
\hline
\end{tabular}

(BRASIL, 2010d; EDQM, 2016b).

Legenda: mi = menor; me = moderado; su = substancial; se = semelhante; er = erro; NLT = não menos que; MNT = não mais que; CCD = cromatografia em camada delgada; $\mathrm{RS}=$ solução referência; $\mathrm{TS}$ = solução amostra; $\mathrm{SR}=$ solução reagente; $\mathrm{CG}=$ cromatografia gasosa.

Nota: ${ }^{1}$ = há omissão na monografia da FB5 sobre a consideração do teor de água no cálculo do doseamento; ${ }^{2}=$ especificações extraídas do método geral. 
No geral, as monografias são convergentes, com a mesma proposta de métodos, ensaios e testes.

As diferenças substanciais se concentram nos testes adicionais da FB5 (identificação para anetol) e na diferença na especificação de cinzas totais acima de 30\% entre a FB5 e a EP8.8.

Há, ainda, a ausência na FB5 da indicação de que o óleo volátil deve ser calculado sem considerar a massa de água da droga vegetal, obtida na determinação de água, que por ser uma omissão foi considerada um erro. Ainda, o método para determinação de óleo volátil na FB5 (BRASIL, 2010c) é bem semelhante ao da EP8.8 (EDQM, 2016b), porém a EP8.8 sempre esclarece, nas monografias específicas, a necessidade de se considerar a droga seca enquanto a FB5 não apresenta essa informação.

Como espécie que não possui ocorrência no Brasil, a origem da matéria-prima não é nacional. Assim, se esperava que os métodos e especificações fossem mais harmonizados, nesse caso, os resultados acompanharam a expectativa.

Por outro lado, como espécie contemplada em todas as edições da Farmacopeia Brasileira, com monografia na FB5 convergente com a EP8.8, e contemplada no FFFB1, se esperava que houvesse registros válidos junto à Anvisa, porém, nesse caso, os resultados não acompanharam as expectativas.

\subsubsection{Krameria lappacea (Dombey) Burdet \& B.B.Simpson [raiz]}

A ratânia, considerando a espécie Krameria lappacea (Dombey) Burdet \& B.B.Simpson, nunca esteve presente em edições anteriores da Farmacopeia Brasileira (Quadro 3), não está relacionada no FFFB1 e nem na IN no 02/2014 (BRASIL, 2011, 2014a), estando apenas na FB5. Não foram encontrados, para a espécie, registros de fitoterápicos válidos na Anvisa (Quadro 5). Conforme a literatura consultada, a espécie não possui ocorrência no Brasil (Apêndice A), havendo registro de ocorrência na Argentina, Bolívia, Chile, Equador e Peru (TROPICOS.ORG, 2016). Em buscas realizadas nos compêndios internacionais em estudo, foram localizadas monografias apenas na EP8.8. Os dados extraídos das monografias estão descritos no Quadro 25. 
Quadro 25 - Comparação entre as monografias de Krameria lappacea (Dombey) Burdet \& B.B.Simpson [raiz] das farmacopeias FB5 e EP8.8.

\begin{tabular}{|c|c|c|c|}
\hline & FB5 & EP8.8 & Classificação \\
\hline Nomenclatura popular & ratânia & rhatany & - \\
\hline Droga vegetal & raiz & raiz & se \\
\hline Marcador 1 & taninos totais (pirogalol) (NLT 5\%) (droga seca) & taninos totais (pirogalol) (NLT 5,0\%) (droga seca) & se \\
\hline Características & $\begin{array}{l}\text { odor inodoro }+ \text { sabor quase insípido }+ \text { fortemente adstringente } \\
\text { (casca) }\end{array}$ & - & - \\
\hline Descrição macroscópica & 1 & 1 & - \\
\hline Descrição microscópica & 2 & 1 & - \\
\hline Figura botânica & 2 & 1 & - \\
\hline Identificação - método 1 & CCD & CCD & se \\
\hline Procedimento 1 & sílica-gel $\left(\mathrm{F}_{254}+0,25 \mathrm{~mm}\right)$ & sílica-gel $(5-40 \mu \mathrm{m})$ ou $(2-10 \mu \mathrm{m})$ & $\mathrm{mi}$ \\
\hline Procedimento 2 & acetato de etila:tolueno:ácido fórmico:água(100:10:10:1) & diclorometano & me \\
\hline Procedimento 3 & $20 \mu \mathrm{L}(\mathrm{TS}) ; 10 \mu \mathrm{L}(\mathrm{RS})$ (banda) & $10 \mu \mathrm{L}$ ou $4 \mu \mathrm{L}(8 \mathrm{~mm})(\mathrm{TS})(\mathrm{RS})(\mathrm{banda})$ & me \\
\hline Procedimento 4 & $\begin{array}{c}10 \mathrm{~g} \text { droga vegetal pulverizada }+100 \mathrm{~mL} \text { etanol } 70 \%+\text { aquecer } \\
(\text { refluxo })\left(10^{\prime}\right)+\text { resfriar }(\text { ambiente })+\text { filtrar (pressão reduzida) }+ \\
\text { evaporar }(\text { etanol })(\text { pressão reduzida })+\text { extrair } 3 \times 25 \mathrm{~mL} \text { acetato } \\
\text { de etila }+ \text { repousar }\left(-18^{\circ} \mathrm{C}\right)(15)+\text { reunir }(\text { fases orgânicas })+ \\
\text { filtrar (papel de filtro) }(5 \mathrm{~g} \text { sulfato de sódio anidro }+ \text { evaporar } \\
\text { (resíduo) (pressão reduzida) }+5 \mathrm{~mL} \text { metanol (TS) }\end{array}$ & $\begin{array}{c}1,0 \text { g droga vegetal pulverizada }(355)+10 \mathrm{~mL} \text { metanol }+ \\
\text { sonicar }\left(10^{\prime}\right)+\text { centrifugar ou filtrar (usar sobrenadante ou } \\
\text { filtrado) (TS) }\end{array}$ & me \\
\hline Procedimento 5 & $1 \mathrm{mg}$ catequina $+2 \mathrm{~mL}$ metanol $(\mathrm{RS})$ & $\begin{array}{c}5 \mathrm{mg} \text { timol }+20 \mathrm{mg} \text { 2,6-dicloroindofenol sódico }+20 \mathrm{~mL} \text { etanol } \\
(60 \%)(\mathrm{RS})\end{array}$ & me \\
\hline Procedimento 6 & secar (capela) & secar (ar) & $\mathrm{mi}$ \\
\hline Procedimento 7 & $254 \mathrm{~nm}$ & fast blue $B 0,5 \%$ & me \\
\hline Procedimento 8 & cloreto férrico $1 \%$ em metanol & - & me \\
\hline Procedimento 9 & descrição de zonas & esquema & me \\
\hline Identificação - método 2 & $\begin{array}{c}3 \mathrm{~g} \text { droga vegetal pulverizada }+60 \mathrm{~mL} \text { água }+ \text { aquecer (refluxo) } \\
\left(15^{\prime}\right)+\text { esfriar }+ \text { filtrar }+ \text { transferir } 2 \mathrm{~mL}+2 \text { gotas ácido } \\
\text { clorídrico } \mathrm{SR}+\text { gotejar gelatina } \mathrm{SR}=\text { precipitado nítido (taninos } \\
\text { totais) }\end{array}$ & - & su \\
\hline Identificação - método 3 & $\begin{array}{c}2 \mathrm{~mL} \text { extrato }+10 \mathrm{~mL} \text { água }+2-4 \text { gotas cloreto férrico } 1 \% \mathrm{em} \\
\text { etanol }=\text { cinza-escuro }(\text { taninos totais })\end{array}$ & - & su \\
\hline Identificação - método 4 & $\begin{array}{c}2 \mathrm{~mL} \text { extrato }+0,5 \mathrm{~mL} \text { vanilina } 1 \% \text { em metanol }+1 \mathrm{~mL} \text { ácido } \\
\text { clorídrico }=\text { vermelho (taninos condensados) }\end{array}$ & - & su \\
\hline Identificação - método 5 & $\begin{array}{l}5 \mathrm{~mL} \text { extrato }+10 \mathrm{~mL} \text { ácido acético } 2 M+5 \mathrm{~mL} \text { acetato de } \\
\text { chumbo } \mathrm{SR}=\text { precipitado esbranquiçado (taninos) }\end{array}$ & - & $\begin{array}{l}\text { su } \\
\text { (continua) }\end{array}$ \\
\hline
\end{tabular}


Quadro 25 - Comparação entre as monografias de Krameria lappacea (Dombey) Burdet \& B.B.Simpson [raiz] das farmacopeias FB5 e EP8.8.

\begin{tabular}{|c|c|c|c|}
\hline & FB5 & EP8.8 & Classificação \\
\hline Testes - método 1 & matéria estranha (NMT 2\%) & $\begin{array}{l}\text { matéria estranha (NMT 2\% + NMT 5\% - fragmentos da coroa } \\
\text { ou raiz }>25 \mathrm{~mm} \text { ) (raiz sem casca em pequenas quantidades) }\end{array}$ & su \\
\hline Testes - método 2 & água $(\mathrm{NMT} 12 \%)\left(100-105^{\circ} \mathrm{C}\right)(5 \mathrm{~h})^{1}$ & $\begin{array}{c}\text { perda por dessecação (NMT } 12,0 \%)(1,000 \mathrm{~g} \text { droga vegetal } \\
\text { pulverizada }(355))\left(105^{\circ} \mathrm{C}\right)\end{array}$ & mi \\
\hline Testes - método 3 & cinzas totais (NMT 5,5\%) & cinzas totais (NMT 5,5\%) & se \\
\hline Testes - método 4 & cinzas sulfatadas (NMT 7\%) & - & su \\
\hline Testes - método 5 & cinzas insolúveis em ácido (NMT 2\%) & - & su \\
\hline Doseamento - método 1 & EAVIS (taninos totais) (NLT 5\%) & EAVIS (taninos totais) (NLT 5,0\%) ${ }^{2}$ & se \\
\hline Procedimento 1 & proteger da luz & proteger da luz & se \\
\hline Procedimento 2 & $\begin{array}{c}0,75 \text { g droga vegetal pulverizada }(180)+150 \mathrm{~mL} \text { água }+ \text { aquecer } \\
(\text { banho-maria })\left(60^{\circ} \mathrm{C}\right)\left(30^{\prime}\right)+\text { resfriar }+ \text { lavar (recipiente) com } \\
\text { água para } 250 \mathrm{~mL}+\text { decantar }+ \text { filtrar (papel de filtro })+ \\
\text { desprezar primeiros } 50 \mathrm{~mL}(\text { filtrado })+\text { transferir } 5 \mathrm{~mL}+\text { água } \\
\text { para } 25 \mathrm{~mL}\left(\mathrm{TS}_{1}\right)\end{array}$ & $\begin{array}{c}0,750 \mathrm{~g} \text { droga vegetal pulverizada }(180)+150 \mathrm{~mL} \text { água }+ \\
\text { aquecer (banho-maria) }\left(30^{\prime}\right)+\text { resfriar }+ \text { lavar (recipiente) com } \\
\text { água para } 250 \mathrm{~mL}+\text { decantar }+ \text { filtrar }(\text { papel de filtro })+ \\
\text { desprezar primeiros } 50 \mathrm{~mL}(\text { filtrado })+\text { transferir } 5 \mathrm{~mL}+\text { água } \\
\text { para } 25 \mathrm{~mL}\left(\mathrm{TS}_{1}\right)\end{array}$ & mi \\
\hline Procedimento 3 & $\begin{array}{c}10 \mathrm{~mL} \text { (filtrado) }+0,1 \mathrm{~g} \text { pó de pele } \mathrm{SQR}+\text { agitar } \\
\text { (mecanicamente) }\left(60^{\prime}\right)+\text { filtrar (papel filtro) }+ \text { transferir } 5 \mathrm{~mL}+ \\
\text { água para } 25 \mathrm{~mL}\left(\mathrm{TS}_{2}\right)\end{array}$ & $\begin{array}{c}10,0 \mathrm{~mL} \text { (filtrado) }+0,10 \mathrm{~g} \text { pó de pele } \mathrm{SQR}+\text { agitar } \\
\text { (vigorosamente) }\left(60^{\prime}\right)+\text { filtrar + transferir } 5,0 \mathrm{~mL}+\text { água para } \\
25,0 \mathrm{~mL}\left(\mathrm{TS}_{2}\right)\end{array}$ & se \\
\hline Procedimento 4 & $\begin{array}{c}50,0 \mathrm{mg} \text { pirogalol + água para } 100 \mathrm{~mL}+\text { transferir } 5 \mathrm{~mL}+\text { água } \\
\text { para } 100 \mathrm{~mL} \text { (imediata utilização) }(\mathrm{RS})\end{array}$ & $\begin{array}{c}50,0 \mathrm{mg} \text { pirogalol + água para } 100,0 \mathrm{~mL}+\text { transferir } 5,0 \mathrm{~mL}+ \\
\text { água para } 100,0 \mathrm{~mL} \text { (imediata utilização) }(\mathrm{RS})\end{array}$ & $\mathrm{se}$ \\
\hline Procedimento 5 & água (BS) & água (BS) & se \\
\hline Procedimento 6 & $\begin{array}{c}\text { transferir } 2 \mathrm{~mL}\left(\mathrm{TS}_{1}\right)\left(\mathrm{TS}_{2}\right)(\mathrm{RS})+1 \mathrm{~mL} \text { reagente } \\
\text { fosfomolibdotúngstico }+10 \mathrm{~mL} \text { água }+ \text { carbonato de sódio } 29 \% \\
\text { para } 25 \mathrm{~mL}+\text { descansar }\left(30^{\prime}\right)\end{array}$ & $\begin{array}{c}\text { transferir 2,0 mL }\left(\mathrm{TS}_{1}\right)\left(\mathrm{TS}_{2}\right)(\mathrm{RS})+1,0 \mathrm{~mL} \text { reagente } \\
\text { fosfomolibdotúngstico }+10,0 \mathrm{~mL} \text { água }+ \text { carbonato de sódio } \\
29 \% \text { para } 25,0 \mathrm{~mL}+\text { descansar }\left(30^{\prime}\right)\end{array}$ & se \\
\hline Procedimento 7 & $760 \mathrm{~nm}$ & $760 \mathrm{~nm}$ & se \\
\hline Procedimento 8 & concentração relativa & concentração relativa & se \\
\hline Procedimento 9 & $\mathrm{TT}=\frac{62,5 \times\left(\mathrm{A}_{1}-\mathrm{A}_{2}\right) \times m_{2}}{\mathrm{~A}_{3} \times m_{1}}$ & $\frac{62,5 \times\left(\mathrm{A}_{1}-\mathrm{A}_{2}\right) \times m_{2}}{\mathrm{~A}_{3} \times m_{1}}$ & $\mathrm{se}$ \\
\hline $\begin{array}{l}\text { Embalagem e } \\
\text { armazenamento }\end{array}$ & 1 & - & - \\
\hline Padrões de referência & pó de pele SQR & pó de pele SQR & - \\
\hline
\end{tabular}

(BRASIL, 2010c, d; EDQM, 2016b) 


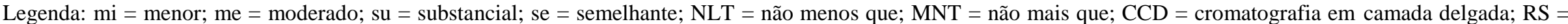
solução referência; TS = solução amostra; BS = solução branco; SR = solução reagente; SQR = substância química de referência; EAVIS = espectrofotometria de absorção no visível; $\mathrm{TT}=$ taninos totais; $\mathrm{A}=$ absorvância; $m=$ massa.

Nota: ${ }^{1}=$ parâmetros extraídos do método geral.

(conclusão) 
No geral, as monografias são convergentes, possuem propostas semelhantes para métodos, ensaios e testes.

As diferenças substanciais se concentram nos testes adicionais da FB5 (quatro para identificação de taninos, cinzas sulfatadas e cinzas insolúveis em água) e na diferença substancial na especificação de matéria estranha acima de $30 \%$ entre as monografias.

Como espécie que não possui ocorrência no Brasil, a origem da matéria-prima não é nacional. Assim, se esperava que os métodos e especificações fossem mais harmonizados, nesse caso, os resultados acompanharam a expectativa.

\subsubsection{Krameria lappacea (Dombey) Burdet \& B.B.Simpson [raiz; tintura]}

A ratânia tintura, considerando a espécie Krameria lappacea (Dombey) Burdet \& B.B.Simpson, nunca esteve presente em edições anteriores da Farmacopeia Brasileira (Quadro 3), atualmente, não está relacionada no FFFB1 e nem na IN nº 02/2014 (BRASIL, 2011, 2014a), estando apenas na FB5. Não foram encontrados, para a espécie, registros de fitoterápicos válidos na Anvisa (Quadro 5). Conforme a literatura consultada, a espécie não possui ocorrência no Brasil (Apêndice A), havendo registro de ocorrência na Argentina, Bolívia, Chile, Equador e Peru (TROPICOS.ORG, 2016). Em buscas realizadas nos compêndios internacionais em estudo, foram localizadas monografias apenas na EP8.8. Os dados extraídos das monografias estão descritos no Quadro 26. 
Quadro 26 - Comparação entre as monografias de Krameria lappacea (Dombey) Burdet \& B.B.Simpson [raiz; tintura] das farmacopeias FB5 e EP8.8.

\begin{tabular}{|c|c|c|c|}
\hline & FB5 & EP8.8 & Classificação \\
\hline Nomenclatura popular & ratânia & rhatany & - \\
\hline Droga vegetal & raiz & raiz & se \\
\hline Derivado & droga vegetal: etanol 70\% (1:5) (maceração ou percolação) & droga vegetal: etanol $70 \%(1: 5)$ & $\mathrm{se}^{1}$ \\
\hline Marcador 1 & taninos totais (pirogalol) (NLT 0,5\%) & taninos totais (pirogalol) (NLT 1,0\%) & su \\
\hline Características & cor marrom-avermelhada & cor marrom-avermelhada & - \\
\hline Identificação - método 1 & CCD & CCD & se \\
\hline Procedimento 1 & sílica-gel $\left(\mathrm{F}_{254}+0,25 \mathrm{~mm}\right)$ & sílica-gel $(5-40 \mu \mathrm{m})$ ou $(2-10 \mu \mathrm{m})$ & mi \\
\hline Procedimento 2 & acetato de etila:tolueno:ácido fórmico:água(60:20:15:15) & diclorometano & me \\
\hline Procedimento 3 & $20 \mu \mathrm{L}(\mathrm{TS}) ; 10 \mu \mathrm{L}$ (RS) (banda) & $10 \mu \mathrm{L}$ ou $4 \mu \mathrm{L}(8 \mathrm{~mm})(\mathrm{TS})(\mathrm{RS})$ (banda) & me \\
\hline Procedimento 4 & $\begin{array}{c}5,0 \mathrm{~mL} \text { tintura }+ \text { evaporar (resíduo) (banho-maria) }+10,0 \mathrm{~mL} \\
\text { água }+ \text { extrair } 3 \mathrm{x} 10,0 \mathrm{~mL} \text { acetato de etila }+ \text { repouso }\left(-18^{\circ} \mathrm{C}\right) \\
\left(15^{\prime}\right)+\text { reunir (fases orgânicas) }+ \text { lavar (recipiente) com } 20,0 \mathrm{~mL} \\
\text { água }(\mathrm{TS})\end{array}$ & r & me \\
\hline Procedimento 5 & $1 \mathrm{mg}$ catequina $+2 \mathrm{~mL}$ metanol $(\mathrm{RS})$ & $\begin{array}{c}5 \mathrm{mg} \text { timol }+20 \mathrm{mg} \text { 2,6-dicloroindofenol sódico }+20 \mathrm{~mL} \text { etanol } \\
(60 \%)(\mathrm{RS})\end{array}$ & me \\
\hline Procedimento 6 & secar (capela) & secar $(\operatorname{ar})$ & mi \\
\hline Procedimento 7 & cloreto férrico $1 \%$ em metanol & fast blue B $0,5 \%$ & me \\
\hline Procedimento 8 & descrição de zonas & esquema & me \\
\hline Testes - método 1 & densidade relativa $(0,891-0,906)$ & - & su \\
\hline Testes - método 2 & etanol $(63,0-67,0 \%)$ & etanol $(63-67 \%)$ & se \\
\hline Testes - método 3 & resíduo seco (NLT 1,9\%) & - & $\mathrm{su}$ \\
\hline Testes - método 4 & - & $\begin{array}{l}\text { metanol e 2-propanol (NMT 0,05\% - metanol) (NMT 0,05\% - 2- } \\
\text { propanol) }\end{array}$ & su \\
\hline Doseamento - método 1 & EAVIS (taninos totais) (NLT 0,5\%) & EAVIS (taninos totais) (NLT $1,0 \%)^{2}$ & su \\
\hline Procedimento 1 & proteger da luz & proteger da luz & se \\
\hline Procedimento 2 & $\begin{array}{c}1,5 \mathrm{~g} \text { tintura + água para } 250 \mathrm{~mL}+\text { filtrar (papel de filtro })+ \\
\text { desprezar primeiros } 50 \mathrm{~mL}(\text { filtrado })+\text { transferir } 5 \mathrm{~mL}+\text { água } \\
\text { para } 25 \mathrm{~mL}\left(\mathrm{TS}_{1}\right)\end{array}$ & $\begin{array}{l}\text { 2,500 g tintura + água par } 250 \mathrm{~mL}+\text { filtrar (papel de filtro) + } \\
\text { desprezar primeiros } 50 \mathrm{~mL}(\text { filtrado) }+ \text { transferir } 5 \mathrm{~mL}+\text { água } \\
\text { para } 25 \mathrm{~mL}\left(\mathrm{TS}_{1}\right)\end{array}$ & mi \\
\hline Procedimento 3 & $\begin{array}{c}10 \mathrm{~mL} \text { (filtrado) }+0,1 \mathrm{~g} \text { pó de pele }+ \text { agitar (mecanicamente) } \\
\left(60^{\prime}\right)+\text { filtrar (papel filtro) }+ \text { transferir } 5 \mathrm{~mL}+\text { água para } 25 \mathrm{~mL} \\
\left(\mathrm{TS}_{2}\right)\end{array}$ & $\begin{array}{c}10,0 \mathrm{~mL} \text { (filtrado) }+0,10 \mathrm{~g} \text { pó de pele } \mathrm{SQR}+\text { agitar } \\
\text { (vigorosamente) }\left(60^{\prime}\right)+\text { filtrar }+ \text { transferir } 5,0 \mathrm{~mL}+\text { água para } \\
25,0 \mathrm{~mL}\left(\mathrm{TS}_{2}\right)\end{array}$ & se \\
\hline Procedimento 4 & $\begin{array}{c}50,0 \mathrm{mg} \text { pirogalol + água para } 100 \mathrm{~mL}+\text { transferir } 5 \mathrm{~mL}+\text { água } \\
\text { para } 100 \mathrm{~mL}(\mathrm{RS})\end{array}$ & $\begin{array}{c}50,0 \mathrm{mg} \text { pirogalol + água para } 100,0 \mathrm{~mL}+\text { transferir } 5,0 \mathrm{~mL}+ \\
\text { água para } 100,0 \mathrm{~mL} \text { (imediata utilização) }(\mathrm{RS})\end{array}$ & se \\
\hline Procedimento 5 & água (BS) & água (BS) & se \\
\hline
\end{tabular}


Quadro 26 - Comparação entre as monografias de Krameria lappacea (Dombey) Burdet \& B.B.Simpson [raiz; tintura] das farmacopeias FB5 e EP8.8.

\begin{tabular}{|c|c|c|c|}
\hline & FB5 & EP8.8 & Classificação \\
\hline Procedimento 6 & $\begin{array}{c}\text { transferir } 2 \mathrm{~mL}\left(\mathrm{TS}_{1}\right)\left(\mathrm{TS}_{2}\right)(\mathrm{RS})+1 \mathrm{~mL} \text { reagente } \\
\text { fosfomolibdotúngstico }+10 \mathrm{~mL} \text { água }+ \text { carbonato de sódio } 29 \% \\
\text { para } 25 \mathrm{~mL}+\text { descansar }\left(30^{\prime}\right)\end{array}$ & $\begin{array}{c}\text { transferir } 2,0 \mathrm{~mL}\left(\mathrm{TS}_{1}\right)\left(\mathrm{TS}_{2}\right)(\mathrm{RS})+1,0 \mathrm{~mL} \text { reagente } \\
\text { fosfomolibdotúngstico }+10,0 \mathrm{~mL} \text { água }+ \text { carbonato de sódio } \\
29 \% \text { para } 25,0 \mathrm{~mL}+\text { descansar }\left(30^{\prime}\right)\end{array}$ & se \\
\hline Procedimento 7 & $760 \mathrm{~nm}$ & $760 \mathrm{~nm}$ & se \\
\hline Procedimento 8 & concentração relativa & concentração relativa & se \\
\hline Procedimento 9 & $\mathrm{TT}=\frac{13,12 \times\left(\mathrm{A}_{1}-\mathrm{A}_{2}\right)}{\mathrm{A}_{3} \times m}$ & $\frac{62,5 \times\left(\mathrm{A}_{1}-\mathrm{A}_{2}\right) \times m_{2}}{\mathrm{~A}_{3} \times m_{1}}$ & $\mathrm{er}^{3}$ \\
\hline $\begin{array}{l}\text { Embalagem e } \\
\text { armazenamento }\end{array}$ & 1 & - & - \\
\hline Padrões de referência & - & pó de pele SQR & - \\
\hline
\end{tabular}

(BRASIL, 2010d; EDQM, 2016b)

Legenda: $\mathrm{mi}=$ menor; $\mathrm{me}=$ moderado; $\mathrm{su}=$ substancial; $\mathrm{se}=$ semelhante; $\mathrm{er}=$ erro; $\mathrm{NLT}=$ não menos que; $\mathrm{MNT}=$ não mais que $\mathrm{CCD}=$ cromatografia em camada delgada; $\mathrm{RS}$ = solução referência; TS = solução amostra; BS = solução branco; $\mathrm{SQR}=$ substância química de referência; EAVIS = espectrofotometria de absorção no visível; TT = taninos totais; $\mathrm{A}=$ absorvância; $m=$ massa.

Notas: ${ }^{1}=$ conforme método geral da EP8.8 a tintura pode ser obtida por percolação ou maceração e por dissolução de extrato produzido com o mesmo líquido extrator; ${ }^{2}=$ parâmetros extraídos do método geral; ${ }^{3}=$ a expressão da FB5 não apresenta possibilidade para inserção da massa de pirogalol utilizada no ensaio o que indica que a diferença entre as expressões seja devido a erro. 
No geral, as monografias não são convergentes. As diferenças substanciais se concentram nos testes adicionais da FB5 (densidade relativa e resíduo seco) e da EP8.8 (metanol e 2-propanol) e na diferença substancial da especificação do doseamento de taninos totais acima de $30 \%$ entre as monografias.

Há, ainda, ausência na expressão para o cálculo de taninos totais da FB5, da massa do pirogalol, embora essa massa esteja descrita no método, que, pelo caráter da omissão, foi considerado um erro. A fórmula foi corrigida na proposta de revisão da monografia apresentada na CP nº 241/2016 (BRASIL, 2016c).

Como espécie que não possui ocorrência no Brasil, a origem da matéria-prima não é nacional. Assim, se esperava que os métodos e especificações fossem mais harmonizados, nesse caso, os resultados acompanharam a expectativa.

\subsubsection{Melissa officinalis L. [folha]}

A melissa esteve presente na $1^{a}$ edição da Farmacopeia Brasileira (Quadro 3), está relacionada no FFFB1 e na Lista de Produtos Tradicionais Fitoterápicos de Registro Simplificado da IN no 02/2014 (BRASIL, 2011, 2014a) e na FB5. Foram encontrados, para a espécie, três registros de fitoterápicos válidos na Anvisa (Quadro 5). Conforme a literatura consultada, a espécie não possui ocorrência no Brasil (Apêndice A), havendo registro de ocorrência na Argentina, Bolívia, Chile, China, Colômbia, Equador, Quirguistão, Paquistão, Rússia, Tajiquistão, Turquemenistão e Estados Unidos da América (TROPICOS.ORG, 2016). Em buscas realizadas nos compêndios internacionais em estudo, foram localizadas monografias apenas na EP8.8. Os dados extraídos das monografias estão descritos no Quadro 27. 
Quadro 27 - Comparação entre as monografias de Melissa officinalis L. [folha] das farmacopeias FB5 e EP8.8.

\begin{tabular}{|c|c|c|c|}
\hline & FB5 & EP8.8 & Classificação \\
\hline Nomenclatura popular & melissa & melissa & - \\
\hline Droga vegetal & folha & folha & se \\
\hline Marcador 1 & derivados hidroxicinâmicos (NLT 4,0\%) & - & $\mathrm{su}$ \\
\hline Marcador 2 & ácido rosmarínico (NLT 2,0\%) & ácido rosmarínico (NLT 1,0\%) (droga seca) & su \\
\hline Marcador 3 & óleo volátil (NLT 0,6\%) & - & su \\
\hline Características & $\begin{array}{l}\text { odor forte + aromático semelhante citral + sabor aromático } \\
\text { agradável + ligeiramente amargo + pouco adstringente }\end{array}$ & odor remanescente limão & - \\
\hline Descrição macroscópica & 2 & 1 & - \\
\hline Descrição microscópica & 3 & 1 & - \\
\hline Figura botânica & 2 & 1 & - \\
\hline Identificação - método 1 & $\mathrm{CCD}$ & $\mathrm{CCD}$ & se \\
\hline Procedimento 1 & sílica-gel $\left(\mathrm{GF}_{254}+0,25 \mathrm{~mm}\right)$ & sílica-gel $(5-40 \mu \mathrm{m})$ ou $(2-10 \mu \mathrm{m})$ & $\mathrm{mi}$ \\
\hline Procedimento 2 & hexano:acetato de etila $(90: 10)$ & acetato de etila:hexano (10:90) & se \\
\hline Procedimento 3 & $20 \mu \mathrm{L}$ (TS);10 $\mu \mathrm{L}$ (RS) (banda) & $20 \mu \mathrm{L} \mathrm{ou} 4 \mu \mathrm{L}$ (TS) (RS) (banda) & me \\
\hline Procedimento 4 & $\begin{array}{c}2 \mathrm{~g} \text { droga vegetal pulverizada }+100 \mathrm{~mL} \text { água }+0,5 \mathrm{~mL} \text { xileno }+ \\
\text { destilar }(1 \mathrm{~h})+\text { transferir (fase orgânica) + lavar (tubo graduado) } \\
\text { com xileno + xileno para } 1 \mathrm{~mL}(\mathrm{TS})\end{array}$ & $\begin{array}{c}2,0 \mathrm{~g} \text { droga vegetal pulverizada }+100 \mathrm{~mL} \text { água }+0,5 \mathrm{~mL} \text { xileno } \\
+ \text { destilar }(1 \mathrm{~h})+\text { transferir (fase orgânica) }+ \text { lavar (tubo } \\
\text { graduado) com xileno + xileno para } 1,0 \mathrm{~mL}(\mathrm{TS})\end{array}$ & se \\
\hline Procedimento 5 & $1 \mu \mathrm{g}$ citronelal $+10 \mu \mathrm{g}$ citral $+25 \mathrm{~mL}$ xileno $(\mathrm{RS})$ & $1,0 \mu \mathrm{L}$ citronelal $+10,0 \mu \mathrm{L}$ citral $+25 \mathrm{~mL}$ xileno $(\mathrm{RS})$ & se/er ${ }^{1}$ \\
\hline Procedimento 6 & secar (ar) & secar (ar) & se \\
\hline Procedimento 7 & solução de anisaldeído + aquecer $\left(100-105^{\circ} \mathrm{C}\right)\left(10-15^{\prime}\right)$ & solução de anisaldeído + aquecer $\left(100-105^{\circ} \mathrm{C}\right)\left(10-15^{\prime}\right)$ & se \\
\hline Procedimento 8 & descrição de zonas & esquema & se \\
\hline Testes - método 1 & matéria estranha (NMT 10,0\% - caules + flores) & $\begin{array}{c}\text { matéria estranha (NMT } 10 \% \text { - caules }>1 \mathrm{~mm}+\text { NMT } 2 \%- \\
\text { outros) }(20 \mathrm{~g} \text { droga vegetal) }\end{array}$ & me \\
\hline Testes - método 2 & $\begin{array}{l}\text { água (NMT 10,0\%) (1 g droga vegetal pulverizada (355) (100- } \\
\left.105^{\circ} \mathrm{C}\right)(2 \mathrm{~h})\end{array}$ & $\begin{array}{c}\text { perda por dessecação (NMT 10,0\%) }(1,000 \mathrm{~g} \text { droga vegetal } \\
\text { pulverizada }(355))\left(105^{\circ} \mathrm{C}\right)(2 \mathrm{~h})\end{array}$ & se \\
\hline Testes - método 3 & cinzas totais (NMT $12,0 \%)$ & cinzas totais (NMT $12,0 \%)$ & se \\
\hline Doseamento - método 1 & EAVIS (derivados hidroxicinâmicos) (NLT 4,0\%) & - & su \\
\hline Procedimento 1 & $\begin{array}{c}0,2 \mathrm{~g} \text { droga vegetal pulverizada }+190 \mathrm{~mL} \text { etanol } 50 \%+\text { aquecer } \\
(\text { banho-maria) }(\text { refluxo })(30 ')+\text { esfriar }+ \text { filtrar }+ \text { lavar (filtro) } \\
\text { com } 10 \mathrm{~mL} \text { etanol } 50 \%+\text { reunir (filtrado }+ \text { líquidos lavagem })+ \\
\text { etanol } 50 \% \text { para } 200 \mathrm{~mL}\left(\mathrm{TS}_{1}\right)\end{array}$ & - & su \\
\hline Procedimento 2 & $\begin{array}{c}1 \mathrm{~mL}\left(\mathrm{TS}_{1}\right)+2 \mathrm{~mL} \text { ácido clorídrico } 0,5 M+2 \mathrm{~mL}((\text { nitrito de } \\
\text { sódio:molibdato de sódio:água }(10: 10: 100))+2 \mathrm{~mL} \text { hidróxido } \\
\text { de sódio } 2 M+\text { água para } 10 \mathrm{~mL}\left(\mathrm{TS}_{2}\right)\end{array}$ & - & su \\
\hline
\end{tabular}


Quadro 27 - Comparação entre as monografias de Melissa officinalis L. [folha] das farmacopeias FB5 e EP8.8.

\begin{tabular}{|c|c|c|c|}
\hline & FB5 & EP8.8 & Classificação \\
\hline Procedimento 3 & $\begin{array}{c}1\left(\mathrm{TS}_{1}\right)+2 \mathrm{~mL} \text { ácido clorídrico } 0,5 M+2 \mathrm{~mL} \text { hidróxido de } \\
\text { sódio } 2 M+\text { água para } 10 \mathrm{~mL}(\mathrm{BS})\end{array}$ & - & su \\
\hline Procedimento 4 & $505 \mathrm{~nm}$ & - & $\mathrm{su}$ \\
\hline Procedimento 5 & concentração relativa & - & su \\
\hline Procedimento 6 & $\mathrm{DHC}=\frac{\mathrm{A} \times 5}{m}$ & - & $\mathrm{su}$ \\
\hline Doseamento - método 2 & CLAE-UV (ácido rosmarínico) (NLT 2,0\%) & CLAE-UV (ácido rosmarínico) (NLT 1,0\%) & $\mathrm{su}$ \\
\hline Procedimento 1 & $332 \mathrm{~nm}$ & $330 \mathrm{~nm}$ & $\mathrm{mi}$ \\
\hline Procedimento 2 & $\begin{array}{l}\text { pré-coluna octadecilsilanizada; ODS }(0,15 \mathrm{~m} \text { x 3,9 mm) }(4 \mu \mathrm{m}) \\
\text { água:ácido trifluoracético }(100: 0,1) 90 \% \text { em acetonitrila:ácido } \\
\text { trifluoracético }(100: 0,1) \rightarrow \text { água:ácido trifluoracético }(100: 0,1) \\
\left.61 \% \text { em acetonitrila:ácido trifluoracético }(100: 0,1)(14)^{\prime}\right)+ \\
\text { água:ácido trifluoracético (100:0,1) } 61 \% \text { em acetonitrila:ácido } \\
\text { trifluoracético }(100: 0,1) \rightarrow \text { água:ácido trifluoracético }(100: 0,1)\end{array}$ & $\begin{array}{l}\text { ácido fosfórico:acetonitrila:água }(1: 19: 80) 100 \% \rightarrow \text { ácido } \\
\text { fosfórico:acetonitrila:água }(1: 19: 80) 55 \% \text { em ácido } \\
\text { fosfórico:metanol: acetonitrila }(1: 40: 59)(20 ')+\text { ácido }\end{array}$ & me \\
\hline Procedimento 3 & $\begin{array}{c}50 \% \text { em acetonitrila:ácido trifluoracético }(100: 0,1)\left(2^{\prime}\right)+ \\
\text { água:ácido trifluoracético }(100: 0,1) 50 \% \text { em acetonitrila:ácido } \\
\text { trifluoracético }(100: 0,1) \rightarrow \text { água:ácido trifluoracético }(100: 0,1) \\
90 \% \text { em acetonitrila:ácido trifluoracético }(100: 0,1)(2 ')+ \\
\text { água:ácido trifluoracético }(100: 0,1) 90 \% \text { em acetonitrila:ácido } \\
\text { trifluoracético }(100: 0,1)\left(5^{\prime}\right)(0,6 \mathrm{~mL} / \mathrm{min})\end{array}$ & $\begin{array}{l}\text { fosfórico:acetonitrila:água }(1: 19: 80) 55 \% \text { em ácido } \\
\text { fosfórico:metanol: acetonitrila }(1: 40: 59) \rightarrow \text { ácido } \\
\text { fosfórico:metanol: acetonitrila }(1: 40: 59) 100 \%\left(5^{\prime}\right)+\text { ácido } \\
\text { fosfórico:metanol: acetonitrila }(1: 40: 59) 100 \% \rightarrow \text { ácido } \\
\text { fosfórico:acetonitrila:água }(1: 19: 80) 100 \%\left(5^{\prime}\right)(1.2 \mathrm{~mL} / \mathrm{min})\end{array}$ & me \\
\hline Procedimento 4 & $\begin{array}{c}0,1 \mathrm{~g} \text { droga vegetal pulverizada }(800)+5 \mathrm{~mL} \text { etanol } 40 \%+ \\
\text { levar (ultrassom) }\left(10^{\prime}\right)+\text { centrifugar }\left(5^{\prime}\right)(1500 \mathrm{rpm})(\mathrm{usar} \\
\text { sobrenadante) }+ \text { extrair } 4 \mathrm{~mL} \text { etanol } 40 \%(\mathrm{ultrassom})\left(5^{\prime}\right)+ \\
\text { centrifugar (usar sobrenadante) }+ \text { etanol } 40 \% \text { para } 10 \mathrm{~mL}+ \\
\text { transferir } 50 \mu \mathrm{L}+0,3 \mathrm{~mL} \text { água }(\mathrm{TS})\end{array}$ & $\begin{array}{c}0,100 \mathrm{~g} \text { droga vegetal pulverizada }(355)+90 \mathrm{~mL} \text { etanol } 50 \%+ \\
\text { ferver (banho-maria) (refluxo) }(30 ')+\text { esfriar + filtrar }+ \text { lavar } \\
\text { (recipiente }+ \text { filtro) com } 10 \mathrm{~mL} \text { etanol } 50 \%+\text { etanol } 50 \% \text { para } \\
100,0 \mathrm{~mL}+\text { filtrar (membrana } 0,45 \mu \mathrm{m})(\mathrm{TS})\end{array}$ & me \\
\hline Procedimento 5 & 10 mg ácido rosmarínico + 10 mL metanol (RS) & $\begin{array}{l}20,0 \mathrm{mg} \text { ácido rosmarínico } \mathrm{SQR}+\text { etanol } 50 \% \text { para } 100,0 \mathrm{~mL}+ \\
\text { transferir } 20,0 \mathrm{~mL}+\text { etanol } 50 \% \text { para } 100,0 \mathrm{~mL}\left(\mathrm{RS}_{1}\right)\end{array}$ & mi \\
\hline Procedimento 6 & - & 5,0 mg ácido ferúlico $+\left(\mathrm{RS}_{1}\right)$ para 50,0 $\mathrm{mL}\left(\mathrm{RS}_{2}\right)$ & me \\
\hline Procedimento 7 & $\begin{array}{c}\text { 7,80 } \mu \mathrm{g} / \mathrm{mL} ; 15,60 \mu \mathrm{g} / \mathrm{mL} ; 31,25 \mu \mathrm{g} / \mathrm{mL} ; 62,50 \mu \mathrm{g} / \mathrm{mL} ; 125 \\
\mu \mathrm{g} / \mathrm{mL} ; 250 \mu \mathrm{g} / \mathrm{mL} \text { ácido rosmarínico em metanol. }\end{array}$ & 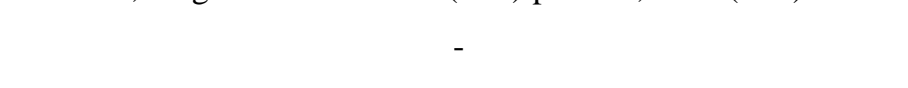 & me \\
\hline Procedimento 8 & $10 \mu \mathrm{L}$ & $20 \mu \mathrm{L}$ & $\mathrm{mi}$ \\
\hline Procedimento 9 & tempo retenção (10,3 - ácido rosmarínico) & tempo retenção (11 - ácido rosmarínico) & $\mathrm{mi}$ \\
\hline Procedimento 10 & - & $\begin{array}{l}\text { retenção relativa }(0,8 \text { - ácido rosmarínico e ácido ferúlico) + } \\
\text { resolução (NMT 4,0 - entre ácido ferúlico + ácido rosmarínico) }\end{array}$ & me \\
\hline
\end{tabular}


Quadro 27 - Comparação entre as monografias de Melissa officinalis L. [folha] das farmacopeias FB5 e EP8.8.

\begin{tabular}{|c|c|c|c|}
\hline & FB5 & EP8.8 & Classificação \\
\hline \multirow{2}{*}{ Procedimento 11} & \multirow{2}{*}{ curva analítica } & $\mathrm{A}_{1} \times \mathrm{m}_{2} \times \mathrm{p} \times 0,2$ & \multirow{2}{*}{ me } \\
\hline & & $\mathrm{A}_{2} \times \mathrm{m}_{1}$ & \\
\hline Doseamento - método 3 & destilação (óleo volátil) (NLT 0,6\%) & - & su \\
\hline Procedimento 1 & 500 mL água & - & su \\
\hline Procedimento 2 & $0,5 \mathrm{~mL}$ xileno & - & su \\
\hline Procedimento 3 & $\begin{array}{c}20 \mathrm{~g} \text { droga vegetal (rasurada não contundida }+ \text { imediata } \\
\text { determinação) }\end{array}$ & - & $\mathrm{su}$ \\
\hline Procedimento 4 & $4 \mathrm{~h}$ & - & su \\
\hline $\begin{array}{l}\text { Perfil cromatográfico- } \\
\text { método } 1\end{array}$ & CG (perfil cromatográfico) & - & $\mathrm{su}$ \\
\hline Procedimento 1 & $\begin{array}{l}\text { ionização por chamas (nitrogênio:ar sintético:, hidrogênio } \\
\qquad(1: 1: 10))\end{array}$ & - & su \\
\hline Procedimento 2 & $\begin{array}{c}\text { coluna }(30 \mathrm{~m} \times 0,25 \mathrm{~mm})+\text { filme polidifenildimetilsiloxano } \\
\qquad(0,25 \mu \mathrm{m})\end{array}$ & - & su \\
\hline Procedimento 3 & injetor $220^{\circ} \mathrm{C}+$ detector $250^{\circ} \mathrm{C}$ & - & su \\
\hline Procedimento 4 & $60{ }^{\circ} \mathrm{C} \rightarrow 300{ }^{\circ} \mathrm{C}\left(3^{\circ} \mathrm{C} / 1^{\prime}\right)$ & - & su \\
\hline Procedimento 5 & hélio (1 mL/min) & - & su \\
\hline Procedimento 6 & óleo volátil:éter etílico $(2: 100)(\mathrm{TS})$ & - & su \\
\hline Procedimento 7 & $1 \mu \mathrm{L}+$ divisão de fluxo $(1: 50)$ & - & su \\
\hline Procedimento 8 & $\begin{array}{c}\text { IRR }(1234 \text { - neral }+1265 \text { - geranial }+1404 \text { - beta-cariofileno }+ \\
1579-\text { óxido de cariofileno })\end{array}$ & - & $\mathrm{su}$ \\
\hline Procedimento 9 & $\begin{array}{l}\text { figura + neral }(30,4-32,9 \%)+\text { geranial }(49,0-53,3 \%)+\text { beta- } \\
\text { cariofileno }(2,6-3,1 \%)+\text { óxido de cariofileno }(3,9-6,4 \%)\end{array}$ & - & su \\
\hline $\begin{array}{l}\text { Embalagem e } \\
\text { armazenamento }\end{array}$ & 1 & - & - \\
\hline Padrões de referência & - & ácido rosmarínico SQR & - \\
\hline
\end{tabular}

(BRASIL, 2010d; EDQM, 2016b)

Legenda: mi = menor; me = moderado; su = substancial; se = semelhante; er = erro; NLT = não menos que; MNT = não mais que; CCD = cromatografia em camada delgada; $\mathrm{RS}=$ solução referência; TS = solução amostra; $\mathrm{BS}=$ solução branco; $\mathrm{SQR}=$ substância química de referência; EAVIS = espectrofotometria de absorção no visível; DHC = derivados hidroxicinâmicos; CLAE-UV = cromatografia liquida de alta eficiência acoplada a detector por espectrofotometria por absorção no ultravioleta; ODS = coluna cromatográfica octadecilsilanizada; $r p m=$ rotações por minuto; $\mathrm{A}=$ absorvância; $m=$ massa; $\mathrm{p}=$ pureza; $\mathrm{CG}=$ cromatografia gasosa; IRR = índice de retenção relativo. Notas: ${ }^{1}=$ o uso de $\mu \mathrm{g}$ em um ensaio qualitativo quando se pode utilizar $\mu \mathrm{L}$, como na EP8.8, parece um erro. 
No geral, as monografias não são convergentes, possuindo várias diferenças substanciais.

As diferenças substanciais se concentram nos métodos adicionais da FB5 (doseamento para os derivados hidroxicinâmicos e óleo volátil, e perfil cromatográfico) e na diferença da especificação do marcador ácido rosmarínico acima de 30\% entre as monografias.

Diferenças substanciais nas especificações como as encontradas, podem ocasionar barreiras sanitárias ao comércio internacional de matérias-primas e produtos acabados. Como espécie que não possui ocorrência no Brasil e com registros de fitoterápicos válidos no Brasil, se esperava que as monografias fossem mais harmonizadas, nesse caso, os resultados não acompanharam a expectativa.

\subsubsection{Mentha $x$ piperita $\mathrm{L}$. [folha]}

A hortelã-pimenta esteve presente na $1^{\mathrm{a}}$ edição da Farmacopeia Brasileira (Quadro 3), está relacionada no FFFB1, na Lista de Medicamentos Fitoterápicos de Registro Simplificado da IN no 02/2014 (BRASIL, 2011, 2014a) e na FB5. Não foram encontrados, para a espécie, registros de fitoterápicos válidos na Anvisa (Quadro 5). Conforme a literatura consultada, a espécie não possui ocorrência no Brasil (Apêndice A), havendo registro de ocorrência na Argentina, Canadá, Chile, China, Equador, El Salvador, Gabão, Índia, Japão, Quirguistão, México, Rússia, Turquemenistão e Estados Unidos da América (TROPICOS.ORG, 2016). Em buscas realizadas nos compêndios internacionais em estudo, foram localizadas monografias na EP8.8 e na USP39-NF34. Os dados extraídos das monografias estão descritos no Quadro 28. 
Quadro 28 - Comparação entre as monografias de Mentha x piperita L. [folha] das farmacopeias FB5, EP8.8 e USP39-NF34.

\begin{tabular}{|c|c|c|c|c|}
\hline & FB5 & EP8.8 & USP39-NF34 & Classificação \\
\hline Nomenclatura popular & hortelã-pimenta & peppermint & peppermint & - \\
\hline Droga vegetal & folha & folha & folha e sumidade florida & su \\
\hline Marcador 1 & $\begin{array}{c}\text { óleo volátil (NLT 1,2\% - inteiras; NLT } \\
0,9 \% \text { - rasuradas) }\end{array}$ & $\begin{array}{c}\text { óleo volátil (NLT 1,2\% - inteiras; NLT } \\
0,9 \% \text { - rasuradas) }\end{array}$ & - & se \\
\hline Características & $\begin{array}{c}\text { odor forte aromático + penetrante + } \\
\text { semelhante ao mentol + sabor aromático } \\
\text { picante }+ \text { sensação de frescor agradável }\end{array}$ & $\begin{array}{l}\text { odor característico }+ \text { penetrante }+ \text { sabor } \\
\text { característico }\end{array}$ & - & - \\
\hline Descrição macroscópica & 2 & 2 & 1 & - \\
\hline Descrição microscópica & 3 & 1 & 3 & - \\
\hline Figura botânica & 2 & 1 & - & - \\
\hline Identificação - método 1 & $\mathrm{CCD}$ & $\mathrm{CCD}$ & - & se \\
\hline Procedimento 1 & sílica-gel $\left(\mathrm{GF}_{254}+0,25 \mathrm{~mm}\right)$ & sílica-gel $\mathrm{GF}_{254}$ & - & se \\
\hline Procedimento 2 & tolueno:acetato de etila $(95: 5)$ & acetato de etila:tolueno $(5: 95)$ & - & se \\
\hline Procedimento 3 & $20 \mu \mathrm{L}$ (TS);10 $\mu \mathrm{L}$ (RS) (banda) & $20 \mu \mathrm{L}$ (TS);10 $\mu \mathrm{L}$ (RS) (banda) & - & se \\
\hline Procedimento 4 & $\begin{array}{c}0,2 \mathrm{~g} \text { droga vegetal recentemente } \\
\text { pulverizada }+2 \mathrm{~mL} \text { diclorometano }+ \\
\text { agitar }+ \text { filtrar }+ \text { evaporar }(\text { secura })\left(40^{\circ} \mathrm{C}\right) \\
+0,1 \mathrm{~mL} \text { tolueno }(\mathrm{TS})\end{array}$ & $\begin{array}{c}0,2 \mathrm{~g} \text { droga vegetal recentemente } \\
\text { pulverizada }+2 \mathrm{~mL} \text { diclorometano }+ \\
\text { agitar (alguns minutos) }+ \text { filtrar }+ \\
\text { evaporar (secura) }\left(40^{\circ} \mathrm{C}\right)+0,1 \mathrm{~mL} \\
\text { tolueno }(\mathrm{TS})\end{array}$ & - & se \\
\hline Procedimento 5 & $\begin{array}{c}50 \mathrm{mg} \text { mentol SQR }+20 \mu \mathrm{L} 1,8 \text {-cineol }+ \\
10 \mathrm{mg} \text { timol }+10 \mu \mathrm{L} \text { acetato de mentila }+ \\
\text { tolueno para } 10 \mathrm{~mL}(\mathrm{RS})\end{array}$ & $\begin{array}{c}50 \mathrm{mg} \text { mentol }+20 \mu \mathrm{L} \text { cineol }+10 \mathrm{mg} \\
\text { timol }+10 \mu \mathrm{L} \text { acetato de mentila }+ \\
\text { tolueno para } 10 \mathrm{~mL}(\mathrm{RS})\end{array}$ & - & se \\
\hline Procedimento 6 & secar $(\operatorname{ar})$ & secar $(\operatorname{ar})$ & - & se \\
\hline Procedimento 7 & $254 \mathrm{~nm}$ & $254 \mathrm{~nm}$ & - & se \\
\hline Procedimento 8 & $\begin{array}{l}\text { anisaldeído } \mathrm{SR}+\text { aquecer }\left(100-105^{\circ} \mathrm{C}\right) \\
\qquad\left(5-10^{\prime}\right)\end{array}$ & $\begin{array}{l}\text { solução de anisaldeído SR + aquecer (100- } \\
\left.\qquad 105^{\circ} \mathrm{C}\right)\left(5-10^{\prime}\right)\end{array}$ & - & se \\
\hline Procedimento 9 & $\begin{array}{l}\text { descrição de zonas } \\
\text { matéria estranha (NMT } 10 \% \text { - caules }\end{array}$ & esquema & - & se \\
\hline Testes - método 1 & $\begin{array}{l}\text { quadrangulares, glabros ou com tricomas } \\
\text { tectores + escassos fragmentos de caules } \\
\text { reconhecidos pelas fibras, além de } \\
\text { numerosos elementos de vaso, fragmentos } \\
\text { de flores) }\end{array}$ & $\begin{array}{c}\text { matéria estranha (NMT 5\% - caules }<1,5 \\
\text { mm) (NMT 2\% - outros) (NMT 8\% - } \\
\text { folhas com manchas marrons Puccinia } \\
\text { menthae) }(10 \mathrm{~g})\end{array}$ & $\begin{array}{l}\text { matéria orgânica estranha (NMT 2,0\% } \\
\text { caules > } 3 \mathrm{~mm}+\text { outros) }\end{array}$ & su \\
\hline Testes - método 2 & água (NMT 12,0\%) & água (NMT 11,0\%) $(20,0 \mathrm{~g})$ & - & $\mathrm{mi}$ \\
\hline Testes - método 3 & cinzas totais (NMT 15,0\%) & cinzas totais (NMT 15,0\%) & - & $\begin{array}{l}\text { se } \\
\text { (contil }\end{array}$ \\
\hline
\end{tabular}


Quadro 28 - Comparação entre as monografias de Mentha x piperita L. [folha] das farmacopeias FB5, EP8.8 e USP39-NF34.

\begin{tabular}{|c|c|c|c|c|}
\hline & FB5 & EP8.8 & USP39-NF34 & Classificação \\
\hline Testes - método 4 & - & $\begin{array}{c}\text { cinzas insolúveis em ácido clorídrico } \\
\text { (NMT 1,5\%) }\end{array}$ & - & su \\
\hline Doseamento - método 1 & $\begin{array}{l}\text { destilação (óleo volátil) (NLT 1,2\% - } \\
\text { inteiras; NLT 0,9\% - rasuradas) }\end{array}$ & $\begin{array}{l}\text { destilação (óleo volátil) (NLT 1,2\% - } \\
\text { inteiras; NLT 0,9\% - rasuradas) }\end{array}$ & - & se \\
\hline Procedimento 1 & 200 mL água & $200 \mathrm{~mL}$ água & - & se \\
\hline Procedimento 2 & $0,5 \mathrm{~mL}$ xileno & $0,5 \mathrm{~mL}$ xileno & - & se \\
\hline Procedimento 3 & $\begin{array}{c}20 \mathrm{~g} \text { droga vegetal (rasurada }+ \text { imediata } \\
\text { determinação) }\end{array}$ & $20,0 \mathrm{~g}$ droga vegetal (rasurada) & - & se \\
\hline Procedimento 4 & $4 \mathrm{~h}$ & $3-4 \mathrm{~mL} / \mathrm{min}(2 \mathrm{~h})$ & - & me \\
\hline $\begin{array}{l}\text { Embalagem e } \\
\text { armazenamento }\end{array}$ & 1 & - & - & - \\
\hline Padrões de referência & mentol SQR & - & - & - \\
\hline
\end{tabular}

Legenda: mi = menor; me = moderado; su = substancial; se = semelhante; NLT = não menos que; MNT = não mais que; CCD = cromatografia em camada delgada; RS = solução referência; $\mathrm{TS}$ = solução amostra; $\mathrm{SR}$ = solução reagente; $\mathrm{SQR}$ = substância química de referência. 
No geral, as monografias da FB5 e da EP8.8 são convergentes, com propostas semelhantes de ensaios e testes, enquanto que a monografia da USP39-NF34 é substancialmente diferente. A monografia da USP39-NF34 para a Mentha x piperita L. pertence ao National Formulary, que apresenta especificações para a excipientes (USP, 2016e). Para uma monografia destinada a excipientes, não se espera que haja especificações para marcadores, havendo apenas testes e ensaios para garantir um mínimo de qualidade e autenticidade do excipiente.

A diferença substancial na definição da droga vegetal para a qual a FB5 e a EP8.8 consideram apenas a folha e USP39-NF34 considera folha e sumidade florida, pode impactar nos resultados alcançados pela droga vegetal em todos os demais métodos, ensaios e especificações da monografia.

Há, ainda, diferenças substanciais nos testes adicionais da EP8.8 (cinzas insolúveis em ácido clorídrico) e na diferença da especificação de matéria estranha acima de $30 \%$ entre as três monografias.

Como espécie que não possui ocorrência no Brasil, a origem da matéria-prima não é nacional. Assim, se esperava que os métodos e especificações fossem mais harmonizados, nesse caso, com exceção da USP39-NF34, os resultados acompanharam a expectativa.

Como a espécie está listada no FFFB1 e na IN ${ }^{\circ}$ 02/2014 e possui monografia na FB5 convergente com a EP8.8, facilitando com que empresas multinacionais possam cumprir os requisitos para obter autorização de comercialização no Brasil, se esperava que houvesse registros válidos no Brasil, porém, nesse caso, os resultados não acompanharam a expectativa.

\subsubsection{Mentha $x$ piperita $\mathrm{L}$. [parte aérea fresca; óleo]}

A hortelã-pimenta, óleo, esteve presente na $1^{\mathrm{a}}$ e $2^{\mathrm{a}}$ edição da Farmacopeia Brasileira, sendo que na $1^{\text {a }}$ edição a droga vegetal era constituída da folha e sumidade florida (Quadro 3), está relacionada no FFFB1, na Lista de Medicamentos Fitoterápicos de Registro Simplificado da IN nº 02/2014 (BRASIL, 2011, 2014a) e na FB5. Não foram encontrados, para a espécie, registros de fitoterápicos válidos na Anvisa (Quadro 5). Conforme a literatura consultada, a espécie não possui ocorrência no Brasil (Apêndice A), havendo registro de ocorrência na Argentina, Canadá, Chile, China, Equador, El Salvador, Gabão, Índia, Japão, Quirguistão, México, Rússia, Turquemenistão e Estados Unidos da América (TROPICOS.ORG, 2016). Em 
buscas realizadas nos compêndios internacionais em estudo, foram localizadas monografias na EP8.8 e na USP39-NF34. Os dados extraídos das monografias estão descritos no Quadro 29. 
Quadro 29 - Comparação entre as monografias de Mentha x piperita L. [parte aérea fresca; óleo] das farmacopeias FB5, EP8.8 e USP39-NF34.

\begin{tabular}{|c|c|c|c|c|}
\hline & FB5 & EP8.8 & USP39-NF34 & Classificação \\
\hline Nomenclatura popular & hortelã-pimenta & peppermint & peppermint & - \\
\hline Droga vegetal & parte aérea fresca & parte aérea florida fresca & parte aérea florida fresca & su \\
\hline Derivado & óleo volátil & óleo volátil & óleo volátil & se \\
\hline Marcador 1 & mentol (NLT 35,0\%) & mentol $(30,0-55,0 \%)^{2}$ & mentol total (inclui ésteres) (NLT 50,0\%) & su \\
\hline Marcador 2 & $\begin{array}{c}\text { acetato de mentila }(3,0-10,0 \%)^{1} \\
\text { incolor ou amarelo pálido ou amarelo }\end{array}$ & $\begin{array}{c}\text { acetato de mentila }(2,8-10,0 \%)^{1} \\
\text { incolor ou amarelo pálido ou amarelo }\end{array}$ & ésteres (acetato de mentila) (NLT 5,0\%) & $\mathrm{su}$ \\
\hline Características & $\begin{array}{l}\text { esverdeado pálido + odor característico + } \\
\text { sabor característico + sensação de frescor }\end{array}$ & $\begin{array}{l}\text { esverdeado pálido + odor característico + } \\
\text { sabor característico + sensação de frescor }\end{array}$ & - & - \\
\hline Identificação - método 1 & $\mathrm{CCD}$ & $\mathrm{CCD}$ & - & se \\
\hline Procedimento 1 & sílica-gel $\left(\mathrm{GF}_{254}+0,25 \mathrm{~mm}\right)$ & sílica-gel $\left(\mathrm{F}_{254}+5-40 \mu \mathrm{m}\right.$ ou 2-10 $\left.\mu \mathrm{m}\right)$ & - & $\mathrm{mi}$ \\
\hline Procedimento 2 & tolueno:acetato de etila $(95: 5)$ & acetato de etila:tolueno $(5: 95)$ & - & se \\
\hline Procedimento 3 & $20 \mu \mathrm{L}(\mathrm{TS}) ; 10 \mu \mathrm{L}$ (RS) (banda) & $\begin{array}{c}20 \text { ou } 2 \mu \mathrm{L} \text { (TS); } 10 \text { ou } 1 \mu \mathrm{L} \text { (RS) (10 ou } 8 \\
\text { mm) (banda) }\end{array}$ & - & $\mathrm{mi}$ \\
\hline Procedimento 4 & $0,1 \mathrm{~mL}$ óleo volátil + $1 \mathrm{~mL}$ tolueno $(\mathrm{RS})$ & $0,1 \mathrm{~g}$ óleo volátil + tolueno para $10 \mathrm{~mL}$ & - & me \\
\hline Procedimento 5 & $\begin{array}{c}50 \mathrm{mg} \text { mentol } \mathrm{SQR}+20 \mu \mathrm{L} 1,8 \text {-cineol }+ \\
10 \mathrm{mg} \text { timol }+10 \mu \mathrm{L} \text { acetato de mentila }+ \\
\text { tolueno para } 10 \mathrm{~mL}(\mathrm{RS})\end{array}$ & $\begin{array}{c}50 \mathrm{mg} \text { mentol }+20 \mu \mathrm{L} \text { cineol }+10 \mathrm{mg} \\
\text { timol }+10 \mu \mathrm{L} \text { acetato de mentila }+ \\
\text { tolueno para } 10 \mathrm{~mL}(\mathrm{RS})\end{array}$ & - & se \\
\hline Procedimento 6 & secar (ar) & secar (ar) & - & se \\
\hline Procedimento 7 & $254 \mathrm{~nm}$ & $254 \mathrm{~nm}$ & - & se \\
\hline Procedimento 8 & $\begin{array}{c}\text { anisaldeído SR }+ \text { aquecer }\left(100-105^{\circ} \mathrm{C}\right) \\
\left(5-10^{\prime}\right)\end{array}$ & $\begin{array}{l}\text { solução de anisaldeído SR + aquecer (100- } \\
\left.105^{\circ} \mathrm{C}\right)\left(5-10^{\prime}\right)\end{array}$ & - & se \\
\hline Procedimento 9 & descrição de zonas & descrição de zonas + esquema & - & se \\
\hline Identificação - método 2 & - & - & $\begin{array}{l}6 \text { gotas óleo volátil }+5 \mathrm{~mL} \text { ácido } \\
\text { nítrico:ácido acético glacial }(1: 300)+ \\
\text { aquecer (béquer água fervente) }\left(5^{\prime}\right)= \\
\text { coloração azul }+ \text { aquecer }=\text { azul intenso }+ \\
\text { fluorescência bronze }+ \text { amarelo ouro }\end{array}$ & su \\
\hline Testes - método 1 & densidade relativa $(0,900-0916)$ & densidade relativa $(0,900-0916)$ & densidade relativa $(0,896-0,908)$ & mi \\
\hline Testes - método 2 & poder rotatório $\left(-30^{\circ} \mathrm{a}-10^{\circ}\right)$ & poder rotatório $\left(-30^{\circ} \mathrm{a}-10^{\circ}\right)$ & poder rotatório $\left(-32^{\circ} \mathrm{a}-18^{\circ}\right)$ & su \\
\hline Testes - método 3 & - & óleos fixos e resignificados (MR) & - & su \\
\hline Testes - método 4 & - & $\begin{array}{l}\text { solubilidade (solúvel - etanol } 96 \%+ \\
\text { diclorometano) }\end{array}$ & $\begin{array}{c}\text { solubilidade }(1: 3 \text { - etanol } 70 \%+\text { NMT } \\
\text { ligeira opalescência })\end{array}$ & $\mathrm{su}$ \\
\hline Testes - método 5 & - & - & $\begin{array}{c}\text { dimetilsulfureto ( } 25 \mathrm{~mL} \text { óleo volátil + } \\
\text { destilar + acrescentar } 1 \mathrm{~mL} \text { (destilado) em }\end{array}$ & su \\
\hline
\end{tabular}


Quadro 29 - Comparação entre as monografias de Mentha x piperita L. [parte aérea fresca; óleo] das farmacopeias FB5, EP8.8 e USP39-NF34.

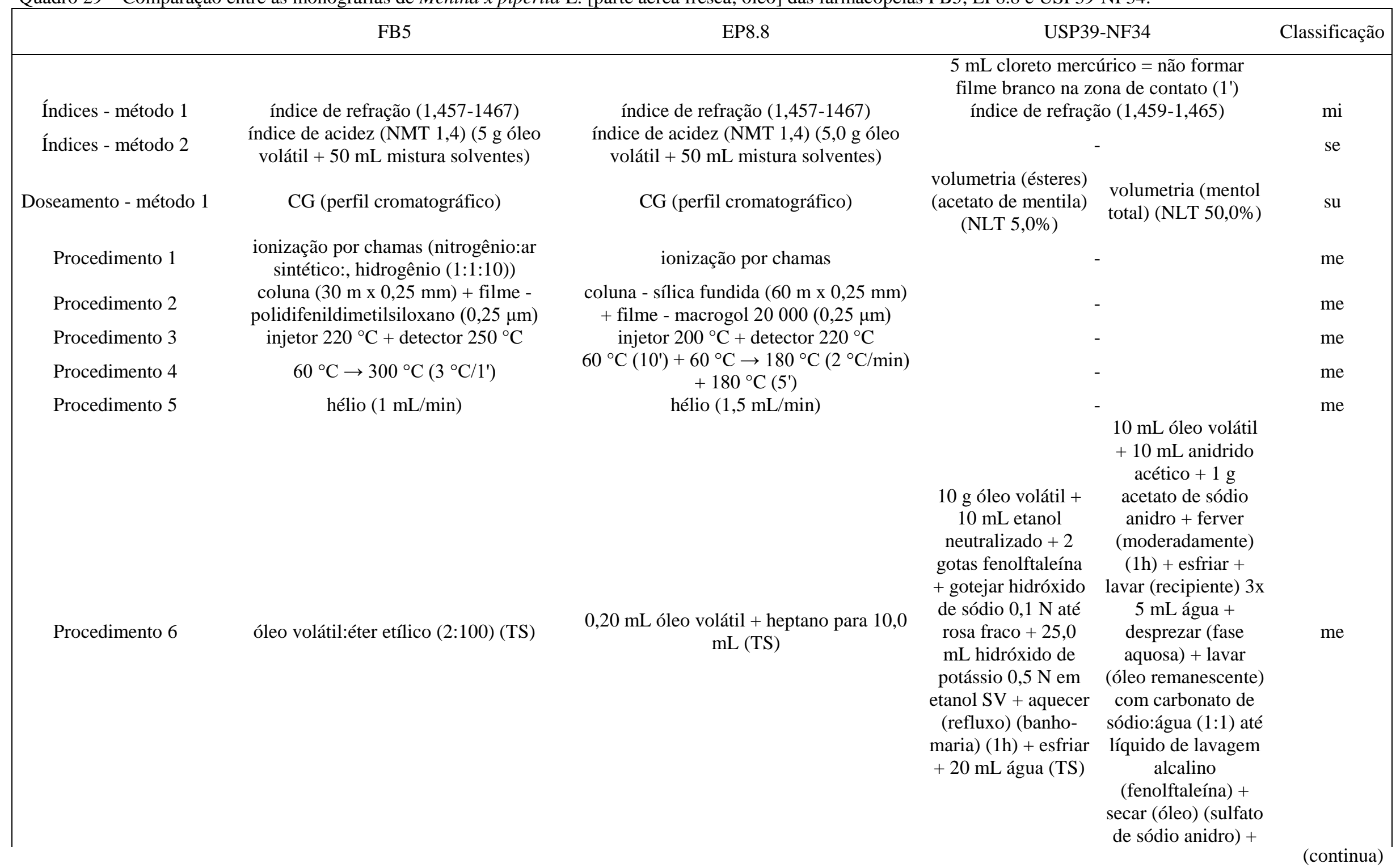


Quadro 29 - Comparação entre as monografias de Mentha x piperita L. [parte aérea fresca; óleo] das farmacopeias FB5, EP8.8 e USP39-NF34.

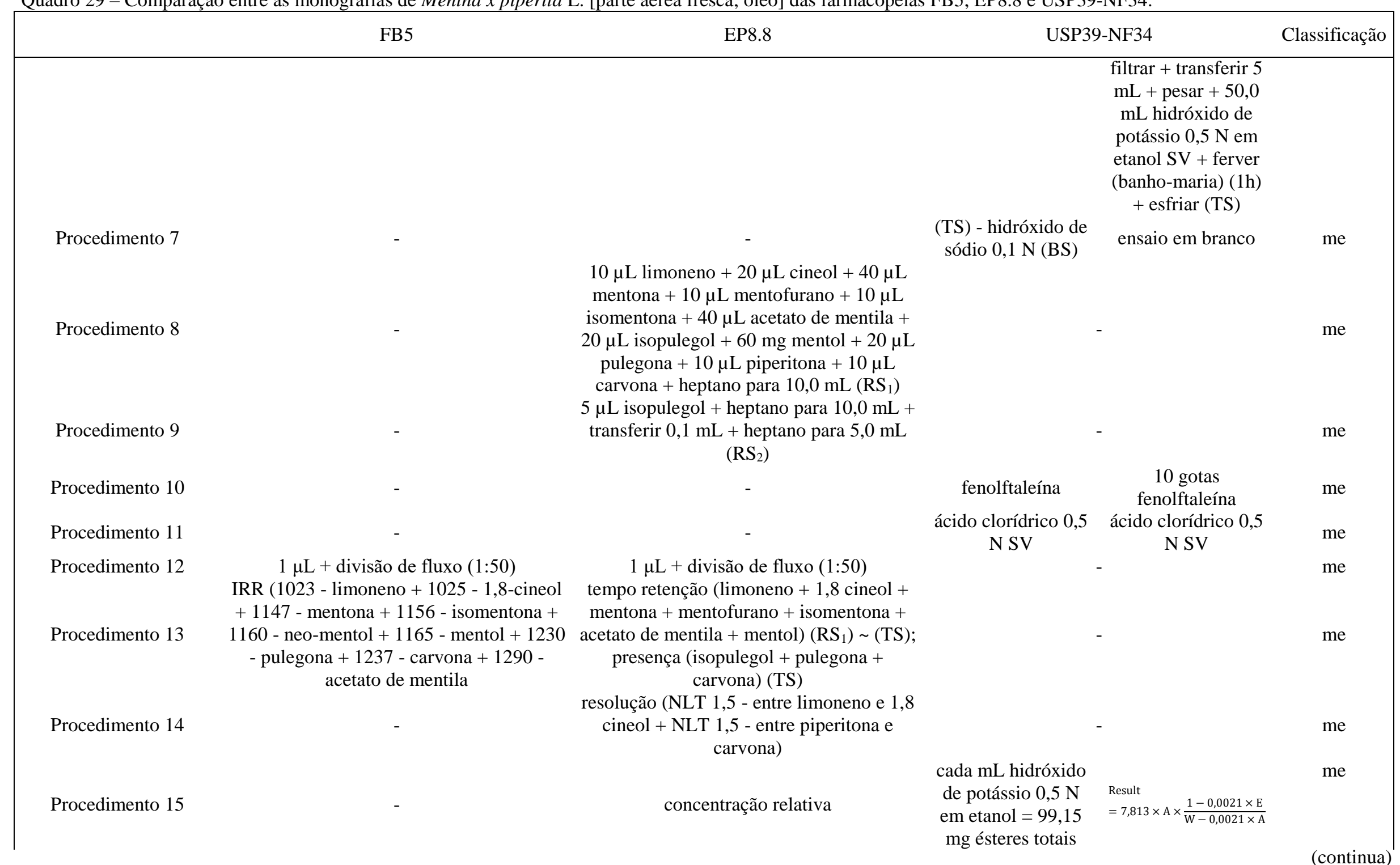


Quadro 29 - Comparação entre as monografias de Mentha x piperita L. [parte aérea fresca; óleo] das farmacopeias FB5, EP8.8 e USP39-NF34.

\begin{tabular}{|c|c|c|c|c|}
\hline & FB5 & EP8.8 & USP39-NF34 & Classificação \\
\hline Procedimento 16 & $\begin{array}{c}\text { figura }+ \text { limoneno }(0,5-5,0 \%)+1,8 \text {-cineol } \\
(0,5-13,0 \%)+\text { mentona }(6,0-30,0 \%)+ \\
\text { isomentona }(2,0-10,0 \%)+\text { neo-mentol } \\
(2,0-3,5 \%)+\text { mentol }(35,0-79,0 \%)+ \\
\text { pulegona (NMT 2,0\%) + carvona (NMT } \\
1,0 \%)+ \text { acetato de mentila }(3,0-10,0 \%)\end{array}$ & $\begin{array}{c}\text { limoneno }(1,0-3,5 \%)+1,8 \text { cineol }(3,5- \\
8,0 \%)+ \text { mentona }(14,0-32,0 \%)+ \\
\text { mentofurano }(1,0-8,0 \%)+\text { isomentona } \\
(1,5-10,0 \%)+\text { acetato de mentila }(2,8- \\
10,0 \%)+ \text { isopulegol (NMT } 0,2 \%)+ \\
\text { mentol }(30,0-55,0 \%)+\text { pulegona (NMT } \\
3,0 \%)+ \text { carvona (NMT 1,0\%) + disregard } \\
\text { limit (pico principal (RS2) - 0,05\%) + } \\
\text { razão 1,8-cineol/limoneno (NLT 2) }\end{array}$ & - & su \\
\hline $\begin{array}{l}\text { Embalagem e } \\
\text { armazenamento }\end{array}$ & 1 & $1^{2}$ & 1 & - \\
\hline Padrões de referência & mentol SQR & - & - & - \\
\hline
\end{tabular}

de referência

mentol SQR

(BRASIL, 2010d; EDQM, 2016b; USP, 2016h).

Legenda: $\mathrm{mi}=$ menor; me = moderado; $\mathrm{su}=$ substancial; $\mathrm{se}=$ semelhante; $\mathrm{NLT}=$ não menos que; $\mathrm{MNT}=$ não mais que; MR = cumpre os requisitos ou o teste; CCD = cromatografia em camada delgada; $\mathrm{RS}=$ solução referência; $\mathrm{TS}=$ solução amostra; $\mathrm{SR}=$ solução reagente; $\mathrm{BS}=$ solução branco; $\mathrm{SV}=$ solução volumétrica; $\mathrm{SQR}=$ substância química de referência; $\mathrm{CG}=$ cromatografia gasosa; $\mathrm{IRR}=$ índice de retenção relativo; $\mathrm{A}=$ volume; $\mathrm{W}=$ massa; $\mathrm{E}=$ percentual de ésteres

Nota: ${ }^{1}=$ especificação extraída do método de doseamento para fins de comparação; ${ }^{2}=$ somente armazenamento.

(conclusão) 
No geral, as monografias da FB5 e da EP8.8 possuem propostas semelhantes de ensaios e testes, enquanto que a monografia da USP39-NF34 é substancialmente diferente. A monografia da USP39-NF34 para o óleo volátil de Mentha x piperita L. pertence ao National Formulary, que apresenta especificações para a excipientes (USP, 2016e).

A diferença substancial na definição da droga vegetal para a qual a FB5 considera apenas parte aérea fresca e a EP8.8 e a USP39-NF34 consideram parte aérea florida fresca, pode impactar nos resultados alcançados pela droga vegetal em todos os demais métodos, ensaios e especificações da monografia.

Há, ainda, diferenças substanciais nos testes adicionais da EP8.8 (solubilidade e óleos fixos e resignificados) e da USP39-NF34 (um ensaio de identificação e os testes de solubilidade e de dimetilsulfureto) e na diferença da especificação do poder rotatório, da matéria estranha e dos marcadores acima de $30 \%$ entre as três monografias.

Como espécie que não possui ocorrência no Brasil, a origem da matéria-prima não é nacional. Assim, se esperava que os métodos e especificações fossem mais harmonizados, nesse caso, os resultados não acompanharam a expectativa.

Como a espécie está listada no FFFB1 e na IN 02/2014 e possui monografia na FB5, se esperava que houvesse registros válidos no Brasil, porém, nesse caso, os resultados não acompanharam a expectativa.

\subsubsection{Myroxylon balsamum (L.) Harms e M. balsamum var. pereirae (Royle) Harms [tronco; óleo-resina]}

O bálsamo-de-tolu esteve presente na $1^{\mathrm{a}}$ e $2^{\mathrm{a}}$ edição da Farmacopeia Brasileira (Quadro 3), não está relacionado no FFFB1 e nem na IN nº 02/2014 (BRASIL, 2011, 2014a), estando apenas na FB5. Foi encontrado, para a espécie, apenas um registro de fitoterápico válido na Anvisa (Quadro 5). Conforme a literatura consultada, a espécie possui ocorrência no Brasil (Apêndice A), sendo nativa, mas não endêmica (REFLORA, 2016). Há, ainda, registro de ocorrência da espécie na Belize, Caribe, Guatemala, Honduras, Sri Lanka, Argentina, Bolívia, Colômbia, Costa Rica, Equador, El Salvador, Guiana, México, Panamá, Peru, Suriname e Venezuela (TROPICOS.ORG, 2016). Em buscas realizadas nos compêndios internacionais em estudo, foram localizadas monografias na EP8.8, na FA7 e na USP39-NF34. Os dados extraídos das monografias estão descritos no Quadro 30. 
Quadro 30 - Comparação entre as monografias de Myroxylon balsamum (L.) Harms e M. balsamum var. pereirae (Royle) Harms [tronco; óleo-resina] das farmacopeias FB5, EP8.8, FA7 e USP39-NF34.

\begin{tabular}{|c|c|c|c|c|c|}
\hline & FB5 & EP8.8 & FA7 & USP39-NF34 & Classificação \\
\hline Nomenclatura botânica & $\begin{array}{c}\text { Myroxylon balsamum (L.) } \\
\text { Harms e Myroxylon balsamum } \\
\text { var. pereirae (Royale) Harms }\end{array}$ & $\begin{array}{l}\text { Myroxylon balsamum (L.) } \\
\text { Harms var. balsamum }\end{array}$ & $\begin{array}{c}\text { Myroxylon balsamum (L.) } \\
\text { Harms }\end{array}$ & $\begin{array}{c}\text { Myroxylon balsamum (L.) } \\
\text { Harms }\end{array}$ & - \\
\hline $\begin{array}{l}\text { Nomenclatura popular } \\
\text { Droga vegetal }\end{array}$ & $\begin{array}{c}\text { bálsamo-de-tolu } \\
\text { óleo-resina }\end{array}$ & $\begin{array}{c}\text { tolu balsam } \\
\text { óleo-resina (tronco) }\end{array}$ & $\begin{array}{l}\text { bálsamo de tolú } \\
\text { óleo-resina }\end{array}$ & $\begin{array}{l}\text { tolu balsam } \\
\text { bálsamo }\end{array}$ & $\mathrm{se}^{-}$ \\
\hline Marcador 1 & $\begin{array}{c}\text { ácidos livres ou combinados } \\
\text { (ácido cinâmico) }(25-50 \%)\end{array}$ & $\begin{array}{c}\text { ácidos livres ou combinados } \\
\text { (ácido cinâmico) }(25,0-50,0 \%) \\
\text { (droga seca) }\end{array}$ & - & - & se \\
\hline Características & $\begin{array}{c}\text { massa castanho-avermelhada }+ \\
\text { dura }+ \text { friável }+ \text { fragmentos } \\
\text { finos amarelo-acastanhados }+ \\
\text { odor semelhante baunilha }+ \\
\text { sabor pouco acre }\end{array}$ & $\begin{array}{c}\text { friável + massa marrom a } \\
\text { marrom-avermelhada }+ \\
\text { fragmentos são amarelo- } \\
\text { amarronzados quando contra a } \\
\text { luz + odor remanescente de } \\
\text { baunilha }\end{array}$ & $\begin{array}{c}\text { semissólido amarelo ou } \\
\text { amarelo-marrom + endurece } \\
\text { com tempo + resinoso + duro + } \\
\text { friável + amolece à quente + } \\
\text { cor marrom a marrom- } \\
\text { avermelhado + translúcido em } \\
\text { camada fina + odor balsâmico } \\
\text { agradável + semelhante } \\
\text { baunilha + sabor aromático + } \\
\text { doce a princípio depois acre }\end{array}$ & - & - \\
\hline Identificação - método 1 & $\mathrm{CCD}$ & CCD & - & - & se \\
\hline Procedimento 1 & sílica-gel $\left(\mathrm{GF}_{254}+0,25 \mathrm{~mm}\right)$ & sílica-gel G & - & - & mi \\
\hline Procedimento 2 & éter de petróleo:tolueno $(5: 95)$ & éter de petróleo:tolueno $(5: 95)$ & - & - & se \\
\hline Procedimento 3 & $\begin{array}{c}20 \mu \mathrm{L}(\mathrm{TS}) ; 10 \mu \mathrm{L}(\mathrm{RS}) \\
\text { (banda) }\end{array}$ & $20 \mu \mathrm{L}$ (TS) (RS) (banda) & - & - & mi \\
\hline Procedimento 4 & $\begin{array}{c}0,4 \mathrm{~g} \text { droga vegetal } \\
\text { fragmentada }+10 \mathrm{~mL} \\
\text { diclorometano }+\operatorname{agitar}\left(5^{\prime}\right)+ \\
\text { filtrar (papel pregueado) }(\mathrm{TS})\end{array}$ & $\begin{array}{c}0,40 \mathrm{~g} \text { droga vegetal } \\
\text { fragmentada }+10 \mathrm{~mL} \\
\text { diclorometano }+\operatorname{agitar}\left(5^{\prime}\right)+ \\
\text { filtrar (TS) }\end{array}$ & - & - & $\mathrm{se}$ \\
\hline Procedimento 5 & $\begin{array}{c}50 \mathrm{mg} \text { cinamato de benzila }+1 \\
\mathrm{~mL} \text { diclorometano }+50 \mu \mathrm{L} \\
\text { benzoato de benzila }+ \\
\text { diclorometano para } 10 \mathrm{~mL} \\
(\mathrm{RS})\end{array}$ & $\begin{array}{c}50 \mathrm{mg} \text { cinamato de benzila }+1 \\
\mathrm{~mL} \text { diclorometano }+50 \mu \mathrm{L} \\
\text { benzoato de benzila }+ \\
\text { diclorometano para } 10 \mathrm{~mL} \\
(\mathrm{RS})\end{array}$ & - & - & se \\
\hline Procedimento 6 & secar (ar) & secar (ar) & - & - & se \\
\hline Procedimento 7 & $254 \mathrm{~nm}$ & - & - & - & $\underset{\text { (conti }}{\operatorname{mi}}$ \\
\hline
\end{tabular}


Quadro 30 - Comparação entre as monografias de Myroxylon balsamum (L.) Harms e M. balsamum var. pereirae (Royle) Harms [tronco; óleo-resina] das farmacopeias FB5, EP8.8, FA7 e USP39-NF34.

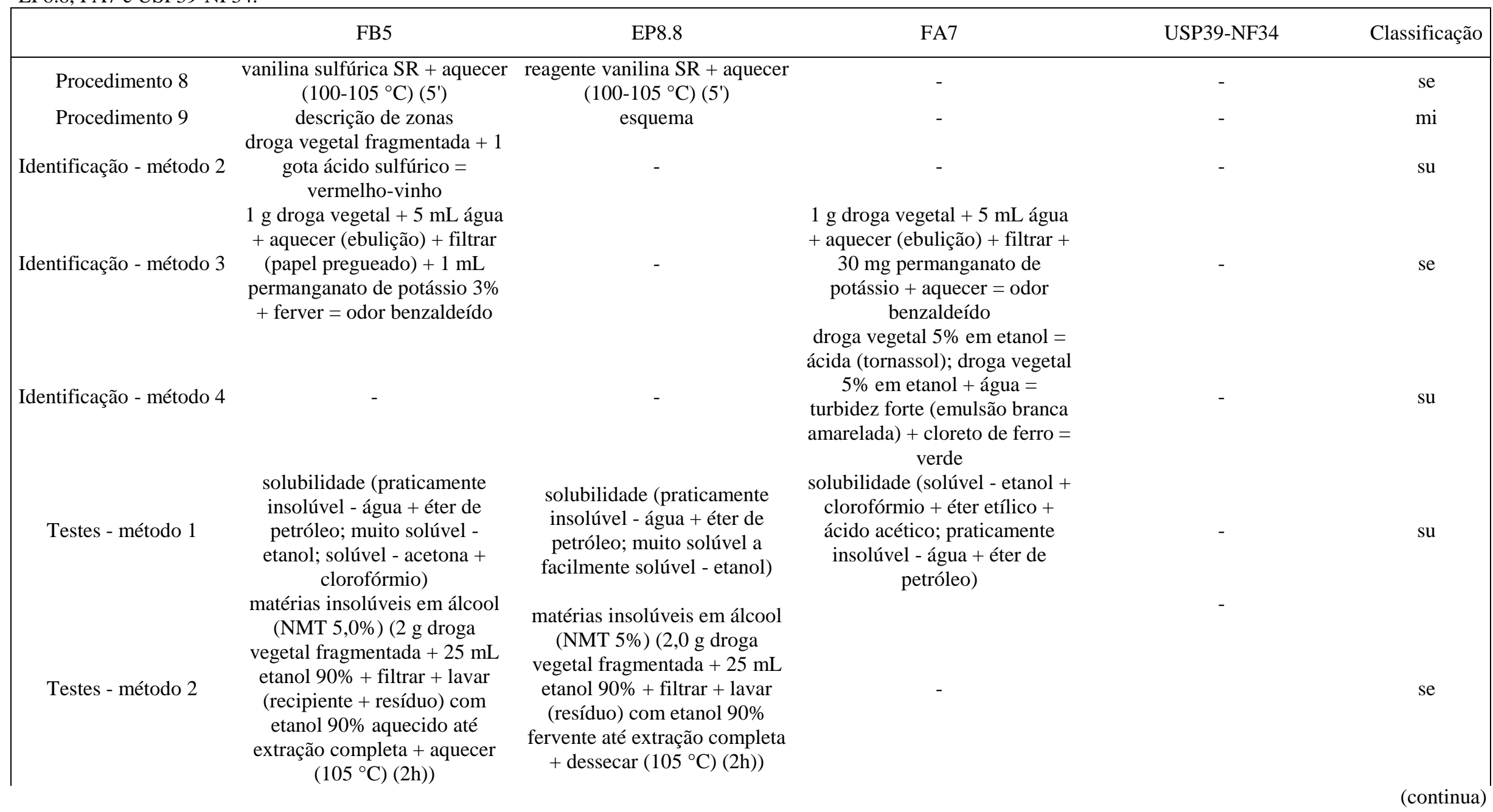


Quadro 30 - Comparação entre as monografias de Myroxylon balsamum (L.) Harms e M. balsamum var. pereirae (Royle) Harms [tronco; óleo-resina] das farmacopeias FB5, EP8.8, FA7 e USP39-NF34.

\begin{tabular}{|c|c|c|c|c|c|}
\hline & FB5 & EP8.8 & FA7 & USP39-NF34 & Classificação \\
\hline Testes - método 3 & $\begin{array}{c}\text { colofônia (coloração não } \\
\text { verde) }(1 \mathrm{~g} \text { droga vegetal }+10 \\
\text { mL éter de petróleo }+ \text { triturar } \\
\left(1-2^{\prime}\right)+\text { filtrar }+10 \text { mL acetato } \\
\text { de cobre } 0,5 \%+\text { agitar }+ \\
\text { observar fase etérea }\end{array}$ & - & $\begin{array}{c}\text { colofônia (coloração não } \\
\text { verde) }(1 \mathrm{~g} \text { droga vegetal }+10 \\
\mathrm{mL} \text { éter de petróleo + triturar } \\
(1-2 \text { ') }+ \text { filtrar }+10 \mathrm{~mL} \text { acetato } \\
\text { de cobre } 0,5 \%+\text { agitar }+ \\
\text { observar fase etérea }\end{array}$ & $\begin{array}{l}\text { colofônia; óleo de colofônia; } \\
\text { copaíba (coloração não verde) } \\
(1 \text { g droga vegetal + } 10 \mathrm{~mL} \\
\text { éter de petróleo + triturar }\left(1-2^{\prime}\right) \\
\text { + filtrar + } 10 \mathrm{~mL} \text { acetato de } \\
\text { cobre } 0,5 \% \text { + agitar + observar } \\
\text { fase etérea }\end{array}$ & se \\
\hline Testes - método 4 & $\begin{array}{l}\text { água (NMT 5,0\%) (2 g droga } \\
\text { vegetal fragmentada + secar } \\
\quad \text { (pressão reduzida) }(4 \mathrm{~h}))\end{array}$ & $\begin{array}{l}\text { perda por dessecação (NMT } \\
5,0 \%)(2,000 \text { g droga vegetal } \\
\text { fragmentada + secar (pressão } \\
\text { reduzida) }(4 \mathrm{~h}))\end{array}$ & - & - & se \\
\hline Testes - método 5 & cinzas totais (NMT $0,3 \%$ ) & $\begin{array}{l}\text { cinzas totais (NMT 0,3\%) } \\
\text { índice de acidez (100-160) }\end{array}$ & - & - & se \\
\hline Índices - método 1 & $\begin{array}{c}\text { índice de acidez }(100-160)(1 \mathrm{~g} \\
\text { droga vegetal }+50 \mathrm{~mL} \text { etanol } \\
\text { neutralizado }+1 \mathrm{~mL} \\
\text { fenolftaleína }+ \text { titular com } \\
\text { hidróxido de potássio } 0,5 \mathrm{M} \\
\mathrm{SV})\end{array}$ & $\begin{array}{c}0,5 \mathrm{~g} \text { droga vegetal }+50 \mathrm{~mL} \\
\text { etanol }+0,5 \mathrm{~mL} \text { solução de } \\
\text { azul ácido } 93+5,0 \mathrm{~mL} \\
\text { hidróxido de potássio } 0,5 \mathrm{M} \\
\text { em etanol + agitar } \\
\text { (vigorosamente) + titular com } \\
\text { ácido clorídrico } 0,5 \mathrm{M}+ \\
\text { determinação branco) }\end{array}$ & $\begin{array}{c}\text { índice de acidez }(112-168)(1 \mathrm{~g} \\
\text { droga vegetal }+50 \mathrm{~mL} \text { etanol } \\
\text { neutralizado }+1 \mathrm{~mL} \\
\text { fenolftaleína }+ \text { titular com } \\
\text { hidróxido de potássio } 0,5 \mathrm{~N}) \\
\text { (TS) }\end{array}$ & $\begin{array}{c}\text { índice de acidez }(112-168)(1 \mathrm{~g} \\
\text { droga vegetal }+50 \mathrm{~mL} \text { etanol } \\
\text { neutralizado }+ \text { fenolftaleína }+ \\
\text { titular com hidróxido de } \\
\text { potássio } 0,5 \mathrm{~N} \mathrm{SV})(\mathrm{TS})\end{array}$ & me \\
\hline Índices - método 2 & $\begin{array}{c}\text { índice de saponificação (154- } \\
\text { 220) }((\mathrm{TS})+25,0 \mathrm{~mL} \text { de } \\
\text { hidróxido de potássio } 0,5 \mathrm{M} \text { em } \\
\text { metanol + aquecer (banho- } \\
\text { maria) }(30 ')+1 \mathrm{~mL} \\
\text { fenolftaleína +titular com ácido } \\
\text { clorídrico } 0,5 M+\text { ensaio em } \\
\text { branco })^{2}\end{array}$ & - & $\begin{array}{c}\text { índice de saponificação (154- } \\
220)((\mathrm{TS})+20,0 \mathrm{~mL} \\
\text { hidróxido de potássio } 0,5 \mathrm{~N} \text { em } \\
\text { etanol + aquecer (banho-de- } \\
\text { vapor) }\left(30^{\prime}\right)+\text { esfriar + } 200 \mathrm{~mL} \\
\text { água + titular com ácido } \\
\text { clorídrico } 0,5 \mathrm{~N}+\text { ensaio em } \\
\text { branco) }\end{array}$ & $\begin{array}{c}\text { índice de saponificação (154- } \\
220)((\mathrm{TS})+\text { hidróxido de } \\
\text { potássio 0,5 N em etanol SV } \\
\text { para 20,0 mL+ aquecer } \\
\text { (refluxo) (banho-de-vapor) } \\
\left(30^{\prime}\right)+\text { esfriar + } 200 \mathrm{~mL} \text { água + } \\
\text { titular com ácido clorídrico } 0,5 \\
\mathrm{~N}+\text { ensaio em branco) }\end{array}$ & $\mathrm{mi}$ \\
\hline Doseamento - método 1 & $\begin{array}{c}\text { volumetria (ácidos livres ou } \\
\text { combinados) (ácido cinâmico) } \\
(25-50 \%)\end{array}$ & $\begin{array}{c}\text { volumetria (ácidos livres ou } \\
\text { combinados) (ácido cinâmico) } \\
(25,0-50,0 \%)\end{array}$ & - & - & se \\
\hline
\end{tabular}


Quadro 30 - Comparação entre as monografias de Myroxylon balsamum (L.) Harms e M. balsamum var. pereirae (Royle) Harms [tronco; óleo-resina] das farmacopeias FB5, EP8.8, FA7 e USP39-NF34.

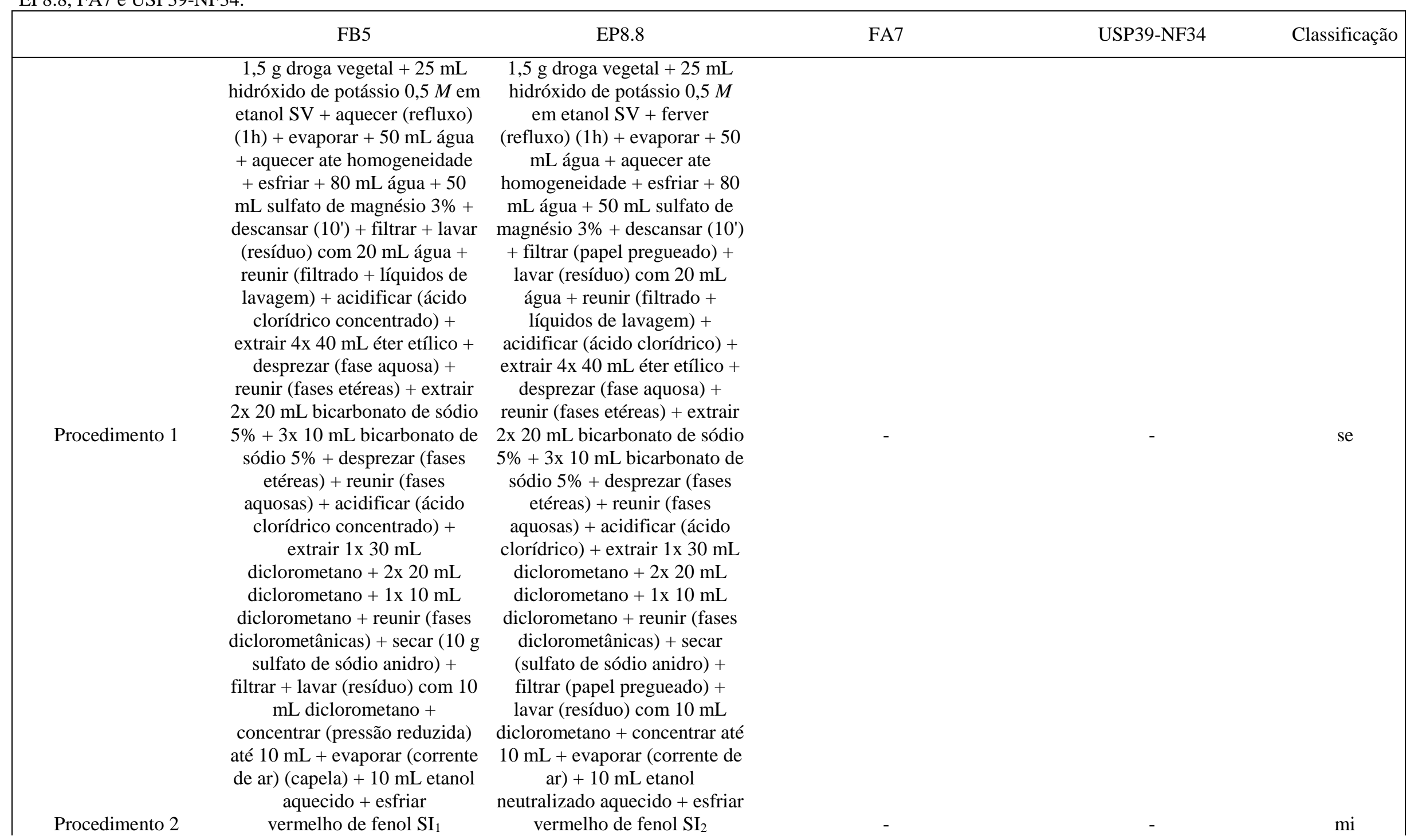


Quadro 30 - Comparação entre as monografias de Myroxylon balsamum (L.) Harms e M. balsamum var. pereirae (Royle) Harms [tronco; óleo-resina] das farmacopeias FB5, EP8.8, FA7 e USP39-NF34.

\begin{tabular}{|c|c|c|c|c|c|}
\hline & FB5 & EP8.8 & FA7 & USP39-NF34 & Classificação \\
\hline Procedimento 3 & $\begin{array}{c}\text { titular com hidróxido de sódio } \\
0,1 M \mathrm{SV} \\
\text { cada } \mathrm{mL} \text { hidróxido de sódio }\end{array}$ & $\begin{array}{c}\text { titular com hidróxido de sódio } \\
0,1 M \\
\text { cada } \mathrm{mL} \text { hidróxido de sódio }\end{array}$ & - & - & se \\
\hline Procedimento 4 & $\begin{array}{c}0,1 M \mathrm{SV}=14,816 \mathrm{mg} \text { ácido } \\
\text { cinâmico }\end{array}$ & $\begin{array}{c}0,1 M=14,82 \mathrm{mg} \text { ácido } \\
\text { cinâmico }\end{array}$ & - & - & se \\
\hline $\begin{array}{l}\text { Embalagem e } \\
\text { armazenamento }\end{array}$ & 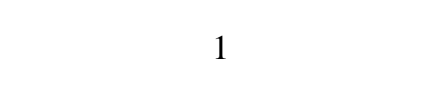 & $1^{3}$ & 1 & 1 & - \\
\hline
\end{tabular}

(ANMAT, 2003b; BRASIL, 2010c, d; EDQM, 2016b; USP, 2016h).

Legenda: mi = menor; me = moderado; su = substancial; se = semelhante; $\mathrm{MNT}=$ não mais que; $\mathrm{CCD}=$ cromatografia em camada delgada; $\mathrm{RS}=$ solução referência; $\mathrm{TS}=$ solução amostra; $\mathrm{SR}=$ solução reagente; $\mathrm{SI}=$ solução indicadora; $\mathrm{SV}=$ solução volumétrica.

Nota: ${ }^{1}=$ há omissão na FB5, FA7 e USP39-NF34 de que o bálsamo é um óleo-resina coletado do tronco ${ }^{2}=$ parâmetros extraídos do método geral; ${ }^{3}=$ apenas armazenamento.

(conclusão) 
No geral, as monografias da FB5 e da EP8.8 são convergentes, possuindo propostas mais semelhantes de ensaios e testes, enquanto que as monografias da FA7 e da USP39-NF34 são substancialmente diferentes.

Quando comparadas à FB5 as diferenças substanciais estão concentradas nos testes adicionais da FB5 (um ensaio de identificação) e da FA7 (um ensaio de identificação) e na existência de critérios adicionais na especificação da solubilidade.

Esse é um caso de um produto com ocorrência no Brasil e em outros países, com registro válidos de fitoterápico no Brasil e com presença de monografia em todas as farmacopeias em estudo.

\subsubsection{Myroxylon balsamum (L.) Harms var.pereirae (Royle) Harms [tronco; bálsamo]}

O bálsamo-do-peru esteve presente na $1^{\mathrm{a}}$ e $2^{\mathrm{a}}$ edição da Farmacopeia Brasileira (Quadro 3), não está relacionado no FFFB1 e nem na IN no 02/2014 (BRASIL, 2011, 2014a), estando apenas na FB5. Foi encontrado, para a espécie, apenas um registro de fitoterápico válido na Anvisa (Quadro 5). Conforme a literatura consultada, a espécie possui ocorrência no Brasil (Apêndice A), sendo nativa, mas não endêmica (REFLORA, 2016). Há, ainda, registro de ocorrência da espécie na Belize, Caribe, Costa Rica, El Salvador, Guatemala, Honduras, México, Panamá, Peru, Sri Lanka (TROPICOS.ORG, 2016). Em buscas realizadas nos compêndios internacionais em estudo, foram localizadas monografias na EP8.8 e na FA7. Os dados extraídos das monografias estão descritos no Quadro 31. 
Quadro 31 - Comparação entre as monografias de Myroxylon balsamum (L.) Harms var. pereirae (Royle) Harms [tronco; bálsamo] das farmacopeias FB5, EP8.8 e FA7.

\begin{tabular}{|c|c|c|c|c|}
\hline & FB5 & EP8.8 & FA7 & Classificação \\
\hline Nomenclatura popular & bálsamo-do-peru & peru balsam & bálsamo de perú & - \\
\hline Droga vegetal & bálsamo do tronco (escarificado à quente) & bálsamo do tronco (escarificado à quente) & bálsamo do tronco (escarificado à quente) & se \\
\hline Marcador 1 & ésteres $(45-70 \%)$ & ésteres $(45,0-70,0 \%)$ & ésteres $(45,0-70,0 \%)$ & se \\
\hline Características & $\begin{array}{c}\text { viscoso + límpido + castanho-escuro a } \\
\text { castanho-avermelhado + castanho- } \\
\text { amarelada (camada fina) + odor } \\
\text { característico + aromático semelhante } \\
\text { baunilha + sabor amargo + acre + não } \\
\text { solidifica ao ar nem por tempo prolongado } \\
\text { ou por aquecimento + não produz } \\
\text { filamentos }\end{array}$ & $\begin{array}{l}\text { viscoso + castanho-escuro + transparente } \\
\text { a castanho-amarelado (camada fina) + não } \\
\text { gruda + não seca + não produz filamentos }\end{array}$ & $\begin{array}{l}\text { viscoso + límpido + castanho-escuro a } \\
\text { castanho-avermelhado + transparente } \\
\text { (camada fina) + não espessa nem } \\
\text { solidifica ao ar + odor balsâmico + } \\
\text { agradável semelhante baunilha + sabor } \\
\text { acre + ligeiramente amargo }\end{array}$ & - \\
\hline Identificação - método 1 & CCD & CCD & CCD & se \\
\hline Procedimento 1 & sílica-gel $\left(\mathrm{GF}_{254}+0,25 \mathrm{~mm}\right)$ & sílica-gel GF 254 & sílica-gel (fluorescência $+0,25 \mathrm{~mm}$ ) & $\mathrm{mi}$ \\
\hline Procedimento 2 & $\begin{array}{l}\text { ácido acético glacial:acetato de } \\
\text { etila:hexano }(0,5: 10: 90)\end{array}$ & $\begin{array}{l}\text { ácido acético glacial:acetato de } \\
\text { etila:hexano }(0,5: 10: 90)\end{array}$ & $\begin{array}{l}\text { hexano:acetato de etila:ácido acético } \\
\text { glacial }(90: 10: 0,5)\end{array}$ & se \\
\hline Procedimento 3 & $10 \mu \mathrm{L}(\mathrm{TS})(\mathrm{RS})$ (banda) & $10 \mu \mathrm{L}(20 \times 3 \mathrm{~mm})(\mathrm{TS})(\mathrm{RS})$ (banda) & $10 \mu \mathrm{L}(\mathrm{TS})(\mathrm{RS})($ banda) & mi \\
\hline Procedimento 4 & $\begin{array}{c}0,5 \mathrm{~g} \text { droga vegetal }+10 \mathrm{~mL} \text { acetato de } \\
\text { etila (TS) }\end{array}$ & $\begin{array}{c}0,5 \mathrm{~g} \text { droga vegetal }+10 \mathrm{~mL} \text { acetato de } \\
\text { etila (TS) }\end{array}$ & $\begin{array}{c}500 \mathrm{mg} \text { droga vegetal }+10 \mathrm{~mL} \text { acetato de } \\
\text { etila (TS) }\end{array}$ & se \\
\hline Procedimento 5 & $\begin{array}{c}4 \mathrm{mg} \text { timol }+30 \mathrm{mg} \text { cinamato de benzila }+ \\
80 \mu \mathrm{L} \text { benzoato de benzila }+5 \mathrm{~mL} \\
\text { acetato de etila (RS) }\end{array}$ & $\begin{array}{c}4 \mathrm{mg} \text { timol }+30 \mathrm{mg} \text { cinamato de benzila }+ \\
80 \mu \mathrm{L} \text { benzoato de benzila }+5 \mathrm{~mL} \\
\text { acetato de etila }(\mathrm{RS})\end{array}$ & $\begin{array}{c}4 \mathrm{mg} \text { timol }+30 \mathrm{mg} \text { cinamato de benzila }+ \\
80 \mu \mathrm{L} \text { benzoato de benzila }+5 \mathrm{~mL} \\
\text { acetato de etila (RS) }\end{array}$ & se \\
\hline Procedimento 6 & - & desenvolver $2 \mathrm{x}$ & desenvolver $2 \mathrm{x}$ & mi \\
\hline Procedimento 7 & secar (ar) & secar $($ ar $)$ & secar $($ ar $)$ & se \\
\hline Procedimento 8 & $\begin{array}{c}\text { ácido fosfomolíbdico } 20 \% \text { em etanol }+ \\
\text { aquecer }\left(100-105^{\circ} \mathrm{C}\right)\left(5-10^{\prime}\right)\end{array}$ & $\begin{array}{c}\text { ácido fosfomolíbdico } 20,0 \% \text { em etanol } \\
96 \%+\text { aquecer }\left(100-105^{\circ} \mathrm{C}\right)\left(5-10^{\prime}\right)\end{array}$ & $\begin{array}{c}\text { ácido fosfomolíbdico } 20 \% \text { em etanol }+ \\
\text { aquecer }\left(100-105^{\circ} \mathrm{C}\right)\left(5-10^{\prime}\right)\end{array}$ & mi \\
\hline Procedimento 9 & $254 \mathrm{~nm}$ & $254 \mathrm{~nm}$ & $254 \mathrm{~nm}$ & se \\
\hline Procedimento 10 & descrição de zonas & descrição de zonas & descrição de zonas & se \\
\hline Identificação - método 2 & $\begin{array}{c}\text { 0,20 g droga vegetal }+10 \mathrm{~mL} \text { de etanol }+ \\
0,2 \mathrm{~mL} \text { cloreto férrico } \mathrm{SR}=\text { verde a verde } \\
\text { oliva } \\
2-3 \text { gotas droga vegetal }+5 \times 2-3 \text { gotas }\end{array}$ & $\begin{array}{c}0,20 \mathrm{~g} \text { droga vegetal }+10 \mathrm{~mL} \text { de etanol } \\
96 \%+0,2 \mathrm{~mL} \text { cloreto férrico } \mathrm{SR}=\text { verde } \\
\text { a verde-amarelado }\end{array}$ & $\begin{array}{c}200 \mathrm{mg} \text { droga vegetal }+10 \mathrm{~mL} \text { de etanol }+ \\
0,2 \mathrm{~mL} \text { cloreto férrico } \mathrm{SR}=\text { verde a verde } \\
\text { oliva }\end{array}$ & $\mathrm{mi}^{1}$ \\
\hline Identificação - método 3 & $\begin{array}{l}\text { ácido sulfúrico concentrado = vermelho- } \\
\text { escuro }+40 \mathrm{~mL} \text { água = violácea (não deve } \\
\text { ocorrer matiz pardo) (adulteração) }\end{array}$ & - & - & su \\
\hline Testes - método 1 & densidade relativa $(1,14-1,17)$ & densidade relativa $(1,14-1,17)$ & densidade relativa $(1,140-1,170)$ & $\begin{array}{l}\text { se } \\
\text { (contil }\end{array}$ \\
\hline
\end{tabular}


Quadro 31 - Comparação entre as monografias de Myroxylon balsamum (L.) Harms var. pereirae (Royle) Harms [tronco; bálsamo] das farmacopeias FB5, EP8.8 e FA7.

\begin{tabular}{|c|c|c|c|c|}
\hline & FB5 & EP8.8 & FA7 & Classificação \\
\hline Testes - método 2 & $\begin{array}{c}\text { bálsamos artificiais }(0,2 \text { g droga vegetal }+ \\
6 \mathrm{~mL} \text { éter de petróleo incolor }+ \text { agitar } \\
\text { (vigorosamente) }=\text { permanecer } \\
\text { transparente }+ \text { partes insolúveis aderidas) }\end{array}$ & $\begin{array}{c}\text { bálsamos artificiais }(0,2 \text { g droga vegetal + } \\
6 \mathrm{~mL} \text { éter de petróleo }+ \text { agitar }= \\
\text { permanecer transparente }+ \text { partes } \\
\text { insolúveis aderidas })\end{array}$ & - & $\mathrm{se}$ \\
\hline Testes - método 3 & $\begin{array}{l}\text { terebintina (sem odor terebintina) } \\
\text { (evaporar } 4 \mathrm{ml} \text { bálsamos artificiais) }\end{array}$ & $\begin{array}{c}\text { terebintina (sem odor terebintina) } \\
\text { (evaporar } 4 \mathrm{ml} \text { bálsamos artificiais) }\end{array}$ & - & se \\
\hline Testes - método 4 & $\begin{array}{c}\text { óleos graxos (transparente) (1 g droga } \\
\text { vegetal }+3 \mathrm{~mL} \text { hidrato de cloral } 1000 \mathrm{~g} / \mathrm{L})\end{array}$ & $\begin{array}{l}\text { óleos graxos (transparente) (1 g droga } \\
\text { vegetal }+3 \text { mL hidrato de cloral } 1000 \\
\mathrm{~g} / \mathrm{L})\end{array}$ & $\begin{array}{l}\text { óleos graxos (transparente) }(1 \mathrm{~g} \text { droga } \\
\text { vegetal }+3 \mathrm{~g} \text { hidrato de cloral } 2000 \mathrm{~g} / \mathrm{L} \\
\text { em água:glicerina }(15: 10)+2 \mathrm{~mL} \text { água })\end{array}$ & mi \\
\hline Testes - método 5 & $\begin{array}{l}\text { solubilidade (praticamente insolúvel - } \\
\text { água; muito solúvel - etanol; solúvel - } \\
\text { clorofórmio + ácido acético; pouco } \\
\text { solúvel - éter etílico + éter de petróleo; } \\
\text { imiscível - óleos graxos exceto óleo de } \\
\text { rícino) }\end{array}$ & $\begin{array}{l}\text { solubilidade (praticamente insolúvel - } \\
\text { água; facilmente solúvel - etanol anidro + } \\
\text { imiscível - óleos graxos exceto óleo de } \\
\text { rícino) }\end{array}$ & $\begin{array}{l}\text { solubilidade (facilmente solúvel em sua } \\
\text { massa - etanol absoluto; parcialmente } \\
\text { solúvel - éter + éter de petróleo + azeites } \\
\text { fixos; praticamente insolúvel - água } \\
\text { (reação ácida tornassol)) }\end{array}$ & su \\
\hline Testes - método 6 & r & - & $\begin{array}{c}\text { colofônia + bálsamo de copaíba (não } \\
\text { verde) }(1 \mathrm{~g} \text { droga vegetal }+10 \mathrm{~mL} \text { éter de } \\
\text { petróleo }+ \text { agitar }\left(2^{\prime}\right)+\text { filttrar }+10 \mathrm{~mL} \\
\text { acetato cúprico } 0,5 \%+\text { agitar (observar } \\
\text { fase etérea)) }\end{array}$ & su \\
\hline Índices - método 1 & $\begin{array}{c}\text { índice de acidez }(56-84)(1 \mathrm{~g} \text { droga } \\
\text { vegetal }+100 \mathrm{~mL} \text { etanol neutralizado }+1 \\
\mathrm{~mL} \text { fenolftaleína }+ \text { titular com hidróxido } \\
\text { de potássio } 0,5 \mathrm{M} \mathrm{SV})\end{array}$ & - & $\begin{array}{c}\text { índice de acidez }(56-84)(1 \mathrm{~g} \text { droga } \\
\text { vegetal }+100 \mathrm{~mL} \text { etanol neutralizado }+1 \\
\mathrm{~mL} \text { fenolftaleína }+ \text { titular com hidróxido } \\
\text { de sódio } 0,1 \mathrm{~N})\end{array}$ & mi \\
\hline Índices - método 2 & $\begin{array}{l}\text { índice de saponificação }(230-255) \\
\text { (resíduo - doseamento) }((\mathrm{TS})+25,0 \mathrm{~mL} \\
\text { de hidróxido de potássio } 0,5 \mathrm{M} \text { em } \\
\text { metanol + aquecer (banho-maria) }\left(30^{\prime}\right)+1 \\
\text { mL fenolftaleína +titular com ácido } \\
\text { clorídrico } 0,5 \mathrm{M}+\text { ensaio em branco })^{3}\end{array}$ & $\begin{array}{c}\text { índice de saponificação }(230-255) \\
\text { (resíduo - doseamento) }((\mathrm{TS})+25,0 \mathrm{~mL} \\
\text { de hidróxido de potássio } 0,5 \mathrm{M} \mathrm{em} \mathrm{etanol} \\
\text { + aquecer (refluxo) }\left(30^{\prime}\right)+1 \mathrm{~mL} \\
\text { fenolftaleína +titular com ácido clorídrico } \\
0,5 \mathrm{M}+\text { ensaio em branco })^{2}\end{array}$ & $\begin{array}{l}\text { índice de saponificação }(230-255) \\
\text { (resíduo doseamento }+20 \mathrm{~mL} \text { etanol + } 20 \\
\mathrm{~mL} \text { hidróxido de potássio } 0,5 \mathrm{~N} \text { em etanol } \\
+ \text { aquecer (refluxo) }(30 \text { ') + fenolftaleína + } \\
\text { titular com ácido sulfúrico } 0,5 \mathrm{~N} \mathrm{SV})\end{array}$ & mi \\
\hline Doseamento - método 1 & gravimetria (ésteres) $(45-70 \%)$ & gravimetria (ésteres) $(45,0-70,0 \%)$ & gravimetria (ésteres) $(45,0-70,0 \%)$ & se \\
\hline Procedimento 1 & $\begin{array}{l}2,5 \mathrm{~g} \text { droga vegetal }+7,5 \mathrm{~mL} \text { hidróxido de } \\
\text { sódio diluído } 8,5 \%+40 \mathrm{~mL} \text { éter etílico } \\
\text { isento de peróxidos + agitar } \\
\text { (vigorosamente) }\left(10^{\prime}\right)+\text { separar (fase }\end{array}$ & $\begin{array}{c}2,50 \text { g droga vegetal + 7,5 mL hidróxido } \\
\text { de sódio } 8,5 \%+40 \mathrm{~mL} \text { éter etílico isento } \\
\text { de peróxidos + agitar (vigorosamente) } \\
\left(10^{\prime}\right)+\text { separar (fase inferior) + agitar (fase }\end{array}$ & $\begin{array}{l}2,5 \mathrm{~g} \text { droga vegetal }+7,5 \mathrm{~mL} \text { hidróxido de } \\
\text { sódio a } 8,5 \%+40 \mathrm{~mL} \text { éter etílico + agitar } \\
\quad \text { (vigorosamente) }\left(10^{\prime}\right)+\text { separar (fase } \\
\text { inferior) + agitar 3x } 15 \mathrm{~mL} \text { éter etílico + }\end{array}$ & se \\
\hline
\end{tabular}


Quadro 31 - Comparação entre as monografias de Myroxylon balsamum (L.) Harms var. pereirae (Royle) Harms [tronco; bálsamo] das farmacopeias FB5, EP8.8 e FA7.

\begin{tabular}{|c|c|c|c|c|}
\hline & FB5 & EP8.8 & FA7 & Classificação \\
\hline & $\begin{array}{l}\text { etérea) + agitar (fase básica) } 3 \times 15 \mathrm{~mL} \\
\text { éter etílico isento de peróxidos }\left(1^{\prime}\right)+ \\
\text { reunir (fases etéreas) + secar }(10 \mathrm{~g} \text { sulfato } \\
\text { de sódio anidro) + filtrar + lavar (sulfato } \\
\text { de sódio) } 2 \times 10 \mathrm{~mL} \text { éter etílico isento de } \\
\text { peróxidos + reunir (fases etéreas) }+ \\
\text { evaporar (secura) + dessecar }\left(100-105^{\circ} \mathrm{C}\right) \\
\left(30^{\prime}\right)+\text { resfriar (dessecador) + pesar }\end{array}$ & $\begin{array}{c}\text { inferior) } 3 \times 15 \mathrm{~mL} \text { éter etílico isento de } \\
\text { peróxidos }(1 ')+\text { reunir (fases etéreas) + } \\
\text { secar }(10 \mathrm{~g} \text { sulfato de sódio anidro) }+ \\
\text { filtrar + lavar (sulfato de sódio) } 2 \times 10 \mathrm{~mL} \\
\text { éter etílico isento de peróxidos + reunir } \\
\text { (fases etéreas) + evaporar }(\text { secura })+ \\
\text { dessecar }\left(100-105^{\circ} \mathrm{C}\right)\left(30^{\prime}\right)+\text { pesar }\end{array}$ & $\begin{array}{c}\text { reunir (fases etéreas) + secar (10 g sulfato } \\
\text { de sódio anidro) + filtrar + lavar (sulfato } \\
\text { de sódio) } 2 \mathrm{x} 10 \mathrm{~mL} \text { éter etílico + reunir } \\
\text { (fases etéreas) + evaporar (secura) + } \\
\text { dessecar }\left(100-105^{\circ} \mathrm{C}\right)\left(30^{\prime}\right)+\text { pesar }\end{array}$ & \\
\hline $\begin{array}{c}\text { Embalagem e } \\
\text { armazenamento }\end{array}$ & 1 & $1^{3}$ & 1 & $\begin{array}{lll}- & - \\
\end{array}$ \\
\hline
\end{tabular}

(ANMAT, 2003b; BRASIL, 2010d; EDQM, 2016b).

Legenda: $\mathrm{mi}=$ menor; su = substancial; se = semelhante; $\mathrm{CCD}=$ cromatografia em camada delgada; $\mathrm{RS}=$ solução referência; $\mathrm{TS}=$ solução amostra; $\mathrm{SR}=$ solução reagente; SV = solução volumétrica.

Nota: ${ }^{1}=$ há pequena diferença na concentração das soluções de cloreto férrico, sendo 10,5\% na FB5 e EP8.8 e 9\% na FA7, ainda na FB5 etanol é o solvente a no mínimo $96,0 \%$ e na FA7 é o solvente $94,9-96 \% ;^{2}=$ parâmetros extraídos do método geral; ${ }^{3}=$ apenas armazenamento. 
No geral, as monografias são convergentes, possuindo propostas semelhantes para ensaios e testes.

Quando comparadas à FB5 as diferenças substanciais estão concentradas nos testes adicionais da FB5 (um ensaio de identificação para adulterante) e da FA7 (um ensaio para colofônia e bálsamo de copaíba) e na existência de critérios adicionais na especificação da solubilidade.

Esse é um caso de um produto com ocorrência no Brasil e em outros países, com registro válidos de fitoterápico no Brasil e com presença de monografia em todas as farmacopeias em estudo.

\subsubsection{Peumus boldus Molina [folha]}

O boldo esteve presente em quase todas as edições anteriores da Farmacopeia Brasileira, com exceção $3^{\text {a }}$ edição (Quadro 3), está relacionado no FFFB1, na Lista de Produtos Tradicionais Fitoterápicos de Registro Simplificado (BRASIL, 2011, 2014a) e na FB5. Foram encontrados, para a espécie, 17 (dezessete) registros de fitoterápicos válidos na Anvisa (Quadro 5). Possuir monografia farmacopeia e poder se submeter a um processo de registro simplificado, pode justificar, ao menos em parte, o fato da espécie estar entre as cinco espécies da Farmacopeia Brasileira com maior número de registros. Conforme a literatura consultada, a espécie não possui ocorrência no Brasil (Apêndice A), havendo registro de ocorrência da espécie no Chile (TROPICOS.ORG, 2016). Em buscas realizadas nos compêndios internacionais em estudo, foram localizadas monografias na EP8.8 e na FA7. Os dados extraídos das monografias estão descritos no Quadro 32. 
Quadro 32 - Comparação entre as monografias de Peumus boldus Molina [folha] das farmacopeias FB5, da EP8.8 e da FA7.

\begin{tabular}{|c|c|c|c|c|}
\hline & FB5 & EP8.8 & FA7 & Classificação \\
\hline Sinonímia botânica & - & - & Boldea boldus (Molina) Looser & - \\
\hline Nomenclatura popular & boldo, boldo-do-chile & boldo & boldo & - \\
\hline Droga vegetal & folha & folha & folha & se \\
\hline Marcador 1 & óleo volátil (NLT 1,5\%) & óleo volátil (NMT 4,0\%) (droga seca) ${ }^{1,2}$ & óleo volátil (NLT 2,0\%) & su \\
\hline Marcador 2 & alcaloides (boldina) (NLT 0,1\%) & $\begin{array}{l}\text { alcaloides (boldina) (NLT 0,1\%) (droga } \\
\text { seca) }\end{array}$ & alcaloides (boldina) (NLT 0,20\%) & $\mathrm{su}^{1}$ \\
\hline Características & $\begin{array}{c}\text { odor aromático característico + } \\
\text { canforáceo }+ \text { levemente acre }+ \text { acentua } \\
\text { com esmagamento }+ \text { sabor amargo + tanto } \\
\text { acre }\end{array}$ & - & - & - \\
\hline Descrição macroscópica & 1 & 1 & 1 & - \\
\hline Descrição microscópica & 2 & 1 & 2 & - \\
\hline Figura botânica & 3 & 1 & 1 & - \\
\hline Identificação - método 1 & $\mathrm{CCD}$ & $\mathrm{CCD}$ & $\mathrm{CCD}$ & se \\
\hline Procedimento 1 & sílica-gel $\mathrm{GF}_{254}$ & sílica-gel $(5-40 \mu \mathrm{m})$ ou $(2-10 \mu \mathrm{m})$ & sílica-gel (fluorescência + 0,25 mm) & $\mathrm{mi}$ \\
\hline Procedimento 2 & metanol:dietilamina:tolueno $(10: 10: 80)$ & dietilamina:metanol:tolueno $(10: 10: 80)$ & tolueno:acetato de etila:dietilamina $(7: 2: 1)$ & me \\
\hline Procedimento 3 & 40 ou $6 \mu \mathrm{L}$ (TS); 20 ou $2 \mu \mathrm{L}$ (RS) (banda) & $\begin{array}{c}40 \text { ou } 6 \mu \mathrm{L}(\mathrm{TS}) ; 20 \text { ou } 2 \mu \mathrm{L}(\mathrm{RS})(15 \text { ou } \\
8 \mathrm{~mm}) \text { (banda) }\end{array}$ & $10 \mu \mathrm{L}$ (TS) (RS) (banda) & mi \\
\hline Procedimento 4 & $\begin{array}{c}0,5 \text { g droga vegetal pulverizada }+21 \mathrm{~mL} \\
\text { ácido clorídrico } 2 M \text { :água }(1: 20)+ \\
\text { aquecer (refluxo) (banho-maria) }\left(10^{\prime}\right)+ \\
\text { resfriar + filtrar + } 2 \mathrm{~mL} \text { hidróxido de } \\
\text { amônio } 6 M+\text { extrair } 2 \times 20 \text { mL éter } \\
\text { etílico (agitação moderada) + reunir (fases } \\
\text { orgânicas) + evaporar (pressão reduzida) } \\
+1 \text { mL metanol (TS) }\end{array}$ & $\begin{array}{c}1,5 \mathrm{~g} \text { droga vegetal pulverizada }(355)+5 \\
\text { mL metanol + sonicar }\left(10^{\prime}\right)+\text { filtrar } \\
\text { (coluna celulose } 3 \times 0,5 \mathrm{~cm})(\text { usar o } \\
\text { primeiro } \mathrm{mL} \text { de eluato) }(\mathrm{TS})\end{array}$ & $\begin{array}{c}100 \mathrm{~g} \text { droga vegetal pulverizada }+10 \mathrm{~mL} \\
\text { ácido sulfúrico } 0,1 \mathrm{~N}+\text { agitar }(2 ')+\text { filtrar } \\
+ \text { ajustar pH } 8 \text { (amoníaco diluído) }+ \\
\text { extrair } 5 \mathrm{x} 30 \mathrm{~mL} \text { clorofórmio + reunir } \\
\text { (fases clorofórmicas) + filttrar (sulfato de } \\
\text { sódio anidro) + evaporar (secura) (banho- } \\
\text { maria) }+0,25 \mathrm{~mL} \text { clorofórmio:metanol } \\
(5: 5)(\mathrm{TS})\end{array}$ & me \\
\hline Procedimento 5 & $2 \mathrm{mg}$ boldina $\mathrm{SQR}+5 \mathrm{~mL}$ metanol $(\mathrm{RS})$ & $\begin{array}{l}2 \mathrm{mg} \text { boldina }+10 \mathrm{mg} \text { bromidrato de } \\
\text { escopolamina }+5 \mathrm{~mL} \text { metanol }(\mathrm{RS})\end{array}$ & $\begin{array}{l}0,1 \mathrm{~g} \text { boldina }+100 \mathrm{~mL} \\
\text { clorofórmio:metanol }(5: 5)(\mathrm{RS})\end{array}$ & me \\
\hline Procedimento 6 & secar (ar) & secar (ar) & secar (ar) & se \\
\hline Procedimento 7 & $365 \mathrm{~nm}$ & - & $366 \mathrm{~nm}$ & $\mathrm{mi}$ \\
\hline Procedimento 8 & $\begin{array}{l}\text { iodobismutato de potássio aquoacético + } \\
\text { secar }\left(5^{\prime}\right)+\text { nitrito de sódio } S R+\left(30^{\prime}\right)\end{array}$ & $\begin{array}{l}\text { solução de iodobismutato de potássio SR } \\
+ \text { secar }\left(5^{\prime}\right)+\text { solução de nitrito de sódio } \\
\text { SR }+\left(30^{\prime}\right)\end{array}$ & $\begin{array}{l}\text { Iodeto de potássio e subnitrato de bismuto } \\
\qquad \text { SR }\end{array}$ & me \\
\hline Procedimento 9 & descrição de zonas & esquema & descrição de zonas & me \\
\hline
\end{tabular}


Quadro 32 - Comparação entre as monografias de Peumus boldus Molina [folha] das farmacopeias FB5, da EP8.8 e da FA7.

\begin{tabular}{|c|c|c|c|c|}
\hline & FB5 & EP8.8 & FA7 & Classificação \\
\hline Identificação - método 2 & $\begin{array}{l}\text { algumas folhas }+ \text { etanol }+ \text { triturar }+ \\
\text { evaporar (banho-maria) }+ \text { gotas vanilina } \\
1 \% \text { ácido clorídrico SR = castanho- } \\
\text { avermelhado ou vermelho intensa }\end{array}$ & - & $\begin{array}{c}1 \text { g droga vegetal pulverizada }+10 \mathrm{~mL} \\
\text { etanol } 80 \%+\text { aquecer (ebulição) }\left(15^{\prime}\right)+ \\
\text { esfriar + filtrar + evaporar (banho-maria) } \\
\text { até } 1 \mathrm{~mL}+1 \text { gota amoníaco }+5 \mathrm{~mL} \text { éter } \\
\text { etílico }+ \text { agitar }\left(2^{\prime}\right)+\text { filtrar (sulfato de } \\
\text { sódio anidro) + evaporar }+2 \mathrm{~mL} \text { vanilina } \\
1 \% \text { em ácido clorídrico }=\text { rosa-alilada } \\
\text { estável por alguns minutos }\end{array}$ & me \\
\hline Testes - método 1 & matéria estranha (NMT 3,0\%) & $\begin{array}{c}\text { matéria estranha (NMT } 4 \% \text { - ramos }+ \\
\text { NMT } 2 \% \text { - outros) }\end{array}$ & $\begin{array}{c}\text { matéria estranha (NMT } 4 \% \text { - ramos; } 2 \% \text { - } \\
\text { outros) }\end{array}$ & su \\
\hline Testes - método 2 & água (NMT 10,0\%) & $\begin{array}{c}\text { água (NMT 10,0\%) (20 g droga vegetal } \\
\text { pulverizada) (destilação) }\end{array}$ & $\begin{array}{l}\text { perda por dessecação (NMT 10\%) (20 g } \\
\text { droga pulverizada + destilação) }\end{array}$ & se \\
\hline Testes - método 3 & cinzas totais (NMT 10,0\%) & cinzas totais (NMT 13,0\%) & cinzas totais (NMT 13\%) & me \\
\hline Testes - método 4 & cinzas insolúveis em ácido (NMT 6,0\%) & - & - & su \\
\hline Testes - método 5 & - & - & microrganismos (MR) & - \\
\hline Testes - método 6 & - & - & aflatoxinas (MR) & su \\
\hline Testes - método 7 & - & - & metais pesados (MR) & su \\
\hline Testes - método 8 & - & - & agrotóxicos (MR) & su \\
\hline Doseamento - método 1 & $\begin{array}{c}\text { CLAE-UV (alcaloides) (boldina) (NLT } \\
0,1 \%)\end{array}$ & $\begin{array}{c}\text { CLAE-UV (alcaloides) (boldina) (NLT } \\
0,1 \%)\end{array}$ & $\begin{array}{c}\text { CLAE-UV (alcaloides) (boldina) (NLT } \\
0,20 \%)\end{array}$ & $\mathrm{su}$ \\
\hline Procedimento 1 & $304 \mathrm{~nm}$ & $304 \mathrm{~nm}$ & $304 \mathrm{~nm}$ & se \\
\hline Procedimento 2 & ODS $(250 \mathrm{~mm} \times 4,6 \mathrm{~mm})(5 \mu \mathrm{m})$ & ODS $(0,25 \mathrm{~m} \mathrm{x} 4,6 \mathrm{~mm})(5 \mu \mathrm{m})$ & ODS $(25 \mathrm{~cm} \mathrm{x} \mathrm{4,6} \mathrm{mm)}(3-10 \mu \mathrm{m})$ & se \\
\hline Procedimento 3 & $\begin{array}{c}\text { (dietilamina:acetonitrila }(0,2: 99,8)):(\text { dietila } \\
\text { mina:água }(0,2: 99,8)+\text { ajustar } \mathrm{pH} \text { para } 3,0 \\
(\text { ácido fórmico anidro })(16: 84)(1,5 \mathrm{~mL} / \\
\min )\end{array}$ & $\begin{array}{c}\text { (dietilamina:acetonitrila }(0,2: 99,8)):(\text { dietila } \\
\text { mina:água }(0,2: 99,8)+\text { ajustar } \mathrm{pH} \text { para } 3,0 \\
\text { (ácido fórmico anidro })(16: 84)(1,5 \mathrm{~mL} / \\
\min )\end{array}$ & $\begin{array}{c}\text { (água:dietilamina }(99,8: 0,2)+\text { ajustar } \mathrm{pH} \\
\text { para } 3,0 \text { (ácido } \\
\text { fórmico)):(acetonitrila:dietilamina } \\
(99,8: 0,2)):(84: 16)(1,5 \mathrm{~mL} / \mathrm{min})\end{array}$ & se \\
\hline Procedimento 4 & $\begin{array}{l}1 \mathrm{~g} \text { droga vegetal pulverizada }+50 \mathrm{~mL} \\
\text { ácido clorídrico } 2 M+\text { aquecer (banho- } \\
\text { maria) (agitação) }\left(80^{\circ} \mathrm{C}\right)\left(30^{\prime}\right)+\text { filtrar }+ \\
\text { retomar }(\text { resíduo }) \text { com } 50 \mathrm{~mL} \text { ácido } \\
\text { clorídrico } 2 M+\text { aquecer }(\text { banho-maria) } \\
\left(\text { agitação }\left(80^{\circ} \mathrm{C}\right)\left(30^{\prime}\right)+\text { filtrar + repetir }\right. \\
(1 \mathrm{x})+\text { filtrar + reunir }(\text { filtrados })+100 \mathrm{~mL} \\
\text { hexano:acetato de etila }(1: 1)+\text { agitar }+ \\
\text { desprezar (fase orgânica) + ajustar pH }\end{array}$ & $\begin{array}{l}\text { 1,000 g droga vegetal pulverizada }(355)+ \\
50 \mathrm{~mL} \text { ácido clorídrico diluído + agitar } \\
\text { (banho-maria) }\left(80{ }^{\circ} \mathrm{C}\right)\left(30^{\prime}\right)+\text { filtrar }+ \\
\text { retomar (resíduo) com } 50 \mathrm{~mL} \text { ácido } \\
\text { clorídrico diluído + agitar (banho-maria) } \\
\left(80^{\circ} \mathrm{C}\right)\left(30^{\prime}\right)+\text { filtrar + repetir }(1 \mathrm{x})+ \\
\text { filtrar + reunir (filtrados })+100 \mathrm{~mL} \\
\text { hexano:acetato de etila }(1: 1)+\text { agitar }+ \\
\text { desprezar (fase orgânica) + ajustar } \mathrm{pH}\end{array}$ & $\begin{array}{l}1 \text { g droga vegetal pulverizada }+50 \mathrm{~mL} \\
\text { ácido clorídrico + agitar (banho-maria) } \\
\left(80{ }^{\circ} \mathrm{C}\right)\left(30^{\prime}\right)+\text { filtrar }+ \text { retomar (resíduo) } \\
+50 \mathrm{~mL} \text { ácido clorídrico + agitar (banho- } \\
\text { maria) }\left(80^{\circ} \mathrm{C}\right)\left(30^{\prime}\right)+\text { filtrar + repetir } 1 \mathrm{x} \\
+ \text { filtrar + reunir (filtrados })+100 \mathrm{~mL} \\
\text { acetato de etila: hexano }(5: 5)+\text { agitar }+ \\
\text { ajustar pH para } 9,5 \text { (amoníaco diluído })+ \\
\text { agitar } 1 \times 100 \mathrm{~mL} \text { diclorometano }+2 \times 50\end{array}$ & $\mathrm{mi}$ \\
\hline
\end{tabular}


Quadro 32 - Comparação entre as monografias de Peumus boldus Molina [folha] das farmacopeias FB5, da EP8.8 e da FA7.

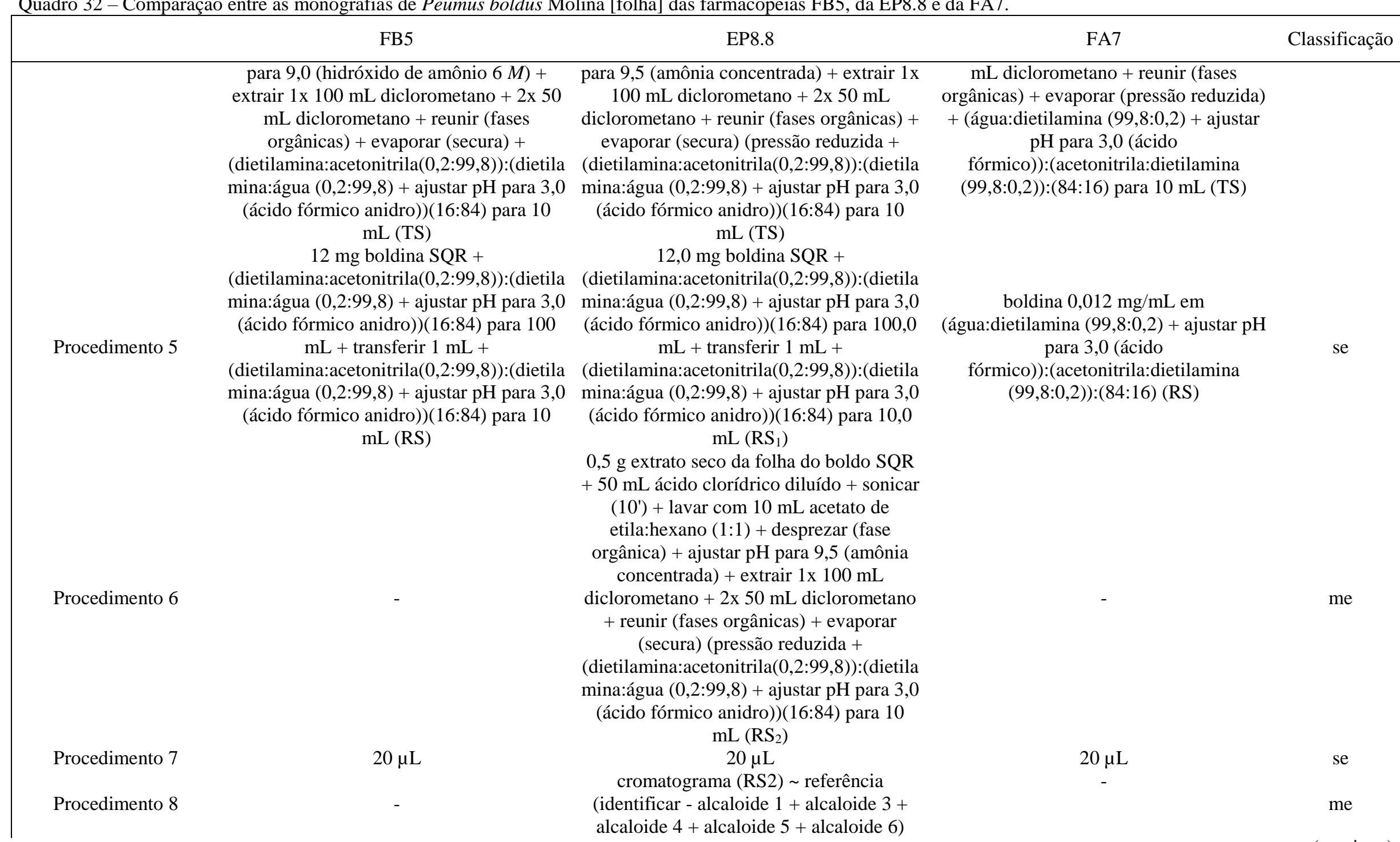


Quadro 32 - Comparação entre as monografias de Peumus boldus Molina [folha] das farmacopeias FB5, da EP8.8 e da FA7.

\begin{tabular}{|c|c|c|c|c|}
\hline & FB5 & EP8.8 & FA7 & Classificação \\
\hline Procedimento 9 & $\begin{array}{c}\text { tempos de retenção relativos (boldina (6'); } \\
0,9 \text { - isoboldina; } 1,0 \text { - boldina; } 1,8 \text { - N- } \\
\text { oxido de isocoridina; } 2,2 \text { - laurotetanina; } \\
2,8 \text { - isocoridina; } 3,2 \text { - N-metil- } \\
\text { laurotetanina) }\end{array}$ & $\begin{array}{c}\text { tempos de retenção relativos (boldina (6'); } \\
0,9 \text { - alcaloide } 1 ; 1,8 \text { - alcaloide } 3 ; 2,0 \text { - } \\
\text { alcaloide } 4 ; 2,9 \text { - alcaloide } 5 ; 3,1 \text { - } \\
\text { alcaloide } 6 \text { ) }\end{array}$ & $\begin{array}{c}\text { tempos de retenção relativos ( } 0,9 \text { - } \\
\text { isoboldina; } 1,8 \text { - N-óxido de isocoridina; } \\
\text { 2,2 - laurotetanina; } 2,8 \text { - isocoridina; } 3,2 \text { - } \\
\text { N-metil-laurotetanina) }\end{array}$ & $\mathrm{mi}$ \\
\hline Procedimento 10 & $\begin{array}{l}\text { resolução (NLT 1,0 - isoboldina e } \\
\text { boldina) }\end{array}$ & $\begin{array}{l}\text { resolução (NLT 1,5 - alcaloide } 1 \mathrm{e} \\
\text { boldina) }\end{array}$ & desvio padrão relativo (NMT 2,0\%) & su \\
\hline Procedimento 11 & concentração relativa & concentração relativa & concentração relativa & se \\
\hline Procedimento 12 & $\%$ de boldina $=\frac{\left(\Sigma \mathrm{A}_{1}\right) \times m_{2}}{\mathrm{~A}_{2} \times m_{1}}$ & $\frac{\left(\Sigma \mathrm{A}_{1}\right) \times m_{2} \times \mathrm{p}}{\mathrm{A}_{2} \times m_{1} \times 100}$ & $\left(\frac{\Sigma \mathrm{r}_{\mathrm{i}}}{\mathrm{r}_{\mathrm{E}}}\right) \times\left(\frac{\mathrm{P}_{\mathrm{E}}}{\mathrm{P}_{\mathrm{M}}}\right)$ & se/er ${ }^{3}$ \\
\hline Doseamento - método 2 & destilação (óleo volátil) (NLT 1,5\%) & $\begin{array}{c}\text { destilação (óleo volátil) (NMT 4,0\%) } \\
\text { (droga seca) }\end{array}$ & destilação (óleo volátil) (NLT 2,0\%) & $\mathrm{su}$ \\
\hline Proce & $500 \mathrm{~mL}$ água & $300 \mathrm{~mL}$ água & 300 & $\mathrm{~m}$ \\
\hline Procedimento 2 & $0,5 \mathrm{~mL}$ xileno & - & $0,5 \mathrm{~mL}$ xileno & me \\
\hline Procedimento 3 & $\begin{array}{l}50 \mathrm{~g} \text { droga vegetal triturada }+100 \mathrm{~mL} \\
\text { água + turbolizar (imediata determinação) }\end{array}$ & $10,0 \mathrm{~g}$ droga vegetal recém-fragmentada) & $10 \mathrm{~g}$ droga vegetal pulverizada & me \\
\hline Procedimento 4 & $4 \mathrm{~h}$ & $2-3 \mathrm{~mL} / \mathrm{min}(3 \mathrm{~h})$ & $2-3 \mathrm{~mL} / \mathrm{min}(2 \mathrm{~h})$ & me \\
\hline $\begin{array}{l}\text { Embalagem e } \\
\text { armazenamento }\end{array}$ & 1 & - & 1 & - \\
\hline Padrões de referência & boldina SQR & $\begin{array}{c}\text { boldina } \mathrm{SQR}+\text { extrato seco da folha do } \\
\text { boldo SQR }\end{array}$ & - & - \\
\hline Rotulagem & - & & 1 & - \\
\hline
\end{tabular}

(ANMAT, 2003b; BRASIL, 2010d; EDQM, 2016b).

Legenda: $\mathrm{mi}=$ menor; me = moderado; $\mathrm{su}=$ substancial; $\mathrm{se}=$ semelhante; $\mathrm{NLT}=$ não menos que; $\mathrm{MNT}=$ não mais que; $\mathrm{MR}=$ cumpre os requisitos ou o teste; $\mathrm{CCD}=$ cromatografia em camada delgada; $\mathrm{RS}$ = solução referência; TS = solução amostra; $\mathrm{SR}=$ solução reagente; $\mathrm{SQR}=$ substância química de referência; CLAE-UV = cromatografia liquida de alta eficiência acoplada a detector por espectrofotometria por absorção no ultravioleta; ODS = coluna cromatográfica octadecilsilanizada;

$\mathrm{P}=m=$ massa; $\mathrm{p}=$ pureza; $\mathrm{A}=\mathrm{r}=$ resposta.

Nota: ${ }^{1}$ = há omissão ou erro na FB5 e na FA7 pela ausência da informação da consideração da massa de água no cálculo do doseamento; ${ }^{2}=$ na monografia é descrito como teste e não como doseamento e um marcador, mas foi deslocado para o marcador e doseamento para fins de comparação; ${ }^{3}=$ a fórmula na FB5 e na FA7 não incluiu a razão entre o fator de diluição da solução amostra e a solução referência. 
No geral, as monografias da FB5 e da EP8.8 são mais semelhantes, porém, com diferenças substanciais. Por outro lado, a monografia da FA7 possui mais diferenças substanciais, embora todas as monografias possuam propostas semelhantes de ensaios e testes.

As diferenças substanciais se concentram nos testes adicionais da FB5 (cinzas insolúveis em ácido), da FA7 (metais pesados, aflatoxinas e resíduos de agrotóxicos) e nas diferenças nas especificações acima de 30\% para a matéria estranha, para o parâmetro de resolução entre picos do CLAE-UV e para os marcadores (óleo volátil e alcaloides).

Há, ainda, a ausência na FB5 e na FA7 da indicação de que o teor dos marcadores deve ser calculado sem considerar a massa de água da droga vegetal, obtida na determinação de água, que por ser uma omissão foi considerada um erro. Considerado que a especificação para a determinação de água na FB5 é de NMT 10\%, a diferença no resultado obtido para o teor, considerando ou não a massa de água, é significativo. A fórmula para o cálculo, em porcentagem, de boldina no doseamento da FB5 e da FA7 não inclui o valor representante da razão entre o fator de diluição da solução amostra e da solução referência, o que por ser uma omissão foi considerado um erro.

Diferenças substanciais nas especificações como as encontradas, podem ocasionar barreiras sanitárias ao comércio internacional de matérias-primas e produtos acabados. Como espécie que não possui ocorrência no Brasil e com registros de fitoterápicos válidos no Brasil, se esperava que as monografias fossem mais harmonizadas, nesse caso, os resultados acompanharam parcialmente a expectativa

\subsubsection{Pimpinella anisum L. [fruto]}

$\mathrm{O}$ anis-doce esteve presente em quase todas as edições anteriores da Farmacopeia Brasileira, com exceção da $3^{a}$ edição (Quadro 3), está relacionado no FFFB1, na Lista de Medicamentos Fitoterápicos de Registro Simplificado da IN no 02/2014 (BRASIL, 2011, 2014a) e na FB5. Não foram encontrados, para a espécie, registros de fitoterápicos válidos na Anvisa (Quadro 5). Conforme a literatura consultada, a espécie não possui ocorrência no Brasil (Apêndice A), havendo registro de ocorrência na Bolívia, China, Colômbia, Egito, El Salvador, Guatemala, México, Nicarágua, Rússia e nos Estados Unidos da América (TROPICOS.ORG, 2016). Em buscas realizadas nos compêndios internacionais em estudo, foram localizadas monografias na EP8.8 e na FA7. Os dados extraídos das monografias estão descritos no Quadro 33. 
Quadro 33 - Comparação entre as monografias de Pimpinella anisum L. [fruto] das farmacopeias FB5, EP8.8 e FA7.

\begin{tabular}{|c|c|c|c|c|}
\hline & FB5 & EP8.5 & FA7 & Classificação \\
\hline Nomenclatura popular & anis-doce + erva-doce & aniseed & anís & - \\
\hline Droga vegetal & fruto & fruto & fruto & se \\
\hline Marcador 1 & óleo volátil (NLT 2,0\%) & óleo volátil (NLT 2,0\%) (droga seca) & óleo volátil (NLT 2,0\%) (droga seca) & $\mathrm{se}^{1}$ \\
\hline Marcador 2 & anetol (óleo volátil) (NLT 87\%) & - & - & su \\
\hline Características & odor agradável + sabor doce anisado & odor remanescente de anetol & - & - \\
\hline Descrição macroscópica & 1 & 2 & 1 & - \\
\hline Descrição microscópica & 2 & 1 & 1 & - \\
\hline Figura botânica & 2 & 1 & 1 & - \\
\hline Identificação - método 1 & CCD & CCD & CCD & se \\
\hline Procedimento 1 & sílica-gel $\left(\mathrm{GF}_{254}+0,25 \mathrm{~mm}\right)$ & sílica-gel $\left(\mathrm{GF}_{254}\right)$ & sílica-gel (fluorescência $+0,25 \mathrm{~mm}$ ) & mi \\
\hline Procedimento 2 & tolueno & tolueno & tolueno & se \\
\hline Procedimento 3 & 2-3 $\mu \mathrm{L}$ (bandas) (TS) (RS) & $\begin{array}{c}2 \mu \mathrm{L}+3 \mu \mathrm{L} \text { (TS) (intervalo } 2 \mathrm{~cm} \text { ) } ; 1 \mu \mathrm{L}+ \\
2 \mu \mathrm{L}+3 \mu \mathrm{L}(\mathrm{RS}) \text { (intervalo } 2 \mathrm{~cm} \text { ) }\end{array}$ & $\begin{array}{c}2 \mu \mathrm{L}+3 \mu \mathrm{L}(\mathrm{TS}) ; 1 \mu \mathrm{L}+2 \mu \mathrm{L}+3 \mu \mathrm{L} \\
(\mathrm{RS})\end{array}$ & me \\
\hline Procedimento 4 & $\begin{array}{c}0,1 \mathrm{~g} \text { droga vegetal pulverizada }+2 \mathrm{~mL} \\
\text { diclorometano }+ \text { agitar }\left(15^{\prime}\right)+\text { filtrar }+ \\
\text { evaporar (secura) (banho-maria) }\left(<60^{\circ} \mathrm{C}\right) \\
+2 \mathrm{~mL} \text { tolueno }(\mathrm{TS})\end{array}$ & $\begin{array}{c}0,10 \mathrm{~g} \text { droga vegetal pulverizada }(1400)+ \\
2 \mathrm{~mL} \text { diclorometano }+ \text { agitar }\left(15^{\prime}\right)+\text { filtrar } \\
+ \text { evaporar (cuidadosamente) (secura) } \\
\text { (banho-maria) }\left(60^{\circ} \mathrm{C}\right)+0,5 \mathrm{~mL} \text { tolueno } \\
(\mathrm{TS})\end{array}$ & $\begin{array}{c}0,1 \text { g droga vegetal pulverizada }+2 \mathrm{~mL} \\
\text { diclorometano }+ \text { agitar }\left(15^{\prime}\right)+\text { filtrar }+ \\
\text { evaporar (cuidadosamente) (secura) } \\
\text { (banho-maria) }\left(60^{\circ} \mathrm{C}\right)+0,5 \mathrm{~mL} \text { tolueno } \\
\text { (TS) }\end{array}$ & se \\
\hline Procedimento 5 & $\begin{array}{c}3 \mu \mathrm{L} \text { anetol }+40 \mu \mathrm{L} \text { óleo de oliva }+1 \mathrm{~mL} \\
\text { tolueno }(\mathrm{RS})\end{array}$ & $\begin{array}{c}3 \mu \mathrm{L} \text { anetol }+40 \mu \mathrm{L} \text { óleo de oliva }+1 \mathrm{~mL} \\
\text { tolueno (RS) }\end{array}$ & $\begin{array}{c}3 \mu \mathrm{L} \text { anetol }+40 \mu \mathrm{L} \text { óleo de oliva }+1 \mathrm{~mL} \\
\text { tolueno (RS) }\end{array}$ & se \\
\hline Procedimento 6 & secar & secar (ar) & secar (ar) & mi \\
\hline Procedimento 7 & $254 \mathrm{~nm}$ & $254 \mathrm{~nm}$ & $254 \mathrm{~nm}$ & se \\
\hline Procedimento 8 & anisaldeído SR $+\underset{\left(5^{\prime}\right)}{\operatorname{aquecer}}\left(100-105^{\circ} \mathrm{C}\right)$ & $\begin{array}{c}\text { ácido fosfomolíbdico } 20,0 \% \text { em etanol } \\
96 \%+\text { aquecer }\left(120^{\circ} \mathrm{C}\right)\left(5^{\prime}\right)\end{array}$ & $\begin{array}{c}\text { ácido fosfomolíbdico } 20,0 \% \text { em etanol + } \\
\text { aquecer }\left(120^{\circ} \mathrm{C}\right)\left(5^{\prime}\right)\end{array}$ & $\mathrm{mi}$ \\
\hline Procedimento 9 & descrição de zonas & descrição de zonas & descrição de zonas & $\mathrm{mi} / \mathrm{er}^{2}$ \\
\hline Testes - método 1 & matéria estranha (NMT 2,0\%) & matéria estranha (NMT 2,0\%) & matéria estranha (NMT 3,0\%) & $\mathrm{su}$ \\
\hline Testes - método 2 & água (NMT 7\%) & $\begin{array}{c}\text { água (NMT } 7,0 \%)(20,0 \mathrm{~g} \text { droga vegetal } \\
\text { pulverizada) }\end{array}$ & $\begin{array}{c}\text { água (NMT 7,0\%) }(10,0 \mathrm{~g}+\text { destilação } \\
\text { azeotrópica) }\end{array}$ & $\mathrm{se}$ \\
\hline Testes - método 3 & cinzas totais (NMT 12\%) & cinzas totais (NMT 12.0\%) & $\begin{array}{l}\text { cinzas totais (NMT } 12,5 \%)(1,0 \mathrm{~g} \text { droga } \\
\text { vegetal finamente pulverizada) }\end{array}$ & mi \\
\hline Testes - método 4 & - & $\begin{array}{c}\text { cinzas insolúveis em ácido clorídrico } \\
\text { (NMT 2,5\%) }\end{array}$ & $\begin{array}{l}\text { cinzas insolúveis em ácido clorídrico } \\
\text { (NMT 2,5\%) }\end{array}$ & su \\
\hline Testes - método 5 & - & - & microrganismos (MR) & - \\
\hline Testes - método 6 & - & - & aflatoxinas (MR) & $\mathrm{su}$ \\
\hline Doseamento - método 1 & destilação (óleo volátil) (NLT 2,0\%) & destilação (óleo volátil) (NLT 2,0\%) & destilação (óleo volátil) (NLT 2,0\%) & se \\
\hline
\end{tabular}


Quadro 33 - Comparação entre as monografias de Pimpinella anisum L. [fruto] das farmacopeias FB5, EP8.8 e FA7.

\begin{tabular}{|c|c|c|c|c|}
\hline & FB5 & EP8.5 & FA7 & Classificação \\
\hline Procedimento 1 & $100 \mathrm{~mL}$ água & $100 \mathrm{~mL}$ água & $100 \mathrm{~mL}$ água & se \\
\hline Procedimento 2 & - & $0,50 \mathrm{~mL}$ xileno & $0,5 \mathrm{~mL}$ xileno & me \\
\hline Procedimento 3 & $\begin{array}{l}20 \mathrm{~g} \text { droga vegetal (pó grosseiro + } \\
\text { imediata determinação) }\end{array}$ & $\begin{array}{c}\text { 10,0 g droga vegetal (pó grosseiro + } \\
\text { imediata determinação) }\end{array}$ & $10,0 \mathrm{~g}$ droga pulverizada & $\mathrm{mi}$ \\
\hline Procedimento 4 & $4 \mathrm{~h}$ & $2,5-3,5 \mathrm{~mL} / \mathrm{min}(2 \mathrm{~h})$ & 3-4 $\mathrm{mL} / \mathrm{min}(2 \mathrm{~h})$ & me \\
\hline Doseamento - método 2 & $\begin{array}{l}\text { GC (anetol) (NLT 87\%) } \\
\text { ionização por chama }\end{array}$ & . & - & su \\
\hline Procedimento 1 & $\begin{array}{c}\text { (nitrogênio:hidrogênio:ar sintético } \\
(1: 1: 10) \text { ) }\end{array}$ & - & - & $\mathrm{su}$ \\
\hline Procedimento 2 & hélio purificado (1 $\mathrm{mL} / \mathrm{min})$ & - & - & su \\
\hline Procedimento 3 & $\begin{array}{l}\text { coluna - sílica }(60 \mathrm{~m} \times 0,25 \mathrm{~mm})+\text { filme - } \\
\text { polietilenoglicol }(0,25 \mu \mathrm{m})\end{array}$ & - & - & su \\
\hline Procedimento 4 & injetor $200{ }^{\circ} \mathrm{C}+$ detector $220^{\circ} \mathrm{C}$ & - & - & $\mathrm{su}$ \\
\hline Procedimento 5 & $\begin{array}{c}60^{\circ} \mathrm{C}\left(5^{\prime}\right)+60^{\circ} \mathrm{C} \rightarrow 210^{\circ} \mathrm{C}\left(2^{\circ} \mathrm{C} / \mathrm{min}\right)+ \\
210^{\circ} \mathrm{C}\left(20^{\prime}\right)\end{array}$ & - & - & su \\
\hline Procedimento 6 & óleo volátil (manter refrigerado) (TS) & - & - & $\mathrm{su}$ \\
\hline Procedimento 7 & $\begin{array}{c}60 \mu \mathrm{L} \text { anetol }+1 \mathrm{~mL} \text { hexano (manter } \\
\text { refrigerado) (RS) }\end{array}$ & - & - & su \\
\hline Procedimento 8 & $1 \mu \mathrm{L}$ (TS) (RS) + divisão de fluxo (1:100) & - & - & su \\
\hline Procedimento 9 & concentração relativa & - & - & su \\
\hline Procedimento 10 & $\begin{array}{l}\text { tempo de retenção }(\mathrm{TS}) \sim \text { tempo de } \\
\text { retenção }(\mathrm{RS}) \text { ou identificação por EM }\end{array}$ & - & - & su \\
\hline $\begin{array}{l}\text { Embalagem e } \\
\text { armazenamento }\end{array}$ & 1 & - & 1 & - \\
\hline
\end{tabular}

(ANMAT, 2003b; BRASIL, 2010d; EDQM, 2016b).

Legenda: $\mathrm{mi}=$ menor; $\mathrm{me}=$ moderado; $\mathrm{su}=$ substancial; $\mathrm{se}=$ semelhante; er = erro; NLT = não menos que; $\mathrm{MNT}=$ não mais que; $\mathrm{MR}=$ cumpre os requisitos ou o teste; $\mathrm{CCD}$ $=$ cromatografia em camada delgada; $\mathrm{RS}=$ solução referência; $\mathrm{TS}$ = solução amostra; $\mathrm{SR}=$ solução reagente; $\mathrm{CG}=$ cromatografia gasosa; $\mathrm{EM}=$ espectrometria de massas.

Nota: ${ }^{1}=$ há omissão ou erro na FB5 pela ausência da informação da consideração de teor no cálculo do doseamento; ${ }^{2}=$ a monografia da FB5 descreve o tracilglicerídeo no terço superior, ao contrário da EP8.8 e da FA7 que o descrevem no terço inferior; ${ }^{3}=$ especificação extraída do método geral. 
No geral, as monografias possuem propostas de ensaios e testes semelhantes, porém há diferenças substanciais.

As diferenças substanciais se concentram nos testes adicionais da FB5 (doseamento para o anetol no óleo volátil), da EP8.8 (cinzas insolúveis em ácido clorídrico) e da FA7 (aflatoxinas). O teor de anetol a ser cumprido pelo óleo volátil dentro da monografia da droga vegetal resulta que, no caso da FB5, para que uma droga vegetal seja aprovada não é suficiente que ela possua determinado teor de óleo volátil, adicionalmente, é necessário, que esse óleo também seja aprovado em seu próprio doseamento.

Há, ainda, a ausência na FB5 da indicação de que o teor dos marcadores deve ser calculado sem considerar a massa de água da droga vegetal, obtida na determinação de água, que por ser uma omissão foi considerada um erro. Considerado que a especificação para a determinação de água na FB5 é de NMT 7,0\%, a diferença no resultado obtido para o teor, considerando ou não a massa de água, pode ser significativo. Na FB5 a descrição da posição do triacilglicerídio é no terço superior, enquanto na EP8.8 e na FA7, em sistemas cromatográficos semelhantes, o descrevem no terço inferior, o que devido ao caráter de inversão foi considerado um erro. O erro foi corrigido na proposta de revisão da monografia na CP $\mathrm{n}^{\mathrm{o}}$ 241/2016 (BRASIL, 2016c).

Diferenças substanciais nas especificações como as encontradas, podem ocasionar barreiras sanitárias ao comércio internacional de matérias-primas e produtos acabados. Por outro lado, como espécie contemplada em quase todas as edições da Farmacopeia Brasileira, no FFFB1 e na IN nº 02/2014, com monografia na FB5, na EP8.8 e na FA7, se esperava que houvesse registros válidos junto à Anvisa, porém, nesse caso, os resultados não acompanharam as expectativas.

\subsubsection{Polygala senega L. [raiz e rizoma]}

A polígala esteve presente em quase todas as edições anteriores da Farmacopeia Brasileira, com exceção da $3^{\mathrm{a}}$ edição, sendo que na $1^{\mathrm{a}}$ e $2^{\mathrm{a}}$ edição a droga vegetal era constituída apenas pela raiz (Quadro 3). A espécie está incluída no FFFB1, na Lista de Medicamento Fitoterápico de Registro Simplificado da IN no 02/2014 (BRASIL, 2011, 2014a), e na FB5. Foram encontrados, para a espécie, três registros de fitoterápicos válidos na Anvisa (Quadro 5). Conforme a literatura consultada, a espécie não possui ocorrência no Brasil (Apêndice A), havendo registro de ocorrência no Canadá e Estados Unidos (TROPICOS.ORG, 2016). Em 
buscas realizadas nos compêndios internacionais em estudo, foi localizada monografia apenas na EP8.8. Os dados extraídos das monografias estão descritos no Quadro 34. 
Quadro 34 - Comparação entre as monografias de Polygala senega L. [raiz e rizoma] das farmacopeias FB5 e EP8.8.

\begin{tabular}{|c|c|c|c|}
\hline & FB5 & EP8.8 & Classificação \\
\hline Nomenclatura botânica & Polygala senega $\mathrm{L}$. & Polygala senega L. e Polygala ssp. & - \\
\hline Nomenclatura popular & polígala & senega & - \\
\hline Droga vegetal & raiz e rizoma & raiz e rizoma & se \\
\hline Marcador 1 & saponinas (ácido oleanólico) (NLT 6\%) & - & su \\
\hline Características & $\begin{array}{c}\text { odor suave + adocicado + lembrando salicilato de metila }+ \\
\text { levemente rançoso }+ \text { sabor inicialmente adocicado }+ \text { depois acre } \\
+ \text { pó da raiz irritante }+ \text { esternutatório + agitado com água } \\
\text { espuma abundante }\end{array}$ & $\begin{array}{c}\text { odor suave + adocicado + levemente rançoso + lembrando } \\
\text { salicilato de metila + pó irritante + esternutatório + agitado com } \\
\text { água espuma abundante }\end{array}$ & - \\
\hline Descrição macroscópica & 1 & 1 & - \\
\hline Descrição microscópica & 2 & 2 & - \\
\hline Figura botânica & 1 & - & - \\
\hline Identificação - método 1 & $\mathrm{CCD}$ & $\mathrm{CCD}$ & se \\
\hline Procedimento 1 & sílica-gel $(\mathrm{G}+0,25 \mathrm{~mm})$ & sílica-gel G & mi \\
\hline Procedimento 2 & fase superior (ácido acético glacial:água:1-butanol (10:40:50)) & fase superior (ácido acético glacial:água:butanol (10:40:50)) & se \\
\hline Procedimento 3 & $10 \mu \mathrm{L}(\mathrm{TS}) ; 10 \mu \mathrm{L}+40 \mu \mathrm{L}$ (RS) (banda) & $10 \mu \mathrm{L}(\mathrm{TS}) ; 10 \mu \mathrm{L}+40 \mu \mathrm{L}(\mathrm{RS})(20 \times 3 \mathrm{~mm})$ (banda) & $\mathrm{mi}$ \\
\hline Procedimento 4 & $\begin{array}{c}1 \mathrm{~g} \text { droga vegetal pulverizada }+10 \mathrm{~mL} \text { etanol } 70 \%+\text { ferver } \\
\text { (refluxo) }\left(15^{\prime}\right)+\text { filtrar }+ \text { resfriar }(\mathrm{TS})\end{array}$ & $\begin{array}{l}1,0 \mathrm{~g} \text { droga vegetal pulverizada }(355)+10 \mathrm{~mL} \text { etanol } 70 \%+ \\
\text { ferver (refluxo) }\left(15^{\prime}\right)+\text { filtrar }+ \text { resfriar }(\mathrm{TS})\end{array}$ & se \\
\hline Procedimento 5 & escina $1 \mathrm{mg} / \mathrm{mL}$ em etanol $70 \%(\mathrm{RS})$ & $10 \mathrm{mg}$ escina + etanol $70 \%$ para $10 \mathrm{~mL}$ & se \\
\hline Procedimento 6 & secar $(\operatorname{ar})$ & $\operatorname{secar}\left(100-105^{\circ} \mathrm{C}\right)$ & $\mathrm{mi}$ \\
\hline Procedimento 7 & anisaldeído SR + aquecer $\left(100-105^{\circ} \mathrm{C}\right)$ & solução de anisaldeído SR + aquecer $\left(100-105^{\circ} \mathrm{C}\right)$ & $\mathrm{mi}$ \\
\hline Procedimento 8 & ácido fosfomolíbdico $20 \%$ em etanol + aquecer $\left(100-105^{\circ} \mathrm{C}\right)$ & $\begin{array}{l}\text { ácido fosfomolíbdico } 20,0 \% \text { em etanol anidro + aquecer (100- } \\
\left.105^{\circ} \mathrm{C}\right)\end{array}$ & $\mathrm{se}$ \\
\hline Procedimento 9 & descrição de zonas & descrição de zonas & se \\
\hline Testes - método 1 & matéria estranha (NMT $2 \%$ - vestígios caules aéreos) & matéria estranha (NMT 2,0\%) ${ }^{1}$ & se \\
\hline Testes - método 2 & água (NMT 10\%) & - & su \\
\hline Testes - método 3 & cinzas totais (NMT 6\%) & cinzas totais (NMT 6,0\%) & se \\
\hline Testes - método 4 & - & cinzas insolúveis em ácido clorídrico (NMT 3,0\%) & su \\
\hline Doseamento - método 1 & EAVIS (saponinas) (ácido oleanólico) (NLT 6\%) & - & su \\
\hline Procedimento 1 & $\begin{array}{l}1 \mathrm{~g} \text { droga vegetal pulverizada }+70 \mathrm{~g} \text { etanol } 50 \%+0,1 \mathrm{~mL} \\
\text { silicone antiespumante }+ \text { pérolas de vidro }+ \text { pesar }+ \text { aquecer } \\
\text { (refluxo) (banho-maria) }\left(60^{\prime}\right)+\text { esfriar }+ \text { etanol } 50 \% \text { até peso } \\
\text { inicial }+ \text { centrifugar }+ \text { separar (solução decantada) }+ \text { pesar }+ \\
\text { concentrar (resíduo) }\left(<60{ }^{\circ} \mathrm{C}\right)+10 \mathrm{~mL} \text { ácido clorídrico } 0,1 M+ \\
\text { lavar (recipiente) } 2 \times 5 \mathrm{~mL} \text { ácido clorídrico } 0,1 M+\text { reunir (fases } \\
\text { ácidas) + extrair } 3 \times 70 \mathrm{~mL} \text { fase superior (clorofórmio:ácido }\end{array}$ & - & su \\
\hline
\end{tabular}


Quadro 34 - Comparação entre as monografias de Polygala senega L. [raiz e rizoma] das farmacopeias FB5 e EP8.8.

FB5

clorídrico 0,1 M:1-butanol $(30: 90 \cdot 180))+$ agitar + descansar

$\left(15^{\prime}\right)+$ reunir (fases orgânicas) + lavar $2 \mathrm{x}$ fase inferior

(clorofórmio:ácido clorídrico 0,1 M:1-butanol (30:90:180) +

desprezar (fase inferior) + evaporar (resíduo) $\left(<60{ }^{\circ} \mathrm{C}\right)+$ ácido acético glacial $98 \%$ + ácido acético glacial para $50 \mathrm{~mL}+$ filtrar (desprezar primeiros $20 \mathrm{~mL}$ ) (TS)

Procedimento 2

$$
\text { ácido acético glacial (BS) }
$$

Procedimento 3

Procedimento 4

Procedimento 5

$0,5 \mathrm{~mL}(\mathrm{TS})(\mathrm{BS})+4 \mathrm{~mL}$ reagente de coloração + aquecer

(banho-maria) $\left(60 \pm 1{ }^{\circ} \mathrm{C}\right)\left(25^{\prime}\right)+$ resfriar (banho de gelo) $\left(30^{\prime \prime}\right)$

$520 \mathrm{~nm}$ (imediata determinação)

$$
\begin{aligned}
& \text { concentração relativa } \\
& \mathrm{A} 0 \%=\frac{463,2 \times \mathrm{A}}{m_{1} \times m_{2}}
\end{aligned}
$$

Embalagem e

armazenamento

$1^{2}$

(BRASIL, 2010d; EDQM, 2016b)

Legenda: mi = menor; su = substancial; se = semelhante; NLT = não menos que; MNT = não mais que; CCD = cromatografia em camada delgada; RS = solução referência; TS = solução amostra; $\mathrm{BS}$ = solução branco; $\mathrm{SR}=$ solução reagente; EAVIS = espectrofotometria de absorção no visível; $\mathrm{AO}=$ derivados do ácido oleanólico; $\mathrm{A}=$ absorvância; $m=$ massa

Nota: ${ }^{1}=$ especificação extraída do método geral; ${ }^{2}=$ apenas armazenamento.

(conclusão) 
No geral, as monografias não são convergentes, embora a identificação proposta para as duas monografias seja bem semelhante.

As diferenças substanciais se concentram nos testes e ensaios adicionais da FB5 (doseamento e especificação para saponinas e determinação de água) e da EP8.8 (cinzas insolúveis em ácido clorídrico).

Diferenças substanciais nas especificações como as encontradas, podem ocasionar barreiras sanitárias ao comércio internacional de matérias-primas e produtos acabados. Como espécie que não possui ocorrência no Brasil e com registros de fitoterápicos válidos no Brasil, se esperava que as monografias fossem mais harmonizadas, nesse caso, os resultados não acompanharam a expectativa.

\subsubsection{Quillaja saponaria Molina [casca]}

A quilaia esteve presente apenas na $1^{\mathrm{a}}$ edição da Farmacopeia Brasileira (Quadro 3), não está relacionada no FFFB1 e nem na IN nº 02/2014 (BRASIL, 2011, 2014a), estando apenas na FB5. Não foram encontrados, para a espécie, registros de fitoterápicos válidos na Anvisa (Quadro 5). Conforme a literatura consultada, a espécie não possui ocorrência no Brasil (Apêndice A), havendo registro de ocorrência na Bolívia e Chile (TROPICOS.ORG, 2016). Em buscas realizadas nos compêndios internacionais em estudo, foi localizada monografia apenas na EP8.8. Os dados extraídos das monografias estão descritos no Quadro 35. 
Quadro 35 - Comparação entre as monografias de Quillaja saponaria Molina [casca] das farmacopeias FB5 e EP8.8.

\begin{tabular}{|c|c|c|c|}
\hline & FB5 & EP8.8 & Classificação \\
\hline Nomenclatura botânica & Quillaja saponaria Molina & Quillaja saponaria Molina s.l. & - \\
\hline Nomenclatura popular & quilaia & quillaia & - \\
\hline Droga vegetal & casca & casca & se \\
\hline Marcador 1 & - & $\begin{array}{l}\text { glicosídeos triterpênicos (quilaia saponina 3) (NLT 6,5\%) (droga } \\
\text { seca) }\end{array}$ & su \\
\hline Características & $\begin{array}{c}\text { praticamente inodora }+ \text { efeito esternutatório }+ \text { sabor acre }+ \\
\text { adstringente }\end{array}$ & - & - \\
\hline Descrição macroscópica & 1 & 1 & - \\
\hline Descrição microscópica & 2 & 1 & - \\
\hline Figura botânica & 2 & 1 & - \\
\hline Identificação - método 1 & $\mathrm{CCD}$ & $\mathrm{CCD}$ & se \\
\hline Procedimento 1 & sílica-gel $\left(\mathrm{GF}_{254}+0,25 \mathrm{~mm}\right)$ & sílica-gel $(2-10 \mu \mathrm{m})$ & mi \\
\hline Procedimento 2 & clorofórmio:etanol:água $(30: 40: 5)$ & $\begin{array}{l}\text { ácido acético anidro:acetato de etila:água:propanol } \\
\qquad(1,5: 30: 30: 40)\end{array}$ & me \\
\hline Procedimento 3 & $15-20 \mu \mathrm{L}$ (TS); 5-10 $\mu \mathrm{L}$ (RS) (banda) & $5 \mu \mathrm{L}(6 \mathrm{~mm})(\mathrm{TS})(\mathrm{RS})$ (banda) & me \\
\hline Procedimento 4 & $\begin{array}{c}1 \mathrm{~g} \text { droga pulverizada }+20 \mathrm{~mL} \text { etanol } 50 \%+\text { agitar }\left(20^{\prime}\right)+\text { filtrar } \\
+ \text { concentrar (secura) (banho-maria) }\left(<50{ }^{\circ} \mathrm{C}\right)+5 \mathrm{~mL} \text { metanol } \\
\text { (TS) }\end{array}$ & $\begin{array}{c}1,0 \mathrm{~g} \text { droga vegetal pulverizada }(355)+5 \mathrm{~mL} \text { metanol }+5 \mathrm{~mL} \\
\text { água }+ \text { sonicar }\left(10^{\prime}\right)+\text { filtrar }(\mathrm{TS})\end{array}$ & me \\
\hline Procedimento 5 & $0,1 \mathrm{~g}$ saponina purificada $\mathrm{SQR}+5 \mathrm{~mL}$ metanol + filtrar $(\mathrm{RS})$ & $\begin{array}{c}10 \mathrm{mg} \text { saponina purificada }+2 \mathrm{mg} \text { sacarose }+1 \mathrm{~mL} \text { água }+1 \mathrm{~mL} \\
\text { metanol }(\mathrm{RS})\end{array}$ & me \\
\hline Procedimento 6 & secar (ar) & secar (ar quente) & $\mathrm{mi}$ \\
\hline Procedimento 7 & anisaldeído SR + aquecer $\left(100-105^{\circ} \mathrm{C}\right)\left(5^{\prime}\right)$ & ácido sulfúrico $10 \%$ em metanol + aquecer $\left(120^{\circ} \mathrm{C}\right)\left(5^{\prime}\right)$ & me \\
\hline Procedimento 8 & descrição de zonas & esquema & me \\
\hline Testes - método 1 & água (NMT 8,0\%) & $\begin{array}{c}\text { perda por dessecação (NMT 10,0\%) }(1,000 \mathrm{~g} \text { droga vegetal } \\
\text { pulverizada }(355))\left(105^{\circ} \mathrm{C}\right)(2 \mathrm{~h})\end{array}$ & me \\
\hline Testes - método 2 & cinzas totais (NMT 6,0\%) & cinzas totais (NMT 10,0\%) & su \\
\hline Testes - método 3 & $\begin{array}{l}\text { cinzas insolúveis em ácido (NMT 1,0\%) } \\
\text { substâncias extraíveis em etanol (NLT 22,0\%) }(5 \mathrm{~g} \text { droga } \\
\text { vegetal pulverizada }+100 \mathrm{~mL} \text { etanol } 45 \%+\text { macerar }(24 \mathrm{~h})(6 \mathrm{~h}-\end{array}$ & cinzas insolúveis em ácido clorídrico (NMT 1,0\%) & me \\
\hline Testes - método 4 & $\begin{array}{c}\text { agitação constante }+18 \mathrm{~h}-\text { repouso })+ \text { filtrar }+ \text { etanol } 45 \% \text { para } \\
100 \mathrm{~mL}+\text { transferir } 20 \mathrm{~mL}+\text { evaporar (secura) (pesa-filtro } \\
\text { tarado) }\left(105^{\circ} \mathrm{C}\right) \text { até peso constante }\end{array}$ & - & $\mathrm{su}$ \\
\hline Índices - método 1 & $\begin{array}{l}\text { índice de espuma (NLT 1000) (0,1 g droga vegetal pulverizada } \\
\left.\quad+100 \mathrm{~mL} \text { água + ferver }\left(5^{\prime}\right)+\text { filtrar + água para } 100 \mathrm{~mL}\right)\end{array}$ & - & $\begin{array}{l}\mathrm{su} \\
\text { (continua) }\end{array}$ \\
\hline
\end{tabular}


Quadro 35 - Comparação entre as monografias de Quillaja saponaria Molina [casca] das farmacopeias FB5 e EP8.8.

\begin{tabular}{|c|c|c|c|}
\hline & FB5 & EP8.8 & Classificação \\
\hline Doseamento - método 1 & - & $\begin{array}{l}\text { CLAE-UV (glicosídeos triterpênicos) (quilaia saponina 3) (NLT } \\
6,5 \% \text { ) }\end{array}$ & su \\
\hline Procedimento 1 & - & $210 \mathrm{~nm}$ & su \\
\hline Procedimento 2 & - & $\operatorname{ODS}(0,25 \mathrm{~m} \times 4,6 \mathrm{~mm})(5 \mu \mathrm{m})$ & su \\
\hline Procedimento 3 & - & acetonitrila:ácido fosfórico $0,1 \%(35: 65)(1,0 \mathrm{~mL} / \mathrm{min})$ & su \\
\hline Procedimento 4 & - & $\begin{array}{c}0,500 \mathrm{~g} \text { droga vegetal pulverizada }(355)+20 \mathrm{~mL} \text { hidróxido de } \\
\text { potássio } 2,0 \%+\text { aquecer (refluxo) (banho-maria) }(2 \mathrm{~h})+\text { esfriar }+ \\
2 \mathrm{~mL} \text { ácido fosfórico + filtrar (algodão) + retomar (resíduo + } \\
\text { algodão) com } 25 \mathrm{~mL} \text { etanol } 96 \%+\text { agitar (cuidadosamente })+ \\
\text { filtrar + reunir (filtrados) + água para } 50,0 \mathrm{~mL}+\text { filtrar } \\
\text { (membrana } 0,45 \mu \mathrm{m})(\mathrm{TS})\end{array}$ & su \\
\hline Procedimento 5 & - & $\begin{array}{l}12,0 \mathrm{mg} \text { saponina quilaia para doseamento } \mathrm{SQR}+\text { etanol } \\
96 \% \text { :ácido fosfórico } 1,0 \%(1: 1) \text { para } 50,0 \mathrm{~mL}\left(\mathrm{RS}_{1}\right)\end{array}$ & su \\
\hline Procedimento 6 & - & $\begin{array}{c}12 \mathrm{mg} \text { saponina quilaia purificada } \mathrm{SQR}+20 \mathrm{~mL} \text { hidróxido de } \\
\text { potássio } 2,0 \%+\text { aquecer (refluxo) (banho-maria) }(2 \mathrm{~h})+\text { esfriar }+ \\
2 \mathrm{~mL} \text { ácido fosfórico }+25 \mathrm{~mL} \text { etanol } 96 \%+\text { agitar } \\
\text { (cuidadosamente) + água para } 50,0 \mathrm{~mL}+\text { filtrar (membrana } 0,45 \\
\mu \mathrm{m})\left(\mathrm{RS}_{2}\right)\end{array}$ & su \\
\hline Procedimento 7 & - & $50 \mu \mathrm{L}$ & su \\
\hline Procedimento 8 & - & $\begin{array}{c}\text { tempo de corrida }(1,2 \text { x ácido glicirrizínico) + cromatograma } \\
\left(\mathrm{RS}_{2}\right) \sim \text { referência (identificar - saponina quilaia } \\
\text { monodesmosídica } 1 \text { e } 3 \text {; saponina quilaia monodesmosídica } 2 \\
\text { entre } 1 \text { e } 3)\end{array}$ & su \\
\hline Procedimento 9 & - & $\begin{array}{c}\text { tempo de retenção }\left(\sim\left(9^{\prime}\right) \text { - saponina quilaia monodesmosídica } 1\right. \\
\sim\left(10^{\prime}\right) \text { - saponina quilaia monodesmosídica } 3 ; \sim\left(13^{\prime}\right) \text { ácido } \\
\text { glicirrizínico })\end{array}$ & su \\
\hline Procedimento 10 & - & concentração relativa & $\mathrm{su}$ \\
\hline \multirow{2}{*}{ Procedimento 11} & \multirow{2}{*}{-} & $\mathrm{A}_{1} \times \mathrm{m}_{2} \times \mathrm{p} \times 2298 \times 0,6$ & \multirow{2}{*}{ su } \\
\hline & & $A_{2} \times m_{1} \times 957$ & \\
\hline $\begin{array}{l}\text { Embalagem e } \\
\text { armazenamento }\end{array}$ & 1 & - & - \\
\hline Padrões de referência & saponina purificada SQR & $\begin{array}{c}\text { saponina quilaia para doseamento } S Q R+\text { saponina quilaia } \\
\text { purificada SQR }\end{array}$ & - \\
\hline
\end{tabular}


(BRASIL, 2010c, d; EDQM, 2016b).

Legenda: $\mathrm{mi}=$ menor; $\mathrm{me}=$ moderado; $\mathrm{su}=$ substancial; se = semelhante; $\mathrm{NLT}=$ não menos que; $\mathrm{MNT}=$ não mais que; $\mathrm{CCD}=$ cromatografia em camada delgada; $\mathrm{RS}=$ solução referência; TS = solução amostra; $\mathrm{SQR}$ = substância química de referência; CLAE-UV = cromatografia liquida de alta eficiência acoplada a detector por espectrofotometria por absorção no ultravioleta; ODS $=$ coluna cromatográfica octadecilsilanizada; $\mathrm{A}=$ resposta; $\mathrm{m}=$ massa; $\mathrm{p}=$ pureza .

Nota: ${ }^{1}=$ conforme método geral o ácido utilizado é o ácido clorídrico diluído enquanto a EP8.8 utiliza o ácido clorídrico concentrado.

(conclusão) 
No geral, as monografias não são convergentes. As diferenças substanciais se concentram nos ensaios e testes adicionais da EP8.8 (doseamento e especificação para glicosídeos triterpênicos), e da FB5 (matéria extraível em etanol e o índice de espuma) e na diferença da especificação de cinzas totais acima de $30 \%$.

Como espécie que não possui ocorrência no Brasil, a origem da matéria-prima não é nacional. Assim, se esperava que os métodos e especificações fossem mais harmonizados, porém, nesse caso, a espécie não possui registros válidos junto à Anvisa, nem está listada em outros compêndios e nem na lista de registro simplificado. Isso pode indicar que há baixa utilização da monografia no Brasil e, pode, eventualmente, explicar, o porquê de a monografia não ser tão harmonizada quanto o esperado.

\subsubsection{Rauvolfia serpentina (L.) Benth. ex Kurz [raiz]}

A rauvólfia esteve presente apenas na $2^{\mathrm{a}}$ edição da Farmacopeia Brasileira (Quadro 3), atualmente, não está relacionada no FFFB1 e nem na IN nº 02/2014 (BRASIL, 2011, 2014a), estando apenas na FB5. Não foram encontrados, para a espécie, registros de fitoterápicos válidos na Anvisa (Quadro 5). Conforme a literatura consultada, a espécie não possui ocorrência no Brasil (Apêndice A), havendo registro de ocorrência na Birmânia, China, Honduras, Índia, Sri Lanka e Tailândia (TROPICOS.ORG, 2016). Em buscas realizadas nos compêndios internacionais em estudo, foi localizada monografia apenas na USP39-NF34. Os dados extraídos das monografias estão descritos no Quadro 36. 
Quadro 36 - Comparação entre as monografias de Rauvolfia serpentina (L.) Benth. ex Kurz [raiz] das farmacopeias FB5 e da USP39-NF34.

\begin{tabular}{|c|c|c|c|}
\hline & FB5 & USP39-NF34 & Classificação \\
\hline Nomenclatura botânica & Rauvolfia serpentina (L.) Benth. ex Kurz & Rauwolfia (L.) Benth. ex Kurz & - \\
\hline Nomenclatura popular & rauvólfia & rauwolfia & - \\
\hline Droga vegetal & raiz & raiz & se \\
\hline Marcador 1 & alcaloides (reserpina-rescinamina) (NLT 0,15\%) (droga seca) & alcaloides (reserpina) (NLT 0,15\%) (droga seca) & me \\
\hline Características & inodora + sabor muito amargo & - & - \\
\hline Descrição macroscópica & 1 & 1 & - \\
\hline Descrição microscópica & 2 & 3 & - \\
\hline Figura botânica & 1 & - & - \\
\hline Identificação - método 1 & $\mathrm{CCD}$ & cromatografia em papel & me \\
\hline Procedimento 1 & sílica-gel GF 254 & papel de filtro (Whatman $\mathrm{n}^{\circ} 1$ ) & me \\
\hline Procedimento 2 & butanol:ácido acético:água (40:10:10) & $\begin{array}{c}\text { fase móvel } 1 \text { (isooctano:tetracloreto de carbono:piperidina:terc- } \\
\text { butanol }(90: 60: 4: 2))+ \text { fase móvel } 2 \text { (clorofórmio:isooctano:terc- } \\
\text { butanol }(75: 75: 2))+ \text { solvente imóvel (formamida:acetona } \\
(30: 100))\end{array}$ & su \\
\hline Procedimento 3 & $10 \mu \mathrm{L}(\mathrm{TS}) ; 5 \mu \mathrm{L}(\mathrm{RS})$ (banda) & $1 \mu \mathrm{L}(\mathrm{TS})(\mathrm{RS})$ & me \\
\hline Procedimento 4 & $\begin{array}{l}1 \mathrm{~g} \text { droga vegetal pulverizada }+5 \mathrm{~mL} \text { metanol }+1 \mathrm{~mL} \text { carbonato } \\
\text { de sódio } 10 \%+\text { ferver (refluxo) }\left(10^{\prime}\right)+\text { esfriar }+ \text { filtrar }(\mathrm{TS})\end{array}$ & $\begin{array}{l}1 \mathrm{~g} \text { droga vegetal pulverizada }+5 \mathrm{~mL} \text { etanol }+ \text { aquecer }(55-65 \\
\left.{ }^{\circ} \mathrm{C}\right)\left(30^{\prime}\right)(\text { agitar ocasionalmente })+\text { esfriar }+ \text { filtrar }(\mathrm{TS})\end{array}$ & me \\
\hline Procedimento 5 & reserpina $10 \mathrm{mg} / \mathrm{mL}$ em metanol (RS) & $\begin{array}{l}1 \mathrm{~g} \text { rauwolfia serpentina } \mathrm{SQR}+5 \mathrm{~mL} \text { etanol }+ \text { aquecer }(55-65 \\
\left.{ }^{\circ} \mathrm{C}\right)\left(30^{\prime}\right)(\text { agitar ocasionalmente) }+ \text { esfriar }+ \text { filtrar }(\mathrm{RS}) \\
\left.\text { papel de filtro (Whatman } \mathrm{n}^{\circ} 1\right)+ \text { solvente imóvel }+ \text { secar }+\end{array}$ & su \\
\hline Procedimento 6 & - & $\begin{array}{c}\text { aplicar (TS) }(\mathrm{RS})+\text { solvente imóvel (TS) }(\mathrm{RS})+\text { secar + } \\
\text { desenvolver com fase móvel } 1(1 \mathrm{~h})\end{array}$ & me \\
\hline Procedimento 7 & secar $\left(100-105^{\circ} \mathrm{C}\right)$ & secar (corrente de ar) $\left(90^{\circ} \mathrm{C}\right)$ & mi \\
\hline Procedimento 8 & iodeto de potássio e subnitrato de bismuto SR + descansar (10') & ácido tricloroacético $25 \%$ em metanol + aquecer $\left(90^{\circ} \mathrm{C}\right)\left(10^{\prime}\right)$ & me \\
\hline Procedimento 9 & - & $\begin{array}{c}\text { desenvolver com fase móvel } 2 \text { (câmara saturada) (hidróxido de } \\
\text { amônio) }\end{array}$ & me \\
\hline Procedimento 10 & $365 \mathrm{~nm}$ & ultravioleta & me \\
\hline Procedimento 11 & descrição de zonas & descrição de zonas & me \\
\hline Testes - método 1 & matéria estranha (NMT 5\%) & matéria estranha (NMT 2,0\% - caules; NMT 3,0\% - outros) & $\mathrm{mi}$ \\
\hline Testes - método 2 & água (NMT $12 \%)\left(100-105{ }^{\circ} \mathrm{C}\right)(5 \mathrm{~h})^{1}$ & perda por dessecação (NMT $12,0 \%)\left(100^{\circ} \mathrm{C}\right)$ & se \\
\hline Testes - método 3 & cinzas totais (NMT 10\%) & - & $\mathrm{su}$ \\
\hline Testes - método 4 & - & cinzas insolúveis em ácido (NMT 2,0\%) & $\mathrm{su}$ \\
\hline Testes - método 5 & - & microrganismos (ausência Salmonella) & - \\
\hline Doseamento - método 1 & EAUV (alcaloides) (reserpina-rescinamina) (NLT 0,15\%) & EAUV (alcaloides) (reserpina) (NLT 0,15\%) & $\begin{array}{l}\text { me } \\
\text { (continua) }\end{array}$ \\
\hline
\end{tabular}


Quadro 36 - Comparação entre as monografias de Rauvolfia serpentina (L.) Benth. ex Kurz [raiz] das farmacopeias FB5 e da USP39-NF34.

\begin{tabular}{|c|c|c|c|}
\hline & FB5 & USP39-NF34 & Classificação \\
\hline Procedimento 1 & $\begin{array}{l}2,5 \mathrm{~g} \text { droga vegetal pulverizada }+100 \mathrm{~mL} \text { etanol + aquecer } \\
\text { (refluxo) }(4 \mathrm{~h}) \text { (proteger da luz) + etanol para } 100 \mathrm{~mL}+\text { transferir } \\
20 \mathrm{~mL}+200 \mathrm{~mL} \text { ácido sulfúrico } 0,25 \mathrm{M}+\text { extrair } 4 \times 60 \mathrm{~mL} \\
\text { clorofórmio + desprezar (fases ácidas) + reunir (fase } \\
\text { clorofórmio) + extrair 4x } 60 \mathrm{~mL} \text { bicarbonato de sódio } 2 \%+ \\
\text { filtrar (fase orgânica) + etanol para } 250 \mathrm{~mL}+\text { transferir } \\
\text { (duplicata) } 25 \mathrm{~mL}+\text { evaporar (resíduo) (banho-maria) }\left(40^{\circ} \mathrm{C}\right) \\
\text { (TS1 + TS2) }\end{array}$ & $\begin{array}{c}\text { 2,5 g droga vegetal finamente pulverizada + } 100 \mathrm{~mL} \text { etanol + } \\
\text { extrair (aparato de extração contínua) }(4 \mathrm{~h}) \text { (proteger da luz) + } \\
\text { lavar (recipiente) etanol para } 100 \mathrm{~mL}+\text { transferir } 20,0 \mathrm{~mL}+200 \\
\text { mL ácido sulfúrico } 0,25 \mathrm{~N}+\text { extrair } 3 \times 25 \mathrm{~mL} 1,1,1 \text { tricloroetano } \\
\text { + reunir (fases tricloroetânicas) + lavar } 50 \mathrm{~mL} \text { ácido sulfúrico } \\
0,5 \mathrm{~N} \text { (líquido de lavagem ácido) + descartar (fase } \\
\text { tricloroetânicas) + extrair (primeira fase ácida) com } 1 \times 25 \\
\text { clorofórmio + 2x } 15 \mathrm{~mL} \text { clorofórmio + } 3 \times 10 \mathrm{~mL} \text { clorofórmio + } \\
\text { lavar (fase clorofórmica) com líquido de lavagem ácido + + } \\
\text { lavar } 2 \times 10 \mathrm{~mL} \text { bicarbonato de sódio } 2 \%+\text { filtrar (fase } \\
\text { clorofórmica) (algodão lavado com clorofórmio) + etanol para } \\
100 \mathrm{~mL}+\text { transferir (duplicata) } 10,0 \mathrm{~mL}+4 \mathrm{~mL} \text { etanol + } \\
\text { evaporar (cuidadosamente) (resíduo) (TS) }\end{array}$ & me \\
\hline Procedimento 2 & $(\mathrm{TS} 1)+5 \mathrm{~mL}$ etanol $+2 \mathrm{~mL}$ ácido sulfúrico $0,25 \mathrm{M}$ & $(\mathrm{TS} 1)+5,0 \mathrm{~mL}$ etanol $+2,0 \mathrm{~mL}$ ácido sulfúrico $0,5 \mathrm{~N}$ & $\mathrm{mi}$ \\
\hline Procedimento 3 & $\begin{array}{c}(\mathrm{TS} 2)+5 \mathrm{~mL} \text { etanol }+1 \mathrm{~mL} \text { ácido sulfúrico } 0,25 M+1 \mathrm{~mL} \\
\text { nitrito de sódio } 0,3 \%\end{array}$ & $\begin{array}{c}(\mathrm{TS} 2)+5,0 \mathrm{~mL} \text { etanol }+1,0 \mathrm{~mL} \text { ácido sulfúrico } 0,5 \mathrm{~N}+1,0 \mathrm{~mL} \\
\text { nitrito de sódio } 0,3 \%\end{array}$ & \\
\hline Procedimento 4 & $\begin{array}{c}20 \mathrm{mg} \text { reserpina } \mathrm{SQR}+25 \mathrm{~mL} \text { etanol + sonicar + etanol para } 50 \\
\mathrm{~mL}+\text { transferir } 5 \mathrm{~mL}+\text { etanol para } 100 \mathrm{~mL}(20 \mu \mathrm{g} / \mathrm{mL})(\mathrm{RS})\end{array}$ & $\begin{array}{c}20,0 \mathrm{mg} \text { reserpina } \mathrm{SQR}+25 \mathrm{~mL} \text { etanol (quente) }+ \text { esfriar }+ \\
\text { etanol para } 50,0 \mathrm{~mL}+\text { transferir } 5,0 \mathrm{~mL}+\text { etanol para } 100,0 \mathrm{~mL} \\
(20 \mu \mathrm{g} / \mathrm{mL})(\mathrm{RS})\end{array}$ & $\mathrm{mi}$ \\
\hline Procedimento 5 & $5 \mathrm{~mL}(\mathrm{RS})+2 \mathrm{~mL}$ ácido sulfúrico $0,25 \mathrm{M}$ & $5 \mathrm{~mL}(\mathrm{RS})+2,0 \mathrm{~mL}$ ácido sulfúrico $0,5 \mathrm{~N}$ & mi \\
\hline Procedimento 6 & $\begin{array}{c}5 \mathrm{~mL}(\mathrm{RS})+1 \mathrm{~mL} \text { ácido sulfúrico } 0,25 M+1 \mathrm{~mL} \text { nitrito de } \\
\text { sódio } 0,3 \%\end{array}$ & $\begin{array}{c}5 \mathrm{~mL}(\mathrm{RS})+1,0 \mathrm{~mL} \text { ácido sulfúrico } 0,5 \mathrm{~N}+1,0 \mathrm{~mL} \text { nitrito de } \\
\text { sódio } 0,3 \%\end{array}$ & $\mathrm{mi}$ \\
\hline Procedimento 7 & $\begin{array}{c}\text { aquecer (banho-maria) }\left(50-60^{\circ} \mathrm{C}\right)\left(20^{\prime}\right)+\text { esfriar (ambiente) }+ \\
0,5 \mathrm{~mL} \text { ácido sulfâmico } 5 \%+\text { aguardar }\left(20^{\prime}\right)\end{array}$ & $\begin{array}{c}\text { aquecer (banho-maria) }\left(50-60^{\circ} \mathrm{C}\right)\left(20^{\prime}\right)+\text { esfriar }+500 \mu \mathrm{L} \text { ácido } \\
\text { sulfâmico } 5 \%+\text { aguardar estabilização cor }\end{array}$ & $\mathrm{mi}$ \\
\hline Procedimento 8 & etanol:água $(2: 1)(\mathrm{BS})$ & etanol:água $(2: 1)(\mathrm{BS})$ & se \\
\hline Procedimento 9 & $390 \mathrm{~nm}$ & $390 \mathrm{~nm}$ & se \\
\hline Procedimento 10 & MAL $=5 \times \frac{\left(A_{1}-A_{2}\right)}{\left(S_{1}-S_{2}\right)}$ & $5 \times \frac{\left(A-A_{0}\right)}{\left(S-S_{0}\right)}$ & $\mathrm{se}$ \\
\hline Procedimento 11 & $\mathrm{AL}=\frac{\mathrm{MAL}}{\mathrm{M}} \times 100$ & - & me \\
\hline $\begin{array}{l}\text { Embalagem e } \\
\text { armazenamento }\end{array}$ & 1 & 1 & - \\
\hline Padrões de referência & reserpina $S Q R$ & rauwolfia serpentina $S Q R$ + reserpina $S Q R$ & - \\
\hline
\end{tabular}


(BRASIL, 2010c, d; USP, 2016h).

Legenda: $\mathrm{mi}=$ menor; $\mathrm{me}=$ moderado; $\mathrm{su}=$ substancial; se = semelhante; $\mathrm{NLT}=$ não menos que; $\mathrm{MNT}=$ não mais que; $\mathrm{CCD}=$ cromatografia em camada delgada; $\mathrm{RS}=$ solução referência; TS = solução amostra; $\mathrm{BS}$ = solução branco; $\mathrm{SR}=$ solução reagente; $\mathrm{SQR}$ = substância química de referência; EAUV = espectrofotometria de absorção no ultravioleta; $\mathrm{A}=\mathrm{S}=$ absorvância; $\mathrm{MAL}=$ massa de alcaloides; $\mathrm{AL}=$ alcaloides; $\mathrm{M}=$ massa.

Nota: ${ }^{1}=$ parâmetros extraídos do método geral.

(conclusão) 
No geral, as monografias são convergentes, com propostas de ensaios e testes semelhantes, porém, com diferenças substanciais.

As diferenças substanciais se concentram nos testes adicionais da FB5 (cinzas totais) e da USP39-NF34 (cinzas insolúveis em ácido) e nas diferenças no método de identificação por cromatografia.

Como espécie que não possui ocorrência no Brasil, a origem da matéria-prima não é nacional. Assim, se esperava que os métodos e especificações fossem mais harmonizados, porém, nesse caso, a espécie não possui registros válidos junto à Anvisa, nem está listada em outros compêndios e nem na lista de registro simplificado. Isso pode indicar que há baixa utilização da monografia no Brasil e, pode, eventualmente, explicar, o porquê de a monografia não ser tão harmonizada quanto o esperado.

\subsubsection{Rheum officinale Baill. e/ou Rheum palmatum L. [raiz e rizoma]}

O ruibarbo esteve presente em todas as edições da Farmacopeia Brasileira, (Quadro 3), contudo, não está relacionada no FFFB1 e nem na IN no 02/2014 (BRASIL, 2011, 2014a), estando apenas na FB5. Foi encontrado, para a espécie, Rheum palmatum L. apenas um registro de fitoterápico válido na Anvisa (Quadro 5). Conforme a literatura consultada, as espécies não possuem ocorrência no Brasil (Apêndice A), havendo registro de ocorrência das espécies na China e Colômbia (TROPICOS.ORG, 2016). Em buscas realizadas nos compêndios internacionais em estudo, foi localizada monografia apenas na EP8.8. Os dados extraídos das monografias estão descritos no Quadro 37. 
Quadro 37 - Comparação entre as monografias de Rheum officinale Baill. e/ou Rheum palmatum L. [raiz e rizoma] das farmacopeias FB5 e da EP8.8.

\begin{tabular}{|c|c|c|c|}
\hline & FB5 & EP8.8 & Classificação \\
\hline Nomenclatura popular & ruibarbo & rhubarb & - \\
\hline Droga vegetal & raiz e rizoma & raiz e rizoma & se \\
\hline Marcador 1 & derivados hidroxiantracênicos (reína) (NLT 2,2\%) (droga seca) & derivados hidroxiantracênicos (reína) (NLT 2,2\%) (droga seca) & se \\
\hline Características & odor característico aromático + sabor amargo + adstringente & odor característico aromático & - \\
\hline Descrição macroscópica & 1 & 1 & - \\
\hline Descrição microscópica & 2 & 1 & - \\
\hline Figura botânica & 1 & - & - \\
\hline Identificação - método 1 & $\mathrm{CCD}$ & $\mathrm{CCD}$ & se \\
\hline Procedimento 1 & sílica-gel $\left(\mathrm{GF}_{254}+0,25 \mathrm{~mm}\right)$ & sílica-gel & mi \\
\hline Procedimento 2 & éter de petróleo:acetato de etila:ácido fórmico anidro (75:25:1) & ácido fórmico anidro:acetato de etila:éter de petróleo (1:25:75) & se \\
\hline Procedimento 3 & $20 \mu \mathrm{L}(\mathrm{TS}) ; 10 \mu \mathrm{L}$ (RS) (banda) & $20 \mu \mathrm{L}(\mathrm{TS})(\mathrm{RS})(\mathrm{banda})$ & $\mathrm{mi}$ \\
\hline Procedimento 4 & $\begin{array}{l}50 \mathrm{mg} \text { droga vegetal pulverizada }(250)+1 \mathrm{~mL} \text { ácido clorídrico } \\
+30 \mathrm{~mL} \text { água }+ \text { aquecer (refluxo) (banho-maria) }(15 \text { ') }+ \text { resfriar } \\
\text { (ambiente) }+25 \mathrm{~mL} \text { éter etílico }+ \text { extrair }+ \text { filtrar (sulfato de } \\
\text { sódio anidro) + evaporar (secura) }+0,5 \mathrm{~mL} \text { éter etílico }(\mathrm{TS})\end{array}$ & $\begin{array}{l}50 \mathrm{mg} \text { droga vegetal pulverizada }(180)+1 \mathrm{~mL} \text { ácido clorídrico } \\
+30 \mathrm{~mL} \text { água }+ \text { aquecer (banho-maria) }\left(15^{\prime}\right)+\text { esfriar }+25 \mathrm{~mL} \\
\text { éter etílico }+ \text { agitar }+ \text { secar (sulfato de sódio anidro }+ \text { filtrar }+ \\
\quad \text { evaporar (fase etérea) (secura) }+0,5 \mathrm{~mL} \text { éter etílico }(\mathrm{TS})\end{array}$ & $\mathrm{mi}$ \\
\hline Procedimento 5 & emodina $0,1 \%$ em éter etílico (RS) & $5 \mathrm{mg}$ emodina $+5 \mathrm{~mL}$ éter etílico $(\mathrm{RS})$ & se \\
\hline Procedimento 6 & secar (ar) & secar (ar) & se \\
\hline Procedimento 7 & $365 \mathrm{~nm}$ & $365 \mathrm{~nm}$ & se \\
\hline Procedimento 8 & hidróxido de potássio $10 \%$ em metanol & hidróxido de potássio $10 \%$ em metanol & se \\
\hline Procedimento 9 & descrição de zonas & descrição de zonas & se \\
\hline Identificação - método 2 & $\begin{array}{l}50 \mathrm{mg} \text { droga vegetal pulverizada }(250)+25 \mathrm{~mL} \text { ácido clorídrico } \\
2 M+\text { aquecer (banho-maria) }\left(15^{\prime}\right)+\text { esfriar }+10 \mathrm{~mL} \text { éter etílico } \\
+ \text { extrair + separar (fase etérea })+10 \mathrm{~mL} \text { hidróxido de amônio } 6 \\
M+\text { agitar = coloração vermelha (fase aquosa amoniacal) }\end{array}$ & $\begin{array}{l}50 \text { mg droga vegetal pulverizada }(180)+25 \mathrm{~mL} \text { ácido clorídrico } \\
\text { diluído + aquecer (banho-maria) }\left(15^{\prime}\right)+\text { esfriar }+20 \mathrm{~mL} \text { éter } \\
\text { etílico + agitar + desprezar (fase aquosa) }+10 \mathrm{~mL} \text { amônia } \\
\text { diluída + agitar = coloração vermelha a violeta (fase aquosa) }\end{array}$ & $\mathrm{mi}$ \\
\hline Testes - método 1 & CCD (raponticina) & CCD (Rheum rhaponticum) & se \\
\hline Procedimento 1 & sílica-gel $\left(\mathrm{GF}_{254}+0,25 \mathrm{~mm}\right)$ & sílica-gel G & $\mathrm{mi}$ \\
\hline Procedimento 2 & metanol:diclorometano $(20: 80)$ & metanol:diclorometano $(20: 80)$ & se \\
\hline Procedimento 3 & $20 \mu \mathrm{L}(\mathrm{TS}) ; 5 \mu \mathrm{L}(\mathrm{RS})$ (banda) & $20 \mu \mathrm{L}(20 \times 3 \mathrm{~mm})(\mathrm{TS})(\mathrm{RS})$ (banda) & $\mathrm{mi}$ \\
\hline Procedimento 4 & $\begin{array}{c}0,2 \text { g droga vegetal pulverizada }+2 \mathrm{~mL} \text { metanol }+ \text { aquecer } \\
\text { (refluxo) }\left(15^{\prime}\right)+\text { esfriar }+ \text { filtrar }(\mathrm{TS})\end{array}$ & $\begin{array}{c}0,2 \mathrm{~g} \text { droga vegetal pulverizada }(180)+2 \mathrm{~mL} \text { metanol }+ \text { ferver } \\
\text { (refluxo) }\left(5^{\prime}\right)+\text { esfriar + filtrar (TS) }\end{array}$ & $\mathrm{mi}$ \\
\hline Procedimento 5 & raponticina $1 \mathrm{mg} / \mathrm{mL}$ em metanol (RS) & $10 \mathrm{mg}$ raponticina $+10 \mathrm{~mL}$ metanol $(\mathrm{RS})$ & se \\
\hline Procedimento 6 & secar $(\operatorname{ar})$ & secar (ar) & se \\
\hline Procedimento 7 & $365 \mathrm{~nm}$ & - & $\mathrm{mi}$ \\
\hline Procedimento 8 & ácido fosfomolíbdico SR & ácido fosfomolíbdico SR & se \\
\hline Procedimento 9 & descrição de zonas & descrição de zonas & $\begin{array}{c}\text { se } \\
\text { (contil }\end{array}$ \\
\hline
\end{tabular}


Quadro 37 - Comparação entre as monografias de Rheum officinale Baill. e/ou Rheum palmatum L. [raiz e rizoma] das farmacopeias FB5 e da EP8.8.

\begin{tabular}{|c|c|c|c|}
\hline & FB5 & EP8.8 & Classificação \\
\hline Testes - método 2 & matéria estranha (NMT 1,0\%) & matéria estranha (NMT $2,0 \%)^{1}$ & su \\
\hline Testes - método 3 & água $(\mathrm{NMT} 12,0 \%)\left(100-105^{\circ} \mathrm{C}\right)(5 \mathrm{~h})^{2}$ & $\begin{array}{c}\text { perda por dessecação (NMT } 12,0 \%)(1,000 \mathrm{~g} \text { droga vegetal } \\
\text { pulverizada }(180))\left(105^{\circ} \mathrm{C}\right)\end{array}$ & se \\
\hline Testes - método 4 & cinzas totais (NMT $13,0 \%$ ) & cinzas totais (NMT 12,0\%) & mi \\
\hline Testes - método 5 & - & cinzas insolúveis em ácido clorídrico (NMT 2,0\%) & su \\
\hline Doseamento - método 1 & EAVIS (derivados hidroxiantracênicos) (reína) (NLT 2,2\%) & EAVIS (derivados hidroxiantracênicos) (reína) (NLT 2,2\%) & se \\
\hline Procedimento 1 & $\begin{array}{c}0,1 \mathrm{~g} \text { droga vegetal pulverizada dessecada }+30 \mathrm{~mL} \text { água }+ \text { pesar } \\
\text { + aquecer (refluxo) (banho-maria) }\left(15^{\prime}\right)+\text { esfriar }+50 \mathrm{mg} \\
\text { bicarbonato de sódio + pesar + água até peso original + } \\
\text { centrifugar + transferir } 10 \mathrm{~mL} \text { (sobrenadante) }+20 \mathrm{~mL} \text { cloreto } \\
\text { férrico } \mathrm{SR}+\text { agitar + aquecer (refluxo) }\left(20^{\prime}\right)(\text { agitar } \\
\text { frequentemente) }+1 \mathrm{~mL} \text { ácido clorídrico }+ \text { aquecer }\left(20^{\prime}\right)+ \\
\text { esfriar + extrair } 3 \times 25 \mathrm{~mL} \text { éter etílico (líquido de lavagem) + } \\
\text { reunir (fases etéreas) + lavar } 2 \times 20 \mathrm{~mL} \text { água + filtrar + éter } \\
\text { etílico para } 100 \mathrm{~mL}+\text { transferir } 10 \mathrm{~mL}+\text { evaporar (resíduo })+10 \\
\mathrm{~mL} \text { acetato de magnésio } 0,5 \% \text { em metanol (TS) }\end{array}$ & 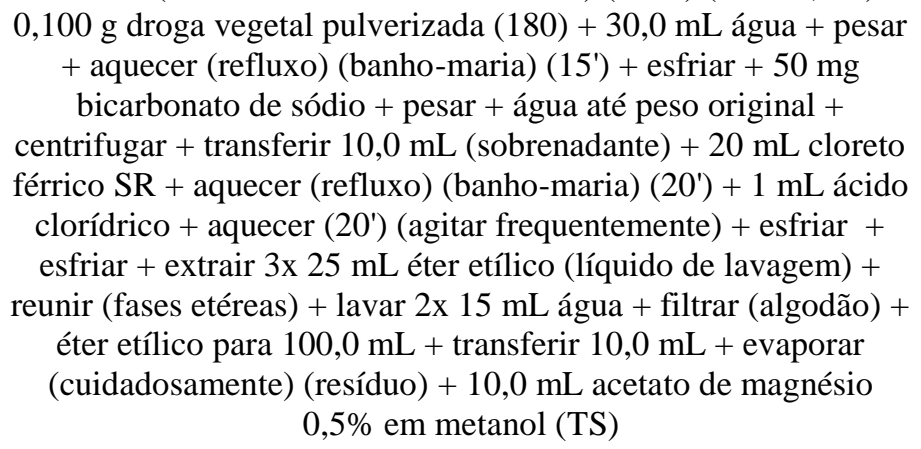 & se \\
\hline Procedimento 2 & metanol (BS) & metanol (BS) & se \\
\hline Procedimento 3 & $515 \mathrm{~nm}$ (imediata determinação) & $515 \mathrm{~nm}$ & me \\
\hline Procedimento 4 & $\mathrm{DHC}=\frac{\mathrm{A} \times 0,68}{m}$ & $\frac{A \times 0,64}{m}$ & $\mathrm{mi}$ \\
\hline $\begin{array}{l}\text { Embalagem e } \\
\text { armazenamento }\end{array}$ & 1 & $\begin{array}{l}m \\
-\end{array}$ & - \\
\hline
\end{tabular}

(BRASIL, 2010d; EDQM, 2016a).

Legenda: mi = menor; me = moderado $; \mathrm{su}=$ substancial $;$ se = semelhante $;$ NLT = não menos que $;$ MNT = não mais que CCD = cromatografia em camada delgada $;$ RS = solução referência; TS = solução amostra; BS = solução branco; SR = solução reagente; EAVIS = espectrofotometria de absorção no visível; DHC = derivados hidroxiantracênicos; $\mathrm{A}=$ absorvância; $m=$ massa

Nota: ${ }^{1}=$ especificação extraída do método geral; ${ }^{2}=$ parâmetros extraídos do método geral. 
No geral, as monografias são convergentes, possuindo ensaios e testes semelhantes.

As diferenças substanciais se concentram no teste adicional da EP8.8 (cinzas insolúveis em ácido clorídrico) a na diferença da especificação da matéria estranha acima de $30 \%$ entre as monografias.

Como espécie que não possui ocorrência no Brasil e com registros de fitoterápicos válidos no Brasil, se esperava que as monografias fossem mais harmonizadas, nesse caso, os resultados acompanharam a expectativa.

\subsubsection{Rosmarinus officinalis L. [sumidade florida; óleo]}

O óleo do alecrim esteve presente na $1^{\mathrm{a}}$ e $2^{\mathrm{a}}$ edições da Farmacopeia Brasileira (Quadro 3), contudo, não está relacionada no FFFB1 e nem na IN no 02/2014 (BRASIL, 2011, 2014a), estando apenas na FB5. Não foram encontrados, para a espécie, registros de fitoterápicos válidos na Anvisa (Quadro 5). Conforme a literatura consultada, a espécie não possui ocorrência no Brasil (Apêndice A), havendo registro de ocorrência na Bolívia, China, Colômbia, Equador, El Salvador, Guatemala, México, Paquistão, Peru, Estados Unidos da América e Venezuela (TROPICOS.ORG, 2016). Em buscas realizadas nos compêndios internacionais em estudo, foi localizada monografia apenas na EP8.8. Os dados extraídos das monografias estão descritos no Quadro 38. 
Quadro 38 - Comparação entre as monografias de Rosmarinus officinalis L. [sumidade florida; óleo] das farmacopeias FB5, FA7 e USP39-NF34.

\begin{tabular}{|c|c|c|c|}
\hline & FB5 & EP8.8 & Classificação \\
\hline Nomenclatura popular & alecrim & resemary & - \\
\hline Droga vegetal & sumidade florida & sumidade florida & se \\
\hline Derivado & óleo volátil & óleo volátil & se \\
\hline Características & $\begin{array}{l}\text { líquido incolor ou amarelo-esverdeado + odor forte } \\
\text { característico + sabor aromático + canforáceo + amargo }\end{array}$ & $\begin{array}{c}\text { líquido límpido }+\begin{array}{c}\text { incolor ou amarelo pálido }+ \text { odor } \\
\text { característico }\end{array}\end{array}$ & - \\
\hline Identificação - método 1 & $\mathrm{CCD}$ & $\mathrm{CCD}$ & se \\
\hline Procedimento 1 & sílica-gel $\left(\mathrm{GF}_{254}+0,25 \mathrm{~mm}\right)$ & sílica-gel & $\mathrm{mi}$ \\
\hline Procedimento 2 & diclorometano & acetato de etila:tolueno $(5: 95)$ & me \\
\hline Procedimento 3 & $10 \mu \mathrm{L}$ (TS) (RS) (banda) & $10 \mu \mathrm{L}(\mathrm{TS})(\mathrm{RS})(\mathrm{banda})$ & se \\
\hline Procedimento 4 & 0,5 mL óleo volátil + acetato de etila para $10 \mathrm{~mL}(\mathrm{TS})$ & $0,5 \mathrm{~mL}$ óleo volátil + tolueno para $10 \mathrm{~mL}(\mathrm{TS})$ & mi \\
\hline Procedimento 5 & $\begin{array}{c}50 \mathrm{mg} \text { borneol }+50 \mathrm{mg} \text { acetato de bornila }+100 \mu \mathrm{L} \mathrm{1,8} \text {-cineol }+ \\
\text { acetato de etila para } 10 \mathrm{~mL}(\mathrm{RS})\end{array}$ & $\begin{array}{c}50 \mathrm{mg} \text { borneol }+50 \mathrm{mg} \text { acetato de bornila }+100 \mu \mathrm{L} \text { cineol }+ \\
\text { tolueno para } 10 \mathrm{~mL}(\mathrm{RS})\end{array}$ & se \\
\hline Procedimento 6 & secar $(\operatorname{ar})$ & secar $(\operatorname{ar})$ & se \\
\hline Procedimento 7 & solução de $p$-anisaldeído + aquecer $\left(100-105^{\circ} \mathrm{C}\right)\left(10^{\prime}\right)$ & reagente vanilina $S R+$ aquecer $\left(100-105^{\circ} \mathrm{C}\right)\left(10^{\prime}\right)$ & mi \\
\hline Procedimento 8 & descrição de zonas & esquema & mi \\
\hline Testes - método 1 & densidade relativa $(0,894-0,912)$ & densidade relativa $(0,895-0,920)$ & $\mathrm{mi}$ \\
\hline Testes - método 2 & poder rotatório $\left(-5^{\circ} \mathrm{a}+15^{\circ}\right)$ & poder rotatório $\left(-5^{\circ} \mathrm{a}+8^{\circ}\right)$ & $\mathrm{su}$ \\
\hline Índices- método 1 & índice de refração $(1,460-1,476)$ & índice de refração $(1,464-1,473)$ & $\mathrm{mi}$ \\
\hline Índices- método 2 & índice de acidez (NMT 1\%) & índice de acidez (NMT 1,0\%) & se \\
\hline $\begin{array}{l}\text { Perfil cromatográfico - } \\
\text { método } 1\end{array}$ & CG (perfil cromatográfico) & CG (perfil cromatográfico) & se \\
\hline Procedimento 1 & $\begin{array}{l}\text { ionização por chamas (nitrogênio:hidrogênio:ar sintético } \\
\qquad(1: 1: 10))\end{array}$ & ionização por chamas & me \\
\hline Procedimento 2 & coluna - $(60 \mathrm{~m} \times 0,25 \mathrm{~mm})+$ filme - polietilenoglicol $(0,25 \mu \mathrm{m})$ & $\begin{array}{c}\text { coluna - sílica fundida }(30-60 \mathrm{~m} \times 0,25 \text { a } 0,53 \mathrm{~mm})+\text { filme } \\
\text { macrogol } 20000(1 \mu \mathrm{m} \text { ou } 0,2 \mu \mathrm{m})\end{array}$ & me \\
\hline Procedimento 3 & injetor $200^{\circ} \mathrm{C}+$ detector $240{ }^{\circ} \mathrm{C}$ & injetor $250^{\circ} \mathrm{C}+$ detector $250^{\circ} \mathrm{C}$ & me \\
\hline Procedimento 4 & $50^{\circ} \mathrm{C}\left(10^{\prime}\right)+50^{\circ} \mathrm{C} \rightarrow 200^{\circ} \mathrm{C}\left(2^{\circ} \mathrm{C} / \mathrm{min}\right)+200^{\circ} \mathrm{C}\left(25^{\prime}\right)$ & $50{ }^{\circ} \mathrm{C}\left(10^{\prime}\right)+50{ }^{\circ} \mathrm{C} \rightarrow 200^{\circ} \mathrm{C}\left(2{ }^{\circ} \mathrm{C} / \mathrm{min}\right)+200^{\circ} \mathrm{C}\left(25^{\prime}\right)$ & se \\
\hline Procedimento 5 & hélio purificado (1 mL/min) & hélio (1 mL/min) & se \\
\hline Procedimento 6 & $\begin{array}{c}0,2 \mathrm{~mL} \text { óleo volátil }+1 \mathrm{~mL} \text { hexano (manter refrigerado + abrigo } \\
\text { da luz) (TS) }\end{array}$ & 0,20 mL óleo volátil + hexano para 10,0 mL (TS) & mi \\
\hline Procedimento 7 & $\begin{array}{c}10 \mathrm{mg} \text { canfeno }+50 \mu \mathrm{L} \text { 1,8-cineol }+50 \mathrm{mg} \text { cânfora }+30 \mathrm{mg} \\
\text { acetato de bornila }+10 \mathrm{mg} \text { borneol }+10 \mathrm{~mL} \text { hexano (manter } \\
\text { refrigerado }+ \text { abrigo da luz) }\left(\mathrm{RS}_{1}\right)\end{array}$ & $\begin{array}{c}20 \mu \mathrm{L} \alpha \text {-pineno }+10 \mathrm{mg} \text { canfeno }+20 \mu \mathrm{L} \beta \text {-pineno }+10 \mu \mathrm{L} \beta \text { - } \\
\text { mirceno }+20 \mu \mathrm{L} \text { limoneno }+50 \mu \mathrm{L} \text { cineol }+10 \mu \mathrm{L} \text {-cimeno }+ \\
50 \mathrm{mg} \text { cânfora }+30 \mathrm{mg} \text { acetato de bornila }+10 \mathrm{mg} \alpha \text {-terpineol }+ \\
10 \mathrm{mg} \text { borneol }+10 \mu \mathrm{L} \text { verbenona }+ \text { hexano para } 10,0 \mathrm{~mL}(\mathrm{RS})\end{array}$ & me \\
\hline
\end{tabular}


Quadro 38 - Comparação entre as monografias de Rosmarinus officinalis L. [sumidade florida; óleo] das farmacopeias FB5, FA7 e USP39-NF34.

\begin{tabular}{|c|c|c|c|}
\hline & FB5 & EP8.8 & Classificação \\
\hline Procedimento 8 & $\begin{array}{c}50 \mu \mathrm{L} \text { 1,8-cineol (eucaliptol) }+30 \mathrm{mg} \text { acetato de bornila }+10 \\
\mathrm{mg} \text { borneol }+10 \mathrm{~mL} \text { hexano }\left(\mathrm{manter}^{2} \text { refrigerado }+ \text { abrigo da }\right. \\
\text { luz) }\left(\mathrm{RS}_{2}\right)\end{array}$ & - & me \\
\hline Procedimento 9 & $1 \mu \mathrm{L}+$ divisão de fluxo (1:50) & $1 \mu \mathrm{L}+$ divisão de fluxo (1:50) & se \\
\hline Procedimento 10 & $\begin{array}{l}\text { tempo de retenção }\left((\mathrm{TS}) \sim\left(\mathrm{RS}_{2}\right) \text { ou a identificação EM }\right)+\text { figura } \\
\quad+\text { pode ocorrer }(\text { acetato de bornila }+ \text { borneol }+\beta \text {-pineno }+\beta \text { - } \\
\text { mirceno + limoneno }+ \text { p-cimeno }+\alpha \text {-terpineol + verbenona })\end{array}$ & $\begin{array}{c}\text { ordem de eluição }(\alpha \text {-pineno }+ \text { canfeno }+\beta \text {-pineno }+\beta \text {-mirceno + } \\
\text { limoneno }+ \text { cineol }+ \text { p-cimeno }+ \text { cânfora }+ \text { acetato de bornila }+ \\
\alpha \text {-terpineol + borneol + verbenona) + tempo de retenção }((\text { TS }) \sim \\
(\mathrm{RS}))+ \text { cromatograma (componentes }(\text { TS }) \sim(\text { RS }))\end{array}$ & me \\
\hline Procedimento 11 & - & $\begin{array}{c}\text { resolução (NLT 1,5 - entre limoneno e cineol + NLT 1,5 - entre } \\
\alpha \text {-terpineol e borneol) }\end{array}$ & me \\
\hline Procedimento 12 & $\begin{aligned} \alpha \text {-pineno (NLT 9\%) }+ & \text { canfeno (NLT 2,5\%) + cineol (NLT 16\%) } \\
& + \text { cânfora (NLT 5\%) }\end{aligned}$ & $\begin{array}{c}\text { tipo espanhol - } \alpha \text {-pineno }(18-26 \%)+\text { canfeno }(8,0-12,0 \%)+\beta- \\
\text { pineno }(2,0-6,0 \%)+\beta \text {-mirceno }(1,5-5,0 \%)+\text { limoneno }(2,5- \\
5,0 \%)+ \text { cineol }(16,0-25,0 \%)+\text { p-cimeno }(1,0-2,2 \%)+\text { cânfora } \\
(13,0-21,0 \%)+\text { acetato de bornila }(0,5-2,5 \%)+\alpha \text {-terpineol }(1,0- \\
3,5 \%)+ \text { borneol }(2,0-4,5 \%)+\text { verbenona }(0,7-2,5 \%) ; \text { tipo } \\
\text { tunisiano - } \alpha \text {-pineno }(9,0-14,0 \%)+\text { canfeno }(2,5-6,0 \%)+\beta- \\
\text { pineno }(4,0-9,0 \%)+\beta-\text {-mirceno }(1,0-2,0 \%)+\text { limoneno }(1,5- \\
4,0 \%)+ \text { cineol }(38,0-55,0 \%)+\text { p-cimeno }(0,8-2,5 \%)+\text { cânfora } \\
(5,0-15,0 \%)+\text { acetato de bornila }(0,1-1,5 \%)+\alpha \text {-terpineol }(1,0- \\
2,6 \%)+ \text { borneol }(1,5-5,0 \%)+\text { verbenona (NMT } 0,4 \%)\end{array}$ & su \\
\hline $\begin{array}{l}\text { Embalagem e } \\
\text { armazenamento }\end{array}$ & 1 & $1^{1}$ & - \\
\hline Rotulagem & - & 1 & - \\
\hline
\end{tabular}

(BRASIL, 2010d; EDQM, 2016b).

Legenda: $\mathrm{mi}=$ menor; $\mathrm{me}=$ moderado; $\mathrm{su}=$ substancial; $\mathrm{se}=$ semelhante $; \mathrm{NLT}=$ não menos que; $\mathrm{MNT}=$ não mais que; $\mathrm{CCD}=$ cromatografia em camada delgada; $\mathrm{RS}=$ solução referência; $\mathrm{TS}=$ solução amostra; $\mathrm{SR}=$ solução reagente; $\mathrm{CG}=$ cromatografia gasosa; $\mathrm{EM}=$ espectrometria de massas.

Nota: ${ }^{1}=$ apenas armazenamento. 
No geral, as monografias possuem propostas de ensaios e testes semelhantes.

As diferenças substanciais se concentram na diferença da especificação do poder rotatório e nas especificações adicionais de marcadores no perfil cromatográfico por cromatografia gasosa.

Diferenças substanciais nas especificações como as encontradas, podem ocasionar barreiras sanitárias ao comércio internacional de matérias-primas e produtos acabados.

Como espécie que não possui ocorrência no Brasil, a origem da matéria-prima não é nacional. Assim, se esperava que os métodos e especificações fossem mais harmonizados, porém, nesse caso, a espécie não possui registros válidos junto à Anvisa, nem está listada em outros compêndios e nem na lista de registro simplificado. Isso pode indicar que há baixa utilização da monografia no Brasil e, pode, eventualmente, explicar, o porquê de a monografia não ser tão harmonizada quanto o esperado.

\subsubsection{Sambucus nigra L. [flor]}

O sabugueiro nunca esteve presente em edições anteriores da Farmacopeia Brasileira (Quadro 3), está contemplado no FFFB1, na Lista de Produtos Tradicionais de Registro Simplificado da IN no 02/2014 (BRASIL, 2011, 2014a) e na FB5. Não foram encontrados, para a espécie, registros de fitoterápicos válidos na Anvisa (Quadro 5). Conforme a literatura consultada a espécie possui ocorrência no Brasil (Apêndice A), sendo cultivada e não endêmica (REFLORA, 2016). Há, ainda, registro de ocorrência da espécie na Bolívia, Chile, China, Equador, México e Estados Unidos da América (TROPICOS.ORG, 2016). Em buscas realizadas nos compêndios internacionais em estudo, foi localizada monografia apenas na EP8.8. Os dados extraídos das monografias estão descritos no Quadro 39. 
Quadro 39 - Comparação entre as monografias de Sambucus nigra L. [flor] das farmacopeias FB5 e EP8.8.

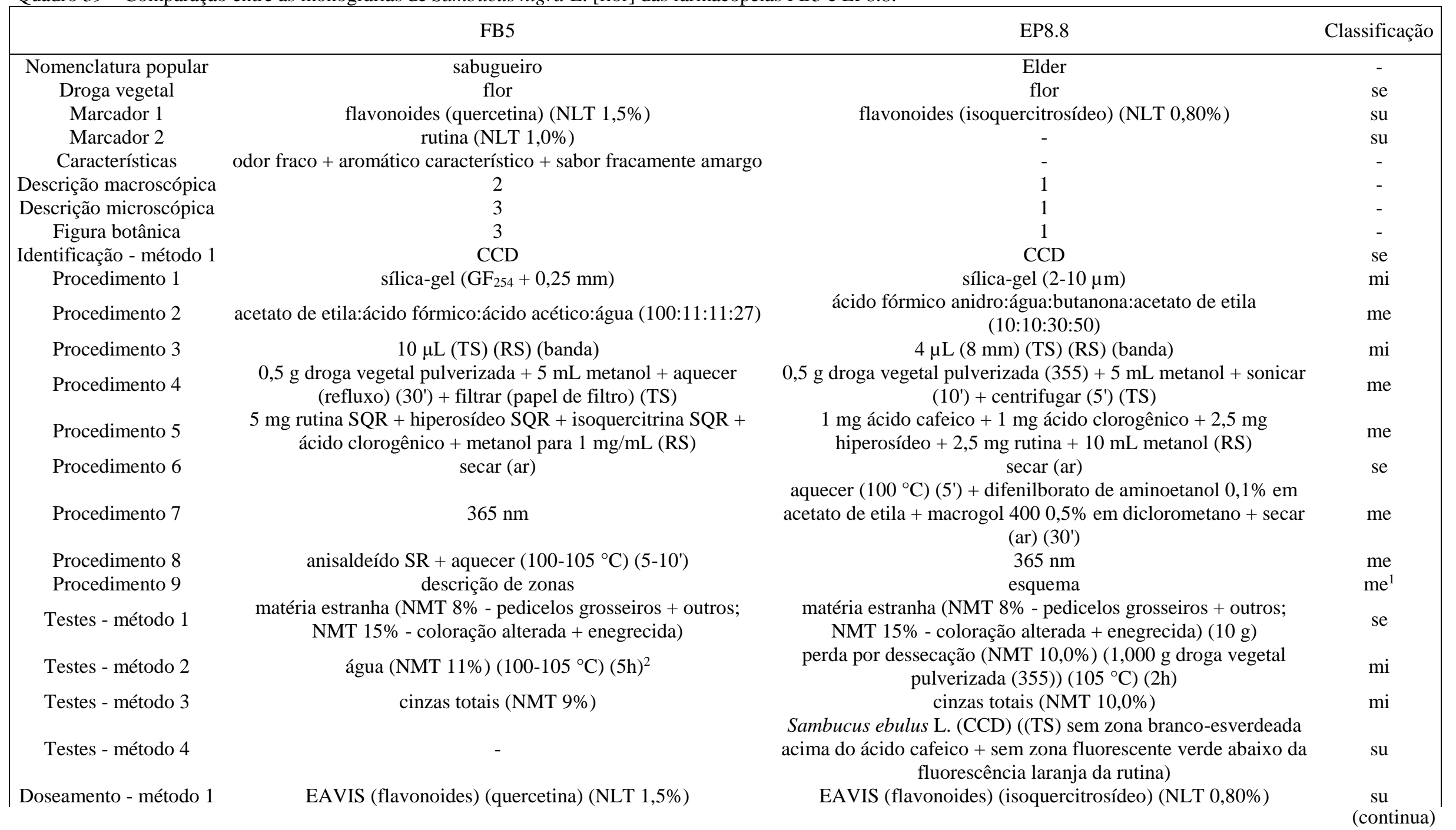


Quadro 39 - Comparação entre as monografias de Sambucus nigra L. [flor] das farmacopeias FB5 e EP8.8.

\begin{tabular}{|c|c|c|c|}
\hline & FB5 & EP8.8 & Classificação \\
\hline Procedimento 1 & $\begin{array}{l}0,1 \mathrm{~g} \text { droga vegetal pulverizada }(800)+0,25 \mathrm{~mL} \text { metenamina } \\
0,5 \%+10 \mathrm{~mL} \text { acetona }+0,5 \mathrm{~mL} \text { ácido clorídrico }+ \text { aquecer } \\
\text { (banho-maria) (refluxo) }(30 \text { ') + filtrar (algodão) }+ \text { retomar } \\
\text { (resíduo }+ \text { algodão }+7 \mathrm{~mL} \text { acetona }+ \text { aquecer }(\text { refluxo })\left(10^{\prime}\right)+ \\
\text { filtrar (algodão) }+ \text { repetir } 1 \mathrm{x}+\text { reunir }(\text { extratos })+\text { esfriar } \\
\text { (ambiente) }+ \text { acetona para } 25 \mathrm{~mL}+\text { transferir } 10 \mathrm{~mL}+10 \mathrm{~mL} \\
\text { água }+ \text { extrair com } 10 \mathrm{~mL} \text { acetato de etila }+ \text { repetir } 2 \times \text { com } 6 \mathrm{~mL} \\
\text { acetato etila + reunir (fases acetato de etila) + lavar (fase acetato } \\
\text { de etila) } 2 \times 15 \mathrm{~mL} \text { água + acetato de etila para } 25 \mathrm{~mL}(\mathrm{TS})\end{array}$ & 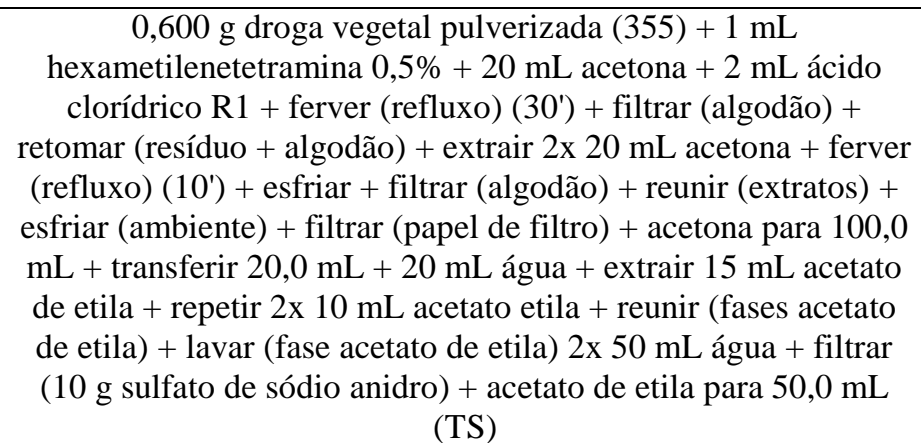 & $\mathrm{mi}$ \\
\hline Procedimento 2 & $\begin{array}{l}10 \mathrm{~mL}(\mathrm{TS})+1 \mathrm{~mL} \text { cloreto de alumínio } 2 \% \text { em metanol + ácido } \\
\text { acético } 5 \% \text { em metanol para } 25 \mathrm{~mL}+\text { descansar }\left(30^{\prime}\right)\end{array}$ & $\begin{array}{c}10,0 \mathrm{~mL}(\mathrm{TS})+1 \mathrm{~mL} \text { cloreto de alumínio } 2 \% \text { em ácido acético } \\
\text { glacial } 5 \% \text { em metanol + ácido acético glacial } 5 \% \text { em metanol } \\
\text { para } 25,0 \mathrm{~mL}+\text { descansar }(30 \text { ') }\end{array}$ & $\mathrm{mi}$ \\
\hline Procedimento 3 & $\begin{array}{c}10 \mathrm{~mL}(\mathrm{TS})+\text { ácido acético 5\% em metanol para } 25 \mathrm{~mL}+ \\
\text { descansar (30') (BS) }\end{array}$ & $\begin{array}{c}10,0 \mathrm{~mL}(\mathrm{TS})+\text { ácido acético glacial 5\% em metanol para 25,0 } \\
\mathrm{mL}+\text { descansar }\left(30^{\prime}\right)(\mathrm{BS})\end{array}$ & se \\
\hline Procedimento 4 & $425 \mathrm{~nm}$ & $425 \mathrm{~nm}$ & se \\
\hline Procedimento 5 & $\mathrm{Q}=\frac{\mathrm{A} \times 15625}{500 \times m \times(100-\mathrm{Pd})}$ & $\frac{\mathrm{A} \times 1,25}{m}$ & me \\
\hline Doseamento - método 2 & CALE-UV (rutina) (NLT 1,0\%) & - & $\mathrm{su}$ \\
\hline Procedimento 1 & $356 \mathrm{~nm}$ & - & $\mathrm{su}$ \\
\hline Procedimento 2 & $\begin{array}{l}\text { pré-coluna octadecilsilanizada }(3-10 \mu \mathrm{m})+\text { ODS }(150 \mathrm{~mm} \times 3,9 \\
\mathrm{mm})(4 \mu \mathrm{m})\end{array}$ & - & su \\
\hline Procedimento 3 & $\begin{array}{c}(0,7 \mathrm{~mL} / \mathrm{min})+\text { acetonitrila:água:ácido trifluoracético } \\
(5: 95: 0,01) 90 \% \text { em acetonitrila:ácido trifluoracético }(100: 0,01) \\
\rightarrow \text { acetonitrila:água:ácido trifluoracético }(5: 95: 0,01) 70 \% \mathrm{em} \\
\left.\text { acetonitrila:ácido trifluoracético }(100: 0,01)(7)^{\prime}\right)+ \\
\text { acetonitrila:água:ácido trifluoracético }(5: 95: 0,01) 70 \% \mathrm{em} \\
\text { acetonitrila:ácido trifluoracético }(100: 0,01) \rightarrow \text { acetonitrila:ácido } \\
\text { trifluoracético }(100: 0,01)\left(1^{\prime}\right)+\text { acetonitrila:ácido trifluoracético } \\
(100: 0,01)\left(3^{\prime}\right)+\text { acetonitrila:ácido trifluoracético }(100: 0,01) \rightarrow \\
\text { acetonitrila:água:ácido trifluoracético }(5: 95: 0,01) 90 \% \mathrm{em} \\
\left.\text { acetonitrila:ácido trifluoracético }(100: 0,01)(1)^{\prime}\right)+ \\
\text { acetonitrila:água:ácido trifluoracético }(5: 95: 0,01) 90 \% \mathrm{em} \\
\text { acetonitrila:ácido trifluoracético }(100: 0,01)\left(6^{\prime}\right)\end{array}$ & - & su \\
\hline
\end{tabular}


Quadro 39 - Comparação entre as monografias de Sambucus nigra L. [flor] das farmacopeias FB5 e EP8.8.

FB5

\begin{tabular}{|c|c|c|c|}
\hline & FB5 & EP8.8 & Classificação \\
\hline Procedimento 4 & $\begin{array}{c}0,25 \mathrm{~g} \text { droga vegetal pulverizada }(800)+5 \mathrm{~mL} \text { etanol } 80 \%+ \\
\text { agitar (turbólise) }\left(5^{\prime}\right)+\text { filtrar (papel de filtro) (pressão reduzida) } \\
+ \text { etanol } 80 \% \text { para } 5 \mathrm{~mL}+\text { filtrar (membrana) }+ \text { transferir } 50 \mu \mathrm{L} \\
+950 \mu \mathrm{L} \text { acetonitrila:água }(1: 9)(\mathrm{TS})\end{array}$ & - & $\mathrm{su}$ \\
\hline Procedimento 5 & $5 \mathrm{mg}$ rutina $\mathrm{SQR}+10 \mathrm{~mL}$ metanol $(\mathrm{RS})$ & - & $\mathrm{su}$ \\
\hline Procedimento 6 & $\begin{array}{c}10 \mu \mathrm{g} / \mathrm{mL} ; 15 \mu \mathrm{g} / \mathrm{mL} ; 20 \mu \mathrm{g} / \mathrm{mL} ; 25 \mu \mathrm{g} / \mathrm{mL} ; 30 \mu \mathrm{g} / \mathrm{mL} ; 35 \\
\mu \mathrm{g} / \mathrm{mL} ; 40 \mu \mathrm{g} / \mathrm{mL} ; 45 \mu \mathrm{g} / \mathrm{mL} ; 50 \mu \mathrm{g} / \mathrm{mL} \text { rutina em metanol }\end{array}$ & - & $\mathrm{su}$ \\
\hline Procedimento 7 & $\begin{array}{c}10 \mu \mathrm{L} \\
\text { tempos de retenção }\left(\left(5^{\prime}\right) \text { - rutina) + pico (majoritário - rutina + }\right.\end{array}$ & - & su \\
\hline Procedimento 8 & $\begin{array}{l}\text { tempo de retenção inferior - ácido cafeoilquímico + } 4 \text { tempo de } \\
\text { retenção superior ( } 2 \text { primeiros espectro semelhante rutina }+2 \\
\text { outros espectro semelhante ácido cafeoilquímico) }\end{array}$ & - & $\mathrm{su}$ \\
\hline Procedimento 9 & curva analítica & - & su \\
\hline $\begin{array}{l}\text { Embalagem e } \\
\text { armazenamento }\end{array}$ & 1 & - & - \\
\hline Padrões de referência & rutina $\mathrm{SQR}$ + hiperosídeo $\mathrm{SQR}+$ isoquercitrina $\mathrm{SQR}$ & - & - \\
\hline
\end{tabular}

\section{(BRASIL, 2010c, d; EDQM, 2016b).}

Legenda: mi = menor; me = moderado; $\mathrm{su}=$ substancial; se = semelhante NLT = não menos que $;$ MNT = não mais que CCD = cromatografia em camada delgada; RS = solução referência; TS = solução amostra; BS = solução branco; SR = solução reagente; SQR = substância química de referência; EAVIS = espectrofotometria de absorção no visível; $\mathrm{A}=$ absorvância; $m=$ massa; $\mathrm{Pd}=$ perda por dessecação; $\mathrm{Q}=$ quercetina; CLAE-UV = cromatografia liquida de alta eficiência acoplada a detector por espectrofotometria por absorção no ultravioleta; ODS = coluna cromatográfica octadecilsilanizada.

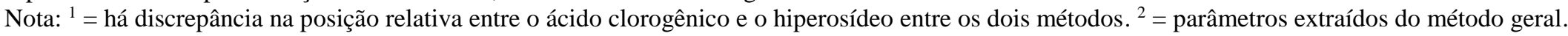


No geral, as monografias não são convergentes. As diferenças substanciais estão concentradas nos ensaios e testes adicionais da FB5 (doseamento e especificação para rutina) e da EP8.8 (testes para o Sambucus ebulus L.)

Há, ainda, diferença no ensaio da CCD na descrição das posições das substâncias de referência na cromatoplaca, enquanto a FB5 relata que o ácido clorogênico está próximo da linha de frente do solvente e que o hiperosídeo possui fator de retenção (Rf) de 0,68 (portanto abaixo do ácido clorogênico) a EP8.8 relata que o hiperosídeo possui Rf superior ao do ácido clorogênico. Pelo caráter de inversão, foi considerado um erro. O erro foi corrigido na proposta de revisão da monografia na $\mathrm{CP}^{\circ}$ 241/2016 (BRASIL, 2016c).

Como a espécie possui ocorrência no Brasil e em outros países, está listada no FFFB1 e na $\mathrm{IN} \mathrm{n}^{\circ}$ 02/2014, e possui monografia na FB5, se esperava que houvesse registros válidos no Brasil, porém, nesse caso, os resultados não acompanharam a expectativa.

\subsubsection{Senna alexandrina Mill. [folíolo]}

O sene esteve presente em todas as edições anteriores da Farmacopeia Brasileira, (Quadro 3), contudo, não está relacionada no FFFB1 (BRASIL, 2011), estando na Lista de Medicamentos Fitoterápicos de Registro Simplificado da IN nº 02/2014 (BRASIL, 2014a) e na FB5. Foram encontrados, para a espécie, 19 (dezenove) registros de fitoterápicos válidos na Anvisa (Quadro 5), sendo a quarta das espécies da Farmacopeia Brasileira com maior número de registros válidos, o que pode ser justificado, ao menos em parte, pela possibilidade de registro simplificado e pela existência de monografia na FB5 para a espécie. Conforme a literatura consultada, a espécie possui ocorrência no Brasil (Apêndice A). Há, ainda, registro de ocorrência da espécie no Caribe, Equador, Índia e México (TROPICOS.ORG, 2016). Em buscas realizadas nos compêndios internacionais em estudo, foram localizadas monografias na EP8.8, na FA7 e na USP39-NF34. Os dados extraídos das monografias estão descritos no Quadro 40. 
Quadro 40 - Comparação entre as monografias de Senna alexandrina Mill. [folíolo] das farmacopeias FB5, EP8.8, FA7 e USP39-NF34.

\begin{tabular}{|c|c|c|c|c|c|}
\hline & FB5 & EP8.8 & FA7 & USP39-NF34 & Classificação \\
\hline Nomenclatura botânica & Senna alexandrina Mill. & $\begin{array}{l}\text { Cassia senna L. e Cassia } \\
\text { angustifolia Vahl }\end{array}$ & Senna alexandrina Mill. & Senna alexandrina Mill. & - \\
\hline Sinonímia botânica & - & $\begin{array}{c}\text { Cassia senna L. (syn. Cassia } \\
\text { acutifolia Delile) }\end{array}$ & $\begin{array}{l}\text { Senna alexandrina Mill. (syn. } \\
\text { Cassia acutifolia Del., Cassia } \\
\quad \text { angustifolia Vahl) }\end{array}$ & $\begin{array}{c}\text { Senna alexandrina Mill. (syn. } \\
\text { Cassia acutifolia Delile, } \\
\text { Cassia angustifolia Vahl) }\end{array}$ & - \\
\hline Nomenclatura popular & sene & senna & sen & senna & - \\
\hline Droga vegetal & folíolo & folíolo & folíolo & folíolo & se \\
\hline Marcador 1 & $\begin{array}{l}\text { derivados hidroxiantracênicos } \\
\text { (senosídeo B) (NLT 2,5\%) } \\
\text { (droga seca) }\end{array}$ & $\begin{array}{c}\text { glicosídeos } \\
\text { hidroxiantracênicos (senosídeo } \\
\text { B) (NLT 2,5\%) (droga seca) }\end{array}$ & $\begin{array}{c}\text { glicosídeos } \\
\text { hidroxiantracênicos (senosídeo } \\
\text { B) (NLT 2,5\%) (droga seca) }\end{array}$ & $\begin{array}{c}\text { glicosídeos antraquinônicos } \\
\text { (senosídeo) (NLT 2,5\%) } \\
\text { (droga seca) }\end{array}$ & se \\
\hline Marcador 2 & senosídeo B $(0,6 \%)$ & - & - & - & su \\
\hline Marcador 3 & senosídeo A $(0,5 \%)$ & - & - & - & su \\
\hline Características & $\begin{array}{l}\text { odor peculiar }+ \text { sabor amargo }+ \\
\text { adstringente }\end{array}$ & - & - & - & - \\
\hline Descrição macroscópica & 2 & 1 & 1 & 3 & - \\
\hline Descrição microscópica & 3 & 1 & 2 & 2 & - \\
\hline Figura botânica & 2 & 1 & 1 & - & - \\
\hline Identificação - método 1 & CCD & CCD & CCD & - & se \\
\hline Procedimento 1 & sílica-gel $\left(\mathrm{GF}_{254}+0,25 \mathrm{~mm}\right)$ & sílica-gel & $\begin{array}{c}\text { sílica-gel (fluorescência }+0,25 \\
\mathrm{~mm})\end{array}$ & - & $\mathrm{mi}$ \\
\hline Procedimento 2 & $\begin{array}{l}\text { acetato de } \\
\text { etila:propanol:água:ácido } \\
\text { acético glacial (40:40:30:1) }\end{array}$ & $\begin{array}{c}\text { ácido acético } \\
\text { glacial:água:acetato de } \\
\text { etila:propanol }(1: 30: 40: 40)\end{array}$ & $\begin{array}{c}\text { acetato de } \\
\text { etila:propanol:água:ácido } \\
\text { acético glacial (40:40:30:1) }\end{array}$ & - & se \\
\hline Procedimento 3 & $10 \mu \mathrm{L}$ (TS) (RS) (banda) & $\begin{array}{c}10 \mu \mathrm{L} \text { (TS) (RS) }(20 \mathrm{~mm}) \\
\text { (banda) }\end{array}$ & $\begin{array}{c}10 \mu \mathrm{L}(\mathrm{TS})(\mathrm{RS})(20 \times 2 \mathrm{~mm}) \\
\text { (banda) }\end{array}$ & - & $\mathrm{mi}$ \\
\hline Procedimento 4 & $\begin{array}{c}\text { 0,5 g droga vegetal pulverizada } \\
+5 \text { mL etanol:água }(1: 1)+ \\
\text { aquecer (ebulição) + filtrar } \\
(\text { TS })\end{array}$ & $\begin{array}{c}\text { 0,5 g droga vegetal pulverizada } \\
(180)+5 \mathrm{~mL} \text { etanol } 96 \% \text { :água } \\
\text { (1:1) + ferver + centrifugar } \\
\text { (usar sobrenadante) (TS) }\end{array}$ & $\begin{array}{c}\text { 0,5 g droga vegetal pulverizada } \\
+5 \mathrm{~mL} \text { etanol:água }(1: 1)+ \\
\text { ferver + centrifugar (usar } \\
\text { sobrenadante) }(\mathrm{TS})\end{array}$ & - & mi \\
\hline Procedimento 5 & $\begin{array}{c}\text { 2,5 mg senosídeo A + 2,5 mg } \\
\text { senosídeo B + } 1 \mathrm{~mL} \text { metanol + } \\
1 \mathrm{~mL} \text { água }(\mathrm{RS})\end{array}$ & $\begin{array}{c}10 \text { mg extrato de sene } \mathrm{SQR}+1 \\
\text { mL etanol } 96 \% \text { :água }(1: 1) \\
(\mathrm{RS})\end{array}$ & $\begin{array}{l}10 \text { mg extrato sene } S Q R+1 \\
\text { mL etanol:água }(1: 1)(R S)\end{array}$ & - & me \\
\hline Procedimento 6 & secar (ar) & secar (ar) & secar (ar) & - & $\begin{array}{l}\text { se } \\
\text { (continua) }\end{array}$ \\
\hline
\end{tabular}


Quadro 40 - Comparação entre as monografias de Senna alexandrina Mill. [folíolo] das farmacopeias FB5, EP8.8, FA7 e USP39-NF34.

\begin{tabular}{|c|c|c|c|c|c|}
\hline & FB5 & EP8.8 & FA7 & USP39-NF34 & Classificação \\
\hline Procedimento 7 & $\begin{array}{c}\text { ácido nítrico } 25 \%+\text { aquecer } \\
\left(120^{\circ} \mathrm{C}\right)\left(10^{\prime}\right)+\text { hidróxido de } \\
\text { potássio } 5 \%\end{array}$ & $\begin{array}{c}\text { ácido nítrico } 20 \%+\text { aquecer } \\
\left(120^{\circ} \mathrm{C}\right)\left(10^{\prime}\right)+\text { esfriar }+ \\
\text { hidróxido de potássio } 5 \% \text { em } \\
\text { etanol } 50 \%\end{array}$ & $\begin{array}{l}\text { ácido nítrico } 20 \%+\text { aquecer } \\
\left(120^{\circ} \mathrm{C}\right)\left(10^{\prime}\right)+\text { esfriar }+ \\
\text { hidróxido de potássio } 5 \% \text { em } \\
\text { etanol } 50 \%\end{array}$ & - & mi \\
\hline Procedimento 8 & descrição de zonas & descrição de zonas & descrição de zonas & - & me \\
\hline Identificação - método 2 & $\begin{array}{c}25 \mathrm{mg} \text { droga vegetal } \\
\text { pulverizada }(180)+50 \mathrm{~mL} \\
\text { água }+5 \mathrm{~mL} \text { ácido nítrico }+ \\
\text { aquecer (banho-maria) }(15 ')+ \\
\text { esfriar }+40 \mathrm{~mL} \text { éter etílico + } \\
\text { agitar + secar (fase etérea) } \\
\text { (sulfato de sódio anidro) + } \\
\text { transferir } 5 \mathrm{~mL}+\text { evaporar } \\
\text { (resíduo) (banho-maria) }+ \\
\text { esfriar + alcalinizar (hidróxido } \\
\text { de amônio) }=\text { coloração } \\
\text { avermelhada }\end{array}$ & $\begin{array}{c}25 \mathrm{mg} \text { droga vegetal } \\
\text { pulverizada }(180)+50 \mathrm{~mL} \\
\text { água }+2 \mathrm{~mL} \text { ácido clorídrico }+ \\
\text { aquecer (banho-maria) }\left(15^{\prime}\right)+ \\
\text { esfriar }+40 \mathrm{~mL} \text { éter etílico + } \\
\text { agitar }+ \text { secar (fase etérea) } \\
\text { (sulfato de sódio anidro })+ \\
\text { transferir } 5 \mathrm{~mL}+\text { evaporar } \\
\text { (resíduo) + esfriar + } 5 \mathrm{~mL} \\
\text { amônia diluída = coloração } \\
\text { amarela + aquecer (banho- } \\
\text { maria) }(2 ')=\text { coloração violeta- } \\
\text { avermelhada }\end{array}$ & $\begin{array}{c}25 \mathrm{mg} \text { droga vegetal } \\
\text { pulverizada }+50 \mathrm{~mL} \text { água }+2 \\
\text { mL ácido clorídrico + aquecer } \\
\text { (banho-maria) }\left(15^{\prime}\right)+\text { esfriar + } \\
40 \text { mL éter etílico + agitar + } \\
\text { secar (fase etérea) (sulfato de } \\
\text { sódio anidro) + transferir } 5 \mathrm{~mL} \\
+ \text { evaporar (resíduo) + esfriar } \\
+5 \text { mL amoníaco diluído = } \\
\text { coloração amarelo-alaranjada } \\
+ \text { aquecer (banho-maria) }(2 ')= \\
\text { coloração vermelha-violeta }\end{array}$ & - & mi \\
\hline Identificação - método 3 & $\begin{array}{c}\text { microssublimação = gotículas } \\
\text { amarelas }+ \text { aguardar = aspecto } \\
\text { cristalino }+ \text { hidróxido de } \\
\text { potássio } 5 \% \text { em etanol = } \\
\text { coloração róseo-avermelhada }\end{array}$ & - & - & - & su \\
\hline Identificação - método 4 & - & - & $\begin{array}{c}500 \mathrm{mg} \text { droga vegetal }+10 \mathrm{~mL} \\
\text { hidróxido de potássio:etanol } \\
(1: 10)+\text { ferver }(2 \text { ) + água para } \\
10 \mathrm{~mL}+\text { filtrar + acidificar } \\
\text { (ácido clorídrico) + agitar com } \\
\text { éter + separar (fase etérea) + } 5 \\
\text { mL hidróxido de amônio } 6 \mathrm{~N}+ \\
\text { agitar = coloração vermelho- } \\
\text { alaranjado }\end{array}$ & $\begin{array}{c}500 \mathrm{mg} \text { droga vegetal } \\
\text { finamente pulverizada }+10 \\
\mathrm{~mL} \text { hidróxido de potássio } 10 \% \\
\text { em etanol + ferver }(2 ')+\text { água } \\
\text { para } 10 \mathrm{~mL}+\text { filtrar + } \\
\text { acidificar (ácido clorídrico) + } \\
\text { agitar com éter etílico + } \\
\text { separar (fase etérea) }+5 \mathrm{~mL} \\
\text { hidróxido de amônio } 6 \mathrm{~N}+ \\
\text { agitar = coloração laranja } \\
\text { vermelho-azulado }\end{array}$ & su \\
\hline
\end{tabular}


Quadro 40 - Comparação entre as monografias de Senna alexandrina Mill. [folíolo] das farmacopeias FB5, EP8.8, FA7 e USP39-NF34.

\begin{tabular}{|c|c|c|c|c|c|}
\hline & FB5 & EP8.8 & FA7 & USP39-NF34 & Classificação \\
\hline Testes - método 1 & $\begin{array}{c}\text { matéria estranha (NMT 2,0\% - } \\
\text { raques foliares) }\end{array}$ & $\begin{array}{c}\text { matéria estranha (NMT 3\% - } \\
\text { órgãos estranhos) (NMT 1\% - } \\
\text { elementos estranhos) }\end{array}$ & $\begin{array}{l}\text { matéria estranha (NMT 3\% - } \\
\text { órgãos estranhos) (NMT 1\% - } \\
\text { elementos estranhos) (outras } \\
\text { matérias estranhas (NMT 8,0\% } \\
\text { - raízes de sene) (NMT 2,0\% - } \\
\text { bainhas e outras) }\end{array}$ & $\begin{array}{c}\text { matéria estranha (NMT 8,0\% - } \\
\text { caules) (NMT 2,0\% vagem + } \\
\text { outros) }\end{array}$ & $\mathrm{su}$ \\
\hline Testes - método 2 & $\begin{array}{c}\text { água (NMT 10,0\%) }(100-105 \\
\left.{ }^{\circ} \mathrm{C}\right)(5 \mathrm{~h})^{1}\end{array}$ & $\begin{array}{c}\text { perda por dessecação (NMT } \\
12,0 \%)(1,000 \text { g droga vegetal } \\
\text { pulverizada }(355))\left(105^{\circ} \mathrm{C}\right) \\
(2 \mathrm{~h})\end{array}$ & $\begin{array}{c}\text { perda por dessecação (NMT } \\
12,0 \%)(1,000 \mathrm{~g} \text { droga vegetal } \\
\text { pulverizada) }\left(100-105^{\circ} \mathrm{C}\right)(2 \mathrm{~h})\end{array}$ & $\begin{array}{l}\text { perda por dessecação (NMT } \\
12,0 \%)(1,0 \text { g droga vegetal } \\
\text { finamente pulverizada) }(105 \\
\left.{ }^{\circ} \mathrm{C}\right)(2 \mathrm{~h})\end{array}$ & me \\
\hline Testes - método 3 & cinzas totais (NMT $12,0 \%$ ) & cinzas totais (NMT 12,0\%) & cinzas totais (NMT $12,0 \%$ ) & cinzas totais (NMT 12,0\%) & se \\
\hline Testes - método 4 & - & $\begin{array}{l}\text { cinzas insolúveis em ácido } \\
\text { clorídrico (NMT 2,5\%) }\end{array}$ & $\begin{array}{l}\text { cinzas insolúveis em ácido } \\
\text { (NMT 3,0\%) }\end{array}$ & $\begin{array}{l}\text { cinzas insolúveis em ácido } \\
\text { (NMT 3,0\%) }\end{array}$ & $\mathrm{su}$ \\
\hline Testes - método 5 & - & 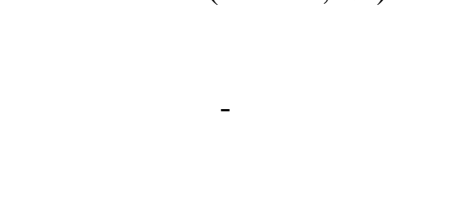 & - & $\begin{array}{l}\text { microrganismos (TAMC - } \\
\text { NMT } 10^{5} \mathrm{UFC/g}+\text { TYMC - } \\
\text { NMT } 10^{3} \mathrm{UFC/g}+\text { TBMC - } \\
\text { NMT } 10^{3} \mathrm{UFC} / \mathrm{g}+\text { ausência } \\
\text { Salmonella e Escherichia coli) }\end{array}$ & - \\
\hline Doseamento - método 1 & $\begin{array}{c}\text { EAVIS (derivados } \\
\text { hidroxiantracênicos) } \\
\text { (senosídeo B) (NLT 2,5\%) }\end{array}$ & $\begin{array}{c}\text { EAVIS (glicosídeos } \\
\text { hidroxiantracênicos) } \\
\text { (senosídeo B) (NLT 2,5\%) }\end{array}$ & $\begin{array}{c}\text { EAVIS (glicosídeos } \\
\text { hidroxiantracênicos) } \\
\text { (senosídeo B) (NLT 2,5\%) }\end{array}$ & $\begin{array}{c}\text { EAVIS (glicosídeos } \\
\text { antraquinônicos) (senosídeo) } \\
\text { (NLT } 2,5 \%)\end{array}$ & se \\
\hline Procedimento 1 & - & proteger luz intensa & proteger luz intensa & proteger luz intensa & me \\
\hline Procedimento 2 & $\begin{array}{c}0,15 \text { g droga vegetal } \\
\text { pulverizada }(180)+30 \mathrm{~mL} \\
\text { água + pesar + aquecer } \\
\text { (refluxo) (manta) }\left(15^{\prime}\right)+ \\
\text { esfriar + pesar + água até peso } \\
\text { inicial + filtrar (desprezar } \\
\text { primeiros } 10 \mathrm{~mL})+ \text { transferir } \\
10 \mathrm{~mL}+1 \text { gota ácido } \\
\text { clorídrico } 2 M+\text { lavar } 3 \times 5 \mathrm{~mL} \\
\text { clorofórmio + desprezar (fase } \\
\text { clorofórmica) + centrifugar } \\
\text { (fase aquosa) (2000 rpm) }\left(10^{\prime}\right) \\
\text { (usar sobrenadante) }(\mathrm{TS})\end{array}$ & $\begin{array}{c}0,150 \text { g droga vegetal } \\
\text { pulverizada }(180)+30,0 \mathrm{~mL} \\
\text { água + pesar + aquecer } \\
\text { (refluxo) (banho-maria) }\left(15^{\prime}\right)+ \\
\text { esfriar + pesar + água até peso } \\
\text { inicial + centrifugar (usar } \\
\text { sobrenadante) + transferir } 20,0 \\
\mathrm{~mL}+0,1 \mathrm{~mL} \text { ácido clorídrico } \\
\text { diluído + agitar } 3 \times 15 \mathrm{~mL} \\
\text { clorofórmio + desprezar (fase } \\
\text { clorofórmica) + } 0,10 \mathrm{~g} \\
\text { bicarbonato de sódio + agitar }\end{array}$ & $\begin{array}{c}150 \mathrm{mg} \text { droga vegetal } \\
\text { pulverizada }+30 \mathrm{~mL} \text { água }+ \\
\text { pesar + aquecer (refluxo) } \\
\text { (banho-maria) }\left(15^{\prime}\right)+\text { esfriar + } \\
\text { pesar + água até peso inicial + } \\
\text { centrifugar (usar sobrenadante) } \\
+ \text { transferir } 20,0 \mathrm{~mL}+0,1 \mathrm{~mL} \\
\text { ácido clorídrico diluído } 10 \%+ \\
\text { agitar } 3 x 15 \mathrm{~mL} \text { clorofórmio + } \\
\text { desprezar (fase clorofórmica) + } \\
100 \mathrm{mg} \text { bicarbonato de sódio + } \\
\text { agitar (3') + centrifugar (usar } \\
\text { sobrenadante) (TS) }\end{array}$ & $\begin{array}{c}0,15 \mathrm{~g} \text { droga vegetal } \\
\text { pulverizada }+30,0 \text { mL água }+ \\
\text { pesar }+ \text { aquecer (refluxo) } \\
\text { (banho-maria) }\left(15^{\prime}\right)+\text { esfriar }+ \\
\text { pesar + água até peso inicial + } \\
\text { centrifugar (usar sobrenadante) } \\
+ \text { transferir } 20,0 \mathrm{~mL}+0,1 \mathrm{~mL} \\
\text { ácido clorídrico diluído + } \\
\text { agitar 3x } 15 \mathrm{~mL} \text { clorofórmio + } \\
\text { desprezar (fase clorofórmica) + } \\
\text { 0,10 g bicarbonato de sódio + } \\
\text { agitar (3') + centrifugar (usar } \\
\text { sobrenadante) (TS) }\end{array}$ & me \\
\hline
\end{tabular}


Quadro 40 - Comparação entre as monografias de Senna alexandrina Mill. [folíolo] das farmacopeias FB5, EP8.8, FA7 e USP39-NF34.

\begin{tabular}{|c|c|c|c|c|c|}
\hline & FB5 & EP8.8 & FA7 & USP39-NF34 & Classificação \\
\hline & & $\begin{array}{l}\left(3^{\prime}\right)+\text { centrifugar (usar } \\
\text { sobrenadante) }(\mathrm{TS})\end{array}$ & & & \\
\hline Procedimento 3 & - & - & - & $\begin{array}{c}\text { senosídeo SQR 0,13 mg/mL } \\
\text { em bicarbonato de sódio } 5 \\
\text { mg/mL (RS) }\end{array}$ & me \\
\hline Procedimento 4 & metanol (BS) & metanol (BS) & metanol (BS) & metanol (BS) & se \\
\hline Procedimento 5 & $\begin{array}{c}\text { transferir } 4 \mathrm{~mL}(\mathrm{TS})+\text { ajustar } \\
\text { pH } 7,0-8,0(80 \mu \mathrm{L} \text { carbonato } \\
\text { de sódio } 5 \%)+8 \mathrm{~mL} \text { cloreto } \\
\text { férrico } 10,5 \%+\text { aquecer } \\
\left.\text { (refluxo) (banho-maria) }(20)^{\prime}\right)+ \\
0,4 \text { mL ácido clorídrico } \\
\text { concentrado + aquecer }(20 ') \\
\text { (agitar frequentemente) + } \\
\text { esfriar + extrair } 1 \times 10 \mathrm{~mL} \text { éter } \\
\text { etílico (líquido de lavagem) })+ \\
\text { 2x } 7 \text { mL éter etílico (líquido de } \\
\text { lavagem) + reunir (fases } \\
\text { etéreas) + lavar } 2 \times 10 \text { mL água } \\
\text { + éter etílico para } 25 \mathrm{~mL}+ \\
\text { transferir } 5 \text { mL }+ \text { evaporar } \\
\text { (resíduo) (banho-maria) }+5 \\
\text { mL acetato de magnésio } 0,5 \% \\
\text { em metanol }\end{array}$ & $\begin{array}{l}\text { transferir } 10,0 \mathrm{~mL}(\mathrm{TS})+20 \\
\text { mL solução de cloreto férrico } \\
\mathrm{R} 1+\text { aquecer (refluxo) (banho- } \\
\text { maria) }(20 \text { ') + } 3 \mathrm{~mL} \text { ácido } \\
\text { clorídrico + aquecer }\left(20{ }^{\prime}\right) \\
\text { (agitar frequentemente) + } \\
\text { esfriar + agitar } 3 \times 25 \mathrm{~mL} \text { éter } \\
\text { etílico (líquido de lavagem) + } \\
\text { reunir (fases etéreas) + lavar } \\
2 \times 15 \mathrm{~mL} \text { água + reunir (fases } \\
\text { etéreas) + éter etílico para } \\
\text { 100,0 mL + transferir } 10,0 \mathrm{~mL} \\
+ \text { evaporar (resíduo) } \\
\text { (cuidadosamente) + 10,0 mL } \\
\text { acetato de magnésio a } 0,5 \% \\
\text { em metanol }\end{array}$ & $\begin{array}{c}\text { transferir } 10,0 \mathrm{~mL}(\mathrm{TS})+20 \\
\text { mL cloreto férrico }+ \text { aquecer } \\
\text { (refluxo) (banho-maria) }(20 ')+ \\
1 \mathrm{~mL} \text { ácido clorídrico }+ \\
\text { aquecer }(20 ') \text { (agitar } \\
\text { frequentemente) + esfriar + } \\
\text { agitar } 3 \mathrm{x} 25 \mathrm{~mL} \text { éter etílico } \\
\text { (líquido de lavagem) + reunir } \\
\text { (fases etéreas) + lavar } 2 \times 15 \\
\mathrm{~mL} \text { água + reunir (fases } \\
\text { etéreas) + éter etílico para } 100 \\
\text { mL + transferir } 10,0 \mathrm{~mL}+ \\
\text { evaporar (resíduo) }+10,0 \mathrm{~mL} \\
\text { acetato de magnésio } 0,5 \% \mathrm{em} \\
\text { metanol }\end{array}$ & $\begin{array}{c}10,0 \mathrm{~mL}(\mathrm{TS})(\mathrm{RS})+20 \mathrm{~mL} \\
\text { solução de cloreto férrico + } \\
\text { aquecer (refluxo) (banho- } \\
\text { maria) }\left(20^{\prime}\right)+1 \mathrm{~mL} \text { ácido } \\
\text { clorídrico + aquecer }\left(20{ }^{\prime}\right) \\
\text { (agitar frequentemente) + } \\
\text { esfriar + agitar } 3 \times 25 \mathrm{~mL} \text { éter } \\
\text { etílico (líquido de lavagem) + } \\
\text { reunir (fases etéreas) + lavar } \\
2 \mathrm{x} 15 \mathrm{~mL} \text { água + reunir (fases } \\
\text { etéreas) + éter etílico para } 100 \\
\text { mL + transferir } 10,0 \mathrm{~mL}+ \\
\text { evaporar (resíduo) + } 10,0 \mathrm{~mL} \\
\text { acetato de magnésio } 0,5 \% \mathrm{em} \\
\text { metanol }\end{array}$ & $\mathrm{mi}$ \\
\hline Procedimento 6 & $\begin{array}{l}515 \mathrm{~nm} \text { (imediata } \\
\text { determinação) }\end{array}$ & $515 \mathrm{~nm}$ & $515 \mathrm{~nm}$ & $515 \mathrm{~nm}$ & me \\
\hline Procedimento 7 & - & - & - & concentração relativa & me \\
\hline Procedimento 8 & $\mathrm{SB}=\frac{\mathrm{A} \times 0,781}{m}$ & $\frac{\mathrm{A} \times 1,25}{m}$ & $\frac{1,25 \times \mathrm{A}}{m}$ & Result $=\left(\frac{A_{U}}{A_{S}}\right) \times C_{S} \times\left(\frac{V}{W}\right) \times 100$ & me \\
\hline Doseamento - método 2 & $\begin{array}{l}\text { CLAE-UV (senosídeo A - } \\
0,5 \% \text { + senosídeo B - 0,6\%) }\end{array}$ & - & - & - & su \\
\hline Procedimento 1 & $270 \mathrm{~nm}$ & - & - & - & $\mathrm{su}$ \\
\hline Procedimento 2 & $\begin{array}{l}\text { pré-coluna octadecilsilanizada } \\
+ \text { ODS }(150 \mathrm{~mm} \times 3,9 \mathrm{~mm})(4 \\
\mu \mathrm{m})\end{array}$ & - & - & - & $\mathrm{su}$ \\
\hline
\end{tabular}


Quadro 40 - Comparação entre as monografias de Senna alexandrina Mill. [folíolo] das farmacopeias FB5, EP8.8, FA7 e USP39-NF34.

\begin{tabular}{|c|c|c|c|c|c|}
\hline & FB5 & EP8.8 & FA7 & USP39-NF34 & Classificação \\
\hline Procedimento 3 & $\begin{array}{c}(0,9 \mathrm{~mL} / \mathrm{min})+\text { água:ácido } \\
\text { trifluoracético }(100: 0,08) 86 \% \\
\text { em acetonitrila }(12 ')+ \\
\text { água:ácido trifluoracético } \\
(100: 0,08) 86 \% \text { em acetonitrila } \\
(12 ') \rightarrow \text { água:ácido } \\
\text { trifluoracético }(100: 0,08) 77 \% \\
\text { em acetonitrila }(7 ')+ \\
\text { água:ácido trifluoracético } \\
(100: 0,08) 77 \% \text { em acetonitrila } \\
\rightarrow \text { água:ácido trifluoracético } \\
(100: 0,08) 70 \% \text { em acetonitrila } \\
(9 ')+\text { água:ácido } \\
\text { trifluoracético }(100: 0,08) 70 \% \\
\text { em acetonitrila } \rightarrow \text { acetonitrila } \\
(3 ')+\text { acetonitrila }\left(2^{\prime}\right)\end{array}$ & - & - & - & su \\
\hline Procedimento 4 & $\begin{array}{c}0,2 \mathrm{~g} \text { droga vegetal pulverizada } \\
(180)+5 \mathrm{~mL} \text { bicarbonato de } \\
\text { sódio } 0,05 \%+\text { sonicar }\left(10^{\prime}\right)+ \\
\text { centrifugar }(2000 \mathrm{rpm})\left(20^{\prime}\right) \\
\text { (usar sobrenadante) }+ \\
\text { completar para } 5 \mathrm{~mL}+\text { filtrar } \\
\text { (membrana) + transferir } 50 \mu \mathrm{L} \\
+150 \mu \mathrm{L} \text { água (TS) }\end{array}$ & - & - & - & $\mathrm{su}$ \\
\hline Procedimento 5 & $\begin{array}{c}10 \mathrm{mg} \text { senosídeo A e B SQR + } \\
10 \mathrm{~mL} \text { metanol } \\
20 \mu \mathrm{g} / \mathrm{mL} ; 25 \mu \mathrm{g} / \mathrm{mL} ; 30 \\
\mu \mathrm{g} / \mathrm{mL} ; 35 \mu \mathrm{g} / \mathrm{mL} ; 40 \mu \mathrm{g} / \mathrm{mL} ;\end{array}$ & - & - & - & su \\
\hline Procedimento 6 & $\begin{array}{c}45 \mu \mathrm{g} / \mathrm{mL} ; 50 \mu \mathrm{g} / \mathrm{mL} \\
\text { senosídeo A e B SQR em } \\
\text { metanol }\end{array}$ & - & - & - & $\mathrm{su}$ \\
\hline Procedimento 7 & $10 \mu \mathrm{L}$ & - & - & - & $\mathrm{su}$ \\
\hline Procedimento 8 & $\begin{array}{l}\text { tempo de retenção (senosídeo) } \\
\left(\left(18,0^{\prime}\right)-B+\left(20,7^{\prime}\right)-A\right)\end{array}$ & - & - & - & $\mathrm{su}$ \\
\hline Procedimento 9 & curva analítica & - & - & - & $\mathrm{su}$ \\
\hline
\end{tabular}

Procedimento 9 curva analítica 
Quadro 40 - Comparação entre as monografias de Senna alexandrina Mill. [folíolo] das farmacopeias FB5, EP8.8, FA7 e USP39-NF34.

\begin{tabular}{|c|c|c|c|c|c|}
\hline & FB5 & EP8.8 & FA7 & USP39-NF34 & Classificação \\
\hline $\begin{array}{c}\text { Embalagem e } \\
\text { armazenamento }\end{array}$ & 1 & $1^{2}$ & 1 & 1 & - \\
\hline Padrões de referência & senosídeo A e B SQR & extrato de sene $S Q R$ & extrato de sene $S Q R$ & senosídeos SQR & - \\
\hline Rotulagem & - & - & - & 1 & - \\
\hline
\end{tabular}

(ANMAT, 2003b; BRASIL, 2010c, d; EDQM, 2016b; USP, 2016h).

Legenda: $\mathrm{mi}=$ menor; me = moderado; su = substancial; $\mathrm{se}=$ semelhante; $\mathrm{NLT}=$ não menos que $; \mathrm{MNT}=$ não mais que $\mathrm{CCD}=$ cromatografia em camada delgada; $\mathrm{RS}=$ solução referência; TS = solução amostra; $\mathrm{BS}=$ solução branco; $\mathrm{SQR}=$ substância química de referência; $\mathrm{TAMC}=$ contagem total de bactérias aeróbias; TBMC = contagem de bactérias Gram-negativas bile tolerantes; TYMC = contagem total de fungos e leveduras; UFC = unidade formadora de colônia; EAVIS = espectrofotometria de absorção no visível; $\mathrm{SB}=$ senosídeo $\mathrm{B} ; \mathrm{rpm}=$ rotações por minuto; $\mathrm{A}=$ absorvância; $m=\mathrm{W}=$ massa; $\mathrm{C}=$ concentração; $\mathrm{V}=$ volume; CLAE-UV = cromatografia liquida de alta eficiência acoplada a detector por espectrofotometria por absorção no ultravioleta; ODS = coluna cromatográfica octadecilsilanizada.

Nota: ${ }^{1}=$ parâmetros extraídos do método geral ${ }^{2}=$ apenas armazenamento. 
As monografias não são convergentes. As diferenças substanciais se concentram nos ensaios e testes adicionais da FB5 (doseamento e especificações separadamente para os senosídeos A e B e o ensaio de identificação por microssublimação), da FA7 (um ensaio de identificação e cinzas insolúveis em ácido), da USP39-NF34 (um ensaio de identificação e cinzas insolúveis em ácido) e da EP8.8 (cinzas insolúveis em ácido clorídrico) e na diferença da especificação para matéria estranha acima de $30 \%$ entre as monografias.

Diferenças substanciais nas especificações como as encontradas, podem ocasionar barreiras sanitárias ao comércio internacional de matérias-primas e produtos acabados. Esse é um caso de um produto com ocorrência no Brasil e em outros países, com registros válidos de fitoterápicos no Brasil e com presença de monografia em todas as farmacopeias em estudo.

\subsubsection{Styrax benzoin Dryand. ou Styrax paralleloneuron Perkins [tronco; resina balsâmica]}

O benjoim esteve presente na $1^{\mathrm{a}}$ e $2^{\mathrm{a}}$ edição da Farmacopeia Brasileira (Quadro 3). Não está contemplado no FFFB1 e nem na IN nº 02/2014 (BRASIL, 2011, 2014a), estando apenas na FB5. Não foram encontrados, para a espécie, registros de fitoterápicos válidos na Anvisa (Quadro 5). Conforme a literatura consultada, a espécie não possui ocorrência no Brasil (Apêndice A). Em buscas realizadas nos compêndios internacionais em estudo, foram localizadas monografias na EP8.8 e na USP39-NF34. Os dados extraídos das monografias estão descritos no Quadro 41. 
Quadro 41 - Comparação entre as monografias de Styrax benzoin Dryand. ou Styrax paralleloneuron Perkins [tronco; resina balsâmica] das farmacopeias FB5, EP8.8 e USP39-NF34.

\begin{tabular}{|c|c|c|c|c|}
\hline & FB5 & EP 8.8 & USP39-NF34 & Classificação \\
\hline Nomenclatura botânica & $\begin{array}{c}\text { Styrax benzoin Dryand. ou Styrax } \\
\text { paralleloneuron Perkins }\end{array}$ & Styrax benzoin Dryand. & $\begin{array}{c}\text { Styrax benzoin Dryand. ou Styrax } \\
\text { paralleloneurus Perkins ou Styrax } \\
\text { tonkinensis (Piérre) Craib ex Hartwich ou } \\
\text { Styrax ssp. }\end{array}$ & - \\
\hline Nomenclatura popular & benjoim & benzoin sumatra & benzoin & - \\
\hline Droga vegetal & resina balsâmica (tronco) & resina balsâmica (tronco) & resina balsâmica (tronco) & se \\
\hline Marcador 1 & ácidos totais (ácido benzoico) $(25-50 \%)$ & $\begin{array}{l}\text { ácidos totais (ácido benzoico) }(25,0- \\
50,0 \%)\end{array}$ & $\begin{array}{l}\text { ácido benzoico (NLT 6,0\% - sumatra; } \\
\text { NLT 12,0\% - siam) } \\
\text { matéria extraível em etanol (NLT 75,0\% - }\end{array}$ & su \\
\hline Marcador 2 & - & - & $\begin{array}{c}\text { sumatra) (NLT 90,0\% - siam) (droga } \\
\text { seca) }\end{array}$ & su \\
\hline Características & $\begin{array}{l}\text { fragmentos arredondados ou ovoides } \\
\text { irregulares + cor creme-esbranquiçada }+ \\
\text { revestidas material resinoso cor castanho- } \\
\text { acinzentada ou castanho-avermelhada + } \\
\text { duras + quebradiças + superfície fratura } \\
\text { rugosa irregular + odor suave balsâmico + } \\
\text { sabor princípio adocicado + levemente } \\
\text { picante + acre }\end{array}$ & $\begin{array}{c}\text { cor creme-esbranquiçada }+ \text { fragmentos } \\
\text { arredondados ou ovoides }+ \text { revestidas } \\
\text { material cor castanho-acinzentada ou } \\
\text { castanho-avermelhada }+ \text { duras }+ \\
\text { quebradiças }+ \text { superfície fratura rugosa } \\
\text { irregular }\end{array}$ & $\begin{array}{l}\text { sumatra - blocos ou pedaços tamanho } \\
\text { variados (forma de lágrimas) compactado } \\
\text { + massa de cor marrom-avermelhado, } \\
\text { cinza-avermelhado, ou castanho- } \\
\text { acinzentado + cor externa amarelada ou } \\
\text { marrom ferrugem + quando fratura branco } \\
\text { leitoso + duro e quebradiço + amolece } \\
\text { pelo calor; siam - forma de lágrimas tipo } \\
\text { seixo com forma e tamanho variável + } \\
\text { compactado + cor externa castanho- } \\
\text { amarelado a marrom enferrujado + } \\
\text { quando fratura branco leitoso + separada } \\
\text { ou ligeiramente aglutinado + duro e } \\
\text { quebradiço + amolece pelo calor }\end{array}$ & - \\
\hline Identificação - método 1 & CCD & CCD & - & se \\
\hline Procedimento 1 & sílica-gel $\left(\mathrm{GF}_{254}+0,25 \mathrm{~mm}\right)$ & sílica-gel $\left(\mathrm{F}_{254}+5-40 \mu \mathrm{m}\right.$ ou 2-10 $\left.\mu \mathrm{m}\right)$ & - & $\mathrm{mi}$ \\
\hline Procedimento 2 & $\begin{array}{c}\text { ácido acético glacial:éter } \\
\text { isopropílico:hexano (10:40:60) }\end{array}$ & $\begin{array}{l}\text { ácido acético glacial:éter } \\
\text { diisopropílico:hexano (10:40:60) }\end{array}$ & - & me \\
\hline Procedimento 3 & $10 \mu \mathrm{L}(\mathrm{TS})(\mathrm{RS})$ (banda) & 10 ou $2 \mu \mathrm{L}$ (TS) (RS) (banda) & - & $\mathrm{mi}$ \\
\hline Procedimento 4 & $\begin{array}{l}0,2 \mathrm{~g} \text { droga vegetal finamente pulverizada } \\
+5 \mathrm{~mL} \text { etanol }+ \text { sonicar }\left(2^{\prime}\right)+\text { centrifugar } \\
\text { (usar sobrenadante) (TS) }\end{array}$ & $\begin{array}{c}0,2 \mathrm{~g} \text { droga vegetal finamente pulverizada } \\
+5 \mathrm{~mL} \text { etanol } 96 \%+\text { sonicar + filtrar } \\
(\mathrm{TS})\end{array}$ & - & me \\
\hline
\end{tabular}


Quadro 41 - Comparação entre as monografias de Styrax benzoin Dryand. ou Styrax paralleloneuron Perkins [tronco; resina balsâmica] das farmacopeias FB5, EP8.8 e USP39-NF34.

\begin{tabular}{|c|c|c|c|c|}
\hline & FB5 & EP 8.8 & USP39-NF34 & Classificação \\
\hline Procedimento 5 & $\begin{array}{l}20 \mathrm{mg} \text { ácido benzoico }+10 \mathrm{mg} \text { ácido } \\
\text { cinâmico }+4 \mathrm{mg} \text { vanilina }+20 \mathrm{mg} \\
\text { cinamato de metila }+10 \mathrm{~mL} \text { etanol }(\mathrm{RS})\end{array}$ & $\begin{array}{c}20 \mathrm{mg} \text { ácido benzoico }+10 \mathrm{mg} \text { ácido } \\
\text { trans-cinâmico }+4 \mathrm{mg} \text { vanilina }+20 \mathrm{mg} \\
\text { cinamato de metila }+10 \mathrm{~mL} \text { etanol } 96 \% \\
(\mathrm{RS})\end{array}$ & - & se \\
\hline Procedimento 6 & - & secar (ar) & - & $\mathrm{mi}$ \\
\hline Procedimento 7 & $254 \mathrm{~nm}$ & $254 \mathrm{~nm}$ & - & se \\
\hline Procedimento 8 & descrição de zonas & descrição de zonas + esquema & - & $\mathrm{mi}$ \\
\hline Identificação - método 2 & $\begin{array}{c}0,5 \mathrm{~g} \text { droga vegetal }+ \text { aquecer }=\text { funde }+ \\
\text { fumaças brancas acres irritantes }+ \\
\text { condensam em lâminas e pequenos } \\
\text { cristais }\end{array}$ & 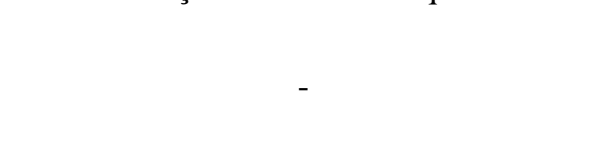 & $\begin{array}{l}\text { fragmentos }+ \text { aquecer }=\text { condensam } \\
\text { (cristais que polarizam a luz }- \text { sumatra }+ \\
\text { cristais que não polarizam - siam) }\end{array}$ & $\mathrm{mi}$ \\
\hline Identificação - método 3 & $\begin{array}{c}1 \mathrm{~g} \text { droga vegetal pulverizada }+10 \mathrm{~mL} \\
\text { permanganato de potássio } 3 \%+\text { aquecer } \\
(\text { levemente) }=\text { forte odor (aldeído } \\
\text { benzoico) } \\
0,2 \mathrm{~g} \text { droga vegetal finamente pulverizada } \\
+10 \mathrm{~mL} \text { etanol + agitar (energeticamente) }\end{array}$ & - & - & su \\
\hline Identificação - método 4 & $\begin{array}{c}\text { + filtrar }+ \text { transferir } 5 \mathrm{~mL}+0,5 \mathrm{~mL} \\
\text { cloreto férrico } 5 \% \text { em etanol }+ \text { agitar }= \\
\text { não desenvolve coloração verde }\end{array}$ & - & - & su \\
\hline Identificação - método 5 & $\begin{array}{c}0,5 \mathrm{~g} \text { droga vegetal pulverizada }+5 \mathrm{~mL} \\
\text { etanol }+ \text { sonicar }\left(2^{\prime}\right)+\text { filtrar }+10 \mathrm{~mL} \\
\text { água }=\text { aspecto leitoso }+ \text { reação ácida } \\
\text { (papel de tornassol) }\end{array}$ & - & $\begin{array}{l}\text { solução em etanol + água = aspecto } \\
\text { leitoso + ácido (papel litmus) }\end{array}$ & $\mathrm{mi}$ \\
\hline Testes - método 1 & $\begin{array}{l}\text { goma dammar (CCD) (sem zona nítida } \\
\text { nos dois terços superiores Rf } 0,4-1,0)\end{array}$ & $\begin{array}{l}\text { goma dammar (CCD) (sem zona nítida } \\
\text { nos dois terços superiores Rf } 0,4-1,0 \text { ) }\end{array}$ & - & se \\
\hline Procedimento 1 & óxido de alumínio $\mathrm{G}(250 \mu \mathrm{m})$ & óxido de alumínio $\mathrm{G}$ & - & $\mathrm{mi}$ \\
\hline Procedimento 2 & éter de petróleo:éter etílico (40:60) & éter de petróleo:éter etílico (40:60) & - & se \\
\hline Procedimento 3 & $5 \mu \mathrm{L}$ (banda) & $5 \mu \mathrm{L}$ (banda) & - & se \\
\hline Procedimento 4 & $\begin{array}{l}0,2 \mathrm{~g} \text { droga vegetal pulverizada }+10 \mathrm{~mL} \\
\text { etanol } 90 \%+\text { aquecer }+ \text { centrifugar }\end{array}$ & $\begin{array}{c}0,2 \mathrm{~g} \text { droga vegetal }+10 \mathrm{~mL} \text { etanol } 90 \%+ \\
\text { aquecer + centrifugar (TS) }\end{array}$ & - & se \\
\hline Procedimento 5 & secar $(\operatorname{ar})$ & secar (ar) & - & se \\
\hline Procedimento 6 & anisaldeído $\mathrm{SR}+\underset{\left(5^{\prime}\right)}{\operatorname{aquecer}}\left(100-105^{\circ} \mathrm{C}\right)$ & $\begin{array}{l}\text { solução de anisaldeído SR + aquecer } \\
\qquad\left(100-105^{\circ} \mathrm{C}\right)\left(5^{\prime}\right)\end{array}$ & - & se \\
\hline
\end{tabular}


Quadro 41 - Comparação entre as monografias de Styrax benzoin Dryand. ou Styrax paralleloneuron Perkins [tronco; resina balsâmica] das farmacopeias FB5, EP8.8 e USP39-NF34.

\begin{tabular}{|c|c|c|c|c|}
\hline & FB5 & EP 8.8 & USP39-NF34 & Classificação \\
\hline Testes - método 3 & $\begin{array}{l}\text { Styrax tonkinensis }(\mathrm{CCD}) \text { (duas zonas de } \\
\text { fraca intensidade sem zonas intensas nas } \\
\text { posições do ácido benzoico e da vanilina) }\end{array}$ & $\begin{array}{l}\text { Styrax tonkinensis }(\mathrm{CCD} \text { - duas zonas de } \\
\text { fraca intensidade sem zonas intensas nas } \\
\text { posições do ácido benzoico e da vanilina) } \\
\text { Styrax tonkinensis }(0,2 \mathrm{~g} \text { droga vegetal } \\
\text { finamente pulverizada }+10 \mathrm{~mL} \text { etanol } \\
96 \%+\text { agitar (energeticamente) + filtrar }+ \\
\text { transferir } 5 \mathrm{~mL}+0,5 \mathrm{~mL} \text { cloreto férrico } \\
\text { SR em etanol } 96 \%=\text { desenvolve } \\
\text { coloração amarelada ligeiramente verde) }\end{array}$ & - & su \\
\hline Testes - método 4 & $\begin{array}{c}\text { colofônia (fase xilênica sem coloração } \\
\text { verde) }(1 \mathrm{~g} \text { droga vegetal }+10 \mathrm{~mL} \text { xileno } \\
+ \text { sonicar }(1 ')+\text { filtrar }+10 \mathrm{~mL} \text { acetato de } \\
\text { cobre } 1 \%+\text { agitar })\end{array}$ & 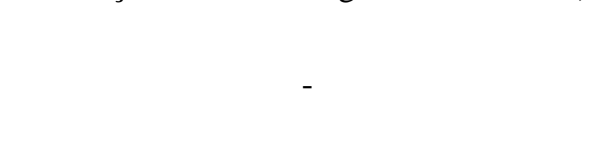 & - & su \\
\hline Testes - método 5 & $\begin{array}{l}\text { substâncias insolúveis em etanol (NMT } \\
25,0 \%)(2 \mathrm{~g} \text { droga vegetal pulverizada }+ \\
25 \mathrm{~mL} \text { etanol } 90 \%+\text { ferver }+ \text { filtrar (vidro } \\
\text { poroso tarado) + lavar } 3 \times 5 \mathrm{~mL} \text { etanol } \\
90 \% \text { (quente })+ \text { aquecer }\left(100-105^{\circ} \mathrm{C}\right)(2 \\
\text { h) + esfriar (dessecador) + pesar) }\end{array}$ & $\begin{array}{l}\text { substâncias insolúveis em etanol (NMT } \\
20,0 \%)(2,0 \mathrm{~g} \text { droga vegetal pulverizada }+ \\
25 \mathrm{~mL} \text { etanol } 90 \%+\text { ferver }+ \text { filtrar (vidro } \\
\text { poroso tarado) + lavar } 3 \times 5 \mathrm{~mL} \text { etanol } \\
90 \% \text { (quente) }+ \text { aquecer }\left(100-105^{\circ} \mathrm{C}\right)(2 \\
\mathrm{h})+ \text { esfriar + pesar) }\end{array}$ & - & me \\
\hline Testes - método 6 & $\begin{array}{l}\text { água (NMT 5,0\%) (2 g droga vegetal (pó } \\
\text { grosseiro)) (pressão reduzida) }(4 \mathrm{~h})\end{array}$ & $\begin{array}{c}\text { perda por dessecação (NMT 5,0\%) }(2,000 \\
\text { g droga vegetal (pó grosseiro)) (pressão } \\
\text { reduzida) }(4 \mathrm{~h})\end{array}$ & - & se \\
\hline Testes - método 7 & cinzas totais (NMT 2,0\%) & cinzas totais (NMT 2,0\%) & - & se \\
\hline Testes - método 8 & $\begin{array}{l}\text { solubilidade (praticamente insolúvel - } \\
\text { água; pouco solúvel - etanol + dissulfeto } \\
\text { de carbono + xileno) }\end{array}$ & - & - & su \\
\hline Testes - método 9 & - & - & $\begin{array}{l}\text { cinzas insolúveis em ácido (NMT 1,0\% - } \\
\text { sumatra; NMT 0,5\% - siam) }\end{array}$ & su \\
\hline Testes - método 10 & - & - & matéria estranha (NMT 1,0\% - siam) & su \\
\hline Doseamento - método 1 & $\begin{array}{l}\text { volumetria (ácidos totais) (ácido } \\
\text { benzoico) }(25-50 \%)\end{array}$ & $\begin{array}{l}\text { volumetria (ácidos totais) (ácido } \\
\text { benzoico) }(25,0-50,0 \%)\end{array}$ & $\begin{array}{l}\text { gravimetria (ácido benzoico) (sumatra - } \\
\text { NLT } 6,0 \% \text {; siam - NLT } 12,0 \% \text { ) }\end{array}$ & su \\
\hline
\end{tabular}


Quadro 41 - Comparação entre as monografias de Styrax benzoin Dryand. ou Styrax paralleloneuron Perkins [tronco; resina balsâmica] das farmacopeias FB5, EP8.8 e USP39-NF34.

\begin{tabular}{|c|c|c|c|c|}
\hline & FB5 & EP 8.8 & USP39-NF34 & Classificação \\
\hline Procedimento 1 & $\begin{array}{l}\text { 0,75 g droga vegetal finamente } \\
\text { pulverizada }+15 \mathrm{~mL} \text { hidróxido de } \\
\text { potássio } 0,5 \mathrm{MSV} \text { em etanol + aquecer } \\
\text { (refluxo) (banho-maria) }(30 \text { ') + esfriar + } \\
\text { lavar (condensador) } 20 \mathrm{~mL} \text { etanol (TS) }\end{array}$ & $\begin{array}{c}0,750 \mathrm{~g} \text { droga vegetal finamente } \\
\text { pulverizada }+15,0 \mathrm{~mL} \text { hidróxido de } \\
\text { potássio } 0,5 \mathrm{M} \text { em etanol + ferver } \\
\text { (refluxo) (banho-maria) }\left(30^{\prime}\right)+\text { esfriar }+ \\
\text { lavar (condensador) } 20 \mathrm{~mL} \text { etanol } 96 \% \\
\text { (TS) }\end{array}$ & $\begin{array}{c}1 \mathrm{~g} \text { droga vegetal pulverizada }+15 \mathrm{~mL} \\
\text { dissulfeto de carbono (quente) }+ \text { filtrar } \\
\text { (algodão) + lavar (algodão) } 5 \mathrm{~mL} \\
\text { dissulfeto de carbono + evaporar } \\
\text { (espontaneamente) }\end{array}$ & me \\
\hline Procedimento 2 & $\begin{array}{l}\text { titular (ácido clorídrico 0,5 M SV) + } \\
\text { ensaio em branco }\end{array}$ & $\begin{array}{c}\text { titular (ácido clorídrico } 0,5 M \text { ) + ensaio } \\
\text { em branco }\end{array}$ & - & se \\
\hline Procedimento 3 & ponto final (potenciometricamente) & ponto final (potenciometricamente) & - & se \\
\hline Procedimento 4 & $\begin{array}{l}1 \mathrm{~mL} \text { hidróxido de potássio } 0,5 \mathrm{MSV} \\
\text { etanol }=61,050 \mathrm{mg} \text { ácido benzoico }\end{array}$ & $\begin{array}{l}1 \mathrm{~mL} \text { hidróxido de potássio } 0,5 \mathrm{M} \text { etanol } \\
=61,05 \mathrm{mg} \text { ácido benzoico }\end{array}$ & - & se \\
\hline Doseamento - método 2 & - & - & $\begin{array}{l}\text { matéria extraível em etanol (NLT 75,0\% - } \\
\text { sumatra benzoin) (NLT 90,0\% - siam } \\
\text { benzoin) (droga seca) ( } 2 \text { g droga vegetal + } \\
\text { cartucho tarado + } 100 \mathrm{mg} \text { hidróxido de } \\
\text { sódio + extrair (aparato extração contínua) } \\
\text { com etanol (5h ou até extração completa) } \\
\left.\quad+\text { secar (cartucho) }\left(105^{\circ} \mathrm{C}\right)(2 \mathrm{~h})\right)\end{array}$ & su \\
\hline $\begin{array}{l}\text { Embalagem e } \\
\text { armazenamento }\end{array}$ & 1 & - & 1 & - \\
\hline Rotulagem & - & - & 1 & - \\
\hline
\end{tabular}

(BRASIL, 2010d; EDQM, 2016b; USP, 2016h).

Legenda: mi = menor; me = moderado; su = substancial; se $=$ semelhante $;$ NLT $=$ não menos que $;$ MNT $=$ não mais que $; C C D=$ cromatografia em camada delgada; RS = solução referência; TS = solução amostra; $\mathrm{SR}=$ solução reagente; SV = solução volumétrica. 
No geral, as monografias da FB5 e da EP8.8 são convergentes, possuindo ensaios e testes semelhantes, e a monografia da USP39-NF34 contém diferenças mais significativas.

As diferenças substanciais se concentram nos ensaios e testes adicionais da FB5 (dois testes de identificação, teste para colofônia e de solubilidade), da EP8.8 (teste para Styrax tonkinensis) e da USP39-NF34 (doseamento e especificação para matéria extraível em etanol, testes para matéria estranha e cinzas insolúveis em ácido) e na diferença da especificação do marcador ácido benzoico acima de $30 \%$.

Diferenças substanciais nas especificações como as encontradas, podem ocasionar barreiras sanitárias ao comércio internacional de matérias-primas e produtos acabados.

Como espécie que não possui ocorrência no Brasil, a origem da matéria-prima não é nacional. Assim, se esperava que os métodos e especificações fossem mais harmonizados, porém, nesse caso, a espécie não possui registros válidos junto à Anvisa, nem está listada em outros compêndios e nem na lista de registro simplificado. Isso pode indicar que há baixa utilização da monografia no Brasil e, pode, eventualmente, explicar, o porquê de a monografia não ser tão harmonizada quanto o esperado.

\subsubsection{Vanilla planifolia Andrews [fruto imaturo]}

A baunilha esteve presente na $1^{\mathrm{a}}$ e $2^{\mathrm{a}}$ edição da Farmacopeia Brasileira (Quadro 3), não está contemplada no FFFB1 e nem na IN nº 02/2014 (BRASIL, 2011, 2014a), estando apenas na FB5. Não foram encontrados, para a espécie, registros de fitoterápicos válidos na Anvisa. Conforme a literatura consultada, a espécie possui ocorrência no Brasil (Apêndice A), sendo nativa e não endêmica (REFLORA, 2016). Há, ainda, registro de ocorrência da espécie no Belize, Caribe, Colômbia, Costa Rica, Equador, El Salvador, Guatemala, Guiana, Honduras, Madagascar e México (TROPICOS.ORG, 2016). Em buscas realizadas nos compêndios internacionais em estudo, foi localizada monografia apenas na USP39-NF34. Os dados extraídos das monografias estão descritos no Quadro 42. 
Quadro 42 - Comparação entre as monografias de Vanilla planifolia Andrews [fruto imaturo] das farmacopeias FB5 e USP39-NF34.

\begin{tabular}{|c|c|c|c|}
\hline & FB5 & USP39-NF34 & Classificação \\
\hline Nomenclatura botânica & Vanilla planifolia Andrews & Vanilla planifolia Andrews e Vanilla tahitensis J. & - \\
\hline Nomenclatura popular & baunilha & vanilla & - \\
\hline Droga vegetal & fruto imaturo & fruto imaturo & se \\
\hline Marcador 1 & extrato hidroetanólico seco (NLT 12\%) & extrato hidroetanólico seco (NLT 12,0\%) & se \\
\hline Características & $\begin{array}{c}\text { odor agradável floral + lembra vanilina (mais sutil e encorpado } \\
\text { que substância isolada) }\end{array}$ & 然 & - \\
\hline Descrição macroscópica & 1 & 2 & - \\
\hline Descrição microscópica & 2 & 2 & - \\
\hline Figura botânica & 1 & - & - \\
\hline Identificação - método 1 & CCD & - & su \\
\hline Procedimento 1 & sílica-gel $\left(\mathrm{GF}_{254}+0,25 \mathrm{~mm}\right)$ & - & su \\
\hline Procedimento 2 & diclorometano:acetona (95:5) & - & su \\
\hline Procedimento 3 & $20 \mu \mathrm{L}$ (TS);10 $\mu \mathrm{L}$ (RS) (banda) & - & su \\
\hline Procedimento 4 & extrato hidroetanólico (doseamento) (TS) & - & su \\
\hline Procedimento 5 & $1 \mathrm{mg}$ vanilina $+10 \mathrm{~mL}$ etanol $(\mathrm{RS})$ & - & su \\
\hline Procedimento 6 & secar (ar) & - & su \\
\hline Procedimento 7 & $254 \mathrm{~nm}$ & - & su \\
\hline Procedimento 8 & descrição de zonas & - & su \\
\hline Identificação - método 2 & $\begin{array}{c}\text { sementes do fruto }+1 \text { gota floroglucinol } 1 \% \text { em etanol }+1 \text { gota } \\
\text { ácido clorídrico = coloração vermelha }\end{array}$ & $\begin{array}{c}\text { cristais (fruto) }+1 \text { gota floroglucinol } 2 \% \text { em etanol + } 1 \text { gota } \\
\text { ácido clorídrico = coloração vermelha }\end{array}$ & mi \\
\hline Testes - método 1 & cinzas sulfatadas (NMT 7,0\%) & & su \\
\hline Doseamento - método 1 & gravimetria (extrato hidroetanólico seco) (NLT 12\%) & gravimetria (extrato hidroetanólico seco) (NLT 12,0\%) & se \\
\hline Procedimento 1 & $\begin{array}{c}2 \mathrm{~g} \text { droga vegetal (fragmentos ou pó grosseiro) }+70 \mathrm{~mL} \\
\text { etanol:água (263:250) + agitar (mecanicamente) }(2 \mathrm{~h}) \text { ou deixar } \\
\text { em contato (uma noite + agitar frequentemente }(8 \mathrm{~h}))+ \\
\text { decantar+ filtrar + lavar (recipiente + resí́luo) } 4 \times 8 \mathrm{~mL} \\
\text { etanol:água }(263: 250)+\text { filtrar + reunir (filtrado + líquidos de } \\
\text { lavagem) + etanol:água }(263: 250) \text { para } 100 \mathrm{~mL}+\text { transferir } 50 \\
\mathrm{~mL}+\text { evaporar (banho-maria) }+ \text { dessecar }\left(105{ }^{\circ} \mathrm{C}\right)(4 \mathrm{~h})+\text { esfriar } \\
\text { (dessecador) + pesar }\end{array}$ & $\begin{array}{c}2 \mathrm{~g} \text { droga vegetal (fragmentos finos ou pó grosseiro) }+70 \mathrm{~mL} \\
\text { etanol diluído }+ \text { agitar (mecanicamente }-(2 \mathrm{~h})) \text { ou (intervalos } \\
\left.\left(30^{\prime}\right)-(8 \mathrm{~h})\right)+ \text { descansar (uma noite) + decantar+ filtrar + lavar } \\
\text { (recipiente + resíduo) etanol diluído + filtrar + reunir (filtrado + } \\
\text { líquidos de lavagem) + etanol diluído para } 100,0 \mathrm{~mL}+\text { transferir } \\
50 \mathrm{~mL}+\text { evaporar (resíduo) (banho-maria) }+ \text { dessecar }\left(105^{\circ} \mathrm{C}\right) \\
\text { (4h)+ pesar }\end{array}$ & $m e^{1}$ \\
\hline $\begin{array}{l}\text { Embalagem e } \\
\text { armazenamento }\end{array}$ & 1 & 1 & - \\
\hline Rotulagem & - & 1 & - \\
\hline
\end{tabular}


(BRASIL, 2010d; USP, 2016h).

Legenda: mi = menor; me = moderado; su = substancial; se = semelhante; NLT = não menos que; MNT = não mais que; CCD = cromatografia em camada delgada; RS = solução referência; TS = solução amostra.

Nota: ${ }^{1}=$ há discrepância no procedimento de manter em contato na necessidade ou não de manter em contato uma noite. 
As monografias são convergentes, embora possuam diferenças substanciais. As diferenças substanciais se concentram nos ensaios e testes adicionais da FB5 (identificação por CCD e cinzas sulfatadas).

Há, ainda, na gravimetria diferença na metodologia de extração na qual a USP39-NF34 determina que a amostra deve permanecer em contato por uma noite, seja com agitação magnética durante duas horas ou com agitação ocasional durante oito horas, enquanto a FB5 determina que a amostra deve permanecer em contato durante a noite apenas se seguir o procedimento de agitação ocasional durante oito horas.

\subsection{CONSIDERAÇÕES FINAIS}

Ao final desse trabalho, podem ser destacados os resultados:

1 - a grande maioria das monografias de drogas vegetais e derivados da FB5, 51 (88\%) monografias, esteve presente em pelo menos uma das edições anteriores da Farmacopeia Brasileira;

2 - desde a publicação da FB1, em 1929, até a edição atualmente vigente, houve uma significativa evolução nas monografias de drogas vegetais e derivados que hoje estão na FB5. Esta evolução pode ser observada no crescimento das monografias com metodologia para doseamento que representavam $28 \%$ na FB1 e atualmente são 95\%;

3 - todas as monografias de drogas vegetais de derivados da FB5 possuem ensaios de identificação por CCD, todas as monografias de óleos voláteis possuem o ensaio de perfil cromatográfico e todas as monografias de drogas vegetais possuem ilustração do material botânico;

4 - o método de doseamento mais utilizado nas monografias de drogas vegetais e derivados da FB5 é o EAVIS, que ocorre 28 vezes dentro das 58 monografias, sendo a segunda metodologia mais utilizada o CLAE-UV, que ocorre 19 vezes;

5 - dentre o total de 153 possibilidades geradas a partir das informações de espécies, drogas vegetais e derivados dos documentos FB5, FFFB1, e IN nº 02/2014, 52 (34\%) aparecem em mais de um documento. Destas, 7 (13\%) mostram divergências quanto a droga vegetal;

6 - apenas 34\% (28 monografias) do total de possibilidades de fitoterápicos apresentadas pelo FFFB1 possuem monografia correspondente para a droga vegetal na FB5;

7 - dentre as 63 espécies contempladas nas monografias de drogas vegetais e derivados, $25(40 \%)$ possuem ocorrência no Brasil; 
8 - ao contrário da USP39-NF34 que contém monografias, em sua maioria, de produtos registrados nos EUA, somente 40\% (25 do total de 63) das espécies da FB5 possuíam registros de fitoterápicos válidos na Anvisa em maio de 2016;

9 - mesmo sem ter sido possível correlacionar com as drogas vegetais e derivados registrados, os 40\% de espécies da FB5 com registros de fitoterápicos válidos estão distribuídos em $47 \%$ das monografias, o que indica que pelo menos $50 \%$ das monografias de drogas vegetais e derivados da FB5 não tem correlação com os produtos registrados na Anvisa;

10 - dentre as 58 monografias de drogas vegetais e derivados da FB5, 37 (64\%) possuem monografias correspondentes nas farmacopeias internacionais em estudo, sendo a EP 8.8 a que possui um maior quantitativo de monografias correspondentes, com 33 monografias (57\%);

11 - das 37 monografias de drogas vegetais e derivados da FB5 que possuem monografias correspondentes nas farmacopeias internacionais, cinco (14\%) se referem a drogas vegetais diferentes;

12 - considerando apenas as 37 monografias de drogas vegetais e derivados da FB5 que possuem monografias correspondentes nas farmacopeias internacionais estudadas, 22 (59\%) monografias foram consideradas convergentes ou harmonizadas com pelo menos uma das monografias comparadas, ressaltando que alguns requisitos, como a identificação botânica, não foram analisados neste estudo; 18 (49\%) monografias possuíam espécies com registros de fitoterápicos válidos na Anvisa em maio de 2016; 10 (27\%) monografias possuem espécie com ocorrência no Brasil; 12 (32\%) monografias possuem espécie listadas na IN nº 02/2014; 13 (35\%) monografias possuem espécie relacionadas no FFFB1; e 34 (92\%) monografias estiveram em pelo menos uma das edições anteriores da Farmacopeia Brasileira;

13 - em geral, as especificações das monografias da FB5 convergem com as da EP8.8 e da FA7, e são mais divergentes da USP39-NF34;

14 - a análise comparativa entre as monografias mostrou que enquanto todas as monografias de drogas vegetais da FB5 e da FA7 possuem ilustrações botânicas, 20 (77\%) de um total de 26 monografias de drogas vegetais avaliadas da EP8.8 as possuem, e nenhuma das monografias da USP39-NF34, alvos desse estudo, as possui; e

15 - o Brasil tem inovado, oferecendo monografias para drogas vegetais que ocorrem no Brasil e não estão contempladas em outros compêndios, tais como as monografias para: endro, carqueja, capim-limão, chapéu-de-couro, pitangueira, espinheira-santa, maracujá-doce, maracujá-azedo, guaraná, abacateiro, quebra-pedra, sabugueiro-do-brasil, estévia e barbatimão; também tem inovado ao oferecer descrições botânicas mais completas contemplando figuras 
ilustrativas dos materiais botânicos. Porém, destas monografias, apenas cinco estão contempladas em registros de fitoterápicos (espinheira-santa, maracujá-doce, guaraná, abacateiro e barbatimão).

16 - as análises comparativas revelaram que é frequente na FB5 a omissão da indicação de que o teor do marcador deve ser calculado excluindo a massa de água da droga vegetal (obtida por meio da determinação de água). E, considerando os limites para a determinação de água, essa diferença pode ser significativa para o resultado. Essa omissão foi observada em todas as determinações de óleo volátil da FB5, que embora utilizem método semelhante ao da EP8.8, não têm inserida a informação de que deve ser excluída a massa de água no cálculo. Por outro lado, a USP39-NF34, que também omite essa informação, discrimina em seu método geral que o cálculo é realizado considerando apenas a massa de droga vegetal da tomada de ensaio, porém, o método descrito na USP39-NF34 é diferente do descrito na FB5 e na EP8.8.

Podendo, ainda, ser discutido:

1 - o principal critério para a inclusão de monografias na FB5 foi, provavelmente, a preocupação com a manutenção das monografias que estavam nas edições anteriores, o que pode ser justificado pelo fato da FB5 revogar as edições anteriores da Farmacopeia Brasileira (BRASIL, 2010b). Ao mesmo tempo, a maior parte das monografias da FB5 possuem monografias correspondentes nas farmacopeias internacionais em estudo. Isto indica que as monografias na FB5, com exceção do aloe (gel mucilaginoso da folha), chapéu-de-couro, maracujá-azedo e salgueiro-branco (total de 7\%), não são inéditas: ou estavam nas edições anteriores ou há monografia correspondente nos compêndios internacionais estudados;

2 - os ensaios e testes constantes na FB5, em sua maioria, estão em consonância, em termos de evolução tecnológica, aos preconizados nas farmacopeias internacionais;

3 - as divergências encontradas, quanto a espécie e droga vegetal, entre os documentos técnicos em vigência no Brasil, FB5, FFFB1, e IN nº 02/2014 indicam a necessidade de adequação para harmonização entre os documentos internos nacionais;

4 - considerando que apenas $34 \%$ das monografias do FFFB1 possuem monografia correspondente para droga vegetal na FB5 (Quadro 4) e que a maioria das espécies do FFFB1 possuem ocorrência no Brasil (68\%) (Tabela 3), se infere que há a necessidade da Farmacopeia Brasileira desenvolver trabalhos para incluir as outras espécies constantes no FFFB1, para que o FFFB1 possa cumprir com o seu papel de facilitador para a entrada de fitoterápicos no mercado brasileiro; 
5 - menos da metade das espécies contempladas nas monografias de drogas vegetais e derivados da FB5 possuem ocorrência no Brasil e, também, menos da metade possuíam registros válidos em maio de 2016, indicando a necessidade de ajuste nas políticas de inclusão de monografias da Farmacopeia Brasileira; e

6 - os resultados indicam, ainda, em razão das diferenças encontradas, que há a possibilidade de que o setor regulado enfrente dificuldades em atender as especificações de qualidade regionais do Brasil e, nesse sentido, o desejo por harmonização das empresas não estaria sendo plenamente atendido. Porém, seria necessário avaliar as efetivas origens das matérias-primas em circulação no Brasil, e avaliar as informações sobre a droga vegetal e o tipo extrato, incluindo a RDD, utilizados nos fitoterápicos registrado a fim de avaliar se as monografias deveriam ser totalmente harmonizadas para atender a realidade dos produtos comercializados no país, ou não.

É importante acrescentar que a harmonização, além de não ser uma tarefa fácil, acarreta, também, em incremento nas dificuldades já existentes, para a inserção de inovações científicas e tecnológicas nos compêndios e normas, uma vez que, com os acordos oficiais de harmonização entre os países, alterações em documentos já harmonizados exigem, novamente, as etapas de negociação previstas.

Assim, ao contrário do passado, quando as farmacopeias exerciam muitas vezes um papel determinante no modo de uso dos produtos pelas populações, possuindo, inclusive, a função de dispensar autorizações de comercialização; atualmente, as principais farmacopeias estão se especializando em atender as demandas regulatórias das agências reguladoras por padronizações de especificações mínimas de controle da qualidade para os produtos com autorização de comercialização (registrados). Nesse quesito, a Farmacopeia Brasileira, ainda tem um longo caminho a percorrer na área dos fitoterápicos.

\section{CONCLUSÃO}

As obras da Farmacopeia Brasileira são construídas em conjunto com a Anvisa, com membros do setor acadêmico brasileiro e com membros do setor regulado, contribuindo, por sua natureza, como um instrumento regulatório essencial para a Anvisa, aplicado tanto no registro como na fiscalização e monitoramento dos produtos sob vigilância sanitária.

Dessa forma, um árduo trabalho contínuo e ativo deve ser realizado para garantir um estado constante de excelência para as monografias de drogas vegetais e derivados da 
Farmacopeia Brasileira, e, para garantir que a farmacopeia possa cumprir o seu papel em fornecer requisitos mínimos de qualidade.

Com a mudança do marco regulatório de fitoterápicos no Brasil e a utilização do FFFB1 na notificação de produtos tradicionais fitoterápicos, cresce ainda mais a necessidade de que a Farmacopeia Brasileira se especialize em elaborar monografias para as espécies de interesse nacional. Pois, os produtos podem ser notificados apenas se possuem monografia farmacopeica em compêndios reconhecidos, e, se espera que os produtos tradicionais fitoterápicos brasileiros estejam incluídos na Farmacopeia Brasileira. Assim, este é um importante direcionamento para a Farmacopeia Brasileira, que pode contribuir para alavancar o mercado nacional de fitoterápicos, alinhando, por consequência com as políticas nacionais de plantas medicinais vigentes.

Também, com o mercado globalizado é necessário analisar cuidadosamente cada espécie a ser incluída na Farmacopeia Brasileira, de modo que se obtenha sempre um trabalho coerente com a realidade nacional e internacional, sendo, quando necessário, harmonizado, convergente ou inédito.

Com este trabalho, conclui-se que a metodologia de trabalho para a inclusão de monografias na Farmacopeia Brasileira (na área de plantas medicinais) não tem se mostrado satisfatória, não atendendo totalmente a realidade do mercado brasileiro, sendo necessário que haja uma maior aproximação com a regulação e a vigilância sanitária, para que os seus documentos sejam mais alinhados entre si e com as políticas regulatórias nacionais, não perdendo de vista que o mercado atual é globalizado e que as matérias-primas possuem circulação mundial.

Como efeito colateral, ao conseguir atender de forma satisfatória o mercado brasileiro, naturalmente a Farmacopeia Brasileira, proveniente de um pais com tamanha biodiversidade, se tornará uma referência para o mercado mundial; porém, antes de almejar status internacional é necessário sanar as inconsistências internas no contexto nacional.

Dessa forma, após a análise dos dados deste trabalho algumas diretrizes são sugeridas para sistematizar as informações e auxiliar no processo de decisão pela revisão ou inserção de novas monografias de fitoterápicos, na Farmacopeia Brasileira, sendo elas:

1 - a necessidade de verificação minuciosa da definição da droga vegetal a ser contemplada, incluindo a espécie correta e o material botânico mais adequado (quando há mais de um comumente empregado); 
2 - a verificação da existência de interesse nacional pela espécie, avaliando se a espécie ocorre no Brasil, se é viável economicamente, e se é utilizada tradicionalmente no Brasil;

3 - a verificação da existência de registro ou notificação de fitoterápicos, o que indica que já existe a necessidade de controle sanitário do produto no mercado nacional;

4 - para a revisão das monografias, avaliar quanto à necessidade de aprimoramento dos ensaios e testes existentes, considerando a função da farmacopeia de fornecer critérios mínimos de qualidade e a realidade da circulação internacional dos fitoterápicos;

5 - incentivar a participação das empresas brasileiras no processo de construção das monografias, de modo que estas forneçam metodologias, contribuindo para que a Farmacopeia Brasileira rapidamente se adeque a realidade dos produtos fitoterápicos do mercado brasileiro; $\mathrm{e}$

6 - avaliar a possibilidade de, ao invés de desenvolver novas monografias não convergentes com as existentes em outros compêndios, incluir integralmente, na Farmacopeia Brasileira, monografias que sejam de interesse para o Brasil e, após a sua incorporação, se necessário, essas sejam adaptadas.

\section{REFERÊNCIAS}

ANMAT. Administración Nacional de Medicamentos Alimentos y Tecnología Médica. Disposición ANMAT no 3165/02. In: COMISSIÓN PERMANENTE DE LA FARMACOPEA ARGENTINA (Org.). Farmacopea Argentina. 7. ed. Buenos Aires: ANMAT, 2003a. v. 1. p. 73-76.

ANMAT. Administración Nacional de Medicamentos Alimentos y Tecnología Médica. Farmacopea Argentina. 7. ed. Buenos Aires: ANMAT, 2003b. Disponível em: <http://www.anmat.gov.ar/webanmat/fna/pfds/Farmacopea_Argentina_2013_Ed.7.pdf>.

ANMAT. Administración Nacional de Medicamentos Alimentos y Tecnología Médica. Historia de la Farmacopea Argentina. In: COMISSIÓN PERMANENTE DE LA FARMACOPEA ARGENTINA (Org.). Farmacopea Argentina. 7. ed. Buenos Aires: ANMAT, 2003c. p. 29-33. Disponível em: <http://www.anmat.gov.ar/webanmat/fna/flip_pages/Farmacopea_Vol_III/files/assets/basic-html/toc.html>.

ANVISA. Agência Nacional de Vigilância Sanitária. Consulta de Produtos - Medicamentos. Disponível em: <http://www7.anvisa.gov.br/datavisa/Consulta_Produto/consulta_medicamento.asp>. Acesso em: 31 maio 2016.

ARGENTINA. Decreto n ${ }^{\circ}$ 202, 12 de junio de 2003. Buenos Aires, Argentina, 2003.

ARGENTINA. Ley n⿳0 16.463, de 23 de julio de 1964. Boletín oficial. Buenos Aires, Argentina, 1964.

BOUIN, A. S.; WIERER, M. Quality standards of the European Pharmacopoeia. Journal of Ethnopharmacology, v. 158, p. 454-457, 2014.

BRANDÃO, M. G. L. et al. Brazilian medicinal plants described by 19 th century European naturalists and in the Official Pharmacopoeia. Journal of Ethnopharmacology, v. 120, p. 141-148, 2008. 
BRANDÃO, M. G. L. et al. Changes in the trade in native medicinal plants in Brazilian public markets. Environmental Monitoring and Assessment, v. 185, p. 7013-7023, 2013.

BRANDÃO, M. G. L. et al. Medicinal plants and other botanical products from the Brazilian Official Pharmacopoeia. Brazilian Journal of Pharmacognosy, v. 16, n. 3, p. 408-420, 2006.

BRASIL. Agência Nacional de Vigilância Sanitária. Consulta Pública $\mathbf{n}^{\circ}$ 159, de 08 de abril de 2016. Diário Oficial da União. Brasília, Brasil, 2016a. Disponível em: <http://portal.anvisa.gov.br/documents/10181/2718201/CP+159-2016+-

+Proposta+de+norma+em+discuss\%25C3\%25A3o.pdf/cf7a51b2-39ef-47bb-876b-06018cfdba87>. Acesso em: 23 out. 2016.

BRASIL. Agência Nacional de Vigilância Sanitária. Consulta Pública $n^{\circ}$ 163, de 11 de abril de 2016. Diário Oficial da União. Brasília, Brasil, 2016b. Disponível em: <http://portal.anvisa.gov.br/documents/10181/2718376/CP+163-2016+-

+Proposta+de+norma+em+discuss\%25C3\%25A3o.pdf/04339840-9168-416e-883f-4999f509ea60>. Acesso em: 23 out. 2016.

BRASIL. Agência Nacional de Vigilância Sanitária. Consulta Pública no 241, de 05 de agosto de 2016. Diário Oficial da União. Brasília, Brasil, 2016c. Disponível em: <http://portal.anvisa.gov.br/consultaspublicas\#/visualizar/321596>. Acesso em: 10 out. 2016.

BRASIL. Agência Nacional de Vigilância Sanitária. Guia para o Programa de Melhoria do Processo de Regulamentação da Anvisa. [Brasília]: Anvisa, 2008a. Disponível em: <http://portal.anvisa.gov.br/documents/33880/2125963/Guia+para+o+Programa+de+Melhoria+do+Processo+de +Regulamenta\%C3\%A7\%C3\%A3o+da+Anvisa/c6d46467-74d4-4b39-89bd-c04493401c73>. Acesso em: 29 set. 2016.

BRASIL. Agência Nacional de Vigilância Sanitária. Instrução Normativa $n^{\circ} 2$ de 13 de maio de 2014. Diário Oficial da União, Poder Executivo. Brasília, 2014a. 14 mai. 2014. Seção 1. p. 58-61.

BRASIL. Agência Nacional de Vigilância Sanitária. Instrução Normativa no 10 de 26 de novembro de 2014. Diário Oficial da União, Poder Executivo. Brasília, 2014b. 27 nov. 2014. Seção 1. p. 47.

BRASIL. Agência Nacional de Vigilância Sanitária. Portaria no 422, de 16 de abril de 2008b. Diário Oficial da União, Poder Executivo. Brasília, 2008b. 17 abr. 2008. Seção 1. p. 55.

BRASIL. Agência Nacional de Vigilância Sanitária. Portaria ${ }^{\circ}$ 452, de 25 de fevereiro de 2013. Diário Oficial da União, Poder Executivo. Brasília, 2013a. 26 fev. 2013. Seção 1. p. 102-103.

BRASIL. Agência Nacional de Vigilância Sanitária. Resolução RDC n 26, de 13 de maio de 2014. Diário Oficial da União, Poder Executivo. Brasília, 2014c. 14 mai. 2014. Seção 1. p. 52-58.

BRASIL. Agência Nacional de Vigilância Sanitária. Resolução RDC nº 10, de 09 de março de 2010. Diário Oficial da União, Poder Executivo. Brasília, 2010a. 10 mar. 2010. Seção 1. p. 52-59.

BRASIL. Agência Nacional de Vigilância Sanitária. Resolução RDC nº 13, de 14 de março de 2013. Diário Oficial da União, Poder Executivo. Brasília, 2013b. 15 mar. 2013. Seção 1. p. 50-56.

BRASIL. Agência Nacional de Vigilância Sanitária. Resolução RDC nº 18, de 03 de abril de 2013. Diário Oficial da União, Poder Executivo. Brasília, 2013c. 05 abr. 2013. Seção 1. p. 67-71.

BRASIL. Agência Nacional de Vigilância Sanitária. Resolução RDC no 37, de 6 de julho de 2009. Diário Oficial da União, Poder Executivo. Brasília, 2009a. 08 jul. 2009. Seção 1. p. 40.

BRASIL. Agência Nacional de Vigilância Sanitária. Resolução RDC no 49, de 23 de novembro de 2010. Diário Oficial da União, Poder Executivo. Brasília, 2010b. 24 nov. 2010. Seção 1. p. 80. 
BRASIL. Constituição da República Federativa do Brasil de 1988. Diário Oficial da União. Brasília, 1988a. Disponível em: <http://www.planalto.gov.br/ccivil_03/Constituicao/Constituicao.htm>. Acesso em: 29 set. 2016.

BRASIL. Decreto no ${ }^{\mathbf{1 7 . 5 0 9}}$, de 04 de novembro de 1926. Diário Oficial da União. Rio de Janeiro, 1926. Disponível em: <http://www2.camara.leg.br/legin/fed/decret/1920-1929/decreto-17509-4-novembro-1926500661-publicacaooriginal-1-pe.html>. Acesso em: 29 set. 2016.

BRASIL. Decreto no 45.502, de 27 de fevereiro de 1959. Diário Oficial da União. Rio de Janeiro, Brasil, 1959a. Disponível em: < http://www2.camara.leg.br/legin/fed/decret/1950-1959/decreto-45502-27-fevereiro-1959384741-publicacaooriginal-1-pe.html>. Acesso em: 29 set. 2016.

BRASIL. Decreto $\mathbf{n}^{\mathbf{0}} \mathbf{7 8 . 8 4 0}$ de 25 de novembro de 1976. Diário Oficial da União. Brasília, Brasil, 1976a. Disponível em: < http://www2.camara.leg.br/legin/fed/decret/1970-1979/decreto-78840-25-novembro-1976427771-publicacaooriginal-1-pe.html>. Acesso em: 17 abr. 2016.

BRASIL. Decreto no 96.607, de 30 de agosto de 1988. Diário Oficial da União. Brasília, Brasil, 1988b. Disponível em: <http://www.planalto.gov.br/ccivil_03/decreto/1980-1989/D96607.htm >. Acesso em: 17 abr. 2016.

BRASIL. Departamento Nacional de Saúde. Portaria no 24, de 14 de abril de 1945. Diário Oficial [da União], Poder Executivo, Rio de Janeiro, 25 mar. 1947. Seção 1, p. 4040.

BRASIL. Departamento Nacional de Saúde. Portaria no 47, de 06 de março de 1943. Diário Oficial [da União], Poder Executivo, Rio de Janeiro, 11 mar. 1943a. Seção 1, p. 3526-3527.

BRASIL. Farmacopeia Brasileira. 3. ed. São Paulo: Organização Andrei Editora, 1977.

BRASIL. Farmacopeia Brasileira. 4. ed. São Paulo: Atheneu, 1996. v. 2, fasc. 1.

BRASIL. Farmacopeia Brasileira. 4. ed. São Paulo: Atheneu, 2000. v. 2, fasc. 2.

BRASIL. Farmacopeia Brasileira. 4. ed. São Paulo: Atheneu, 2001. v. 2, fasc. 3.

BRASIL. Farmacopeia Brasileira. 4. ed. São Paulo: Atheneu, 2002. v. 2, fasc. 4.

BRASIL. Farmacopeia Brasileira. 4. ed. São Paulo: Atheneu, 2003a. v. 2, fasc. 5.

BRASIL. Farmacopeia Brasileira. 4. ed. Brasília: Diário Oficial da União, 2005a. v. 2, fasc. 6.

BRASIL. Farmacopeia Brasileira. 5. ed. Brasília: Anvisa, 2010c. v. 1.

BRASIL. Farmacopeia Brasileira. 5. ed. Brasília: Anvisa, 2010d. v. 2.

BRASIL. Farmacopeia Brasileira. 4. ed. São Paulo: Atheneu, 1988c. v. 1.

BRASIL. Farmacopeia dos Estados Unidos do Brasil. 1. ed. Rio de Janeiro: [s.n.], 1929.

BRASIL. Farmacopeia dos Estados Unidos do Brasil. 2. ed. São Paulo: Indústria Gráfica Siqueira, 1959b.

BRASIL. Formulário de Fitoterápicos da Farmacopeia Brasileira. 1. ed. Brasília: Anvisa, 2011.

BRASIL. Formulário Nacional da Farmacopeia Brasileira. 1. ed. Brasília: Anvisa, 2005 b.

BRASIL. Formulário Nacional da Farmacopeia Brasileira. 2. ed. Brasília: Anvisa, 2012.

BRASIL. Lei $\mathbf{n}^{\circ}$ 10.742, de 06 de outubro de 2003. Diário Oficial da União. Brasília, Brasil, 2003b. Disponível em: 〈http://www.planalto.gov.br/ccivil_03/leis/2003/L10.742.htm\#art13>. Acesso em: 26 set. 2016.

BRASIL. Lei $n^{0} 6.360$ de 23 de setembro de 1976. Diário Oficial da União. Brasília, Brasil, 1976b. Disponível em: <http://www.planalto.gov.br/ccivil_03/leis/L6360.htm>. Acesso em: 26 set. 2016. 
BRASIL. Lei no 9.782, de 26 de janeiro de 1999. Diário Oficial da União. Brasília, Brasil, 1999. Disponível em: <http://www.planalto.gov.br/ccivil_03/leis/L9782.htm>. Acesso em: 17 abr. 2016.

BRASIL. Memento Fitoterápico da Farmacopeia Brasileira. 1. ed. Brasília: Anvisa, 2016d. Disponível em: <http://portal.anvisa.gov.br/documents/33832/2909630/Memento+Fitoterapico/a80ec477-bb36-4ae0-b1d2e2461217e06b>. Acesso em: 3 out. 2016.

BRASIL. Ministério da Saúde. Política Nacional de Plantas Medicinais e Fitoterápicos. 1. ed. Brasília, Brasil: Ministério da Saúde, 2006a.

BRASIL. Ministério da Saúde. Política nacional de práticas integrativas e complementares no SUS. 1. ed. Brasília, Brasil: Ministério da Saúde, 2006b.

BRASIL. Ministério da Saúde. Relação de Plantas Medicinais de Interesse ao SUS. Agência Saúde. Brasil: Ministério da Saúde. Disponível em: <http://bvsms.saude.gov.br/bvs/sus/pdf/marco/ms_relacao_plantas_medicinais_sus_0603.pdf>. 2009b

BRASIL. Ministério das Relações Exteriores. Política Externa - Mercosul. Disponível em: <http://www.itamaraty.gov.br/pt-BR/politica-externa/integracao-regional/686-mercosul>. Acesso em: 4 out. 2016.

BRASIL. Suplemento da Farmacopeia dos Estados Unidos do Brasil. 1. ed. Rio de Janeiro: Diário Oficial, 1943 b.

BRASIL. Terceiro Suplemento da Farmacopeia Brasileira. 1 ed. Rio de Janeiro: Diário Oficial, 1951.

CALIXTO, J. B. Efficacy, safety, quality control, marketing and regulatory guidelines for herbal medicines (phytotherapeutical agents). Brazilian Journal of Medical and Biological Research, v. 33, n. 2, p. 179-189, 2000.

CARVAlHO, A. C. B. Plantas Medicinais e Fitoterápicos: Regulamentação Sanitária e Proposta de Modelo de Monografia para Espécies Vegetais Oficializadas no Brasil. 2011. 318 f. Tese (Doutorado em Ciências da Saúde) - Universidade de Brasília, Brasília, 2011.

CARVALHO, A. C. B. et al. Regulation of herbal medicines in Brazil. Journal of Ethnopharmacology, v. 158, p. 503-506, 2014. Disponível em: <http://dx.doi.org/10.1016/j.jep.2014.08.019>.

DE VALÉCIO, M. Guia da Farmácia - Fitoterápicos ganham espaço. Disponível em: $<$ http://www.guiadafarmacia.com.br/edicao-257-reajuste-de-precos/426-suplementos-especiais/fito-2016/10793fitoterapicos-ganham-espaco>. Acesso em: 3 out. 2016.

EDQM. European Directorate for the Quality of Medicines \& HealthCare. 5.8 Pharmacopoeial harmonisation. In: EUROPEAN PHARMACOPOEIA (Org.). European Pharmacopoeia. 8.7 ed. Strasbourg: EDQM, 2016a. p. 5617-5630.

EDQM. European Directorate for the Quality of Medicines \& HealthCare. European Pharmacopoeia. 8.8 ed. Strasbourg: EDQM, 2016b. Disponível em: <http://online6.edqm.eu/ep808/>.

EDQM. European Directorate for the Quality of Medicines \& HealthCare. Herbal drugs. In: EUROPEAN PHARMACOPOEIA (Org.). European Pharmacopoeia. 8.8 ed. Strasbourg: EDQM, 2016c. p. 746-747.

EDQM. European Directorate for the Quality of Medicines \& HealthCare. II. Introduction. In: PHARMACOPOEIA, E. (Org.). European Pharmacopoeia. 8.8 ed. Strasbourg: EDQM, 2016d.

EDQM. European Directorate for the Quality of Medicines \& HealthCare. Microbiological quality of herbal medicinal products for oral use and extracts used in their preparation. In: EUROPEAN PHARMACOPOEIA (Org.). European Pharmacopoeia. 8.8 ed. Strasbourg: EDQM, 2016e. p. 571-572. 
EDQM. European Directorate for the Quality of Medicines \& HealthCare. Microbiological quality of non-sterile pharmaceutical preparations and substances for pharmaceutical use. In: EUROPEAN PHARMACOPOEIA (Org.). European Pharmacopoeia. 8.8 ed. Strasbourg: EDQM, 2016f. p. 559.

EDQM. European Directorate for the Quality of Medicines \& HealthCare. Preface. In: EUROPEAN PHARMACOPOEIA (Org.). European Pharmacopoeia. 8.8 ed. Strasbourg: EDQM, 2016g. p. i-iii.

EDQM. European Directorate for the Quality of Medicines \& HealthCare. Results list report - NetlS TM technology. In: EUROPEAN PHARMACOPOEIA (Org.). European Pharmacopoeia. 8.8 ed. Strasbourg: EDQM, 2016h.

EIGA. European Industrial Gases Association. Comparison of European, US and Japanese Pharmacopoeia Monographs for Medicinal Gases. Brussels: EIGA, 2011.

ELOFF, J. N.; NTLOEDIBE, D. T.; VAN BRUMMELEN, R. A simplified but effective method for the quality control of medicinal plants by planar chromatography. African journal of traditional, complementary, and alternative medicines: AJTCAM / African Networks on Ethnomedicines, v. 8, n. 5 Suppl, p. 1-12, 2011.

EMA. European Medicines Agency. Herbal products - European Union monographs and list entries. Disponível em:

<http://www.ema.europa.eu/ema/index.jsp?curl=pages/regulation/general/general_content_001132.jsp\&mid=W C0b01ac0580033809>. Acesso em: 25 ago. 2016.

EUROMONITOR. International Euromonitor - Country Report - Herbal/Traditional Products in Brazil. Disponível em: <http://www.euromonitor.com/herbal-traditional-products-in-brazil/report>. Acesso em: 3 out. 2016.

FAN, T. P. et al. Future development of global regulations of Chinese herbal products. Journal of Ethnopharmacology, v. 140, p. 568-586, 2012. Disponível em: <http://dx.doi.org/10.1016/j.jep.2012.02.029>.

FOLASHADE, O.; OMOREGIE, H.; OCHOGU, P. Standardization of herbal medicines -A review. International Journal of Biodiversity and Conservation, v. 4, n. 3, p. 101-112, 2012. Disponível em: <http://www.academicjournals.org/IJBC>. Acesso em: 20 ago. 2016.

FORTE, J. S.; RAMAN, A. Regulatory Issues Relating to Herbal Products—Part 3: Quality and Its Determination. Journal of Medicinal Food, v. 3, n. 1, p. 59-69, 2000.

GIA. Global Industry Analysts. MCP-1081: Herbal Supplements and Remedies - A Global Strategic Business Report - Market Research Report Collections - WWW.StrategyR.com. Disponível em: <http://www.strategyr.com/pressMCP-1081.asp>. Acesso em: 30 set. 2016.

HALLMANN-MIKOŁAJCZAK, A. [Ebers Papyrus. The book of medical knowledge of the 16th century B.C. Egyptians]. Archiwun Historii Filozofii Medycyny, v. 67, n. 1, p. 5-14, 2004.

HEALTH CANADA. Drugs and Health Products - Compendium of Monographs. Disponível em: <http://www.hc-sc.gc.ca/dhp-mps/prodnatur/applications/licen-prod/monograph/index-eng.php>. Acesso em: 25 ago. 2016.

HMPC. Committee on Herbal Medicinal Products. Community Herbal Monograph on Cassia senna L., fructus and Cassia angustifolia Vahl, fructus. London: HMPC, 2006a. Disponível em: <http://www.ema.europa.eu/docs/en_GB/document_library/Herbal_-

_Community_herbal_monograph/2009/12/WC500018202.pdf>. Acesso em: 26 ago. 2016.

HMPC. Committee on Herbal Medicinal Products. Community Herbal Monograph on Cassia senna L. and Cassia angustifolia Vahl, folium. London: HMPC, 2006b. Disponível em: <http://www.ema.europa.eu/docs/en_GB/document_library/Herbal_-

_Community_herbal_monograph/2009/12/WC500018215.pdf>. Acesso em: 26 ago. 2016. 
HMPC. Committee on Herbal Medicinal Products. Community Herbal Monograph on Hamamelis virginiana L., folium. London: HMPC, $2009 . \quad$ Disponível em: <http://www.ema.europa.eu/docs/en_GB/document_library/Herbal_-

_Community_herbal_monograph/2010/04/WC500089247.pdf>. Acesso em: 26 ago. 2016.

HMPC. Committee on Herbal Medicinal Products. Community herbal monograph on Hamamelis virginiana L., cortex. London: HMPC, $2011 . \quad$ Disponível em: $<$ http://www.ema.europa.eu/docs/en_GB/document_library/Herbal_-

_Community_herbal_monograph/2010/04/WC500089244.pdf>. Acesso em: 26 ago. 2016.

HÖLLEIN, L. et al. Routine quality control of medicines in developing countries: analytical challenges, regulatory infrastructures and the prevalence of counterfeit medicines in Tanzania. TrAC Trends in Analytical Chemistry, v. 76, p. 60-70, 2015. Disponível em: <http://www.sciencedirect.com/science/article/pii/S0165993615300820>. Acesso em: 20 dez. 2015.

ICH. International Council for Harmonisation of Technical Requirements for Pharmaceuticals for Human Use. Articles of Association, adopted by ICH Founding Members at ICH Inaugural Assembly on October 23, 2015. [Geneva]: ICH. Disponível em: <http://www.ich.org/fileadmin/Public_Web_Site/ABOUT_ICH/Organisational_changes/ICH_Articles_of_Assoc iation_Adopted_by_Founding_ICH_Members_October_23_2015_for_publication.pdf>. Acesso em: 26 ago. 2016.

ICH. International Council for Harmonisation of Technical Requirements for Pharmaceuticals for Human Use. Frequently Asked Questions Q4B: Evaluation and Recommendation of Pharmacopoeial Texts for Use in the ICH Regions, 26 April 2012. ICH Q4B Frequently Asked Questions Document. Geneva: ICH, 2012. Disponível em: <http://www.ich.org/fileadmin/Public_Web_Site/ICH_Products/Guidelines/Quality/Q4B/Q4B_Frequently_Aske d_Questions_26.April.pdf>. Acesso em: 26 ago. 2016.

INIC, S.; KUJUNDZIC, N. The original Croatian pharmacopoeia from 1901. Pharmazie, v. 67, p. 652-657, 2012.

KAN, L.-B. Introduction to chinese medical literature. Bulletin of the Medical Library Association, v. 53, n. 1, p. $60-70,1965$.

KEITEL, S. The need for pharmacopoeial harmonisation: in the context of international trade, the need to develop global quality standards for medicines is increasing. Pharmaceutical Technology Europe, v. 25, n. 4, p. $20,2013$. Disponível em: <http://go.galegroup.com.ez54.periodicos.capes.gov.br/ps/i.do?id=GALE\%25 7CA334277907\&v=2.1\&u=capes\&it=r\&p=AONE\&sw=w\&asid=b78e13458b42f00f8ce0e94c9d63bf9f $>$.

Acesso em: 7 out. 2015.

LEONTI, M. et al. A comparison of medicinal plant use in Sardinia and Sicily-De Materia Medica revisited? Journal of Ethnopharmacology, v. 121, n. 2, p. 255-267, 2009.

LEONTI, M.; CASU, L. Traditional medicines and globalization: Current and future perspectives in ethnopharmacology. Frontiers in Pharmacology, v. 4, n. July, p. 1-13, 2013.

MERCOSUL. Grupo Mercado Comum. MERCOSUL/GMC/RES. No 31/2011 - Estratégia para a Farmacopeia MERCOSUL. $\quad$ Montevidéu, 2011. Disponível em: <http://www.mercosur.int/innovaportal/v/3186/2/innova.front/resoluciones-2011>.

MOREIRA, D. L. et al. Traditional use and safety of herbal medicines1. Revista Brasileira de Farmacognosia, v. 24, $248-257, \quad 2014 . \quad$ Disponível <http://www.sciencedirect.com/science/article/pii/S0102695X1400012X>.

PAULA, A. et al. Iniciativas de convergência regulatória em saúde nas Américas: histórico, evolução e novos desafios. Rev Panam Salud Publica Pan, v. 39, n. 5, p. 281-287, 2016.

PDG. Pharmacopoeial Discussion Group. Working Procedures of the Pharmacopoeial Discussion Group (PDG) Revised version (June 2010). Pharmaeuropa, v. 22, n. 4, p. 590-592, 2010. 
PERFEITO, J. P. S. O registro sanitário de medicamentos fitoterápicos no Brasil: uma avaliação da situação atual e das razões de indeferimento. 2012. 162 f. Dissertação (Mestrado em Ciências da Saúde) - Universidade de Brasília, Brasília, 2012. Disponível em: <http://repositorio.unb.br/bitstream/10482/10429/1/2012_JoaoPauloSilverioPerfeito.pdf>.

RATES, S. M. K. Plants as source of drugs. Toxicon, v. 39, p. 603-613, 2001.

REDCHENKOVA, V. N.; KHISHOVA, O. M. Comparative analysis of the requirements of some pharmacopoeias on medicinal extracts. Pharmaceutical Chemistry Journal, v. 40, n. 1, p. 40-43, 2006.

REFLORA. Flora do Brasil 2020 em construção. Disponível em: <http://floradobrasil.jbrj.gov.br/reflora/listaBrasil/>. Acesso em: 25 jul. 2016.

SAITO, H. Regulation of herbal medicines in Japan. Pharmacological research, v. 41, n. 5, p. 515-519, 2000.

SHARMA, R. et al. An overview of standardization of herbal medicines: authentication \& quality control evaluation. ASIO Journal of Pharmaceutical \& Herbal Medicines Research, v. 1, n. 1, p. 55-61, 2015. Disponível em: <http://albertscience.com/asset/images/uploads/14526921446336.pdf>. Acesso em: 16 abr. 2016.

SHIKOV, A. N. et al. Medicinal Plants of the Russian Pharmacopoeia; Their history and applications. Journal of Ethnopharmacology, v. 154, n. 3, p. 481-536, 2014. Disponível em: <http://dx.doi.org/10.1016/j.jep.2014.04.007>.

THE PLANT LIST. Version 1.1. Disponível em: <http://www.theplantlist.org/>. Acesso em: 25 jul. 2016.

TROPICOS.ORG. Missouri Botanical Garden. Disponível em: <http://www.tropicos.org>. Acesso em: 25 jul. 2016.

UNCTAD. United Nations Conference on Trade Development. Systems and National Experiences for Protecting Traditional Knowledge, Innovations and Practices. Geneva: UNCTAD, 2000. Disponível em: <http://unctad.org/en/docs/c1em13d2.en.pdf>. Acesso em: 30 set. 2016.

URDANG, G. The development of pharmacopoeias. A review with special reference to the pharmacopoea internationalis. Bulletin World Health Organization, v. 4, p. 577-603, 1951.

USP. United States Pharmacopeial Convention. 〈561〉 Articles of Botanical Origin. In: United States Pharmacopeial Convention. The Pharmacopeia of the United States of America, Thirty-Ninth Revision and The National Formulary, Thirty-Fourth Edition. 39-34. ed. Rockville: USP, 2016a. p. 377-391. Disponível em: <http://www.uspnf.com/uspnf/login>.

USP. United States Pharmacopeial Convention. General Notices. In: United States Pharmacopeial Convention. The Pharmacopeia of the United States of America, Thirty-Ninth Revision and The National Formulary, Thirty-Fourth Edition. 39-34. ed. Rockville: USP, 2016b. p. 7633-7642. Disponível em: <http://www.uspnf.com/uspnf/login>.

USP. United States Pharmacopeial Convention. Members and Delegates of the United States Pharmacopeial Convention as of May 31, 2015. In: United States Pharmacopeial Convention. The Pharmacopeia of the United States of America, Thirty-Ninth Revision and The National Formulary, Thirty-Fourth Edition. 39-34. ed. Rockville: USP, 2016c. p. xxi-xxvii. Disponível em: <http://www.uspnf.com/uspnf/login>.

USP. United States Pharmacopeial Convention. Mission and Preface. In: United States Pharmacopeial Convention. The Pharmacopeia of the United States of America, Thirty-Ninth Revision and The National Formulary, Thirty-Fourth Edition. 39-34. ed. Rockville: USP, 2016d. p. 8197-8200. Disponível em: <http://www.uspnf.com/uspnf/login>.

USP. United States Pharmacopeial Convention. Our History - USP Milestones - A Timeline. Disponível em: <http://www.usp.org/about-usp/our-history/usp-milestones-timeline>. Acesso em: 25 ago. 2016e. 
USP. United States Pharmacopeial Convention. People 2015 - 2020 Revision Cycle. In: United States Pharmacopeial Convention. The Pharmacopeia of the United States of America, Thirty-Ninth Revision and The National Formulary, Thirty-Fourth Edition. 39-34. ed. Rockville: USP, 2016f. p. 7615-7621. Disponível em: <http://www.uspnf.com/uspnf/login>.

USP. United States Pharmacopeial Convention. Products - USP-NF. Disponível em: <http://www.usp.org/store/products-services/usp-nf>. Acesso em: 25 ago. 2016g.

USP. United States Pharmacopeial Convention. The Pharmacopeia of the United States of America, ThirtyNinth Revision and The National Formulary, Thirty-Fourth Edition. 39-34. ed. Rockville: USP, 2016 h. Disponível em: <http://www.uspnf.com/uspnf/login>.

VEIGA JUNIOR, V. F.; MELLO, J. C. P. As monografias sobre plantas medicinais. Revista Brasileira de Farmacognosia, v. 18, n. 3, p. 464-471, 2008.

VLIETINCK, A.; PIETERS, L.; APERS, S. Legal requirements for the quality of herbal substances and herbal preparations for the manufacturing of herbal medicinal products in the European Union. Planta Medica, v. 75, n. 7, p. 683-688, 2009.

WECHSLER, J. Regulatory convergence sought for global pharma market: manufacturers work with international authorities to harmonize drug registration and supply-chain oversight. Biopharm International, v. 26, n. 5, p. 12, 2013. Disponível em: <http://go-galegroup.ez54.periodicos.capes.gov.br/ps/i.do?id=GALE\%25 7CA332893630\&v=2.1\&u=capes\&it=r\&p=AONE\&sw=w\&asid=90647d411ba5ede01 ad087559364d8ea>.

Acesso em: 2 mar. 2016.

WHO. World Health Organization. Expert Committee on Specifications for Pharmaceutical Preparations Annex 1 - Good pharmacopoeial practices. WHO Technical Report Series, v. 55, n. 996, 2016a. Disponível em: <http://apps.who.int/medicinedocs/documents/s22398en/s22398en.pdf>. Acesso em: 11 set. 2016.

WHO. World Health Organization. Good pharmacopoeial practices (Revised draft for comments - Working document QAS/13.526/Rev6). Geneva: World Health Organization, 2015a

WHO. World Health Organization. Guidelines for Assessing Quality of Herbal Medicines with Reference to Contaminants and Residues. Geneva: World Health Organization, 2007a.

WHO. World Health Organization. Guidelines on Good Agricultural and Collection Practices (GACP) for Medicinal Plants. Geneva: World Health Organization, 2003. Disponível em: <http://apps.who.int/medicinedocs/pdf/s4928e/s4928e.pdf>. Acesso em: 30 set. 2016.

WHO. World Health Organization. Guidelines on Good Manufacturing Practices (GMP) for Herbal Medicines. Geneva: World Health Organization, 2007b. Disponível em: <http://apps.who.int/medicinedocs/documents/s14215e/s14215e.pdf>. Acesso em: 30 set. 2016.

WHO. World Health Organization. Index of World Pharmacopoeias and Pharmacopoeial Authorities (Working document QAS/11.453/Rev.5) August 2016. Geneva: World Health Organization, $2016 \mathrm{~b}$.

WHO. World Health Organization. International Pharmacopoeia. 15. ed. [S.l: World Health Organization.], 2015b.

WHO. World Health Organization. International Regulatory Cooperation for Herbal Medicines (IRCH). Disponível em: <http://www.who.int/medicines/areas/traditional/irch/en/>. Acesso em: 30 set. $2016 \mathrm{c}$.

WHO. World Health Organization. Monographs on Selected Medicinal Plants volume 2. Geneva: World Health Organization, 2004.

WHO. World Health Organization. Monographs on Selected Medicinal Plants volume 3. Geneva: World Health Organization, 2007c. Disponível em: <http://apps.who.int/medicinedocs/documents/s14213e/s14213e.pdf>. Acesso em: 30 set. 2016. 
WHO. World Health Organization. Monographs on Selected Medicinal Plants volume 4. Geneva: World Health Organization, 2009. Disponível em: <http://apps.who.int/medicinedocs/documents/s16713e/s16713e.pdf>. Acesso em: 30 set. 2016.

WHO. World Health Organization. The International Pharmacopoeia. WHO Drug Information, v. 27, n. 2, p. 119-128, 2013a.

WHO. World Health Organization. Traditional Medicine Strategy 2002-2005. Geneva: World Health 2002. Disponível

em:

<http://www.wpro.who.int/health_technology/book_who_traditional_medicine_strategy_2002_2005.pdf>.

Acesso em: 29 set. 2016.

WHO. World Health Organization. Traditional Herbal Remedies for Primary Health Care. New Delhi: World Health Organization, 2010.2 Disponível em: <http://apps.who.int/medicinedocs/documents/s22298en/s22298en.pdf>. Acesso em: 30 set. 2016.

WHO. World Health Organization. Traditional Medicine Strategy 2014-2023. Switzerland: World Health Organization, 2013 b.

Disponível

em: <http://apps.who.int/iris/bitstream/10665/92455/1/9789241506090_eng.pdf>. Acesso em: 30 set. 2016.

WHO. World Health Organization. Updated edition of Quality control methods for medicinal plant materials. Geneva: World Health $\quad 2011 . \quad$ Disponível em: <http://apps.who.int/medicinedocs/documents/h1791e/h1791e.pdf>. Acesso em: 30 set. 2016. 


\section{APÊNDICE A}

Apêndice A - Nomenclatura botânica, nomenclatura popular das espécies da Farmacopeia Brasileira e do Formulário de Fitoterápicos, sinonímias consideradas nas buscas exaustivas descritas na dissertação e dados brutos da pesquisa de ocorrência das espécies no Brasil.

\begin{tabular}{|c|c|c|c|c|c|c|}
\hline $\mathrm{N}^{\mathrm{o}}$ & $\begin{array}{l}\text { Nomenclatura } \\
\text { botânica }\end{array}$ & $\begin{array}{l}\text { Nomenclatura } \\
\text { Popular }\end{array}$ & Sinonímias consideradas & Acesso em: & $\begin{array}{c}\text { Ocorrência } \\
\text { no Brasil }\end{array}$ & Acesso em: \\
\hline 1 & $\begin{array}{l}\text { Achillea } \\
\text { millefolium } \mathrm{L} .\end{array}$ & $\begin{array}{l}\text { mil-folhas/ mil- } \\
\text { em-rama }\end{array}$ & 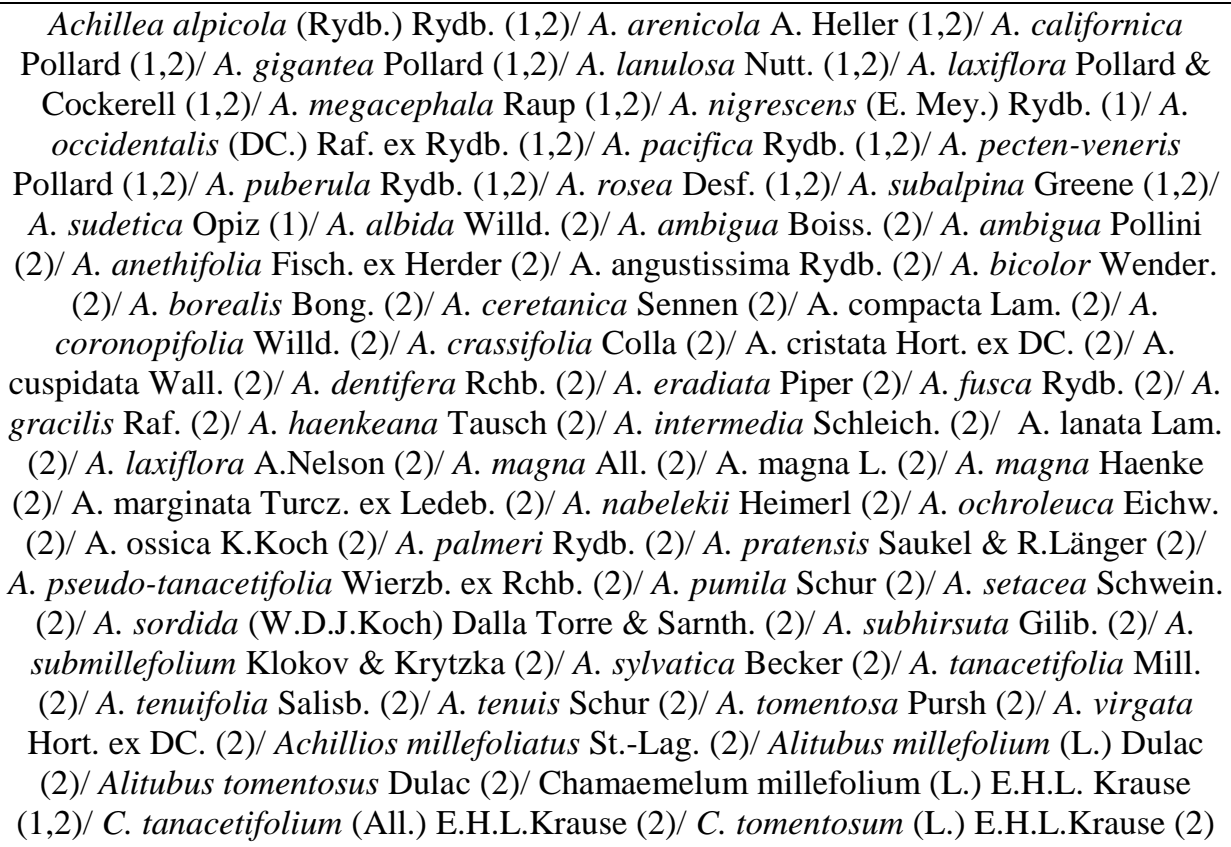 & 07/06/2016 & $\operatorname{sim}(1)$ & $24 / 07 / 2016$ \\
\hline 2 & $\begin{array}{l}\text { Achyrocline } \\
\text { satureioides } \\
\text { (Lam.) DC. }\end{array}$ & $\begin{array}{l}\text { macela/ } \\
\text { marcela/ } \\
\text { marcela-do- } \\
\text { campo }\end{array}$ & $\begin{array}{l}\text { Achyrocline candicans (Kunth) DC. }(1,2) / \text { A. vargasiana DC. }(1,2) / \text { Gnaphalium } \\
\text { candicans Kunth }(1,2) / \text { G. satureioides Lam. }(1,2) / \text { G. rufum Willd. ex Less. }(2) / G . \\
\text { saturejaefolium Poepp. ex DC. }(2)\end{array}$ & 07/06/2016 & $\operatorname{sim}(3)$ & $24 / 07 / 2016$ \\
\hline 3 & $\begin{array}{l}\text { Aesculus } \\
\text { hippocastanum } \\
\text { L. }\end{array}$ & $\begin{array}{l}\text { castanha-da- } \\
\text { índia }\end{array}$ & $\begin{array}{l}\text { Hippocastanum vulgare Gaertn.(1,2)/ Aesculus asplenifolia Loudon (2)/ A. } \\
\text { memmingeri K.Koch (2)/ A. procera Salisb. (2)/ A. septenata Stokes (2) }\end{array}$ & 07/06/2016 & não $(1,3)$ & $24 / 07 / 2016$ \\
\hline 4 & $\begin{array}{l}\text { Allium sativum } \\
\text { L. }\end{array}$ & alho & $\begin{array}{l}\text { Allium pekinense Prokh. }(1,2) / \text { A. arenarium Sadler ex Rchb. }(2) / \text { A. controversum } \\
\text { Schrad. ex Willd. (2)/ A. longicuspis Regel }(2) / \text { A. ophioscorodon Link }(2) / \text { Porrum } \\
\text { ophioscorodon (Link) Rchb. }(2) / \text { P. sativum }(\text { L.) Rchb. }(1,2)\end{array}$ & $07 / 06 / 2016$ & não $(1,3)$ & $24 / 07 / 2016$ \\
\hline
\end{tabular}

(continua) 


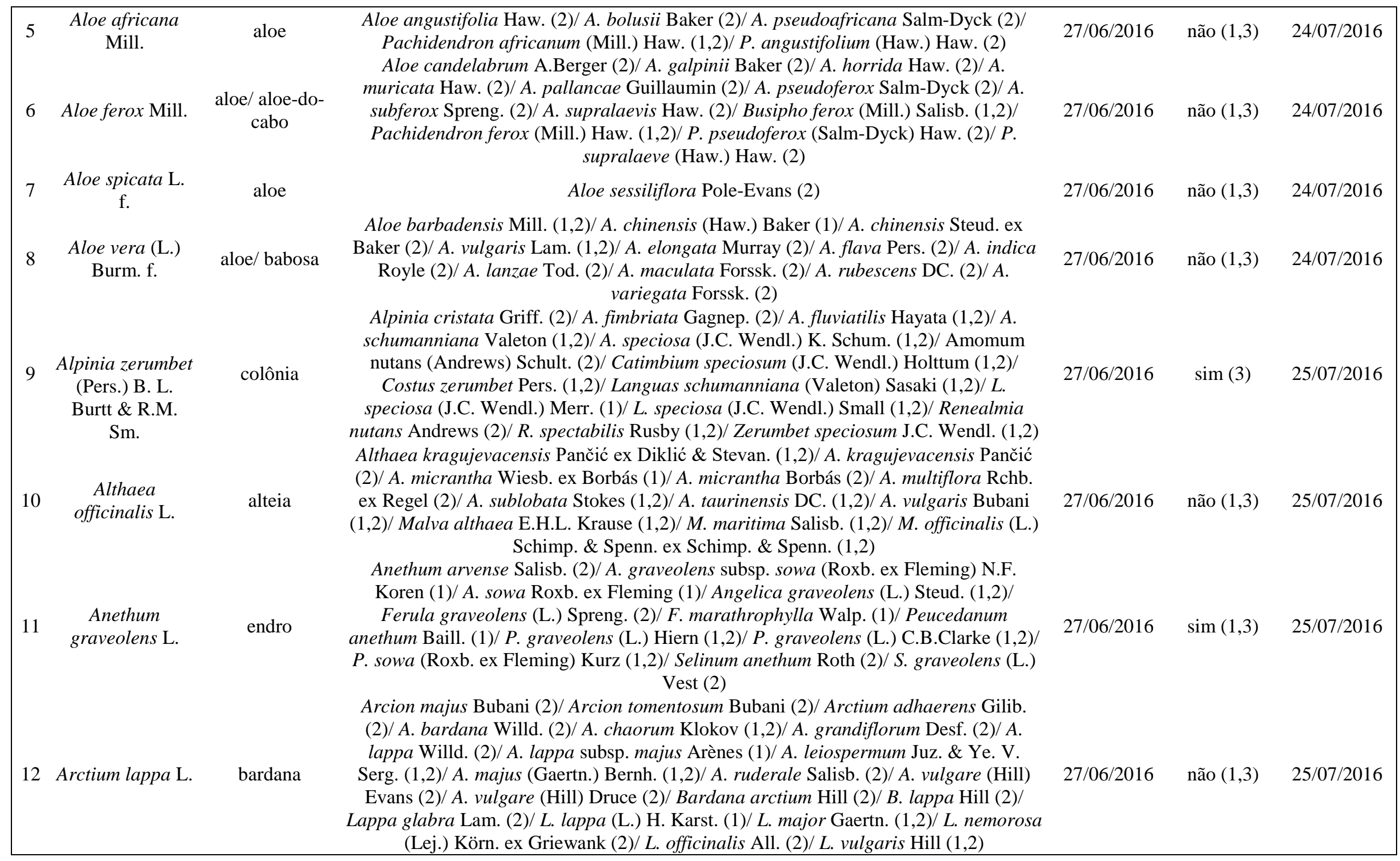




\begin{tabular}{|c|c|c|c|c|c|c|}
\hline 13 & $\begin{array}{c}\text { Arnica montana } \\
\text { L. }\end{array}$ & arnica & $\begin{array}{c}\text { Arnica alpina Willd. ex Steud. (2)/ A. angustifolia Turcz. ex Ledeb. (2)/ A. helvetica } \\
\text { G.Don ex Loudon (2)/ A. lowii Holm (2)/ A. petiolata Schur (2)/ A. plantaginifolia } \\
\text { Gilib. (2)/ Cineraria cernua Thore (2)/ Doronicum arnica Garsault (2)/ D. montanum } \\
\text { (L.) Lam. (2)/ D. oppositifolium Lam. (2) }\end{array}$ & $27 / 06 / 2016$ & não $(1,3)$ & $25 / 07 / 2016$ \\
\hline 14 & $\begin{array}{l}\text { Atropa } \\
\text { belladonna L. }\end{array}$ & beladona & $\begin{array}{l}\text { Atropa acuminata Royle (1)/ A. borealis Kreyer ex Pascher (2)/ A. cordata Pascher (2)/ } \\
\text { A. digitaloides Pascher (2)/ A. lethalis Salisb. (2)/ A. lutescens Jacquem. ex C.B.Clarke } \\
\text { (2)/ A. mediterranea Kreyer ex Pascher (2)/ Belladonna baccifera Lam. (2)/ B. } \\
\text { trichotoma Scop. (2)/ Boberella belladonna (L.) E.H.L.Krause (1,2) }\end{array}$ & $27 / 06 / 2016$ & não $(1,3)$ & $25 / 07 / 2016$ \\
\hline 15 & $\begin{array}{l}\text { Baccharis } \\
\text { trimera (Less.) } \\
\text { DC. }\end{array}$ & $\begin{array}{l}\text { carqueja/ } \\
\text { carqueja- } \\
\text { amarga }\end{array}$ & $\begin{array}{l}\text { Baccharis genistelloides (Lam.) Pers. (1)/ B. genistelloides subsp. crispa (Spreng.) } \\
\text { Joch. Müll. (1)/ Molina trimera Less. }(1,2)\end{array}$ & $27 / 06 / 2016$ & $\operatorname{sim}(1,3)$ & $25 / 07 / 2016$ \\
\hline 16 & $\begin{array}{l}\text { Caesalpinia } \\
\text { ferrea Mart. ex } \\
\quad \text { Tul. }\end{array}$ & jucá & $\begin{array}{c}\text { Apuleia ferrea (Mart.) Baill. (1)/ Caesalpinia ferrea Mart. (1)/ Libidibia ferrea (Mart.) } \\
\text { L.P. Queiroz (1) }\end{array}$ & $08 / 07 / 2016$ & $\operatorname{sim}(1,3)$ & $25 / 07 / 2016$ \\
\hline 17 & $\begin{array}{l}\text { Calendula } \\
\text { officinalis L. }\end{array}$ & calêndula & $\begin{array}{c}\text { Calendula aurantiaca Kotschy ex Boiss. (2)/ C. eriocarpa DC. (2)/ C. hydruntina } \\
\text { (Fiori) Lanza (2)/ C. prolifera Hort. ex Steud. (2)/ C. } \times \text { santamariae Font Quer (2)/ } \\
\text { Caltha officinalis (L.) Moench (2) }\end{array}$ & $27 / 06 / 2016$ & $\operatorname{sim}(1)$ & $25 / 07 / 2016$ \\
\hline 18 & $\begin{array}{c}\text { Casearia } \\
\text { sylvestris } \mathrm{Sw} .\end{array}$ & $\begin{array}{l}\text { guaçatonga/ } \\
\text { erva-de-bugre/ } \\
\text { erva-de-lagarto }\end{array}$ & 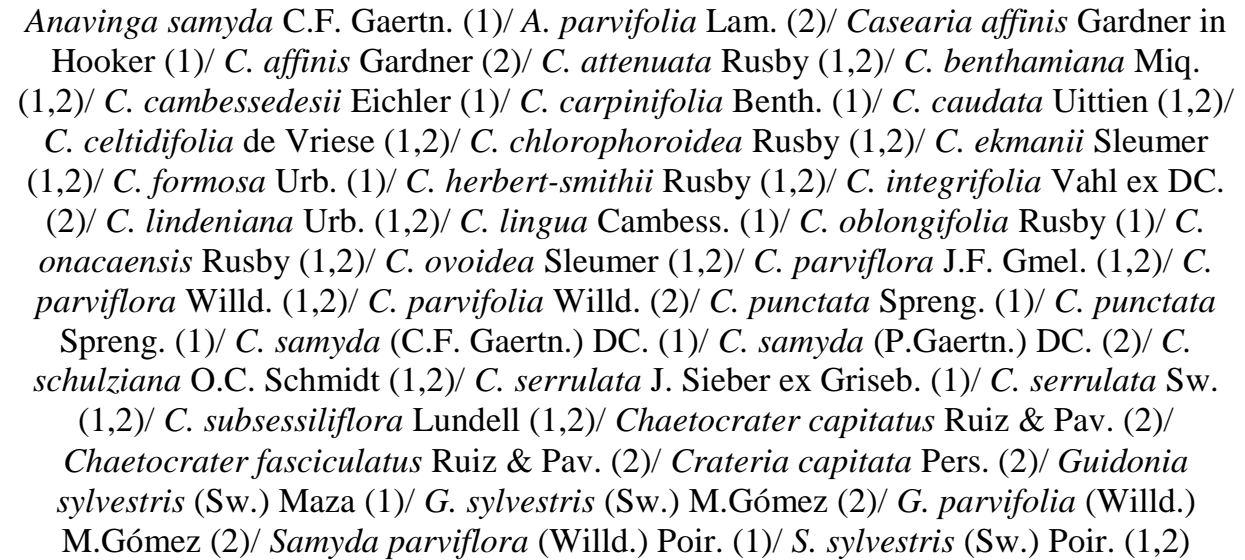 & 08/07/2016 & $\operatorname{sim}(1,3)$ & $25 / 07 / 2016$ \\
\hline 19 & $\begin{array}{l}\text { Centella asiatica } \\
\text { (L.) Urb. }\end{array}$ & centela & $\begin{array}{l}\text { Centella biflora (P. Vell.) Nannf. (1)/ C. boninensis Nakai ex Tuyama (2)/ C. coriacea } \\
\text { Nannf. (1)/ C. dusenii Nannf. (1)/ C. erecta (L. f.) Fernald (1)/ C. floridana (J.M. } \\
\text { Coult. \& Rose) Nannf. (1)/ C. glochidiata (Benth.) Drude (2)/ C. hirtella Nannf. (1,2)/ } \\
\text { C. repanda (Pers.) Small (1)/ C. triflora (Ruiz \& Pav.) Nannf. (1)/ C. tussilaginifolia } \\
\text { (Baker) Domin (2)/ C. ulugurensis (Engl.) Domin (2)/ C. uniflora (Colenso) Nannf. }\end{array}$ & 08/07/2016 & $\operatorname{sim}(1,3)$ & $25 / 07 / 2016$ \\
\hline
\end{tabular}


20 Cinchona

calisaya Wedd. quina-amarela

Cinnamomum

$21 \operatorname{cassia}(\mathrm{L}.) \mathrm{J}$

Presl

verum J. Presl

canela/ canela-

do-ceilão

(2)/ Chondrocarpus asiaticus Nutt. (2)/ Chondrocarpus triflorus Nutt. (2)/ Glyceria

asiatica Nutt. (2)/ G. repanda (Pers.) Nutt. (1)/ G. triflora Nutt. (2)/ Hydrocotyle asiatica fo. luxurians Donn. Sm. (1)/ H. asiatica L. (1,2)/ H. biflora P. Vell. $(1,2) / H$. brasiliensis Scheidw. ex Otto \& F. Dietr. $(1,2) / H$. brevipedata St. Lager \& St.-Lag.

$(1,2) / H$. erecta L. f. (1)/ H. ficarifolia Stokes $(1,2) / H$. ficarioides Lam. $(1,2) / H$. ficarioides Michx. (1)/ H. inaequipes DC. $(1,2) / H$. lurida Hance $(1,2) / H$.

nummularioides A. Rich. $(1,2) / H$. reniformis Walter $(1,2) / H$. repanda Pers. $(1,2) / H$.

sylvicola E. Jacob Cordemoy $(1,2) / H$. triflora Ruiz \& Pav. (1,2)/ H. tussilaginifolia Baker (2)/ H. uniflora Colenso (2)

Cinchona amygdalifolia Wedd. (1,2)/ C. australis Wedd. (1,2)/ C. boliviana Wedd. (1)/

C. carabayensis Wedd. $(1,2) / C$. delondriana Wedd. $(1,2) / C$. euneura Miq. $(1,2) / C$. forbesiana Howard ex Wedd. $(1,2) / C$. gammiana King (2)/ C. gironensis Mutis (2)/ C. hasskarliana Miq. $(1,2) /$ C. josephiana (Wedd.) Wedd. $(1,2) /$ C. ledgeriana (Howard)

Bern. Moens ex Trimen (1,2)/ C. officinalis L. (1)/ C. pahudiana Howard $(1,2) / C$. peruviana Howard (1,2)/C. thwaitesii King (2)/ C. weddelliana Kuntze $(1,2) /$

Quinquina calisaya (Wedd.) Kuntze $(1,2) /$ Q carabayensis (Wedd.) Kuntze $(1,2) / Q$. ledgeriana (Howard) Kuntze $(1,2)$

Camphorina cassia (Nees \& T.Nees) Farw. (2)/ Cinnamomum aromaticum Nees $(1,2) /$ C. cassia (L.) D. Don (1,2)/ C. cassia Nees ex Blume (1)/ C. cassia Siebold (1)/ C.

longifolium Lukman. (2)/ C. medium Lukman. (2)/ C. nitidum Hook. (2)/ Laurus cassia L. $(1,2) /$ L. cassia Nees $(2) /$ L. cassia Nees \& T. Nees (1)/ Neolitsea cassia (L)

Kosterm. (1,2)/ Persea cassia (L.) Spreng. $(1,2)$

Camphora mauritiana Lukman. (1)/ Camphorina cinnamomum (L.) Farw. (2)/ Cinnamomum alexei Kosterm. (2)/ C. aromaticum J.Graham (2)/ C. barthii Lukman.

(2)/ C. bengalense Lukman. (2)/ C. biafranum Lukman. (2)/ C. bonplandii Lukman.

(2)/ C. boutonii Lukman./ C. capense Lukman. (2)/ C. cayennense Lukman. (2)/ C.

cinnamomum (L.) H.Karst. (2)/ C. commersonii Lukman. (2)/ C. cordifolium Lukman.

(2)/ C. decandollei Lukman. (2)/ C. delessertii Lukman. (2)/ C. ellipticum Lukman. (2)/ C. erectum Lukman. (2)/ C. humboldtii Lukman. (2)/ C. iners Wight (2)/ C. karrouwa Lukman. (2)/ C. leptopus A.C.Sm. (2)/ C. leschenaultii Lukman. (2)/ C. madrassicum Lukman. (2)/ C. maheanum Lukman. (2)/ C. mauritianum Lukman. (2)/ C. meissneri Lukman. (2)/ C. ovatum Lukman. (2)/ C. pallasii Lukman. (2)/ C. pleei Lukman. (2)/

C. pourretii Lukman. (2)/ C. regelii Lukman. (2)/ C. roxburghii Lukman. (2)/ C.

sieberi Lukman. (2)/ C. sonneratii Lukman. (2)/ C. vaillantii Lukman. (2)/ C. variabile Lukman. (2)/ C. wolkensteinii Lukman. (2)/ C. zeylanicum Blume $(1,2) /$ C. zeylanicum Breyn. (1)/ C. zollingeri Lukman. (2)/ Laurus cinnamomum L. (1,2)

Citrus

NOMENCLATURA BOTÂNICA NÃO ENCONTRADA NA LITERATURA CONSULTADA

$11 / 07 / 2016 \quad \begin{array}{ll}\operatorname{sim}(1,3) & 25 / 07 / 2016\end{array}$




\begin{tabular}{|c|c|c|c|c|c|c|}
\hline & $\begin{array}{l}\text { subsp. } \\
\text { aurantium }\end{array}$ & & & \multicolumn{3}{|c|}{$\begin{array}{l}\text { aurantium } \\
\text { L.] }\end{array}$} \\
\hline 24 & $\begin{array}{l}\text { Cola nitida } \\
\text { (Vent.) Schott \& } \\
\text { Endl. }\end{array}$ & noz-de-cola & $\begin{array}{l}\text { Cola nitida A. Chev. (1)/ C. vera K.Schum. (2)/ Bichea nitida (Vent.) Farw. (2)/ } \\
\text { Sterculia nitida Vent. }(1,2)\end{array}$ & $11 / 07 / 2016$ & não $(1,3)$ & $25 / 07 / 2016$ \\
\hline 25 & $\begin{array}{l}\text { Copaifera } \\
\text { langsdorffii } \\
\text { Desf. }\end{array}$ & copaíba & $\begin{array}{c}\text { Copaiba langsdorfii (Desf.) Kuntze (1,2)/ Copaifera nitida Mart. ex Hayne (1)/ C. } \\
\text { nitida Hayne }(2) / C \text {. sellowii Hayne }(1,2)\end{array}$ & $11 / 07 / 2016$ & $\operatorname{sim}(1,3)$ & $25 / 07 / 2016$ \\
\hline 26 & $\begin{array}{l}\text { Copaifera } \\
\text { multijuga Hayne } \\
\text { Copaifera }\end{array}$ & copaíba & Copaiba multijuga (Hayne) Kuntze (1) & $11 / 07 / 2016$ & $\operatorname{sim}(1,3)$ & $25 / 07 / 2016$ \\
\hline 27 & $\begin{array}{l}\text { paupera } \\
\text { (Herzog) Dwyer }\end{array}$ & copaíba & Copaiba paupera Herzog $(1,2)$ & $11 / 07 / 2016$ & $\operatorname{sim}(1,3)$ & $25 / 07 / 2016$ \\
\hline 28 & $\begin{array}{l}\text { Copaifera } \\
\text { reticulata Ducke }\end{array}$ & copaíba & $\begin{array}{c}\text { SINONÍMIA BOTÂNICA NÃO ENCONTRADA NA LITERATURA } \\
\text { CONSULTADA }\end{array}$ & $11 / 07 / 2016$ & $\operatorname{sim}(1,3)$ & $25 / 07 / 2016$ \\
\hline 29 & $\begin{array}{l}\text { Cordia } \\
\text { verbenacea DC. }\end{array}$ & erva-baleeira & $\begin{array}{c}\text { Varronia verbenacea (DC.) Borhidi (1)/ V. curassavica Jacq. (1)/ NOMENCLATURA } \\
\text { BOTÂNICA NÃO ENCONTRADA NA LITERATURA (2) }\end{array}$ & $11 / 07 / 2016$ & $\operatorname{sim}(1,3)$ & $25 / 07 / 2016$ \\
\hline 30 & $\begin{array}{l}\text { Crataegus } \\
\text { azarolus } L .\end{array}$ & cratego & $\begin{array}{l}\text { Azarolus crataegoides Borkh. (2)/ A. maroccana (Lindl.) M.Roem. (2)/ Crataegus } \\
\text { ruscinonensis Gren. \& Blanc (2)/ Lazarolus oxyacanthoides Borkh. (2)/ Mespilus } \\
\text { azarolus (L.) All. (2)/ M. azarolus (L.) Duhamel (2)/ Pyrus azarolus (L.) Scop. (2) }\end{array}$ & $11 / 07 / 2016$ & não $(1,3)$ & $25 / 07 / 2016$ \\
\hline 31 & $\begin{array}{l}\text { Crataegus } \\
\text { laevigata (Poir.) } \\
\text { DC. }\end{array}$ & cratego & $\begin{array}{l}\text { SINONÍMIA BOTÂNICA NÃO ENCONTRADA NA LITERATURA } \\
\text { CONSULTADA }\end{array}$ & $11 / 07 / 2016$ & não $(1,3)$ & $25 / 07 / 2016$ \\
\hline 32 & $\begin{array}{l}\text { Crataegus } \\
\text { monogyna Jacq. }\end{array}$ & cratego & 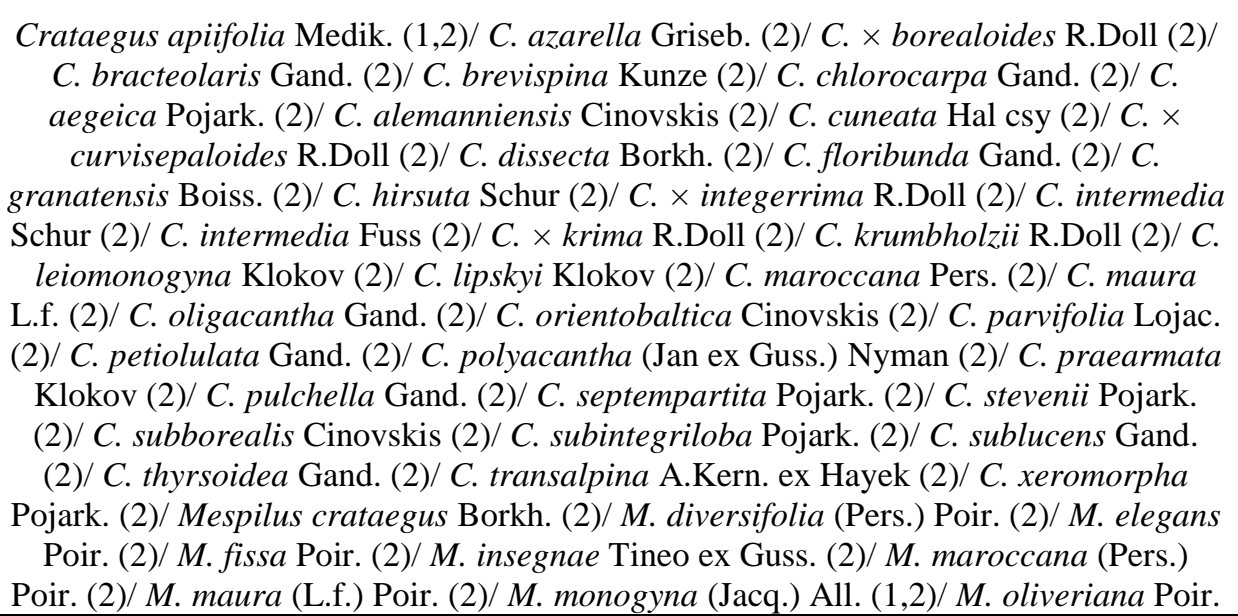 & $11 / 07 / 2016$ & não $(1,3)$ & $25 / 07 / 2016$ \\
\hline
\end{tabular}


33 Crataegus nigra Waldst. \& Kit.

\section{Crataegus}

pentagyna

$34 \begin{gathered}\text { pentagyna } \\ \text { Waldst. \& Kit. }\end{gathered}$

ex Willd.

Crataegus

35 rhipidophylla

Gand.

36 Curcuma longa

L.

Cymbopogon

37 citratus (DC.)

Stapf

Cynara

38 Cynara

\section{Datura}

9 stramonium $\mathrm{L}$

Echinodorus grandiflorus estramônio

cratego

cratego

cúrcuma/

açafrão/

açafrão-da-

terra

capim-limão/

capim-santo/

capim-cidró/

capim-cidreira/ cideira

alcachofra

chapéu-decouro
(2)/ M. polyacantha Jan ex Guss. (2)/ Oxyacantha apiifolia (Medik.) M.Roem. (2)/ $O$. azarella (Griseb.) M.Roem. (2)/ O. elegans (Poir.) M.Roem. (2)/ O. granatensi (Boiss.) M.Roem. (2)/ O. monogyna (Jacq.) M.Roem. (2)

\section{SINONIMIA BOTANICA NÃO ENCONTRADA NA LITERATURA} CONSULTADA

11/07/2016 não $(1,3) \quad 25 / 07 / 2016$

Azarolus oliveriana (Dum.Cours.) M.Roem. (2)/ A. platyphylla (Lindl.) M.Roem. (2)/ Crataegus atrofusca Steven (2)/ C. colchica Grossh. (1,2)/ C. elbursensis Rech.f. (2)/ C. melanocarpa M. Bieb. (1,2)/ C. oliveriana (Dum.Cours.) Bosc (2)/ C. platyphylla Lindl. (2)/ Mespilus atrofusca Steven ex K.Koch (2)/ M. melanocarpa (M.Bieb.) Poir. (2)/ M. oliveriana Dum.Cours. (2)/M. pentagyna (Waldst. \& Kit. ex Willd.) Wenz. (2)/ M. pentagyna (Waldst. \& Kit. ex Willd.) Spreng. (2)/ Phaenopyrum melanocarpum (M.Bieb.) M.Roem. (2)/ P. pentagynum (Waldst. \& Kit. ex Willd.) M. Roem (2) Crataegus appressidens Pojark. (2)/ C. curvisepala Lindm. (1,2)/ C. laciniata Steven ex Besser (2)/ C. microphylla Gand. (2)/ C. oxyacantha L. (2)/ C. praemonticola Holub (2)/ C. pseudokyrtostyla Klokov (2)/ C. rosaeformis Janka (2)/ C. rosiformis Janka (2)/ C. silesiaca Hrabětova (2)/ C. subrotunda Klokov (2)/ Mespilus oxyacantha (L.) Crantz (2)/ Oxyacantha laciniata (Steven ex Besser) M. Roem (2)

Amomum curcuma Jacq. (1,2)/ Curcuma brog Valeton (2) C. domestica Valeton $(1,2) /$ C. ochrorhiza Valeton (2)/ C. soloensis Valeton (2)/ C. tinctoria Guibourt (2)/ Kua domestica (L.) Medik. (1,2)/ Stissera curcuma Giseke (2)/ S. curcuma Raeusch. (1,2)

Andropogon citratus DC. (1,2)/ A. citratus DC. ex Nees (1)/ A. cerifer Hack. $(1,2) / A$. ceriferus Hack. (2)/ A. citriodorum hort. ex Desf. (1)/ A. citriodorus Desf. (2)/ A.

fragrans C.Cordem. (2)/ A. roxburghii Nees ex Steud. (1,2)/ A. schoenanthus L. (1)/ Cymbopogon nardus (L.) Rendle (1)

$$
\text { Cynara cardunculus L. (1)/ C. cardunculus subsp. cardunculus (1) }
$$

Datura bernhardii Lundstr. (2)/ D. bertolonii Parl. ex Guss. (1,2)/ D. cabanesii

P.Fourn. (2)/ D. capensis Bernh. (2)/ D. ferocissima Cabanès \& P.Fourn. (2)/ D. ferox

Nees (2)/ D. hybrida Ten. (2)/ D. inermis Juss. ex Jacq. (1,2)/ D. laevis L.f. (2)/ D.

loricata Sieber ex Bernh. (2)/ D. lurida Salisb. $(1,2) / D$. microcarpa Godr. (2)/ D.

muricata Godr. (2)/ D. nigra Hassk. (1)/ D. parviflora Salisb. (1,1)/ D. praecox Godr.

(2)/ D. pseudostramonium Sieber ex Bernh. $(1,2) /$ D. tatula L. $(1,2) / D$. wallichii

Dunal (2)/ Stramonium foetidum Scop. $(1,2) /$ S. spinosum Lam. $(1,2) /$ S. tatula (L.) Moench (1)/ S. vulgatum Gaertn. $(1,2)$

Alisma floribundum Seub. (1)/ A. grandiflorum Cham. \& Schltdl. (1,2)/ Echinodorus argentinensis Rataj $(1,2) /$ E. floridanus R.R.Haynes \& Burkhalter (2)/ E. floribundus
$11 / 07 / 2016$

11/07/2016 não (1,3) 25/07/2016

11/07/2016 não $(1,3) \quad$ 25/07/2016

$11 / 07 / 2016 \quad \operatorname{sim}(1,3) \quad 25 / 07 / 2016$

$11 / 07 / 2016 \quad \operatorname{sim}(1,3) \quad 25 / 07 / 2016$ 


\begin{tabular}{|c|c|c|c|c|c|c|}
\hline & (Cham. \& & & (Seub.) Seub. (1)/ E. longiscapus Arechav. (1)/ E. muricatus Griseb. (1)/ E. pellucidus & & & \\
\hline & Schltdl.) Micheli & & Rataj (2)/ E. sellowianus Buchenau (1)/ & & & \\
\hline 41 & $\begin{array}{l}\text { Echinodorus } \\
\text { macrophyllus } \\
\text { (Kunth) Micheli }\end{array}$ & $\begin{array}{l}\text { chapéu-de- } \\
\text { couro }\end{array}$ & Alisma macrophyllum Kunth $(1,2) /$ Echinodorus scaber Rataj (1) & $11 / 07 / 2016$ & $\operatorname{sim}(1,3)$ & $25 / 07 / 2016$ \\
\hline 42 & $\begin{array}{l}\text { Elettaria } \\
\text { cardamomum } \\
\text { (L.) Maton }\end{array}$ & cardamomo & $\begin{array}{c}\text { Alpinia cardamomum (L.) Roxb. (1,2)/ Amomum cardamomum L. (1,2)/ A. ensal } \\
\text { Raeusch. (2)/ A. racemosum Lam. (2)/ A. repens Sonn. (2)/ A. uncinatum Stokes (2)/ } \\
\text { Cardamomum elletari Garsault (2)/ C. malabaricum Pritz. (2)/ C. minus (Gaertn.) } \\
\text { Kuntze (2)/ C. officinale (L.) Salisb. (1)/ C. officinale Salisb. (2)/ C. verum Oken (2)/ } \\
\text { Elettaria repens Baill.(2)/ Matonia cardamomum (L.) Stephan \& Church }(1,2) / \\
\text { Zingiber minus Gaertn. (2) }\end{array}$ & $11 / 07 / 2016$ & não $(1,3)$ & $25 / 07 / 2016$ \\
\hline 43 & $\begin{array}{c}\text { Eugenia uniflora } \\
\text { L. }\end{array}$ & pitangueira & 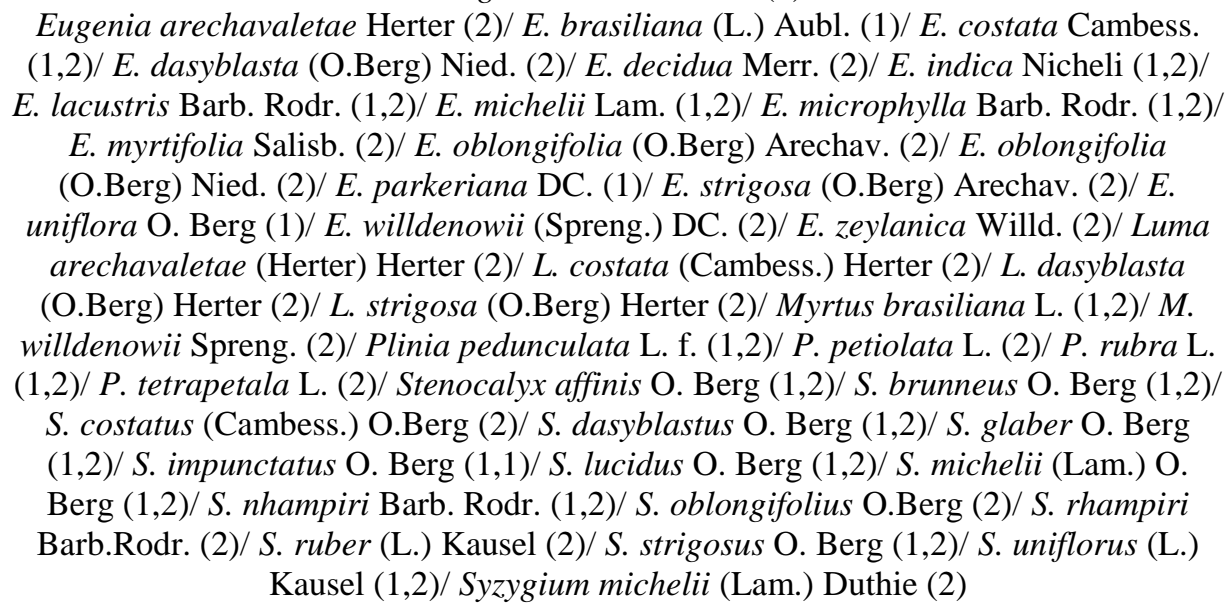 & $11 / 07 / 2016$ & $\operatorname{sim}(1,3)$ & $25 / 07 / 2016$ \\
\hline 44 & $\begin{array}{c}\text { Foeniculum } \\
\text { vulgare Mill. }\end{array}$ & funcho & 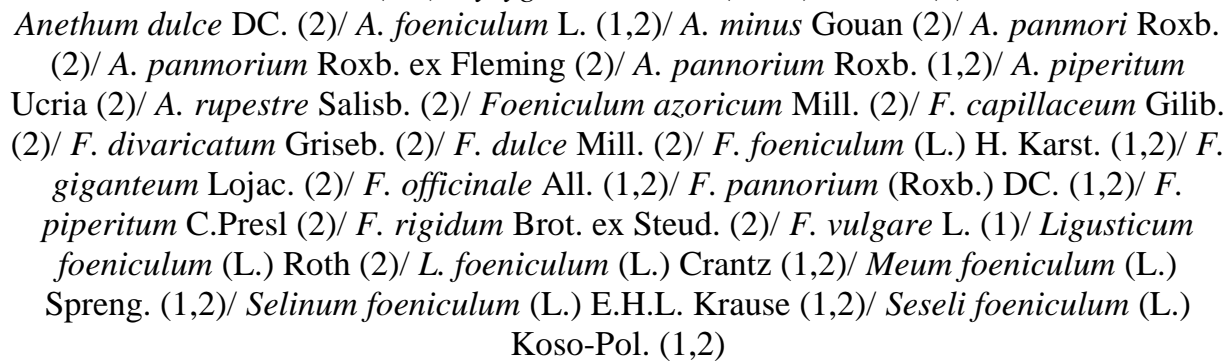 & $12 / 07 / 2016$ & $\operatorname{sim}(1,3)$ & $25 / 07 / 2016$ \\
\hline 45 & $\begin{array}{c}\text { Gentiana lutea } \\
\text { L. }\end{array}$ & genciana & $\begin{array}{c}\text { Asterias hybrida G.Don (2)/ A. lutea (L.) Borkh. }(1,2) / \text { Coilantha biloba Bercht. \& } \\
\text { J.Presl (2)/ Gentiana major Bubani (2)/ G. lutea Ruiz \& Pav. ex G. Don (1)/ } \\
\text { Gentianusa lutea (L.) Pohl }(1,2)\end{array}$ & $12 / 07 / 2016$ & não $(1,3)$ & $25 / 07 / 2016$ \\
\hline
\end{tabular}




\begin{tabular}{|c|c|c|c|c|c|c|}
\hline 46 & $\begin{array}{c}\text { Hamamelis } \\
\text { virginiana } \mathrm{L} \text {. }\end{array}$ & hamamelis & $\begin{array}{c}\text { Hamamelis androgyna Walter }(1,2) / H \text {. corylifolia Moench }(1,2) / \text { H. dioica } \text { Walter } \\
(1,2) / H . \text { macrophylla Pursh }(1,2) / \text { Trilopus dentata } \text { Raf. }(1,2) / T \text {. estivalis } \text { Raf. }(1,2) / T \text {. } \\
\text { nigra } \text { Raf. }(1,2) / T . \text { parvifolia (Nutt.) Raf. }(1,2) / T \text {. rotundifolia Raf. }(1,2) / T \text {. virginica } \\
\text { Raf. (2)/T. virginica (L.) Raf. (1) }\end{array}$ & $12 / 07 / 2016$ & não $(1,3)$ & 25/07/2016 \\
\hline 47 & $\begin{array}{c}\text { Hydrastis } \\
\text { canadensis } \mathrm{L} .\end{array}$ & hidraste & $\begin{array}{l}\text { SINONÍMIA BOTÂNICA NÃO ENCONTRADA NA LITERATURA } \\
\text { CONSULTADA }\end{array}$ & $12 / 07 / 2016$ & não $(1,3)$ & $25 / 07 / 2016$ \\
\hline 48 & $\begin{array}{l}\text { Hyoscyamus } \\
\text { niger } \mathrm{L} \text {. }\end{array}$ & meimendro & $\begin{array}{c}\text { Hyoscarpus niger (L.) Dulac (2)/ Hyoscyamus agrestis Kit. (2)/ H. agrestis Kit. ex } \\
\text { Schult. (1)/ H. bohemicus F.W. Schmidt (1,2)/ H. pallidus Waldst. \& Kit. ex } \\
\text { Willdenow (2) }\end{array}$ & $12 / 07 / 2016$ & não $(1,3)$ & $25 / 07 / 2016$ \\
\hline 49 & $\begin{array}{l}\text { Illicium verum } \\
\text { Hook f }\end{array}$ & anis-estrelado & Illicium san-ki Perr. $(1,2)$ & & não $(1,3)$ & $25 / 07 / 2016$ \\
\hline 50 & $\begin{array}{c}\text { Justicia } \\
\text { pectoralis Jacq. }\end{array}$ & $\begin{array}{l}\text { chambál } \\
\text { chachambá/ } \\
\text { trevo-cumaru }\end{array}$ & $\begin{array}{l}\text { Dianthera pectoralis (Jacq.) J.F. Gmel. }(1,2) / \text { D. pectoralis (Jacq.) Murray }(1,2) / \\
\text { Ecbolium pectorale (Jacq.) Kuntze }(1,2) / \text { Justicia stuebelii Lindau }(1,2) / \text { Leptostachya } \\
\text { pectoralis (Jacq.) Nees \& Mart. (2)/ Psacadocalymma pectorale (Jacq.) Bremek. }(1,2) / \\
\text { Rhytiglossa pectoralis (Jacq.) Nees }(1,2) / \text { Stethoma pectoralis (Jacq.) Raf. }(1,2)\end{array}$ & $12 / 07 / 2016$ & $\operatorname{sim}(1,3)$ & $25 / 07 / 2016$ \\
\hline 51 & $\begin{array}{l}\text { Krameria } \\
\text { lappacea } \\
\text { (Dombey) } \\
\text { Burdet \& } \\
\text { B.B.Simpson }\end{array}$ & ratânia & $\begin{array}{c}\text { Krameria canescens Willd. ex Schult. }(1,2) / \text { K. iluca F. Phil. }(1,2) / \text { K. linearis Poir. (1)/ } \\
\text { K. pentapetala Ruiz \& Pav. }(1,2) / \text { K. triandra Ruiz \& Pav. }(1,2) / \text { Landia lappacea } \\
\text { Dombey }(1,2)\end{array}$ & $12 / 07 / 2016$ & não $(1,3)$ & $25 / 07 / 2016$ \\
\hline 52 & $\begin{array}{l}\text { Lippia alba } \\
\text { (Mill.) N.E. Br. } \\
\text { ex Britton \& P. } \\
\quad \text { Wilson }\end{array}$ & $\begin{array}{l}\text { erva-cidreira- } \\
\text { de-arbusto/ } \\
\text { lípia }\end{array}$ & 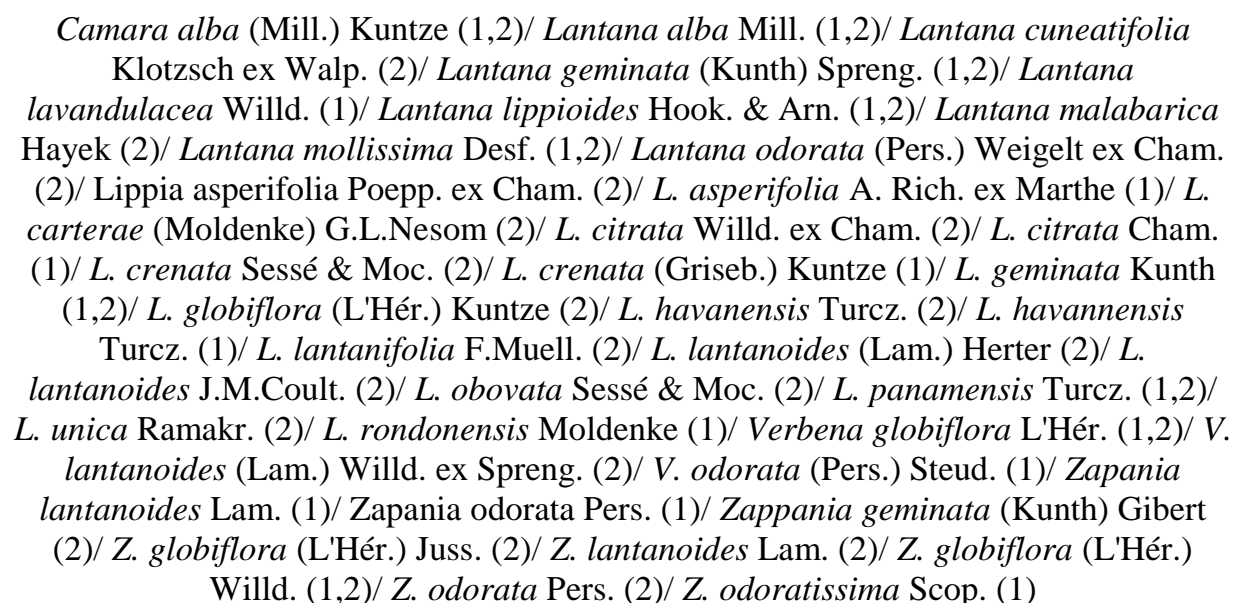 & $12 / 07 / 2016$ & $\operatorname{sim}(1,3)$ & $25 / 07 / 2016$ \\
\hline 53 & $\begin{array}{l}\text { Lippia sidoides } \\
\text { Cham. }\end{array}$ & $\begin{array}{l}\text { alecrim- } \\
\text { pimenta }\end{array}$ & $\begin{array}{l}\text { SINONÍMIA BOTÂNICA NÃO ENCONTRADA NA LITERATURA } \\
\text { CONSULTADA }\end{array}$ & $12 / 07 / 2016$ & $\operatorname{sim}(1,3)$ & $25 / 07 / 2016$ \\
\hline
\end{tabular}




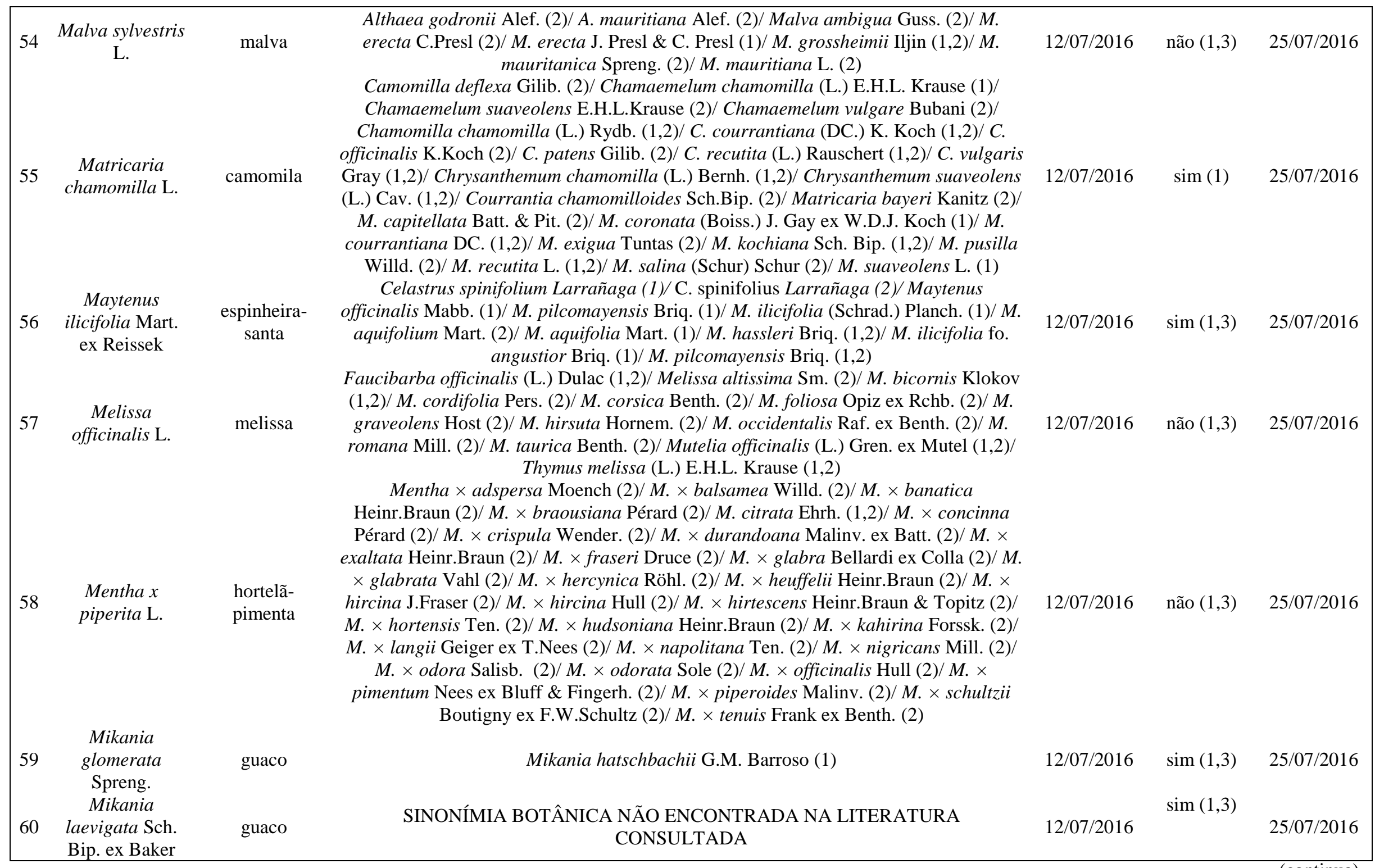




\begin{tabular}{|c|c|c|c|c|c|c|}
\hline 61 & $\begin{array}{l}\text { Momordica } \\
\text { charantia } \mathrm{L} .\end{array}$ & $\begin{array}{l}\text { melão-de-são- } \\
\text { caetano }\end{array}$ & $\begin{array}{l}\text { Cucumis argyi H. Lév. }(1,2) / \text { C. intermedius M.Roem. (2)/ Momordica chinensis } \\
\text { Spreng. }(1,2) / \text { M. elegans Salisb. }(1,2) / M . \text { indica L. }(1,2) / \text { M. muricata Willd. }(1,2) / M \text {. } \\
\text { operculata Vell. (1)/M. sinensis Spreng. }(1,2) / M \text {. thollonii Cogn. (2)/Sicyos fauriei } \mathrm{H} \text {. } \\
\text { Lév. }(1,2)\end{array}$ & $12 / 07 / 2016$ & $\operatorname{sim}(1,3)$ & $25 / 07 / 2016$ \\
\hline 62 & $\begin{array}{l}\text { Myroxylon } \\
\text { balsamum (L.) } \\
\text { Harms }\end{array}$ & $\begin{array}{l}\text { bálsamo-de- } \\
\text { tolu (óleo- } \\
\text { resina)/bálsam } \\
\text { o-do-peru } \\
\text { (bálsamo do } \\
\text { tronco) }\end{array}$ & $\begin{array}{l}\text { Myroxylon balsamum Druce (1)/ / M. punctatum Klotzsch (1)/ M. toluiferum A. Rich. } \\
(1,2) / \text { M. toluiferum Kunth (1)/ Myroxylum balsamum (L.) Harms (1)/ Myrospermum } \\
\text { toluiferum DC. (2)/ Myrospermum toluiferum (A. Rich.) DC. (1)/ Toluifera balsamum } \\
\text { L. (1,2) }\end{array}$ & $12 / 07 / 2016$ & $\operatorname{sim}(1,3)$ & $25 / 07 / 2016$ \\
\hline 63 & $\begin{array}{l}\text { Passiflora alata } \\
\text { Curtis }\end{array}$ & $\begin{array}{l}\text { maracujá-doce/ } \\
\text { maracujá }\end{array}$ & Passiflora alata Aiton (1)/ P. latifolia DC. $(1,2) /$ P. phoenicia Lindl. $(1,2)$ & $12 / 07 / 2016$ & $\operatorname{sim}(1,3)$ & $25 / 07 / 2016$ \\
\hline 64 & $\begin{array}{l}\text { Passiflora edulis } \\
\text { Sims }\end{array}$ & $\begin{array}{l}\text { maracujá- } \\
\text { azedo }\end{array}$ & $\begin{array}{c}\text { Passiflora diaden Vell. }(1,2) / \text { P. gratissima A. St.-Hil. }(1,2) / \text { P. incarnata } \mathrm{L} .(1,2) / P . \\
\text { iodocarpa Barb. Rodr. }(1,2) / \text { P. middletoniana Paxton }(1,2) / \text { P. minima Blanco }(1) / P . \\
\text { pallidiflora Bertol. }(1,2) / \text { P. picroderma Barb. Rodr. }(1,2) / \text { P. pomifera } \mathrm{M} \text {. Roem. } \\
(1,2) / \text { P. rigidula J. Jacq. }(1,2) / \text { P. rubricaulis Jacq. }(1,2) / \text { P. vernicosa Barb. Rodr. } \\
(1,2) / \text { P. verrucifera Lindl. }(1)\end{array}$ & $12 / 07 / 2016$ & $\operatorname{sim}(1,3)$ & $25 / 07 / 2016$ \\
\hline 65 & $\begin{array}{l}\text { Passiflora } \\
\text { incarnata } \mathrm{L} \text {. }\end{array}$ & maracujá & $\begin{array}{c}\text { Granadilla incarnata (L.) Medik. (1)/ Passiflora incarnata Ker Gawl. (1)/ P. kerii } \\
\text { Spreng. (1)/ P. edulis Sims (1) }\end{array}$ & $12 / 07 / 2016$ & $\operatorname{sim}(1,3)$ & $25 / 07 / 2016$ \\
\hline 66 & $\begin{array}{l}\text { Paullinia } \\
\text { cupana Kunth }\end{array}$ & guaraná & Paullinia sorbilis Mart. $(1,2)$ & $12 / 07 / 2016$ & $\operatorname{sim}(1,3)$ & $25 / 07 / 2016$ \\
\hline 67 & $\begin{array}{c}\text { Persea } \\
\text { americana Mill. }\end{array}$ & abacateiro & $\begin{array}{c}\text { Laurus persea } \text { L. }(1,2) / \text { Persea drymifolia Schltdl. \& Cham. }(1,2) / \text { P. edulis Raf. }(1,2) / \\
\text { P. floccosa Mez }(1,2) / \text { P. gigantea L.O. Williams }(1,2) / \text { P. gratissima C.F. Gaertn. } \\
(1,2) / P . \text { leiogyna S.F. Blake }(1,2) / \text { P. nubigena L.O. Williams }(1,2) / P . \\
\text { paucitriplinervia Lundell }(1,2) / \text { P. persea }(\text { L. } \text { Cockerell }(1,2) / \text { P. steyermarkii C.K. } \\
\text { Allen }(1,2)\end{array}$ & $12 / 07 / 2016$ & $\operatorname{sim}(1,3)$ & $25 / 07 / 2016$ \\
\hline 68 & $\begin{array}{l}\text { Peumus boldus } \\
\text { Molina }\end{array}$ & $\begin{array}{l}\text { boldo/ boldo- } \\
\text { do-chile }\end{array}$ & $\begin{array}{c}\text { Boldea boldus (Molina) Looser (1,2)/ B. fragrans Endl. (1)/ B. fragrans (Pers.) Endl. } \\
\text { (2)/ Boldu boldus (Molina) Lyons (1,2)/ Boldu chilanum Nees (2)/ Boldu chilensis } \\
\text { Schult. \& Schult.f. (2) }\end{array}$ & $12 / 07 / 2016$ & não $(1,3)$ & $25 / 07 / 2016$ \\
\hline 69 & $\begin{array}{l}\text { Phyllanthus } \\
\text { niruri L. }\end{array}$ & quebra-pedra & 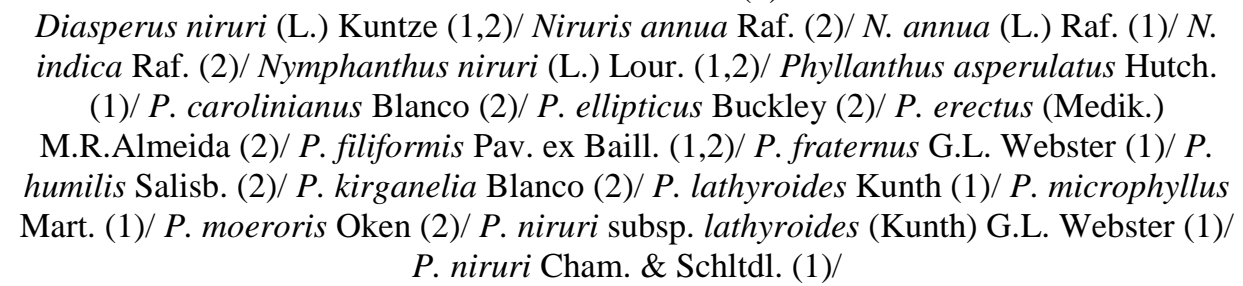 & $12 / 07 / 2016$ & $\operatorname{sim}(1,3)$ & $25 / 07 / 2016$ \\
\hline
\end{tabular}




\begin{tabular}{|c|c|c|c|c|c|c|}
\hline 70 & $\begin{array}{l}\text { Phyllanthus } \\
\text { tenellus Roxb. }\end{array}$ & quebra-pedra & $\begin{array}{l}\text { Diasperus corcovadensis (Müll.Arg.) Kuntze (2)/ D. tenellus (Roxb.) Kuntze }(1,2) / \\
\text { Phyllanthus brisbanicus F.M.Bailey (2)/ P. corcovadensis Müll. Arg. }(1,2) / \text { P. minor } \\
\text { Fawc. \& Rendle (2)/ P. tenellus Benth. (1)/ P. tenellus Müll. (1) }\end{array}$ & $12 / 07 / 2016$ & $\operatorname{sim}(1,3)$ & $25 / 07 / 2016$ \\
\hline 71 & $\begin{array}{l}\text { Pilocarpus } \\
\text { microphyllus } \\
\quad \text { Stapf ex } \\
\text { Wardleworth }\end{array}$ & jaborandi & Pilocarpus microphyllus Stapf (1)/ P. microphyllus Stapf ex Holmes (1) & $12 / 07 / 2016$ & $\operatorname{sim}(1,3)$ & 25/07/2016 \\
\hline 72 & $\begin{array}{l}\text { Pimpinella } \\
\text { anisum } \mathrm{L} .\end{array}$ & $\begin{array}{c}\text { anís-doce/ anís/ } \\
\text { erva-doce }\end{array}$ & $\begin{array}{l}\text { Anisum vulgare Gaertn. }(1,2) / \text { A. odoratum Raf. (2)/ A. officinale DC. (2)/ A. } \\
\text { officinarum Moench (2)/ Apium anisum (L.) Crantz }(1,2) / \text { Carum anisum (L.) Baill. } \\
(1,2) / \text { Ptychotis vargasiana DC. }(2) / \text { Selinum anisum (L.) E.H.L. Krause }(1,2) / \text { Seseli } \\
\text { gilliesii Hook. \& Arn. }(1,2) / \text { Sison anisum }(\text { L.) Spreng. }(1,2) / \text { Tragium anisum }(\text { L.) } \\
\text { Link }(1,2)\end{array}$ & $12 / 07 / 2016$ & não $(1,3)$ & $25 / 07 / 2016$ \\
\hline 73 & $\begin{array}{l}\text { Plantago major } \\
\quad \text { L. }\end{array}$ & $\begin{array}{l}\text { tanchagem/ } \\
\text { tansagem/ } \\
\text { tranchagem }\end{array}$ & $\begin{array}{c}\text { Plantago borysthenica Wissjul. }(1,2) / \text { P. dregeana Decne. }(1,2) / \text { P. gigas H. Lév. }(1,2) / \\
\text { P. intermedia Gilib. }(1) / P . \text { jehohlensis Koidz. }(1,2) / \text { P. latifolia Salisb. }(1,2) / \text { P. } \\
\text { macronipponica Yamam. }(1,2) / \text { P. major subsp. pleiosperma Pilg. }(1) / \text { P. officinarum } \\
\text { Crantz }(1) / \text { P. pauciflora Gilib. }(1) / \text { P. sawadai (Yamam.) Yamam. }(1,2) / \text { P. sinuata } \\
\text { Lam. }(1) / P . \text { villifera Kitag. }(1,2)\end{array}$ & $12 / 07 / 2016$ & $\operatorname{sim}(1,3)$ & $25 / 07 / 2016$ \\
\hline 74 & $\begin{array}{l}\text { Plectranthus } \\
\text { barbatus } \\
\text { Andrews }\end{array}$ & $\begin{array}{l}\text { boldo-africano/ } \\
\text { boldo- } \\
\text { brasileiro/ } \\
\text { boldo-nacional }\end{array}$ & $\begin{array}{c}\text { Coleus forskohlii (Willd.) Briq. (1)/ C. barbatus (Andrews) Benth. (1)/C. barbatus } \\
\text { (Andrews) Benth. ex G.Don (2)/ C. coerulescens Gürke (2)/ C. adolfi-friderici Perkins } \\
\text { (2)/ C. penzigii Dammann ex Baker (2)/ C. speciosus Baker f. (2)/ C. vestitus Baker } \\
\text { (2)/ Ocimum asperum Roth (2)/ Orthosiphon asperus (Roth) Benth. ex Sweet (2)/ } \\
\text { Plectranthus asper (Roth) Spreng. (2)/ P. coerulescens (Gürke) R.H.Willemse (2)/ P. } \\
\text { comosus Sims (2)/ P. pseudobarbatus J.K.Morton (2) }\end{array}$ & $12 / 07 / 2016$ & não $(1,3)$ & $25 / 07 / 2016$ \\
\hline 75 & $\begin{array}{c}\text { Polygala senega } \\
\text { L. }\end{array}$ & polígala & Polygala albida Steud. (2)/ Senega officinalis Spach (2) & $12 / 07 / 2016$ & não $(1,3)$ & $25 / 07 / 2016$ \\
\hline 76 & $\begin{array}{l}\text { Polygonum } \\
\text { punctatum Elliot }\end{array}$ & $\begin{array}{l}\text { erva-de-bicho/ } \\
\text { pimenteira- } \\
\text { d'água }\end{array}$ & $\begin{array}{l}\text { Discolenta punctata (Elliott) Raf. }(1,2) / \text { Persicaria punctata } \text { (Elliott) Small }(1,2) / \\
\text { Persicaria robustior } \text { (Small) E.P. Bicknell }(1) / \text { Polygonum acre Kunth }(1,2) / P . \text { acre } \\
\text { Lam. }(1,2) / \text { P. epilobioides Wedd. }(1,2) / \text { P. punctatum Buch.-Ham. ex D. Don }(1) / P \text {. } \\
\text { punctatum Elliott }(2) / \text { P. hydropiperoides Michx. (1)/ P. robustius (Small) Fernald (1) }\end{array}$ & $12 / 07 / 2016$ & $\operatorname{sim}(1,3)$ & $25 / 07 / 2016$ \\
\hline 77 & $\begin{array}{l}\text { Punica } \\
\text { granatum L. } \\
\text { Quillaja }\end{array}$ & romã & $\begin{array}{l}\text { Punica florida Salisb. (1,2)/ P. grandiflora Steud. (2)/ P. grandiflora hort. ex Steud. } \\
\text { (1)/ P. nana L. }(1,2) / \text { P. spinosa Lam. }(1,2) / \text { Rhoea punica } \text { St.-Lag. (2) }\end{array}$ & $12 / 07 / 2016$ & não $(1,3)$ & $25 / 07 / 2016$ \\
\hline 78 & $\begin{array}{l}\text { saponaria } \\
\text { Molina }\end{array}$ & quilaia & Quillaja molinae (Molina) DC. (1)/ Q. poeppigii Walp. (1) & $12 / 07 / 2016$ & não $(1,3)$ & $25 / 07 / 2016$ \\
\hline 79 & $\begin{array}{l}\text { Rauvolfia } \\
\text { serpentina }(\mathrm{L} .) \\
\text { Benth. ex Kurz }\end{array}$ & rauvólfia & $\begin{array}{l}\text { Ophioxylon album Gaertn. (2)/ O. obversum Miq. (2)/ O. salutiferum Salisb. (2)/ O. } \\
\text { serpentinum L. (1,2)/ O. majus Hassk. (1)/ O. trifoliatum Gaertn. (2)/ Rauvolfia } \\
\text { obversa (Miq.) Baill. (2)/ R. trifoliata (Gaertn.) Baill. (2) }\end{array}$ & $12 / 07 / 2016$ & não $(1,3)$ & $25 / 07 / 2016$ \\
\hline
\end{tabular}




\begin{tabular}{|c|c|c|c|c|c|c|}
\hline 80 & $\begin{array}{l}\text { Rheum officinale } \\
\text { Baill. }\end{array}$ & ruibarbo & $\begin{array}{l}\text { SINONÍMIA BOTÂNICA NÃO ENCONTRADA NA LITERATURA } \\
\text { CONSULTADA }\end{array}$ & $12 / 07 / 2016$ & não $(1,3)$ & $25 / 07 / 2016$ \\
\hline 81 & $\begin{array}{l}\text { Rheum } \\
\text { palmatum } \mathrm{L} \text {. }\end{array}$ & ruibarbo & Rheum potaninii Losinsk. $(1,2) /$ R. qinlingense Y.K. Yang, J.K. Wu \& D.K. Zhang & $12 / 07 / 2016$ & não $(1,3)$ & $25 / 07 / 2016$ \\
\hline 82 & $\begin{array}{l}\text { Rosmarinus } \\
\text { officinalis L. }\end{array}$ & alecrim & $\begin{array}{l}\text { Rosmarinus angustifolius Mill. (2)/ R. communis Noronha (2)/ R. flexuosus Jord. \& } \\
\text { Fourr. (2)/ R. latifolius Mill. (2)/ R. laxiflorus Noë (2)/ R. laxiflorus Noë ex Lange (2)/ } \\
\text { R. palaui (O.Bolòs \& Molin. ) Rivas Mart. \& M.J.Costa (2)/ R. prostratus Mazziari } \\
\text { (2)/ R. rigidus Jord. \& Fourr. (2)/ R. serotinus Loscos (2)/ R. tenuifolius Jord. \& Fourr. } \\
\text { (2)/ Salvia fasciculata Fernald (2)/ S. rosmarinus Schleid. (1,2) }\end{array}$ & $12 / 07 / 2016$ & não $(1,3)$ & $25 / 07 / 2016$ \\
\hline 83 & Salix alba L. & $\begin{array}{l}\text { salgueiro- } \\
\text { branco/ } \\
\text { salgueiro }\end{array}$ & $\begin{array}{c}\text { Argorips alba } \text { Raf. (2)/ A. cerulea Raf. (2)/ Salix pallida Salisb. (2)/ S. pameachiana } \\
\text { Barratt (2) }\end{array}$ & $12 / 07 / 2016$ & não $(1,3)$ & $25 / 07 / 2016$ \\
\hline 84 & $\begin{array}{l}\text { Salvia officinalis } \\
\text { L. }\end{array}$ & sálvia & $\begin{array}{c}\text { Oboskon cretica (L.) Raf. (2)/ Salvia chromatica Hoffmanns. (2)/ S. clusii Vilm. (2)/ S. } \\
\text { cretica L. (2)/ S. crispa Ten. (2)/ S. digyna Stokes (2)/ S. grandiflora Ten. (2)/ S. } \\
\text { hispanica Garsault (2)/ S. minor Garsault (2)/ S. papillosa Hoffmanns. (2)/ S. tricolor } \\
\text { Vilm. (2) }\end{array}$ & $12 / 07 / 2016$ & $\operatorname{sim}(3)$ & $25 / 07 / 2016$ \\
\hline 85 & $\begin{array}{l}\text { Sambucus } \\
\text { australis Cham. } \\
\text { \& Schltdl. }\end{array}$ & $\begin{array}{l}\text { sabugueiro-do- } \\
\text { brasil }\end{array}$ & Sambucus pentagynia Larrañaga (1) & $12 / 07 / 2016$ & $\operatorname{sim}(1,3)$ & $25 / 07 / 2016$ \\
\hline 86 & $\begin{array}{l}\text { Sambucus nigra } \\
\text { L. }\end{array}$ & sabugueiro & Sambucus graveolens Willd. $(1,2) /$ S. peruviana Kunth (1) & $12 / 07 / 2016$ & $\operatorname{sim}(3)$ & 25/07/2016 \\
\hline 87 & $\begin{array}{l}\text { Schinus } \\
\text { terebinthifolia } \\
\text { Raddi }\end{array}$ & $\begin{array}{l}\text { aroeira-da- } \\
\text { praia }\end{array}$ & $\begin{array}{l}\text { Sarcotheca bahiensis Turcz. }(1,2) / \text { Schinus antiarthritica Mart. ex Marchand (1)/ S. } \\
\text { mellisii Engl. }(1,2) / \text { S. mucronulata Mart. }(1,2) /\end{array}$ & $12 / 07 / 2016$ & $\operatorname{sim}(1,3)$ & 25/07/2016 \\
\hline 88 & $\begin{array}{l}\text { Senna } \\
\text { alexandrina } \\
\text { Mill. }\end{array}$ & sene & $\begin{array}{c}\text { Cassia acutifolia Delile }(1,2) / \text { C. alexandrina (Garsault) Thell. }(1,2) / \text { C. angustifolia } \\
\text { Vahl }(1,2) / \text { C. angustifolia M.Vahl }(2) / \text { C. senna L. }(1,2) / \text { Senna acutifolia } \text { (Delile) } \\
\text { Batka }(1,2) / \text { S. alexandrina Garsault }(1,2) / \text { S. angustifolia (Vahl) Batka }(1,2)\end{array}$ & $12 / 07 / 2016$ & $\operatorname{sim}(1,3)$ & $25 / 07 / 2016$ \\
\hline 89 & $\begin{array}{l}\text { Stevia } \\
\text { rebaudiana } \\
\text { (Bertoni) } \\
\text { Bertoni }\end{array}$ & estévia & Eupatorium rebaudianum Bertoni $(1,2) /$ Stevia rebaudiana (Bertoni) Hemsl. $(1,2)$ & $12 / 07 / 2016$ & $\operatorname{sim}(1,3)$ & $25 / 07 / 2016$ \\
\hline 90 & $\begin{array}{l}\text { Stryphnodendro } \\
\text { n adstringens } \\
\text { (Mart.) Coville }\end{array}$ & barbatimão & $\begin{array}{c}\text { Acacia adstringens Mart. }(1,2) / \text { Mimosa barbadetimam Vell. }(1,2) / \text { M. virginalis } \\
\text { Arruda }(1,2) / \text { Stryphnodendron barbatimam Mart. }(1,2)\end{array}$ & $12 / 07 / 2016$ & $\operatorname{sim}(1,3)$ & $25 / 07 / 2016$ \\
\hline 91 & $\begin{array}{l}\text { Styrax benzoin } \\
\text { Dryand. }\end{array}$ & benjoim & $\begin{array}{l}\text { SINONÍMIA BOTÂNICA NÃO ENCONTRADA NA LITERATURA } \\
\text { CONSULTADA }\end{array}$ & $12 / 07 / 2016$ & não $(1,3)$ & $25 / 07 / 2016$ \\
\hline
\end{tabular}




\begin{tabular}{|c|c|c|c|c|c|c|}
\hline 92 & $\begin{array}{l}\text { Styrax } \\
\text { paralleloneuron } \\
\text { Perkins }\end{array}$ & benjoim & $\begin{array}{l}\text { SINONÍMIA BOTÂNICA NÃO ENCONTRADA NA LITERATURA } \\
\text { CONSULTADA }\end{array}$ & $12 / 07 / 2016$ & não $(1,3)$ & $25 / 07 / 2016$ \\
\hline 93 & $\begin{array}{l}\text { Symphytum } \\
\text { officinale L. }\end{array}$ & confrei & Consolida major Garsault (2)/ C. major Gilib. (2)/ Symphytum peregrinum Ledeb. (2) & $12 / 07 / 2016$ & não $(1,3)$ & $25 / 07 / 2016$ \\
\hline 94 & $\begin{array}{l}\text { Taraxacum } \\
\text { officinale } \mathrm{F} . \mathrm{H} \text {. } \\
\text { Wigg }\end{array}$ & dente-de-leão & $\begin{array}{c}\text { Crepis taraxacum (L.) Stokes (2)/ Leontodon taraxacum L. (1,2)/ L. vulgare Lam. } \\
(1,2) / \text { Taraxacum officinale L. (1)/ T. campylodes G.E.Haglund (2)/ T. dens-leonis } \\
\text { Desf. }(1,2) / \text { T. officinale (L.) Weber ex F.H.Wigg. }(2) / \text { T. mexicanum DC. }(1) / T \text {. } \\
\text { retroflexum H. Lindb. (1)/ T. subspathulatum A.J. Richards }(1,2) / \text { T. sylvanicum R. } \\
\text { Doll }(1) / \text { T. taraxacum (L.) H. Karst. }(1,2) / \text { T. tenejapense A.J. Richards }(1) / T \text {. vulgare } \\
\text { Schrank (1)/ T. vulgare (Lam.) Schrank (2) }\end{array}$ & $12 / 07 / 2016$ & $\operatorname{sim}(1)$ & $25 / 07 / 2016$ \\
\hline 95 & $\begin{array}{l}\text { Vanilla } \\
\text { planifolia } \\
\text { Andrews }\end{array}$ & baunilha & 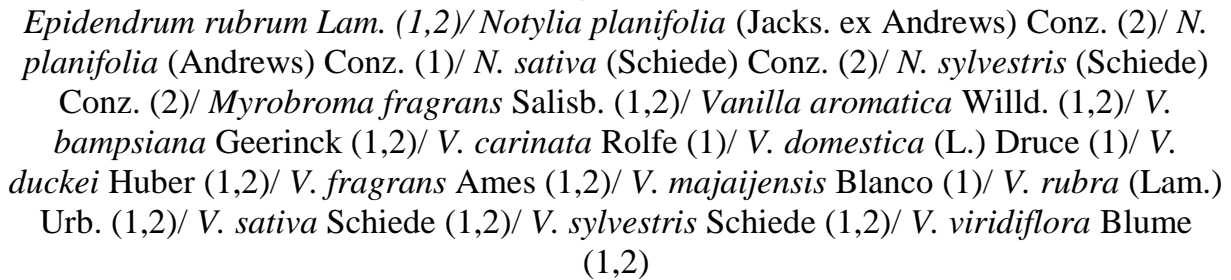 & $12 / 07 / 2016$ & $\operatorname{sim}(1,3)$ & $25 / 07 / 2016$ \\
\hline 96 & $\begin{array}{l}\text { Vernonia } \\
\text { condensata } \\
\text { Baker }\end{array}$ & boldo-baiano & $\begin{array}{l}\text { Acmella ciliata (Kunth) Cass. (2)/ A. fimbriata (Kunth) Cass. (2)/ Ceratocephalus } \\
\text { ciliatus (Kunth) Kuntze (2)/ C. fimbriatus (Kunth) Kuntze (2)/ C. poeppigii (DC.) } \\
\text { Kuntze (2)/ Gymnanthemum amygdalinum (Delile) Sch. Bip. ex Walp. (1)/ Spilanthes } \\
\text { ciliata Kunth (2)/ S. fimbriata Kunth (2)/ S. melampodioides Gardner (2)/ S. poeppigii } \\
\text { DC. (2)/ S. popayanensis Hieron. (2)/ Vernonanthura condensata (Baker) H. Rob. (1)/ } \\
\text { Vernonia condensata Baker (2) }\end{array}$ & $12 / 07 / 2016$ & $\operatorname{sim}(1,3)$ & $25 / 07 / 2016$ \\
\hline 97 & $\begin{array}{l}\text { Vernonia } \\
\text { polyanthes } \\
\text { (Spreng.) Less }\end{array}$ & assa-peixe & $\begin{array}{c}\text { Cacalia polyanthes (Less.) Kuntze }(1,2) / \text { Chrysocoma arborea Vell. (2)/ C. } \\
\text { phosphorica Vell. (2)/Vernonanthura phosphorica (Vell.) H. Rob. }(1,2) / \text { Vernonia } \\
\text { brasiliensis Mart. ex DC. (2)/ V. corcovadensis Gardner (2)/ V. patens Less. (2)/V. } \\
\text { polyanthes Less. (2)/V.psittacorum DC. (2) }\end{array}$ & $12 / 07 / 2016$ & $\operatorname{sim}(1)$ & $25 / 07 / 2016$ \\
\hline 98 & $\begin{array}{l}\text { Zingiber } \\
\text { officinale } \\
\text { Roscoe }\end{array}$ & gengibre & $\begin{array}{l}\text { Amomum angustifolium Salisb. }(2) / \text { A. zingiber } \text { L. }(1,2) / \text { A. zinziba } \text { Hill }(2) / \text { Curcuma } \\
\text { longifolia Wall. }(1,2) / \text { Zingiber aromaticum Noronha }(1,2) / \text { Z. cholmondeleyi } \\
\text { (F.M.Bailey) K.Schum. (2)/ Z. majus Rumph. }(1,2) / \text { Z. missionis Wall. }(1,2) / Z \text {. } \\
\text { sichuanense Z.Y. Zhu, S.L. Zhang \& S.X. Chen }(1,2) / \text { Z. zingiber } \text { (L.) H. Karst. }(1,2)\end{array}$ & $12 / 07 / 2016$ & $\operatorname{sim}(3)$ & $25 / 07 / 2016$ \\
\hline
\end{tabular}

(BRASIL, 2010d, 2011; REFLORA, 2016; THE PLANT LIST, 2013; TROPICOS.ORG, 2016)

Legenda: (1) = sítio eletrônico do Missouri Botanical Garden; (2) = sítio eletrônico do The Plant List; (3) sítio eletrônico do Reflora.

Notas: para a determinação das sinonímias primeiramente o sítio eletrônico do Missouri Botanical Garden (1) foi consultado, o qual também foi considerado para as correções nos nomes botânicos; foram incluídas como sinonímia todos os nomes constantes na pagina do nomenclatura botânica consultada (constantes em: "synomyns", "accepted names", "basionym", etc.), em seguida o sítio eletrônico do The Plant List (2) foi consultado, foram verificadas todas as sinonímias descritas, tendo sido acrescentadas as com pelo menos duas estrelas de nível de confiança, no caso de ter sido encontrada sinonímia anteriormente listada pela referência (1) com nível de confiança apenas de uma 
estrela, esta foi excluída, não foram incluídas como sinonímias as variedades; para a determinação da ocorrência da espécie no Brasil primeiramente o sítio eletrônico do Reflora (3) foi consultado inserindo o gênero da nomenclatura botânica e de todas as sinonímias para localizar as entradas para as espécies (nomenclatura botânica e sinonímias), foram consideradas com ocorrência no Brasil as que possuíam a informação "nativa", "cultivada", "naturalizada" ou outra informação que confirmasse sua presença no Brasil, em seguida o sítio eletrônico do Missouri Botanical Garden (2) foi consultado considerando para a pesquisa todas as espécies listadas (nomenclatura botânica e sinonímias) e, em cada página, foi verificada a existência de registro de ocorrência no Brasil na aba "distributions". 


\section{APÊNDICE B}

Apêndice B - Descritivos utilizados na busca por produtos registrados no sítio eltrônico da Anvisa Consulta Produto - Medicamentos

\begin{tabular}{|c|c|}
\hline Nomenclatura botânica & Entradas para a busca \\
\hline Achillea millefolium $\mathrm{L}$. & ACHILLEA/ ACHILL/ ALITU/ CHAMAE/ MIL \\
\hline Achyrocline satureioides (Lam.) DC. & ACHYR/ GNAPH/ MACEL/ MARCEL \\
\hline Aesculus hippocastanum $\mathrm{L}$. & AESCULUS/ HIPPO/ CASTANHA \\
\hline Allium sativum $\mathrm{L}$. & ALLIUM/ PORR/ ALHO \\
\hline Aloe africana Mill. & ALOE/ PACHI \\
\hline Aloe ferox Mill. & ALOE/ FEROX/ PACHI \\
\hline Aloe spicata L. f. & ALOE \\
\hline Aloe vera (L.) Burm. f. & ALOE \\
\hline $\begin{array}{l}\text { Alpinia zerumbet (Pers.) B. L. Burtt \& R.M. } \\
\text { Sm. }\end{array}$ & $\begin{array}{l}\text { ALPINIA/ ZERUM/ COLON/ AMOM/ CATIM/ LANGU/ } \\
\text { RENEAL }\end{array}$ \\
\hline Althaea officinalis L. & ALTHA/ MALVA/ ALTEIA \\
\hline Anethum graveolens $\mathrm{L}$. & ANETH/ GRAVEO/ FERULA/ PEUCE/ ENDRO \\
\hline Arctium lappa $\mathrm{L}$. & ARCTIUM/ BARDA/ ARCION/ LAPPA \\
\hline Arnica montana $\mathrm{L}$. & ARNICA/ CINER/ DORON \\
\hline Atropa belladonna $\mathrm{L}$. & ATROPA/ BELLAD/ BELAD \\
\hline Baccharis trimera (Less.) DC. & BACCH/ TRIMER/ CARQ \\
\hline Caesalpinia ferrea Mart. ex Tul. & ALPINIA/ FERREA/ CAESALPINIA/ LIBID/ JUCA \\
\hline Calendula officinalis $\mathrm{L}$. & CALENDULA/ CALTHA \\
\hline Casearia sylvestris $\mathrm{Sw}$. & $\begin{array}{l}\text { CASEA/ SAMYDA/ GUACA/ ERVA/ ANAVIN/ CHAETOC/ } \\
\text { CRATER/ GUIDON }\end{array}$ \\
\hline Centella asiatica (L.) Urb. & $\begin{array}{l}\text { CENTELLA/ CENTELA/ CHONDR/ GLYCERIA/ } \\
\text { HYDROCOTY }\end{array}$ \\
\hline Cinchona calisaya Wedd. & CINCHONA/QUINQUINA/QUINA \\
\hline Cinnamomum cassia (L.) J. Presl & CINNAM/ CINAMON/ CANELA/ CASSIA \\
\hline Cinnamomum verum J. Presl & CINNAM/ CINAMON/ CANELA/ CAMPHOR \\
\hline Citrus aurantium L. subsp. aurantium & CITRUS/ LARANJA \\
\hline Cola nitida (Vent.) Schott \& Endl. & COLA/ NITIDA \\
\hline Copaifera langsdorffii Desf. & COPAIFERA/ COPAI \\
\hline Copaifera multijuga Hayne & COPAIFERA/ COPAI \\
\hline Copaifera paupera (Herzog) Dwyer & COPAIFERA/ COPAI \\
\hline Copaifera reticulata Ducke & COPAIFERA/ COPAI \\
\hline Cordia verbenacea DC. & CORDIA/ VERBENA/ VARRONIA/ ERVA \\
\hline Crataegus azarolus $L$. & CRATAEGUS/CRATEG/ AZAROLUS/ MESPILUS \\
\hline Crataegus laevigata (Poir.) DC. & CRATAEGUS/CRATEG \\
\hline Crataegus monogyna Jacq. & CRATAEGUS/CRATEG/ MESPILUS/ OXYACANT \\
\hline Crataegus nigra Waldst. \& Kit. & CRATAEGUS/CRATEG \\
\hline $\begin{array}{l}\text { Crataegus pentagyna Waldst. \& Kit. ex } \\
\text { Willd. }\end{array}$ & $\begin{array}{l}\text { CRATAEGUS/CRATEG/ MESPILUS/ AZAROLUS/ } \\
\text { PHAENOP }\end{array}$ \\
\hline Crataegus rhipidophylla Gand. & CRATAEGUS/CRATEG/ MESPILUS/ OXYACANT \\
\hline Curcuma longa $\mathrm{L}$. & CURCU/ ACAFRAO/ DOMESTICA \\
\hline Cymbopogon citratus (DC.) Stapf & CYMBOP/ CAPIM/ ANDROPOG \\
\hline Cynara scolymus L. & CYNARA/ ALCACHOF \\
\hline
\end{tabular}




\begin{tabular}{|c|c|}
\hline Datura stramonium $\mathrm{L}$. & DATURA/ STRAM \\
\hline $\begin{array}{l}\text { Echinodorus grandiflorus (Cham. \& } \\
\text { Schltdl.) Micheli }\end{array}$ & ECHIN/ ALISMA/ CHAPEU \\
\hline Echinodorus macrophyllus (Kunth) Micheli & ECHIN/ ALISMA/ CHAPEU \\
\hline Elettaria cardamomum (L.) Maton & ELET/ CARDA/ AMOMUM/ MINUS \\
\hline Eugenia uniflora $\mathrm{L}$. & $\begin{array}{l}\text { EUG/ UNIF/ LUMA/ MIRT/ MYRT/ PLIN/ STEN/ SYZYG/ } \\
\text { PITANGUE }\end{array}$ \\
\hline Foeniculum vulgare Mill. & FOEN/ ANET/ FUNCH \\
\hline Gentiana lutea $\mathrm{L}$. & GENT/ LUTE/ ASTER/ COILAN/ GENCIA \\
\hline Hamamelis virginiana $\mathrm{L}$. & HAMAM/ TRILOP \\
\hline Hydrastis canadensis $\mathrm{L}$. & HYDR/ CANAD/ HIDRAS \\
\hline Hyoscyamus niger $\mathrm{L}$. & HYOS/ HIOS/ MEIMEN \\
\hline Illicium verum Hook. f. & ILLI/ ILIC/ ANIS \\
\hline Justicia pectoralis Jacq. & JUSTI/ PECT/ CHAMB/ TREVO \\
\hline $\begin{array}{c}\text { Krameria lappacea (Dombey) Burdet \& } \\
\text { B.B.Simpson }\end{array}$ & KRAM/ TRIA/ LAPPA/ RATAN \\
\hline $\begin{array}{l}\text { Lippia alba (Mill.) N.E. Br. ex Britton \& P. } \\
\text { Wilson }\end{array}$ & $\begin{array}{c}\text { LIPP/ LANTANA/ ALBA/ VERBENA/ ZAPANIA/ } \\
\text { ZAPPANIA/ ERVA }\end{array}$ \\
\hline Lippia sidoides Cham. & LIPP/ SIDO/ ALECRIM \\
\hline Malva sylvestris $\mathrm{L}$. & MALVA/ SYLV/ ALTHA \\
\hline Matricaria chamomilla $\mathrm{L}$. & MATR/ CAMO/ CHAM/ CHRYSA \\
\hline Maytenus ilicifolia Mart. ex Reissek & MAIT/ MAYT/ ESPIN \\
\hline Melissa officinalis $\mathrm{L}$. & MELI/ FAUCIBAR/ MUTEL/ THYM \\
\hline Mentha x piperita $\mathrm{L}$. & MENTHA/ MENTA/ HORTELA \\
\hline Mikania glomerata Spreng. & MIK/ GUACO \\
\hline Mikania laevigata Sch. Bip. ex Baker & MIKANIA/ LAEVIG/ GUACO \\
\hline Momordica charantia $\mathrm{L}$. & MORMO/MOMOR/ CUCUM/ SICY/ MELAO \\
\hline Myroxylon balsamum (L.) Harms & MYRO/MIRO/BALS \\
\hline Passiflora alata Curtis & PASS/ ALAT/ MARAC \\
\hline Passiflora edulis Sims & PASS/ EDU/ MARAC \\
\hline Passiflora incarnata $\mathrm{L}$. & PASS/ INCAR/ MARAC \\
\hline Paullinia cupana Kunth & PAUL/ CUPA/ GUARA \\
\hline Persea americana Mill. & PERS/ ABAC \\
\hline Peumus boldus Molina & PEUM/ BOLD \\
\hline Phyllanthus niruri L. & PHYL/ NIRUR/ QUEBR \\
\hline Phyllanthus tenellus Roxb. & PHYL/ DIASPER/ QUEBR \\
\hline $\begin{array}{l}\text { Pilocarpus microphyllus Stapf ex } \\
\text { Wardleworth }\end{array}$ & $\mathrm{PILO} / \mathrm{JABO}$ \\
\hline Pimpinella anisum $\mathrm{L}$. & PIMP/ PTYCH/ SESEL/ SISON/ ANIS \\
\hline Plantago major $\mathrm{L}$. & PLANT/ TANC/TANS \\
\hline Plectranthus barbatus Andrews & PLEC/ BARB/ COLEUS/ OCIMU/ BOLD \\
\hline Polygala senega $\mathrm{L}$. & POLY/ POLIG/ SENEG \\
\hline Polygonum punctatum Elliot & POLIG/ POLY/ ERVA/ PUNC/ PERSIC/ BICH \\
\hline Punica granatum $\mathrm{L}$. & PUNIC/ GRAN/ ROMA \\
\hline Quillaja saponaria Molina & QUIL/ SAPON \\
\hline Rauvolfia serpentina (L.) Benth. ex Kurz & RAUV/ RALV/ OPHIOX/ RAUW/ SERP \\
\hline Rheum officinale Baill. & RHEU/ RUIB \\
\hline Rheum palmatum $\mathrm{L}$. & RHEU/ RUIB/ PALM \\
\hline
\end{tabular}


Rosmarinus officinalis L.

$$
\text { Salix alba } \mathrm{L} \text {. }
$$

Salvia officinalis L.

Sambucus australis Cham. \& Schltdl.

Sambucus nigra L.

Schinus terebinthifolia Raddi

Senna alexandrina Mill.

Stevia rebaudiana (Bertoni) Bertoni

Stryphnodendron adstringens (Mart.) Coville

Styrax benzoin Dryand.

Styrax paralleloneuron Perkins

Symphytum officinale L.

Taraxacum officinale F. H. Wigg

Vanilla planifolia Andrews

Vernonia condensata Baker

Vernonia polyanthes (Spreng.) Less

Zingiber officinale Roscoe
ROSM/ SALVIA/ ALEC

SALIX/ ALBA/ ARGOR/ SALGU

OBOS/ SALVIA

SAMBUCUS/ SABUG

SAMBUCUS/ SABUG

SCHINUS/ SARCO/ AROEIR

SENNA/ CASSIA/ SENE/ SENA

STEVIA/ EUPATOR

STRYP/ ACACIA/ MIMOSA/ BARBAT

STYRAX/ BENJ

STYRAX/ BENJ

SYMPHYTUM/ CONSOLI/ CONFREI

TARAXACUM/ LEON/ LEAO

VANILLA/ EPIDEND/ NOTYL/ MYROBR/ BAUN VERNONIA/ VERNON/ ACMEL/ CERATOC/ SPIL/ GYMN/ BAIAN

VERNONIA/ VERNON/ POLYAN/ CHRYS/ ASSA/ PEIXE ZINGI/ AMOMUM/ CURCUMA/ GENGI 